\title{
BRITISH GAME BIRDS AND WILDFOWL
}



THE GUN AT HOME \& ABROAD 
Only 950 copies of "British Game Birds and Wildfowl" have been printed. The first $\mathbf{5 0 0}$ of these being Vol. I of the $\mathbf{5 0 0}$ complete sets of

"The Gun at Home and Abroad."

This is set No......3.9.

Subscriber's Name 


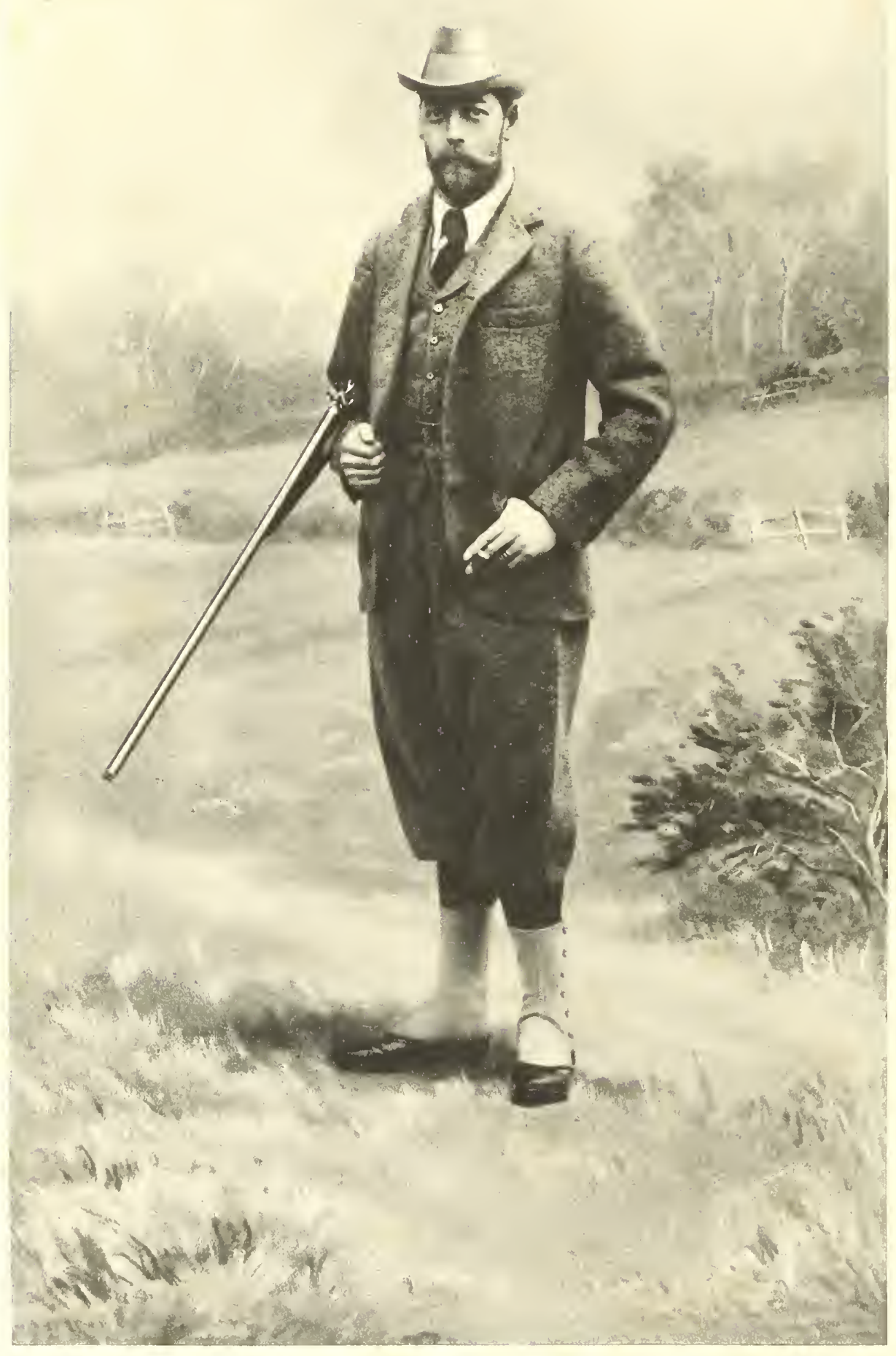




\section{THE GUN AT HOME AND ABROAD}

\section{BRITISH GAME BIRDS AND WILDFOWL}

BY

W. R. OGILVIE-GRANT

MAJOR ARTHUR ACLAND HOOD

J. G. MILLAIS
CAPT. AYMER MAXWELL

COL. R. F. MEYSEY-THOMPSON

J. E. HARTING

ABEL GHAPMAN

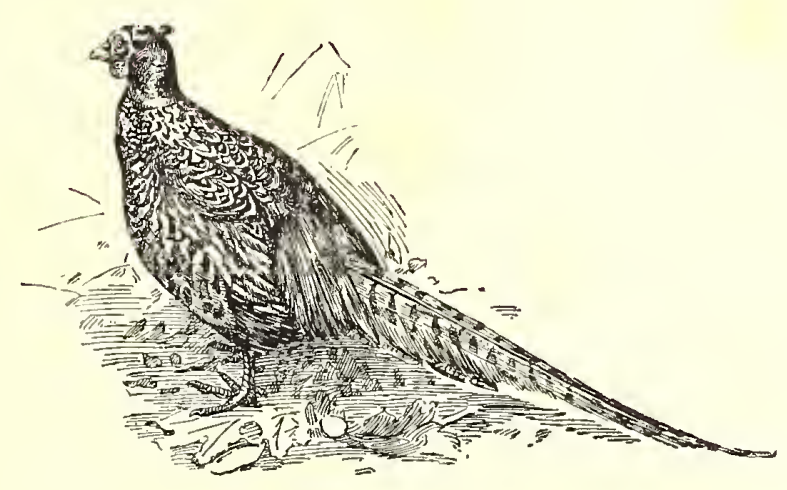

LONDON

THE LONDON \& COUNTIES PRESS ASSOCIATION L ${ }^{\mathrm{TD}}$ 6 HENRIETTA STREET - COVENT GARDEN - W.C. MCMXII 
DEDICATED BY GRAGIOUS PERMISSION TO HIS MAJESTY KING GEORGE V 


\section{PREFACE}

T $\mathbf{N}$ this Volume the plan adopted is to give first the natural history of the various species of British Game Birds and Wildfowl, and next, under the head of each kind, to describe the various methods of shooting in vogue, supplemented by hints on the rearing and management of game, the art of "driving," the management of grouse moors, heather burning, and other kindred matters. These subjects are all dealt with by authors who write from personal experience, and are authorities on their subjects.

The Natural History portion of the present Work by Mr Ogilvie-Grant contains much new and interesting matter. Many remarkable facts regarding the moult and change of plumage in game-birds have been brought together, while one subject at least-the eclipseplumage assumed by the male Capercaillie during the autumn moult-has not been previously elucidated. The eclipse-plumage of the game-birds is a subject about which very little is generally known, and it is of great interest to naturalists. The males of both the Black Grouse and Common Partridge assume a partial eclipse-plumage in July, and this is figured and fully described: also the nesting plumage donned by the hen Partridge. Again, in the Red Grouse (the only game-bird peculiar to the British Isles) the various types of plumage observable in both sexes have never previously been fully figured, and the remarkable variation in their plumage is well shown in Mr Lodge's admirable watercolour drawings. In the chapter on Pheasants will be found a carefully revised list of all the known forms divided into groups, with the exact geographical distribution of each species.

In the chapter on Wildfowl a special feature is Mr Ogilvie-Grant's very useful Key to all the species of the Duck-tribe which may possibly be met with in British waters. By the aid of this it is believed that sportsmen will be able with very little trouble to name any bird which they may happen to shoot.

The Publishers desire to thank Lord Westbury, Lord Ashburton, Baron de Pallandt Eerde, Mr R. H. Rimington-Wilson and Mr A. J. Gillott for their practical help with some of the illustrations, and they are greatly indebted to Major Arthur Acland Hood for his assistance during the progress of the Work.

In conclusion, they desire to express their appreciation of the labour bestowed by Mr J. E. Harting, who at their request read all the proof sheets with a view to eliminate inadvertent repetition, and to secure that uniformity of treatment which is desirable when several authors are engaged upon the same scheme. 
The following is a list of those who have kindly associated themselves with this work before publication, and to whom the thanks of the Publishers are due.

H.H. Maharajah of Patiala

H.H. Maharajah Gaekwar of Baroda, G.C.S.I.

H.H. Maharajah of Bhavnagar, K.C.S.I.

H.H. Maharajah Scindia of Gwalior, G.C.V.O., G.C.S.I.

H.H. Rajah Sir Bhuri Singh, K.C.S.I.

H.H. Maharajah Kuma of Tikari

Nawabzadu Col. Obaidulla Khan of Bhopal

Duke of Alba

Duke of Manchester

Duke of Portland, K.G., P.C., G. C. V.O.

Marquis of Tweeddale

Earl of Clancarty, J.P., D.L.

Earl Compton

Earl of Durham

Earl of Egmont

Earl of Essex, J.P.

Earl Howe, G.C.V.O.

Earl of Kintore, P.C., G.C.M.G.

Earl of Morley, J.P.

Earl of Plymouth, C.B., P.C., D.L., J.P.

Earl of Portarlington

Earl of Ranfurly, P.C., G.C.M.G., K.C.M.G.

Earl of Seafield

Earl of Strathmore, D.L., J.P.

Earl of Warwick, D. L., J.P.

Earl of Westmorland, J.P.

Viscount Anson

Viscount Coke

Viscount Lewisham, M.P.

Viscount Massereene and Ferrard, D.S.O.

Viscount Northland

Lord Airedale

Lord Ashburton

Lord Camoys

Capt. Lord John Cavendish, D.S.O.

Lord Cheylesmore, K.C.V.O.

Lord Clinton, D.L., J.P.

Lord Crawshaw, J.P.

Lord Ninian Crichton-Stuart, M.P.

Lord Decies, D.S.O.

Lord Deramore, D.L., J.P.

Lord Herbert

Lord Herschell, M.V.O.

Lord Holden

Lord Victor Paget

vi
Lord Rendlesham

Lord Sackville

Lord St Oswald, D.L., J.P.

Lord Savile, K.C.V.O., J.P.

Lord Strathcona, G.C.M.G., G.C.V.O.

Lord Tweedmouth, D.S. O., M.V.O.

Lord Waleran, P.C., D.L., J.P.

Baron de Pallandt Eerde

Baron Bruno Schroder

Hon. W. L. Bailey

Hon. K. P. Bouverie

Major Hon. A. Hanbury-Tracey, C.M.G.

Capt. Hon. J. Coke

Capt. Hon. J. Dawnay, D.S.O.

Capt. Hon. Arthur O'Neill, M.P.

Capt. Hon. H. C. O'C. Prittie

Capt. Hon. Algernon Strutt

Hon. Arthur Brodrick

Hon. Dudley Carleton, J.P.

Hon. Gilbert Hastings

Hon. E. Lindley-Wood, M.P.

Hon. A. E. S. Mulholland

Hon. A. J. Mulholland

Hon. J. H. Savile

Hon. W. F. D. Smith, D.L., J.P.

Hon. Henry J. Stonor, C.V.O.

Hon. John H. Ward, C.V.O.

Hon. Guy Wilson, D.S.O., M.P.

General Sir Arthur Paget, C.V.O., C.B., K.C.V.O., K.C.B.

Sir Frederic E. S. Adair, Bart, J.P.

Sir Matthew Arthur, Bart

Sir A be Bailey, K.C.M.G., D.L., J.P.

Sir Randolf L. Baker, Bart, M.P.

Sir Theodore Brinckman,Bart, C.B.

Sir Hervey Bruce, Bart

Sir George Bullough

Sir Francis Burdett, Bart

Sir Archibald Campbell, Bart, of Succoth

Sir Foster Cunliffe, Bart

Sir John Swinnerton Dyer, Bart

Sir William Hart Dyke, Bart, P.C. J.P., D.L.

Sir John Eardley-Wilmot, Bart

Sir Walter Egerton, K.C.M.G., C.M.G.

Sir Ailwyn E. Fellowes, P.C., K.C.V.O.

Sir William Garstin, G.C.M.G., K.C.M.G.

Sir Thomas Glen-Coats, Bart, C.B.
Sir Richard Graham, Bart, J.P., D.L. Sir William Jaffray, Bart Sir Robert W. B. Jardine, Bart

Sir John Kelk, Bart, J.P.

Sir Arthur Lawson, Bart Sir Edmund Giles Loder, Bart, J.P. Sir Victor Mackenzie, Bart Sir William Mackenzie Sir Charles T. Mander, Bart Capt. Sir Mervyn Manningham. Buller, Bart

Sir Charles H. T. Metcalfe, Bart

Sir Powlett Milbank, Bart, J.P., D.L. Sir Richard Musgrave, Bart, D.L.,

J.P.

Rev. Sir William Hyde Parker, Bart Sir W. Eley Quilter, Bart, M.P. Sir Charles Bine Renshaw, Bart Sir John Rolleston, M.P. Sir Thomas A. Salt, Bart Sir Archibald H. M. Sinclair, Bart Sir H. Lincoln Tangye Sir Peter Walker, Bart Sir Robert J. Walker, Bart Sir Charles Watson, Bart Sir George Younger, Bart, M.P. Rt Hon. Robert Farquharson Major-General V. Hatton, C.B. Major-General H. B. Peters, J.P.

Lt-Col. John G. Adamson

Col. J. H. Abbot-Anderson

Col. Charles R.Prideaux-Brune,J.P. Lt-Col. R. H. Carr-Ellison Col. F. H. Custance, C.B.

Col. Max C. Fleischman

Col. John R. Gray

Col. Reginald Hoare

Col. George H. Holdsworth

Col. Frank Johnson

Col. H. R. Lloyd

Col. H. C. Lowther

Col. James M. MoCalmont, M.P.

Col. J. M. Rogers

Col. W. A. Scott, C.B.

Col. Victor W. Bates Van de Weyer, J.P.

Lt-Col. J. A. C. Younger

Major H. B. Dalgety

Major F. J. Carruthers

Major Ralph P. Cobbold

Major H. G. Henderson, M.P.

Major F. F. Hopwood

Major R. F. Peel, M.P.

Major M. Pitt 
Major James E. Platt

Major R. A. Scott

Major R. F. Ratcliffe, M.P.

Major G. F. Trotter, D.S.O.

Major G. Dalrymple White, M.P.

Major H. H. Wigram

Capt. Geoffrey V. S. Bowlby

Capt. Robert B. Brassey

Capt. H. R. Bruce

Capt. J. Campbell

Capt. E. Clive Coates

Capt. Christian Combe

Capt. C. R. C. de Crespigny

Capt. Quintin Dick

Capt. Alex. T. Gordon

Capt. W. Higson

Capt. Michael Hughes

Capt. A. Glen Kidston

Capt. J. A. Morrison, M.P.

Capt. G. M. Mundy

Capt. J. H. J. Phillips

Capt. F. Rose

Capt. J. M. Stewart

Capt. Warwick

Capt. M. S. Williams

Capt. Herbert H. Wilson

G. L. Courthope, Esq., M.P.

Angus V. Hambro, Esq., M.P.

S. Hill-Wood, Esq., M.P.

Rowland Hunt, Esq., M.P.

Percy H. Illingworth, Esq., M.P.

O. Locker Lampson, Esq., M.P.

G. C. H. Wheler, Esq., M.P.

A. Stanley Wilson, Esq., M.P.

J. Wood, Esq., M.P.

George M. Fowler, Esq., C.M.G.

C. P. Skerrett, Esq., K.C.

Baron A. de Than

Count Emmanuel de Lambertze

Count George Festetics

Frank H. Aarons, Esq.

G. Aguet, Esq.

Lionel Ames, Esq.

Carrol H. Ansdell, Esq.

W. B. Anderson, Esq.

Harold D. Anstruther, Esq.

George F. Ashmead-Bartlett, Esq.

Philip H. Ashworth, Esq.

Francis M. Baer, Esq.

H. Barker-Hahlo, Esq.

V. R. Balfour-Browne, Esq.

Wm. Bean, Esq., J.P.

W. Beardmore, Esq.

Richard Berridge, Esq.

Bryan B. Bellew, Esq.

J. Bell-Irving, Esq.

J. J. Bell-Irving, Esq.

G. L. Bevan, Esq.

J. B. Blessig, Esq.
F. N. Blundell, Esq.

James Blyth, Esq.

W. Norman Boase, Esq.

Henry C. Bond, Esq.

Leo Bonn, Esq.

A. E. Bowen, Esq.

John H. Bridges, Esq.

J. Douglas Broad, Esq.

A. M. Brodrick, Esq.

Stanley Brotherhood, Esq.

R. H. Bruce, Esq.

F. Bryce, Esq.

I. Bullough, Esq.

Charles W. L. Bulpett, Esq.

A. E. Butter, Esq.

Charles A. J. Butter, Esq.

C. A. Cain, Esq.

Duncan Campbell, Esq.

J. Cameron-Head, Esq., of Inverailort

Henry M. Carlisle, Esq.

Emilio N. Casares, Esq.

L. E. Chalmers, Esq.

Edward F. Chance, Esq.

Abel Chapman, Esq.

Fred J. M. Christie, Esq.

Kenneth M. Clark, Esq.

George Clark, Esq.

A. E. Clerk, Esq

W. Brodrick Cloete, Esq.

Leonard Clow, Esq.

John D. Cobbold, Esq.

Leonard L. Cohen, Esq.

Ralph T. Cole, Esq.

H. C. S. Combe, Esq.

Bernard H. Conrad, Esq.

A. Wynne Corrie, Esq.

H. A. Cox, Esq.

William Henry Cox, Esq.

John Coxon, Esq.

Philip Arthur Sambrooke Crawley, Esq.

Leonard Cripps, Esq.

Gordon Crosdale, Esq.

Horace Czarnikow, Esq.

Robert Davidson, Esq.

Fred L. Davis, Esq.

A. A. Delmege, Esq.

J. Dewrance, Esq.

George Dixon, Esq.

F. D. Docker, Esq.

Norman F. Druce, Esq.

Arthur John Dorman, Esq.

M. Drummond, Esq.

Alfred H. Duggan, Esq.

Alex. L. Duncan, Esq.

F. Dunsford, Esq.

A. Percy Eccles, Esq.

F. Eustace Faithfull, Esq.
W. de Falbe, Esq.

Alfred Farquhar, Esq.

Sydney Farrar, Esq.

A. H. Fass, Esq.

B. S. Faudel-Phillips, Esq.

A. R. Fellowes, Esq.

Mark Fenwick, Esq.

Brinsley Fitzgerald, Esq.

J. D. Fletcher, Esq.

David Forbes, Esq.

S. Ford, Esq.

R. Oswald Fordham, Esq.

Phipps Foster, Esq.

Walter T. Fremlim, Esq.

J. S. H. Fullerton, Esq.

C. Gairdner, Esq.

Charles T. Garland, Esq.

Frederick Garside, Esq.

Francis T. Gervers, Esq.

Henry Wallis Gilbey, Esq.

Alfred J. Gillott, Esq.

Alastair S. Gilmour, Esq.

Hugh S. Gladstone, Esq., F.Z.S., F.R.S.E.

Francis E. Goad, Esq.

Spencer H. Gollan, Esq.

C. W. Gordon, Esq.

Joseph Gould, Esq.

Percy N. Graham, Esq.

J. W. H. Grant, Esq.

Loudon Greenlees, Esq.

R. N. Halfhead, Esq.

R. Halsey, Esq.

C. Eric Hambro, Esq.

R. O. Hambro, Esq.

N. Dalrymple Hamilton, Esq.

A. Hanbury, Esq

Arthur Hawley, Esq.

Holford Harrison, Esq

Frank P. Heath, Esq.

Hugh L. Heber-Percy, Esq.

Brodie Henderson, Esq.

F. Henderson, Esq.

S. Heilbut, Esq.

Richard Hennessy, Esq.

John 'T. Hibbert, Esq.

Cecil M. Higgins, Esq.

A. P. Hill, Esq.

J. A. Hill, Esq.

P. K. Hodgson, Esq.

Eardley Wilmot B. Holt, Esq.

G. N. Horlick, Esq.

J. Hamilton Houldsworth, Esq.

Holcombe Ingleby, Esq.

G. C. L. Insole, Esq.

C. Bower Ismay, Esq.

James H. Ismay, Esq.

R. Jardine, Esq.

Harry Wyndham Jefferson, Esq. 
W. J. H. Jones, Esq.

H. Kent, Esq.

Stephenson Kent, Esq.

Rohert Molesworth Kindersley, Esq.

Jersey de Knoop, Esq.

Percy Laming, Esq.

Arthur Lampard, Esq.

H. Lawrence, Esq.

W. H. Leslie, Esq.

M. Liddell, Esq.

Alex. Littlejohn, Esq.

R. E. Longfield, Esq.

A. W. Lyle-Kidd, Esq.

A. C. McCorquodale, Esq.

W. Dalziel Mackenzie, Esq.

Thos. Mackie, Esq.

Angus Mackintosh, Esq.

Colin MacIver, Esq.

C. C. McLeod, Esq.

W. N. McMillan, Esq.

Duncan J. Macpherson, Esq.

C. C. Macrae, Esq.

Lionel H. Mander, Esq.

Percival R. Mann, Esq.

T. Hugh Mann, Esq.

George E. T. Manners, Esq.

F. N. Kay Menzies, Esq.

C. A. Mills, Esq.

J. D. Mills, Esq.

J. E. Mitchell, Esq.

James F. Montaǵ, Esq.

W. B. Morris, Esq.

H. E. Morritt, Esq.

R. G. Mortimer, Esq.

Charles A. Murray, Esq.

W. Murray, Esq.

F. G. Naumann, Esq.

G. C. Neilson, Esq.

W. Newall, Esq.

Charles R. I. Nicholl, Esq.

A. J. North, Esq.

E. de C. W. Oakeley, Esq.

C. H. Oliverson, Esq.

Roland Orred, Esq.

T. C. Owen, Esq.
Cecil B. Pape, Esq.

Marriott Parkinson, Esq.

T. W. Parkinson, Esq., M.D.

Edward Paul, Esq.

E. Paul, Esq.

Edward Charles Pearce, Esq.

Horace O. Peacock, Esq.

Hugh Peel, Esq.

Fred R. Pelly, Esq.

Charles James Phillips, Esq.

F. D. Pirie, Esq.

John H. Platt, Esq.

George J. Poston, Esq.

C. B. Prescott, Esq.

J. Henry Preston, Esq.

A. V. Pryor, Esq.

Percy C. V. Quilter, Esq.

A. D. Ramsay, Esq.

Thomas Ramsden, Esq.

Cecil Frank Raphael, Esq.

Frank Reddaway, Esq.

John Sherard Reeve, Esq.

Marshall Reid, Esq.

T. Ritchie, Esq.

F. A. Roberts, Esq.

G. P. Roch, Esq.

Charles M. Rolker, Esq.

D. Sanday, Esq.

W. Samson, Esq.

Dr H. Sauer

Harold Schwind, Esq.

H. Alan-Scott, Esq.

H. B. Sedgwick, Esq.

H. S. Seldon, Esq.

Gerard Craig Sellar, Esq.

Stephen Sellon, Esq.

Agnew Ruskin Severn, Esq.

D. A. Shennan, Esq.

Nathaniel Sherwood, Esq.

Beckwith Smith, Esq.

E. W. Stanyforth, Esq.

F. C. Stern, Esq.

W. Burton Stewart, Esq.

J. Stewart-Clark, Esq.

Fred W. Stobart, Esq.
Hartley Straker, Esq.

G. Stuart-Ogilvie, Esq.

Edwin Tate, Esq.

R. R. Tattersall, Esq.

Frank Humbert Taylor, Esq.

T. L. Taylor, Esq.

Wilfrid F. Tempest, Esq.

Hugh Lloyd Thomas, Esq.

George A. Tihhitt, Esq.

Ernest W. Thompson, Esq.

Marmaduke A. Thorpe, Esq.

J. W. Todd, Esq.

M. Tosetti, Esq.

J. J. Van Alen, Esq.

Wm. Van der Weyer, Esq.

D. von Braun, Esq.

V. C. Vickers, Esq.

T. L. Villiers, Esq.

J. Monro Walker, Esq.

Percy Wallace, Esq.

Arthur James Walmsley, Esq.

Bernard Walsh, Esq.

B. J. Warwick, Esq.

W. H. A. Wharton, Esq.

W. E. Whineray, Esq.

G. Cecil Whitaker, Esq.

C. W. Sofer Whitburn, Esq.

R. W. White-Thomson, Esq.

A. Whitelaw, Esq.

Graeme A. Whit elaw, Esq.

J. H. A. Whitley, Esq.

A. V. Willeox, Esq.

A. T. Williams, Esq.

C. R. Williams, Esq.

C. P. Wills, Esq.

Walter Winans, Esq.

Cecil de Winton, Esq.

Arthur H. Wood, Esq.

Robert Woodhouse, Esq.

ADDENDA

H. H. The late Maharajah of Cooch Behar

The late Lord Wenlock

The late Hon. C. Brand 


\section{CONTENTS}

PREFACE

CAPERCAILLIE: NATURAL HISTORY. W. R. Ogilvie-Grant

Page v

CAPERCAILLIE SHOOTING. J. G. Millais

BLACK GROUSE: NATURAL HISTORY. W. R. Ogilvie-Grant 22

BLACK-GAME SHOOTING. Capt. Aymer Maxwell 32

RED GROUSE: NATURAL HISTORY. W. R. Ogilvie-Grant 44

RED GROUSE SHOOTING. Col. R. F. Meysey.Thompson 62

MANAGEMENT OF MOORS. " " " , 68

HEATHER BURNING. Major A. Acland Hood 82

PTARMIGAN : NATURAL HISTORY. W. R. Ogilvie-Grant 89

PTARMIGAN SHOOTING. Col. R. F. Meysey-Thompson 98

PHEASANTS : NATURAL HISTORY. W. R. Ogilvie-Grant 101

PHEASANT REARING. Col. R. F. Meysey.Thompson 121

PHEASANT SHOOTING. , , " , 134

COMMON PARTRIDGE: NATURAL HISTORY. W. R. Ogilvie-Grant 137

RED-LEGGED PARTRIDGE: NATURAL HISTORY. " " , 148

PARTRIDGE REARING. Major A. Acland Hood 154

PARTRIDGE SHOOTING. " , , , 169

$\begin{array}{lllll}\text { NOTABLE BAGS. } & , \quad, \quad, & 183\end{array}$

QUAIL: NATURAL HISTORY. W. R. Ogilvie-Grant 193

QUAIL SHOOTING. J. E. Harting 203

WOODCOCK : NATURAL HISTORY. W. R. Ogilvie-Grant 223

WOODGOCK SHOOTING. Major A. Acland Hood 243

COMMON SNIPE : NATURAL HISTORY. W. R. Ogilvie-Grant 261

GREAT SNIPE: NATURAL HISTORY. " " , , , 273

JACK SNIPE: NATURAL HISTORY. $\quad, \quad, \quad, \quad, \quad, \quad, \quad 277$

SNIPE SHOOTING. Col. R. F. Meysey-Thompson 283

WILDFOWL: NATURAL HISTORY. W. R. Ogilvie-Grant 289

WILDFOWL SHOOTING. Abel Chapman $\quad 384$

GAME LAWS AND LICENCES. J. E. Harting 422 



\section{PHOTOGRAVURE FRONTISPIECE HIS MAJESTY KING GEORGE V}

\section{COLOURED ILLUSTRATIONS*}

PLATE I. Capercaillie, Male and Female facing page 8

II. Black Grouse, Male and Female 24

III. Black Grouse. Female assuming Male plumage; Male in eclipse plumage (July to September)

IV. Black Grouse. Young in first plumage; Young in down

V. Male Hybrid, Black Grouse and Capercaillie. Male Hybrid, Black Grouse and Red Grouse

VI. Red Grouse. Males in winter-summer plumage, Red, Black and White-spotted forms

VII. Red Grouse. Females in autumn-winter plumage, Black, Whitespotted and Red forms

VIII. Red Grouse. Females in autumn-winter plumage, Buff-spotted and Buff-barred forms

$\begin{array}{rr}\text { IX. Red Grouse. Female in summer plumage ; Male in autumn plumage } & 80 \\ \text { X. Red Grouse. Young in down ; Young in first plumage } & 88\end{array}$

XI. Ptarmigan. Male and Female in summer plumage 92

XII. Ptarmigan. Male and Female in autumn plumage 96

XIII. 1 and 2, Ptarmigan, Male and Female in winter plumage; 3, Common Partridge, Male, September to June; 4, Common Partridge, Male, June to September, showing eclipse plumage on head and neck; 5, Common Partridge, Female, October to April; 6, Common Partridge, Female, April to October, showing breeding plumage on head and neck

XIV. Common Pheasant, Male and Female 112

$\begin{array}{ll}\text { XV. Mongolian Pheasant, Male and Female } & 128\end{array}$

XVI. Common Partridge, Male and Female 144

XVII. Common Partridge. Young in first plumage; Young in down 152

$\begin{array}{ll}\text { XVIII. Common Partridge. Variations in colour } & 160\end{array}$

$\begin{array}{ll}\text { XIX. Red-legged Partridge, Male and Female } & 168\end{array}$

XX. Red-legged Partridge. Young in first plumage; Young in down; Immature assuming adult plumage 176

XXI. Red-legged Partridge. Variations in colour 192

XXII. Quail, Male and Female 208

XXIII. Woodcock, Rufous variety and normal plumage $\quad 240$

XXIV. Common Snipe and Jack Snipe 280

XXV. Mallard, Male and Female (Red-headed Pochards passing overhead) 304

XXVI. Pintail, Male and Female (Wigeon in background) 332

*T The illustrations in colour have been reproduced by Messrs Ben Johnson $\mathcal{E}$ Sons, Limited, of York, from original
water-colour drawings specially executed for this work by GEORGE E. LODGE. No artist's proofs have been issued. 


\section{HALF-TONE PLATES}

PLATE XXVII. Heads of Wild Swans and Geese (G. E. Lodge)

XXVIII. , , Wild Ducks and Teal

XXIX. " , Scoters and Eiders

,

XXX. ", , Pochards and Mergansers ",

\section{OTHER ILLUSTRATIONS}

The Shipka Pass. From the picture by Douglas Adams 


\section{CAPERCAILLIE*}

\section{TETRAO UROGALLUS}

(Plate I)

Tetrao urogallus, Linn., Syst. Nat., i, p. 273 (1766); Gould, Birds Europe, v, pl. 248 (1837); Dresser, Birds Europe, v, p. 223, pls. 489, 490 (1873); Seebohm, Hist. Brit. Birds, ii, p. 440 (1884); Saunders, ed. Yarrell, Brit. Birds, iii, p. 45 (1884); Meyer, Unser Auer-Rackel-und Birkwild, etc., p. 1, pls. 1-3 (1887); Harvie-Brown, Capercaillie in Scotland (1888); Millais, Game Birds, p. 1, pls. and woodcuts (1892); Lilford, Col. Fig. Brit. Birds, pt. xxvii (1894); Ogilvie-Grant, Cat. Birds Brit. Mus., xxii, p. 60 (1893) ; id., Game Birds, i, p. 49 (1895); Saunders, Ill. Man. Brit. Birds, p. 491 (1899); Millais, Brit. Game Birds, p. 1, 3 pls. (1909).

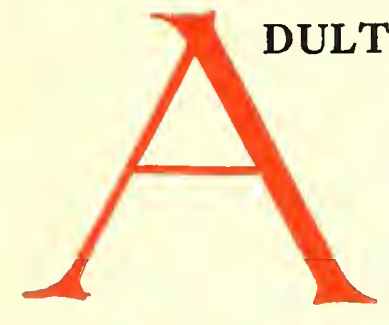

male (September to July). - Head and neck dark grey, mottled with black, shading into dull black on the forehead, sides of the head, chin and throat, the latter being more or less glossed with green; mantle, lower back, and rump black, covered with wavy white lines; inter-scapular region washed with reddishbrown; wing-coverts and scapulars reddish-brown, finely mottled with black. Quills and primary coverts dark brown, the middle primary quills white towards the base of the outer web, and the secondary quills mottled with reddish-brown on the outer web, and tipped with white. Chest, dark glossy green, shading into black on the breast and abdomen, most of the feathers of the abdomen and flanks tipped, and mixed with white; thighs and vent mostly white; feathers on the legs brownish-black, both the upper and under tail-coverts black, tipped with white; tail black, with an irregular marbled white band across the terminal half of the feathers. Axillaries and under wing-coverts white, a few of the outermost ones being dark brown. Bill yellowish horn-colour; feet dark leaden-grey. Wattle above the eye scarlet.

Total length about 35 inches; wing $14 \cdot 6$ inches; tail $12 \cdot 3$ inches; tarsus $2 \cdot 8$ inches.

July to September.-The eclipse-plumage of the male capercaillie is not yet known, as no examples of this species killed in July and August are at present available for examination. That it has an eclipse-plumage is, however, pretty certain, for in the allied species from Kamchatka (Tetrao kamtschaticus) we know that such is the case. A male of the latter species killed in Kamchatka on August 14 by Major G. E. H. BarrettHamilton, and now in the British Museum, is in full moult, with the

\footnotetext{
* The name Capercaillie, or Capercailzie, as sometimes written, is said to be derived from the Celtic gabur, a goat, and coille, a wood, i.e. "Goat of the Wood," in allusion to the long beard-like feathers on the throat of the male bird. But see Harting, Handbook of British Birds, 1901, p. 128.
} 


\section{THE GUN AT HOME AND ABROAD}

wings and tail partially grown; it has the chin, throat, cheeks and forepart of the neck clad in white feathers, barred and edged with black, giving these parts an irregularly mottled appearance, which is no doubt protective, and very similar to that assumed by the blackcock in August.

Males in first autumn-plumage.-By December young males are very similar in plumage to the adult, but may be recognized by their much smaller size and by the absence of the marbled white band across the tail-feathers.

Adult female.-Head, neck, and upper parts of the body black, barred with rufous-buff, and tipped with white, except on the back ; wing-coverts and secondary quills similar, but the buff markings are more broken and irregular; the primary quills and their coverts dark brown, mottled with rufous on the outer web. Throat and fore-neck rufous-buff, shading into darker rust-red on the chest; rest of the underparts rufous-buff, barred with black and tipped with white; legs soiled white, mottled with black. Tail chestnut, barred with black and tipped with white. Axillaries and under wing-coverts white, marked with black and rufous. Bill brownish horn-colour, paler at the tip and along the edges, feet greyishbrown. Total length about 25 inches; wing $11 \cdot 7$ inches; tail $7 \cdot 3$ inches; tarsus $2 \cdot 1$ inches.

In some adult females the white tips of the body feathers are almost or entirely wanting, and the breast and abdomen are nearly uniform rufous-buff, with less conspicuous black bars. These differences in plumage appear to be purely individual, and seem to represent a rufous phase of coloration. It should be noted that the under tail-coverts do not extend nearly to the end of the middle tail-feathers. (Fig. 1.)

Females in first autumn-plumage resemble the adult.

Young birds of both sexes in first plumage are much like the female, but the wing-coverts and scapulars have buff shaft-stripes and a buff spot at the extremity of the feathers.

Young in down.-Top of the head buff, mottled with black, and with a V-shaped blackish mark on the forehead; an irregular black band behind the eyes and extending on to the sides of the neck; in some a transverse blackish band across the whitish-buff occiput; nape, wing-coverts, and rump pale fawn-colour; back mottled with greyish-buff, and with a very irregular double line of black on each side of the spine; remainder of the head and underparts pale buff, inclining to yellowish-white on the throat. 


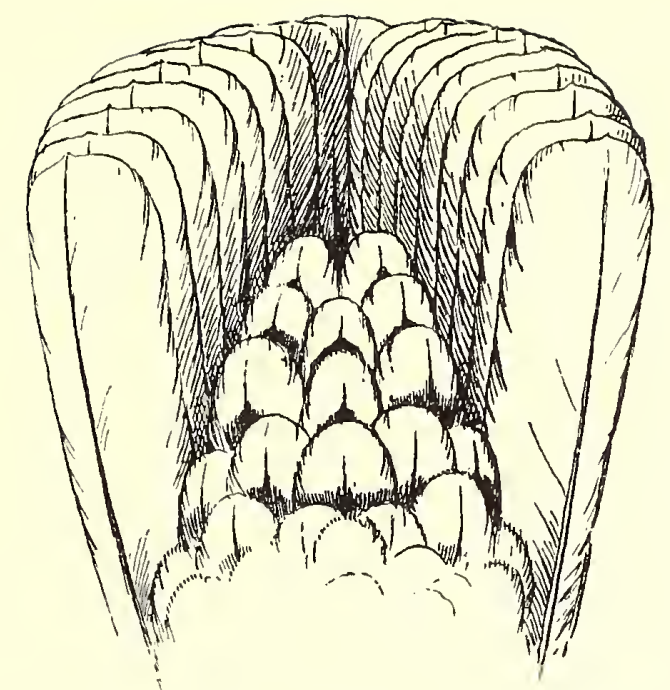

Fig. 1.

Tail of female Capercaillie : under tail-coverts shorter than the middle tail-feathers.

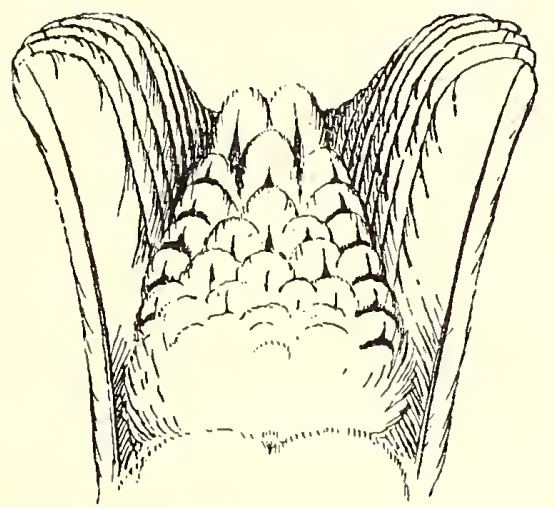

Fig. 2.

Tail of Greyhen : under tail-coverts longer than the middle tail-feathers. 



\section{CAPERCAILLIE}

Female assuming male plumage.-It is by no means unusual for females which have become barren to assume, more or less, the plumage of the male. In the most common type the chest becomes metallic-green, like that of the male, the head and neck are largely mixed with grey and black vermiculated feathers, and there are also some mottled black and grey feathers on the back, sides and breast. Females in almost complete male-plumage are sometimes met with, and look like small cocks.

Variations in plumage are uncommon in this country, but partially white birds are sometimes seen, and are less rare in Scandinavia and Russia.

General distribution.-The capercaillie is met with in the pine-forests of Europe, and Northern and Central Asia, extending in the west to Great Britain, and in Scandinavia as far north as lat. $70^{\circ}$, in the east as far as Lake Baikal, and northwards to about lat. $67^{\circ}$; southward it ranges to the Pyrenees, Alps, Carpathians, north-east Turkestan, and the Altai Mountains.

Allied species. - In the Ural Mountains a beautiful light-coloured capercaillie (Tetrao uralensis), is found. In the male the head, neck, mantle and back, etc., are grey, finely mottled with black, the wings and shoulder-feathers light reddish-brown, the chest green, and the breast and belly mostly white. The female also has the general colour of the plumage much paler than that of the female of $T$. urogallus, and the white tips to the shoulder-feathers much wider.

Although at first sight this splendid capercaillie, by far the handsomest of the genus, appears to be very distinct from typical examples of $T$. urogallus, from Norway and Sweden, the writer has examined numerous birds with the plumage intermediate in colour between the dark Scandinavian bird and the light-coloured Ural form. These birds come into the London market in considerable numbers, and are believed to be imported from some of the more southern provinces of Russia, but the exact locality is difficult to ascertain. Though some of these intermediate birds have much white on the breast and belly, and are altogether lighter than Western European examples, the Ural birds are so much paler than the palest of them and so constant in their coloration that they may fairly be considered as representing a distinct sub-species.

Males are occasionally shot in this country with a great deal of white on the breast and belly, but this is due, no doubt, to partial albinism.

Eastwards its place is taken in North-eastern Siberia and the Island of Saghalien by an allied species, the slender-billed capercaillie 


\section{THE GUN AT HOME AND ABROAD}

more sheltered woods, their plumage sometimes becomes so drenched that they are unable to rise out of the long heather where they have taken refuge.

Position of legs during flight. - In flight the legs are always fully extended beneath the tail, as in all other game-birds. It is desirable to emphasize this point, for it has been stated in print by a recognized authority on the subject that the legs are tucked up under the body in flight. As a matter of fact the Passerine birds, such as sparrows, crows, and the hosts of small birds included in that order, are probably the only group that do not extend the legs under the tail in flight. The Picarian birds, such as the woodpeckers, nightjars, and swifts, may also tuck them up, but on this point we are uncertain, their legs being so short that it is very difficult to observe their position. All the hawks, cormorants, gannets, swans, ducks, cranes, storks, herons, bustards, waders, gulls, petrels, rails, divers, grebes and pigeons, as well as the game-birds, fly with the legs fully extended behind, only bringing them forward when about to alight.

Breeding habits.-The pairing-habits of the capercaillie are very interesting, and somewhat similar to those of the black grouse, but the meeting place of the males is generally some particular pine-tree known as the "leking place," though a flat-topped rock in the forest is sometimes selected. Here, in the months of April and May the male may be seen at dawn and sunset with outstretched neck, drooping wings, and tail erected and spread like a fan, uttering his "spel " or love-song. This consists of three notes, likened by Lloyd to the sounds pellep, klickop and hede, each being repeated several times. Towards the end of the song, the bird turning his head backwards and giving vent to extraordinary noises, works himself up into such a state of blind excitement, that he is oblivious to the world. Mr Millais states that the love-song is divided into three parts : firstly, klick-kleck repeated at intervals, and gradually increasing in speed; secondly, a sound like the drawing of a cork from a bottle; thirdly, in the moments of extreme excitement, noises like those made by the grinding of a knife on a stone, or of two cats fighting!

The whole performance lasts for two or three minutes, and is often immediately repeated. The hens meanwhile remain on the ground beneath the tree, and are paired with by the victorious male who has challenged and driven off all comers. Only the older cocks "spel," the younger and weaker birds being driven from the field. Tremendous fights take place for the sovereignty of each harem, and both combatants may sometimes 


\section{GAPERGAILLIE}

be captured, having fought till they are so completely exhausted that they are unable to move. One or other of the birds engaged is not unfrequently left dead on the battle-field.

While the cock is uttering his "spel," it is the custom in many countries to stealthily stalk and shoot it. A careful advance is made during the moments of ecstasy, and while the bird is careless of surrounding objects, the hunter gradually gets within shooting distance.

During the rest of the year the cock is a very silent bird, but occasionally, like the blackcock, he makes a pseudo-erotic display in autumn, and utters his love-song in the early morning and evening. The usual call of the female resembles the syllables coq coq, and when wounded both sexes utter a peculiar hissing sound, and spread out their feathers, but they rarely, if ever, attempt to defend themselves.

Towards the end of April the hens seek their nesting-places, and many leave the higher woods for the low grounds, where they remain with their broods till the autumn.

Nest.-The nest is merely a hollow scraped in the ground by the female among heather, blaeberry, and bracken in woods and forests. A favourite place is at the base of a stump or among the branches of a fallen tree. Unusual sites are occasionally resorted to, and nests have been found in trees ten or fifteen feet from the ground.

Eggs.-The eggs vary considerably in number, from four, five, or six, to as many as twelve. When more are found in one nest, they are probably the produce of more than one female. They are generally laid in May, but sometimes not till early in June in the higher woods. The eggs are pale brownish-buff, spotted with reddish-brown, and are much like those laid by the greyhen, but somewhat larger, measuring on the average $2 \cdot 2$ inches by $1 \cdot 6$ inch.

Incubation lasts for about thirty days.

General habits. -The female capercaillie cannot be called a good mother. She is easily put off her nest, and is more careless than other game-birds with her young, losing many by leading them, soon after they are hatched, over drains in the woods, and out of which they are unable to scramble. An instance of this came under the writer's notice when procuring a group of these birds for the Natural History Museum. Out of twelve nests inspected in one wood, one with twelve eggs was finally selected and closely watched till the young had been hatched.

At 5 a.m. one morning the keeper reported that the hen had taken off 


\section{THE GUN AT HOME AND ABROAD}

her brood of seven, leaving five eggs in the nest. It was-found that these five eggs were on the point of hatching, and all were brought out under a fowl. The hen capercaillie having meanwhile been watched, was soon overhauled, but was accompanied by one chick only! The remaining six were picked up in ditches between the spot where she had been found and her nest. She may have been an exceptionally careless mother; or it is possible she may have been disturbed by the presence of the watcher, though he was careful to keep out of sight. On the other hand, the female, when accompanied by her brood, is very courageous, and boldly defends her young from any intruder. The chicks are very active and able to fly soon after they are hatched, but they are so delicate in the early stages of their growth, and so sensitive to damp, that a great many perish.

The old cock capercaillies are generally to be found in the higher pinewoods, except in the pairing-season, when, for a time, they visit the lower grounds. Being extremely wary, and endowed with unusually keen sight and quick hearing, they are well able to take care of themselves during the shooting-season. The hens and young birds are much less timid, and are consequently more frequently killed. Like the greyhens, female capercaillies should, generally speaking, be spared, unless the species is becoming too numerous in any particular locality; in which case they can be very easily thinned out.

The hens will often remain sitting in the larch-and fir-trees until guns walking in line through a wood are almost beneath them, or they will rise with a great clatter of wings out of the deep blaeberry and bracken, whereas the old cocks, if there are any about, make off long before the line approaches. The cocks are, however, easily driven by a few experienced beaters, and in this way often afford splendid shooting. It would be difficult to imagine a finer sight than these grand birds present as they sail almost noiselessly overhead. Their apparently leisurely flight renders the pace at which they travel most deceptive, and consequently in spite of their great size, they are often missed. In winter, capercaillie often congregate in flocks, and when driving the woods late in the year in places where they are plentiful, it is not an unusual sight to see as many as half a dozen birds on the wing at one time. It is at this season, when the ground is covered with snow, that most damage is done to the young trees.

When on the ground the movements of the cock capercaillie are slow and dignified, and his carriage is very erect. On the stubble-fields the males may often be seen stalking solemnly about among the stooks, while 


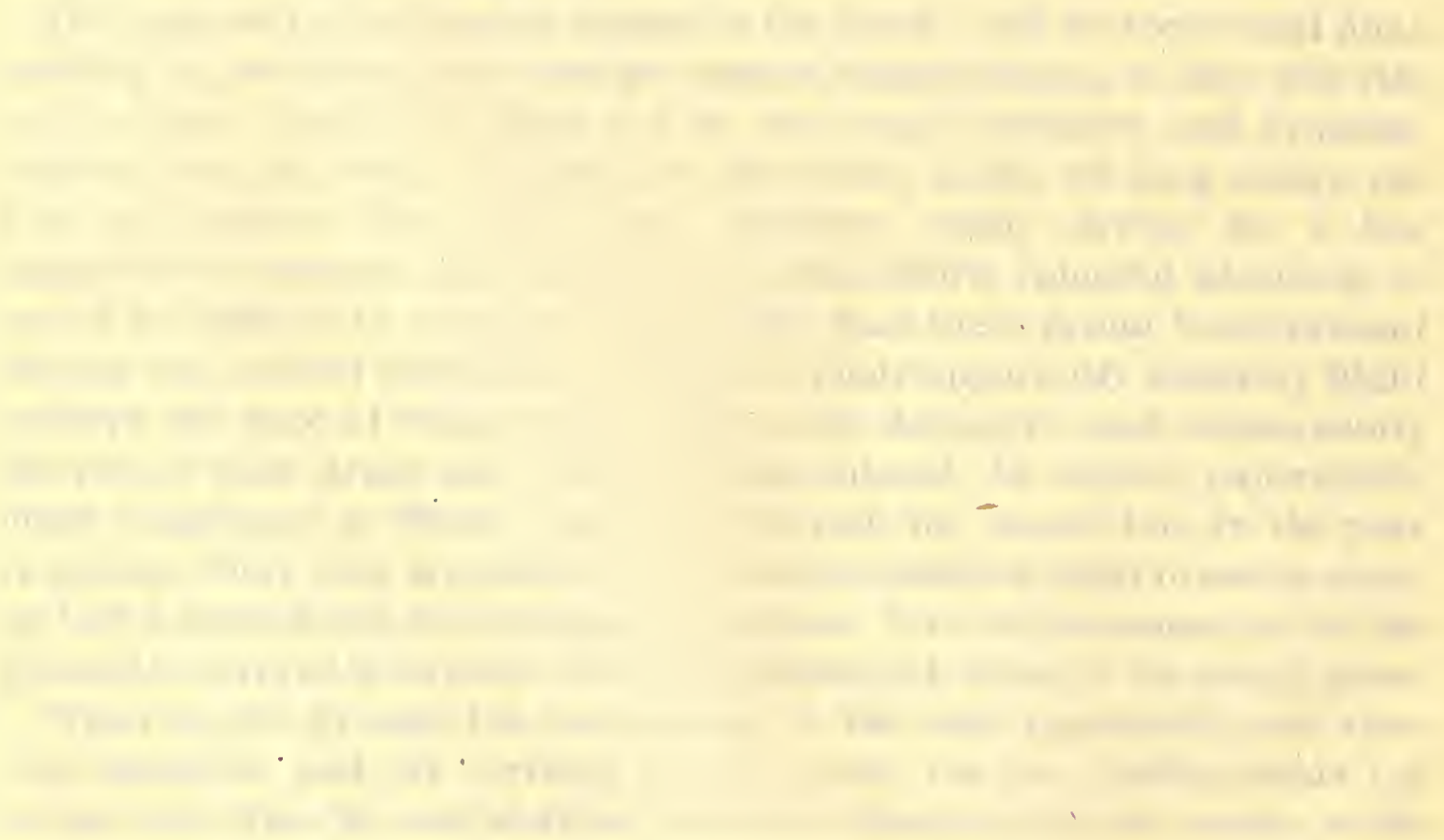




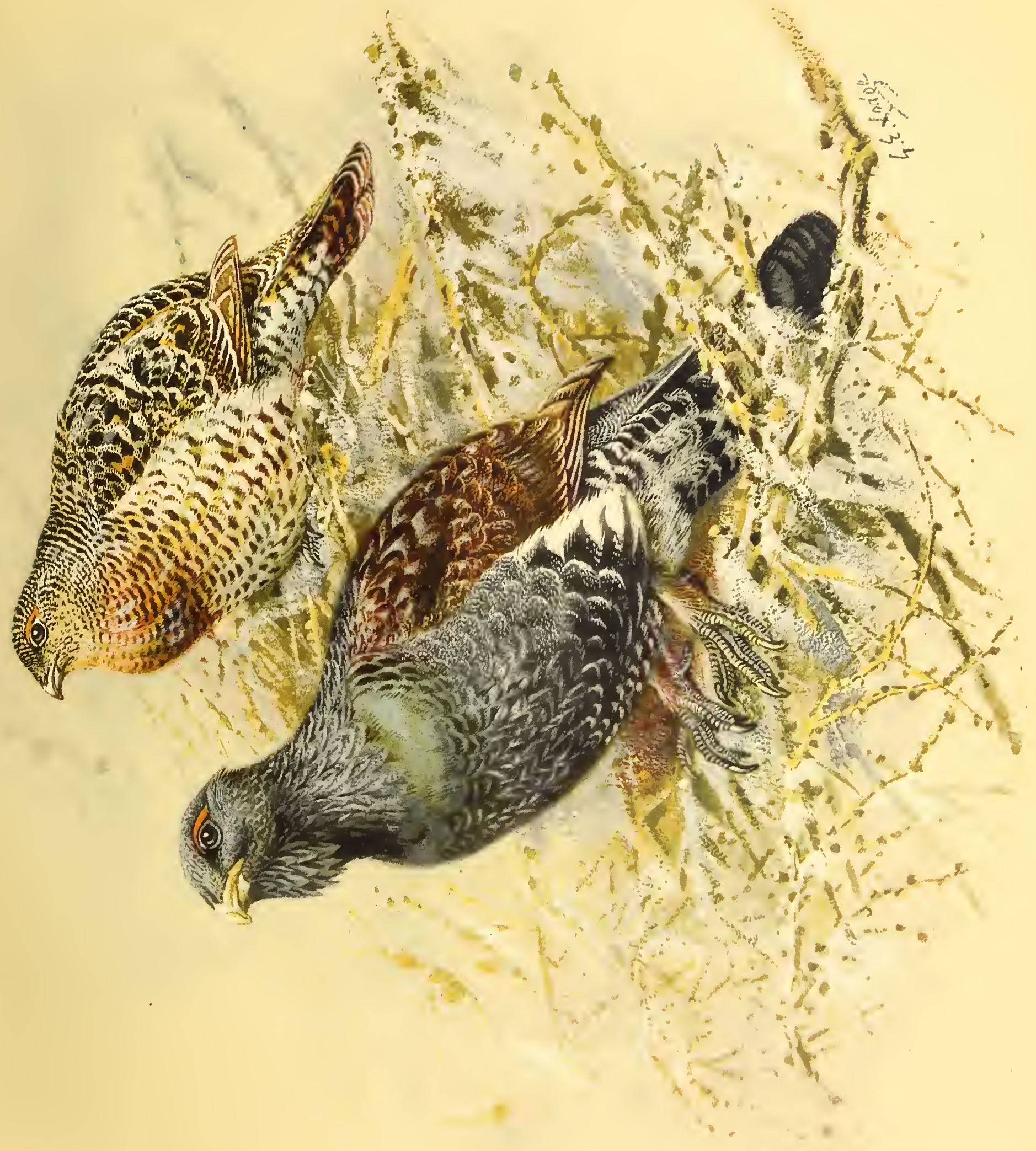




\section{GAPERGAILLIE}

the females display much greater activity. The latter wander much more than the males, and the rapid spread of the species in Scotland during recent years is no doubt due to the fact that the hens sometimes travel long distances to nest. Often, too, finding no males of their own kind, wandering females pair with the blackcock, and the beautiful male hybrids not unfrequently shot in outlying localities are always a sure indication of the gradual spread of the capercaillie. Such hybrids appeared in Aberdeenshire and other northern counties long before the capercaillie had become common there.

Like the black grouse, the capercaillie is polygamous, and the females are estimated by Mr Millais to outnumber the males by about ten to one.

Seebohm, on the contrary, asserts that the males exceed the females in number, but this is no doubt a mistake.

Hybrids.-As already mentioned, the female capercaillie frequently mate with the blackcock, especially in outlying districts, and the beautiful hybrids which result have been described and figured in the account of the latter species. (Plate V.)

The capercaillie has also been known to cross with the willow-grouse and pheasant, the male hybrids with the latter being very ungainly looking birds, and possessing none of the beauty of either male parent.

Enemies.-The enemies of the capercaillie are the same as those of the black grouse and the pheasant. The hens are often careless about covering up their eggs when leaving the nest, and as the latter is often situated in a comparatively open and exposed position, many eggs are destroyed by vermin.

Eclipse-plumage.-Since the above was put in type, I have received, through the kindness of the Marquess of Breadalbane, several male capercaillies in full eclipse-plumage. The sides of the head and neck are covered with short grey feathers mottled with pale sandy-brown, and the chin and throat with short dull black feathers devoid of green gloss. On the sides of the head and neck, as well as on the chin and throat a few of the long pointed feathers of the breeding - plumage are usually retained and are very conspicuous a mong the short eclipse-feathers. These differ so little in general tint from the breeding-plumage, that it is difficult to see what advantage the bird derives from the change. Possibly it is the survival of an ancient plumage worn by the ancestral stock before the long pointed ornamental feathers on the sides of the head and throat had been developed in the modern bird.

W. R. OGILVIE-GRANT. 


\section{CAPERCAILLIE SHOOTING}

T $T$ is somewhat unfortunate that no law has been passed regulating the shooting of the Capercaillie to a season suitable to its position as a bird of game, it being one of the best we now have, although at first its apparent clumsiness and size might suggest the reverse. Capercaillie have increased somewhat slowly since their re-introduction, and those sportsmen who could indulge in its chase have, until recently, been few, and of little account, politically speaking ; wherefore the great grouse has remained in the position of any ordinary wild bird, which may be shot from August 1 to March 1. This is not fair, because it induces young sportsmen, who love to fire at anything that flies, however slowly, to shoot them too soon, and game salesmen to purchase, and expose them for sale in August, when they are, it must be admitted, at their best, from a culinary point of view. On the other hand, if shooting takes place in August the birds which are killed are almost invariably old females and young, a proportion of which, at least ought to be spared. Moreover the female Capercaillie and young rising singly out of dense raspberries at a distance of fifteen yards, and flying slowly straight away, are not such game as any shooter, in the proper sense of the word, is proud to kill.

In the older forests of Perthshire, where Capercaillie shooting has been practised for fifty years and more, only a few are killed early in the season, and these are generally outlying birds tempted to make a meal of cranberry and blaeberry on the open edge of the wood, where black-game or even grouse are to be found. They meet their death in ignominious fashion because they afford that pleasing variety to the bag so keenly desired by some sportsmen.

Capercaillie have now 'extended their range, to a great extent, within the last ten years, and have crossed into Aberdeenshire via Forfarshire, and made their way up through Nairn to Ross-shire, so that it is not too much to say that in the near future the species will be common in nearly the whole of the forest areas of Scotland where it receives protection. This is a satisfactory outlook for the shooter because, for the most part, the great forests of Scotland are devoid of any game suitable to sport with the gun, except a few mountain and brown hares and rabbits. When woods become old, black-game desert them, but not so Capercaillie, which often obtain their food on the largest Scotch firs, and will make these great silent columns of timber their home. It is too much to expect 


\section{CAPERGAILLIE SHOOTING}

that Capercaillie may always be shot just at the season when it is most delightful to seek them. Those crisp frosty days of pellucid clearness and absolute stillness in late October and early November, when the gentle tap of the beater's stick can be heard a mile away, and the crashing flapflap of the old cock caper as he first leaves his tree, can be detected at half that distance, are the days to attack the cock o' the woods. This is too late in the season for busy men who rush north on August 12 and count themselves fortunate if they can snatch a little fresh air and strenuous exercise to recruit their energies. They must needs drive their woods when grouse get wild and the old Blackcocks have ceased to come to the stubbles; hence the best of Capercaillie shooting is not experienced.

After the first snowfall in October is a good time to commence Capercaillie shooting, as it enables the sportsmen to kill whatever comes along, a pleasurable feature in Highland sport. This driving of woods for Capercaillie has charms for the contemplative sportsman, for it is unaccompanied by all the fuss, noise and artificiality of pheasant shooting and grouse driving. If the host-and he should always manage the beats if possible-knows his ground, it is both a pleasure to himself and his few guests that they are all engaging in a sport which requires just a little woodcraft and cunning to ensure success. The young man who persistently smokes cigarettes and tells amusing stories in a loud voice as he walks to his post will not make a successful capercaillie shooter, and will most effectually spoil all chances of birds coming forward to his fellow guests. In the morning, at which time Capercaillie are not on feed, they sit high on the branches of fir and larch, generally on the slope of a hill occupying the west side of a valley, and enjoying the morning sun. In such a position they are swift to take alarm, and although they do not fly readily until danger is imminent, they can both hear and sometimes see all that is going on in the woods around. Consequently it is most desirable for success in this sport that strict silence should be maintained once the wood is reached, and that each of the guns should proceed to his post as quietly as possible. The gunner is often asked to stand in a certain part of a wood or on its outskirts, and it is here that he must exer cise his observation. Capercaillie, after the first movement into the air, when they make a loud flapping with the wings, travel at a rapid pace, often sailing hundreds of yards without a sound. Moreover, when passing between high tree tops, they often swing and sway with such rapidity as to appear much smaller birds than they really are. In consequence, 


\section{THE GUN AT HOME AND ABROAD}

it is of the highest importance to take up one's position in such a spot where one can find clear spaces to right and left and overhead, and where one can at any rate get a fair snap at the passing bird, but also that one can have some view ahead towards the most likely point above the woods from which Capercaillie may approach.

I remember once introducing Mr G. E. Lodge, the artist of this volume and a keen observer of birds, to the joys of Capercaillie shooting. He had never killed one, so I put him in a spot in the Big Wood at Stobhall, where he was certain of a shot in the first drive. After the beat he said he had shot a Capercaillie and a Woodcock. The "Woodcock," when picked up, proved to be another Capercaillie, whose erratic flight he had mistaken for a very different bird. To shoot Capercaillie successfully one must be a good as well as a quick shot. The view of the great bird is often transient, and in that moment of firing decision must be made at once, and the shot placed well forward, so as to align in pattern on the head and neck. The breast, and the crop especially, if distended with food, as it generally is in the evening, is most difficult to penetrate, and a shot that would kill outright a Pheasant, or even a Blackcock, will only be "acknowledged" by the Capercaillie, which in all probability will hold on for a considerable distance before falling to the ground, and being lost. In this respect it is tougher to kill than any woodpigeon, but with the pattern striking the head and neck, even as far as forty yards the Capercaillie comes crashing into the trees, and he is yours. I have seen an old cock Capercaillie killed dead at sixty-five yards, only one No. 4 pellet having penetrated the brain, but this was in the nature of a fluke, perpetrated by a man who ought to have known better than to fire so long a shot.

I have always found a full choke 12 -bore, loaded with 42 grs. Schultze and $1 \frac{1}{8}$ No. 4 shot, the best for shooting Capercaillie. With a full choke gun the chances of kill or miss are far greater than with an ordinary cylinder and modified choke gun, whilst No. 4 shot gives just that additional penetration so necessary in shooting a large bird. When shooting in northern woods in October and November one may often have a chance of killing a good roebuck while driving caper, so it is well to have four or five cartridges in one particular pocket loaded with No. 1 shot. These can be quickly substituted for the smaller shot when the Roe is seen approaching.

As regards the beaters only a small number are necessary, even for 12 


\section{GAPERGAILLIE SHOOTING}

a very large wood, but it is well that they should all be experienced men who know the ground, and will keep a good line. Uniformity of line is far more important in this form of sport than a straggling line with numbers who always make too much noise. The head keeper having given the guns adequate time to allow them to get into position, should himself direct the beat from the centre, using a whistle or small horn to work his flanks if he finds the right or the left getting too far forward. The line should advance slowly, each beater tapping on the bark of the fir trees as he passes them. The old cocks are nearly always the first to move, and will often leave a wood on the very first tap of a beater's stick half a mile away.

I remember once at Murthly that we were about to drive a part of the big wood in which I knew there were only three old cocks. It was not my intention that these birds should come to me, and I had only just posted the last gun and was walking to my position on the right flank when, on looking up, I saw two of the cocks almost over my head. I killed them both, and saw the third pass over the head of the shooter next to me. He had not observed it, and had in fact laid his gun on the ground, not expecting game so soon.

It is generally when the beaters have reached a point half way through the beat that Capercaillie begin to show up. If there is a wood behind the guns they pass straight on, and are quite fearless of shots once they have made up their minds where to go. If the drive is on a steep hill side it is not uncommon to see them coming over at a great height, sometimes higher than any pheasants, and I have even seen them at Rohallion, Struan, Monzie, and Ladywell, quite out of shot. In the lower woods of Aberdeen, Stirling, Forfar, etc., Earn and Tay valleys, Capercaillie are never very high, but generally offer a fair shot at a reasonable height. In large isolated woods in which the birds are accustomed to pass the whole year, they are generally loath to leave, and when driven forward they come to the end and swing up hill or down hill, and away back again over the beaters. In many cases they alight in the high branches of the trees immediately in front of the shooters who are often placed outside the wood. This is a mistake, because a fair shot is seldom obtained. It is better to place the guns in spots from which they can see about fifty to a hundred yards just inside the wood, where chances are obtained before the birds settle or break back.

What used to be one of the best isolated woods in Scotland for Caper= 
caillie was Logierait, Ballinluig, since, alas, blown down in the great gale of 1896. More than half way up the hill at the south end was a large rock which jutted out above the timber, and from this a splendid view could be obtained of the whole valley. Every Capercaillie that moved in this wood could be seen from this point of vantage, and I had many a good stand on this rock, when various tenants rented the shooting from the Duke of Atholl between 1887 and 1895 .

Instances are on record of a cock Capercaillie attacking a person who had come near his beat in the courting season, but I have never seen one attempt any resentment when winged, as I have several times heard imaginative shooters relate. A winged cock looks somewhat formidable when you go to pick it up and kill it, but beyond hissing and displaying the long feathers of the neck it will offer no resistance.

There are few estates in the north where Capercaillie should be driven more than twice in the season, and a third time is only necessary when previous hunts have proved a failure. It must be remembered, however, that in some woods the birds are, to a certain extent, locally migratory, and sometimes take long flights, so that in one a wood may be deserted by them, and in the next a fine lot of birds may be seen. I remember being somewhat disappointed at finding no Capercaillie in two woods which were, as a rule, a certain find for them, and guests who were anxious to add them to their list of slain, departed with, I feel sure, the fixed idea that Murthly was not much of a place for Capercaillie. The day they left I went with the three keepers to drive one of these woods and shoot a certain roebuck whose head I coveted, and had crept quietly to my post when I heard a gentle cracking and flapping of some birds in a big Scotch fir about sixty yards to my front. Getting some obstacles in the way I crawled slowly forward and then saw that the cause of disturbance was a whole pack of Capercaillie on feed. I counted fifteen, and observed their movements for ten minutes before the beaters came up and put them to flight. These birds had probably just come in from the hills above, and although bred on the place, had certainly been absent for some time. In November, 1890, forty Capercaillie were killed at Foulis Wester, Strathearn, in one day. I was there at the regular shoot in November, 1891, and I think we killed four birds, nearly the whole of the stock having left during the previous spring. The sportsman must not expect to shoot Capercaillie as he does Pheasants, Partridges, or Grouse. They are still comparatively scarce, and he must count himself fortunate 


\section{GAPERCAILLIE SHOOTING}

if he gets two or three days at them in a season. It is only by staying up in the Highlands long after other shooters have left for the south, and by enjoying the hospitality of local tenants and proprietors, that a close acquaintance with this noble bird is possible.

Two or three cocks and half a dozen hens to each gun may be reckoned quite a good day, though, if his experience is extensive, he will do better than this. A successful stand at Capercaillie is something to remember, and occurs but seldom; it has this delightful attribute, that you never know when it will come or where. The largest number I ever saw in one drive was at Murthly. In December, 1884, I and two Cambridge friends were just clearing up cock Pheasants in the woods. There had been a three days' gale with snow, and the Big Wood was swarming with capers. I placed my dear old friend W.L.J., one of the most delightful of men and one of the worst shots in existence, in a spot near the keeper's house in the Big Wood, and no fewer than thirty-eight caper sailed over his head. He killed one, and was well pleased, I am glad to say. The best "stand" I ever had was at Dupplin one November day in 1889 , when I got four cocks and six hens in one short drive. I have been one of the guns when the following bags of Capercaillie have been made in Perthshire between 1883-1898 : Ladywell, 35 cocks ; Logierait, 33 ; Dupplin, 28, 27 ; Murthly, $28,25,22,21,20,18$, etc. ; Rohallion, 18 (12 cocks); and many bags of 18 and under. The largest number of Capercaillie ever killed in one day was at Fotheringham, in Forfarshire, in November, 1894. The birds had been increasing there for some time, and had done much damage to the crops, so an organized battue was arranged by Mr Walter Fotheringham, the proprietor, and 107 birds fell to the guns. James Keay, our old keeper at Murthly who gave me these particulars, was present and counted the birds. No doubt a larger bag of Capercaillie might be killed on the Taymouth estates, the site of their reintroduction, than at any other place in Scotland, but the present Marquis of Breadalbane kills very few, as he likes to see them flying about, and thinks they do not do much damage to timber. In 1862 it was estimated that there were at least 1,000 to 2,000 Capercaillie on the Taymouth estates, but this I think was an over-estimate at the time, though at the present date it is well within the mark.

It is not difficult to maintain and to increase a stock of Capercaillie provided the woods are suitable and the birds have bred there. The great thing is to avoid killing too many hens, and to keep down the vermin, especially foxes and hooded crows. Female Capercaillie usually place their 


\section{THE GUN AT HOME AND ABROAD}

nests in somewhat exposed situations, generally in the open forest at the foot of a Scotch fir, beech, or oak, and their nests when vacated, are easily observed by the sharp-eyed crow. Of late years Highland proprietors have taken much interest in arboriculture, with the result that all creatures hostile, or thought to be injurious to trees, have been exterminated without compunction. Under this ban comes the Capercaillie, I think most unjustly. Capercaillie are accused of destroying young plantations wholesale, but this is a gross libel on these noble birds, because they seldom, if ever, resort to very young plantations, and never if there are no big roosting trees. Moreover, at Murthly, which is one of the finest estates for trees in the kingdom, where all the conifers grow to their largest size, and young plantations are numerous, the question of Capercaillie injuring young timber was never advanced, nor were the birds ever seen or known to touch any trees except larch, birch, and Scotch fir of reasonable size, and these they only prune, as it were, scarcely arresting their growth. The top shoot is often bitten off young forest trees, but the sinner in this respect is generally the Black grouse. By far the worst enemy of young fir and larch is the squirrel, whose favourite food at certain seasons is the shoots of conifers. Another ridiculous theory is that Capercaillie drive off Pheasants. This is most unlikely even if we consider the comparative activity of the two species, and even if it were the case I cannot imagine any sportsman preferring the smaller to the larger bird in the great fir forests. The latter is not the true home of the Pheasant, and as there are always plenty of coverts frequented by Pheasants where the Capercaillie seldom, if ever, come, it seems churlish to desire the presence of this much pampered creature everywhere.

Capercaillie are now so generally distributed in the localities they frequent, that they may be found in all the little outlying woods on the large estates. It is pleasant, therefore, to the shooter satiated with grouse and pheasants to be able to have little improvised drives, taken at haphazard at the end of a long day on the moor, and to have a chance at the noblest game bird these islands contain. Many a man would sooner shoot an old cock caper than scores of grouse, so that to the average shooter this little variety often affords a red-letter day. Wet days are not the time to pursue the caper. In heavy rain they lie close in the thickets or bracken, and will not leave the trees. Last year an enthusiastic young sportsman ousted me out of bed at $5.30 \mathrm{a} . \mathrm{m}$. to come and help to beat a wood I knew well contained many Capercaillie. By breakfast time, after an immense amount of 


\section{GAPERCAILLIE SHOOTING}

climbing over fallen timber and crashing through fern brakes, we arrived home soaked to the skin, having seen one small sodden hen, which was shot, and disturbed another.

On leaving a tree in a wood the Capercaillie makes a loud flapping noise and falls several feet earthwards to clear the branches before getting under weigh. The bird is then difficult to shoot, especially so as it nearly always leaves the tree on the other side to that on which it hears a noise. There is therefore little, or to speak more correctly only a poor, chance of shooting this bird by walking through its haunts. The larger the timber too the greater the sound man makes in walking, so that the bird is on the alert long before the shooter comes within gunshot. I have killed Capercaillie often when walking through woods in Scotland, but do not remember ever to have come within shot of them by day in the large forests of Scandinavia and the Carpathians. In the latter a shooter only surprises them when on feed on the ground in the early morning and in the evening.

Our friends on the Continent think us very unsportsmanlike to shoot the Capercaillie by driving in Scotland. We, on our part, can hardly see the fun of potting with a shot-gun a large bird like a Capercaillie, as it sits on the summit of a withered pine in the early morning. But both are wrong, because neither understand the finer points of the game. I have often enjoyed both these sports, and can only say that comparisons are odious. Both methods of shooting the Capercaillie are admirable sport, and can, in no circumstances, be compared. A man who only shoots or fishes has no right to say to a golfer that he cannot see the fun of hitting a ball into a hole, and, vice versa, the golfer might retort that murdering tame pheasants or standing up to your waist in icy water to catch nothing is not sport. Neither understands the finesse or the multifarious experience and skill required to ensure success, and so we must leave each sport to charm its particular votaries.

Feeling that my experience of Capercaillie was incomplete without stalking the cocks when " singing" in spring, I first tried the game in Scotland. One April morning I heard from the worthy keeper that two cocks had been located on certain trees in the Big Wood here, and that I had better come at once and try the methods of continental attack. In the dark I set out for the first "spel " tree, and had got to within 300 yards of it before $I$ heard the old cock in full song. Extreme caution was now necessary -I had learnt that no noise must be made during the first part of the song, for the bird stands erect and vigilant. After waiting a few minutes I 


\section{THE GUN AT HOME AND ABROAD}

advanced very carefully, and became aware of a curious clicking noise proceeding from the tree, which, on a closer approach, I found to be the regular commencement of the first part of the main song. Klick-kleckKlick-kleck-Klick-kleck went the bird, making a pause of ten to fifteen seconds between each call, that seemed to be like two sticks knocked together. The cry was continued crescendo for some moments, the pace getting quicker and quicker, until it finished in a clear ringing note, which continental observers call "the ringing of the bell." It certainly has a metallic clanking sound, which it is impossible to express onomatopæically.

There was then a slight pause, and several notes were uttered like the uncorking of a bottle, quickly repeated. These sounds were all very loud, and could doubtless be heard at a distance of half a mile, especially the "uncorking" note, but the third phase of the song-a curious twittering sound something like the twittering of little birds or the gentle grinding of a knife-was so low that the observer had to be within 100 yards to hear it. It is only during the utterance of the latter part of the song that the male Capercaillie can be approached with any degree of safety; in consequence one has to guess the moments at which it is taking place when advancing at a distance. Also it is of such short duration that not more than three or four long paces can be undertaken by the sportsman, and he must then keep perfectly still until the next third part occurs again. I found that there was no difficulty in stalking the first cock, owing to the soft nature of the ground, and the absence of dry sticks, so fatal to success in Austria and the Carpathians. When within 150 yards I clearly saw the cock outlined against the clear sky of the rising dawn, and getting trees in line, reached a point within $\mathbf{8 0}$ yards, where I could clearly observe his movements. At first he was very alert, standing up to his full height and looking about in expectation of some disturbance, or looking down at the hens, which were somewhere on the ground close by, although I could not detect them. Then, as he commenced his klicking notes, he still kept upright, but as the song proceeded the head was gradually sunk, the tail spread, and the wings trailed down. In the final phase of the show the bird appeared to be oblivious to all surroundings in the excitement of the moment, and to roll from side to side as he spread the feathers of the neck and tail to the fullest extent. By taking unusual care I eventually succeeded in getting within thirty yards of this cock, and killed him with a shot just as he finished his song. There was a momentary pause, and 


\section{GAPERCAILLIE SHOOTING}

then three hens rose from a thicket about forty yards distant, and flew noisily away. The next day I stalked the second cock, and watched it for a long time. The ground was also very favourable for silent approach, so much so that I got within twenty yards of it before allowing it to escape, as I did not wish to kill it. Three days later I stalked a third cock on the edge of the Buffalo Park at Rohallion. Here the ground was far more difficult, and full of fallen debris ; nevertheless I got within forty yards of the male, who had just left his tree, and was still displaying on the top of a stone wall. I think I could also have killed this bird had I wished to do so. This small experience of stalking the Capercaillie in spring convinced me that in Scotland, at any rate, there was no great difficulty in getting within shot of one's quarry, provided care and patience were exercised, and this was due to the fact that the yielding heather and moss of Highland woods were all in favour of the sportsman. Two subsequent visits to the Garpathian highlands of Galicia, however, convinced me that in that country the stalker must both have unusual luck as well as skill and local knowledge to shoot the bird in spring, for the woods there are vast, dry, and very high. The ground, too, as in Russia, is covered with swamps and broken dry sticks, to tread on one of which is generally disastrous.

In the Carpathians and Hungary, but not, I believe, in Bohemia, the male Capercaillie shows off in the evening as well as in the morning. Prince Demidoff, who has stalked many Capercaillie in spring, tells me that in a certain wood south of St Petersburg large assemblies of Gapercaillie sometimes occur in the spring. On one occasion (the owner of the place related to him) over eighty males were showing at one and the same time, and it was impossible to stalk a single bird, owing to their numbers.

At the time I wrote my last work on "The Natural History of British Game Birds" (1908), I had never heard the male Capercaillie attempt any song in the autumn, but I felt sure that it did not differ from the Blackcock in this respect, and received a communication from Prince Fürstenberg to the effect that it was by no means rare for the male to sing in autumn. It was therefore a great pleasure to hear the song one October morning in 1910 as I was snatching a hurried breakfast in my hut in the Carpathians. Peeping out of the door I could just make out the form of a cock caper seated on the top of a dead spruce. He was evidently suspicious, for he could hear the men moving about in the "koliba" 


\section{THE GUN AT HOME AND ABROAD}

close by, and did not stay long. The notes did not seem to me so loud or so varied as the spring call, but I could see that his actions were the same.

In the evening the cock moves towards his "spel " tree about sunset, and after he has fed. Here he utters a different cry like the notes Ackack-ee-ach, something like the noise of a person being sick. The bird repeats this over and over again, long after all other creatures have gone to rest.

In Norway it is sometimes necessary to replenish the pot, and where ryper are absent or scarce some sport may be found by using a trained setter or even an elk-hound to hunt Gapercaillie when on feed in the evening. The elk-hound, when the large game is scarce, will often, to one's great annoyance, take the sportsman up to Capercaillie, but the same kind of dog, specially trained to follow capers, is a valuable animal, superior to a setter, who is apt to be both wild and noisy in the woods. I have shot a few capers in this manner with an elk-hound held in leash, and have always been more interested in the skill and nose of the little hound than in this particular form of shooting. Walking home in the evening, when there was no chance of disturbing elk, I have twice shot cock Capercaillie with the Mannlicher rifle, and this form of sport, and a very high-class one it is, is much practised both in Norway and Sweden in the winter. One Christian Fiskum, my hunter in the Namsen valley in 1899, and said to be a wonderful rifle shot, told me that he spent every winter in stalking Capercaillie with the rifle. On the steep slopes of the Namsen valley a pack of Gapercaillie can be spied on the snow-laden trees two or three miles away, and Christian would soon run to them on his "ski." The last approach has to be carefully made, and at 100 yards Christian would sometimes kill two and three birds out of a pack before the rest took wing. His method is always to select the bird that is nearest the ground, and as this falls it does not alarm the others. The next lowest is then selected and killed, but if by any chance a lower bird has been overlooked, that is easy to do in the dense foliage, the noise created by the bird last shot always alarmed the unseen bird below, who at once takes to flight and scares all the others. Christian has several times killed as many as four out of one flock, but this is unusual. This hunter kills as many as 100 to 150 every winter, and sends them frozen in a sledge to market.

To British sportsmen the prospect of increased opportunities of shooting the Capercaillie, in Scotland at least, are very favourable, and everything 


\section{CAPERCAILLIE SHOOTING}

should be done to further the interests of so grand a bird. There are many great woods, in England, Wales, and Ireland, where it would do well if only some interest were taken in establishing the species in the way the Duke of Bedford has done at Woburn. Personally I should like to see Roe and Capercaillie everywhere, as they may be seen in many parts of Germany and Austria. Our Teutonic neighbours are keen agriculturists, arboriculturists, and sportsmen, and they do not grumble when a little damage is done by birds and beasts, for the gain on the other side, both in sporting rents and the pleasures of hunting, are entirely on the credit side.

J. G. MILLAIS. 


\section{BLACK-GROUSE}

\section{LYRURUS TETRIX}

(Plates II-IV)

Tetrao tetrix, Linn, Syst. Nat. i, p. 274 (1766); Gould, Birds Europe, v, pl. 250 (1837); Saunders, ed. Yarrell, Brit. Birds, iii, p. 60 (1882) ; Seebohm, Hist. Brit. Birds, ii, p. 435 (1884) ; Lilford, Col. Fig. Brit. Birds, pt. vii (1891); Millais, Game Birds, p. 21, pls. and woodcuts (1892); Saunders, Ill. Man. Brit. Birds, p. 493 (1899).

Lyrurus tetrix, Swains. and Richards. Faun. Bor.-Amer. ii, p. 497 (1831) ; Ogilvie-Grant, Cat. Birds Brit. Mus. xxii, p. 53 (1893) ; id., Handbook Game Birds, i, p. 45 (1895) ; Millais, Nat. Hist. Brit. Game Birds, p. 18, pls. (1909).

Walsingham and Payne-Gallwey, "Badminton Library" Moor and Marsh, p. 45 (1886).

DULT male. (September to July)--General colour black;
the feathers of the head, neck, lower back and rump
widely margined with purplish steel-blue, those of the
mantle more narrowly edged with the same colour.
The outer webs of the outer primary quills pale brown,
more or less mottled with white, the basal part of the innermost primary and secondary quills white, the secondaries being also narrowly margined at the extremity with white. Except in the most adult examples, there are usually traces of rufous mottlings on the outer secondaries. Axillaries, under wing-coverts, and under tail-coverts pure white, though in some examples the latter have a black heart-shaped spot at the extremity. Thighs more or less mixed with white. Naked skin and wattle above the eye scarlet; bill black; feet horny brown. Total length 23.5 inches; wing 10.3 inches; tail 8.8 inches; tarsus 1.9 inch.

Adult male.-(July to September).-In summer, when the males are moulting, the black feathers on the back and sides of the head and nape, and often some of those of the upper mantle, are replaced by a temporary plumage of chestnut or brownish-buff and black barred feathers, somewhat like those of the female. The chin and throat are more or less white. This "eclipse" plumage is retained until the quills of the wings and tail have been renewed; the new black feathers on the head and neck being the last to appear, and often incomplete until the latter half of September.

Immature male in first autumn-plumage.-The blue gloss on the plumage is much less brilliant, many of the feathers on the head and neck are narrowly fringed with rufous, and the wing-coverts, scapulars and secondary quills are more or less densely vermiculated with the same colour. The first primary quill is more pointed than in the adult, and the 


\section{BLAGK-GROUSE}

tail is shorter, the outer feathers being much less curled at the extremity, and the tips of the middle feathers are narrowly margined with white.

Young male in first plumage.-Resembles the immature female, but when about as large as a partridge, the black feathers of the first autumnplumage begin to appear on the sides and middle of the breast and belly, likewise on the shoulders and back, and in the tail.

Adult female. -Top of the head, neck and back barred with rufous-buff and black; wing-coverts, scapulars and secondaries very similar, but mottled rather than barred and blotched with black; the longer wingcoverts, scapulars and secondary quills irregularly tipped with whitish. Primary quills dark brown, mottled on the outer web with buff, the basal part of the inner primaries and secondaries white. Sides of the head, chin, and throat buff, spotted with black and rufous, and fringed with white; abdomen and flanks more mottled with black, legs white, finely mottled with dusky. The under tail-coverts whitish or pale rufous, barred with black, and widely tipped with white, and extending beyond the middle pair of tail-feathers (p. 2, fig. 2). Tail black, mottled with rufous, and tipped with white. Total length 17 inches; wing 8.9 inches; tail 4.5 inches; tarsus $1 \cdot 6$ inch.

Immature female in first autumn plumage. - Can be distinguished from the adult by having the first primary quill more pointed at the extremity, and mottled with rufous-buff.

Young females in first plumage are much like the adult female, but have the rufous-buff shaft-streaks at the ends of the wing-coverts, scapulars, outer secondaries.

Young in down.-Crown rather bright chestnut, bordered with black; forehead and lores buff, with a $\Lambda$-shaped black patch behind the bill; two wide buff superciliary stripes surround the crown and almost unite with one another on the occiput; two irregularly shaped blackish patches behind the eyes and on the sides of the nape. General colour above buff, inclining to chestnut on the wing-coverts and rump; a wide blackish band down the back of the neck, commencing on the occiput, and becoming double on the dorsal region; the cheeks and throat yellowish-white; rest of the under parts pale buff.

Black grouse are also commonly known as black-game : the males as blackcocks, and the females as greyhens.

Female assuming male plumage.-Greyhens which have become barren either from age or from some accidental cause, such as a shot in the 
ovary, commonly assume a partial male plumage. The most complete examples are very handsome birds, with the chin barred black and white, the throat pure white, and with much black in the plumage, especially on the lower back, breast and abdomen. The white bases of the secondary quills are much more extensive, and form a visible white speculum on the wing when closed, as in the blackcock. The tail is long, deeply forked, and black, the tips of the feathers being narrowly edged with white.

Male assuming female plumage.-In the British Museum there is a specimen procured at Perm, East Russia, which is said to be a male in female plumage. It resembles the most complete form of female in male plumage, described above, and is a very handsomely marked bird. The determination of the sex in this specimen is, however, somewhat doubtful, and probably rests on the authority of some Russian taxidermist.

Variations in plumage. - Variations in plumage are not very common among black-game, but birds with partially white plumage are occasionally met with. Pied blackcocks, with their whole body-plumage spangled with white, are sometimes shot, and are curious and distinctly handsome birds. There is a very fine mounted specimen in the Natural History Museum, presented by Mr G. Ashley Dodd in 1908. A very similar looking bird was presented to the National Collection some years previously by the late Lord Tweedmouth, but, on close examination, it proved to be "a fake," all the white feathers having been neatly glued in among the black plumage by some dishonest person!

Males have been shot with the wings and tail white, with the whole underside white, and with the entire plumage silvery grey ; and females with the plumage pure white, greyish -white, and pale buff.

Besides these, other remarkable birds of both sexes in mixed plumage have from time to time been obtained, and a large number of these interesting specimens are to be seen in the Hon. Walter Rothschild's splendid collection at Tring.

General distribution.-The black grouse is found in suitable localities over the greater part of Europe and Northern and Central Asia. In the west it ranges to Great Britain, Holland, Scandinavia and Russia up to $69^{\circ} \mathrm{N}$. lat. ; eastwards it extends to North-east Siberia up to about $67^{\circ} \mathrm{N}$. lat.; though it is not known to occur in the Pyrenees, it is met with in North Italy, North Caucasus, the Tian Shan Mountains, and South Manchuria. 


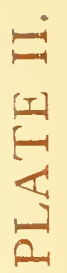

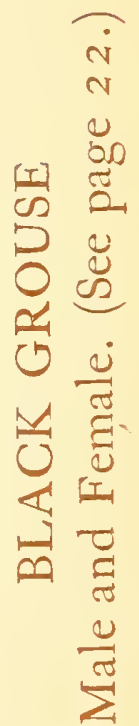




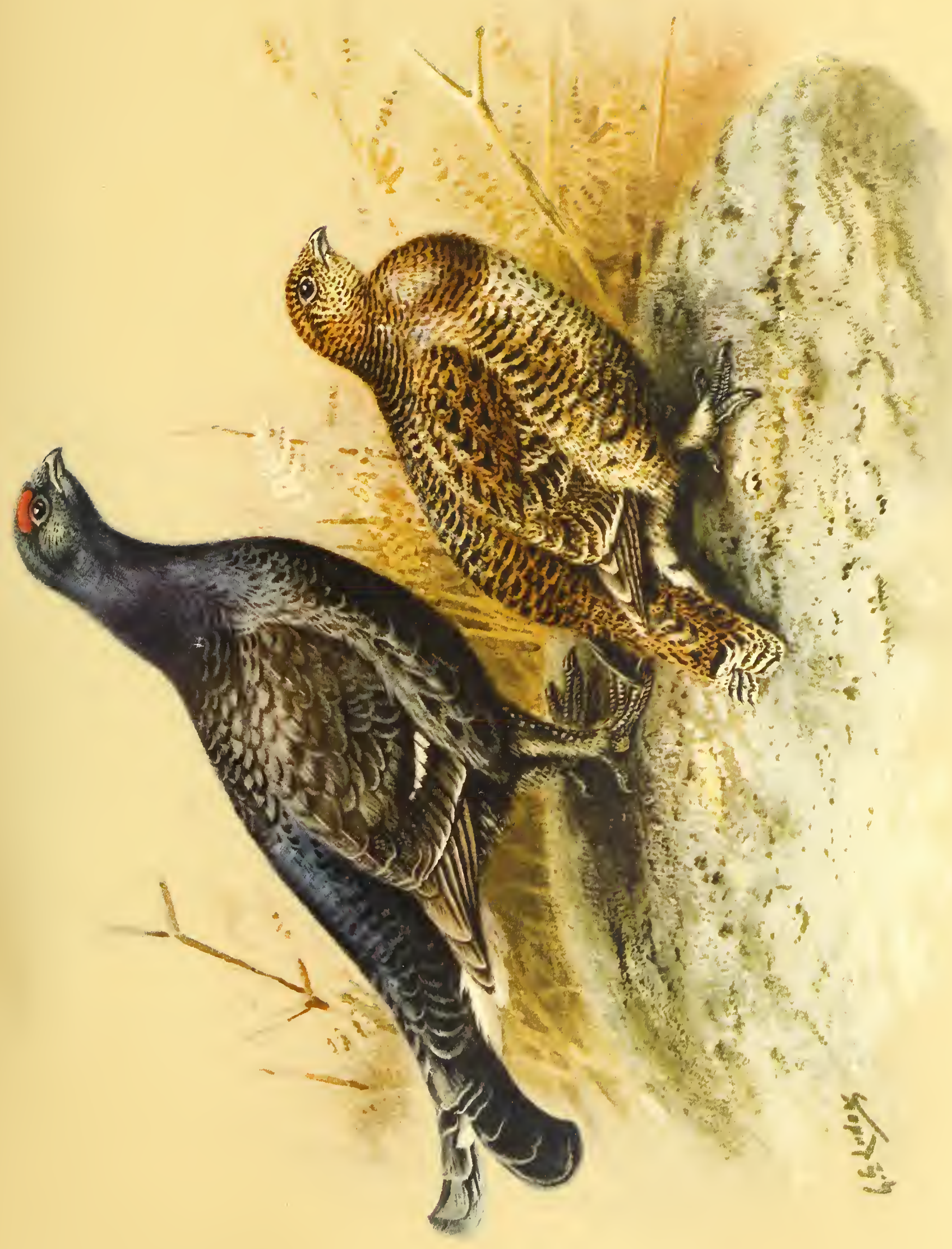





\section{BLACK-GROUSE}

Allied species. - In the Caucasus Mountains L. tetrix is represented by a very distinct and less robust species, the Caucasian black grouse (L. mlokosiewiczi).

The male has a remarkably developed tail, and is entirely black, and the female is easily distinguished from that of $L$. tetrix by having the bars and markings on the breast much finer. The young male in its first autumn-plumage is peculiar in that it assumes a hen-like plumage which is retained throughout the first year, and thus differs entirely from the young male of $L$. tetrix.

Distribution in the British Isles.-On the moorland districts of North Devon and Somerset it is still to be found in some numbers, but these are rapidly decreasing; and in Cornwall, South Devon, Dorset and Wiltshire it has now become very scarce. In other southern counties, where it formerly flourished, it is now extinct, or nearly so. Attempts have been made to re-introduce the species in various counties, but with small success, and even in Bedfordshire and Norfolk, where numbers have been turned down during recent years, it does not appear likely to re-establish itself permanently. A few are still met with in many parts of Wales and in Shropshire, and in parts of Herefordshire, Staffordshire and Derbyshire they are still tolerably numerous. In Lancashire, Cumberland, Yorkshire, Durham, and Northumberland they become gradually more numerous as one goes northwards. In Scotland the black grouse is generally distributed, and plentiful in suitable districts, its increase or disappearance in any locality being largely influenced by the age of the woods and other local conditions. On some of the Inner Hebrides it still flourishes, but in the Outer Hebrides, and in the Orkney and Shetland Islands, as well as in Ireland, it does not exist, and attempts to introduce the species have not met with success.

Food.-The food of the black grouse is very varied : tender shoots of heather and blaeberry, grass seeds, the tops of flowering rushes, berries of various kinds, grain, young shoots and buds of larch, fir, alder, and especially of birch, are favourite articles of diet. Insects are also freely eaten, and large quantities of grit to assist digestion. In autumn the crops of the birds may frequently be found filled with rowan berries, and their partiality for this extremely acrid fruit is truly astonishing.

Flight.-The flight is very rapid and well sustained, and though the bird with its comparatively slow, regular wing-beats does not appear to be travelling as fast as a driven grouse, it can easily outstrip the latter. 


\section{THE GUN AT HOME AND ABROAD}

This may be seen when both species are being driven together towards the "butts."

When once a line of flight has been determined on by the black grouse it is not easily turned from its course, and, in this respect, resembles the red-legged partridge.

Breeding habits.-Black-game are polygamous, that is to say, one male pairs with many females. The pairing-season commences towards the end of March or beginning of April, when the cocks are in the habit of resorting at dawn and sunset to some particular spot to display their charms to the females and give battle to their rivals. The extraordinary pantomime gone through by each male as he struts round the arena, generally an open patch of ground, worn nearly bare by constant traffic, is a most entertaining sight, and will amply repay anyone who does not mind rising early.

In Perthshire, the writer has had many opportunities of observing these courting-grounds. One very favourite "lek" was situated on the grassy edge of a moor, just outside a fir-wood, enclosed by a stone dyke. It was thus easily approached, and offered an exceptional chance of seeing without being seen. With drooping wings, outspread tail, and many other curious antics, accompanied by an occasional spring into the air, the blackcocks endeavour to secure the goodwill of the greyhens and when two birds meet, a slight skirmish takes place, in which a few feathers are lost. As a rule no serious fights, such as one sees between capercaillie or red grouse, occur, merely a "round with the gloves" to entertain the admiring but somewhat apathetic greyhens; but occasionally, when two old rivals who have already established their claims chance to meet, a furious " set-to" may be witnessed, the fight lasting till one of the birds is ignominiously chased off the courting-ground, or, more often, till both birds are thoroughly exhausted, bleeding and torn. These strange entertainments last till the hen birds have laid all their eggs and commenced to sit, when the cocks are seen no more, the hatching of the eggs and rearing of the young being exclusively the task of the other sex.

In autumn there is a revival of these scenes at the courting-grounds, and on fine October mornings I have several times witnessed a number of blackcocks rehearsing for the coming spring entertainment, and heard them uttering the same crooning love-notes, but the whole performance was tame compared with that seen in April.

On arriving at the "lek" the blackcocks utter a peculiar prolonged 26 


\section{BLAGK-GROUSE}

vibrating crooning or cooing note, which is their love-song, and can be heard at a long distance on still mornings, but when fighting they utter a hoarse crow at intervals. At other times they are remarkably silent birds and seldom make any sound when flushed.

Nest.-The nest, a slight hollow scratched in the ground, usually well concealed among blaeberry, heather, and grass, is sometimes situated in the open, but more often in open fir woods or in fir plantations.

Eggs. - Eight or ten yellowish-buff eggs, spotted with reddish-brown, and measuring about 2 inches by 1.4 inch, are laid in May, and incubation lasts about 24 days.

General habits.-The greyhen is generally considered a bad mother, and justly so, for she is easily scared from her nest, and seldom returns if once frightened. When her young are hatched she does not exercise sufficient care to save them from falling into drains and such like deathtraps, and in this and other ways generally manages to lose more than half her brood before they are many days old.

At the same time I have known instances when the hen has exhibited great devotion, preferring to perish herself rather than desert her brood. During a disastrous wood-fire on the Black Isle I once saw a greyhen with seven or eight young become surrounded by a ring of blazing heather and fir trees. She might easily have saved herself, but as the young were too small to fly, she would not leave them, and all perished. For the first few weeks of their lives, the young birds feed chiefly on insects, especially on ants and their pupæ. During the early stages they are very delicate birds, and grow so slowly that they take at least four months to reach maturity.

The season for shooting black-game is from August 20 to December 10, except in Somerset and Devon and in the New Forest where it is from September 1 to December 10. They are not really fit to shoot till the end of October.

Though the blackcock is usually an extremely wary and alert bird, his boldness at times amounts to foolhardiness or stupidity, as the following instances will show. Some years ago when shooting in the North of Scotland two guns killed twenty-four blackcocks in a couple of hours between 3.30 and $5.30 \mathrm{p} . \mathrm{m}$., as they flighted from a large fir-wood to some stubble-fields about half a mile distant. It was the best bag of blackgame that had been made for many years in that locality, but the birds were much more plentiful then than they are at the present time. A drive 
in the wood had produced two or three cocks, and these were set up on paling posts as decoys, the guns being concealed a quarter of a mile apart among the stooks. Parties of birds were constantly to be seen leaving the wood to feed on the oats and barley; sometimes a lot of old cocks, at other times a mixed pack of young cocks and greyhens. One lot of five old cocks passed rather wide of one of the guns, and only one was killed; after flying for a few hundred yards the remaining four turned and flew straight back over the decoy, leaving two more of their number behind. Two continued their course towards the wood for about a quarter of a mile, till they were nearly within shot of the other gun, then once more turned back and, heedless of the fate of their three companions, came straight to their death. Thus the same gun killed all five cocks within a few minutes. They had apparently made up their minds to solve the mystery of the decoy-birds on the posts, or die in the attempt.

On another occasion in the same locality a fine old cock was observed perched on a paling-post in the stubble fields, and the keeper (with his perennial gun) was sent round to try and drive it and other black-game in the field, over the guns. The old cock allowed the man to approach within thirty yards of it and shoot it as it sat ! A good many labourers were working at the harvest on some of the neighbouring stubbles, and the bird must have mistaken the man's occupation.

The following incident will serve to show how extremely wily the blackcock usually is. A small drive for black-game was being carried out on a hill-side covered with birch trees, rough patches of brambles and bracken. The first few cocks came over the guns in the usual manner, but several others, which followed, alighted on the ground before coming within shot, and made good their escape on foot. One bird was seen to enter a small isolated patch of brambles, and to remain there. When the drive was over, with the aid of a keeper and a retriever, an attempt was made to dislodge it, but without success, and the general opinion was that it must have "run on." No sooner, however, had the guns moved off out of shot than the cunning old bird emerged from its hiding place and flew quietly off. This instance also shows the remarkable power which blackgame, in common with other game-birds, possess of voluntarily suppressing all scent in time of danger and of baffling the efforts of the best dogs to find them.

The greyhens are not nearly so wild as the blackcocks, and when they rise on the open moor are often mistaken for grouse by those who are not 


\section{BLAGK-GROUSE}

versed in the great difference in the flight of the two birds. Many hens are thus shot which should be carefully spared. The coveys of young blackgame are very tame, and being very slow-growing birds, only half grown by the middle of September, fall an easy prey to the unscrupulous gunner. In autumn the coveys are very fond of repairing to the turnip-fields, where they feed on the tops and find an abundance of insects. If disturbed they will rise singly or in pairs, and may be easily killed down to the last bird by some party legitimately engaged in shooting partridges. For this reason the shooting of black-game ought not to commence until the end of October, by which date the young cocks have usually assumed a large part of their first autumn-plumage, and are more able to take care of themselves.

In July and August when the old blackcocks are in full moult and have assumed the "eclipse," chestnut, and black barred plumage on the head and neck, and sometimes also on the upper mantle, they are usually to be met with singly, and are rarely seen. For a time, when the moult is at its height, being devoid of tail-feathers, and possessing very few flightfeathers, they seek safety by hiding and skulking in dense covert, such as long heather, juniper and gorse. Even if hunted for with good dogs, they are very difficult to find, for they squat so closely and suppress their scent so successfully, that they are often passed by undetected. Some years ago, when specimens of old blackcocks in their "eclipse" plumage were required for the Natural History Museum, it required days of careful search to obtain four in a locality where black-game were known to be particularly numerous. More miserable looking objects than these moulting cocks it would be difficult to imagine, and it was hard to believe that such sorry looking birds would soon be transformed into the noble blackcocks to be met with a month or two later.

In late autumn and winter the males, especially the old birds, keep much together in packs or small parties. In Strath Naver, in Sutherlandshire, where some ten years ago black-game were plentiful, the writer once saw a pack of about two hundred, apparently all old cocks.

Position of legs in flight.-They flew close overhead over the valley, their tails looking abnormally long, while their legs, fully extended and pressed closely against the white under tail-coverts, were plainly visible. All game-birds carry their legs in this manner when in flight, a fact which is worth emphasizing, as the contrary has been stated in print. 


\section{THE GUN AT HOME AND ABROAD}

Like other comb-toed grouse, such as the capercaillies and hazelhens and the various allied forms found in North America, black-game spend much of their time in the trees, where they are perfectly at home. One of the most beautiful sights in the world is a number of blackcocks and greyhens feeding on the buds of the birch-trees with the sun shining on their burnished plumage. On some of the small islands in Loch Ard, in Southern Perthshire, I have frequently watched them thus, and so tame that they scarcely took any notice of the passing fishing boats. The ease with which these heavy birds moved about among the slim birches, and their graceful movements as they picked off the buds was truly astonishing. On the ground their natural gait is slow and dignified, but if wounded they can run very swiftly, and if not looked for immediately are often lost. They often roost on the ground among the heather and juniper bushes, but also in the Scotch firs.

Though often found far out in the open moor, the true home of the black grouse is lower down the hill-sides, where woods of fir and birch afford the seclusion it loves. The sides of rocky mountain-streams, clad with heather and bracken and with scattered birch and rowan trees, are favourite resorts; likewise reed-beds, clumps of alder growing in marshy situations, and young fir-and larch-plantations. The cultivated lands in the immediate neighbourhood of the woods they frequent are much resorted to, and they may frequently be found feeding in the early morning and afternoon both on the stubble-fields and among the standing crops, while reference has been already made to their partiality for turnips.

Hybrids.-Hybrids between the male of this species and the female capercaillie are by no means rare; it also occasionally crosses with the red grouse, willow-grouse and hazel-hen, and more commonly with the pheasant, the Rev. F. C. R. Jourdain having recorded at least fifty known examples of the latter. ("Zoologist," September, 1906.)

The male hybrid with the capercaillie is a large and very handsome bird, with the tail somewhat forked. It is easily recognized by the purple gloss on the chest, quite unlike the glossy green chest of the male capercaillie or the steel-blue chest of the blackcock. (Plate V.)

The female of this hybrid is much like the greyhen, and for that reason is no doubt often overlooked, but it may be recognized by having a nearly square tail and the under tail-coverts shorter than the middle pair of tail-feathers, which are about equal to the outer pair. 


\section{BLACK-GROUSE}

In the greyhen, as already mentioned, the under tail-coverts extend beyond the middle pair of tail-feathers, which are considerably shorter than the outer pair. In the female capercaillie the tail is rounded, and the under tail-coverts are much shorter than the middle pair of tail-feathers (p. 2, figs. 1 and 2).

Enemies.-The chief enemies of black-game are the hooded and carrioncrows, which take numbers of eggs and young. Foxes, stoats, weasels and peregrines are also occasionally destructive, as they are among other game-birds. Probably quite as many young are lost through want of care shown by the hen as from attacks made on them by vermin.

W. R. OGILVIE-GRANT. 


\section{BLACK-GAME SHOOTING}

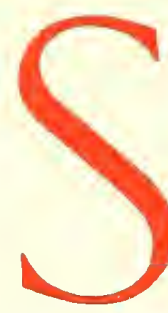

GIENTISTS will have it that black-game can show a better claim to be called the "grouse" than the bird so familiar to us all under that name. Nor have we to search far back through the misty records of the past for evidence on the subject-though the locality named (Eltham) in the first mention of the "Grows" makes it certain that the bird referred to in this document of the early sixteenth century was in truth a Blackcock-we need go back no further than the days of our grandfathers to find "black grouse" and "red moor fowl" the accepted terms in the parlance of sport. But modern custom has conferred on the most popular of our gamebirds the exclusive title to be known as "the grouse," and the rightful heir must rest content with a less distinctive name, at least among the vulgar.

This sometimes leads to errors, and should it ever be your fortune to correspond with any of the German-speaking race on the subject of "Black game," you will soon find yourself at cross purposes, for he will write to you of their singular size and ferocity in his district, and tell you how his favourite hound was slain by a wounded "black-game" (wild boar).

Presently you will realize that the Teutonic mind renders black-game into "Schwarzwild," and indeed "black-game and other beasts of prey" is no uncommon insertion in the anglicized sporting advertisements from Austria and Hungary. Should you pursue the subject further, you will be somewhat disgusted to find that continental sportsmen think it fair play to shoot Blackcocks at the "lek," when our code would never countenance such desecration of the courtship of spring.

Unfortunately, although in these islands we forbear to take advantage of creatures of the wild when their natural cunning is dulled by the master influence of all, yet our game laws are not above reproach in other respects, at least so far as black-game are concerned, being apparently framed only to suit the convenience of those who have taken a moor for the opening months of the season, and would have all the shooting they can in their short autumn holiday, rather than with any thought of giving fair play to the finest of our native game-birds.

For full six weeks after the law allows them to be shot (August 20) blackgame are not fit to figure in the game list at all, and this is just the time when the vast majority are slaughtered by grouse shooters. For at this time of year the old cocks are all skulking in strict seclusion, renewing 


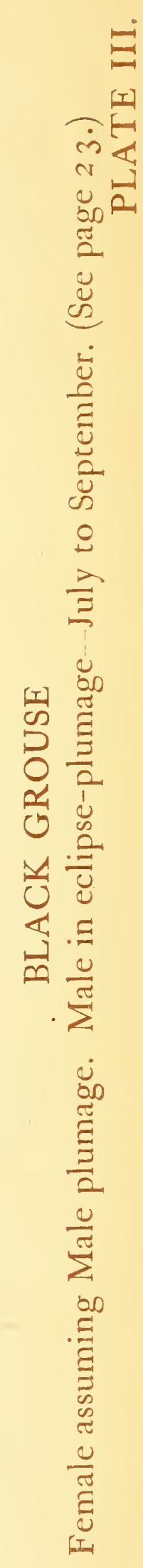




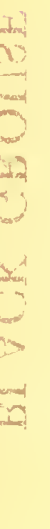




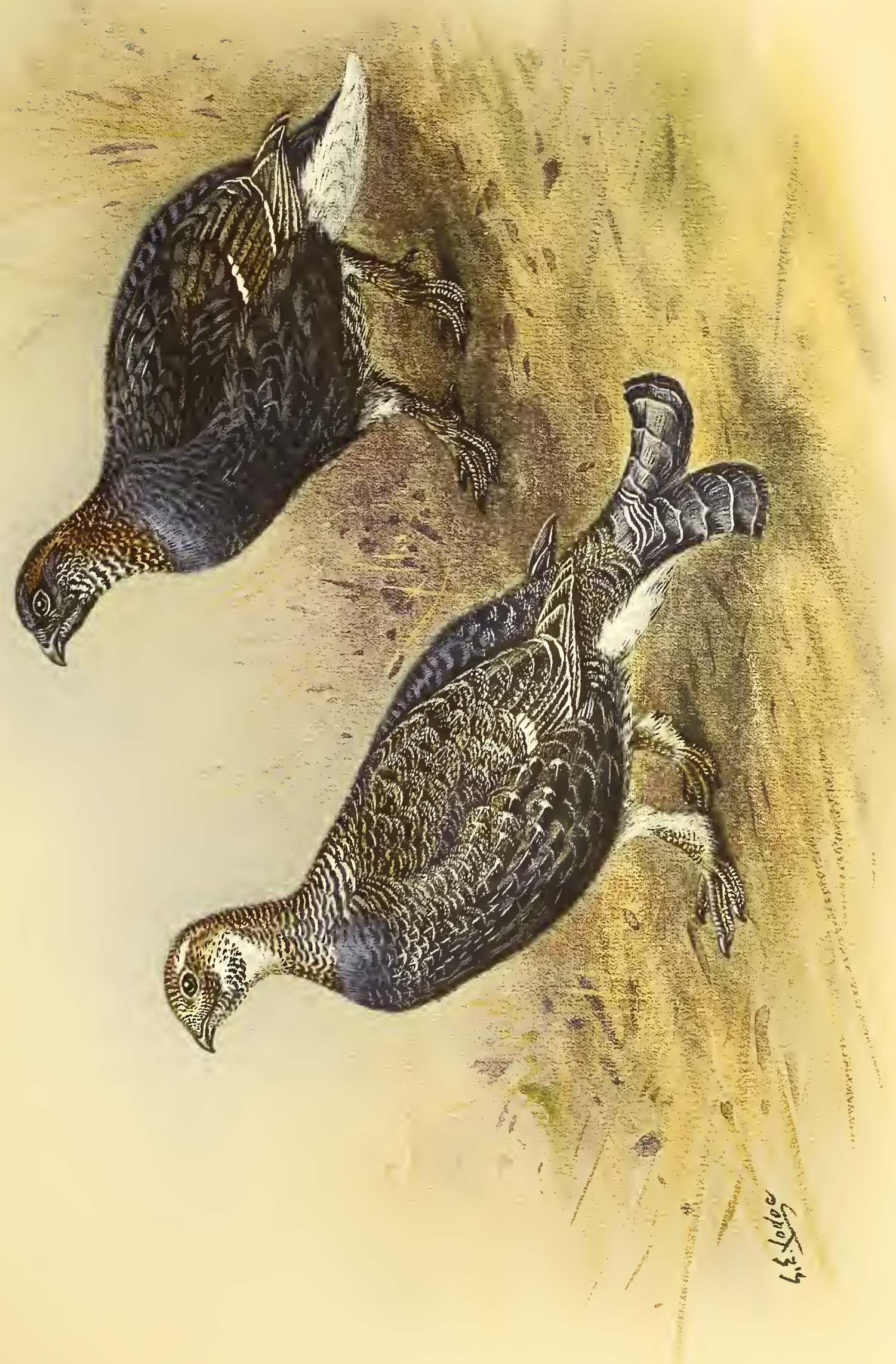





\section{BLACK-GAME SHOOTING}

their fine feathers, and recruiting their strength and pride after doughty deeds in the love tournaments of spring and summer; while the young cocks are still but half grown poults under maternal supervision, and fall the easiest of victims to the gun as they flutter up one by one out of the bracken patches on the moor, if indeed the services of the gun be required at all, for a moderately active dog could catch most of them without any difficulty.

Not thus should we treat the bird, which but a short two months later would prove as worthy an antagonist in the field as our country can show. So we may safely pass over black-game shooting in August and early September as a recreation-it cannot be called a sport-unworthy of record, at which the veriest tyro may-and does-easily glut himself with slaughter, probably reading afterwards with incredulous contempt the eulogy of the Blackcock as the wildest and wariest of game-birds, written by some one who has known this noble bird at its best.

October is, beyond doubt, the month of all others for the pursuit of the Blackcock, and most of us who have once experienced its varied delights will give high place among our most cherished memories of sport to some late autumn day on the fringe of the moor.

If uncertainty of what the day may bring forth lend an added charm to sport, then must such a day rank high among its fellows. For we live in a time when the methods of business are applied to every branch of human industry, whether work or play. There is no longer place for the old-fashioned keeper, who passed most of the summer months in social converse, accumulating that store of racy anecdote with which he was wont to delight us in the autumn, but who took the field on the "twelfth" or the "first" without the haziest idea as to how the birds had fared since last they were called on to face the guns. His room has been filled by some clever exponent of the higher preservation of game, and while the beneficial results of his science and skill are easily recognizable in the incomparably increased yield of the ground, at the same time there is the feeling, which cannot fail to be at times somewhat irksome to most of us, of knowing before we start in the morning that, given fair weather and fair shooting, these coverts should give us so many hundred Pheasants, or those farms or that beat of moorland so many brace of Partridges or Grouse. Nor is it hard, now that almost every nest on the ground has its place among the carefully tabulated records of the keeper's notebook, to form such estimates with singular accuracy. 


\section{THE GUN AT HOME AND ABROAD}

At least with black-game such exactitude of forecast can never exist ; here the glorious element of chance must ever play a very important part in the proceedings, nor can any man venture to hazard with confidence what the morrow shall bring forth. For black-game are born wanderers on the face of the earth, here in their scores to-day, yet vanished without rhyme or reason to-morrow. No change in the weather, or shortage of food supply on which to lay the blame; only they have followed their own wayward fancy and betaken themselves elsewhere.

A striking instance of this trait comes back to the memory. It was some winters ago, and I was among the guests bidden to shoot the coverts at a hospitable Scotch mansion, which lies in a pleasant valley among the Westland hills. One of the underkeepers, coming in from his distant moorland beat to lend a hand with the Pheasants in the policies, brought news of a pack of black-game, only to be reckoned by hundreds, all old cocks, with never a greyhen among them, seen daily for some little time past on the borders of the moor.

The plans for shooting the home coverts on the following day were too far matured to admit of alteration-a covert shoot of any size takes no little trouble and time to organize, and cannot be postponed at willso it was not till the second morning that we set off for the outlying beat, with high hopes of laying out in the evening such a row of fine old black fellows, as should be worth many thousand Pheasants. We had a pleasant enough day ; there were a few Woodcock and a sprinkling of wild Pheasants in the scattered wood of birch and alder that clung to the lower slopes of the hillside; the moor above yielded a fair number of Grouse in the drives of the afternoon, but so far as the aim and object of the day was concerned, we might as well have stayed at home, for we hardly saw a Blackcock at all. To emphasize the already patent fact of their absence, fate ordained that there should be scarcely a minute of the day when a greyhen was not sailing over some part of the line. So numerous in fact did the greyhens become in the moorland drives of the evening, that the keeperrightly or wrongly-decided that it would be well to thin their numbers a little. The word to slay and spare not was given, and in the last double drive before dark, no fewer than fifty-two greyhens-most of them happily of uncertain age-had fallen by the butts, eventually to figure as a most respectable total in the game card, where distinctions of sex are fortunately suppressed. All this points to grasping the skirts of happy chance without delay, such time as the Blackcocks are reported to be "in." 


\section{BLACK-GAME SHOOTING}

In many other ways a black-game day has charms denied to any other form of regular shooting. But few are fortunate enough to have the shooting over such favoured ground as will admit of a day being expressly set aside for the purpose, and they issue their invitations to this shoot with care beyond the ordinary. You may be asked to shoot people's pheasants, partridges or grouse for a hundred different reasons; perhaps you are a social acquisition to any party, valuable to keep things going in the drawing-room after dinner; or a good shot and good company so long as everything is to your liking; or a friend of the family or local big wig ; or you may be the owner of wide acres of your own, prolific in game, and only asked on the principle of " scratch my back, and I'll scratch yours."

Any of these qualifications will probably ensure you plenty of shooting in the course of the season, but none of them are likely to gain you admittance to the small, select circle from which the guns for the black-game day are chosen. Each gun-if the day is to be a success-must be a good shot and something more. He must know enough to realize that this is no "cut and dried" form of shooting, and to appreciate a "hot corner" at its true value when all goes well, yet equally prepared to accept the times which will come when things don't quite come off, and he hardly gets a shot, as all in the day's work. Then he must be on the alert the whole time, with a grasp of the situation which shall enable him to decide at an instant's notice when he should let the leaders of a big strung-out pack pass unscathed, though offering the most tempting shots, lest the drive be spoilt for the other guns. He must be able to choose his own stand for a drive, and crawl into his place without unduly exposing himself to view, and should further be ready to walk the roughest hillside with the beaters, and snatch a lightning chance at some old Blackcock sailing back high over the birches.

If but one gun of the party fail in any of these particulars, you may feel sure that he will cheat the bag of its due many a time before the end of the day, if indeed he does not succeed in spoiling what would probably have been the most killing drive, for it is surprising what a malign delight the fates that preside over our sport seem to take in exposing the weak point in a line. And so those of us who take pride in knowing a little about shooting in general, quite apart from any question of marksmanship, are as pleased when the welcome letter arrives bidding us make one of the small party to drive the Blackcocks, as though there had been conferred on us a regular diploma for woodcraft. 


\section{THE GUN AT HOME AND ABROAD}

And it is essential that the party should be small, just enough for the work in hand and no more; four guns and perhaps twice as many keepers and beaters making a full muster; any larger display of force is apt to disturb the ground too much, and drive the black-game off the scene of operations altogether.

Thus there is a pleasing sense of informality about the whole affair; a skirmish in our woodland warfare, and not a set battle. Instead of the marshalled army of beaters, stops, and flankers following the carefully ordered sequence of drives or rises, there is only, as it were, a marauding patrol, moving over the country with a freedom denied to more formal arrays.

The country, too, wherein we shall seek our game, is perhaps of all others the most pleasing to the eye, whether of sportsman or artist. The higher ground above is an open sweep of moorland which falls, here in steep rocky faces, there in long gentle slopes, down to the valley of the river beneath. As you descend, the heather yields to rough hill pastures, studded with clumps of ancient thorns, overgrown with rushes and bounded by low, crumbling stone walls. A scattered growth of alder, rowan and birch, straying far up the hillside, follows each deep, narrow glen hollowed out through the ages by the course of the mountain streamlets. On the more fertile ground of the lower slopes, straggling patches of oat stubbles and turnips surround the occasional croft or hill farm, while a long rambling wood of heavier timber-oak, ash and fir-follows the banks of the brawling little river.

Even when the black-game prove a failure, there is always a fair chance of filling every column in the game book before the day is over. Duck, teal and snipe from some marshy hollow on the banks of the river; grouse, hares and rabbits from the edge of the moor; a few wild pheasants and plump moorland partridges-beloved of the epicure-from the odd acres of turnips; and roe, woodcock and pigeon from the wooded river bank.

These only to fall back on if things go wrong; when all goes well, the undoing of the Blackcock is the sole aim and end of each move in the game. For the most part the drives are short; the pack is marked down by some keen eye-and the dark heavy form of a Blackcock is a noticeable enough object among the light tints of an autumn landscape-the guns stealthily gain their places as close up to the pack as they can approach with safety, while the drivers are working their way round to the far side.

The actual driving is simple enough, consisting of little more than 36 


\section{BLAGK-GAME SHOOTING}

flushing the birds. Once on the wing, the Blackcock is a singularly independent individual, with strong preconceived notions as to which way he means to go, and flankers, flags and beaters have little effect on his flight. The writer remembers well seeing a big pack of black-game in a grouse drive break out over a whole row of flankers without paying the slightest attention to their frantic demonstrations, presently to swing round and come back into the drive right over the beaters' heads and on to the guns. Another time an old stager came swinging in from a flank at the end of a drive, passing over the outside butt, and so down the whole line receiving the fire of each of five guns in turn. He was certainly well up, and travelling apace, but there was no particular reason why every one should have missed him clean. At least one would have thought that the noise of the guns, and whistling of the shot, would have disturbed his equanimity sufficiently to make him avoid any repetition of the performance; yet on reaching the end of the line, he changed his mind and decided that, after all, he would rather go the other way. A slight increase in height was the only noticeable concession to the guns beneath, as he came straight back down the line, presently to vanish in the direction whence he came, no whit the worse for such a salute as would have pleased an Indian rajah.

And this is the bird that sportsmen in every other country in Europe will tell you it is good sport to lie up for on a spring morning, and plaster on the ground as he courts his greyhen-or rather hens, for his affections are somewhat comprehensive-with quaint antics and insistent, if unmusical, voice.

While Blackcocks can thus show themselves at times quite oblivious of any human attempts to control their movements, the wind-so allimportant a factor in the flight of all our other game-birds-as a rule exercises only a very minor influence on their course.

It is true that they will always evince marked disinclination to fly straight down wind, when it is blowing at all hard, owing to the discomfort of having their tails blown about. Apart from this they will fly whither they list, with that calm deliberation that characterizes all their proceedings, careless from which airt the wind may blow, and facing, without trouble, a wind which no Grouse or Partridge could live against.

This is often evident in the later grouse drives of the season. In some up-wind drive when any Grouse that rises more than a few feet off the ground at once swings back over the beaters, only those coming forward 


\section{THE GUN AT HOME AND ABROAD}

who cheat the wind by hugging closely the face of the hill, seeking the lee of every inequality in the ground. But in the same drive you may often see black-game thirty feet and more up in the air, coming straight on, right in the teeth of the wind, with leisurely, powerful flight. Only a very stiff breeze makes them drop down to join the lower-flying grouse.

This leisurely appearance of their flight, a few beats of the strong pinions, alternating with that easy sailing through the air which makes the pace so deceptive, is the cause of perhaps half the missed Blackcockand no bird is more often or more consistently missed by the average gun; of the other half a goodly proportion must be set down to the account of nerves. A Blackcock never looks hurried, and not till you have seen Grouse, Partridges, and black-game rise together in front of the beatersno uncommon sight when some turnip field bordering on the moorland is being brought to the guns-will you ever really appreciate the driving power that lies in the easy motions of those strong wings. For if they have any distance to travel before they reach the guns, the black-game will easily outpace the rest; the Grouse-apparently flying much fasterarriving quite appreciably later, with the Partridges, which look as though they were going double the pace of either, last of all. Indeed, with a short three hundred yards between his butt and the crest of the hill whence all the game rose as the first beater's flag came in view, the writer has had fair chance of a right and left at all three in turn, using only one gun, and loading between each effort; a fine test of markmanship, whereof the result was unhappily not worthy of record.

For the rest, only those happy mortals who never know what nerves mean can hope to escape those otherwise unaccountable moments of hopeless failure; to most of us the Blackcock only comes as an occasional joy; and over-anxiety to make the most of a rare chance often defeats its own purpose. It is easier to keep cool and use one's judgment when the birds are sufficiently remote, as is the case in most woodland drives when they can be treated much like Pheasants. But in a moorland drive the big pack often comes bearing down on a butt at the level of a man's head, and then the occupant must have his nerves well under control, if he is to do himself justice, and shoot as well as he would under normal conditions. For there is something peculiarly disconcerting in the heavy black forms, sailing along with set wings and looming larger every second ; once yield to this influence, and a feeling of utter impotence creeps over 38 


\section{BLACK-GAME SHOOTING}

you, to be followed by a wild moment of the "scatters"* as the pack sweeps round your butt, and on and away into the distance, leaving you ruefully to eject the empty cartridges from your gun, wondering how on earth it was possible to miss such a huge target, and feeling acutely that every one within sight-guns, keepers and flankers-has mentally set you down as a hopeless bungler.

Apart from experience, the best palliative of this evil lies in a fixed concentration of purpose. If the gun choose one bird when they are still some little way out of shot, set his teeth, grip his gun, and decide that his quarrel lies with that particular individual and no other, he should find him easy enough to stop at ten yards' range, and the confidence born of success may well bring down another to join the first.

For, after all, the average Blackcock is not in itself a very difficult shot; for the most part he flies straight ahead without swerve or curl; only very occasionally - when they have been much shot at-they have been known to dive on the shot, a well-known practice of Grouse. And so a really good performer with the gun soon learns enough of their ways never to be deceived by the apparent want of speed in their flight, and thereafter turns most of his chances into a fair certainty. His habitual accuracy stands him in good stead, for no bird requires to be more cleanly killed. And so it will always fare badly with the more casual sportsman, who has been accustomed, in shooting other game, to rest satisfied with every shot that brings a bird to the ground, indifferent whether the charge was lodged in front or behind.

For no bird will take more shot in the wrong place without effect than the Blackcock; head and neck are as vulnerable as in any other bird, but elsewhere he will carry as much shot as would kill a Pheasant twice over; the shock may knock him all endways for the moment, but-if only wounded in the body -he will almost always manage to recover his balance and keep going somehow, gradually gathering strength as he goes, until he is lost to view. Therefore the hard hit birds of doubtful performers that just carried over the nearest skyline are rarely worth wasting much time looking for-they are probably in the next parish.

It is far otherwise with the suicidal greyhen, which courts destruction at every turn. It is almost impossible to miss a greyhen-many of us have often wished it were less so when the damning corpse is produced

\footnotetext{
* The writer makes no apology for the use of the noun "scatters," although it finds no place in the dictionary. It suggested itself to a friend as he watched some startled coots departing across the water in the absurd manner peculiar to their kind, and is sufficiently expressive to require no explanation.
} 
THE GUN AT HOME AND ABROAD

at the end of a grouse drive-and one of the most annoying sights on a moor is to watch the arrant duffer missing all the grouse that pass his way, but successfully plastering every greyhen that comes within his reach.

While such indiscriminate slaughter should naturally be utterly discountenanced, at the same time it seems that an undue sanctity is sometimes attached to the sex at large; a preponderance of old barren hens is always an undesirable feature of the ground, and it may be well to allow a careful gun some licence with hens that are unmistakably old ones. In this respect young Blackcocks deserve a consideration they rarely receive; and it is sound policy to spare any cocks that show visible traces of the brown feathers of youth, thereby ensuring a young and healthy stock for the following year, which is the most important consideration in every branch of game preservation.

To one unacquainted with their ways it might well seem strange that a mere handful of beaters should be considered enough for the purposes of driving black-game, when double and treble the number are required to drive Grouse or Partridges; but black-game are most consistent in their lines of flight, and the observant keeper soon comes to know exactly which way they will go of their own free will when disturbed from a certain direction, and thus finds that a very few men are sufficient for his purpose.

No other game-bird varies so much as the Blackcock in degree of susceptibility to the approach of danger. Other game-birds pack and grow wild as the season advances, but black-game are tame one day and wild the next, influenced in this respect to a surprising extent by every change in the weather. Sometimes on clear, sunny days they are almost impossible to approach at all, leaving the ground altogether on the first suspicion of danger; at other times, and especially on misty, wet days, they appear utterly oblivious to the most obvious danger, settling again within a few hundred yards after passing over the guns, and allowing themselves to be herded back like sheep over the very spot, where the experience of but a few minutes before should have impressed on the dullest intelligence the presence of danger.

When the shooting party is reduced to one, there is a most sporting method of outwitting Blackcocks open to the enterprising individual -the stalk with the small rifle. This is further most beneficial to the ground, for the old cocks can then be singled out for destruction. 
-

草

되

崩

군

U

虫

플

点

$\Xi$

כ 


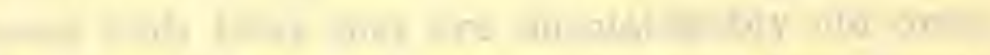

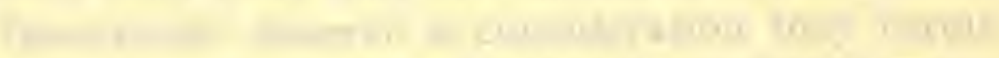




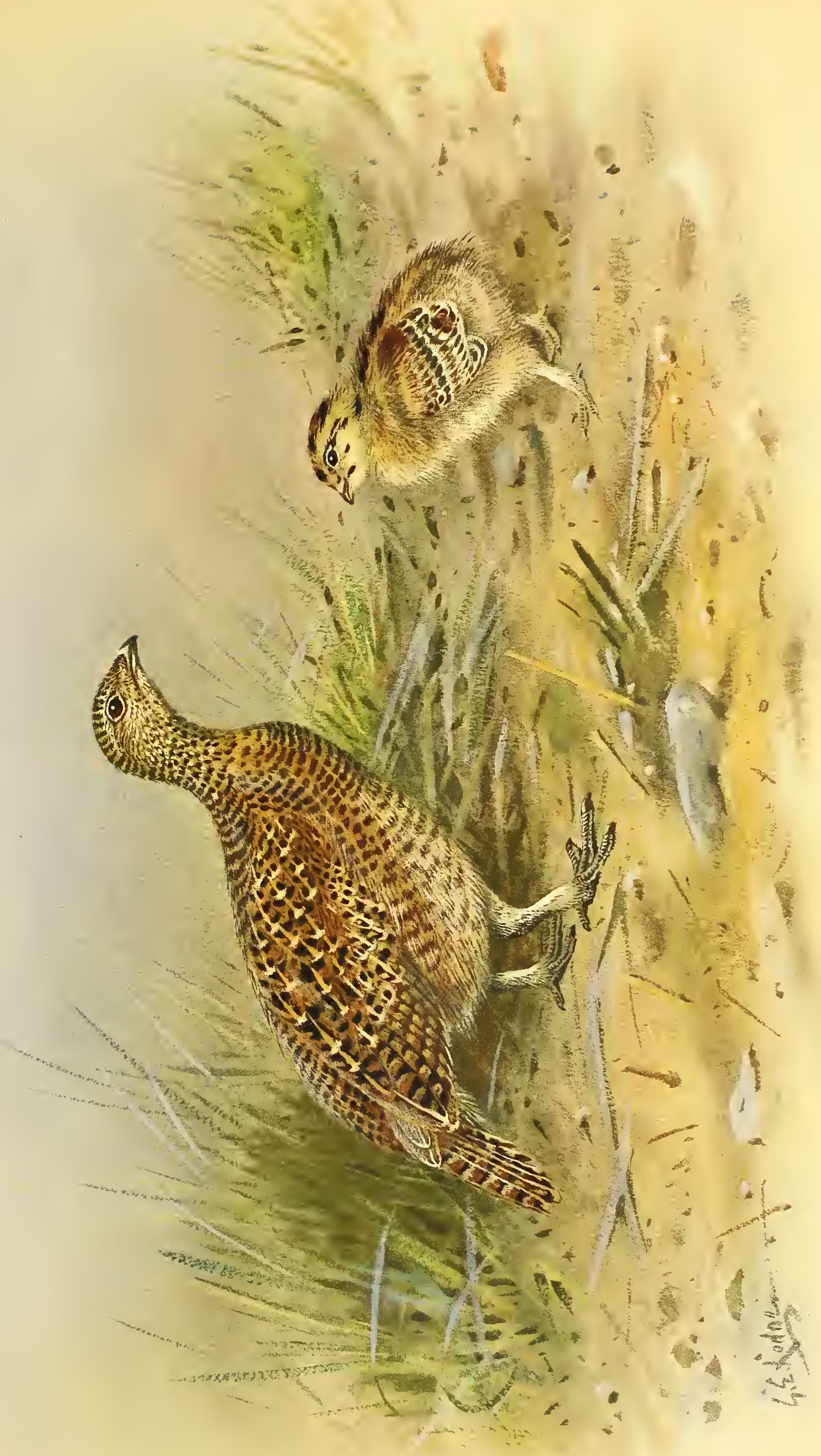





\section{BLACK-GAME SHOOTING}

Mr Thomas Ranken sends me the following notes on a by-day of this nature in the border country, where his singular skill with the rifle resulted in a somewhat remarkable total :

"I have looked up my game book and find that on October 31, 1906, using a $\cdot 303$ rifle, I shot thirty-nine black-game and nine various on Commonside, Linhope, Castle Weary, Caerlanrig and Falnash farms, Teviot Head. I killed only one greyhen, and that was an accident. So far as I can remember, it was a dampish, misty sort of day, so the black-game were not very wild. I had a motor car with me, which I left at the farms. All the stalking and shooting was done on the fields and grassy knolls; as soon as a pack fairly took to the hill, I hurried back to the car and went on to the next farm. There was a lot of hard, wet crawling, I remember, and I generally got up within 70 or 80 yards, though I killed one Blackcock at 180 yards-but, as a rule, I don't like taking long shots with so light a cartridge. I fired the first shot a little before nine o'clock, and an hour later was back in the car with ten birds out of the first pack, as the result of half a dozen short stalks. After that I didn't succeed in getting fairly on terms with another pack until the last hour of the day, when I got eleven out of a pack, and four at one stalk. That year, the total for the season for our party on Teviot Head was 392 black-game; best day forty, mostly young cocks, as the old cocks did not drive so well -but my bag on that day was nearly all made up of frosty-whiskered old veterans."

It is sad to record that in most parts of Scotland black-game are steadily decreasing. Nor may we ever hope to see them again in the numbers that used to frequent such favoured ground as the Duke of Buccleuch's estates in Dumfries-shire, where in the sixties 1,500 was no unusual total for the season, and where on one occasion 247 black-game (of which over 200 were cocks), fell to eleven guns in a day's shooting over the Kirkconnel ground.

Should Government afforestation of waste lands ever take place on a large scale in Scotland, doubtless the black-game would, if countenanced, increase abundantly among the young woods, but it is to be feared that their presence in any numbers would be wholly inimical to the successful conduct of the operations of forestry, so destructive are they to the buds of larch and Scotch fir.

In Dumfries and Galloway alone among Scotch counties, do the blackgame seem to exist in numbers at all comparable to the records of the 


\section{THE GUN AT HOME AND ABROAD}

past. Here Mr Hughh Gladstone, of Capenoch, killed with three other guns, 114 black-game on the Auchanbrae beat on October 25, 1910, and seventytwo black-game on the Auchanhessname beat on the following day; the same year three guns killed over seventy Blackcocks in a short day on the High Moss of Cree, the property of the Earl of Galloway (on which moor a falling Blackcock struck the muzzle of a gun with such a force as to snap the small of the stock in two); while on the Earl of Stair's estates in Wigtownshire, Viscount Dalrymple, shooting over Barnshangan moor with a party of five other guns, in October, 1905, killed 105 blackgame (almost all of which were cocks), besides 111 brace of Grouse, some twenty brace of Partridges, and six other varieties of game. It is interesting to note, as an example of the disastrous effect of the protracted drought of last summer (1911) among the young black-game, that in the autumn, out of a total of 150 Blackcocks killed on the Lochinch moors only two were young birds.

Except in the three northern border counties, black-game are now far from plentiful in any part of England. They are either extinct or else steadily decreasing in all their former strongholds, such as the moors of Devon and Somerset, and the forests of Wolmer and Bere. In the volume which should be our standard authority on the game-birds of Britain, it is stated twice that 100 black-game have recently been killed in a day on the Earl of Lichfield's moor at Cannock Chase, in Staffordshire, but the statement has unfortunately no foundation in fact.*

The Earl of Lichfield has kindly furnished me with an excerpt from his game book, showing the best results during recent years on this prolific little moor :

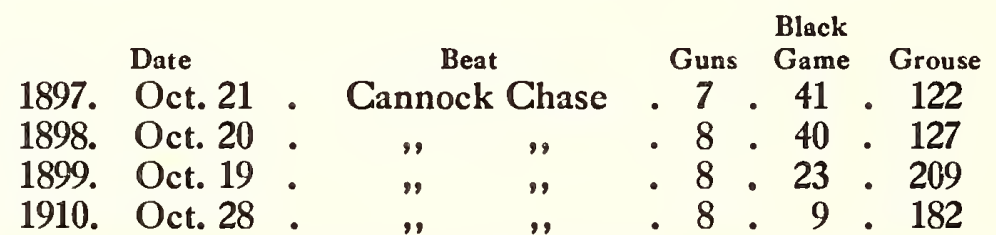

Only 1,200 acres are driven in the day; the black-game are indigenous, but the Grouse were probably introduced at the beginning of the nineteenth century. It has the distinction of being the southernmost grouse moor in England; it is also "common land," and visited by crowds of people in summer time. It is a hunting country, and on the last of the days given

*The Natural History of British Game Birds, by Mr J. G. Millais, 1909, pp. 20 and 22. The writer must plead guilty to having copied this statement without verification, deeming the source of information to be sufficient guarantee for its accuracy (Grouse and Grouse Moors, 1910). 


\section{BLAGK-GAME SHOOTING}

above, hounds in full cry crossed through the middle of the drive that was in progress. In the sixties of last century, before coal pits, colliery towns, high roads, and summer trippers came to invade its wild solitudes, Cannock Chase was a notable resort of game and wildfowl in general, and of black-game in particular. Lord Berkeley Paget informs me that he can remember it as an open moorland of over 20,000 acres, with only two small woods on it, and two roads across it, one of which was seldom used. From the pages of his game book Lord Berkeley Paget sends me some interesting records of these times long past. In one day's driving 252 black-game were killed; on another day 189; while on one occasion my informant killed 126 black-game to his own gun in the day.

Such records as these may be given without fear of rousing a spirit of emulation, for they will never again be equalled, until the secret of rearing black-game like pheasants be mastered by some game preserver, clever beyond his fellows.

AYMER MAXWELL. 


\section{RED GROUSE}

\section{LAGOPUS SCOTICUS}

\section{(Plates VI-X)}

Tetrao scoticus, Lath. Gen. Syn. Suppl. i, p. 290 (1787); Seebohm, Brit. Birds, ii, p. 428 (1884). Lagopus scoticus, Leach, Syst. Cat., p. 27 (1816) ; Gould, Birds Europe, v, p. 252 (1837); Saunders ed. Yarrell, Brit. Birds, iii, p. 73 (1882); Millais, Game Birds, p. 43, pls. and woodcuts (1892) ; Lilford, Col. Fig. Brit. Birds, pt. xix (1893); Ogilvie-Grant, Ann. Mag. Nat. Hist. (6) xii, p. 62 (1893) ; id., Cat. Birds Brit. Mus., xxii, p. 35 (1893) ; id., Ann. Scot. Nat. Hist. (1894), p. 129, pls. v and vi ; id., Handbook Game Birds, i, p. 27, pls. II and III (1895); Saunders, Ill. Man. Brit. Birds, p. 495 (1899); Millais, Nat. Hist. Brit. Game Birds, p. 37, pls. (1909); Wilson, P.Z.S. 1910, p. 1,000, pls. lxxviii-xcv, xcvii-ci.

Walsingham and Payne-Gallwey in "Badminton Library," Moor and Marsh, Grouse, (1886) ; Macpherson, in "Fur and Feather Series," The Grouse, pp. 3-79, (1894).

The Grouse in Health and in Disease, 2 vols. 4to (1911).

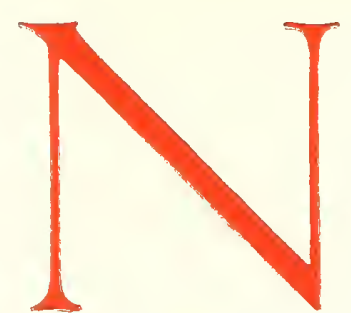

O group of birds, so far as we are aware, goes through so many, or such varied, annual changes of plumage as the members of the genus Lagopus, which includes the red grouse, the willow-grouse, and the four species of ptarmigan. Unlike the other members of this genus, which undergo three distinct changes of plumage in the year, in summer, autumn and winter, the red grouse has only two, but its chief peculiarity lies in the fact that the changes of plumage in the male and female occur at different seasons.

The male has no distinct summer-plumage, but has distinct autumnand winter-plumages, and retains the latter throughout the breedingseason.

The female has a distinct and very complete summer-plumage, which is fully assumed by the end of April or the beginning of May; also a distinct autumn-plumage, which is retained till the following spring.

To put it more concisely, both male and female have two distinct moults during the year, but in the male they occur in autumn and in winter, and in the female in summer and autumn, the former having no distinct summer-plumage, and the latter no distinct winter-plumage.

In the willow-grouse and the different species of ptarmigan there are three distinct changes of plumage in summer, autumn and winter in both male and female alike, the winter-plumage being white in all.

The red grouse is considered by most ornithologists to be merely an insular form of the willow-grouse, and it might naturally be supposed that as the British species does not turn white in winter, such protective 44 


\section{RED GROUSE}

plumage being unnecessary in the localities it inhabits, the winter-moult had been gradually dropped.

Now this is the case with the female only, and we find the male, for no very apparent reason, changing his newly acquired black and buff-barred autumn-plumage for a winter-garb of chestnut and black. Dr E. A. Wilson, the Field Observer to the Grouse Disease Inquiry, who has for some years been studying the plumage question, has suggested a possible explanation of this strange want of agreement. He believes that the autumn-plumage of the male grouse, which in many respects closely resembles the summeror breeding-plumage of the female, was originally a breeding-dress, but that owing to disease it has gradually been deferred till the end of May or beginning of June. This postponement, at first a matter of neces sity, has now become an established habit. He says : "It appears almost as though the pathological postponement of the moult, which is, after all, nothing but a sign and a symptom of disease, has gradually developed into a normal habit in the life of a bird; and one is led to think that this habitual disability in the cock grouse, which results from Strongylosis during the nesting, courting, and breeding-season (a disability which causes the death of about eight cocks to every hen in April and in May) may have caused the alteration in the season of the moult, simply because the vis vitce of the cock bird, insufficient as we now know it to be at the close of winter for the ordinary calls of reproduction, would be still more disastrously insufficient if preceded by an early moult.

"At the present time the cock undoubtedly breeds in the winterplumage, without any further acquisition of new feathers, and, as has recently been pointed out by $\mathrm{Mr}$ Ogilvie-Grant, what have been regarded as new 'spring-feathers' on the neck by Mr Millais, are in fact the old autumn-feathers, which on that part of the body do not become worn or faded."

The changes of plumage in the genus Lagopus are the more difficult to understand from the fact that the species are subject to great individual variation, and this is especially the case with the red grouse. These variations or types of plumage may be classed under three headings in the male, and under five in the female, but it should be remembered that when the male is in autumn-plumage (June to October), and the female is in summer-plumage (April to July), and the greater part of the plumage of the upperparts, chest and sides of the body is black, margined and barred with tawny-buff, all individuals, be they male or 
THE GUN AT HOME AND ABROAD

female, closely resemble one another, and the individual type or variety is, for the time being, lost, except on the underparts of the body.

In the early part of the shooting-season, the males, especially, are still mostly in their autumn black and buff-barred plumage, while the females are more advanced; but by October, unless the normal changes have been retarded by disease, both sexes are clean moulted, and the different types are once more clearly marked.

Different types of male.-In the male in winter-summer plumage (October to June) the ordinary varieties may be divided into three distinct types : a red form, a black form and a white spotted form.

(1.) The red form.-The general colour is rufous-chestnut, without any white spots on the breast. This form is mostly to be found in the western counties of Scotland, England and Wales, from Caithness southwards, also in the Hebrides and the low grounds of Ireland.

(2.) The black form.-Typical examples of the really black form are rarely met with, and are usually found mixed with either the red or whitespotted forms, but most often with both, and specimens in mixed plumage are those most commonly met with. Almost entirely black examples have been obtained in Gaithness, Sutherlandshire, Perthshire, Stirlingshire, Dumbartonshire and Yorkshire; and more or less typical birds from Ross-shire, Aberdeenshire, Morayshire, Kincardineshire, Stirlingshire, Fifeshire and Lancashire.

(3.) The white spotted form.-The feathers of the breast and belly, and sometimes those of the head and upperparts, are tipped with white. The most typical examples of this variety are found, as a rule, on the high grounds of the north of Scotland, and are certainly most characteristic of the Highlands, but well-marked examples occur occasionally in most parts of the bird's range, including the north of Ireland.

Different types of female. - In the female in autumn-winter-plumage (August to April) no less than five distinct types are recognizable, the red, the black, the white-spotted, the buff-spotted and the buff-barred.

(1.) The red form.-The red type is much less common among females than it is among males, but its geographical distribution is, broadly speaking, much the same; that is to say, red examples are most commonly met with on the west coast of Scotland, England and Wales, and in the Hebrides.

(2.) The black form.-Typical black females are extremely uncommon, but good examples have been obtained in Caithness, Inverness-shire, 46 


\section{RED GROUSE}

Perthshire, Stirlingshire and one or two other counties, while very dark birds with a large admixture of black in the plumage, have been examined from Inverness-shire and Dumbartonshire.

(3.) The white-spotted form.-As in the male, typical examples are most numerous and characteristic in birds from the Highlands. The white spotting may be found on birds belonging to the red, the black, or the buff-spotted types.

(4.) The buff-spotted form.-This is much the commonest type, and that usually met with; the feathers of the upperparts are spotted at the tip with whitish or pale buff.

(5.) The buff-barred form.-This type is characteristic of the majority of birds from Ireland. The upperparts are coarsely barred with buff and black, and the female in autumn-plumage resembles the female from Great Britain in breeding-plumage.

The breeding-plumage of the buff-barred form does not differ from the autumn-plumage, and in spring we find the old autumn-feathers being replaced by an almost perfectly similar plumage. The advantage of this change is not apparent, the old plumage being equally protective.

Adult male. Autumn-plumage, from the end of May or beginning of June to the beginning of October.-After the breeding-season a very complete autumn-moult takes place, the quills, tail, and feathers on the feet being entirely renewed. In most examples the feathers of the upperparts are black, margined, and irregularly barred with tawny-buff; the bars usually cross the feathers more or less transversely, but in some individuals the outer bars are more or less concentric, and parallel with the marginal band, giving the upperparts a somewhat scaled appearance. The feathers of the chest are rather widely barred with buff or rufous-buff and black, and some of the flank-feathers are more narrowly barred with the same colours. The rest of the underparts varies according to the type to which the individual belongs, being chestnut, black, or white-spotted, or a mixture of all three. Birds obtained early in June having commenced their autumn-moult on the neck and upper mantle display three different sets of feathers: the bright new black and buff autumn-feathers, those belonging to the previous autumn (some of which are almost invariably retained), and the old winter-plumage, the feathers of the two last-named plumages being very worn and faded.

Males at this season, no matter to what type they belong, bear a much closer resemblance to one another than they do in their winter-plumage, 


\section{THE GUN A'T HOME AND ABROAD}

only the underparts of the body (the lower breast and belly) differing conspicuously. The first feathers of the winter-plumage begin to appear on the rump and lower back towards the end of August or beginning of September.

The autumn-plumage always commences to appear on the head and neck, while with the winter-plumage the reverse obtains, the new feathers appearing first on the rump, etc., the moult gradually spreading towards the head. The feathers of the legs and feet are moulted in June, and at that season the legs of healthy birds are almost bare; in July the new white feathers begin to appear and the claws are shed.

Adult male. Winter-summer-plumage, from October to the end of May.General colour above, black, with finely mottled bars of dark chestnut; the head, neck and chest mostly rich chestnut, finely marked with black; the flanks mottled and barred with the same colours, the chestnut colour usually predominating. Generally a greater or lesser number of autumn-feathers are retained, and are conspicuous by their light buff and black markings among the new winter-plumage. The rest of the underparts remain the same as after the autumn-moult. The general colour of each bird varies according to the type to which it belongs, some being darker, some lighter.

When once the winter-moult is complete, no change whatever takes place in the plumage of the male till the following autumn-moult, which commences towards the end of May, except that the feathers become bleached and worn at the extremities.

It is by no means unusual to find birds, which have been suffering from disease, their natural change being greatly retarded, still completing their winter-plumage in spring, especially on the head and neck, which are the last portions to moult. These feathers have been quite erroneously regarded as representing a partial breeding-plumage in the male, but their black and chestnut markings show them to be merely deferred winter-plumage.

Adult female. Autumn-winter-plumage. August to March.-The upperparts are black, with narrow irregular bars and mottlings of rufous and with a small distinct buff spot at the tip of most of the feathers; the chest and flank-feathers narrowly and often irregularly barred with rufous and black, and usually more or less tipped with buff. The rest of the underparts is chestnut, mottled and barred with black, or black, barred with chestnut. The typical white-spotted form differs in having the feathers of the under- 

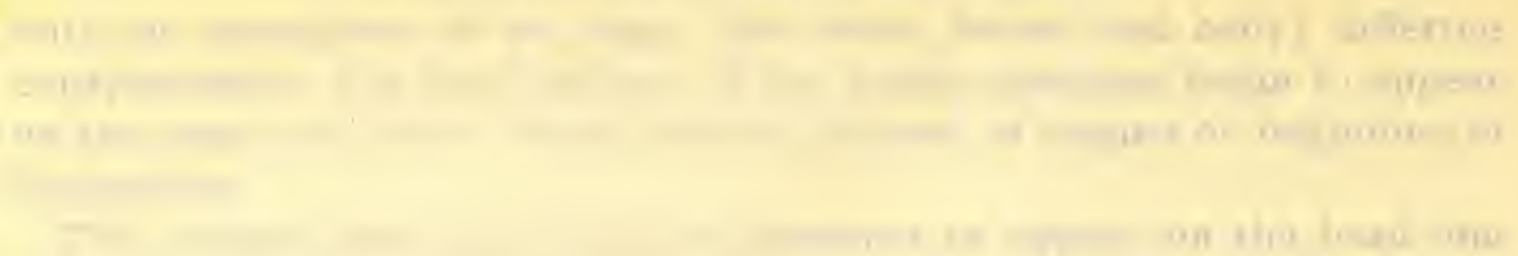

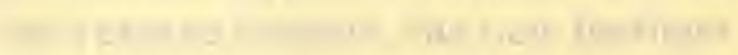
tin mill

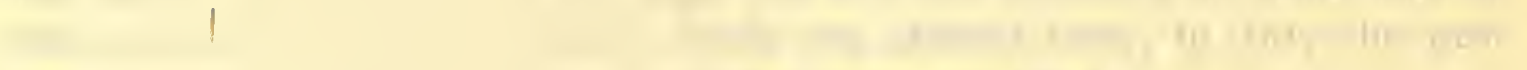
(2)

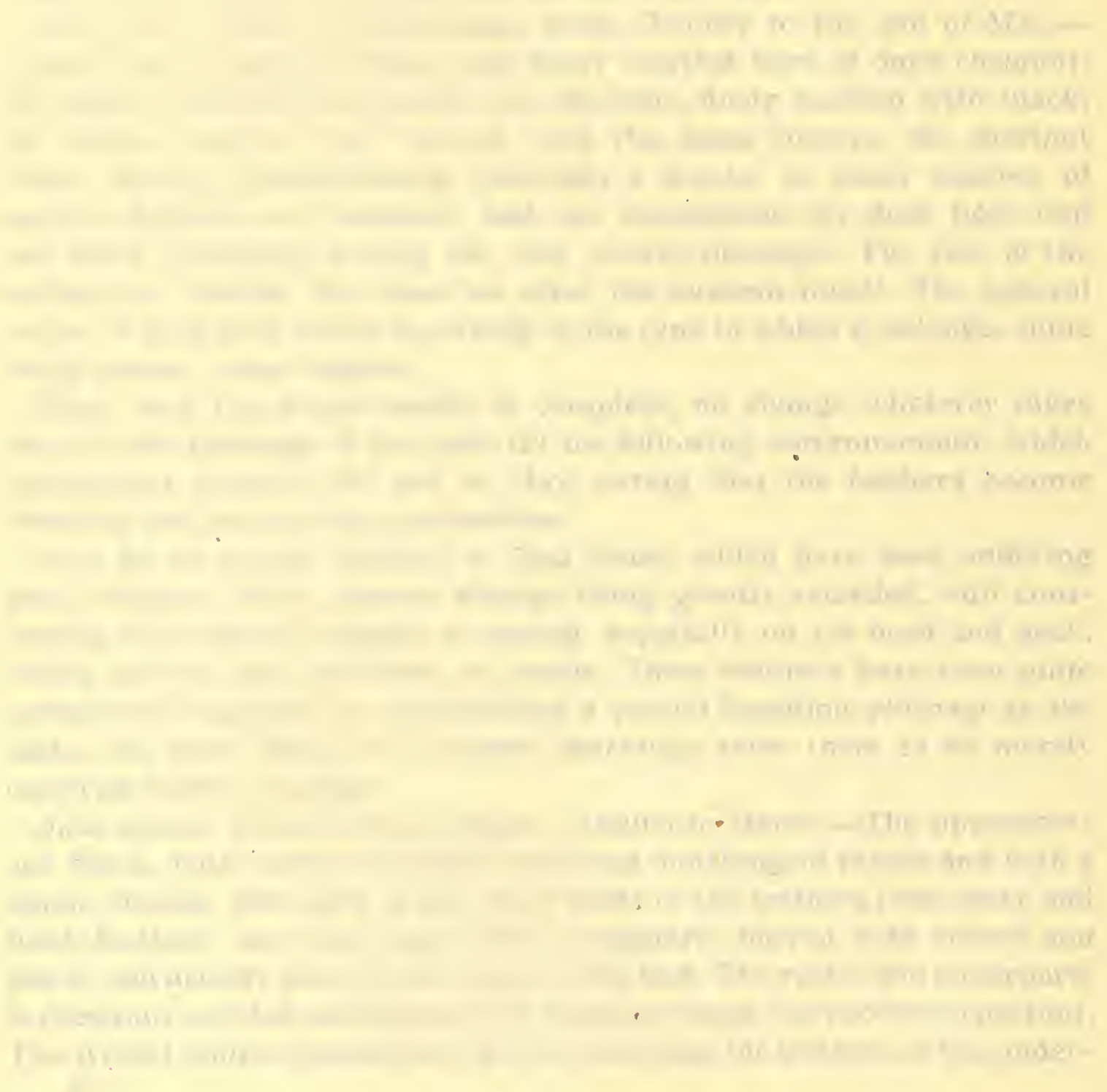




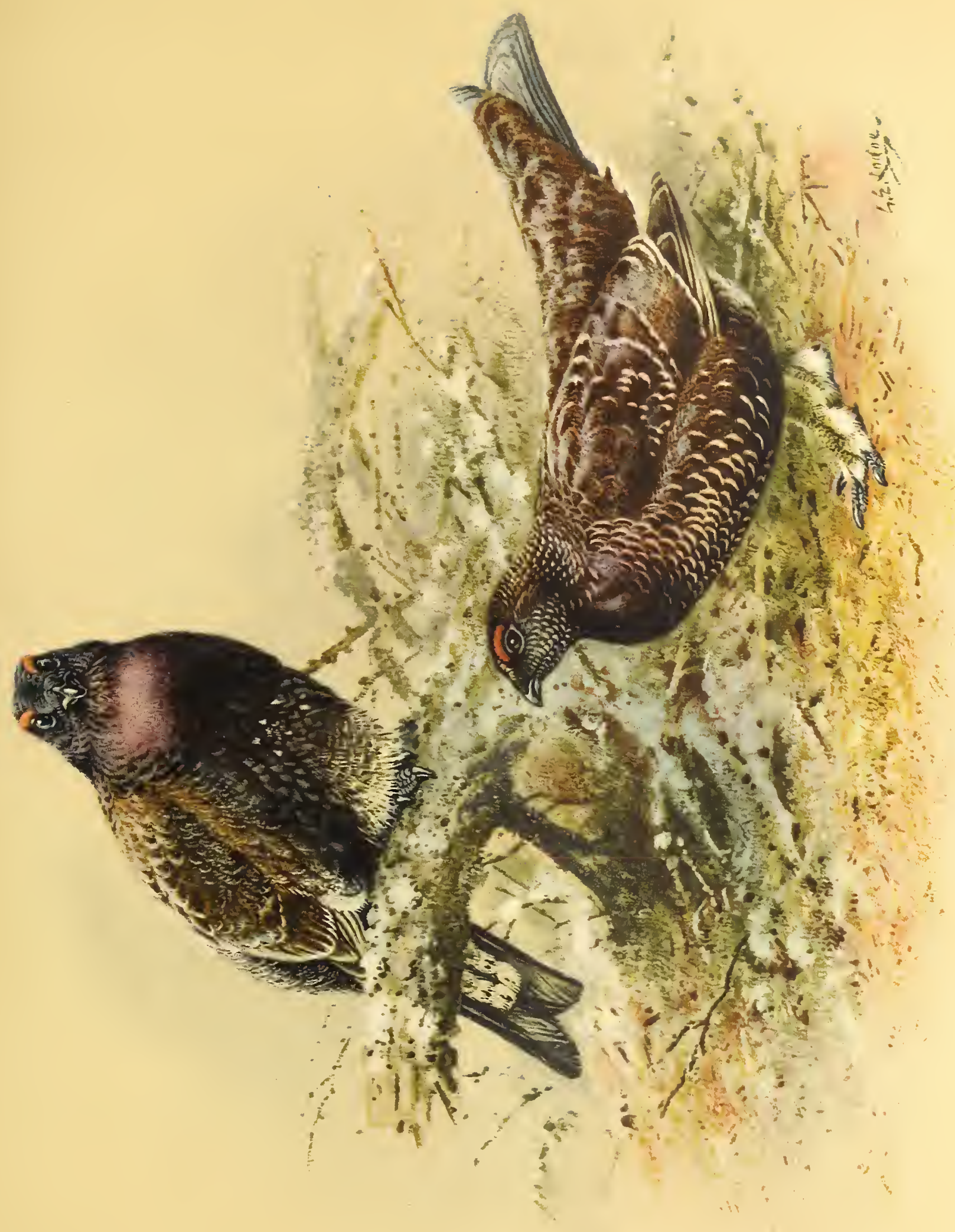





\section{RED GROUSE}

parts widely tipped with white. The form described above is the commonest or buff-spotted form of the female in autumn-winter-plumage. In typical examples of the red form, in which the predominating colour of the whole plumage is bright chestnut, the buff spots at the tips of the feathers of the upperparts are usually absent, and this is also the case in the much rarer black form. In the buff-barred form, from Ireland, the terminal buff spot takes the form of a marginal bar, and the feathers are practically indistinguishable from those of the breeding-or summer-plumage.

Adult female. Summer-plumage. April to July.-The summer-moult of the upperparts is very complete, and the transformation from the autumnwinter-plumage very marked. Every female assumes the summerplumage, and at that season all the different types closely resemble one another, but the colour of the underparts generally indicates to which type each individual belongs. In the average female, which is in full breeding-dress by the first week in May, the upperparts may be described as black, each feather being rather widely margined, barred and marked with bright buff.

This plumage, however, varies much in different individuals, birds from the west of Scotland and England and from Ireland having the buff bars much brighter and wider than in the more finely mottled and darker specimens which are generally characteristic of the east of Scotland.

All the feathers of the fore-neck and chest are widely barred with black and yellowish-buff. Many (about a third) of the finely mottled rufous and black autumn-winter-feathers of the sides and flanks are replaced by widely, and often irregularly barred buff and black feathers, similar to those of the chest. These summer-feathers, especially those of the sides and flanks, are longer and altogether larger than those of the autumnwinter-plumage which they mask.

The rest of the underparts remain unchanged till the autumn moult; only those parts which are conspicuous are changed, and the protection afforded by the summer-plumage is so perfect, that when the female is sitting on its nest among the heather and dead grass, it may easily be overlooked, though only a few yards distant.

In July the legs and feet of healthy females are bare and covered with new feathers still in the sheath. The claws have likewise been shed, and the new ones are very small.

Young in first plumage.-In July they resemble the adult female in summer-plumage in their general coloration, but the buff markings on 
THE GUN AT HOME AND ABROAD

the feathers of the upperparts are more concentric, and the flank-feathers of the adult plumage begin to appear about that time. By the month of November the young are generally indistinguishable from the adults.

Young in down.-Crown very dark chestnut, narrowly bordered with blackish, which extends in a line across the forehead to the base of the bill, and in a wide band down the back of the neck; lores and wide superciliary stripes extending to the occiput, buff; two or three irregularly shaped patches of blackish behind the eye and on the side of the neck; rest of the upperparts, including the wings, mottled with buff, rufousbuff, and blackish; the black markings on the dorsal region forming two rather well-marked bands, one on each side of the spine, bordered externally by a pale buff area; cheeks and throat pale yellowish-buff; rest of the underparts pale tawny-buff, brightest on the chest and belly.

When the young chestnut and black feathers make their appearance on the scapulars and wings, each has a white spot on the extremity, giving the birds a pretty spangled appearance.

Variations in colour. - Outside the types already described, variations in colours are not very numerous; but albinos, or partially white individuals are not very uncommon; sometimes a covey will be found in which several birds have the majority of the flight-feathers white, and so closely resemble certain willow-grouse in summer, that it would seem as though this abnormality must be due to atavism. Pale coloured, cream-coloured, creamy-brown, or pale brown birds, with all the ordinary darker markings on the plumage are occasionally shot.

One of these cream-coloured birds was, many years ago, brought to Mr George R. Gray, at the British Museum, and offered for purchase by Warwick the dealer, who no doubt told him it came from Perthshire. Partly, perhaps, through being deaf, and led astray by the abnormal colour of the specimen, Gray entered the locality as "Persia," a country where, needless to say, no grouse exists. Subsequently Gray described the bird as a new species and called it Lagopus persicus! A beautiful figure of it by Wolf is given in Elliot's monograph of the Tetraonidoe (pl. xx), where it is shown crouching in fear of a passing falcon! This curious mistake was discovered by the writer when preparing his Catalogue of the Gamebirds in the British Museum.

A very remarkable male, shot at Loch Swin, Argyllshire, on August 19, 1892 (see P.Z.S., 1910, pt. i, p. 1033, pl. xcvii), has the greater part of the plumage almost devoid of dark markings; the head, neck, chest and sides 


\section{RED GROUSE}

of the body are very bright uniform light chestnut, and the feathers of the upperparts are fringed and spotted at the extremity with yellowish-buff. This male was an old bird when shot, and had assisted in rearing several broods.

Distribution in the British Isles.-The red grouse is peculiar to the British Isles. It is generally distributed over the moors of Scotland, being found from sea-level to the highest point where ling (Calluna) and heath (Erica) flourish. It is also found in the Inner and most of the Outer Hebrides and ranges as far north as the Orkneys, being met with on the Mainland and other islands where suitable ground occurs.

In England it is numerous in the northern counties, especially in Yorkshire and Derbyshire, and extends southwards into Staffordshire and Shropshire; while in Wales it is plentiful on most of the moors. In Ireland it is much less numerous, but occurs on most of the moorlands and peatbogs. On the Continent the red grouse has been successfully introduced in Belgium and West Germany.

Allied species.-The nearly allied willow-grouse or Ryper (Lagopus lagopus), is a circumpolar species inhabiting the tundras of the northern portions of Europe, Asia and America. It is easily distinguished from the red grouse by its white flight-feathers, and by the fact that in winter its plumage is pure white, with the exception of the black outer tailfeathers, which remain unchanged. In its summer-plumage, which is very fully assumed by the birds inhabiting the more temperate parts of its range, such as South Norway, the male willow-grouse, except for its white primaries, closely resembles the male red grouse in wintersummer-plumage; but in birds found in higher latitudes, much of the white body-plumage of winter is retained in the breeding-season, and merely interspersed here and there with summer-feathers.

The female willow-grouse, whether inhabiting the far north or the more southern parts of its range, always assumes a very complete breedingdress, and is very similar to the female red grouse in summer-plumage, except that the flight-feathers are always white.

It is an interesting fact that in quite young willow-grouse the first flightfeathers are greyish-brown, mottled with buff, and very similar to those of the young red grouse.

Food.-Grouse feed chiefly on the young shoots of the ling, supplemented in autumn by various berries and fruits to be found on the moors. In some districts, especially, they are partial to a diet of oats, and visit the stooks 


\section{THE GUN AT HOME AND ABROAD}

and stubble-fields in the early morning and afternoon, often in large packs, sometimes remaining there till quite late in the evening. They also, to some extent, visit turnip-fields, and may not infrequently be flushed there along with black grouse. When very hard pressed for food they have been observed feeding on the haws, birch-buds, etc., settling on the thorn-hedges and trees to reach these strange foods.

They are extremely partial to grit, of which they pick up large quantities, and often travel long distances to obtain a suitable supply. A constant supply of good grit is essential to their welfare, and without it they are unable to digest their food.

Flight.-When flushed, grouse rise from among the heather with considerable noise, and with a few very rapid strokes of their short, powerful wings, are soon travelling at a great rate of speed. When once well under way they skim on with motionless wings, flapping them rapidly every few seconds to accelerate the pace. When flying they generally keep near the surface of the ground, unless they have to cross some valley or wish to move from one part of the moor to another, when they often fly at a great height. They are capable of protracted flights of many miles, and often cross wide arms of the sea when migrating to the lower grounds in search of food. The legs are fully extended in flight, and carried under the tail, as may be easily seen when the birds are passing over the "butts" and travelling up wind.

Breeding habits.-As a rule the nesting-season does not commence till the middle of April, the eggs being generally laid towards the end of that month or early in May; but in mild open winters red grouse may be seen in pairs early in the year, even in January. When the early months are stormy and unfavourable, the birds continue to congregate in packs, their movements being greatly affected by the weather. Heavy snow-storms drive them from the high ground to the lower and more sheltered parts of the moor, but unless the storms are unusually late and severe, they gradually return as the snow melts to their accustomed breeding-grounds.

Unlike the polygamous black grouse and capercaillie, or even the ptarmigan, the red grouse has no favourite spot which is resorted to in the courting-season. They are very restless in spring, and the cocks may constantly be seen chasing the hens over the moors when not engaged in fighting off other suitors.

In the pairing-season the former are very pugnacious, the old cocks being especially so, and for this reason they should be shot down as 


\section{RED GROUSE}

much as possible, for they not only invariably harass and disturb the other birds, but are themselves less valuable for breeding purposes.

These quarrelsome old birds should always be treated as vermin, and shot for a month or two after the close of the shooting-season.

When fighting, they stand erect and spread their tails, and strike at one another with their bills and wings. When the fight is protracted, one or other of the birds is often very badly injured or blinded.

Nesting.-The nest is generally placed in a dry, open situation among growing heather, not too rank, and in the immediate neighbourhood of young food-heather. A shallow depression is scratched in the ground and lined with a little dead grass and a few bits of heather. Eggs are sometimes found in March, but from April to the beginning of May is the normal time, and most of the eggs are laid towards the end of April. The date of laying varies, however, in different localities according to latitude and elevation.

Eggs.-The number of eggs in a nest varies greatly; the average number is probably from six to eight, but small clutches of four or five, or as many as ten or twelve are not uncommon. Larger numbers, such as fifteen and seventeen have been recorded, but were probably the produce of two hens.

The eggs are of a rather long oval shape, one end being rather more pointed than the other. The ground is pale olive or stone-colour, spotted and blotched all over with dark reddish-brown or sometimes bright chestnut in freshly-laid eggs. The markings are often confluent, and conceal the greater part of the ground-colour. The average measurement is about $1 \cdot 75$ inch by $1 \cdot 23$ inch.

General habits.-The hen grouse is an excellent and hardy mother, and will remain on her nest during the heavy falls of snow which so often occur in April and early May, being sometimes completely covered. At such times, when the bird is absent in search of food, the eggs may become buried in a snow drift, but unless incubation is considerably advanced, this does not necessarily mean that they are lost. A considerable percentage are no doubt destroyed, but in many cases, as soon as the snow has melted, the hen returns to her nest and successfully hatches her brood. A few days of continuous rain seem to have a much more disastrous effect, for, in such circumstances, the sitting birds frequently desert their nests, being unable to withstand the incessant wet. On the whole, the eggs of the grouse seem to be unusually impervious to changes of temperature, 
THE GUN AT HOME AND ABROAD

and even hard frost, unless it is very severe, does not seem able to destroy their vitality. Before incubation commences the hen often adopts the protective measure of covering up her eggs with grass or heather, which no doubt saves them from the effects of frost. Like other game-birds, the hen grouse, when sitting on the nest, is able to suppress all scent, and thus remains undetected. This fact, coupled with the marvellously protective colour of the summer-plumage, must save many a bird from destruction by dogs and vermin.

Incubation lasts for twenty-three or twenty-four days, and the young are able to leave the nest soon after they are hatched-being carefully tended by both parents. The hen, when menaced by danger, attempts to lead away the intruder by feigning a broken wing, and fluttering along the ground, while the young squat among the heather, their beautifully patterned down of buff and chestnut assimilating so closely with their surroundings that they are most difficult to find.

Besides the many enemies which levy their toll on young grouse, such as foxes, stoats, and weasels, and their numerous feathered enemies in the shape of gulls, crows, etc., the chicks have to reckon with the ravages of a fatal disease now known as Coccidiosis, caused by an intestinal parasite (Eimeria avium). (See p. 58.) This disease attacks the chicks when they are quite young, and sometimes accounts for the disappearance of almost the whole of the stock.

For the first few weeks the chicks subsist largely on insect food, though tender shoots of heather and blaeberry also form a part of their diet; as they grow older they feed principally on heather.

Though grouse feed more or less throughout the day, their principal feeding time is in the early morning and evening, when the crop is completely filled. In the morning they are usually to be found on the lower grounds about the burns, but as the day advances they move to the higher broken ground and rocks, where they love to sun and dust themselves on the dry peaty banks. By creeping quietly up the cracks in the early morning, it is easy to get among the birds unobserved and watch the antics of the cocks as they spring a yard or two perpendicularly into the air and then drop to the ground, uttering their well-known crow, $a-a-u c k$, cuck, cuck, cuck, cuck, cuck, cuck, err-ra. This is usually uttered on the ground, the bird standing nearly erect, especially towards the finish, when the tip of the tail touches the ground, the back of the neck and crop being considerably distended. The cock has numerous other calls, uttered 


\section{RED GROUSE}

at other times, which sound like wurrów, wurrów, wurrów; erá-a, er-á; go báck, go báck, go báck; or wáy, a-wáy, $a$-wáy. When uneasy or disturbed either when with young or when wounded, the note is $u k, u k-k u k, k u k$, $u k-k u k$. The ordinary call of the hen bird may be rendered as yap, yap, yap or youe, youe, youe; she also makes a low wheedling or whining noise, similar to that made by a fowl; or it may be likened to the wheel of a barrow that wants oiling.

The crowing or "becking" of the cock is not confined to the breedingseason, when with erected comb and swollen eye-wattles, he stands up and challenges his neighbours, but may be heard at all seasons, especially on frosty autumn-and winter-mornings. The grouse, when adult, is one of the hardiest of birds, and is but little affected by wet or snow as long as food is obtainable.

The high ground is only deserted when the surface of the snow becomes covered by an icy crust, and the birds are no longer able to burrow and reach the heather beneath. The packs will then fly for long distances in search of feeding-grounds, and will cross wide firths in their search for heather, as has been frequently recorded. In hard winters large packs from the Cawdor moors, in Nairnshire, have been known to cross the Moray Firth to the narrow low-lying moors on the Black Isle, and, if disturbed, to continue their northward course, crossing the Cromarty Firth.

Except on some of the northern and western moors, grouse, especially the young birds, often begin to pack quite early in August, but as a rule the older birds, except in wet, stormy weather, do not do so till later in the year. In the north of Scotland, and in the Hebrides, the grouse are generally very tame, and sit very close, unless the weather is wet and stormy. In Skye I have found them as tame on the last day of the shooting season as they were on August 12. When grouse pack the males and females generally form separate parties, and it is not uncommon to find that most of the birds killed in one drive are cocks, while on another beat the reverse obtains. Generally speaking, the packs of hens are less partial to the higher ground than the cocks, and their movements are more erratic. The reason of this habit of packing is due to various causes, such as bad weather, lack of food, and the disturbance caused by shooting and driving.

Weight.-The average weight of a cock grouse in late autumn is about twenty-four ounces; but birds have been weighed of twenty-eight and 


\section{THE GUN AT HOME AND ABROAD}

even thirty ounces. The average weight of healthy hen grouse at the same season is about twenty-two ounces, and some may weigh as much as twenty-six ounces. When suffering from disease the weight rapidly decreases, and males and females fall to about fourteen ounces, or even less, before they die.

Diseases.-The Final Report of the Committee of Inquiry on Grouse Disease forms a vastly interesting and exhaustive monograph on the life-history of the red grouse, both in health and disease, and is a most complete and valuable work. It has now been ascertained by the Committee that only two diseases give rise to widespread mortality among grouse, viz., Cobbold's Strongylosis, the cause of the true "Grouse Disease" among adult birds, and Coccidiosis, which proves so destructive to the chicks.

The term "grouse disease" is a fallacious and too comprehensive expression, for it has now been definitely ascertained that grouse, like other birds, suffer and die from several diseases which have all been attributed by unscientific observers to one cause. The Committee have satisfied themselves that two diseases are responsible for the large percentage of deaths among grouse, and that each is caused by an animal parasite.

Dealing first with the principal enemy of the grouse, the nematode worm, Trichostrongylus pergracilis (Cobbold), the facts ascertained are briefly as follows: Nearly every grouse (at least ninety-five per cent) is more or less infested by these thread-like worms, which live in the paired creal appendices or blind-guts; but as long as the bird is healthy, well fed and in high condition, these parasites do not increase in undue numbers, nor do they materially affect its health. When the stock on the moor is too heavy, i.e., when on a thoroughly well-burnt and well-caredfor moor, the food supply of young heather is insufficient to support the number of birds on the ground, the grouse fail to obtain sufficient nutriment, and, consequently, cannot maintain their proper standard of condition. When in this somewhat impoverished state the balance of Nature is upset, and the parasitic " strongles," as Cobbold called them, almost always present in some numbers, get the upper hand. As has been already stated, they inhabit the paired cæca, which are unusually lengthy in the grouse and carry out such an active and important part in the digestive system. When the cæca become infested by abnormal numbers of these creatures (as many as ten thousand may be present in one grouse), the 


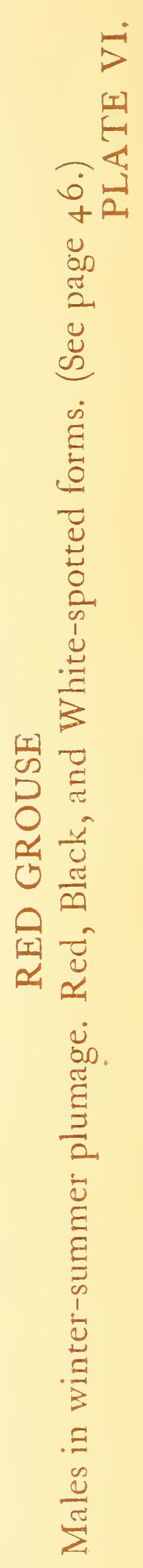




\section{.}

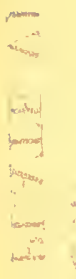




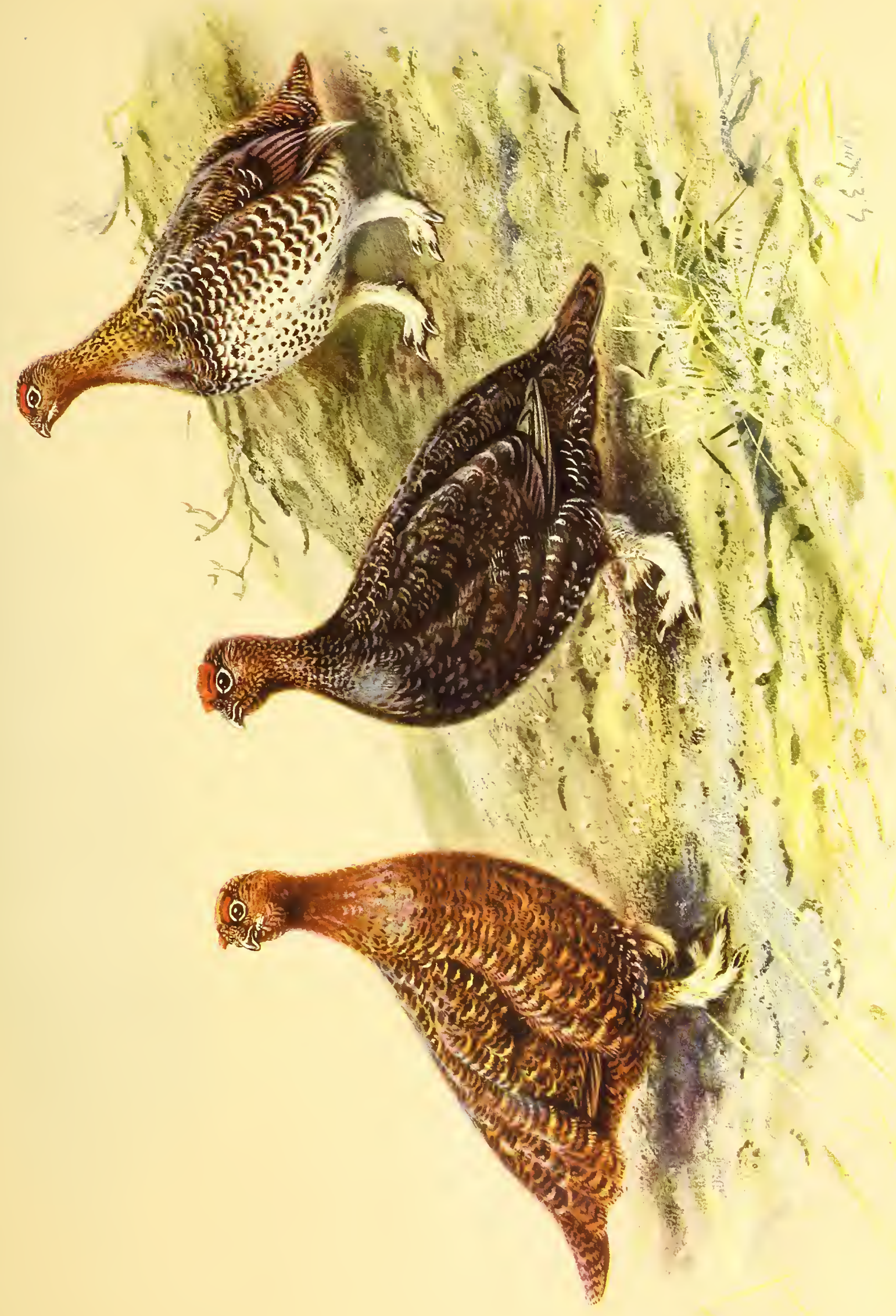




\section{RED GROUSE}

mucous membrane becomes highly inflamed and incapable of absorbing nutriment. The food, consequently, remains in the cæca undigested and in a dried up condition. The nematodes meanwhile flourish vastly, and find perfectly congenial surroundings among the mass of rotting matter; but the poor grouse rapidly loses weight and condition, and presently dies. The fact is, to put it in plain English, that the most fatal disease among grouse is appendicitis in its most acute form, for, unlike the human subject, the grouse possesses two appendices, which play a highly important part in its economy, and these are rendered functionless owing to their inflamed condition. This disease has been named Strongylosis.

A few species of nematode worms lead an entirely free life, but Trichostrongylus pergracilis is parasitic in the grouse in its mature stage. Practically every grouse contains these worms in scores, if not in hundreds, each worm lays thousands of eggs, and every grouse-dropping contains hundreds of fully segmented eggs and of larvæ free or still contained in the egg-shell. It can, therefore, be easily realized that the larvæ are scattered in countless millions over the grouse moors. Dr Shipley writes: "The eggs give rise to larvæ in about two days, the larvæ surround themselves, about the eighth day, with a capsule or cyst, and under go 'a rest cure.' After a period of quiescence they quickly change into second and active larval forms, which are minute, transparent, and quite invisible. These lead a perfectly free life, and in wet weather gradually squirm and crawl among the leaves and flowers of the heather, where they remain until swallowed by the grouse. When once inside the grouse, the larvæ make their way along the alimentary tract and enter the cæca, where they rapidly develop into adults." That is, briefly, the explanation of the worst form of grouse disease.

Dr R. T. Leiper, who has assisted the Committee by working out the development of this small threadworm, concludes his account with the following remarks: "The rapid death of the egis of Trichostrongylus pergracilis in fæces that have undergone temporary drying indicates that the drier the moor the more efficacious will wind and sun prove as natural antagonists to 'Grouse Disease.' Again, as the infective forms of the parasite occur on the 'food' heather, it is evident that the greater amount of 'food' heather in proportion to each bird, the less likely is it to become infected. As the periodical burning of heather increases eventually not only the area of food heather, but at the same time destroys, in the only effective way known, the living parasites upon the area of 
heather burned, the policy of heather-burning, advocated by other members of the Committee upon other grounds, receives additional support.

"The practicability and value of a periodical cutting of the heather requires further consideration by those acquainted with local conditions; but if practicable, such a measure should not only be a means of ridding large areas of the moor of infective material, and of bringing about a rapid increase in the 'food' heather area, but might also be applicable to those parts of a moor, and in those seasons of the year, when burning is impossible."

A second and entirely different parasite accounts for the death of young birds in summer. It is well known that after an excellent hatching-season the young grouse during the first six weeks of their life are often practically wiped out. This misfortune generally occurs when the moors are being left perfectly quiet, before August 12, and causes grave disappointment to many an expectant tenant. The cause of this second murrain is a coccidium, whose complicated life-history has been worked out by $\mathrm{Dr}$ H. B. Fantham. This protozoan parasite, known as Eimeria avium, first passes into the birds in the form of an oval cyst, which is picked up in the food, grit or water. The moors are said to be peppered over with millions of these cysts, which are very resistant to changes of temperature and moisture, and live for a long time. In the duodenum the chitinous wall of the cyst is dissolved by the pancreatic juices, and eight spores are liberated. Each of these enters one of the epithelial cells lining that part of the intestine, and ultimately destroys it. As the coccidia multiply, which they do rapidly, other portions of the alimentary canal, especially the cæca, are attacked, and the birds soon succumb to what has been called Coccidiosis. After a time males and females are produced and fuse, and result in cysts which pass from the bird and are scattered all over the moor. The chief external symptoms of this disease are said to be diarrhoea, loss of weight, and feeble flight. Internally there is inflammation of the alimentary tract, the lining membrane of which is destroyed, the blood corpuscles undergo a marked change, and an anæmic condition prevails. "Coccidiosis may be spread from moor to moor by the agency of flies. The maggots of certain flies readily eat the cysts, and it has been shown, both experimentally and on the moor, that the cysts pass through the bodies of both maggot and fly undigested and unharmed." Coccidiosis proves equally fatal to the chicks of fowls and pheasants, as well as to young pigeons. Dr Fantham's account, published 


\section{RED GROUSE}

in the Final Report of the Grouse Disease Inquiry, contains a fully illustrated and detailed life-history of this avine coccidium. He is specially insistent that all infected corpses should be burned, not buried.

Various preventive measures and modes of treatment are suggested, and though perhaps impossible to apply to grouse in their wild state, must prove most valuable in the case of all hand-reared game-birds, fowls, etc.

From ten to fifteen grains of catechu dissolved in a gallon of water has been proved to be of the most definite service where the treatment of Coccidiosis is possible. Lime may possibly prove of great service when its effect on the heather-growth has been carefully investigated. Any conditions tending to raise the general vitality of the birds also make them more resistant to disease. An abundant supply of healthy young heather, by raising the general standard of health of the birds, is probably one of the best safeguards against this insidious disease.

Among the host of writers who have from time to time advanced theories as to the possible cause or causes of the so-called "grouse disease," we may specially mention Dr Spencer Cobbold, Dr R. Farquharson, Mr W. Colquhoun, Dr D. G. F. Macdonald and Dr E. Klein. To Dr Cobbold is undoubtedly due the honour of having been the first to discover the true cause of the principal disease from which grouse suffer. During the great epidemic of 1872 and 1873 he examined large numbers of birds which had succumbed, and pointed out that death was in most cases due to the presence in vast numbers of the nematode worm, which he named Strongylus pergracilis. Subsequent writers strenuously opposed the views set forth in Dr Cobbold's pamphlet, and derided what was termed the parasite theory. Dr R. Farquharson, Mr Andrew Wilson and Dr E. Klein believed that "the disease" was typically an acute and infectious pneumonia, probably due to over-stocking, adverse seasons, and inferior food caused by early frosts. Dr Klein believed that the true "grouse disease" was in every case an acute infectious pneumonia due to a specific bacillus; but it has now been practically proved that he was mistaken, and that his deductions were founded on a misinterpretation of the post-mortem changes in the dead bird. Dr Seligman found that the bacillus which Dr Klein considered to be the specific cause of grouse pneumonia was, in fact, only to be discovered in any numbers some twelve or more hours after death, when colonies of the Bacillus coli had escaped from their proper sphere in the intestine and invaded the lung-tissue. His views 


\section{THE GUN AT HOME AND ABROAD}

have been subsequently fully confirmed by Dr Cobbett and Dr Graham Smith, who arrived at a very definite conclusion as to the absence of pneumonia in the birds which they examined.

It is nearly twenty years since Dr Klein made his investigation on " grouse disease," and the study of bacteriology was then, comparatively speaking, in its infancy. The significance of the fact that certain bacteria normally invade the tissues at the time of, or after, death, was not duly recognized.

It is quite clear that one of the most important signs of disease, whether it be Strongylosis or Coccidiosis, is a loss of weight, and this loss of condition, even to emaciation, which follows on Strongylosis, is a character to which full prominence is given by all writers about "grouse disease," though no measurement of actual weights had ever been recorded, so far as was known, before the recent Inquiry was undertaken.

The careful examination of some thousands of grouse, both healthy and diseased, has added very largely to the number of species of parasites, both external and internal, which inhabit them. A few years ago only two internal parasites were known in the grouse, but we now know that what Dr Shipley calls a " considerable fauna" lives both in and on them. There are eight species of insect or mite living among the feathers or on the skin, and the alimentary canal, lungs and other organs are peopled by no less than fifteen different species of parasites. Some of these are negligible, but two at least are associated with the grave disorders which often terminate in death. The insects and mites which live on the skin are interesting because they possibly form a second host of the tape-worms which are injurious to the lining of the alimentary canal. There are two species of bird-lice, very numerous on diseased birds; two species of flea, occasionally met with, which may possibly serve as a second and larval host of the most dangerous tape-worm; ticks occasionally found; a common cheese or flower-mite, sometimes present in great numbers on the skin of grouse; and, lastly, two species of $\mathrm{fly}$, one of which is the well-known grouse-fly. All these creatures have been carefully examined, but the investigation up to the present has failed to reveal the larva of the grouse tape-worm. Of the fifteen internal parasites only four or five demand attention. When the Committee commenced work, the large tape-worm (Davainea urogalli), which lives in the small intestine all the year round, and the slender thread-worm (Trichostrongylus pergracilis), which inhabits the paired cæca or blind-guts, were the only 


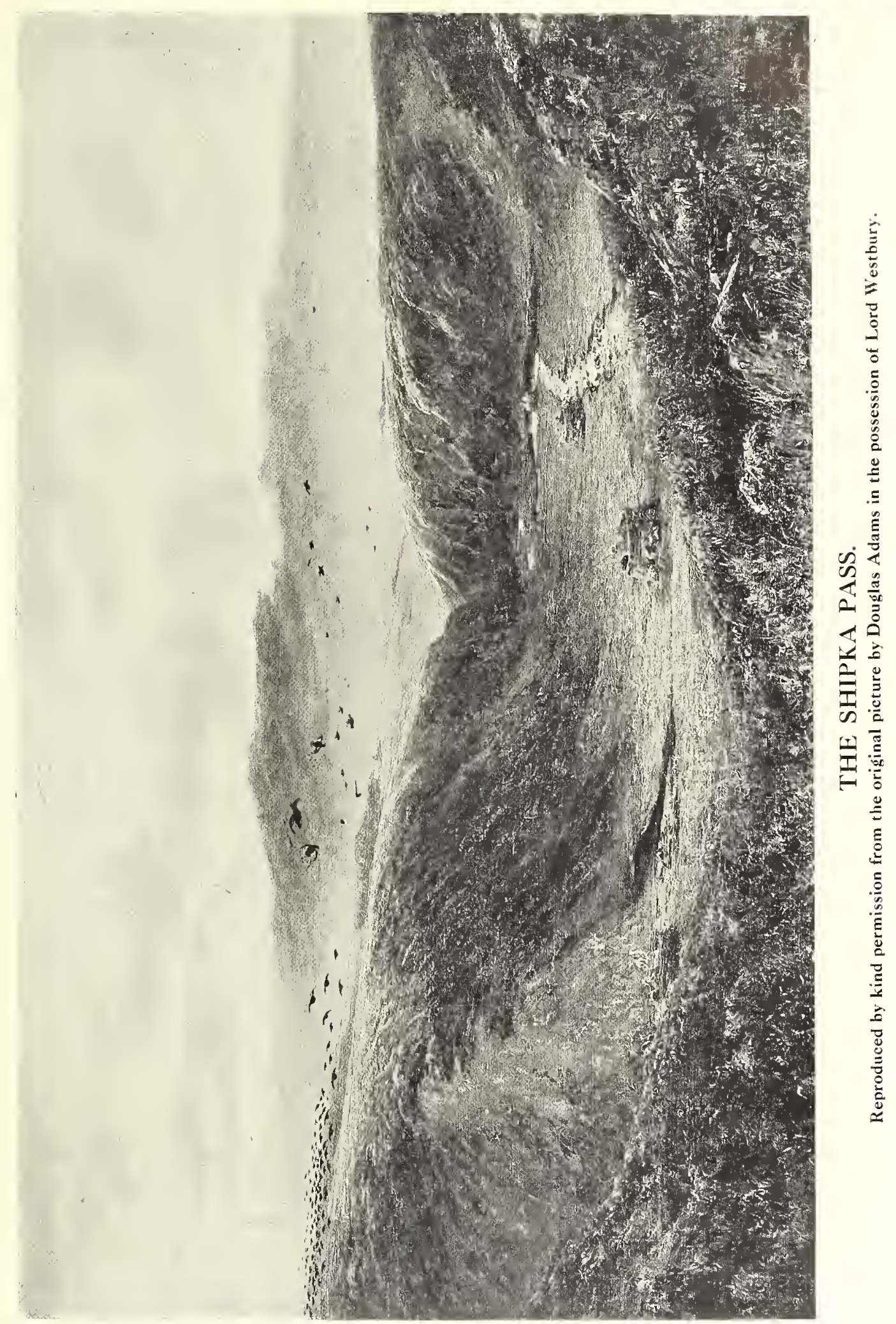




\section{RED GROUSE}

species known to occur in the grouse. The latter, as already stated, is the cause of one of the two principal diseases. The more slender tape-worm (Hymenolepis microps) is also said to some extent to be associated with disease and, like the large species, inhabits the duodenum or upper end of the small intestine, sometimes in incredible numbers. It disappears during the winter-months. Three round worms also exist in grouse, and one of them (Trichosoma longicolle) inhabits the duodenum and may prove of importance, as it is allied to a form which lives in the human appendix, and is at times the cause of appendicitis. Besides the worms, there are seven protozoan parasites living in the intestines or in the blood of grouse. Most are harmless, but one, a coccidium, already referred to, is the cause of disease in young grouse.

Finally it may be worth mentioning that there is a wide-spread popular belief that diseased grouse can be recognized by their beak, colour of their plumage and by the lack of feathers on their feet. As regards the former it may be stated at once that the colour of the plumage has nothing to do with the diseased state of the bird and is purely individual. The feathering of the feet is another matter. During the autumn moult every healthy bird moults the feathers of the legs and feet between June and August, but birds in a diseased state with the moults all retarded may be found moulting their leg-feathers between January and March, in which case it is a sure sign of disease.

Hybrids.-The red grouse occasionally crosses with the black grouse, and much more rarely with the ptarmigan. Hybrids with the former species are probably always the result of a union between a blackcock and a hen grouse. The males are large and very handsome birds, showing very clearly the characters of both parents, the tail being more or less forked, and the toes feathered at the base and naked and combed at the extremity.

Apparent hybrids between red grouse and ptarmigan, of which I have examined several, are occasionally obtained on the high grounds in Scotland in company with birds of the latter species. They show the characters of both species, and appear in winter to assume partially the white plumage of the ptarmigan. The feeding-ranges of the two species practically touch, and there is therefore no reason to doubt that a stray old cock grouse inhabiting the higher parts of the moors may occasionally pair with a hen ptarmigan.

W. R. OGILVIE-GRANT. 


\section{GROUSE SHOOTING}

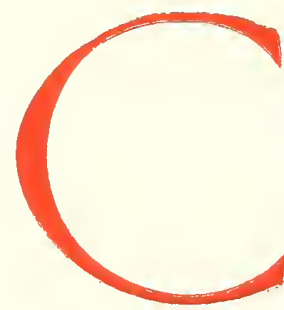

OMPARATIVELY few grouse are now shot in England except by driving, though in many parts of Scotland shooting over dogs is still enjoyed, where grouse lie well. If driving is to be practised on a moor it is not advisable to begin with pointers or setters, for then it becomes a case of burning the candle at both ends, the young birds which lie well, and which should provide the future stock-birds, being killed over the dogs ; whilst when driving commences, the more forward birds are killed also in considerable numbers. "Driving" moors, and "dogging" moors should be kept quite distinct. There is no more enjoyable form of sport, where the birds are sufficiently plentiful and lie well, than shooting over dogs, and for this purpose the setter is perhaps to be preferred to the pointer, being generally hardier, whilst the feather between the toes protects the feet better from the friction of the heather. But whatever the kind of dogs their training must be irreproachable, for badly broken dogs add much to the weariness of the flesh on a hot August day, on a steep hillside! The largest bag ever made by one gun over dogs was that credited to the late Maharajah Duleep Singh, at Grantully, in Perthshire, on August 12, 1871, when he killed 220 brace. According to Greener in "The Gun and its Development" (p. 535), "His Highness used three guns, and only one brace of dogs working at a time. He commenced at 5 o'clock, and continued till late in the afternoon." Part of the time the Maharajah certainly had more than one brace of dogs at work, I believe three brace, for he wrote an enthusiastic letter to my father, describing the day, and how he rode a pony, and went from one brace of dogs to another as they found game, dismounting in order to shoot.

Another way of shooting grouse is stalking them amongst broken ground, and amongst the peat-hags on the high tops, when the gunner needs to be very cautious and very quick to be successful. Moreover, he must be on his guard against the treacherous mist, or he may not be able to find his way home, unless he is very well acquainted with the locality. If running water can be found, he will probably be able to follow that till he reaches a clearer atmosphere, or some landmark which tells him where he is ; or if there is a wind blowing he should also have a sense of the right direction. But a misty day is often a calm one, without any sun to show the points of the compass, and then he must look at any patches of heather he may meet, and observe the way in which it grows, 


\section{GROUSE SHOOTING}

remembering that for some cause the branches nearly always lean to the East, and so also do rushes-perhaps attracted by the first rays of the morning sun. The north can usually be discovered by examining a big upstanding rock, when the north side will be the one more thickly covered with lichen than any other, whilst the south side will be almost bare. In this way the points of the compass may be sufficiently determined to make good an escape from the clouds.

On misty mornings, and especially on sunny mornings after a hoar frost, with no wind blowing, grouse are partial to sitting on walls, and may then be stalked by creeping very close to the wall on the side to which the tail is directed. Very often the sentinel bird thus takes up his post, and it by no means follows that if it flies off the others will take alarm at once, for they may not have noticed its departure if they are huddled up half asleep, or are busy picking bents, or other trifles. Old cocks can often be circumvented in this way, and may be seen from afar through good stalking-glasses. When stalking grouse in broken ground care must be taken not to creep straight down wind upon them, for though they have not such keen scent as wild ducks, they can detect human scent a good long way off, if the stalker carelessly gives them the wind.

"Becking," and also " Carting to grouse," are other ways of obtaining a few shots when birds are otherwise unapproachable, and particularly when old cocks have to be killed. The former is most successful at daybreak, almost before it is possible to distinguish forms, for grouse begin to move very early. When an old cock is heard to "brag," issuing the well-known challenge, a skilful caller will bring him flying up at once, eager to drive off his supposed rival. In the daytime a good imitation of the hen grouse clucking to her brood is often more successful than the challenge of the cock. Carting can only be carried out on fairly level moors, though many a shot can be obtained by merely walking alongside a pony used to the moor, and who will stand quiet at the discharge of the gun. These ways are only for the dweller on the moors, when a few birds are required, after the grouse-driving parties are over for the season.

Grouse-driving has so often been described that only a few hints, rather by way of memoranda, will here be given :

(1) Let the first drive be down-wind if possible, for grouse will return home against a gale, but when first flushed against the wind nearly always 
THE GUN AT HOME AND ABROAD

make a short circle, and then turn down-wind. If the first drive is downwind the grouse will come back against the wind in the return drive, when flushed a second time.

(2) When grouse are in full feather, after the beginning of October, the use of shot smaller than No. 5 invariably results in many wounded birds carrying on and then towering, or dropping dead, out of sight. At the beginning of the season, however, No. 6 is certainly preferable.

(3) A blinded bird ascends like one about to tower, but instead of suddenly collapsing, and falling a heap of feathers, it comes down with its wings outspread. Such a bird is very much on the alert, and, when approached, suddenly darts off with great swiftness, and if there is no one at hand with a gun, it will probably escape.

(4) The heather should be kept closely burned for at least fifty yards round the butts to facilitate picking up the dead birds.

(5) When selecting sites for butts try to arrange that no natural alighting ground is a short distance in front-unless the butts are concealed from observation-otherwise the birds which alight will all turn back when approached by the drivers.

(6) When possible, choose a site where the grouse will have to pass over green ground when they arrive within range, grass, fern, or rushes; for when the light is bad it is very difficult to see a low-flying grouse sufficiently clearly against dark heather, and many birds are wounded in consequence-instead of being killed.

(7) Where feasible, the butts should be placed low down, so that the grouse fly over them, as they are much more easily seen against the sky, and consequently a larger percentage are brought to the bag.

(8) Grouse are much more easily killed when the ground is level for some distance before and behind the butts, for then the grouse fly also on a level plane. Grouse usually follow the contour of the ground, so that if it rises suddenly, or falls away, the birds also continually alter the level of their flight, which greatly increases the difficulty of the shot.

(9) It is easier to kill birds flying to the left if the ground falls away in that direction than if it rises, for the natural tendency is to pull the muzzle of the gun downwards when swinging it to the left, and vice versa to the right. The natural deflection coincides therefore with the flight of the grouse when following falling ground.

(10) Butts made with foundations of stone, the upper half only being of peat, are almost everlasting. The stones should not be raised quite 64 


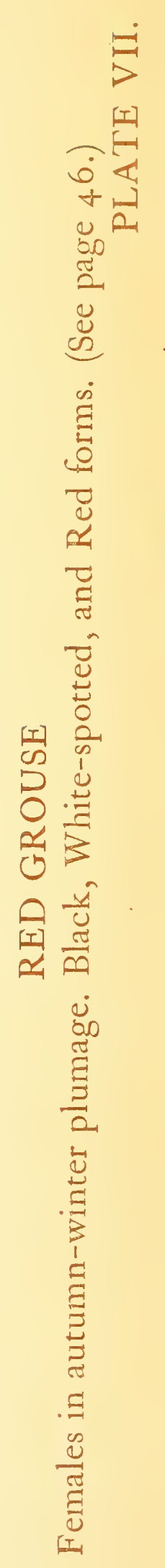


TAML 0 at

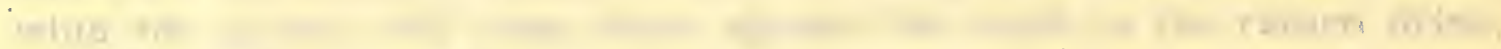

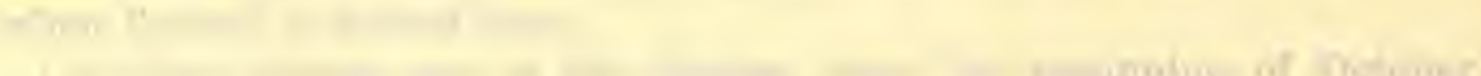
2.

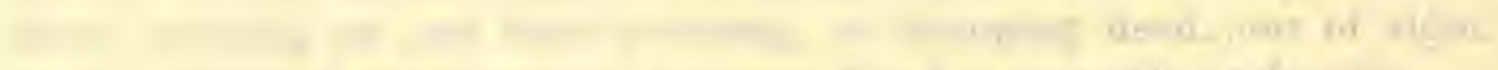

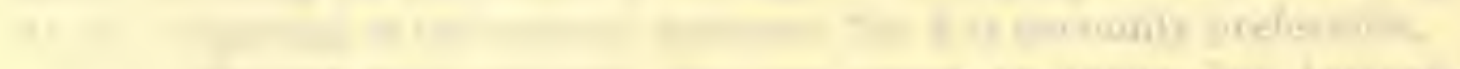

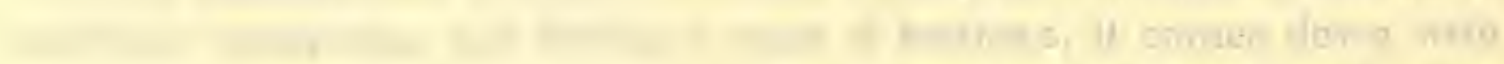

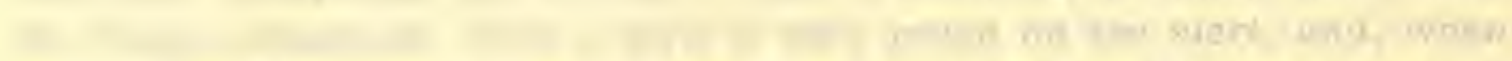
This

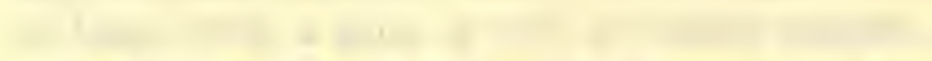

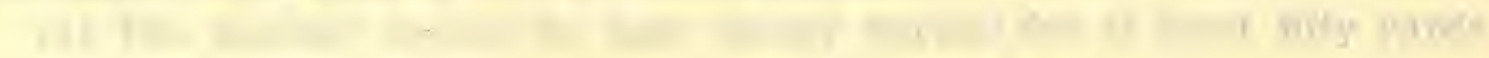

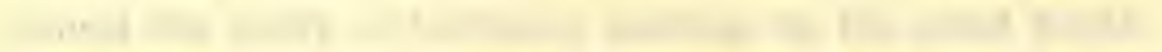

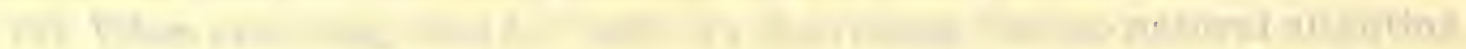
Hath |

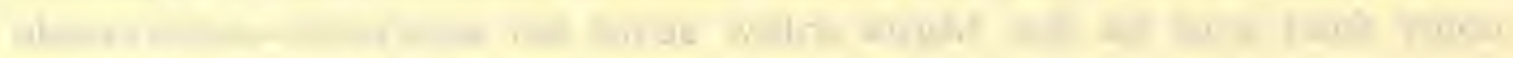

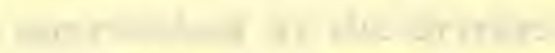

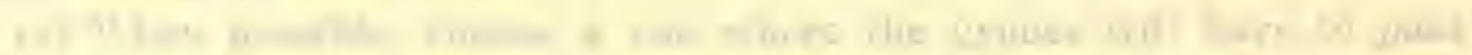

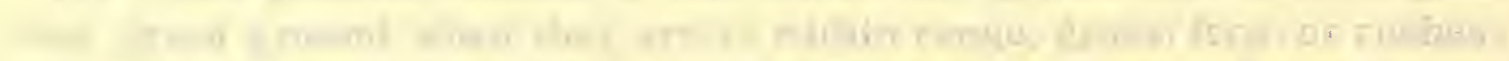

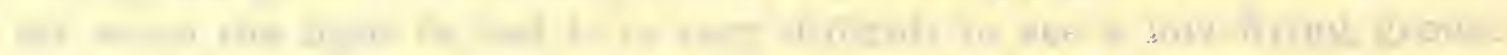

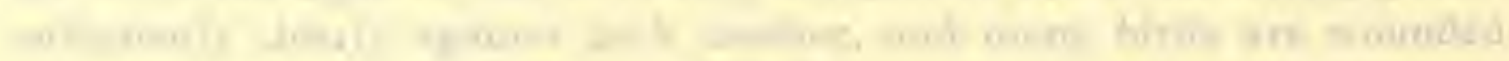
in.

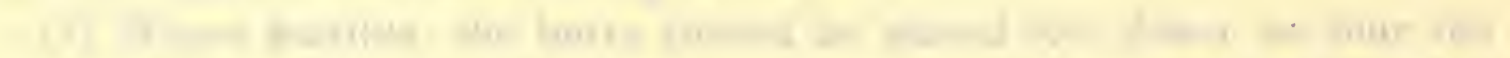

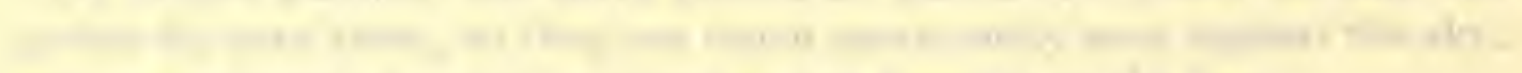
-

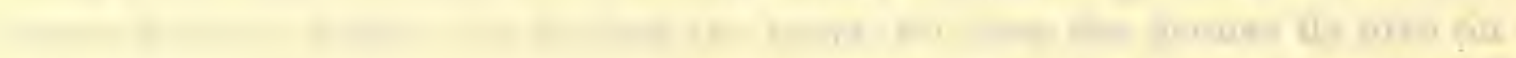
1

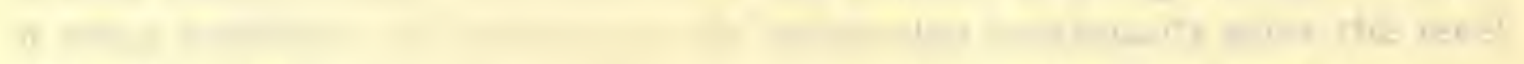

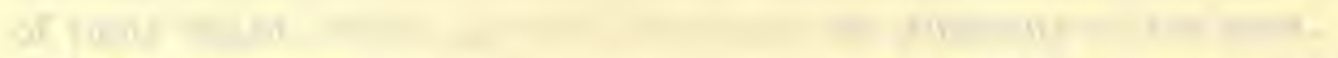

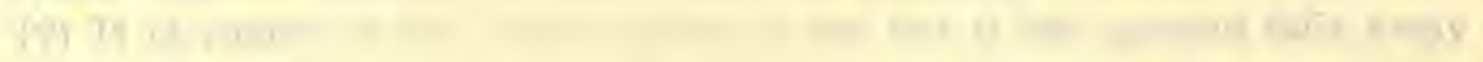

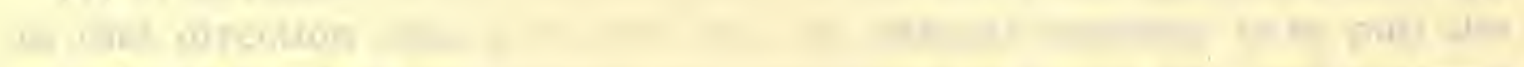

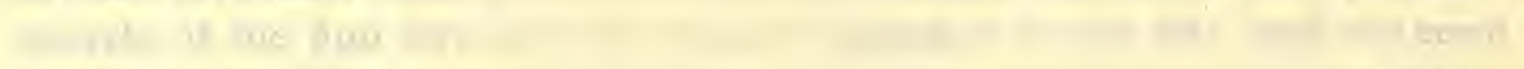

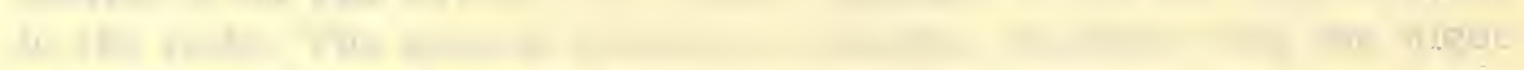

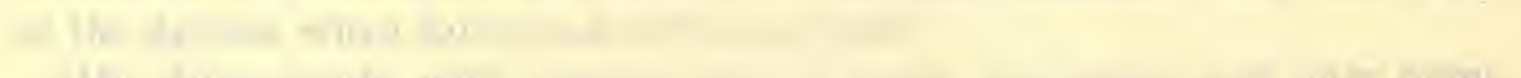

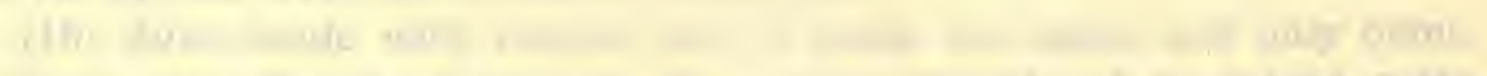

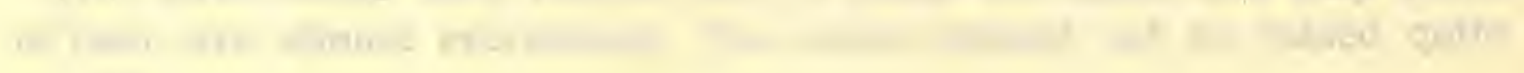
$+2$ 


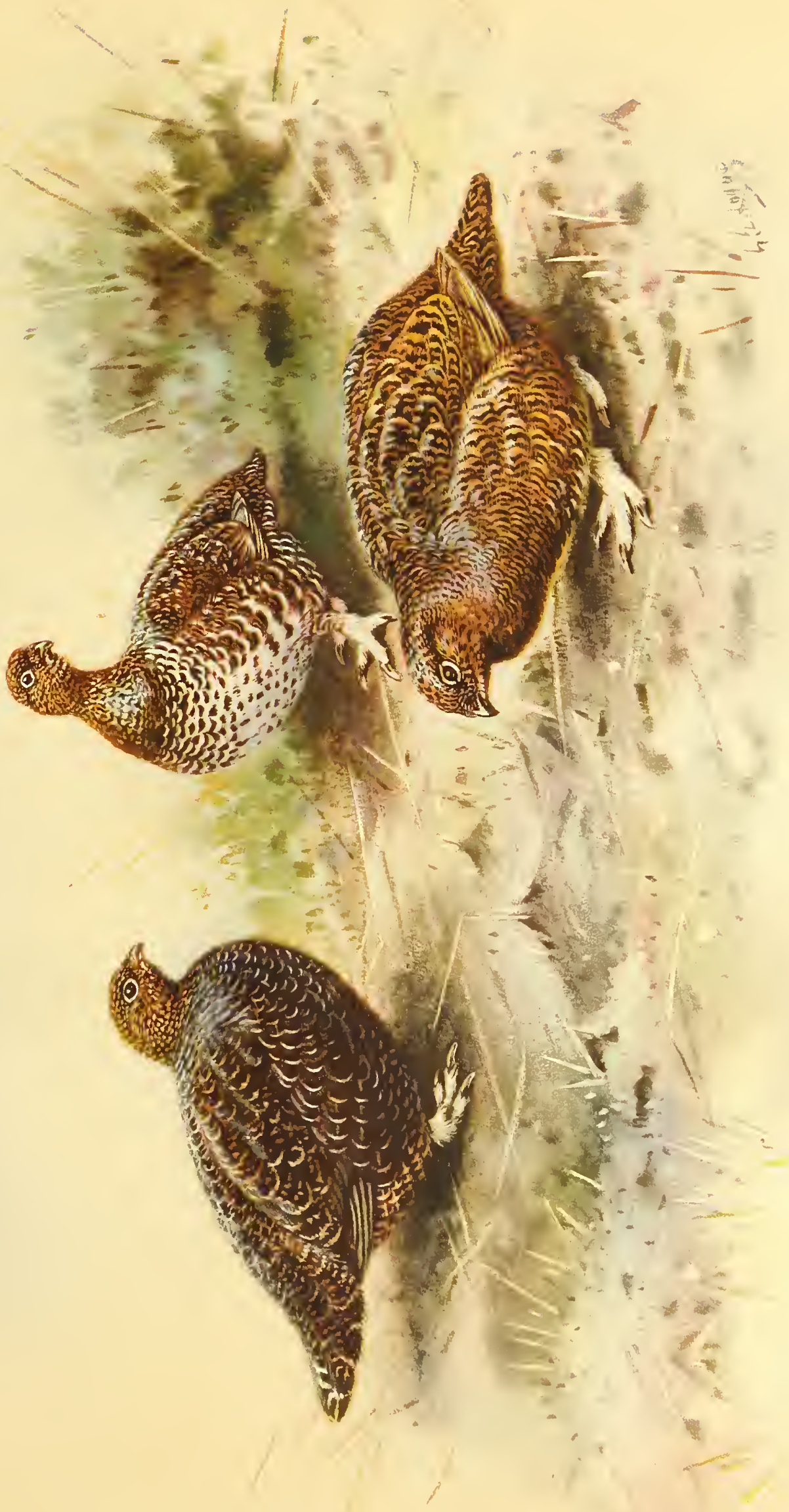





\section{GROUSE SHOOTING}

as high as a gun, so that the latter will rest against soft sods when leaned against the side. Stones are apt to scratch the barrels and also dent them.

(11) A wooden shelf, with projecting pegs to form gun-rests, fixed in a corner not quite the height of a gun from the ground, is a great help and convenience.

(12) The floor of the butt should always be level and firm, and also be well-drained. If the floor slopes it is not easy to maintain a true balance at the moment of firing; and if there is a miry mass under foot, the heel will sink as the trigger is pulled, particularly when the bird is high in the air. In either case the aim is much interfered with, and a miss is the probable result.

(13) If the drainage is good, grass sods make the best flooring, after they have settled and become firm, but new-laid sods are so unstable they almost ensure bad shooting. A flooring of flag-stones is very good, firm, and comparatively dry in wet weather, though not quite so comfortable to the feet as sound grass.

(14) Permanent butts should be large enough to contain three persons without crowding, and a retriever besides. A post should be driven into the ground well inside the butt, to fasten the dog to in case of need.

(15) Butts should be so enclosed that shelter is afforded from whatever quarter a storm may come. The extra labour is well repaid by the more accurate shooting, for no one can shoot in his best form when exposed to an icy wind, or a pitiless hailstorm, or fast-falling snow when shooting late in the autumn. Moreover, birds come on with less swerving when they do not see the forms of the shooters, and therefore present easier marks.

(16) The top sod of the butts should have an irregular outline, something after the fashion of battlements ; or else have long-stalked heather growing upwards, to hide the head of the gun on the watch. It is an instructive, amusing, and not unfamiliar sight to the denizen of the moors, skilled in every wile of the grouse, to see his neighbour in the next butt, from down South, standing up to his full height, with head and shoulders in full view of the grouse, and yet with a touching belief the simple birds will come within range and be killed! Sometimes, indeed not unfrequently, the master may be seen taking due precautions to hide behind his butt, yet standing bolt upright behind him is his careless loader.

(17) Forty-five to fifty yards are quite far enough for the butts to be 
THE GUN AT HOME AND ABROAD

apart, for by the time the grouse have entered the " danger zone," when, for the safety of your neighbour, it is unsafe to fire, the grouse are still a long way off, if flying on the exact centre line between the two butts. Moreover it is much safer for the butts to be close, for then the firer sees the next one so plainly, when the gun is at his shoulder, he does not think of firing; whereas, when the butts are seventy or eighty yards apart, they are scarcely noticed by the firer in the absorption of the moment.

(18) It is an unpardonable sin for anyone to aim at a grouse and follow it with his gun across the next butt, with his finger on the trigger, even though he does not fire till it is quite safe. It is a very dangerous practice of which no one should be guilty.

\section{RECORD BAGS}

It is an extraordinary circumstance that with all the improvement in the way of guns, cartridge cases, smokeless powder, and the knowledge of driving grouse, the great bag made by Sir Frederick Milbank on August 20,1872 , has never since been equalled. It was a wonderful performance, and for just forty years this record has stood. There was no idea of endeavouring to achieve a record performance, or to beat some one else's total, but he simply took his part in the ordinary way as a member of the party, and no extra effort was made to prolong the shooting beyond the arrangements for the day. This made the sporting conditions quite ideal.

A statement of these conditions may be of interest, and have been lately sent to me by his son, as the following letter will show :

\section{Barningham Park, Barnard Castle. October 20, 1911.}

Dear Meysey-Thompson,

On back of this you will find what you want about my father's shoot at Wemmergill. We had, as you will see by the list, eight drives, and I send you what my father killed in each of the eight drives. This I have copied from his own handwriting to-day. We were six guns, but one gun came late, and missed three drives, which made a big difference, in a day like that, to the bag. I hope this will give you all the information you require.

\section{Sincerely yours,}

POWLETT C, MILBANK. 


\section{GROUSE SHOOTING}

\begin{tabular}{|c|c|c|c|c|}
\hline Drive & & & 48 & ouse \\
\hline " & & & 76 & . \\
\hline ", & 3 & & 92 & ", \\
\hline ," & & & 29 & " \\
\hline ", & 5 & & 140 & " \\
\hline ", & 6 & 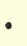 & 190 & , \\
\hline " & 7 & & 111 & ", \\
\hline ", & & & 42 & " \\
\hline Total & & & 728 & \\
\hline
\end{tabular}

August 20, 1872.

Total killed that day, 2,070 grouse.

Had 8 drives.

Sir F. Millbank used 3 guns, black powder and pin-fire cartridges.

No. of guns shooting, 6 .

Total bag for season, 17,074 grouse.

The guns shooting were : Sir F. Milbank, Powlett Milbank (son), Mark Milbank (brother), Lord Rivers (who came late), Mr T. Preston (Moreby Hall), J. Collinson (keeper).

The record bag for one day's grouse-driving was made by $\mathrm{Mr}$ Rimington Wilson's party of nine guns on August 24, 1904, on Broomhead Moor, when 2,743 grouse were killed; and another immense bag was made by the same number of guns on August 30, 1893; 2,648 grouse being killed on that occasion. During the last season, 1911, a very remarkable bag was made by the Duke of Buccleuch's party at Roan Fell, Langholme, for only eight guns took part, of whom one was a lad still at Eton College, and who shot with only one gun, though it is stated he shot extremely well. On this day Captain Hon. J. Dawnay made a magnificent bag, shooting with two guns, No. 6 shot, and 33 grs. E.C. powder. His successive drives were as follows :

\begin{tabular}{|c|c|c|c|c|}
\hline Drive & e 1 & . . & & rouse \\
\hline " & 2 & . & 63 & , \\
\hline ", & 3 & . & 120 & ", \\
\hline , & 4 & & 180 & , \\
\hline ", & 5 & & 86 & ," \\
\hline & 6 & & 35 & ", \\
\hline ", & 7 & & 35 & ", \\
\hline Cotal & & & & \\
\hline
\end{tabular}

The total bag for the day was 2,523 grouse and it will be noted there were only 7 drives during the day.

The party consisted of : Lord Dalkeith, Lord George Scott, Lord Henry Scott, Lord Francis Scott, Lord E. Hamilton, Lord Whitchester (at Eton College), Hon. D. Cairns, and Hon. J. Dawnay.

The largest number of grouse killed by one gun in one day is 1,070 , by Lord Walsingham, on Blubberhouses Moor, on August 30, 1888, in twenty drives, shooting by himself alone. He had previously, under the same conditions, killed 842 grouse on August 28, 1872, on the same moor, in sixteen drives.

R. F. MEYSEY-THOMPSON. 


\section{MANAGEMENT OF GROUSE MOORS}

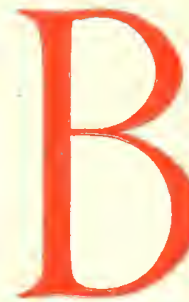

IRDS of the moorland and mist, associated as they are in the minds of most persons with the lofty and rugged mountains which are their chief habitat, grouse seem to be the essence of the hills, and fit in delightfully with their romantic surroundings. Yet, wild as they are, grouse will become tame under appropriate conditions, and, being of a bold and pugnacious disposition, soon lose all fear of man.

Nesting.-It is observable that grouse never make their nests in heather so dense that the chicks cannot get through it and be led out into the open, but if strips are burned as long as possible in such expanses, about twenty to thirty feet wide, grouse will take advantage of these, and make their nests a yard or two within the old heather, where perhaps there have been none for years. The favourite sites, however, are where the surrounding heather is rather thin, for there the chicks can move freely after the various insects which form their staple food when newly hatched. But they also eat heather from the very first, picking up the shoots which she drops as they follow the hen, until they are able to forage for themselves, and peck off the tender shoots of such heather as they can reach. When nesting amongst heather which has been recently burned, the old birds select a site where the burnt stalks have weathered and become ashen grey, and since the eggs, especially after a spell of wet, have a tendency to become also grey in colour, it is instinct no doubt which guides the parents in choosing a place where the eggs will assimilate in appearance with their surroundings, and so be less conspicuous than they otherwise would. Grouse will frequently occupy an old nest again if the egg-shells are cleared out, and a few fresh dried bents are placed at the bottom.

Hand-rearing.-When young grouse are hatched under a hen they are not difficult to rear, provided the hens are quiet and careful mothers. The coops should be placed on a flag, or board, for fear vermin may get in and destroy the brood, and put down in short heather, which the chicks will soon begin to pick for themselves. At first a wooden run must be placed in front of the coop, to prevent the chicks from rambling too far before they can fly, which they will do when ten days to a fortnight old; and as the runs have often to be put down on uneven ground, some small pieces of zinc should be provided to fill up any interstices, and if the bottom of the zinc is fairly ragged, and is used with a see-saw motion, it will penetrate 68 

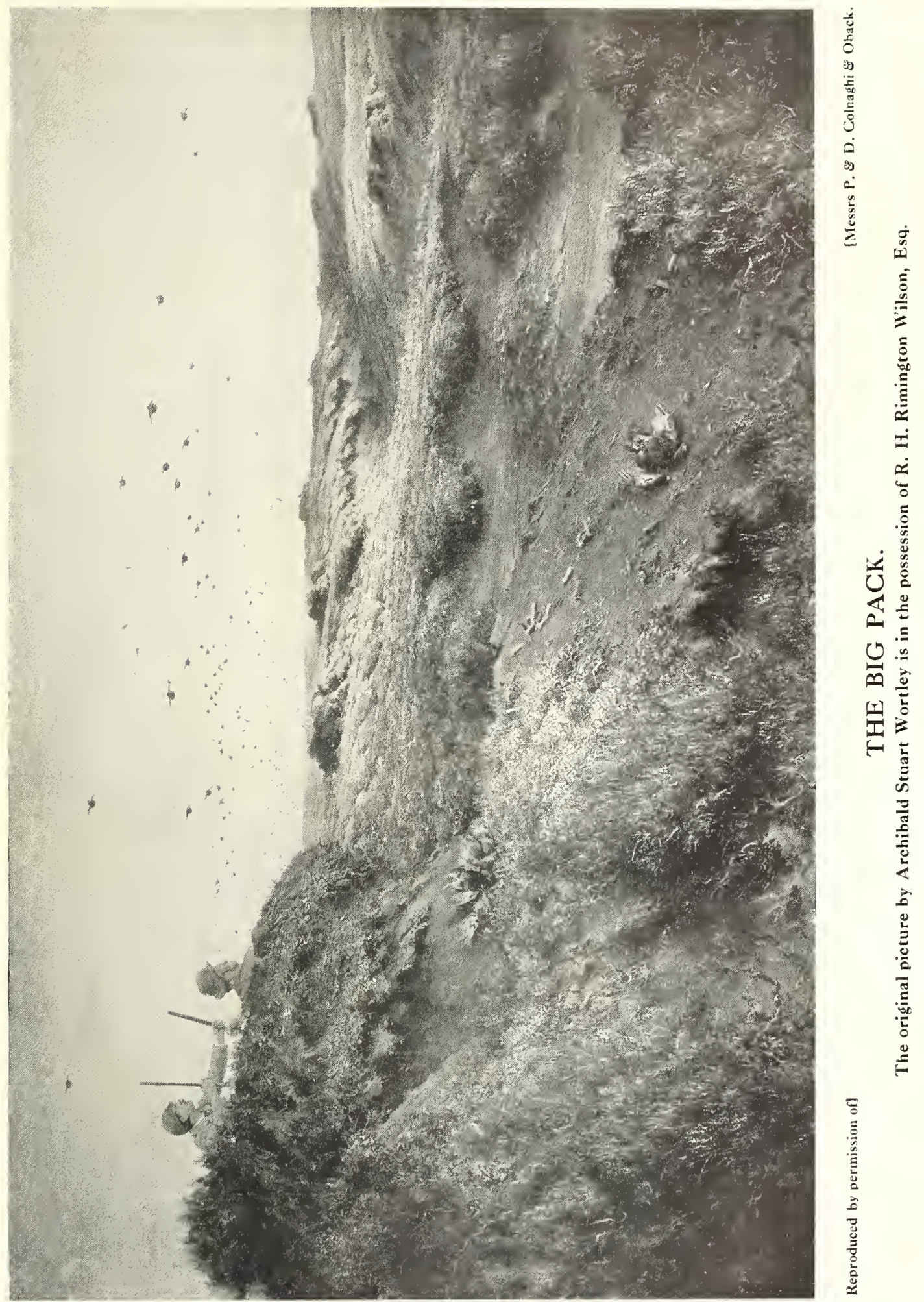



\section{MANAGEMENT OF GROUSE MOORS}

with ease any soil however hard, provided it is not really stony. If the coop cannot be placed upon heather, this will have to be supplied fresh every day.

The hen should have a ball of barley meal, as large as one of her own eggs, not later than 10 a.m. ; and the last thing at night, when the coop and run should be moved on to fresh ground, some oats or other corn should be given to her.

For the first week the chicks require feeding several times a day on coarse ground oatmeal, a little hard-boiled egg, leaves of young heather picked for them off the shoots, and some insect food, ants' eggs, if procurable, and some grouse-rearing meal. During the second and third weeks feed on well-boiled rice, canary seed, millet, dari, hemp and rape, mixed with a little hard-boiled egg, and very small quantity of meat, together with some green food, chopped watercress or lettuce, and young heather. This should be mixed with the grouse-meal just mentioned till crumbly, and not more should be given than the little birds can consume at a time. For the first fortnight they should be fed every two hours; the third week every three hours ; the fourth week every four hours ; until at last twice a day is quite sufficient. As the chicks get older a little biscuit meal added to the food makes a slight change. Water should be given them from the second day in shallow vessels in which they cannot drown themselves, if a patent water-fountain is not used. A plentiful supply of grit for the hen and young ones should also not be forgotten. The run may be removed as soon as the young birds can fly a little.

Water supply. - On many moors, especially on the eastern ones of Yorkshire adjoining Whitby and Scarborough, water is very scarce. Grouse are thirsty birds, possibly on account of their very thick plumage which, though it acts as an admirable great-coat in wild stormy weather, must often be uncomfortably close when the sun gives out great heat, so that unless water is artificially provided great tracts of heather are ill adapted to rearing young broods. The usual means of doing this is either to conduct the water by little runnels in various directions where springs are available, or by depositing water fountains in sufficient numbers in the localities where they are needed. When selecting one of these vessels it is important to note whether the reservoir is so closed to external influences that no microbes, or other deleterious matter, can gain an entrance, so that the water may remain sweet and wholesome for a considerable period. Some are self-filling, mist and dew, in addition to rain, sufficing usually to 


\section{THE GUN AT HOME AND ABROAD}

keep the pan filled, though often the price is against their being used on a large scale. An excellent contrivance planned by $\mathrm{Mr}$ Wormald has the merit of costing little, but it needs replenishing from time to time, one filling lasting about a fortnight; it has for some years been in use on the Gross Cliff Moor, where it has given every satisfaction. It is supplied by Dickson, Lawrence Street, York, at the price of 1s. 11d., a small piece of india-rubber tubing being required in addition. When one or two hundred fountains have to be replenished some contrivance is needed for conveying the water, and nothing is better adapted to this purpose than the pack-saddle used by the water-carriers of Spain, which can be borne by any pony or donkey. It holds either the Spanish water-vessels, or the cans in use for carrying milk on a man's back in the West Yorkshire mountains, two being placed on each side of the saddle.

When runnels are made they should be very shallow, with sloping sides, to obviate the danger of young birds getting drowned. On many moors a considerable area is encroached upon by bracken, which becomes useless, or nearly so, for nesting, though in very hot weather grouse freely resort there on account of the welcome shade from the powerful rays of the sun. It can, however, be extirpated with attention, for if cut closely in the spring before the fronds have finally uncurled, and again later in the summer when fresh growth has sprung up, in the course of a very few years it will entirely disappear.

Drainage. -On most moors there are tracts which are constantly wet, a pan of clay underlying the top layer of peat, and there the heather gives place to water-loving plants. Frequently such places can be drained to advantage, although grouse often select a dry little spot in such localities for a nest, but danger of destruction from a sudden flooding is ever present, either from a thunder storm, or from an excessively wet period setting in, which is often fatal to eggs and chicks. Grouse, especially old cocks, are partial to such spots, uncongenial as they seem, for their night quarters, though, of course, in very limited numbers, and the reason appears to be that they find themselves safe there from an attack by four-footed vermin, which cannot easily steal upon them unawares, under cover of the darkness. But this is no reason for leaving such places undrained if the cost of doing so does not seem prohibitive. Drains should be shallow ones, a spit deep, a spit's width at the bottom, and two at the top, with the sides carefully sloped, and the excavated earth thrown clear away to prevent any danger of obstruction from its falling in again, being very good rules to follow. 


\section{MANAGEMENT OF GROUSE MOORS}

The main drain should never run straight down the hill, but be taken slantwise, with the cross-drains running into it in herring-bone fashion. Such shallow drains are of great use in running off the surface water, while they do not deplete the moss of too much of the supply it should conserve for a droughty period. Favourite places for snipe should be carefully left untouched. Snipe only frequent certain spots, and there are always plenty of places where no snipe ever go which can be drained without having recourse to the others. The presence of snipe on a moor adds much to the attraction, for they make a welcome variety in the bag.

Heather burning.-One of the most important items in the management of a moor is the burning of the heather, and this is not the easy matter to decide upon which many persons appear to think. What may suit the needs of one locality may be most unsuitable, even prejudicial, in another. Where limestone is present, especially at high altitudes, heather requires much coaxing to get it to grow at all when sheep are grazed there, and if there should be too large a stock of sheep the heather will soon disappear altogether. To burn in such a locality, and there are hundreds of thousands of acres of such grouse-ground, would be very foolish, for the sheep would consume the young shoots of the heather as it tried to struggle through the grass, and kill it entirely. But where the soil is peat, sand, or gravel, burning can be carried out with impunity, there being no fear of the grass smothering the heather. The late $\mathrm{Mr}$ W. Prior was keeper on a moor adjoining that on which the writer has lived for many years, and he used to point out a batch of heather which he knew for a fact was eighty years old, and yet was only about eight or ten inches high, green and flourishing, and on which the grouse fed as freely as on any other. If a match were applied to this heather it would never come up again, owing to the attentions of the sheep, and the writer could show numbers of places similar in every way, where burning would be equally prejudicial. About 2,000 feet above the sea-level there is heather from two or three inches in height to six inches, that has never been burned in the memory of man, and if such ground were burned it would take a lifetime to replace.

How important it is to burn heather when feasible is clearly shown by the Report of the Grouse Committee, for the beneficent action of the fire destroys in its course the eggs and larva of the deadly parasites which attack the grouse. Since the crowding together of large numbers of birds -either through stress of weather, or from being attracted to favourite 


\section{THE GUN AT HOME AND ABROAD}

feeding grounds-increases the sources of infection almost by geometrical progression, it is very desirable to tempt the birds to break up the packs as much as possible, and this is largely helped by burning in strips and small patches. It has long been known that where the heather grows rather thinly the burning should be done in patches of a quarter acre as near as possible, and, where it grows very thickly, in strips of twenty to thirty feet wide, and as long as can be conveniently managed, in order to obtain the best nesting and feeding results. There is an additional reason for this practice, since it has been shown that the risk of infection is thereby much diminished.

Anything which affects the food supply reacts upon the grouse, and hence it is that outbreaks of disease usually make their appearance in the spring, after the privations of winter. If the stock is healthy, bad weather in the breeding season does little harm, but the health of the birds depends very much upon the quality of the food supply during the months of February, March, and April. The state of the heather at that period depends, on ordinary moors, on two things: the character of the previous season, and the amount of the stock of sheep. When this last is excessive, although the weather may have been ideal, the heather has no chance of affording a supply of good food, and a summary glance will tell at once what are the prevailing conditions. Where there are too many sheep there can be no proper bloom, and, consequently, no seeds. Unfortunately in the West Riding of Yorkshire, in Lancashire, and in Westmorland, thousands of acres fall under this category.

Food in winter. - Where the heather has fair play the winter food supply depends on (1) good growth in the spring; (2) good bloom in the summer; (3) good seed in the autumn in the preceding year; and when these conditions have been favourable, a large breeding stock may be left in the confident belief that the health of the birds will be good in the following spring. They will then be able to resist the ravages of the strongyles, and rear large broods-though if there should be a prolonged spell of hot dry weather when the chicks hatch out, there is danger of considerable numbers succumbing to Coccidiosis-the conditions then being favourable to its development. The chief danger, however, to be apprehended in the springtime is a prolonged late fall of snow, either when the grouse are laying, for then the nests get covered up, and the hens cannot find them again, or just after the chicks are hatched, when they succumb to the cold and have difficulty in obtaining insect food. There is not so much damage done by 


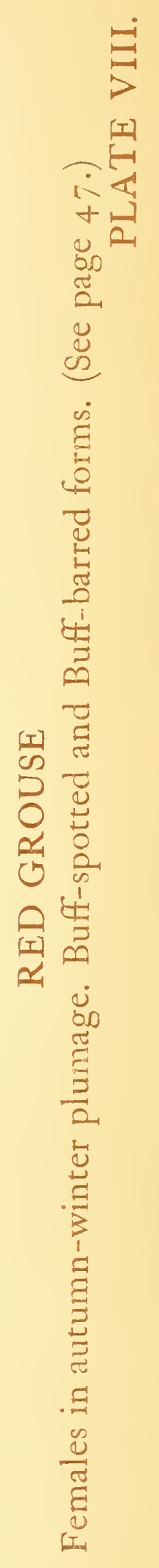




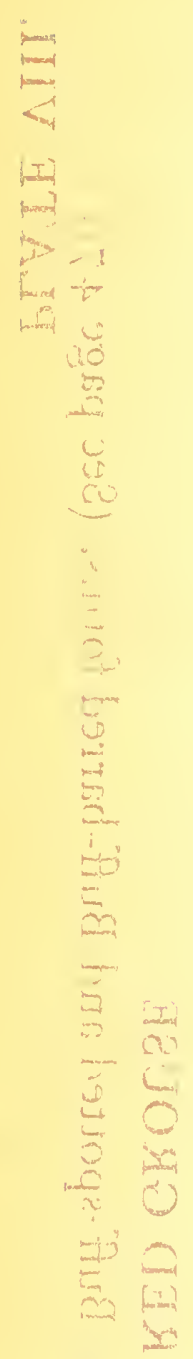

$i$

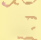

$\underline{z}$

3

3

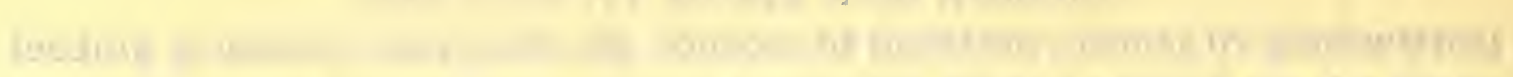

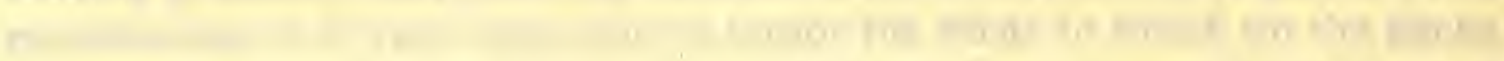

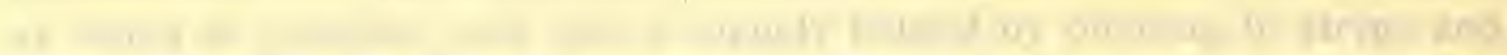

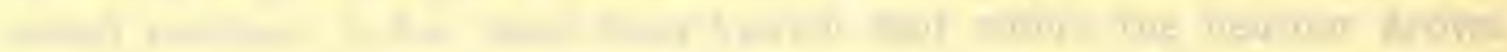

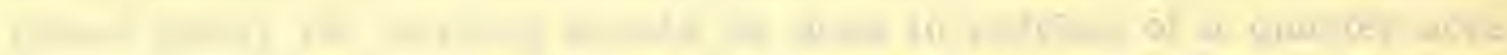

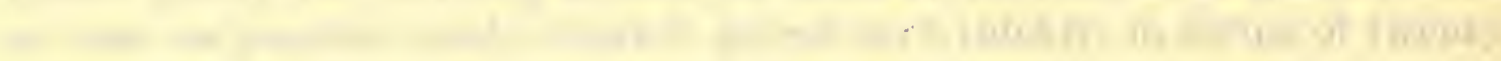
10.

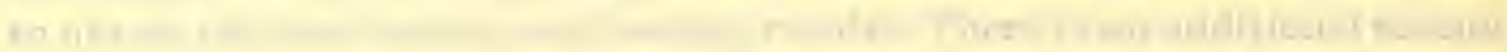

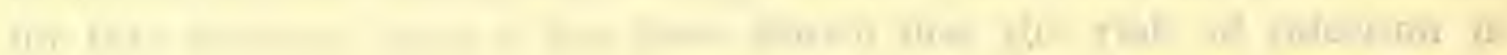

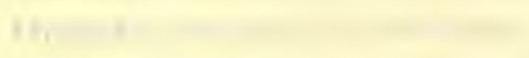

Jwoge

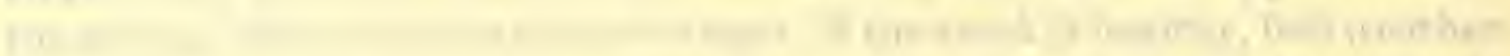
1. 1.

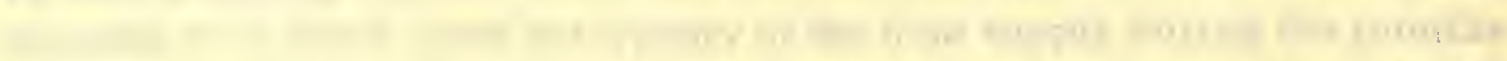
4.

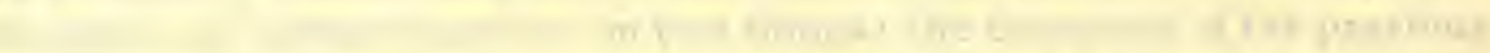

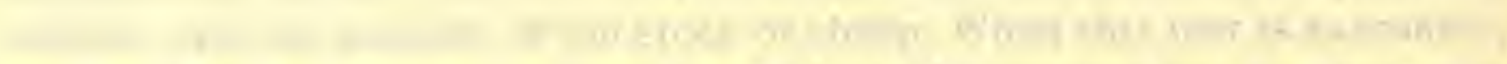

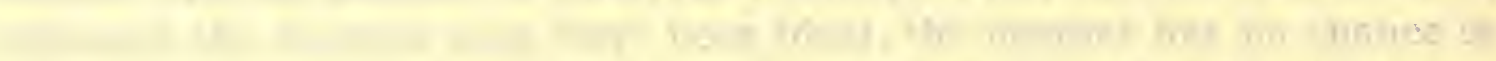

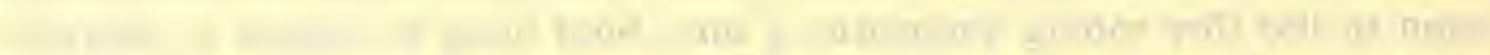

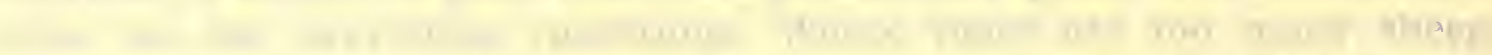
the

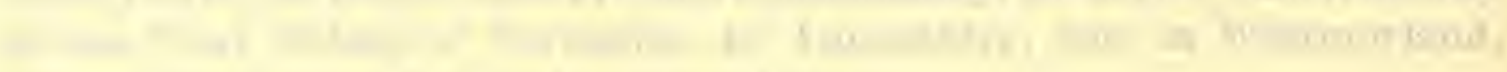

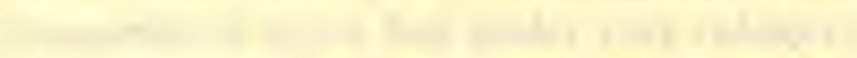

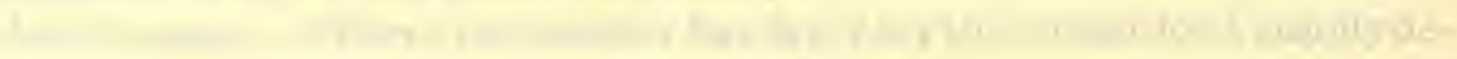

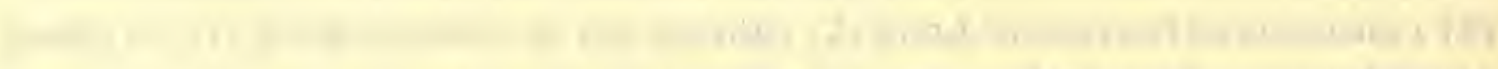

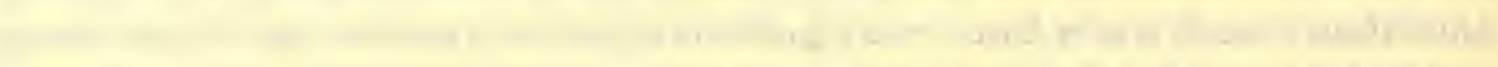

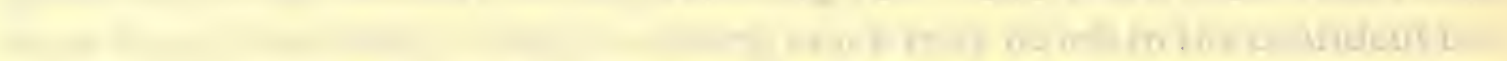

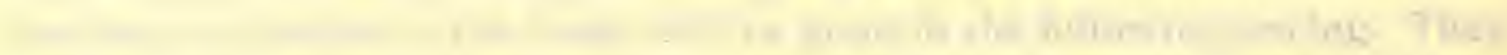

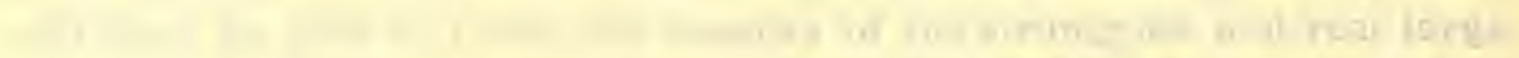

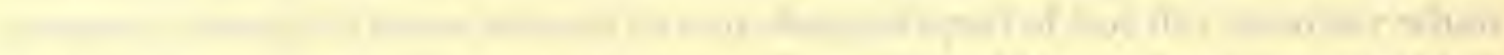
thations

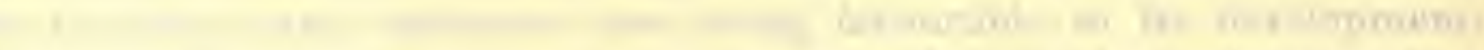

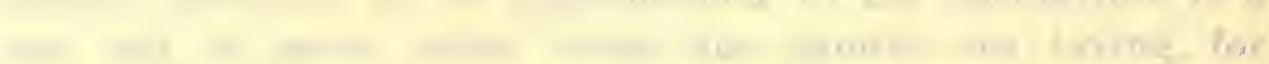

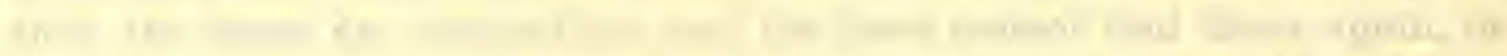

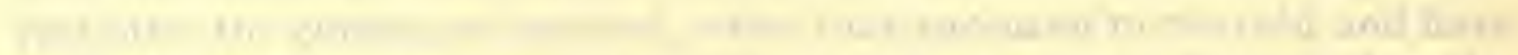

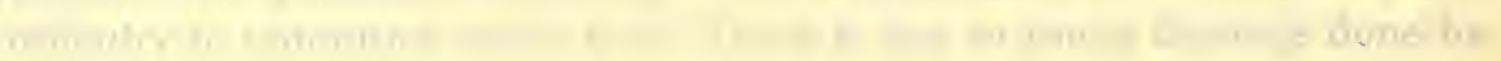




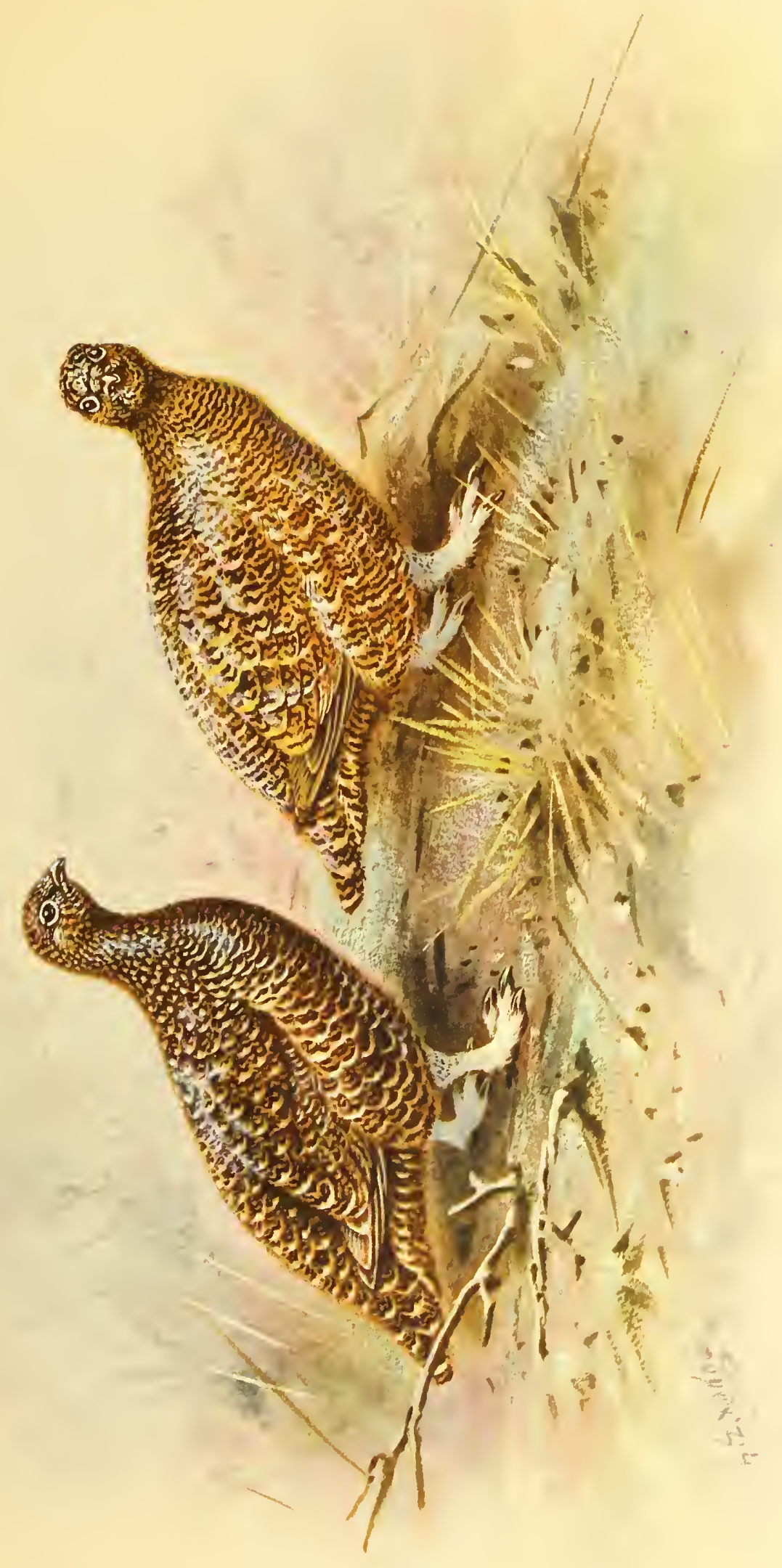





\section{MANAGEMENT OF GROUSE MOORS}

snow when the hens are sitting, unless it should fall when they are off their nests, and the latter get covered up, but the grouse are good judges of weather, and are not often deceived in this respect. They are very devoted, however, and if a really deep fall should occur, they may sit so close, and for so long a time, as to get weak from hunger, and may not be able to obtain sufficient food, having to travel a long way for it. Many a hen dies on her nest from sheer weakness after a prolonged storm.

Effects of snow.-Even when a nest is snowed over whilst the hen is still laying, it by no means follows that the eggs are rendered unfertile, for it is surprising what vitality they possess, and what an amount of cold they can withstand, far more than those of either partridges or pheasants. It may be here pointed out that grouse are excessively shy birds when laying, and if then surprised and put off the nest, they will at once desert it. Even if the hen notices a person stop and look in her direction, it is generally sufficient to cause her to forsake her nest. After she has been sitting a few days it is different, and hardly anything will alarm her sufficiently to cause her to desert. It is therefore necessary to keep the moor absolutely undisturbed during the period of laying. A hen grouse takes about a fortnight to lay a full clutch.

The Committee of Inquiry on grouse disease assert that the health of the birds is of far greater importance than the weather, and bad weather does little harm if the stock is healthy. Per contra, if the stock is unhealthy, bad weather at breeding time will result in a poor crop of young birds, and if the heather growth is indifferent the birds should be closely shot down in the autumn, leaving only a moderate stock, which may then find sufficient food to keep themselves in a thriving condition in the following spring. Grouse are extremely hardy birds, and so long as the food is good, what kind of weather it may be during the winter seems to be immaterial. But it is a bad sign, as the autumn advances, to find the feathers on the legs of the grouse not properly developed, and when this state of things is observed, the more grouse that are shot the better.

Moorland plants.-There are many other plants besides heather which make up the bill of fare, and on some moors a failure of the heather is not of such serious consequence as it is on others. Where the blaeberry, whortleberry or bilberry (Vaccinium myrtillus), is prevalent, grouse eat largely, in the late winter, of the shoots containing the buds, and in the summer they eat the leaves, and berries when they are ripe. In the springtime they also eat quantities of the stalks and tops of cotton-grass (Eriophorum), 


\section{THE GUN AT HOME AND ABROAD}

which in some localities is very prevalent. On the high mountains they are fond of the small bedstraw (Galium saxatile), which grows profusely on the limestone, and is the chief food there of the mountain partridge. They also eat the leaves of the crowberry, at some seasons, which sheep do not seem to have much relish for; but of all the dainties they indulge in, perhaps the one they love most is the moss rush (Juncus squarrosus), which at the season of its ripeness tempts the grouse to leave the moor and scatter over the green hillsides during the day time, revelling in their change of diet.

When grouse are hard put to it in a prolonged storm they will eat almost anything they can get, and during the tremendous snow of 1895, ere the grouse had to forsake the regions of upper Wharfedale, Wensleydale, and Swaledale, and betake themselves to the far off arable lands in the low country, they perched on the hawthorns in packs and devoured every bud which could be obtained. And yet the following season was the best grouse year the writer has known during his residence there of nineteen years.

Best time for burning. - The experience gained during that period has shown that autumn burning answers best, and if done as soon as the moor will burn, whilst the heather is still full of sap, with a fairly brisk breeze, the fire does not tarry, and so the roots do not get burned. The shoots then spring up the very next year from heather of any age; but when burned in the spring -which is usually very severe in that region-with little sap in the plants, the fire strikes deeper down, and it is often three or four years, and even more, before old heather shows any signs of sprouting.

When engaged in burning McPherson's (Inverness) "heather-burner" is one of the greatest boons, for it enables the operator to keep the fire alight with ease, and to cover much more ground in a given time, and in a wet climate it is needful to make the most of any opportunity for burning which offers. The tool needs a long handle, and that of an old hay-rake is very suitable for the purpose, as it just fits into the socket of the burner.

Another useful implement is a "heather-beater," armed with which, three men, or even two, can subdue a fire that might otherwise get beyond control. It is made of thin sheet-iron, $2 \mathrm{ft}$. 6 ins. long by $1 \mathrm{ft} .6$ ins. broad, and is screwed on to poles $8 \mathrm{ft}$. or $10 \mathrm{ft}$. long, for which hazel or birch boughs come in very handy. It is used by dropping it on to the fire and drawing it slowly over the burning mass, thus 


\section{MANAGEMENT OF GROUSE MOORS}

smothering the flames, and not by beating them down. It is so handy that it is easy to keep on fashioning, and leaving unburned, small patches of heather, which are available at once both as nesting sites as soon as the young growth has carpeted the ground, and also as shelter for the chicks at the approach of danger.

Grouse, when feeding, prefer heather of eight or ten inches in height to that of a shorter growth, no doubt because, as they stand upright, often even on tiptoe, to reach the topmost shoots, they can see danger from afar, and keep a guarded look-out whilst they are feeding. Considering the immense number of shoots they devour each time, morning and evening, it would require hours for each meal if they had to stoop to pick low heather for each mouthful, as they have to do when seeking grit on the ground, for directly they swallow a piece they look up to see if danger is approaching. With the few pieces of grit which are required this slow way does not matter, but with heather it is different. The late Mr Prior once counted the contents of a grouse's crop, which contained $\mathbf{9 , 7 0 0}$ separate pieces, the bulk being green heather leaves (about 8,700 ), whilst the remainder of the mass was made up of heather blossoms, a small number of grass stalks, and a few bilberry stalks and leaves. Grouse, when feeding, nip off the shoots in rapid succession, jerking their heads with a motion quite different from that of geese grazing; but, then, the latter are picking grass close to the ground, of short growth as a rule, and of firm habit, whilst the heather has considerable spring, and is perhaps ten inches high. The goose therefore pulls the blade of grass towards it, tucking in its chin as it plucks at the grass, but the grouse, reaching up to its full height, nips off the leaf of the heather with a sideways twist, sometimes breaking off a sprig with three or four leaves at a time.

Supply of grit. - One of the most important requirements of a moor is an ample supply of grit, and the want of it may render large tracts of otherwise suitable ground unfit for nesting, if the chicks cannot get a supply of this necessary. Grouse prefer quartz grit, and will travel far to obtain it, and much can be done to improve a moor deficient in this respect by bringing some from elsewhere, and putting it down regularly at certain placeswhich the grouse will soon find out-and frequent. Old cartridge boxes form handy receptacles, and can be put down in spots where the grit would otherwise pass out of sight, such as mossy ground. In snowstorms it is well to lay bare patches of road, down to the road-metal, and thus afford the grouse a chance of obtaining some grit. Very small stuff, as 


\section{THE GUN AT HOME AND ABROAD}

fine as coarse sand, is required for immediate use, with larger pieces to make an impression on the coarse stalks which are eaten from time to time. Grouse have two chief meals, the first one very early in the morning, and the second one late in the afternoon, both consisting of heather leaves ; but all day long they keep picking up tit-bits in the shape of berries, seeds, and insects. They usually seek for grit about an hour before dusk, or in the forenoon.

Sheep.-The conditions under which sheep are allowed on a moor have a most important bearing upon its welfare, especially where there is also a liberal growth of grass. On moors which have no "white ground," where the soil is all black, and peaty, and also where the soil consists of hungry sandy gravel, the problem of sheep does not need to be solved. It settles itself, for grass will not thrive on such soils, and sheep cannot eat ling by itself for long without getting " ling-sick," and then they must be removed, or they will die. On such moors there will never be any inordinate number of sheep, for no more can permanently abide there than the scanty growth of herbage will support. But on the rich limestone hills, and where millstone grit abounds, the heather has a constant struggle with the grass for its very existence. If the sheep are concentrated in any one locality they will quickly exterminate the heather, and this may be seen on thousands of acres which now are green, but which formerly were all heather. A good farmer, who intends to pass his life on his farm, and honestly pay his way, will always take care so to stock his holding that the heather flourishes, and then the farm will be kept at its utmost productiveness, yet do no harm to the game. There are, however, far too many sheep farmers who, seeing their chance, will take a holding well supplied with heather and grass, and spoil both by putting on far too large a stock of sheep than the land can permanently carry; and then, having ruined both the pasturage and the shooting, ask for a reduction of rent, on the ground that there is not sufficient keep for their sheep, when, if their request is not granted, they throw up their farm and move elsewhere. When landlords and agents do not understand such wiles, they fall easy victims to imposition. To prevent any chance of concentrating too many sheep on any particular spot, a deaf ear should be turned to all entreaties for putting up barriers such as stone walls and wire fences, which are not necessary, although the tenant may make out a specious tale that his neighbour's sheep come from afar to graze on some particular favourite spot. Sheep have their own especial ranges, which they do not exceed 


\section{MANAGEMENT OF GROUSE MOORS}

when left to themselves, and when they arrive at their self-imposed limit they turn round and feed back again. The number of strange sheep which may intrude is therefore never likely to be very great, even if there is no barrier between the holdings, and whilst some of the neighbours' sheep may trespass over the boundary, in another part the process will probably be reversed. Moreover, if each farmer is limited as to the number of sheep he may have, which should invariably be the case, each will watch his neighbour most vigilantly to see that the number allowed him is not exceeded; but the moment fences are erected, neither man cares how many sheep the other has, and does not trouble himself in the least about them. The only fences which should be allowed are those protecting lowlying fields, where no heather exists. On the moor there should be nothing but boundary stones to mark the line of demarcation, and if these are painted white they are easily seen, and are quite sufficient.

Each holding should be reckoned as having so many "gaits" attached to it, a " gait " being sufficient to graze one sheep. It is then easy to reduce the number of gaits if it is seen that the moor is losing its heather. As a gait is only let for a rent of eighteen pence to half a crown, a reduction of a hundred sheep would only mean a loss of rent of $\$ 1210$ s. per annum, taking it at the highest figure; while it might make all the difference between the moor going back or not, and consequently affect the number of grouse.

In calculating sheep gaits lambs are not taken into account until the ewe is shorn, about the end of June, after which a lamb is reckoned as half a sheep gait until it is "dipped" at the latter end of the following October. It then commences a full gait.

When cattle are allowed on a moor a two-year-old bullock is reckoned equal to four sheep.

Bullocks do not touch heather until snow falls : they will then eat it, and should be removed until the thaw comes, to be put back accordingly, and a clause to this effect should be inserted in all agreements. If it happens to be a hard winter the beasts may have to be removed several times, but in a mild winter the owner scores. It does no harm to have a few bullocks with the sheep, and if a moor is calculated at one hundred sheep, it might be advisable to arrange for, say, eighty sheep gaits, and five cattle gaits.

The first sign that the stock of sheep is excessive is that no little shoots are to be seen springing from the heather, each plant exhibiting a close- 


\section{THE GUN AT HOME AND ABROAD}

cropped appearance, like furze does on a rabbit-haunted common; and then when August comes there are so few flowers the moor has a dark appearance, instead of the lovely pink hue it should present. When heather has reached this stage it will require fully three years' entire rest before it is able to recover itself. If, however, these danger signals are not attended to and the stock of sheep reduced, the latter will gradually devour all the green leaves of the heather, which will assume a very dark appearance owing to the superabundance of stalks, many of which will be pulled up and be seen lying about. On examining them closely it will be noted that only very few sickly looking leaves are to be found at the extremities of any of the branches, and the heather will so completely disappear that it is only by examining the roots of the grass that it can be discerned to have existed there. It will then take some years to recover, even if the sheep are almost entirely withdrawn. It is better not to attempt any burning, for the roots will throw up shoots if given the chance, whereas if fire be applied the roots may be destroyed, and as there is no heather seed with which to originate a new growth, the whole of the heather will be exterminated.

When arranging for burning it must be borne in mind that plenty of long heather is required on a moor for shelter from heat and from storms, while much of the wildness of grouse at the present day arises from there being so little long heather now to be found on most moors. In the old days of shooting over dogs the value of long heather was well understood, for it was there the bulk of the bag was made, the birds crouching in it, and lying like stones. There must also be plenty of rather thin long heather for nesting sites; and heather of eight to ten inches for feeding. If this be kept in mind, and also that the plots burned should not exceed as a maximum half an acre in extent, or the strips more than thirty feet in width, the moor should attain its highest grouse-bearing capacity. But moors over-burned may be seen in every direction, whole hill sides being set on fire at once, and hundreds of acres left black and bare, and one wonders where the unfortunate grouse are expected to find places to nest in, and for shelter, for the next ten years to come.

Long old heather is of great value in severe snow storms, for the wind, which generally accompanies the snow, keeps on shaking this heather, so that the snow settles down to the roots and a good deal of food lies exposed. Without such a supply the birds will have to leave the moor, and many may never find their way back. 


\section{MANAGEMENT OF GROUSE MOORS}

Sheep do not eat much ling, unless they are overcrowded, until the old grass has died down in winter, and as soon as the grass begins to die all sheep should be taken off the moor, which in most seasons would be towards the end of January, though it may be necessary any time after the end of November. Sheep do most harm in February, March, April and May, when the early shoots are growing, and are eagerly eaten by the sheep, the old rotten grass being distasteful to them. They should not be allowed back on the moor till the end of May, and as the young birds are then just hatched, the dogs need to be kept under strict control, or a whole brood may be quickly snapped up. Sheep can do a great deal of harm to the heather in snow time, and should then never be allowed on the moor.

On properly managed estates the tenants are never allowed on the moor, but are obliged to leave their sheep under the care of a shepherd, paid £1 per week by them, but under the control of the estate bailiff. At shearing time, and at dipping time, there is a general gathering of the tenants to take away their sheep, when they have been brought down from the moor by the shepherd. The latter has to find his own dog, but he is allowed to act as a driver on shooting days, and thus supplement his weekly wages.

At the end of October every ewe should be cleared off the moor, and put with the tups in the enclosures, only "hoggs" being then allowed on the moor, lambs being thus designated after dipping time, till after the first shearing. By this method the grouse are not being daily harried by the shepherd driving the ewes up to the tups, which effectually clears the grouse away for the time being, especially when every tenant is allowed to go on the moor whenever he wills.

Grouse do a great deal of courting about the beginning of November, and when the moor is quiet, may be constantly seen in pairs pursuing each other with rapid flight, the cock only a yard, or less, behind the hen, and wheeling and twisting in every direction, the two never varying their distance, and being apparently swayed by the same impulse, while the whole time the hen is uttering a not unmusical low note. It is probable that at the same time choice is being made of a locality for the future nest, though the actual site may not be selected until the spring.

Young grouse, after their plumage is complete, may be distinguished from old ones by examining the second flight-feather, which in a bird of the year is very narrow, ending in an acute angle; every additional year 
THE GUN AT HOME AND ABROAD

the web gets broader, and consequently the end of the feather rounder, until a really old bird is as round at the top as a man's thumb.

Vermin, both winged and furred, must of course be kept down; but the poor kestrel should be spared, whose usefulness in destroying voles-its especial food-is inestimable. The same plea cannot be advanced for the hedgehog, which, interesting as it is, and useful for devouring beetles, is a terror when it finds a nest of eggs. It will also attack a brood of tiny chicks before they can fly, and as it will tackle a hen pheasant, it would probably cope successfully with the parent grouse. Fortunately, however, hedgehogs are no great frequenters of moors, being unable to make their way well through the heather.

Grouse-netting. - On many moors, especially in the West Riding of Yorkshire, the baneful shadow of the grouse-netter is seen. It is incredible the area from which they can draw their supplies, and the far-reaching mischief they can do. The method is to erect nets ten feet high, in thirty feet lengths, which may extend for two miles, and when grouse fly into them the section between two poles usually falls to the ground, enveloping the birds, whilst the remaining lengths of the nets are left standing. The object is to take the birds alive, for sale to persons possessed with the fallacious idea of introducing new blood, or stocking some hitherto grouseless land; and for such purposes the birds sell readily from fifteen shillings to a guinea a brace, and sometimes more. For this purpose small areas of moor are rented, or holdings obtained which are frequented by grouse, or across which they fly, for it is not necessary the birds should ever alight in order to be caught. All that is necessary is that there should be well-stocked moors in the vicinity, and then to set the nets in a favourite line of flight-when the netters are able to guarantee the birds have been captured on their own ground! The writer has known one such case where the nets gradually reduced the birds on four surrounding moors to such an extent that they became very scarce; and one moor which had easily produced 250 brace fell away so much that during the last two years the nets were set in the vicinity the total bag was but 41 brace and 106 brace. The year the netting was stopped the bag rose to 137 brace; two years later it was 172 brace; and last year (1911) 249 brace, showing that in four years' time the moor had recovered its former productiveness. It was also found that while the moor on which the nets were placed had had very few nests annually, the numbers caught in the nets had averaged between four and five hundred brace. Such facts speak for 80 


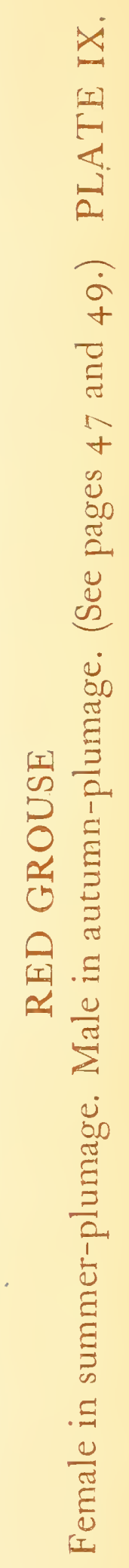


an the

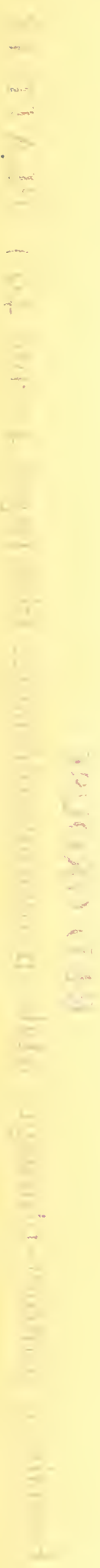




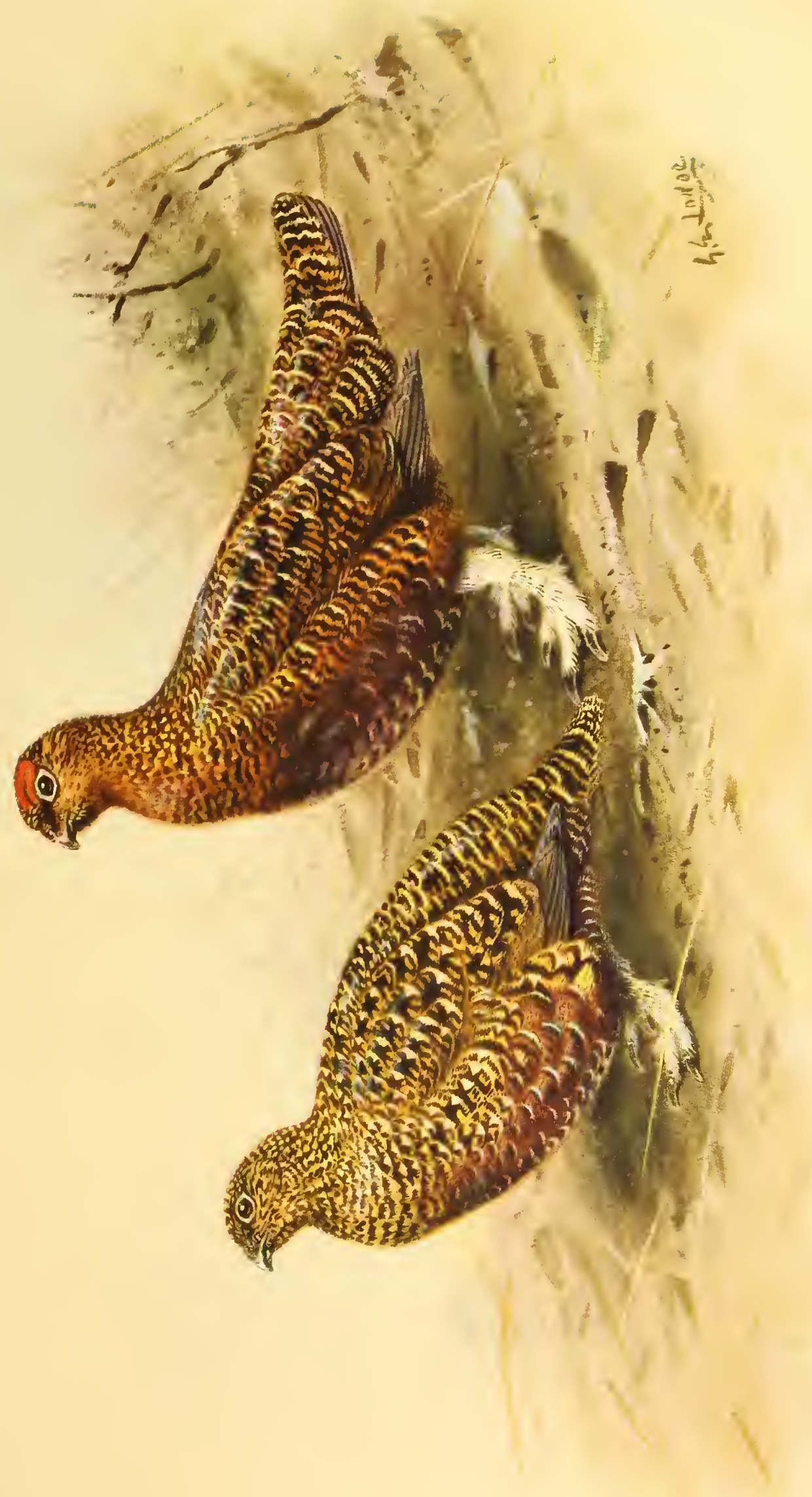





\section{MANAGEMENT OF GROUSE MOORS}

themselves: moreover, the majority of the birds caught are hens. The only way to cope successfully with the netters is to start netting also, when probably the rival netters will catch so few, they will abandon the attempt. In one case where this was done, and where the owner kept on with only 850 yards of netting after the others had stopped, 324 grouse were caught, of which only 97 were cocks, while 227 were hens. The grouse were marked and turned out again on a distant moor, though sixty-one birds were too much injured and had to be killed. Of the marked birds only three were caught a second time.

R. F. MEYSEY-THOMPSON. 


\section{HEATHER BURNING}

NYONE who is interested in the subject of the preserva-
tion of grouse, or the management of a grouse moor,
should, if he has not already done so, read the excel-
lent and exhaustive Report issued by the Committee
of Inquiry on Grouse Disease, 1911.
This Report deals with the life history of the Grouse in every particular, each subject being dealt with by a practical expert, and may be considered as the last word on a very interesting topic.

The Committee was appointed, as most shooting men know, to examine into the causes of that mysterious and devastating malady known as "Grouse Disease," and, if possible, to find a remedy for it. The scientists who aided the Committee examined hundreds of dead grouse, the contents of their crops, made careful anatomical examination of their intestines, and to put it shortly, the conclusion they came to is as follows :

Apart from the question of whether Klein's pneumonia has any existence in reality, all the outbreaks of disease amongst grouse which have come under the observation of the Committee can be ascribed either to Strongylosis or to Coccidiosis, the only two diseases which the Committee now recognize as causing widespread mortality amongst grouse.

Strongylus pergracilis (Cobbold) is a worm which is nearly always present in the bodies of grouse. If the bird is strong and healthy, i.e., if it is well fed and unwounded, this worm has no great effect on its well-being, but should the bird lose strength and condition the worms get the upper hand, increasing very rapidly, and gradually causing death.

Coccidiosis is caused by a microscopic protozoal parasite, Eimeria avium, which infests the lining epithelium of the alimentary canal of grouse. Young chicks are far more susceptible than adult birds, and in order to prevent as much as possible the ravages of these parasites it is necessary that the grouse should be healthy and well fed.

The Committee went very carefully into the food question, and on page 83 of the Report there is an instructive table, giving the monthly dietary of the grouse for the year, by which it is proved that the species of heather, known as Calluna vulgaris, is their staple food; they eat the young shoots, flowers and seed heads of this plant, which provides, roughly speaking, from 80 to 90 per cent of their food throughout the 


\section{HEATHER BURNING}

year. It is therefore very necessary for the owner of a moor to encourage the growth of this Calluna vulgaris to the utmost capacity of the ground, and the only way to do this is by judiciously burning the heather.

It is only in recent years that on the majority of moors heather burning has been properly looked after, and indeed at the present time there are many thousands of acres of old heather in England and Scotland which, from the grouse and the sheep-feeding point of view, would be far better burnt.

It is generally conceded that from one-twelfth to one-fifteenth of a moor should be burnt each year, and to get over this extent of ground on a big moor during the few days in spring when the weather is favourable is a very difficult job.

Heather can be burned at all times of the year in England. In Wales it is customary to burn in the spring, whilst in Scotland, by Statute, heather burning can only be carried out between November 1 and April 10 ; though on high wet moors an extension to April 28 can be obtained.

The winter season gives so few opportunities for successful burning that the Grouse Committee invited the opinion of English, Scottish and Welsh landlords, keepers, and farmers for or against the practice of burning in autumn.

The results are summarized on page 405 of the Report by Lord Lovat as follows :

(1) That in the interests of sheep and grouse autumn burning is advisable on all moors.

(2) That it is necessary on large moors.

(3) That it is the only possible method of getting high ground, with a northern exposure, into a proper rotation of heather crop.

The Committee are further of opinion that

(4) In the north of England the evidence goes to show that, whether springing from the root or from the seed, the growth of heather following autumn or spring burning is identical.

(5) That on the more northern moors the heather is probably slightly slower in reaching maturity after autumn burning, especially on shallow peat or hard ground.

(6) That while there is a certain prejudice, especially amongst older keepers, against autumn burning, this prejudice does not appear to be founded on substantial grounds. The majority of those who expressed themselves as opposed to autumn burning were found, 
THE GUN AT HOME AND ABROAD

on examination, not to have themselves tried it, and to have based their opinion either on general reasons or second-hand information.

(7) That on 95 per cent of the moors in England on which autumn burning had been tried, the practice had been continued with the full sanction and approval of the farmers interested.

(8) That at least 75 per cent of the larger moors examined are insufficiently burned, and that in many cases an extension of the burning period would enable a larger stock of both sheep and grouse to be maintained.

(9) That autumn burning is necessary in the interests of the health of the grouse and sheep, and that legislation in Scotland, making it permissible to burn after October 1 should be introduced into Parliament without delay.

The sheep farmers were consulted on this question very thoroughly, and they drew attention to the following additional points :

(1) That where heather is allowed to grow too old, there is a danger of its place being taken by bracken after burning, whereas if the heather is burned young, the fresh growth has more vitality, and usually defeats the bracken.

(2) That old heather is undesirable, because after burning many "burrens" or bare sticks are left, which tear the wool off the sheep's bellies.

(3) That sheep farmers prefer the heather to be burned in large patches -because otherwise a large enough area is not burned each year; but that they have no objection to the heather being burned in strips and patches provided the total area burned reaches the full proportion of the moor. This proportion was estimated from one-ninth to one-twelfth of the moor.

As things are at present, on the majority of moors nothing like the right proportion is annually burned. In the few days available, generally estimated at ten full days or twenty half days per year, it would take a very large number of men to burn say 1,000 acres of a 15,000 acre moor, and the first expense is likely to deter many owners. But as regards this financial side of the question, this first cost would soon be more than recouped by the increased yield of both grouse and sheep, and therefore the rents obtainable-and once the old stick heather has been got rid of, it is much easier to burn twelve or fifteen years' growth. 


\section{HEATHER BURNING}

With regard to the actual burning, Mr Rimington Wilson's head keeper, Mr Ward, has kindly given a few notes. As he is an expert in the matter, and Broomhead Moor is mentioned in the Grouse Committee's Report as being perhaps the best burned and cared for moor in the British Isles, his advice is valuable. He says:

"The time for burning the heather here is from December to the end of March, or not later than the second week in April. Broomhead is a small moor of not more than 4,000 acres.

"The keeper should decide before December what ground wants burning, so that when it is dry enough to burn, he will notice in what direction the wind is, and supposing it is in the north he will go to the ground which lies facing the north, for the wind will have dried the heather more there than it will have done on ground which lies away from the wind and is sheltered; and further, he will be able to burn up hill, a great advantage, as by burning up hill it will burn much cleaner than if it were burnt down hill.

"It is best to burn in frosty weather when the ground is hard ; if it is burnt then it will not destroy the roots or seeds, and the peat is not liable to get on fire.

"No fire should be more than thirty or forty yards wide, and if the heather is old it should be burnt in long strips. If the heather is not very old twenty yards wide is quite wide enough.

"It is wise to put a few strips through young heather, as the young grouse will be able to change their ground better than they would if it were all thick heather.

"You get the best results with a moderate wind; if the wind is very light the heather will burn very slow, if the wind is very strong it will drive the fire too fast, so that it will not have time to burn clean, but will only take the top off and leave the bottom and 'fog moss.'

"Again, in a strong wind, you never know where the fire is going to stop, as it will sometimes drive it across ground you have burnt the year before.

"It is best to run your fires towards a deep gully or stream. On no account burn towards the boundary with a strong wind, or even with any wind unless you are certain that it is impossible for it to get out of hand and over the boundary. It is a singular thing that when fires do get over the march they are generally large fires and do a lot of harm. 
THE GUN AT HOME AND ABROAD

"Do not burn against the wind, as it will burn slow and you are wasting time. As a rule you will not have many fine days during the burning season to waste.

"Heather burning lamps are very useful, as you can light your fire twenty yards wide, and if you do that you will be able to start flogging it out when it has burnt about fifteen to twenty yards.

"It is not advisable to let the leading fire get too far in front of you, for, supposing it was eighty yards in front, and the wind suddenly changed, you would have a very large fire, which might get the better of you.

"The lamps are very useful where the ground is broken, and for burning out gullies.

"Always burn all covert sixty yards in front, and eighty yards behind, the butts: it makes it so much easier to pick up game after a drive.

"If you have been burning from north to south, and the next day or so the wind changes to east or west, you will be able to put some fires through from one burn to another, so that the heather will be left in square patches. At the end of a burn you can sometimes save a little of the old heather, say about three or four yards, which will come in useful for the grouse to nest in."

It is also a good plan on a driving moor to leave a certain amount of old heather half a mile in front of the line of butts for the packs to collect in.

The great point to aim at in heather-burning is eventually to have all your ground covered with heather-in no case more than fifteen or sixteen years old-and to bring it into a regular rotation of crop.

The grouse will then be provided with as much good food as the ground will carry. There will be no useless land; and in the hard weather which generally comes in January, February, March, April and May, there will be a sufficiency of food to keep the breeding stock of grouse in good health, and enable them to withstand the attacks of strongyles.

It is the thick bushy heather of ten to fifteen years old that still carries succulent shoots half way down the stem in the late winter and early spring.

By careful and sufficient burning, large numbers of the strongyle larva and many millions of that destructive beetle Lochmoea suturalis, Thomson, which has destroyed thousands of acres of good heather in Ayrshire and other counties of Scotland, will be cleared off the ground. There is 86 


\section{HEATHER BURNING}

nothing so cleansing as fire. Again, by burning in strips and patches the grouse will not be encouraged to pack together too close, and there will be less risk of fouling the ground.

In connexion with the all important question of food there is another almost as necessary to the welfare of the grouse, and that is a plentiful supply of grit of the right kind, which is most necessary to aid digestion. In regard to this I have a suggestion to make to owners of moors.

In hard weather, with deep snow on the ground, it must be very difficult for grouse to find a necessary supply of grit, especially on flat moors, where there are no rocky faces jutting out. And at this time the food they succeed in obtaining must require more than the usual powers of digestion. It would be a comparatively easy task to rig up a rough sledge and drag loads of grit over the snow to different parts of the moor ; the grouse would soon find the heaps, and this would assist them greatly in their struggle for existence.

That the heather is less nutritious, and therefore more difficult to digest in early spring, has been proved by the Grouse Committee's researches (p.399), where it was found that the weights of crop contents show that in late winter and early spring up to two hundred and fifty grains of heather are found in the average afternoon crop, as against fifty grains at any other time of the year.

It was also found by dissection that grouse have apparently the power to keep a certain amount of grit in the gizzard, but the conclusion arrived at was that probably when the bird felt itself short of grit it took less food, and thereby lost weight and strength, becoming more liable to the attack of strongylosis. If this conclusion be correct, the artificial supply in hard weather of heaps of good quartz grit is a good idea. In connexion with this question of "grit" supply, The Mackintosh writes to us from Moy, July, 1912. "I have been hard at work breaking more ground for grit : without plenty of grit it is impossible to have a healthy stock of grouse."

To sum up then this question of heather burning. The ideal moor should be so carefully and thoroughly burnt that there should be a succession of heather patches and strips ranging from the freshly burnt clean ground, to heather of not more than fifteen or sixteen years old. In no case should any old stick heather be tolerated. Where there are long stretches of flats where little or no grit is easily available, at any rate in hard weather, 


\section{THE GUN AT HOME AND ABROAD}

loads of quartz grit should be deposited directly the snow is thick on the ground. In addition to the above, the growth of all ground berries such as blaeberries and cranberries should be encouraged, as these afford a healthy change of diet, and form a reserve for hard weather. Should the moor be heavily stocked with sheep it would be wise to wire in certain stretches of moor where such berries exist, in order to let the plants get a proper hold and increase, and at the same time the young heather would get a better chance, for sheep are very fond of both.

A. ACLAND HOOD. 


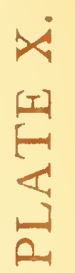

i

ह

a

อ.

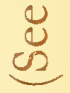

(I)

己

更

$0 \stackrel{2}{0}$

$\Omega \stackrel{\infty}{5}$

岌.

일

$\vdots$
0
0
0
0
0
$\vdots$
0
0 


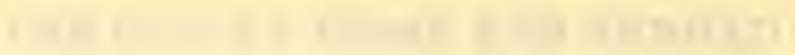

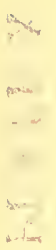

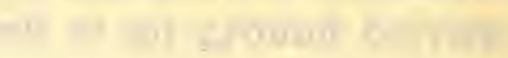

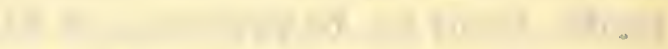

a. :

baymil an

$\vdots$ 


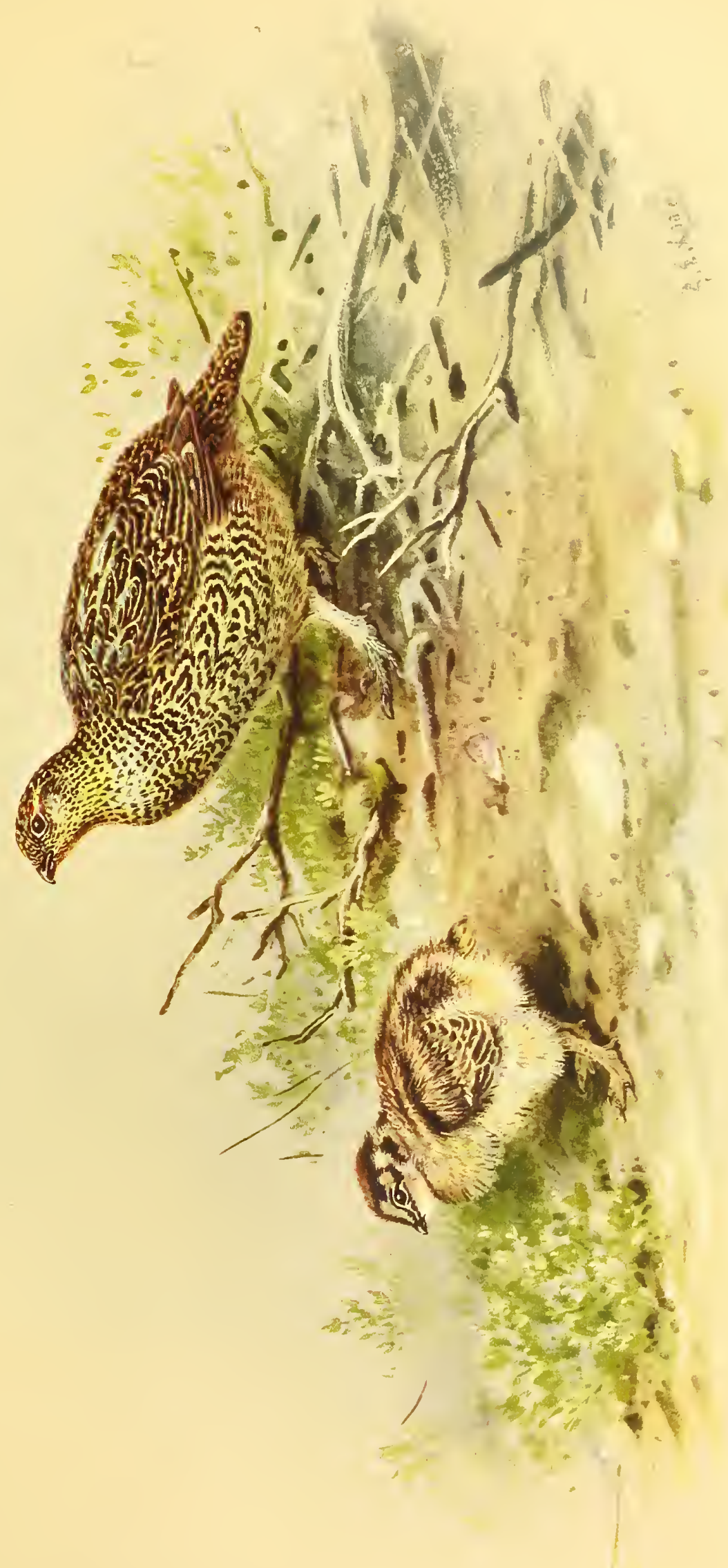




\section{COMMON PTARMIGAN}

\section{LAGOPUS MUTUS}

\section{(Plates XI-XIII)}

Tetrao mutus, Montin, Phys. Salsk. Handb. i, p. 155 (1776-86); Seebohm, Hist. Brit. Birds, ii, p. 424 (1884).

Lagopus mutus, Leach, Syst. Cat., p. 27 (1816) ; Gould, Birds Europe, v, pl. 253 (1837); Saunders, ed. Yarrell, Brit. Birds, iii, p. 83 (1882) ; Lilford, Col. Fig. Brit. Birds, pt. ix (1891); Millais, Game Birds, p. 63, pls. and woodcuts (1892); Ogilvie-Grant, Cat. Birds Brit. Mus. xxii, p. 44 (1893); id., Handbook Game Birds; i, p. 38 (1895) ; Saunders, Ill. Man. Brit. Birds, p. 497 (1899); Millais, Nat. Hist. Brit. Game Birds, p. 63, pls. (1910).

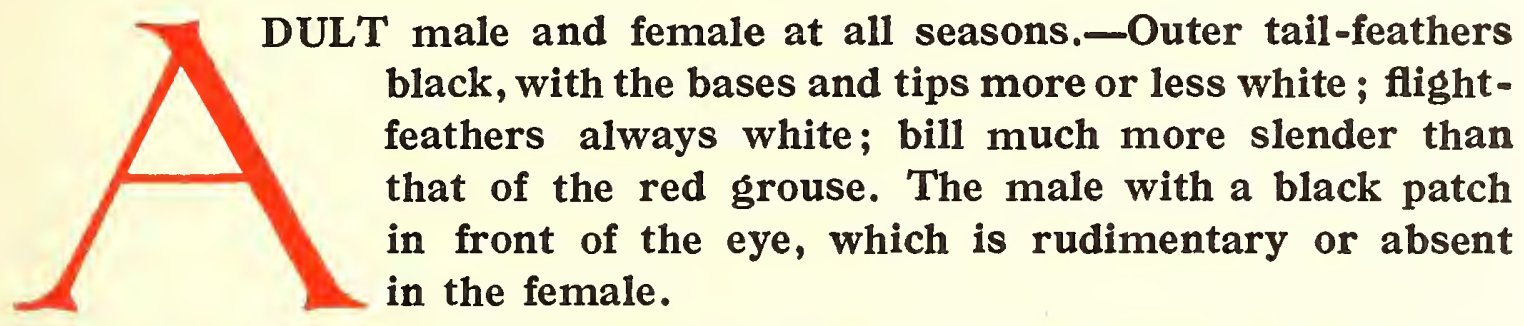

Adult male in summer-plumage. (April to July).-General colour of the head, upper parts of the body, sides and flanks dark brown or blackishbrown, more or less finely mottled and barred with grey and rusty on the back, rump and upper tail-coverts; chin and throat mostly white; the upper part of the breast blackish-brown, usually somewhat mottled with rufous; * the quills, outer wing-coverts and rest of the under parts of the body white; middle pair of tail-feathers black, usually with remains of white tips or pure white, remaining tail-feathers black, often partly white towards the base, and narrowly tipped with white. Wattle and comb above the eye scarlet, bill black. (Plate XI.)

Total length 14.5 inches; wing 7.6 inches; tail 4.6 inches ; tarsus 1.3 inch.

Adult female in summer-plumage. (April to July).-General colour above black, mixed with rufous-buff, most of the feathers being edged with white or pale buff; chin usually white; breast, sides, flanks and under tailcoverts rufous-buff, barred with black; middle pair of tail-feathers black, barred with rufous, and much like the upperparts, $f$ remaining tailfeathers black, more or less tipped with white, as in the male, and often with a large portion of the basal part white; quills and outer wingcoverts white. (Plate XI.)

\footnotetext{
* Males in their first breeding-season are browner and more mottled on the chest and upper part of the breast than older birds.

†Some females retain their old pair of middle tail-feathers, but in the majority they are replaced by a pair matching the summer-plumage: a very remarkable point noted by Macgillivray, but since lost sight of.
} 


\section{THE GUN AT HOME AND ABROAD}

In July the light edges of the feathers of the upper parts of the body become worn and faded, and the general colour is darker than in May.

Eye-wattle scarlet; bill black.

Total length 14 inches; wing $7 \cdot 4$ inches; tail $4 \cdot 1$ inches ; tarsus $1 \cdot 3$ inch. Adult male in autumn-plumage. (August to October).-General colour of the upper parts of the body, chest, upper breast and sides grey, finely mottled with black, and sometimes with buff; throat barred with black and white; quills, outer wing-coverts, and rest of the underparts white.

The middle pair of tail-feathers vary much; in some birds they are black, or black mottled with sandy-brown, and tipped with white, in some one is black, tipped with white, the other pure white; again in others both feathers are pure white. (Plate XII.)

Adult female in autumn-plumage. (August to October).-Very similar to the male, but usually to be distinguished by retaining a few of the buff and black feathers of the summer-plumage. The middle pair of tail-feathers are usually sandy-brown, mottled with blackish, and tipped with white, but in some birds one or both feathers may be pure white. (Plate XII.)

In both male and female the feathers on the legs and toes are moulted and renewed between June and September, and the claws are also shed, as in the red grouse.

Adult male in winter-plumage. (November to March).-All the plumage is pure white, with the exception of a black patch extending from the base of the bill to behind the eye, and the tail-feathers, which, like the quills, remain unchanged, after the autumn-moult. (Plate XIII. Fig. 1.)

Adult female in winter-plumage. (November to March).-Similar to the male, but with the black patch in front of the eye absent or undefined. (Plate XIII. Fig. 2.)

Birds of the year differ only from the adult in having the outer primary quills mixed with blackish along the terminal portion of the shafts.

Young birds in first plumage have the general colour of the head, upper parts of the body, chest and sides black, rather finely barred and mottled with rufous-buff, most of the feathers having a whitish spot at the extremity; the primary quills brownish-black, mottled with buff on the outer web; the rest of the underparts whitish, obscurely barred with dusky; tail-feathers black, with irregular bars and markings of buff.

Nesting.-Very similar to that of the red grouse.

The descriptions of the summer-, autumn- and winter-plumages of the adult birds given above may be considered as fairly typical of the 90 


\section{GOMMON PTARMIGAN}

seasons in which they occur, but the individual variation in this species being almost as great as in the red grouse, it has been found impossible to give more than a general description. It must also be borne in mind that the plumage of every individual is constantly changing month by month, either by moult, or by the wearing off of the light tips of the feathers; likewise that the changes in plumage are greatly influenced by the mildness or severity of the climate in which the birds are found. For instance, the majority of the ptarmigan inhabiting Scotland are only to be seen in complete white plumage in exceptionally severe winters, and usually retain a good many of the old summer-and autumn-feathers on the top of the head and back; while male birds from the northern parts of Scandinavia, etc., never complete either their summer- or autumn-plumage, but retain a large amount of white plumage throughout the year.

These irregularities in attaining the full seasonal plumages are no doubt protective, and help to render the birds less visible when crouching among the stones and rocks and hiding from their many enemies.

General distribution.-The ptarmigan makes its home among the high stony table-lands and rocks above the limits of tree-growth and heather. The exact eastern limits of its range are somewhat difficult to define, but the typical form with a grey autumn-plumage inhabits the mountains of Europe, while that met with in some of the ranges of Central Asia should be referred to the more northern rufous form (Lagopus rupestris), which was the bird found by Seebohm on the Yenesei at $71 \frac{1}{2}^{\circ} \mathrm{N}$. latitude. In the west it ranges to the mountains of Scotland, the Lofoden Islands, Scandinavia and Finland, and in the north to the Kola Peninsula and Ural Mountains. Southwards it is met with in the higher parts of the Pyrenees, and is said to occur in the mountains of Asturias and Leon. It is also found in the Alps, Tyrol, Styria and Carinthia. Its eastern range, as already stated, is difficult to define, owing to lack of material.

Allied forms.-In Greenland, Iceland, Northern, Central, and Eastern Asia, and in Japan, its place is taken by a closely allied form (L. rupestris), which has a more rufous-brown plumage in summer and autumn, all the forms being, of course, indistinguishable in their white winter-dress.

From the Aleutian Chain, Alaska and Arctic America numerous forms have been described under different names, and from the mountains of Newfoundland a grey form, very similar to the typical European bird, 
THE GUN AT HOME AND ABROAD

has been distinguished as $L$. welchi. Broadly speaking, the ptarmigan may be regarded as a circum-polar species, represented by slightly varying forms throughout its wide range. It is quite certain, however, that some of the forms described from Arctic America are based on a very insufficient series of specimens, and that the great variability of the ptarmigan, as found in Scotland or in Scandinavia, has not been duly considered. The bird described by Stejneger as $L$. ridgwayi from the Commander Islands, in which the male in summer-plumage is nearly black on the back and breast, can be matched exactly by some specimens killed in Norway at the same season. In Spitzbergen a larger and apparently distinct form (L. hyperboreus) occurs with more white on the basal part of the tail-feathers, but very few examples have at present been examined.

Distribution in the British Isles.-The range of the ptarmigan in the British Isles is now confined to the higher mountains of Scotland, from Perthshire and Argyllshire northwards, wherever suitable stony and barren plateaux of sufficient elevation, studded with rocks and boulders, are to be found. It was formerly met with on the highest hills of Dumfries-shire and Galloway, but disappeared about 1822, and a subsequent attempt to re-stock that district proved unsuccessful. It still lingers in Arran and Rum, where it has been re-introduced, also in Mull, Islay and Jura, while in Skye it is found in small numbers. It does not extend to the Orkney and Shetland Islands, but is said to have occurred in small numbers on the hills of Hoy (Orkneys), up till 1831. From Lewis, Harris and North and South Uist it seems to have almost disappeared during recent years.

There appears to be some grounds for supposing that the ptarmigan existed in former times on the fells of Cumberland and Westmoreland. Macpherson in his "Fauna of Lakeland" gives his reasons for believing that the species was to be found in the mountains about Keswick till the end of the eighteenth century. A ptarmigan "said to have been killed on Skiddaw" was still preserved in Hutton's local museum at Keswick in 1841, but when the collection was broken up in 1855 the specimen was lost sight of.

On the mountains of Ireland it is unknown, and attempts to introduce it have not met with success.

Food.-The food consists of the green tops of the blaeberry (Vaccinium myrtillus), and crowberry (Empetrum nigrum), leaves of dwarf sallow and 92 
का

ค. . 

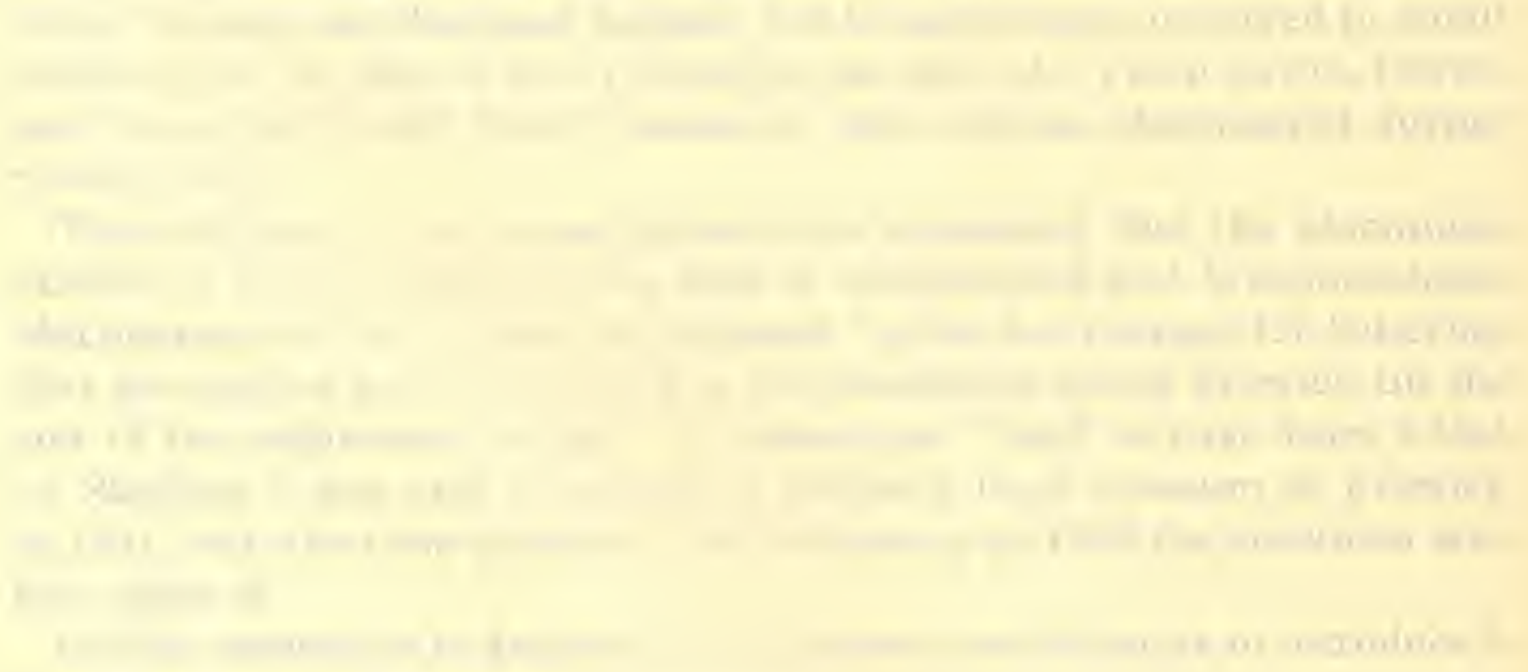

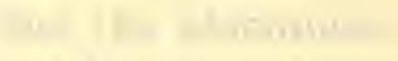
. 


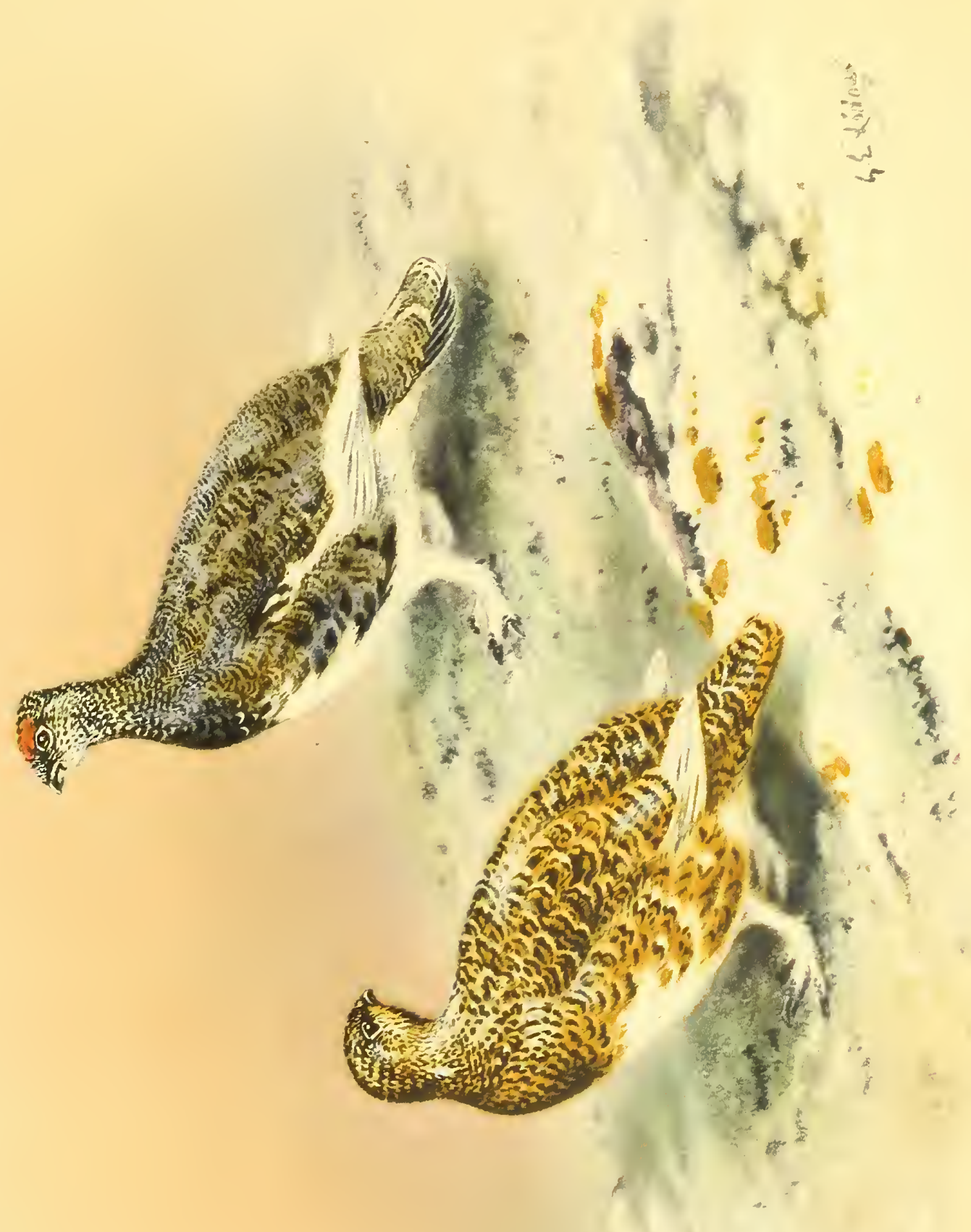


birch, and various kinds of berries, seeds and buds of mountain plants. The crops of several examined in November contained woody shoots and buds of blaeberry, and a few leaves of the same plant, also shoots of crowberry. Ptarmigan are also said to eat the green tops of heather and ling, and probably do so, but none of the birds examined by myself and others contained either of these plants.

Unlike the red grouse, ptarmigan never visit the low grounds in search of grain, but when feeding in the early morning and evening they move a little lower down the slopes in search of food. Like all game-birds, they swallow large quantities of quartz grit to aid digestion.

Flight.-The flight of the ptarmigan is much like that of the red grouse, but even more rapid and powerful, especially when traversing steep hill-sides. They are, however, much harder to flush, trusting to the protective coloration of their plumage, which harmonizes so perfectly with their surroundings at all seasons of the year, and prefer to escape by hiding themselves, crouching flat amongst the broken stony ground.

When flushed on the steep rocky faces of the mountains, they generally fly straight out over the abyss below, and then drop swiftly down hill, much like rock-pigeons, following the slopes of the ground till they reach some distant place of safety. There can be no doubt that ptarmigan are capable of undertaking long flights, for they traverse considerable distances when crossing from one hill to another in the north of Scotland.

Breeding habits.-Like the red grouse, the ptarmigan is monogamous, and it resembles that species in most of its breeding-habits. In the pairing-season, however, which commences in April, the birds are said to resort in small flocks to favourite courting-grounds, like the polygamous black grouse and capercaillie. Unlike those birds, the same spots do not seem to be used year after year, and vary much in the character of their surroundings, being sometimes a bare flat amongst granite slabs at the top of the mountain, at other times a sheltered nook among the rocks, interspersed with the various Alpine plants on which the birds feed. I have never personally observed this habit of the ptarmigan as described by $\mathrm{Mr}$ J. G. Millais, and several reliable stalkers and keepers who have been questioned on the subject have no knowledge of it.

Mr Millais writes: "To these recognized places of meeting a covey repairs at daybreak, the cocks separating, and each taking up his position at some distance apart from the other. They then commence their croaking $a-r-r-r$ to attract the notice of the hens, who reply at once 
with their plaintive ee-ac until one of the latter approaches to within a few paces of the rock on which a cock is standing with his neck stretched to its fullest extent, and tail raised and expanded.

"Being now pleased with the success of his music, he turns round and round, and literally 'spreads himself,' to use an Americanism, until such time as he flies off the rock and commences the love-chase.

"Ptarmigan do not fight nearly so much as grouse, or even partridges, but a cock whose reiterated calls have received no response from the fair sex, often leaves his post and proceeds in search of a mate, of course having to trespass on the grounds of one of his adjacent rivals to do so. This is naturally resented at once by the rightful proprietor, and a fight ensues, the various phases of which are similar to grouse-combats in their character. As often as not the intruder gets the best of it, in which case the hen manifests no uneasiness as to her change of masters, and rather enjoys the fight while it lasts, running round and round the combatants, uttering her one querulous cry.

"The pairing-season being over by the middle of May, the hen selects her nesting-place, which is jealously guarded by the male."

The nest is unusually difficult to find, for the hen bird sits very closely, and so nearly matches her surroundings in colour that she is very easily overlooked.

Nest.-A hollow is selected as a nesting-site, generally in an open position with a southern aspect, among the low stunted plants, such as cranberry, cloudberry, dwarf azalea and Silene acaulis, where lichencovered fragments of rock lie scattered about on the desolate mountain tops. Sometimes the bird scrapes out a shallow cavity in the ground for this purpose, but as often as not a natural depression is used as a nest, and slightly lined with a little dead grass or with any small pieces of dry material available and a few feathers.

About the middle or end of May, or even in June in late seasons, from eight to ten, or even twelve, eggs are laid. As many as seventeen have been found, but these are probably the produce of more than one hen.

Eggs.-The eggs are much like those of the red grouse in appearance, but the ground-colour is usually lighter, being pale brownish-white or brownish-buff, and the dark brown surface-blotches and markings are less numerous. The average measurements of eggs of this species are $1 \cdot 7$ inch by $1 \cdot 1$ inch. Incubation lasts about twenty-four days. The young 


\section{COMMON PTARMIGAN}

leave the nest soon after they are hatched, and are assiduously cared for by both parents.

General habits.-The tameness and boldness of ptarmigan during the breeding-season are perhaps more marked than in any other species of British game-bird. If suddenly disturbed with quite young chicks, the female, not content with going through the usual performance of feigning a broken wing and shuffling along over the ground while the young are scattering and hiding themselves among the short herbage and stones, will sometimes actually come at the intruder. On one occasion an irate mother actually ran between the writer's feet, striking at his boots with her wings, while the cock remained perched on a rock a few yards off, uttering every few minutes his deep croaking cry, er-aar, which is more like the hoarse bleating of a sheep than anything else. The young, even in their earliest stages, are extraordinarily active, and can run at a great pace. They are great adepts at hiding, and when they crouch flat on the ground, even in open spots, are extremely difficult to detect, so closely does their downy plumage match their surroundings.

Mr Millais says that if the hen bird is flushed singly, and the young, even if fully grown, do not follow at once, she sometimes flies straight away for about 200 yards and then suddenly shoots up into the air for twenty or thirty feet, at the same time calling loudly $a c k-a c k-a c k$, or $e e-a c k$, to attract attention.

Soon after the young are hatched the male is said by some writers to leave them to the care of their mother and take himself off to join other bachelor friends on the highest tops of the mountains. Later in August, when the young can fly strongly, and have been taken to the higher ground by their mother, he rejoins his brood. This, however, is contrary to our experience of ptarmigan in Scotland, the male being always somewhere in the vicinity of his young, and most solicitous as to their welfare. Both parents remain with their brood until the late autumn snows, when they join with other coveys, and sometimes form large packs, if the weather is wet and stormy. At such times they become extremely wild, and will rise far out of shot; but in fine weather they are extraordinarily tame, and, as already stated, always prefer to squat on the approach of danger, trusting to the marvellously protective colour of their plumage to escape observation. It is wonderful how difficult it is for the sharpest eyes to pick them out among the stones and rocks, even when one knows they are close at hand. The first actual intimation of their presence is often the 


\section{THE GUN AT HOME AND ABROAD}

sudden whirring of wings as they rise almost at one's feet. The old cock rises first, and is immediately followed by the rest of the covey, flying in rather open order. The old cocks are very fond of perching on the great granite boulders that lie scattered over the desolate ground they love to frequent, and on fine warm days in summer and autumn may often be seen in such situations uttering their hoarse cry, and seldom taking flight till one is close to them. From these eminences they watch over the welfare of the covey, and often unwittingly betray its presence.

Like the red grouse, ptarmigan feed regularly in the morning and evening, and for that purpose generally seek the lower grounds, 1,000 feet or more below the tops, which they frequent during the rest of the day.

Their object in doing so is no doubt to obtain a better and more plentiful supply of food. On sunny days they are fond of basking among the rocks while they digest their morning's meal. The ptarmigan is an extraordinarily hardy bird, and is affected by severe weather even less than the red grouse ; it is only in winter and in very heavy snow-storms that they leave the gloomy tops for a somewhat lower elevation. Even in such weather they constantly burrow in the snow in search of food, their snowy breasts becoming curiously discoloured as if by soot, so much so that the birds look as though they had been living in the proximity of some large town.

Driving ptarmigan is seldom practicable, owing to the difficult nature of the ground they frequent, but in some places in Scotland where it is possible, and has been attempted, fair bags have been made, and as many as sixty brace have been killed in a day. They are best shot over dogs, and as their pursuit is generally undertaken in fine weather, when grand views can be obtained from the highest ground, an off day after ptarmigan, even if only a few brace are found, is generally a delightful experience.

Enemies.-The chief enemies of the ptarmigan in this country are the fox, the golden eagle, and, to some extent, the peregrine. Foxes levy a heavy toll on their numbers, but by far their most dreaded enemy is the golden eagle, which is constantly pursuing them, hunting and driving them with a skill and knowledge of their habits which renders escape almost impossible.

Ptarmigan are, however, so little molested by shooting tenants, except now and again on an off day, that the numbers killed by eagles do not seriously diminish their numbers. Most proprietors of deer-forests welcome this killing off of ptarmigan, grouse and blue hares, which so often 

the

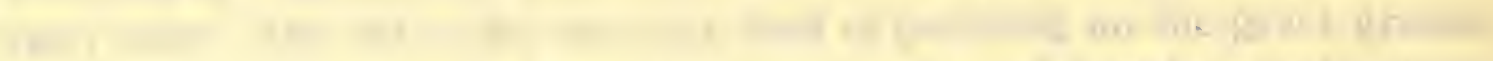

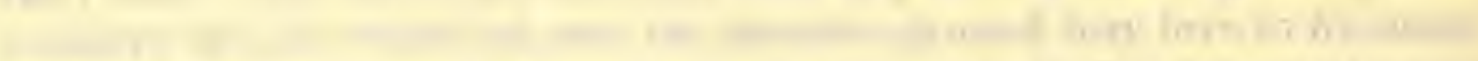
and

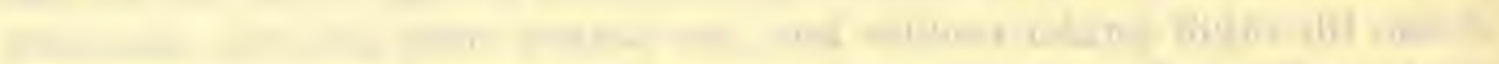

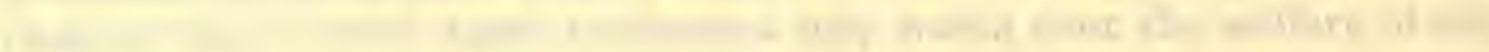




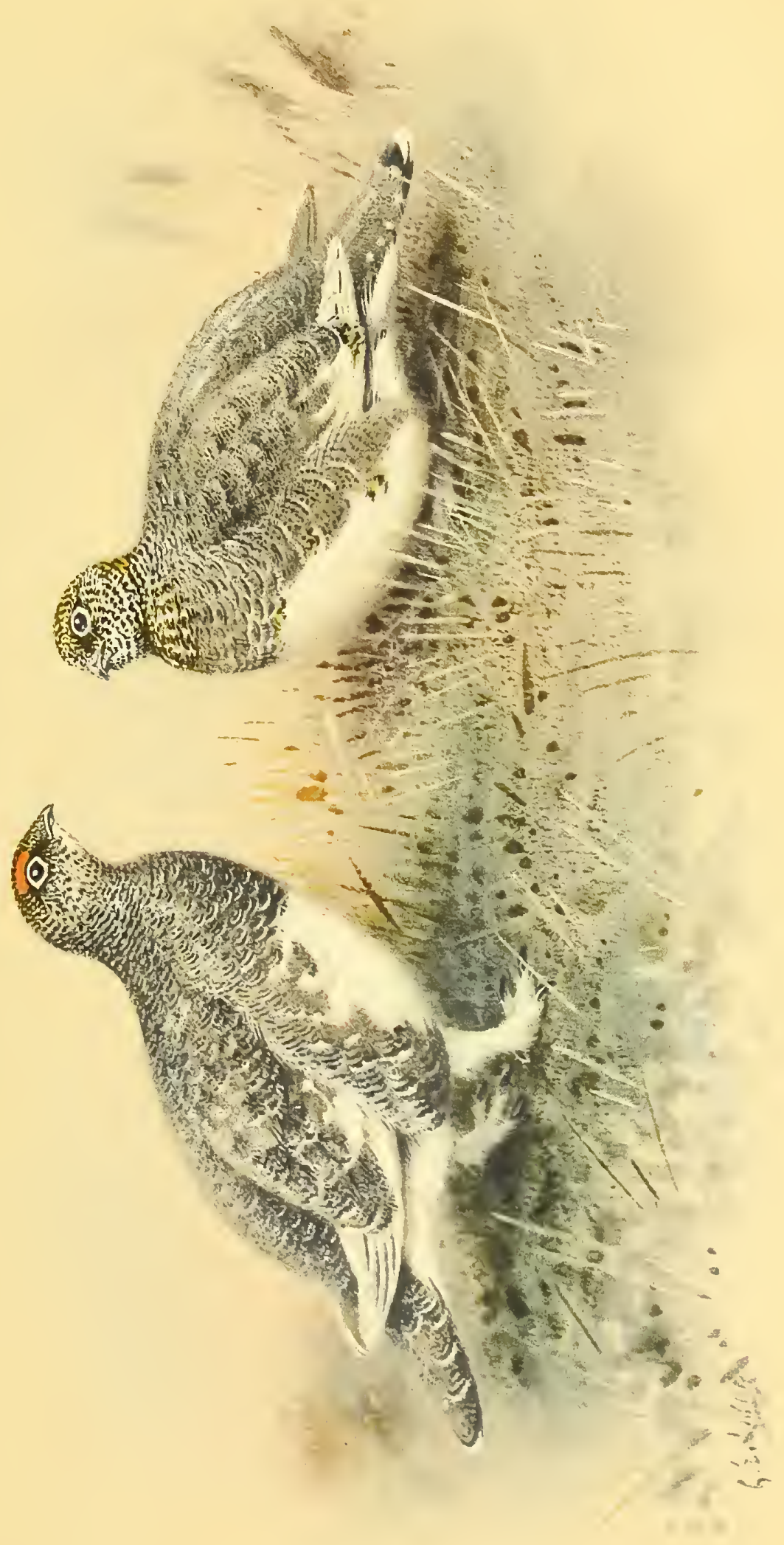




\section{COMMON PTARMIGAN}

seriously interfere with the stalking, and certainly no right-thinking man who has had the privilege of watching the golden eagle in his wild surroundings, will grudge him the means of living. In the nesting-time hooded crows and gulls account for a number of eggs and chicks, the eggs being often very imperfectly covered when the bird leaves the nest.

Ptarmigan suffer from the same diseases as grouse, but though in some seasons large numbers die, they do not as a rule appear to be affected to the same extent. Possibly the more remote parts of the ground on which they live, and the comparatively small amount of interest taken in their welfare, has caused the extent of their troubles to be overlooked and minimized.

Hybrids.-As the feeding ranges of the ptarmigan and red grouse overlap in many places, it is not surprising that two such closely allied species should occasionally inter-breed, and the astonishing thing is that they apparently so seldom do so. During an experience of more than thirty years the writer has examined only two or three birds which seemed to be undoubted hybrids between the two species. Two of these were shot on high ground (3,000 to 3,500 feet) in widely different localities in Scotland in company with ptarmigan, and showed the characters of both parents very plainly. Many of the birds supposed to be hybrids are no doubt only partially white red grouse, and there can be no doubt that true hybrids are rare.

W. R. OGILVIE-GRANT. 


\section{PTARMIGAN SHOOTING}

HE haunts of the Ptarmigan (Lagopus mutus) are on those mountains which tower above the 2,000 feet level, and though in severe storms these hardy birds may descend a little lower, and also in the summer time may make an excursion to a neighbouring top, at a lower elevation, they soon return to their lofty solitudes, where utter desolation reigns around. The wild beauty of the scene is shared chiefly with the Peregrine falcon, the Raven, and the Golden eagle, all of which take toll of these companions of their solitude. In the summer time, however, the Blue hare may be found also sharing the tops, with an occasional old cock Grouse and Golden plover.

Winter or summer the colour of the plumage so assimilates to the surroundings that it is a frequent occurrence, even to those experienced in the habits of Ptarmigan, suddenly to find a brood sitting close at hand, whose presence had been quite unsuspected. Ever fearful of danger in the air, they sit perfectly motionless, lest any movement on their part may betray them to the keen sight of their enemies-the Eagle and the Peregrine falcon-soaring aloft. The Eagle will seize them on the ground as well as on the wing, but the Peregrine only strikes at a flying quarry. This is probably the reason of the tactics of Ptarmigan when once they rise into the air. With a wild rush they spring from the earth, and whirl outwards over the yawning abyss beneath, only to wheel suddenly back and follow the contour of the mountain until they alight. They do not usually fly very far, though the pace is very rapid for their short journey. Sometimes they go skimming along close to the ground without making any outward curve in their flight, this being generally the case when they happen to be close to the shoulder of the mountain when disturbed, especially when large rocks and boulders are scattered about in confusion, affording invaluable protection from the stoop of a falcon. In such cases the flight will be a very short one, and in all probability the brood will alight directly it is out of sight.

The Ptarmigan is always a bird of moods, and especially on still calm days, will stand or walk about, flirting his tail, within five-andtwenty yards of the intruder, regarding him with curiosity, and unsuspicious of danger. At other times it is difficult for the shooter to get within range, and it is most provoking to see plenty of birds, and yet to keep stumbling along after them without any chance being afforded of getting 98 


\section{PTARMIGAN SHOOTING}

a shot. As a matter of policy it is better to creep round the hill on the level, instead of trying to follow the birds up or down, for this is very exhausting work, and holds out scanty hope of reward when the birds are wild. The climax comes if the birds depart over the valley to a neighbouring top ; or a thick mist, or snow-storm settles down on the hill !

So far as the British Islands are concerned, ptarmigan shooting at the present day is confined to the higher mountains of Scotland and the Hebrides. There is a tradition that Ptarmigan were formerly to be found in Cumberland, as well as in Wales, but while there is some evidence of the former existence of these birds in the Lake District there is none to warrant the conclusion that they once existed in the Principality. Nor were they ever to be found in Ireland. The best hills in Scotland for Ptarmigan, in the opinion of Lord Walsingham, are in Ross-shire around Loch Maree, and in the forest of Auchnashellac; Sutherland, Caithness, and parts of Perthshire also afford good sport on their highest peaks and ridges. Mr J. G. Millais writing in 1909 from long experience says :" On the mountains of Scotland the Ptarmigan is most abundant in West Ross-shire, especially on Coulin, Dundonald, Inverewe, Braemore, Loch Maree district, and $I$ have seen large numbers in the Auchnashellac deer forest. South of this they are very plentiful on Kintail, Applecross, and the high peaks of Branlen. In fact, all the mountains of over 2,000 feet south of the Caledonian Canal are inhabited by Ptarmigan; and I have seen them in every high deer forest in which I have stalked in Argyll, Ross, Inverness and Perthshire. They are particularly numerous on the western tops of Blackmount, and on the hills on the east side of Glencoe. In eastern Perthshire there are a fair number on the highest hills about Pitlochry, Dunalastair, Dalnaspidal, Athole, and the whole range of the Grampians. This line they follow into Aberdeenshire where they are still numerous from Rothiemurcus and Mar to Ballater. In West Sutherland they are not nearly so common as they used to be, and seem to be dying out there; but on the eastern mountains throughout the property of the Duke of Sutherland they still hold their own in small numbers. On the borders of Caithness the Ptarmigan is a disappearing species. Ben Lomond may be considered the southern limit in Scotland."

For those who enjoy mountaineering, the pursuit of the Ptarmigan is always attractive, but once their haunts are fairly reached, the tameness of the birds rather militates against sport. In some places it is possible to carry out a ptarmigan drive, and Mr Millais has heard of as many as 


\section{THE GUN AT HOME AND ABROAD}

sixty brace being killed in a day by driving; but; as he truly remarks, the pleasant way is to go out alone with one keeper and a steady old dog, when, if all goes well, a bag of ten or fifteen brace may be secured. The best bags of Ptarmigan are credited to the Hon. Geoffrey Hill who in August and September 1866, shot on August 25, 122 ; on August 29, 82 ; and on September 17, 60 birds. Lord Walsingham once shot forty-seven on the summit of Ben Hope in Sutherland and had he reached the ground in the morning instead of in the afternoon, the number of birds found would certainly have enabled him to make a very much larger bag. On August 22, 1898, 45 $\frac{1}{2}$ brace of $P$ tarmigan were shot at Drumochter, Inverness-shire, although Mr G. S. Albright, who reported it, omitted to state how many guns contributed to the bag. For one gun, Mr Millais says, forty birds have often been shot in a day, but a larger bag is rare. In a single drive at Gaick twenty-seven have been killed, while sixty brace have been bagged there in one day by several guns. The average weight of a Ptarmigan is $20 \mathrm{oz}$. or rather less than that of a Red grouse.

It is after Ptarmigan have assumed the winter plumage that the task of seeking them becomes both arduous and dangerous in the extreme, for when the winter snow lies deep, and mist, snowstorms, and extreme cold have to be faced, it needs a hardy and robust constitution to withstand the rigours of the climate, and to find pleasure in so doing. The nerves, too, must be in good order, for a sudden slip on a treacherous slope may end in dire disaster.

From the fact of their haunts being at high altitudes Ptarmigan are not very often molested by shooters ; an additional safeguard being the fact that so many of the ptarmigan hills are situated in deer forests, where the ordinary game shooter is not received as a rule with much welcome. In such localities these birds are generally free to live their own wild life, mostly secure from human molestation. Long may they remain so.

R. F. MEYSEY-THOMPSON. 

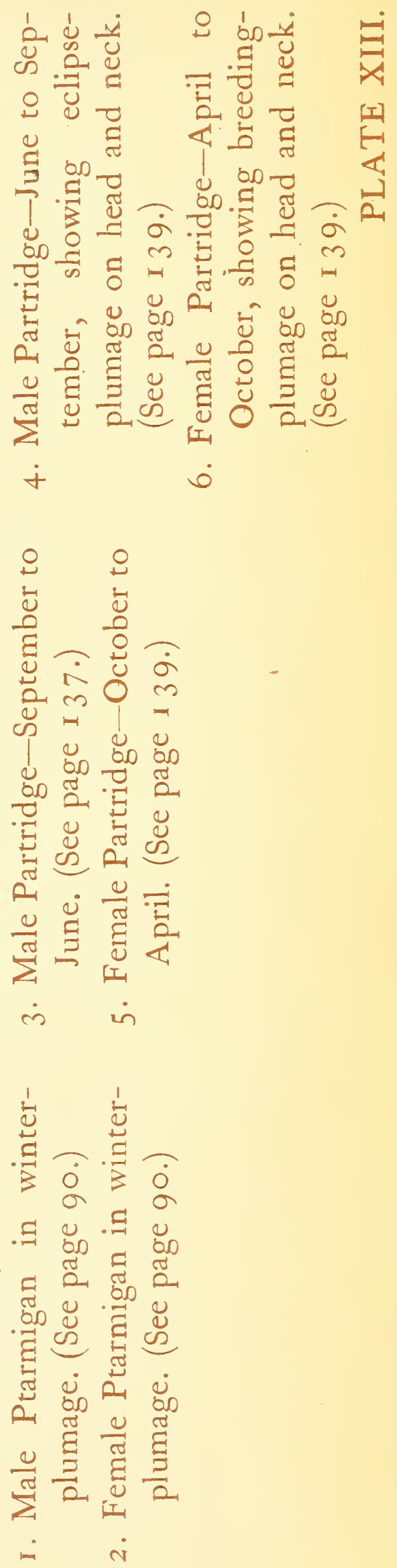


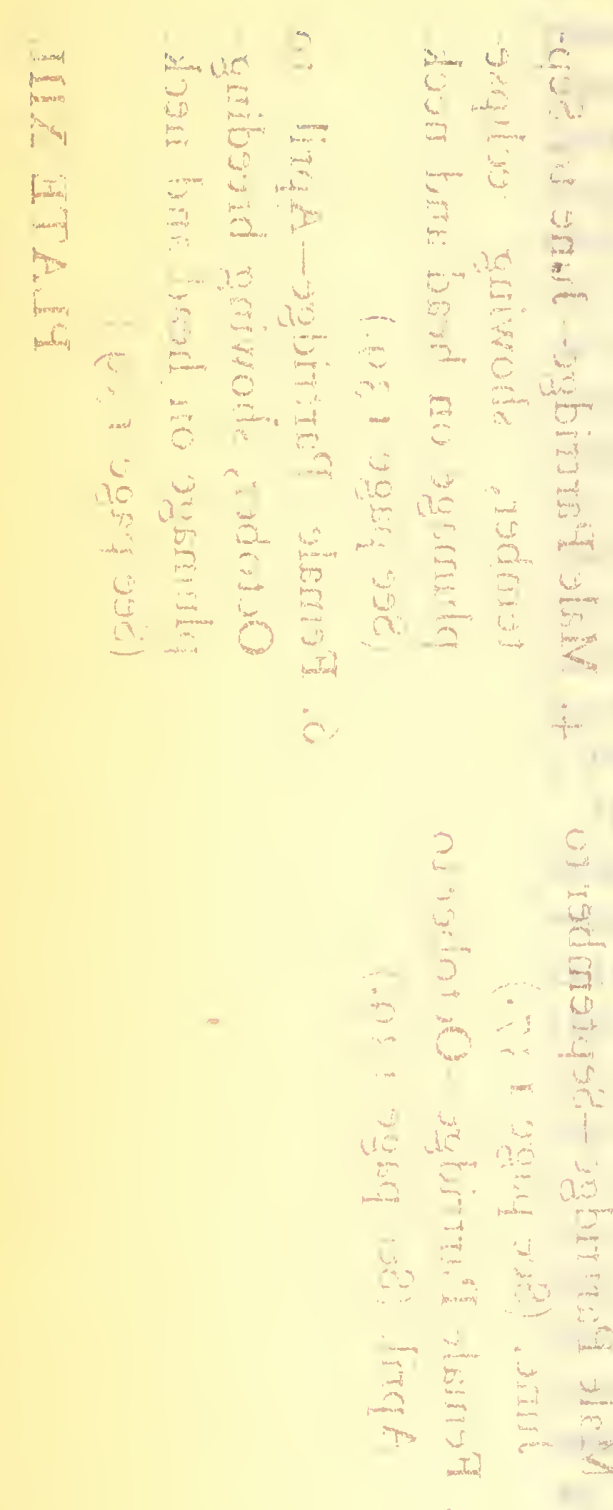

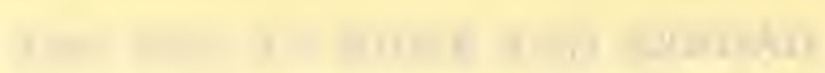

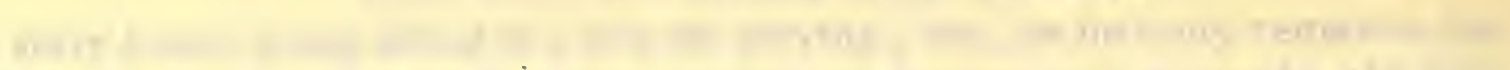





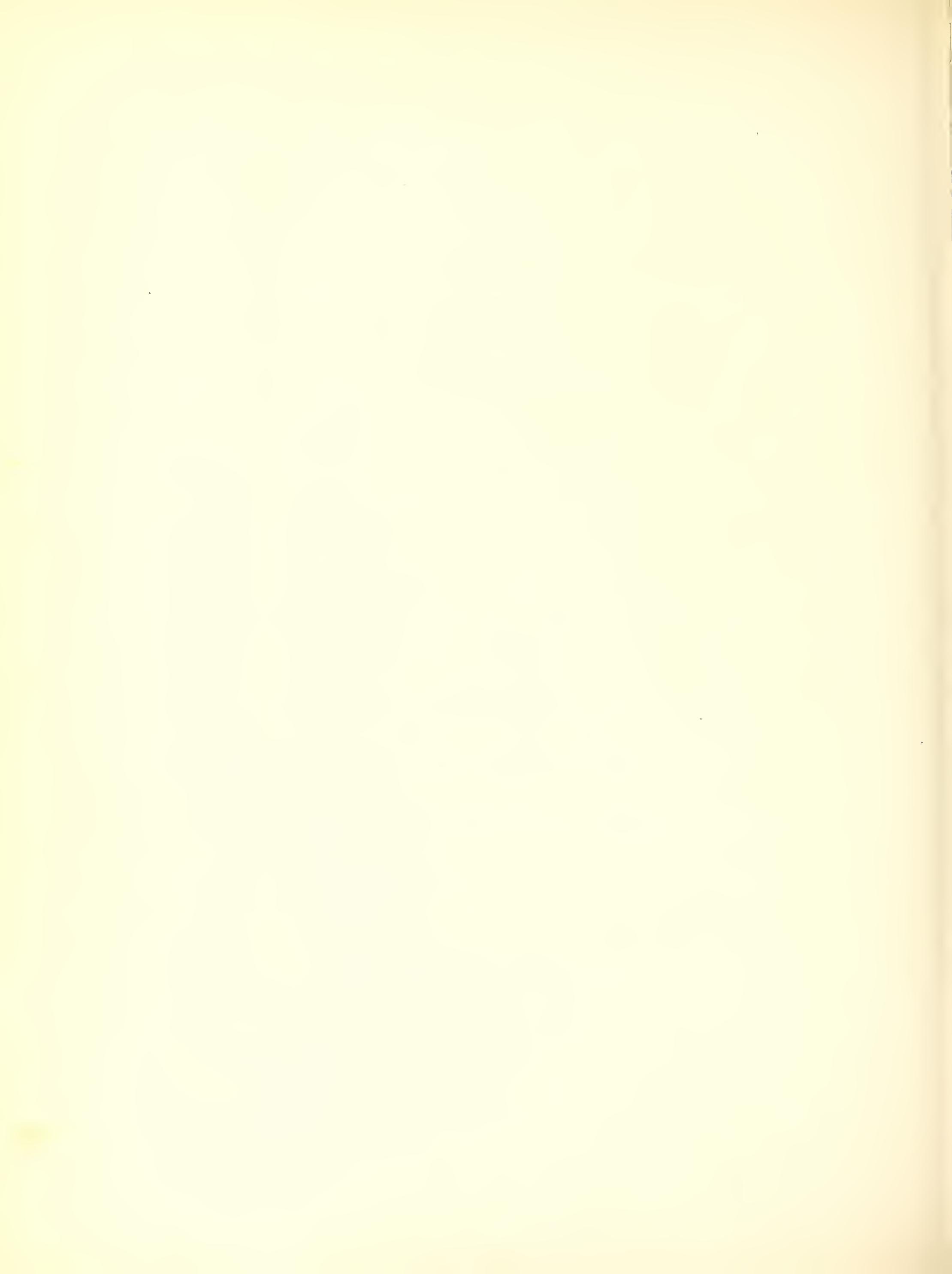




\section{COMMON PHEASANT \\ PHASIANUS COLCHICUS \\ (Plate XIV)}

Phasianus colchicus, Linn., Syst. Nat., i, p. 271 (1766); Gould, Birds Europe, pl. 247 (1837); id., Birds Asia, vii, pl. 34 (1869); Elliot, Monogr. Phasian. ii, pl. 2 (1872); Dresser, Birds Europe, vii, p. 85, pl. 469 (1879); Ogilvie-Grant, Cat. Birds Brit. Mus., xxii, p. 320 (1893); id., Handbook Game Birds, ii, p. 9 (1897); Macpherson, in "Fur and Feather Series," Pheasants, (1895); Buturlin, Ibis, 1904, pp. 379, 385 ; 1908, pp. 584, 586; Millais, Nat. Hist. Brit. Game Birds, p. 74, pl. (1909).

Walsingham and Pay: e-Gallwey, in the "Badminton Library," Field and Covert, Pheasant, p. 181 (1886).

DULT male.-Crown of the head bronze-green; rest of the head and neck dark-green, shading into purple on the sides and front of the neck. Feathers of the mantle, chest, breast, and flanks fiery orange ; the first narrowly margined with purplish-green, the three last named widely edged with rich purple; those of the upper back

and scapulars mottled in the middle with black and buff, margined by consecutive bands of buff, black, and orange-red, and tipped with purplish-lake. Lower back, rump and upper tail-coverts red-maroon, glossed with purplish-lake or oily-green, according to the way in which the light falls on the feathers. Most of the wing-coverts sandy-brown or claybrown; middle of the breast and sides of the belly dark purplish-green; middle of the belly and rest of the underparts dark-brown, mixed with rufous. Quills brown, barred and mottled with whitish-buff. Tail-feathers olive down the middle, with narrow, wide-set black bars and widelyedged on each side with rufous, glossed with purplish-lake. Iris darkbrown; naked skin on the sides of the face, and wattles crimson-scarlet; bill whitish-horn-colour; legs and toes brownish-horn-colour, the former armed with a pair of spurs.

Total length about 37.5 inches; wing 10 inches; tail 21 inches; tarsus $2 \cdot 8$ inches.

Males in first autumn-plumage resemble the adult, but the plumage is less pure and bright, the tail is shorter, and the spurs are much less developed.

Adult female.-General colour sandy-brown, barred with black; feathers of the back and sides of the neck tinged with pinkish and with metallic purple or green margins; those of the mantle, sides of the breast and flanks chestnut, with black middles and pinkish-grey margins; an elongated patch of white black-tipped feathers below the eyes; quills more 


\section{THE GUN AT HOME AND ABROAD}

coarsely barred and mottled with buff than in the male; tail-feathers reddish-brown down the middle, shading into sandy-olive on the sides and with wide irregular triple bars of black, buff, and black.

Total length about 24.5 inches; wing 8.5 inches; tail 11.5 inches; tarsus $2 \cdot 4$ inches.

Females in first autumn-plumage resemble the adult.

Young males and females in first plumage.-Very similar in general colour and markings to the adult female as regards the plumage of the head and back, but most of the feathers have a narrow buff shaft-stripe and a subterminal buff cross-bar; the lower back and rump blackish, barred and widely margined with sandy-buff; wing-coverts black with buff shafts, widely margined and sometimes barred with pale sandybrown. Underparts pale whitish-buff, sometimes brighter on the chest, which is spotted and mottled with blackish; sides of the body mottled with black, the markings on the feathers being often more or less concentric. The secondaries and tail-feathers are marked very similarly to those of the female, but the former are very pointed at the extremity, and the latter much shorter-about four inches in length.

Young in down.-Crown dark chestnut-brown, which colour is continued in a narrow line to the base of the bill, and with a sandy-buff submarginal line on either side; forehead, wide superciliary stripes, and sides of the head buff; a dark-brown triangular spot beneath the ear; occiput and nape of a more rufous-chestnut, like the inter-scapular region, wing-coverts and rump; back buff, with three wide dorsal stripes, one down the middle and one on either side, all three being often confluent on the rump, and the median one $\mathrm{X}$-shaped, much widened out at the extremities. Underparts uniform pale yellowish-buff. The quills in the birds described (killed in June) are about half an inch in length.

Female assuming male plumage.-Hen pheasants which have become barren, either from age or through disease, or from an injury to the ovary, generally assume the plumage of the cock to a greater or less extent, and in many instances the male plumage is so completely donned that it is only by their smaller size, much shorter tail, and usually by the absence of black margins to the feathers of the chest and breast that the true sex of the individual can be detected from its external appearance. Occasionally females in normal plumage are to be found with well-developed spurs. I have dissected two such birds, and in 102 


\section{THE COMMON PHEASANT}

each case found that the ovary had been destroyed by a shot-wound, the pellet being embedded in the organ, and having caused a tumorous growth.

Males assuming female plumage.-Occasionally very old males, and more often young males of the year assume a plumage like that of the female to a greater or less extent ; the tail-feathers of the latter often presenting the blended characters of both sexes, the proximal part being male and the distal part female, or the reverse. This assumption of the female plumage, in young birds at least, appears to be invariably due to constitutional weakness, and in all the specimens examined the testes were normal. In most cases the birds appear to outgrow this weakness and assume the normal male plumage at the following moult.

Variation in colour.-Variation in colour amongst pheasants is not very common. The best known is the so-called Bohemian pheasant, which has the general colour of the plumage light brownish-buff. White birds, and partially white birds are comparatively common among hand-reared pheasants, but I have never seen one among wild birds of the different species met with in Asia.

General distribution.-Owing to the introduction of the common pheasant into most countries of Europe, its natural range is now difficult to define. Both its generic and specific names are derived from a river of Transcaucasia, the Colchian Phasis, marked on modern maps as the Rion, which enters the Black Sea near Poti. According to Mr S. A. Buturlin the true habitat of this species is very restricted, and confined to the western parts of Transcaucasia, bordering the south-eastern and eastern coasts of the Black Sea, and extending northwards as far as Sukhumkale. It is also found in a wild state through the northern portions of Asia Minor, Greece, Southern Turkey, along the western shores of the Black Sea as far north as the Balkans, and in Albania. It may, however, have been introduced into these countries at some remote period and also into the island of Corsica, where it is known to have occurred since 1531 . It was undoubtedly imported at a very early period from the River Phasis to the shores of Southern Greece, and was well-known and highly appreciated as a bird for the table by the Romans in the middle of the first century A.D. This is proved by the references to the pheasant made in the works of several of the early Latin writers, and the River Phasis was said to have been stripped of its birds to supply the luxury and extravagance of the dwellers in ancient Rome. 
THE GUN AT HOME AND ABROAD

Introduction into the British Isles.-The pheasant was almost certainly Introduced into England by the Romans, for the first certain record of its existence there is to be found in ancient manuscript regulations drawn up by King Harold in A.D. 1059, and preserved in the British Museum. These allowed the canons of Waltham Abbey one pheasant as an alternative fare to a brace of partridges, etc. The date of its introduction into Ireland is unknown, but it was said to be plentiful there in 1589 . The earliest mention of its existence in Scotland is in old Scots Acts dated June 8, 1594, in which King James prohibited the slaying of pheasants, etc., and ordained that any person found guilty of doing so should pay a fine of one hundred pounds.*

The pheasant has long been acclimatized in most parts of Europe, with the exception of the higher latitudes of Scandinavia and Russia, but at what date, and how it was first imported to these countries there is now no means of finding out. Macpherson is of opinion that it was probably brought to France by Roman officers employed on foreign service about the same period that it was introduced into England. Its establishment in Spain and Portugal has only recently been accomplished, early efforts having proved entirely futile.

It is interesting to note that remains of several species of pheasant-like birds, which have been referred to the genus Phasianus, have been found In the lower Pliocene and upper and middle Miocene deposits of France, Switzerland, Germany, and Greece, and if these remains have been correctly referred to Phasianus, the range of that genus must at one time have extended over the greater part of Europe. Towards the end of the eighteenth century the ring-necked pheasant from South China, $P$. torquatus (renamed $P$. gmelini by Buturlin), began to be imported into England, and interbred freely with the common pheasant, gradually producing the perfectly fertile race of hybrids generally met with in these islands at the present time. One rarely now meets with a pure bred male of $P$. colchicus among the enormous numbers of pheasants killed in this country; even in specimens which appear at the first glance to be pure bred (that is in those which have no trace of a white ring), the subterminal green bar of the ring-necked pheasant is usually more or less developed on the feathers of the lower back, and the basal part of the middle tailfeathers is rather widely barred with black. During recent years numbers of pure bred $P$. colchicus have been imported from Transcaucasia to

* That is one hundred pounds Scots $=\$ 86 \mathrm{~s} .8 \mathrm{~d}$., the Scots pound being equivalent to 1s. 8d.-Ed. 104 


\section{THE COMMON PHEASANT}

this country, but, so far as we know, their introduction has made little or no impression on the mongrel stock with which these islands are now populated.

Subsequent to the introduction of the ring-necked pheasant, the smaller green-breasted Japanese species $\boldsymbol{P}$. versicolor was imported, and it again interbred freely with both the common and ring-necked pheasants. Male hybrids of the first cross with either of these species are remarkably handsome birds, surpassing both in size and beauty, either of the parents. Such crossbred birds are much recommended for turning down in preserves, not only on account of their large size and excellent table qualities, but because of their more sedentary habits. It appears that they seldom stray from the coverts where they have been reared, are less given to running, rise more rapidly, and fly with greater power.

The late Mr J. Horne of Hereford always maintained, and we think with justice, that the first-cross between the common and Japanese pheasants was the finest and most sporting bird that could possibly be put down in any covert.

In recent years other species of pheasants have been imported to this country for purposes of sport. The extremely handsome Prince of Wales's pheasant, $P$. principalis, first discovered by the late Dr J. E. T. Aitchison in 1884 in the Murghab basin in North-west Afghanistan, was successfully imported by Colonel M. Sunderland in 1903, and is regarded as a valuable addition to our game birds. It is a very handsome species, the male having the lower back and rump maroon, the wing-coverts white, the feathers of the chest and breast broadly tipped with purplish red-bronze, and the flank-feathers broadly tipped with dark purplish-green. Typical examples have no trace of a white ring on the neck, but in some birds traces of white are present.

Another splendid species is the Mongolian pheasant, $P$. turcestanicus with a wide white collar round the neck, white wing-coverts, and the lower back and rump maroon. The ear-tufts are inconspicuous, and the wattles below the eyes unusually large, especially in the breeding season. It is a rather larger bird than $P$. colchicus, and interbreeds freely both with that species and with $P$. torquatus, the crosses with the latter being, in the opinion of many, the best birds that can be turned down, either for sporting purposes or for the table. The hybrids are very large birds, some weighing as much as five pounds. The pure-bred Mongolian pheasant is not so good a bird for our coverts as the half-bred, as in 
some places at least it appears to have a greater tendency to wander than its allies, and is less ready to rise. (Plate XV.)

Lastly, we must mention the magnificent and very distinct Reeves's pheasant, $P$. reevesii, from the mountains of Northern and Western China. The male has an immensely long tail, which in old birds attains a length of at least five feet. This species has at various times been turned down on some of the large sporting properties in Great Britain, but it has not proved a success, except in such places as Guisachan, in Inverness-shire, where the breed was successfully maintained for some years. Our coverts are, as a rule, totally unsuited to the bird's habits, its natural haunts being the wild gorges and rough woods about the head waters of the Yangtze. The males are very quarrelsome, and drive away other pheasants, moreover, they rarely interbreed with either the common or the ringnecked species, and the hybrids are said to be invariably infertile.

That all our introduced species of pheasants, except the very distinct $P$. reevesii, should be capable of crossing and recrossing with one another and of producing a perfectly fertile race of hybrids, is one of the most curious surprises in Nature. The home of $P$. colchicus in Transcaucasia is thousands of miles distant from that of $P$. torquatus in South China, and is still further removed from that of $P$. versicolor, which is peculiar to Japan. Moreover, these three species are entirely different from one another in plumage, as different as any three species of the same genus can well be. The fact that they interbreed in captivity, or when turned down in a semi-domesticated state in the same country, and that their offspring have proved perfectly fertile, has induced some authors to regard all the Asiatic pheasants as local races or sub-species of $P$. colchicus, a conclusion which appears to be erroneous.* Mr Buturlin has devoted much time and study to the genus Phasianus, and has published the results of his work in the "Ibis" (1904, pp. 377-414; 1908, pp. 570-592). He recognizes thirty-five species and sub-species of "True blue-andgreen-headed Pheasants," and though, no doubt, some of the sub-species recognized appear to have very small claims to warrant their bearing a distinct name, two dozen or more can be easily distinguished, and inhabit well-defined geographical areas, being shut off from their allies by insurmountable natural barriers in the shape of great mountain-ranges and wide deserts.

The geographical distribution of the true pheasants with the crown of * See Seebohm on Phasianus colchicus and its allies, Ibis. 1887 p. 158.-Ed, 106 


\section{THE GOMMON PHEASANT}

the head green or greenish-bronze is very interesting. All are natives of Asia, extending to Japan and Formosa. They fall naturally into three main groups, two of which are divisible into two minor sections.

A. General colour of the lower back, rump and upper tail-coverts maroon or bronze-red, glossed with purple or green.

(a) With no white ring round the neck, or with only traces of one. $P$. colchicus and allies.

(b) With a broad white ring round the neck. $P$. mongolicus and allies.

B. General colour of the lower back, rump, and upper tail-coverts greenish- or bluish-slate-colour, with a rust-coloured patch on either side.

(c) With no white ring round the neck, or with only traces of one. $P$. decollatus and allies.

(d) With a white ring round the neck. P.torquatus and allies.

C. General colour of the lower back, rump and upper tail-coverts greenish-slate-colour, without a rust-coloured patch on the sides (underparts uniform dark-green). $P$. versicolor.

All the maroon-rumped species (A) are found west of about $90^{\circ} \mathrm{E}$. longitude, while those with grey rumps (B) are met with only to the east of that line.

Roughly speaking, all the species with a white ring round the neck are northern forms, while those without that ornament, or with only traces of it, are met with further south.

$P$. colchicus and its allies (a) which have no white ring, but have a maroon-coloured rump, inhabit the area south of about $41^{\circ} \mathrm{N}$. latitude, and west of about $90^{\circ}$ E. longitude; while $P$. mongolicus and $P$. turcestanicus (b), both of which have a well-marked white collar as well as a maroon rump are met with north of about $41^{\circ} \mathrm{N}$. latitude, and west of about $90^{\circ} \mathrm{E}$. longitude.

Again, among the grey-rumped species (B), $P$. decollatus and $P$. elegans (both beautiful Chinese species), as well as other allied forms (c) without white collars or with only traces of that ornament, occur south of about $40^{\circ} \mathrm{N}$. latitude, and east of about $90^{\circ} \mathrm{E}$. longitude ; while the ring-necked forms (d) of which $P$. torquatus is typical, though found as far south in China as Canton and in Formosa, range far north to the Amur River about $50^{\circ} \mathrm{N}$. latitude.

Thus, on the whole, one may regard the ringed form as the northern type, and those without the white ring as the southern type. That all 


\section{THE GUN AT HOME AND ABROAD}

the species have probably sprung from an ancestral ringed-form seems to be indicated by the fact that a partial white ring occurs in certain individuals of the southern species, which are normally devoid of that ornament. Possibly they still occasionally revert to a ringed ancestral stock. It is a mistake to regard such partially ringed individuals as wild hybrids, for in most cases the country which each species inhabits is entirely shut off by enormous ranges of mountains which effectually bar all intercourse between the ringed species and their southern allies. For instance, it is not uncommon to find examples of $P$. principalis from the Murghab basin and of $P$. shawi from the valleys of Yarkand with an imperfect white ring round the neck, yet it is practically impossible for either of these species to meet with the ring-necked forms $P$. mongolicus or $P$. turcestanicus, both the latter being shut off by high mountains and impassable deserts. It must, however, be added that wild hybrids certainly sometimes occur between $P$. zarudnyi and $P$. chrysomelas, which both inhabit the valley of the Amu-Darya. In this instance, however, there is nothing to prevent the two species from meeting and occasionally inter-breeding.

It is interesting to recall the fact that $P$. turcestanicus, which inhabits the valley of the Syr-Darya, though turned down in the Zarafshan Valley in 1881-83, had practically disappeared in 1890.* In the Zarafshan Valley a very distinct species, $P$. zerafshanicus, lacking the white ring, or with only traces of one, and most nearly allied to $P$. principalis, is indigenous. In some examples of this bird, notably in the type specimen, there are traces of a white collar, possibly indicating the influence of the introduction of $P$. turcestanicus. Mr Douglas Carruthers recently obtained a number of examples of the Zarafshan pheasant, which have no trace of a white collar, but illustrate very clearly the remarkable difference in colour between freshly moulted autumn specimens and those in worn breeding plumage, a difference so great that, if borne in mind, it will deter the makers of new sub-species from giving names to single specimens which differ slightly in tint.

Of the thirty-five forms recognized by $\mathrm{Mr}$ Buturlin in his latest review of the "True blue-and-green-headed Pheasants," probably ten or more might with advantage be suppressed, the characteristics which are said to distinguish them being of the slightest, and the material on which they are founded (in some instances on one or two specimens only) being quite insufficient. No allowance seems to have been made for individual

\footnotetext{
"Tarnovski, Field, xxvii, p. 409 (1891).
} 


\section{THE COMMON PHEASANT}

variation or for the very marked changes caused by wear and fading, which so greatly alter the colours and markings of the plumage that birds killed at the end of spring and in summer, before they have moulted, seem very different when compared with others of the same species procured in the late autumn and winter-months.

For those who are interested in the importation of Asiatic pheasants for turning down in their coverts, or for their aviaries, the following list of species may prove of value, as indicating the country in which each is to be found:

A. With maroon or bronze-red rump.

a. With no white collar, or only traces of one.

1. Common pheasant, P. colchicus. Western Transcaucasia, and possibly also parts of Asia Minor, Greece and Turkey, as far north as the Balkans and Albania.

2. Caucasian pheasant, $P$. septentrionalis (a sub-species of $P$. colchicus). North Caucasia, western coast of the Caspian Sea from the Apsheron Peninsula northwards to the mouth of the Volga.

3. Talisch pheasant, $P$. talischensis (a sub-species of $P$. colchicus). Southwestern and southern coasts of the Caspian Sea, from the Apsheron Peninsula to Mazandaran.

4. Persian pheasant, P. persicus. South-eastern coast of the Caspian Sea, basins of the Atrek and Gurgan rivers and their tributaries to the Potemkine Peninsula and Ashourada Island, possibly also ranging into western Mazandaran.

5. Prince of Wales's pheasant, $P$. principalis. North-western Afghanistan and Southern Turkestan, basins of the Murghab and Tajend rivers $(=P$. komarowi).

6. Zarudny's pheasant, $P$. zarudnyi (a sub-species of $P$. principalis). Lower Amu-Darya, from Kiva to Chardjui.

7. Gordius's pheasant, $P$. gordius (a sub-species of $P$. principalis). Upper Amu-Darya, from Chardjui to Kelif (=P.tshardjuensis).

8. Zarafshan pheasant, $P$. zerafshanicus. Bokhara, Zarafshan Valley.

9. Oxus pheasant, $P$. chrysomelas. Amu-Darya basin, from eastern Bokhara to the Sea of Aral (=P. bianchii).

10. Shaw's pheasant, $P$. shawi. Western portion of East Turkestan, valleys of the Aksu, Kashgar, Yarkand and Khotan rivers $(=P$. chrysomeloides and $P$. insignis). 


\section{THE GUN AT HOME AND ABROAD}

11. Tarim pheasant, $P$. tarimensis. Eastern portion of East Turkestan, from Karaschar, the lower Tarim and Cherchen-Darya to Lob-nor.

b. With a wide white collar.

12. Mongolian pheasant, $P$. mongolicus. North-eastern Turkestan and Southern Dzungaria, the basins of lakes Issyk-kul, Balkash, Ala-kul, and Zaisan and their tributaries; eastwards along the Ili River to Kulja, Lake Ebi-nor and Guchen in Southern Dzungaria.

13. Turkestan pheasant, $P$. turcestanicus (a sub-species of $P$. mongolicus). Syr-Darya basin, from the Alai to the Sea of Aral.

B. With the rump greenish-or bluish-slate-colour, and with a rust-coloured patch on either side.

c. With no white ring round the neck or with a partial ring widely broken in front.

14. Chinese ringless pheasant, $P$. decollatus. Sze-chuan, Hu-nan, Queichow, North-eastern Yunnan and Upper Annam (Mus. Rothschild).

15. Berezowski's pheasant, $P$. berezowskii. Southern Kan-su and Southern Shen-si, Tsin-ling Mountains.

16. Alashan pheasant, $P$. alaschanicus. Western slopes of the Southeastern Alashan Mountains, Ordos, east to Kalgan (=P. pewzowi).

17. Strauch's pheasant, $P$. strauchi. Kan-su to the Southern Alashan (=P. sohokhotensis).

18. Vlangali's pheasant, $P$. vlangalii. Eastern Zaidam.

19. Sze-chuan pheasant. $P$. süehschanensis. North-western Sze-chuan.

20. Stone's pheasant, P.elegans. Western Yunnan, Northern Shan States.

d. With a wide white collar.

21. Formosan pheasant, $P$. formosanus Formosa.

22. Chinese ringed pheasant, $P$. torquatus. South-eastern China, from Canton northwards to the lower Hoang-ho, and westwards to $\mathrm{Hu}$-nan. (=P. gmelini.)

23. Manchurian pheasant, $P$. pallasi. Central and Northern Manchuria and Ussuriland ( $=P$. alpherakyi and $P$. ussuriensis).

24. North-east Chinese pheasant, $P$. kiangsuensis (a sub-species of P. pallasi). North China and South-east Mongolia, Pe-chili, Shan-si, North-eastern Ordos, Corea and the Island of Tsu-shima (=P. karpowi and $P$. buturlini). 


\section{THE COMMON PHEASANT}

25. Sa-tscheu pheasant. P. satscheuensis. Sa-tscheu (Sachjow Oasis), northern slopes of the Nan-Shan Mountains.

26. Kobdo pheasant, $P$. hagenbecki. Kobdo, north of the Great Altai Mountains.

C. Rump greenish-slate-colour, without a rust-coloured patch on either side.

27. Japanese pheasant, $P$. versicolor. Japan, except the Island of Yezo.

It is by no means certain that all the species mentioned in the above list are really distinct. $P$. alaschanicus appears to be very doubtfully separable from $P$. decollatus, and apparently one male only has been examined. A careful re-examination of the large number of ring-necked pheasants of the $P$. torquatus group now in the Natural History Museum and in the Tring Museum seems to indicate that $P$. kiangsuensis from North China is not distinct from $P$. karpowi from Corea, and that the latter is only distinguishable from $P$. pallasi by the darker colour of the flank-feathers. Typical $P$. torquatus, with pale straw-coloured flankfeathers and a narrower white ring round the neck, often incomplete in front, inhabits the whole of South-eastern China as far north as the Hoang-ho. Beyond that great river, and northwards to the Amur the birds met with have a much wider white collar, widest in front of the neck, and I am strongly of opinion, after examining many specimens, that at most two forms with a wide collar can be recognized: the more southern, with rather darker, more coppery flanks; and the more northern (Central and Northern Manchuria and Ussuriland), with paler, more straw-coloured flanks. However this may be, it will not greatly matter to importers of live pheasants whether their wide-ringed birds come from North-eastern China or from Manchuria, for the birds are very closely allied sub-species.

Food.-In a wild state pheasants feed on various kinds of grain, especially on wheat and barley, on grass-seeds and the flowers of the rush, on grapes, and all sorts of forest-fruits and berries; likewise on vegetable matter of many kinds, including the fronds of the polypody fern. They are also very partial to animal food, such as snails and worms, as well as ants and various other insects and their larva. In this country their food is perhaps even more varied, and to the above list may be added -especially in spring-all sorts of bulbous roots, including those of the buttercup and wild arum; also strawberries, blackberries, hips, haws, yew-berries and leaves, elder and holly berries, acorns, beech-mast, 
THE GUN AT HOME AND ABROAD

grass, clover, and bits of bracken and other ferns; even such hard fare as hazel-nuts being sometimes eaten. In autumn they constantly repair to the potato- and turnip-fields, feeding to some extent on the former, but probably the seeds of various weeds and the endless variety of insects and larvæ to be found there are the chief attraction. By destroying enormous numbers of wire-worms and such like injurious grubs, they more than counterbalance any harm done in spring to newly-sown barley, etc. Like other game-birds, pheasants swallow quantities of grit to aid digestion.

Flight.-Though both rapid and powerful while it lasts, the flight of the pheasant is seldom long sustained, and probably from one to two miles is the greatest distance most birds are capable of flying, even when assisted by high wind. Instances are, however, recorded of individuals accomplishing even longer flights, and crossing the Humber near Grimsby, a distance of about four miles; but more often when attempting to cross wide lakes and rivers the birds become exhausted before reaching the opposite shore, and having settled on the water, accomplish the remainder of their journey by swimming, which comes quite naturally to them. In rising, pheasants make a loud whirring sound caused by the rapid beats of their short rounded wings, and if flushed on open ground seldom rise to any great height. In high cover they at first rise upwards almost perpendicularly, and mount until they have cleared the highest trees, then shape their course with rapid and almost incessant wing-beats for the covert they wish to reach. They continue to rise gradually until they have attained a sufficient elevation to enable them to surmount all intermediate obstacles, but no sooner have they reached the desired elevation, which may vary from twenty to sixty yards, or even more, according to the nature of the ground, than they gradually begin to drop, and finally glide along with outspread wings as they approach the point where they mean to alight. When flying, a pheasant is always either ascending or descending; practically speaking, it never flies horizontally, for the moment the zenith is reached its flight begins to decline. If there is any wind blowing the line of flight is sure to curve more or less to the right or left, and really high birds dropping and curling, as they travel down wind at the rate of an express train, are probably as difficult to kill as any game-bird.

Breeding habits. - From the evidence of various observers residing in the Caucasus, published by the late Mr Macpherson,* there appears to be

* Fur and Feather Series, The Pheasant, pp. 23, et seq.

112 


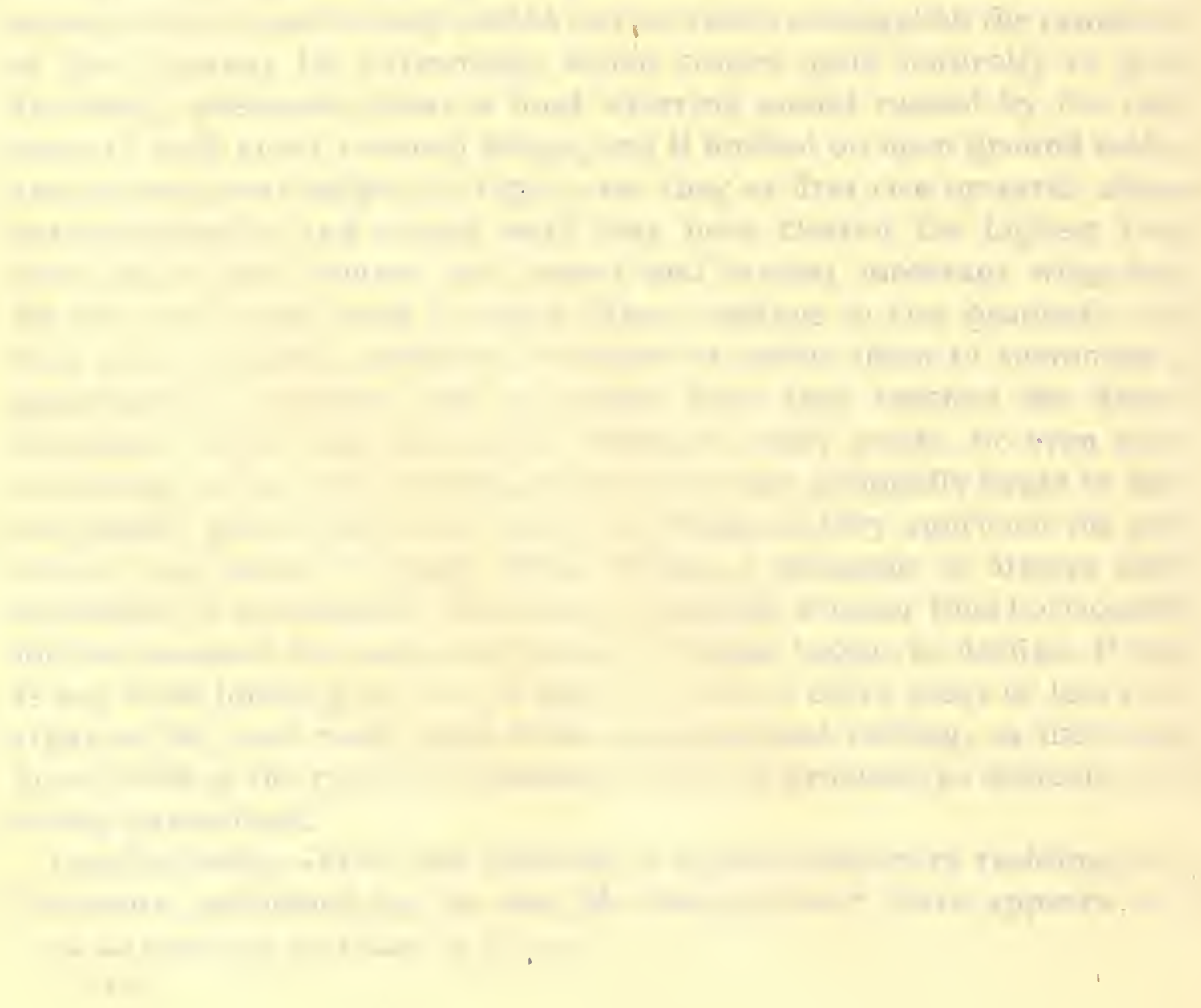




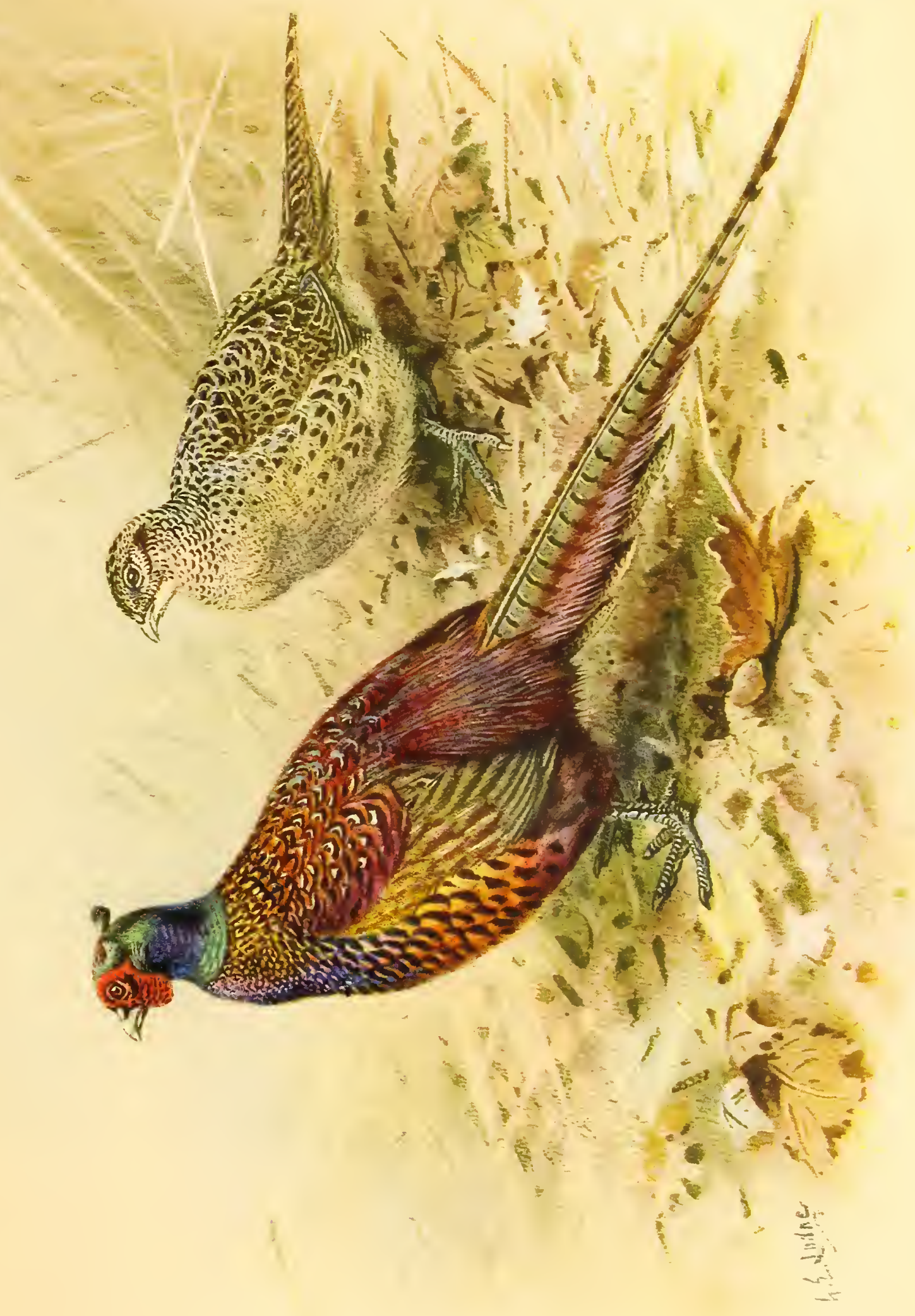




\section{THE GOMMON PHEASAN'T}

little doubt that the common pheasant in a wild state is polygamous, and though a male may be met with in company with a female and her brood, he is not necessarily the parent bird, but merely a " hanger on." Writing of Strauch's pheasant, $P$. strauchi, which inhabits parts of the province of Kansu, in China, the Russian traveller Prjevalsky, who was the first to discover and describe the species, tells us that the young are "always accompanied by both parents, and that very often the male bird defends the young even more vigorously than the female." It was on this evidence, practically the only reliable information to be found on the breeding habits of any pheasant in a wild state, that I suggested that the usually polygamous habits of our common pheasant had probably been acquired. As in this country, wild pheasants begin to pair in March, the cock birds engaging in fierce combats, which sometimes end fatally for the weaker bird, the victor remaining at the head of five or more hens. The males use much the same methods of fighting as gamefowls: they spring into the air and try to strike one another on the head with their spurs, which are fairly long and sharp in old birds. The hens, too, often fight fiercely with one another in spring, and utter a low growling note when about to engage an adversary. The male loves to display his beautiful plumage to the females. After stalking majestically about before the particular bird he wishes to captivate, with scarlet face-wattles inflated, ear-tufts erected, and his plumage all puffed out, he lowers his head and neck, droops and extends the wing on the side nearest the female, and at the same time expands the feathers of the rump and tail, turning the latter half over so as to show off its beautiful colour and markings to the fullest extent. Thus he struts past the hen, who often displays a lamentable indifference, real or assumed; but, nothing daunted, he turns about and shows the other side of his brilliant body till she is finally subjugated. At such times the cock pheasant makes use of a gentle crooning note, something like that made by poultry when feeding contentedly. When the pairing-season is over the hens leave the cock and devote themselves to the duties of incubation, and the latter, except in rare instances, where pheasants are scarce, takes no further interest in any of them.

Nest.-In the Caucasus the hen pheasant is said to make her nest, as a rule, in thick reeds or other dense undergrowth, choosing the driest piece of ground she can find. Having fixed on a suitable spot, and lined it with soft grass or reeds, she lays from ten to fifteen eggs between April 


\section{THE GUN AT HOME AND ABROAD}

and the middle of May. The habits of the wild bird thus differ little from those of our semi-domesticated bird, which scratches out a slight hollow in the ground in some spot more or less hidden from view by dead ferns, brambles, or coarse tufts of grass and other herbage, and roughly lines it with a few stems of grass and dead leaves. Nests in woods are sometimes situated in quite open places. In this country reed-beds are seldom, if ever, resorted to for nesting-purposes, but some of the closely allied Asiatic species, such as $P$. principalis, which inhabits the Murghab Valley, habitually select such situations, and pass most of their time there.

Though the nest is almost invariably on the ground, in covert, or on the sunny side of a thick hedgerow, individual hens occasionally develop very eccentric habits, and resort to stacks, the tops of walls covered with ivy, and even to trees, utilizing old squirrel's dreys, or the nests of sparrowhawks, wood-pigeons, etc. In such cases, when the young are hatched many feet from the ground, a considerable percentage are no doubt killed in making their perilous descent to the ground.

Eggs.-The usual number of eggs laid is from eight to fifteen, and though as many as thirty are sometimes found in a nest, these are no doubt the produce of more than one hen. The eggs are of a broad oval shape, somewhat pointed at the smaller end, and generally uniform brown or olive-brown in colour, or more rarely bluish-green, with a rather smooth polished shell. The average measurements are 1.8 inch by $1^{\cdot 4}$ inch. The pheasant often lays its eggs in the nests of other birds, such as the partridge, red-legged partridge, grouse, grey-hen, capercaillie and landrail, and occasionally in nests of wild duck and woodcock. The writer once found a nest of the common partridge which contained a mixed assortment, including eggs of the red-legged partridge and pheasant.

Incubation.-The period of incubation varies from twenty-two to twentyfive days, but twenty-three or twenty-four days is the usual time. The hen pheasant sits very closely on her eggs, her plumage generally assimilating well with the surroundings of the nest, but she is not nearly such a good mother as the partridge, and is much more inclined to desert her nest if disturbed. Even when the young are hatched she is generally much less solicitous about their welfare than the majority of game-birds, and, if disturbed, usually flies off and leaves her young to look after themselves. This habit is often extremely disastrous to the brood, especially when the chicks are very small, for, on her return, she is apparently perfectly satis114 
fied if she finds one or two of her scattered brood, the remainder being left to perish. For this reason it is most important that coverts, where wild birds are breeding, should not be disturbed by irresponsible persons during the nesting-season, and gamekeepers cannot be blamed for treating trespassers with scant courtesy.

When leaving her nest in the morning and evening in search of food the hen pheasant is usually careful to cover up her eggs with dead leaves, and she generally quits and returns to her nest on the wing, thus avoiding, as far as possible, the danger of being tracked by her enemies.

In rare instances cock pheasants have been known to share the duties of incubation and of tending the young. Occasionally barren females are extremely vindictive and destructive, attacking and killing the young pheasants which are being reared under domestic hens. A case of this kind came under our notice in Hertfordshire: Many young had been killed, and brown owls, etc., were at first suspected as the culprits, but when a watch had been set, an old hen pheasant was seen to fly to the coops from the neighbouring covert, and instantly commence to kill the chicks. Other similar cases have been recorded.

As soon as the newly hatched chicks have been dried and warmed by their mother, she leads them away and teaches them to hunt for food, which at first consists principally of insects and their larvæ, especially wood-ants and their pupæ, as well as worms and small molluscs. The young are extraordinarily active little birds, and run with great agility among the grass and herbage. As they grow up the hen pheasant wanders with her brood from place to place, wherever the three great essentialswater, food, and quiet-are to be found. Water is an absolute necessity, and many wild birds perish in very dry seasons for want of it.

General habits.-In a wild state pheasants are very shy and timid birds, and we learn from the writings of Mr Djanaschvili in "Caucasian Agriculture," that its unsociable habits are proverbial among the Georgians of the Zakatal district, the saying "unsociable as a pheasant" being a common expression among them. Their favourite home is thick covert, wood with plenty of undergrowth, in the immediate neighbourhood of cultivated land, where they can come out to feed in the early morning and evening. Oak, hazel and fir plantations are chiefly resorted to, the proximity of water being also an essential. Though they often perch and usually roost in trees, pheasants are essentially ground-birds, and when menaced by their enemy-man-always prefer to escape by running. 


\section{THE GUN AT HOME AND ABROAD}

Old cocks especially, which have learnt wisdom from past experience, are extremely artful, and will often run for long distances far in front of the beaters, before they eventually fly out at some unguarded spot in the covert; often, too, they refuse to rise at all, and on nearing the end of the covert, run back between the beaters as fast as their legs can carry them, generally managing to escape.

The crow of the cock pheasant resembles the syllables or-ork which are often repeated several times in succession, and may be exactly imitated by opening the mouth and drawing the breath in sharply to the back of the throat. This call is generally to be heard in the morning and evening, especially about sunset, when the birds are going to roost, but during the pairing-season it may be heard at all times of the day, and is usually accompanied or followed by a few very rapid wing-beats, producing a whirring sound. The call is also uttered when the birds are flushed or suddenly startled by any loud noise, such as the report of a gun, or a clap of thunder. On the ground the cock pheasant holds himself very erect when calling; he also frequently crows three times in succession as he rises, if he has been squatting in covert.

He has another metallic note like klink, klink, klink, which is heard just before he flies up to his tree to roost, and as he rises and settles on his perch, he utters a series of or-orks, so that all the pheasant-world may know that he has turned in for the night.

Every cock bird calls as he flies up to roost, and it is thus easy to ascertain approximately how many cock birds there are in any covert. The trees selected for roosting in vary much: larch, spruce, and silver firs, oaks, beech and poplars are perhaps those most resorted to in the order mentioned. Pheasants are very fond of roosting over or near running water, and for this reason often select deciduous trees, though there may be plenty of spruce and larch in the coverts close at hand. One spot in particular comes to mind, a canal in Wales, bordered by large naked poplar trees, where most of the pheasants in the neighbourhood come to roost, even on winter-nights, when one would imagine that the snug coverts all round would offer a much safer and more pleasant resting place. It is true that these poplar trees support large bunches of mistletoe, on the berries of which the birds feed, but the supply is, after all, a very limited one. In summer and early autumn the young birds generally, and the old birds occasionally, roost on the ground, but by the end of September most of the youngsters have learnt to perch in trees. The 116 


\section{THE COMMON PHEASANT}

hen pheasant has a weak, sharp call, which, like the cock, she utters when startled. A dog or fox running through a covert will put all the birds up into the trees, where they remain till the intruder has gone, all the cocks crowing at intervals, and the hens chiming in with their feeble notes.

In the early morning and evening, when pheasants chiefly feed, the wild-bred birds leave the woods and visit the neighbouring fields, and often remain there throughout the day if they can find suitable covert. On estates where birds are reared they naturally repair to the places where they are regularly fed, but even then, as they grow older, they visit the fields more and more to vary their diet with insects and plants not to be met with in the woods.

In wet stormy weather they generally prefer to remain in the woods, and are usually to be found feeding about the edges of the covert. In summer and autumn they love the potato- and turnip-fields and seek out sunny spots where they can dust themselves in the dry sandy soil.

In this country pheasants seem to thrive best on a light sandy soil, and in such situations appear to increase, but in most parts they would soon die out were it not for the constant introduction of fresh stock and artificial feeding in bad weather.

By nature the pheasant is a wanderer, and, especially in the spring, will often stray miles in search of more congenial surroundings and change of diet, and if put down in woods not entirely suited to its taste will soon leave them, unless constantly checked and driven in.

Mr Millais' ideal wood for keeping pheasants is described by him as follows: "In this country, where grass- and reed-beds are absent, I should describe a perfect pheasant-covert as one on sandy soil, having a slight southern slope, and protected on the ridge by a belt of Douglas firs; the valley should be intersected by a stream fringed with long grass and reeds, and the adjoining fields in high cultivation of buckwheat, oats, wheat and turnips. The actual covert should consist of thickets, kept open in spaces, of brambles, snowberry, thorns, a few hollies, and other short berrygrowing bushes, and the whole of the ground well covered with various kinds of grass that run well to seed. Oaks and firs are the best trees for roosting purposes, but should not be allowed to grow too densely."

As has already been remarked, pheasants in a wild state love the dense undergrowth and thick reed-beds bordering the rivers of the Caucasus, and their love for such situations, when attainable in this country, is always in evidence. The dense reed-beds fringing Loch Spiney, in Elgin- 
THE GUN AT HOME AND ABROAD

shire, and other similar Highland lochs, are always sure to contain a number of birds which have wandered there from the neighbouring woods, and they may often be seen rising with duck and snipe.

The closely allied Prince of Wales's pheasant $(P$. principalis), inhabiting the Murghab Valley in Afghanistan and Turkestan, lives in the tamarisk and grass-jungle growing in the bed of the river. It not only wades through the water in moving from one place to another, but swims, and is perfectly at home in thickets where there is always water to a depth of two or three feet. In the morning and evening the birds leave their dense shelter for the more open and dry country, where they pick up their food. That our mongrel pheasants in this country can not only swim, but dive, is well known, for shot birds that drop in water, unless mortally wounded, will at once start swimming for the nearest land, and will often cause the dogs sent in to retrieve them some trouble by diving before they are captured. When swimming, they look like water-hens resting lightly on the water with most of the body exposed, and with their tails held high.

Hybrids. - The pheasant crosses freely with other species of its own kind, and the hybrids are, so far as we know, perfectly fertile. All the species of Phasianus: $P$. torquatus, $P$. versicolor, $P$. principalis, and $P$. turcestanicus which have been introduced into our coverts have interbred with $P$. colchicus and there is every reason to believe that any two species will produce fertile offspring, that the hybrids will mate with other hybrids, or with pure-bred birds of another species ad infinitum. For this reason as above mentioned some naturalists hold that all the true pheasants are merely local varieties or sub-species of one form, but such a view appears to me to be an entirely wrong one. It is absurd to regard the Chinese ring-necked pheasant, $P$. torquatus, from Southern China, or the green-breasted, $P$. versicolor, which is only found in Japan, as sub-species of $P$. colchicus, because the birds, when artificially brought together in the same pens or woods pair with one another and produce fertile hybrids. No ornithologist regards the pintail, the gadwall and the wigeon as subspecies of the mallard, they are even considered by most naturalists as representing different genera, yet we know that in a semi-domestic state (and occasionally also in a wild state), they not only pair together, but produce perfectly fertile races which can be interbred to any extent. Why, then, should we not regard all the species of ducks mentioned above and many other allied forms found in different parts of the world as subspecies of the mallard? It would be just as sensible and as near the truth. 
There is such a craze at the present time among a few modern naturalists for regarding nearly every bird as a sub-species of something else, to which it is often only remotely related, that the term has practically ceased to have a defiite meaning. The term sub-species, if properly understood, is no doubt a very useful one, and has a very real meaning for expressing closely allied local races which are undeserving of specific rank, but it cannot, with propriety, be applied to totally distinct species because they interbreed and produce fertile offspring when artificially brought together. The pheasant, besides interbreeding with its nearest allies, will cross with the somewhat distinct Reeves' pheasant ( $P$. reevesii), and Elliot's pheasant (Calophasis ellioti), also with the cheer, golden, Amherst, kalij and silver pheasants, with domestic fowls of all sorts, especially game-bantams, and with guinea-fowl, but such hybrids are rarely, if ever, fertile. More strange are the wild hybrids produced between pheasant and black grouse, and occasionally between pheasant and capercaillie. Many instances of the former are on record, and are probably, in most cases, the offspring of a blackcock and hen pheasant, but the cock pheasant has also been known to pair with the greyhen and produce young. Most of the hybrids recorded have been males, possibly because the females are less conspicuously different, and are more readily overlooked. The hybrid with the capercaillie is very rare, and only three or four instances, all males, have been recorded as occurring in Argyllshire and Aberdeenshire. They are large, ungainly-looking birds, without the beauty of either parent, and are probably produced by the union of a cock pheasant and hen capercaillie. Plates of both the black grouse and capercaillie hybrids will be found in Mr Millais' "Game-Birds and Shooting Sketches."

Enemies.-The pheasant has many enemies, both furred and feathered; of the former the principal are foxes, stray dogs, domestic cats and, of course, where they occur, wild cats, polecats, stoats, weasels and rats. The four first named take the hen pheasants on their nests, and the others, especially rats, kill numbers of chicks and young birds. Foxes occasionally cause great damage by getting into the wire enclosure where hens are kept for laying, and display extraordinary powers of climbing. An instance of this occurred when a mangy fox which had already visited the pheasant pen and killed a large number of hens, paid a second evening call, and was seen in the act of clambering up the high wire fence with apparently little difficulty. 


\section{THE GUN AT HOME AND ABROAD}

Hedgehogs are said by many people to be destructive to both chicks and eggs, and there seems to be little doubt that they are so ; but crows, rooks, jackdaws, and magpies are much worse enemies. Rooks are sometimes very bad egg-hunters, and will kill the chicks in very dry seasons, but crows, both black and hooded, are the most serious menace, and a family party of these birds will carry off and suck every "wild-laid" egg in a covert. Of course such a catastrophe is due to bad management, for it should be easy for a keeper to trap every pair of crows when they are nesting, long before the young pheasants are hatched. Hawks and owls do a certain amount of damage at times, especially sparrow-hawks and individual tawny owls if they happen to have young near the fields where young pheasants are being reared. Very occasionally a kestrel will take to carrying off chicks, and the individual may have to be killed, but these useful and valuable birds should be carefully protected.

Diseases.-Young pheasants suffer from many diseases, especially hand-reared birds. One of the commonest of these is "gapes," caused by small worms which infest the wind pipe ; "cramps," a disease of the bones of the legs caused by a bacillus described by Klein, and pneumonia are also common causes of death; but the most deadly is coccidiosis, popularly known as "white diarrhœa," caused by a parasitic protozoan, Eimeria avium, the oöcysts of which are picked up with the food, grit, and drink. The disease is often started by infected hens used as foster-mothers, which have become chronically affected. They foul the ground with their excrement, and rapidly scatter the oöcysts of this deadly complaint, which spreads rapidly and often sweeps off an entire stock of young pheasants. Another very probable cause of mortality has recently been pointed out by Mr W. P. Pycraft. He discovered, lodged in the posterior nares of a number of young birds, the larvæ of the ovoviviparous fleshfly (Sarcophaga), and is of opinion that death is due to myiasis, set up by these maggots. The small active larvæ could be easily deposited by the flies in the nostrils of the chick, and would quickly make their way thence to the back of the nasal chamber. For information on the subject of rearing young pheasants the reader should consult Tegetmeier's "Pheasants : their Natural History and Practical management." Valuable hints will also be found in "The Grouse in Health and in Disease" (i, pp. 266-271), being the final Report of the Committee of Inquiry on Grouse Disease, published in 1911. 


\section{PHEASANT REARING}

O those who can carry their memories back over a long series of years the vast increase in the number of pheasants in the British Isles is very marked, and this is perhaps the more striking since it is by no means the case with partridges. In the "fifties" and "sixties" of the last century partridges were much more numerous than they are at present-excepting in certain localities where the latest up-to-date methods are practised on their behalf; and where in those days two guns, shooting over pointers or setters on manors of a few hundred acres, could obtain five-and-twenty to thirty brace in the day, it would be difficult now to obtain a modest bag of twelve or fifteen brace. Yet on these small manors, which afford the bulk of the shooting in England, there is often now a fair sprinkling of pheasants. High farming, and the cutting down of the old straggling fences, which are ever such a protection both in nesting time and in stormy weather, have been accountable for the dwindling away of the partridge in the one case; whilst the very great increase in the number of pheasant rearers has been the reason for the other, since the general stock of pheasants has been thus greatly augmented. It is well this is so, for the pheasant affords an immense amount of sport; and whether it is hunted by a team of spaniels down a hedgerow, or comes over with the partridges in a drive, or sails overhead as a grand rocketer, there is a genuine feeling of satisfaction when it is hit well forward, and comes down with a thud upon the ground.

Where small shootings are not managed in a sportsmanlike way, and adjoin the coverts of, perhaps, wealthier neighbours who rear extensively, there is apt to be friction betwixt the two parties if every pheasant is potted which strays over the boundary. If, in addition, attractive food is cunningly laid to induce the birds to come and seek it on "Tom Tiddler's ground," it is scarcely to be wondered at if the peace is hardly kept between the two neighbours. On one occasion I was shown a small spinney which followed the rise of a hill for barely two hundred yards, and which was not more than twenty-five yards broad in any part, and was told by the proprietor that this was a wonderful wood for pheasants, and that he had already killed eighty-four out of it. Having expressed surprise at its capabilities, a cross-examination elicited the fact that about three thousand pheasants were reared and turned out in the valley below, and that he himself fed heavily in the copse on purpose to attract them. In response to a further question my informant stated that he was 


\section{THE GUN AT HOME AND ABROAD}

accustomed to shoot the little wood every day when he was at home, very often twice a day, and that he scarcely ever had it driven without getting one or two shots. As the leaf was then not off the oaks by the end of the shooting season that spinney must have proved very productive; but it would have been interesting to have heard the other side of the question, and to know the views of the neighbouring head keeper and his assistant on the adjoining beat !

Pheasants are birds of predilections, and one of these in a rather flat country is to go and examine any group of trees situated on an isolated hill. They may not stay, especially if it is but a grove, and not large enough to be termed a wood, but sooner or later every bird in the vicinity will stray up there on a visit of inspection, and this is the opportunity for the man on the spot! Especially do pheasants seek such a place when wandering about in a good acorn year, searching for the food they like, and if only the group of trees contains some oaks or beeches, the attraction to the pheasants will be all the greater. Another fancy is for running water, and pheasants almost always prefer to go down a stream, where, if they find comfortable quarters, they will take up their residence for some time. Pheasants are as much birds of the swamp as of the wood, and love to wander about such ground-picking up all kinds of aquatic delicacies, even venturing to wet their feet in pursuit of these.

Besides grubs, of which they consume a vast number, pheasants are of further service to the farmer in their taste for the bulbs of buttercups, and pignuts (Bunium flexuosum). In the autumn I have found their crops quite crammed with these roots, which was unexpected, for when feeling them from the outside they felt like acorns.

When a large stock of pheasants is desired it is necessary to supplement the natural supply with artificially reared birds, and, even on small estates, if only a few extra birds are reared each year it makes a wonderful difference when the day of reckoning comes. The cost need not be prohibitive, if only a keeper is permanently employed, for the wages will be the chief expense. One man can look after the hatching of two hundred eggs and the subsequent rearing, if he is allowed an assistant for about six weeks in the summer time, and again for a month to assist in watching, before the coverts are shot. The hints contained in this article therefore will have more reference to small and medium sized shootings, than to estates where many thousand birds are reared, and where highlyskilled keepers are necessarily employed. 


\section{PHEASANT REARING}

Picking up eggs.-When looking for eggs laid by wild birds, if a hen is found on a nest she should be left alone, and the keeper should return again at a later hour; if the bird is still there, and appears to be sitting, the man should come again early the next morning and take the egiss when she leaves to feed. She will then probably make another nest, and lay again elsewhere.

If however she is only laying, the keeper may by careful management induce the hen to keep on laying, and thus obtain a number of eggs, sometimes as many as forty. If there is only one egg it should be taken, and an artificial one left in its place. This should be done every morning, the nest being revisited, the newly laid egg taken away, the artificial one always being left, and this game carried on until no more eggs are laid.

If there are several eggs in the nest when it is found they should all be taken, three or four artificial ones being left in their place, and each morning, when the nest is revisited, the newly-laid egg should be taken away. There may, however, be no artificial eggs at hand to place in the nest, and in this case some of those already in it must be left there. These should all be marked with the date of finding them, and it is well to add some secret mark in invisible ink, so that the eggs can be sworn to in case they are stolen, and recovered. The next morning the newlylaid egg must be marked with the date of that day, and one of the earlier ones taken away, this process being repeated every day, the egg with the earliest date being always brought away. In this way no egg will be left too long before it is placed under a hen to be hatched. If two pheasants are found to be laying in the same nest it is better to bring all the eggs away at once, when both birds will probably lay again elsewhere.

A very useful aid to keepers when gathering eggs is the "Foster mother egg-belt," supplied by the well-known game food manufacturers, Gilbertson and Page, Hertford. This has a number of pockets containing cotton wool in which eggs can be placed without fear of breakage, and which are kept warm if partially incubated.

Laying pens. - If it is desired to obtain the required eggs for the rearing field from hens placed in pens, care should be taken to catch up the requisite birds some time before the laying season commences, that they may get over their wildness, or few eggs will prove fertile. Where sufficient accommodation is available it is preferable to take up the hens in October, before they have been shot at, and before the memories of the amenities of the rearing field have passed out of mind. There is 


\section{THE GUN AT HOME AND ABROAD}

then little likelihood of a shot-corn being lodged in any part of the body, especially in the ovaries, so that with healthy, tame hens, a good supply of fertile eggs should be secured. The cocks need not be caught until a much later period, for, if vigorous and in good health, there is no fear of their neglecting their opportunities. Where a good supply of wild cocks is at hand some keepers like to give them a chance of flying into open pens to the hens, thinking the progeny will be more vigorous, but this is a plan which is not very desirable, for the attentions of the wild birds are uncertain, and failure may be the result. The best proportion of the sexes is generally considered to be about five hens to one cock. If the hens are caught up in October they are easily captured, without being frightened, by leaving the coops on the rides, one or two of the brood hens being still left in the coops. A spare coop should have the door hitched up, and a feather from the wing of a barn-door fowl makes an excellent wedge to keep up the door, while it is easily pulled out when it is required to drop the barrier. Some corn should be thrown inside at every feed, to accustom the birds to go freely in and out to pick up the grain scattered within. When it is determined to catch up some young hens the keeper puts the food in as usual, and then waits a little way behind until a hen enters. As soon as it is inside the keeper steps quietly up, pulls out the feather, and lets down the door, and can then take the bird out at his leisure; of course it cannot see him approach when it is once fairly inside the coop. If it is to be left a short time, it is better to close the front with the usual board, both to prevent the captive struggling to escape, and the others from noticing it has been made a prisoner.

Movable pens are preferable to permanent ones, for they can be constantly pushed on to fresh ground. When permanent a pen should be eight feet high, thirty feet wide, and sixty feet long, surrounded by wire netting, and with the top covered over with tarred netting to prevent the birds from hurting themselves if they should chance to fly up against it. Boarding may be placed round the bottom of the wire netting, of such a height that a dog or fox standing on its hind legs cannot see over it; for if the birds are subjected to this annoyance it takes some time before they get over their fright and settle down again. Small fir trees or low shrubs planted inside are very desirable, for pheasants are fond of sitting in them on fine days to enjoy the sun. A little roof of boards should be erected so that the pheasants may have a dry place to dust in during wet weather; and some fir branches are required, inclined against 


\section{PHEASANT REARING}

the corners, so that the hens can get behind and lay their egis in fancied concealment. It is very conducive to the bad habit of eating the eggs if there is no place for laying, and the eggs are dropped all over the enclosure. If this should occur it is important to find out at once which hen is guilty, and to remove her to a separate pen, lest she should teach the others to adopt the same habit. Sometimes it is difficult to discover the culprit, and some assistance in doing so may be found by doctoring an egg with a little washing-blue, some of which may dye the feathers adjoining the beak if she indulges in this vagary. After she is removed an attempt to cure her may be made by inserting something obnoxious in an egg, such as paraffin; but it must be remembered that remedies like mustard and cayenne pepper which might deter a barn-door fowl, may, on the contrary, be looked upon rather as delicacies by a pheasant! Another plan is to soak an egg in a strong solution of caustic soda, and let it get thoroughly dry before leaving it in the way of the offending hen, while yet another remedy is to leave artificial eggs about for some time previous to eggs being laid, so that the hens may make the attempt to eat them if they so wish, and, being foiled, will be deterred from attacking the real eggs when they appear.

If pheasants have been caught up very late they will be extremely wild, and will be continually flying up against the roof unless their wings are cut, but the manner in which this is done depends upon what is intended to be done with the hens after they have finished laying. If the intention is to turn them out before they have quite finished laying, to give them a chance of hatching a few eggs for themselves, it is better to cut away only the broad web of three or four of the large wing-feathers, which will prevent the birds from rising to a height in the air, but still enable them to fly sufficiently to get out of the way of a dog or fox. This method also does not prevent the hen from brooding small chicks, which the total loss of these feathers will do. Protection is also retained for important internal organs, by the closing of the quills when folded with the narrow outside part of the web still adhering; and this is further enhanced if the first two feathers are left untouched, and also a tip to each feather of about an inch of the broad web. Only one wing should be thus treated, as this causes the bird to be lop-sided, a further hindrance to effective flight.

But if it is purposed to retain the hens until the full clutch is laid, the wing may be cut in the usual manner, if preferred; and then the stumps had better be pulled out, which can be done without difficulty, as soon 


\section{THE GUN AT HOME AND ABROAD}

as all the eggs have been laid, when the new feathers will begin to grow at once, and in about three weeks' time will be sufficiently developed to make it safe to turn the bird out at large.

With fixed pens a little lime should be scattered over the ground as soon as the hens are gone, and the ground should then be dug over. After this is completed a few spadefuls of fresh earth may be scattered over, bringing in fresh insect life, for the former supply will be quite exhausted, and then some hay-seeds should be thrown broadcast over the surface of the soil. Unless abnormally droughty weather should set in, the young grass will have made a good growth before the autumn is far advanced. A further supply of insect food can be assured for the hens when they are again established in the pens, if a small heap of partially decayed manure is made in one corner and renewed from time to time, when the pheasants will usefully employ some of their time in searching out the tit-bits it contains.

Feeding.-For laying-hens in the pens there is no better egg-producing mixture than grain just sprouted sufficiently to show a little white rootlet protruding. To make it, the grain-wheat or barley-should be placed in the copper as soon as the water has become just hot enough to be unbearable to the hand, in fact, just above blood heat. The fire should be raked out, the grain allowed to remain in the copper twenty-four hours, and then taken out and placed in a box for two days. By that time it will have sprouted sufficiently, but it must be used without delay, as it will not keep good for more than a day or two, and it is therefore necessary to prepare only enough for present need, and to keep continually making a fresh supply.

The morning meal for the hens may consist of powdered biscuit soaked in water until it swells, then made dry with barley meal, and afterwards mixed with sprouted grain in the proportion of one-third. The evening meal may consist of the sprouted grain alone. If the hens should show any signs of scour a little Epsom salts mixed in the food is the best remedy which can be employed.

A supply of grit must never be forgotten, and though fairly large pieces are of use, it is the very small ones, indeed some almost as fine as sand, which are most beneficial, and of these there should be a plentiful supply for daily use. All birds seem to prefer quartz, but flint and road scrapings are also eagerly swallowed.

The water supply needs careful attention and frequent renewal, for, 126 


\section{PHEASANT REARING}

if contaminated, it may easily disseminate internal parasites and other diseases. There are various patterns of self-filling water-troughs on the market, between whose merits there is little to choose, the essential points being that whatever the form of reservoir it should be so covered in as to be completely germ-proof, the drinking vessels attached being so constructed that little water is contained in them at a time, needing constant replenishment, whilst the trough is so narrow that the chance of its being fouled by the birds themselves is reduced to a minimum. Another point is that if the heat of the soil beneath the vessel is prevented from ascending there will be greater condensation of moisture at night, and less evaporation in the daytime, and even when the surrounding atmosphere on a clear night may be above freezing point, in the vessel itself the water may show a film of ice. This is effected by excavating not less than two feet of soil, then laying six inches of puddled clay at the bottom, and over this straw to the depth of quite a foot. Another layer of clay should be placed over the straw to keep out the wet, and prevent it from rotting, and a broad flag-stone should be laid on the top of the clay, to make a platform for the water-fountain. It may be observed on a winter's night how the moisture on a flagged footpath begins to freeze earlier than the puddles in the adjoining soil, demonstrating the faculty of the stone for inducing cold under favourable circumstances.

Rearing. - When the eggs have come from some distance, and had a railway journey, there is some displacement of the yolk, and to allow this to become settled it is advisable to place them on end for two days, reversing them at the end of the first twenty-four hours, before putting them under a hen. Pheasants begin to lay about April 15. The nesting boxes should be placed on the ground if possible, and should never be in more than a single tier. If the hens are set in coops they should be sheltered from the sun. When set in a house a thick sod of earth should be placed at the bottom of each box, not too dry but slightly damp, with the grass clipped closely down. An excellent method is to lay the sod with the grass downwards, and then scoop out a hollow from the back nearly half way through, not quite the full size of the nest. The sod should then be reversed, and placed in position, and the grass side should be pressed down with the closed fist, making a very natural hollow for the eggs to rest in, the tendency then being for the eggs to keep rolling inwards. Before placing the eggs in the nest a light covering of wheat chaff, a good handful will do, should be 


\section{THE GUN AT HOME AND ABROAD}

put all over the sod, the chief reason being that it is not desirable for the egis to touch each other, for the feet of the hen must go between the eggis, and the chaff keeps the latter just sufficiently apart, working its way in between the eggs, and thus lessening the risk of breakage. Keating's insect powder should be well dusted amongst the chaff, and this should be done twice or thrice during the period the hen is sitting. Some powder should also be dusted amongst her feathers before she is first placed on the nest, for to the irritation caused by vermin is often due an unwillingness to sit. All eggs should have the date of commencing to sit marked in pencil upon them, and then, if an incubator is at hand, it is a good plan to take the eggs from the hen about three days before hatching, and, substituting others instead, put them into the incubator to hatch out, so that there is no danger of the hen treading on the chicks as they leave the shell. Birds can be afterwards given to the hen when twenty-four hours old, a few at a time, and withdrawing a similar amount of eggs, and as some hens do not take kindly to the little strangers if they see them put through the bars of the coop, the latter should be slipped in behind, when they can nestle under the hen unobserved, the back of the coop being slightly lifted up for the purpose.

A frequent cause of chicks being unable to extricate themselves from the shell is too much damp, for a dry shell and inner membrane are more brittle than when moist. In the natural state the nest gets gradually drier as the hatching point is approached, for, as every one knows, the hen then sits very close, and no rain can penetrate beneath her body; while the natural moisture of the ground underneath has by that time been evaporated. If the chick is twenty-four hours overdue something must be done at once. If it can be heard tapping, and the exact spot is located, the sheil may be broken at that point, and also the membrane carefully pierced, and then, if it has not been done too late, the chick will speedily do the rest, and find its way out. It is a great mistake to give too many chicks to a hen, for though she may appear at first to brood twenty with ease, they soon grow to double the size, and yet require to be covered by the hen for warmth. Those on the outside may easily get a fatal chill. By the time the birds are four or five weeks old so large a brood will sadly overcrowd a coop when shut up for the night, the temperature will get too high, and the air become excessively foul.

Coops.-These should invariably be made of some sort of pine-wood, and the more freely it is impregnated with turpentine the better, for this is an 128 


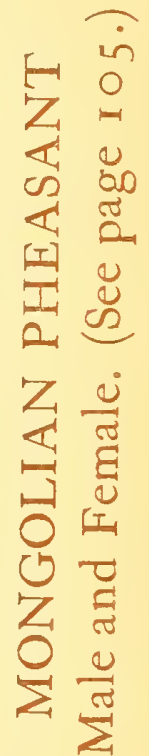




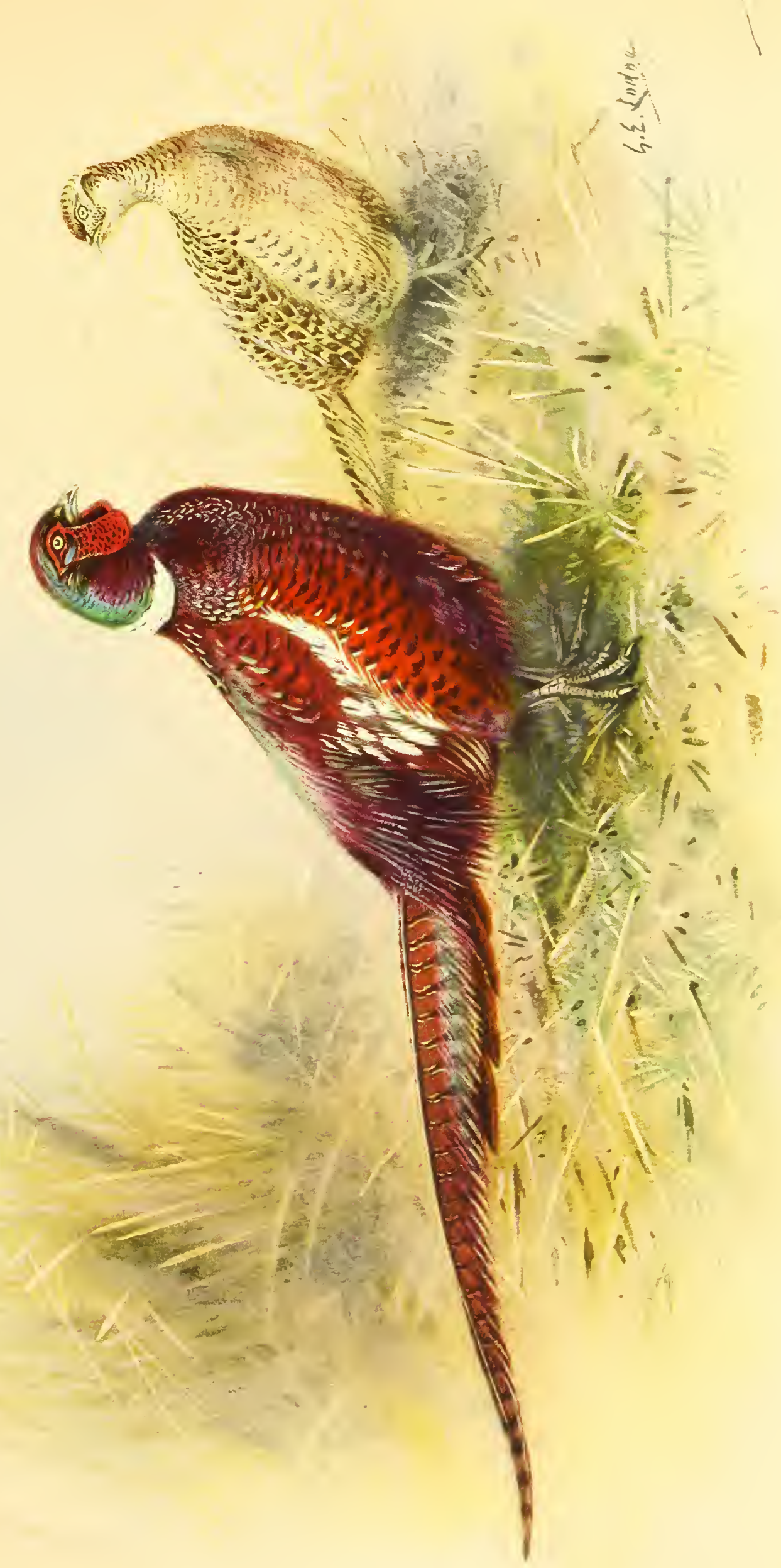





\section{PHEASANT REARING}

excellent disinfectant, and is not popular with fleas or other insects! They should have a peaked roof, high enough for the tallest hen to stand upright under with ease, and the sides should be well sloped, so that while the hen can move backwards and forwards in the centre, she cannot approach the sides without difficulty, and then there is ample room for the chicks without fear of their being trodden upon. Each corner should have a small board nailed across, so that a tiny chick will not be tempted to creep into it instead of nestling under the hen, and thus get a fatal chill.

When young birds have to be sent away to a distance they travel best if packed as soon as hatched and sent off at once to their destination, for they require no food for the first twenty-four hours. All that has to be done is to provide against cold, and have food and warmth ready for them upon arrival. Light cardboard boxes to hold two dozen, and one dozen, are made on purpose for this trade, the former being eleven inches by eleven inches, and the latter eleven inches by five and a half inches, and five and a half inches high, with holes for ventilation. Hay is packed round the sides to make it warm and cosy for the chicks, and inside is placed a quantity of chaff. The distances the chicks can thus travel in safety is surprising, and the writer has seen such boxes at York Station on their way to the South of Ireland.

Food for chicks.-There is nothing better for young pheasants at first than Gilbertson and Page's British meal, with a very little hard-boiled egg, chopped onion tops, and well-boiled rice. Very many young pheasants die every year from overfeeding, and one of the principal causes is giving them egg three or four times a day. They are sure to cram themselves with it and overload their digestion, when fermentation sets in, and then diarrhoa, and finally death ensues. During the third week meat should be added to the diet, such as boiled rabbit, or best greaves. This latter requires all the fat which is possible to be extracted, and this is done by placing the tallow crap in a bucket, pouring boiling water over it, and leaving it for about a quarter of an hour, with a cloth placed over the vessel to keep in the heat. While still hot, and before the melted fat has had time to consolidate again, the mass should be lifted out and placed on a fine sieve to drain, a little cold water being poured over to cool it as quickly as possible. When given to the birds, the meat should be mixed with good barley meal. Green food from the very first is most essential to the chicks, and in a state of Nature the old hen picks off little pieces from the blades of grass, which they eagerly eat, and which keeps them from becoming 
THE GUN AT HOME AND ABROAD

thirsty. Until the birds are old enough to help themselves they should be supplied with similar food, when that pest of the rearer, green scour, will seldom make its appearance. This is not usually seen until the birds are several days old, and the common cause of the ailment is too small a supply of green food from the very first, and when the birds are sufficiently advanced to pick it for themselves, they eat such an inordinate quantity, being unaccustomed to it, but craving for it, that they suffer in consequence. Sound small grain should also be frequently supplied, and plenty of grit, but at first they are better without water, and this should not be given to them until they are three weeks old. If the weather should be very hot, and the chicks appear to be drooping, a little water may be thrown in a spray on to the grass with a syringe, when the birds will pick the drops off the foliage. If they do not get water when they require it, they will be extra keen to swallow "cuckoo spit" in a dry time, and if the spittle insect gets alive into a young bird's crop, and remains there exuding the "spittle," fatal consequences follow only too often. The best preventative is to add chopped up green food to the meal when mixing it, and to supply drinking fountains on the rearing field when the birds are sufficiently old.

The value of bone meal, made from fresh unboiled bones, is not univer sally recognized, but in the form of finest flour it is easily added to meal, and is assimilated by the youngest chicks. New milk also is very desirable, when it can be obtained cheaply, and can be used for mixing the meal, when it takes the place of custard or curd. If a brood begins to fall off, and is ceasing to progress, one of the best of pick-me-ups is to mix a feed or two with a little fresh blood, obtained from the nearest butcher's shop. During the second week of their lives little chicks may require a stimulant, especially if the weather is wet and cold, and many a life may be saved by the addition of the following mixture to the feed at night, when a stimulant appears desirable :

$$
\begin{array}{ll}
\text { Gallengall, } 1 \mathrm{lb} ; & \text { Cayenne, } \frac{1}{4} \text { oz. ; } \\
\text { Cinnamon, } \frac{1}{2} \mathrm{lb} ; & \text { Powdered ginger, } \frac{1}{2} \mathrm{oz} .
\end{array}
$$

A tablespoonful of the mixture should be added for every twenty birds. At any time if a bird looks sickly a little of the powder mixed with a pellet of oatmeal, and put down its throat, will very likely revive it.

If it is necessary to place a coop with newly-hatched chicks upon damp ground, a dry sack should be folded and placed under the hen. This can easily be washed afterwards, and a number of sacks should always be on 


\section{PHEASANT REARING}

hand. Coker mats are also sold for the same purpose, for which they are well fitted; while dry boards are also very useful when the chicks get a little older, and a little sand dusted over them greatly assists the keeping of them clean.

If the weather is both wet and cold a warm bed will revive many a chick, and is easily contrived by making a hole in the ground and putting a hot half-brick into it, with a dry sod over it, and the sack on the top.

The coops should always be disinfected immediately after the rearing season is over, before they are stacked away for the winter, and if a large wooden tub is procured which will hold four coops at a time, the work can be rapidly completed. Pure chloride of lime should be put into the water, and the coops dipped into the solution. It is a good plan to have the field intended for rearing grazed closely by stock during the autumn, but allowed to grow a few inches in the spring, before the coops are placed there, and then to cut narrow rides the width of the coops. The latter should be kept a considerable distance apart, at least fifty yards, to allow for shifting the coops constantly on to fresh ground, for excepting in very wet weather, they should not be allowed to occupy the same spot more than two days. To move them daily a yard or two is preferable. It is well to shift the coops towards the evening, so that the birds have the advantage of sweet ground for the night. The rides will require frequent re-cutting as the grass grows, while the long grass on each side provides shelter for the little chicks, and also plenty of insect food. A long furrow turned over with the plough is an excellent plan, down one side of each ride, for the furrow acts as a drain, and the sod soon dries after rain, which the chicks are quick to detect, and avail themselves of, for sitting upon. Some shelter should be provided also for the birds to run to if a hawk is about, and fir branches with their butts fixed in the ground outside a circle, with the tops inwards, make an excellent retreat. If the branches of beeches are cut during the previous autumn, when the leaf is still well on, they answer even better than fir, for the spindles of the latter gradually drop off, whilst the beech leaves will remain on the whole rearing season.

Vermin.-Previous to the coops being placed on the field all four-footed vermin should be closely trapped, including moles, for their runs are frequently used by weasels, which thus gain unsuspected access to the middle of the rearing ground. The barn owl, as proved by the castings, seldom takes pheasant chicks, and the same with kestrels, though occasionally an individual develops a taste in this direction, when it should be at 
once destroyed, for, like a man-eating tiger, the appetite grows with the indulgence of it. The brown owl is more mischievous, and so is the little owl, but the greatest pest of all are jackdaws, and these take a heavy toll unless precautions are taken in localities where they exist in numbers. Foxes need to be carefully guarded against or they may commit great havoc in a single night, and sometimes it is necessary to erect netting all round the field of such a height that they cannot jump over. Generally it is sufficient to provide a continual supply of rooks, or rabbits, in the vicinity of the earth if there is a litter of young cubs ; while two or more lamps should be lighted at night at either end of the rearing field, and an alarm gun be set with the wire close enough to the ground for a fox to run against it. "Renardine," and oil of tar are also useful for scaring foxes, though they will get accustomed to anything of the kind after a time. An excellent method is to run a long wire the whole length of the field, and attach a dog to it by a chain, so that it can travel up and down it, a barrel being placed somewhere along the line to serve for a kennel.

Young pheasants should be removed to the coverts as soon as they are old enough to perch, and when all have been shifted, it is well to purify the field from all taint by the use of fire if, as is often the case, it is unavoidably necessary to use the same field the following season. A rough day should be selected, when the wind will sweep the fire along quickly, so that the roots of the grasses do not get burned, and then the herbage has a chance of starting before the coming winter. The sooner, therefore, the burning is carried out the better.

When in the coverts pheasants require to be generously fed to keep them at home, but even then they stray considerably, especially in a year when acorns and beech-mast are very plentiful, and they require to be constantly checked and headed back. Indian corn and barley are the staple foods; the latter causes the flesh to be more delicate, and more highly appreciated when the birds come to table. All corn is more appetizing and nourishing if boiled, and if a pound of cheap treacle is put in the copper with the grain, it makes a very attractive mixture. When the grain has been cooked it should be allowed to cool in its own liquor, which it will largely absorb, and then not a drop will be wasted. Pheasants are fond also of raisins, the seeds of the sunflower, and especially of Jerusalem artichoke roots, in all of which they may be indulged; but perhaps the best " non-straying mixture" is the sprouted corn, which has been already described. When using it in the coverts an excellent plan is to scatter 132 


\section{PHEASANT REARING}

some of the grain on the top of the rotten straw at the bottom of the straw stacks - of which there should be one or two in each covert-and then turn all over with a fork, burying the grain lightly beneath the straw. The pheasants will then spend much time, and find much occupation, in scratching for the hidden grain, instead of wandering about the fields. Self-acting feeders are often of use, particularly in places which cannot be visited conveniently every day, as a hungry bird can thus obtain a meal when the scattered grain has been all picked up. If pheasants should attack newly-sown corn sprouting in the fields, a sure way of checking them is to soak similar grain in a decoction of quassia, and scatter it thinly over the top of the ground which they are frequenting. They dislike the taste so much they will very soon cease to trouble that field, and in a few days the young plants will have passed the attractive stage for the pheasants.

R. F. MEYSEY-THOMPSON. 


\section{PHEASANT SHOOTING}

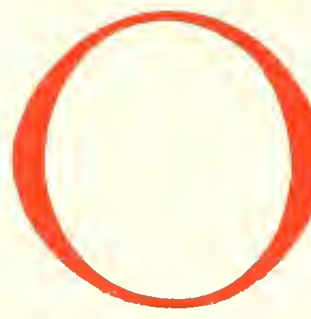

$N$ the day of shooting a covert, stops should be placed very early in the morning on the outsides, for when it promises to be fine the birds, especially the cocks, very quickly set off wandering in search of food. The stops should not be far away from the covert, about 100 yards, and when the covert is being beaten they should be drawn in still closer, unless they are at the very end, for if the game once comes out of the wood it will very likely make a dash for safety, in spite of the stops. If, however, their attention is drawn to the stops before they have stepped into the open, they will be chary about showing themselves outside. The stops at the end of the covert, however, if no guns are placed there, should be about 100 yards away, and then any pheasants flying forward will probably stay their flight, and drop into the wood; whereas if they are over the men before they notice them they will be alarmed, and flying on may not be seen again. Pheasants driven out of one covert and fleeing to another will not stay there, unless it is well stopped, if the wood is a small one, but will run right through it, perhaps for a mile, before they think they are safe. If pheasants have to be driven back to the covert they have just left, it is well to leave them quiet for an hour or more, or a number are sure to break out in any direction rather than return to where they think there is danger. Hedges leading from a wood, or broken ground where a pheasant can run unseen, must always be carefully guarded; though if these lie between two coverts, and there is only a limited number of stops available, the birds may be allowed to make use of their legs, and to run forward into the other wood.

The ends of coverts should not be bare, or the birds, when they run forward, will note the guns placed there, and will then break back rather than come out. If there is no under-covert some strong thorn branches, or beach boughs with withered leaves on, should be firmly implanted in the soil a little distance from the end, and if this is done at the end of March the herbage will spring up and interlace with the branches during the summer, and having their support, does not get beaten flat if snow should fall, making excellent covert for the birds. The branches should be placed in blocks several yards square, with lanes between for the beaters to walk along. Each spring the rotten stuff should be removed and burned, and fresh branches put in its place. To prevent too large a number of pheasants congregating together, and getting up en masse, it is well worth trying 134 


\section{PHEASANT SHOOTING}

the following plan. A length of small-meshed wire netting should be run across the wood, about a hundred yards from the end, and inclined outwards at an acute angle, so that if three-feet netting is used, the topmost edge is about two feet six inches from the ground. The pheasants jump upon it, and finding their footing insecure at once take wing, and thus come forward in constant succession. The netting must be strong, and secured with stout posts, or the whole may collapse with the weight of the birds. If the country is very flat, pheasants may be made to rise to a good height by placing a few stops at the end of the covert, about twenty yards from it, and putting the guns a hundred yards or more behind them, The birds will then rise to clear the first rank, and keep on rising when they see the second row behind it. An ingenious plan for outwitting pheasants the writer used frequently to see carried out successfully in a hill-country, is as follows: Long coverts clothed some hill-sides for miles, occupying the steep ground between where it was possible to cultivate the fields, and the top, which was flat table-land, under cultivation. There was a fair sprinkling of wild pheasants, and the mode of coping with them was to send forward half the beaters about a quarter or half a mile ahead, with orders to station themselves across the wood and to keep on tapping loudly. The other beaters, with the guns interspersed between them (except that there was one outside the wood at the top and bottom), then advanced and beat about half the distance, the pheasants scuttling on ahead-excepting a few which occasionally rose. Then as open a spot as could be found was selected, and the guns remained there, while the beaters who were with them advanced about fifty yards further into the wood, remaining there, and tapping gently. A signal was then given by one of the guns on the outside, when the stops who had been sent on became beaters in turn, and beat back towards the guns. The pheasants thus found themselves being driven back between two lines, and, true to their nature to return home, rose into the air when they came near the new set of stops, and flying over the trees, gave excellent shots to the guns stationed behind. After this beat was finished the party proceeded outside the wood to where the first stops had been placed, and the whole process was again gone through, over the next portion of the wood. In this way an average of about eighty pheasants a day was obtained, besides a good many rabbits and some woodcocks.

It is very annoying when a fox is present in a wood which is being beaten, where there are a number of pheasants, for as it moves about it scatters 


\section{THE GUN AT HOME AND ABROAD}

them in every direction, and until it has left the covert no amount of management on the part of the keeper can control the pheasants, and make them go in the desired direction. The peculiar call of the cock pheasants in such circumstances soon betrays what is up. It is quite easy, however, to arrange that no fox shall be there when shooting is in progress, if a little trouble is taken in the matter. A number of pegs should be driven into the ground at intervals along the sides of the main covert, each topped with a piece of rag, and the previous evening the keeper should proceed along the line of pegs, and sprinkle all the rags with either "renardine" or oil of tar, when no fox will venture there that night. If "renardine" has been used for stopping out the rabbits, then oil of tar should be put on the rags, and vice versa. After the shooting is finished the sticks and rags should be collected the same evening. The odour will quickly disappear, and foxes will be in the covert again the next day.

The morning after a shoot, all fences and fields should be early driven inwards towards the coverts, for many birds may have passed the night there, and hand-reared ones may be inclined to wander off the estate. The feed in the coverts should be thrown down at daybreak, for the returned birds will be very hungry, and will soon wander if they do not find it at the accustomed place; an extra quantity therefore should be given.

It should ever be borne in mind that an essential detail of a day's shooting, contributing in a great measure to its success, is a due consideration of the respective skill of the shooters. If where the tallest birds are sure to come, a gun is placed who is only equal to birds flying at the height of a low tree, while one who can "fetch them out of the skies" is put where the other ought to be, the organizer of the day can only blame himself if the results are disappointing.

R. F. MEYSEY-THOMPSON. 


\title{
COMMON PARTRIDGE
}

\author{
PERDIX PERDIX \\ (Plates XVI-XVIII)
}

Tetrao perdix, Linn., Syst. Nat., 1, p. 276 (1766).

Perdix cinerea, Latham, et auctorum plurimorum; Gould, Birds Europe, iv, pl. 262 (1837); Dresser, Birds Europe, vii, p. 131, pls. 474 and 475 (1878) ; Saunders, ed. Yarrell Brit. Birds, iii, p. 105 (1882) ; Seebohm, Hist. Brit. Birds, ii, p. 452 (1884); Lilford, Col. Fig. Brit. Birds, pt. ix (1891); Macpherson, in " Fur, Feather and Fin Series," Partridge (1893) ; Saunders, Ill. Man. Brit. Birds, p. 501 (1899).

Walsingham \& Payne-Gallwey, in "Badminton Library," Field and Covert, Partridge, p. 139 (1886); Harting, Handbook Brit. Birds, p. 146 (1901).

Perdix robusta, Homeyer \& Tancré, Mitth, Orn. ver. Wien., vii, p. 92 (1883); ix, pl. figs. 3-5 (1885). [Altai Mts.]

Perdix perdix, Ogilvie-Grant, "Field," Nov. 21, 1891, and April 9, 1892; id., Ann. Mag. N. H. (6), xii, p. 62 (1893) ; id., Cat. B. Brit. Mus., xxii, p. 185 (1893); id., Handbook Game Birds, i, p. 143, pl. xii (1895); Millais, Nat. Hist. Brit. Game Birds, p. 111, 5 pls. (1909); Ogilvie-Grant, Bull. Brit. Orn. Cl. xxix, p. 41 (1911); id., Witherby's Brit. Birds, v, p. 234, pls. (1912).

\section{DULT male. (September to June).-General colour above, brownish-buff (washed with grey in birds from North- ern Europe), with narrow, close-set, wavy cross-bars and lines of black. Lesser and median wing-coverts and scapulars blotched on the inner web with chestnut, and with a longitudinal buff shaft-stripe only (fig. 2).}

Top of the head brown, with a few narrow buff shaft-stripes; rest of the head, throat and fore-neck bright rust-red; breast and sides pale grey, finely mottled with black, and barred on the sides and flanks with chestnut; a large horse-shoe-shaped chestnut patch on the lower part of the breast;* rest of the underparts whitish. First flight-feather with the extremity rounded (fig. 4). The scaling on the feet pale horn-grey. (Plate XVI.)

Total length 12.6 inches; wing 6.2 inches; tail 3.5 inches; tarsus $1 \cdot 7$ inch.

In May the plumage of the cock bird becomes much faded and worn, the feathers on the upperparts of the body becoming quite grey from wear and exposure; all the rich brown tints of the mantle, back, etc., disappear, and the wings are much paler, the conspicuous shaft-streaks becoming nearly white. At this season male examples from the British Isles are greyer than the greyest examples from North Russia killed in autumn and winter, an interesting point which I have recently recorded.

\footnotetext{
* The chestnut horse-shoe mark on the breast is never entirely absent in the cock, but is sometimes reduced to a few chestnut spots. The variety with a white horse-shoe, that is to say with an entire absence of chestnut on the breast-feathers, is often met with among hen birds. 


\section{THE GUN AT HOME AND ABROAD \\ COMMON PARTRIDGE (Perdix perdix)}

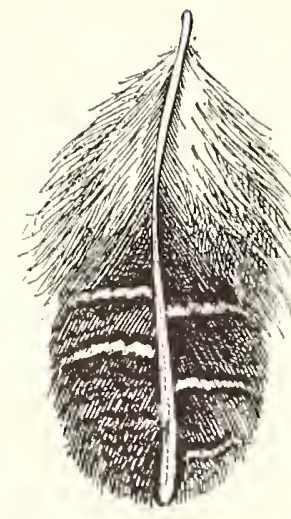

Fig. la.

Covert from wing of female.

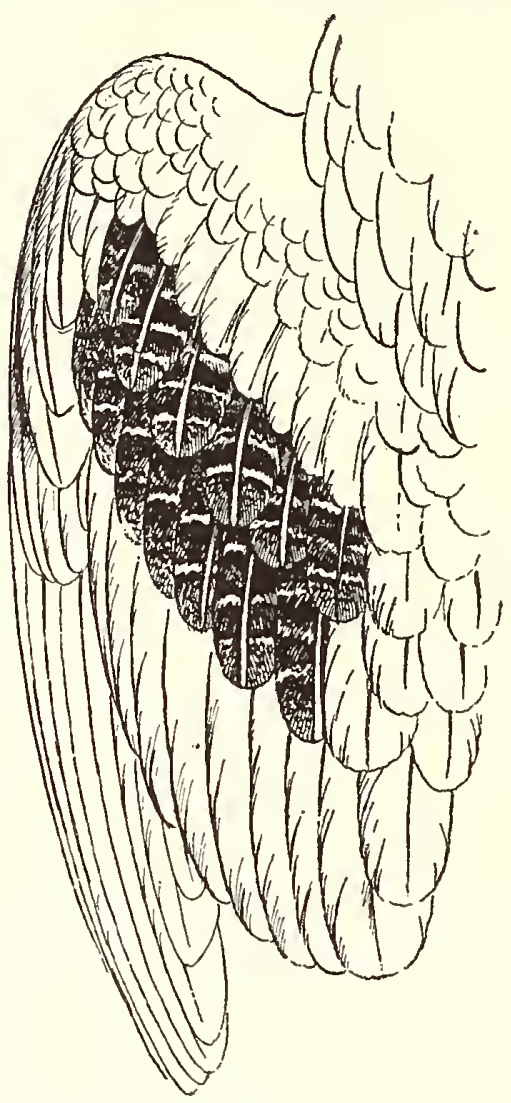

Fig. 1.

Wing of female Partridge, showing barred wing-coverts. s natural size.
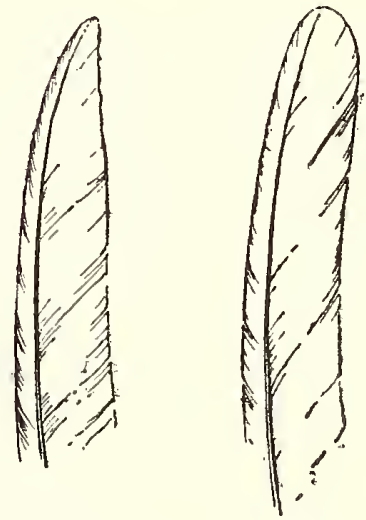

Fig. 4.

Fig. 3.

Fig. 3, First fight-feather of bird of the year showing pointed extremity. Fig. 4. First flight-feather of old bird showing rounded extremity.

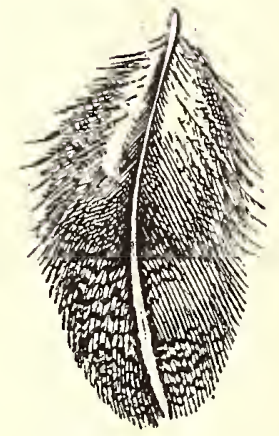

Fig. 2.

Covert from wing of male. 


\section{GOMMON PARTRIDGE}

Adult male. (June to September).-During the autumn-moult, the adult male assumes a partial "eclipse" plumage on the sides of the head and on the neck. The crown of the head is clad in brown feathers with scarcely a trace of pale shaft-streaks; the neck is similarly clad, but each feather has a pale buff shaft-streak, narrowly bordered with black, a plumage which closely resembles that of the female, and more remotely that of the immature bird. The forehead, eyebrow-stripes, chin and throat become so bleached that they are very pale rufous, instead of bright rust-red. (Plate XIII, fig. 4.)

This curious partial eclipse-plumage was first observed and commented on by Mr G. E. Lodge, and has recently been described by me for the first time. It frequently happens that adult male birds shot in early September, and still retaining many feathers of the "eclipse" plumage on the sides of the neck, are mistaken for very "forward" young birds of the year; but an examination of the first flight-feather will afford conclusive evidence on this point.

In old birds this feather is rounded at the extremity (fig. 4); while in birds of the previous year, still carrying the pointed quill of the first plumage, the feather is so worn and faded that it cannot be mistaken for that of a young bird.

Adult female.-Easily distinguished from the male by having the crown of the head, and back and sides of the neck, brown, with distinct buff shaftstreaks; the ground-colour of the lesser and median wing-coverts and scapulars mostly black, with wide-set, somewhat wavy, buff cross-bars, in addition to the longitudinal buff shaft-stripe down the middle of each feather (figs. 1 and 1a); and the chestnut patch on the lower part of the breast smaller, or sometimes absent. Birds of the latter type are generally described as having a white horse-shoe on the breast. (Plate XVI.)

In May the hen bird assumes a partial breeding-plumage on the sides of the head and on the neck and upper mantle, many of the feathers being replaced by black and buff feathers, with a buff shaft-streak and buff subterminal spot, which in some cases forms an irregular necklet. This change produces a much more mottled appearance on the head and neck and is doubtless protective. These spotted feathers are retained till September, and are often plainly visible in old females shot in the early part of that month. This interesting point was unknown until recently when I recorded it for the first time. (Plate XIII, fig. 6.)

Hen birds which have become sterile from old age or from accident 


\section{THE GUN AT HOME AND ABROAD}

(generally caused by a pellet of shot injuring the ovary), are occasionally met with in partial male plumage. These birds are usually characterized by having a very large horse-shoe-shaped patch of chestnut on the breast, as much developed as in the adult male; and by the wingcoverts, which are barred with buff on one web only, the other being uniform and blotched with chestnut, as in the male.

Young in first-autumn plumage.-By October the young birds of both sexes resemble the adults, but may always be recognized by having the first primary flight-feather pointed (fig. 3); this quill being carried till the moult in the following autumn. The scaling of the feet is yellowish or brownish-horn colour till about the month of January, when it becomes bluish-grey, as in the old birds. In young females the chestnut patch on the breast is often well developed, and sometimes nearly as large as in the adult male.

Young in first plumage. - The whole of the upperparts, as well as the chest and breast, are brownish-buff, and each feather of the mantle, chest and breast has a pale buff or whitish black-edged shaft-stripe. The wing-coverts and scapulars are black, with buff cross-bars and shaft-stripe, very similar to those of the adult female. (Plate XVII.)

The adult plumage first appears on the sides of the chest and breast, and on the flanks, rump, and upper tail-coverts; at the same time the feathers of the tail, inner primary, and secondary quills, and the lesser and median wing-coverts are renewed. It is therefore easy, at a comparatively early period, to distinguish, even in "squeakers," the young males and females by the markings on the wing-coverts.

Young in doren have the top of the head reddish-brown, mottled with black, the upper parts of the body similar, but mixed with buff, and with three more or less distinct longitudinal black streaks, one on the nape, and one on either side of the spine, the sides of the head and neck buff, spotted and streaked with black, and the underparts pale yellowish-white. (Plate XVII.)

Variations in colour.-These may be divided into three types. (Plate XVIII):

A. The chestnut variety. Known as the Mountain-Partridge (Perdix montana, Brisson). In the most typical examples of erythrism the entire head and neck are bright rufous-buff, and the rest of the plumage rich chestnut, some of the feathers of the upperparts, especially of the wing coverts, being usually more or less vermiculated with pale grey or yellowish-white and black. The quills are washed with the same chestnut 140 


\section{COMMON PARTRIDGE}

tint. In this form the sexes cannot be distinguished by the plumage of the wing-coverts, for the characteristic markings are absent.

All intermediate stages can be found between the most typical chestnut forms and normal examples.

This marked variety, first described from the mountains of Lorraine, has been procured in almost every county in England, and also in Scotland. It was described as the "Cheshire Partridge" by Latham so long ago as 1823.

B. The grey variety. In this form the forehead, eyebrow stripes, chin and throat are whitish, washed with very pale rufous, and the general colour of the rest of the plumage is clear grey, vermiculated with black. The horse-shoe patch on the breast is pale greyish-brown, or pale faded chestnut-colour.

C. Pale varieties and albinos. These vary greatly in colour. Some are tawny white, and have the forehead, eyebrow-stripes, chin and throat of the normal rust-red colour, and a deep chestnut horse-shoe-shaped patch on the breast ; the back, rump, upper tail-coverts and flanks barred with chestnut, and the wing-coverts and scapulars blotched with the same colour. Others are nearly pure white, with faintly indicated dusky vermiculations all over the plumage, and white shaft-stripes on the wingcoverts and scapulars. In the grey and white varieties ( $B$ and $C$ ), the characteristic sexual markings of the wing-coverts can generally be distinguished quite clearly.

Between these three principal types of variation many curiously marked intermediate varieties may be found, generally among birds of the year. This is probably due to the fact that birds exhibiting any marked peculiarity in the colour of their plumage are generally singled out and shot. Only once have I examined an example showing traces of melanism. This singular variety, an immature female, which was shot by $\mathrm{Mr}$ W. Fitzherbert Brockholes, in Lancashire, is now on exhibition in the Bird Gallery at the Natural History Museum. It has a considerable amount of black beneath and round the eyes, and the markings on the wing-coverts are abnormally coarse.

Birds with the horse-shoe mark on the breast of a very dark blackishchestnut colour are occasionally met with. Mr Digby has recorded in the "Field" of February 7, 1891, two dark varieties, one of which had the head, neck and breast tinged with sooty black.

Distribution.-The range of the common partridge (often known as the grey 
THE GUN AT HOME AND ABROAD

partridge includes Europe and Western and Central Asia; extending in the west to Scandinavia and the British Isles, in the east to the Barabinska Steppes, Tian Shan and the Altai Mountains, and in the south to Northern Spain and Portugal, Italy as far as Naples, the Caucasus, Asia Minor and Northern Persia. In the more southern parts of its range it inhabits, as a rule, the higher and more mountainous districts, being met with up to about 4,000 feet, while above that elevation a slightly different race is met with, of which we shall speak presently.

Allied species.-Further east its place is taken by the bearded partridge (Perdix daurica), which ranges from Central Asia, to Amurland, Manchuria, and the sources of the Yangtze-kiang. The bearded partridge is easily recognized by the elongate feathers on the sides of the throat, which form a beard, and by the buff-coloured breast and black horse-shoeshaped patch. Other allied species are Prjevalsky's partridge ( $P$. sifanica), from Northern Tibet and Western China, and Mrs Hodgson's partridge ( $P$. hodgsonia), which inhabits the highlands of Southern Tibet, and extends into Northern India. The two last named are both Alpine species, met with at elevations ranging from 10,000 to 19,000 feet, and are readily distinguished by having the breast white, barred with black; $P$. hodgsonice has also a black patch on the breast, which is wanting in $P$. sifanica.

It is not surprising to find that a species so widely distributed as the common partridge has received more than one specific name in different parts of its range, apart from the numerous names which have been bestowed on mere individual variations. Altum has named the birds from North Holland (Eastern Friesland), $P$. sphagnetorum; those from Scandinavia, $P$. scanica; and those from East Prussia, $P$. lucida; but his reasons for doing so are not apparent.

Examples from Northern Spain have been separated as Perdix charrela by Seoane, and as $P$. hispaniensis by Reichenow; and those from the Altai Mountains, which form the eastern limit of the range of the species, have been described as Perdix robusta by Homeyer and Tancré on account of their supposed larger size. There appears, however, to be no tangible specific difference between examples from Western Europe and those from Asia, if allowance be made for very slight variations caused by individual differences and varied surroundings. A smaller high-ground or Alpine form known as the migratory partridge was distinguished as Perdix damascena by Brisson in 1760. It is perfectly similar in plumage to the common partridge, but somewhat smaller; the feet and toes, and 
apparently also the bill are said to be yellowish in the adult, instead of horn-grey. Large flocks of these so-called migratory partridges visit the plains of Central and Southern Europe during the winter months, and are reported not to associate with birds of the common species. They are probably merely individuals which breed at higher elevations and are driven down in cold weather to the plains and valleys in search of food. Very little, however, has been recorded about this migratory form, and although its existence has been known for more than a century, very few examples are available at the present time for examination. Those which have come under our notice have all been birds of the year, which still retained the pointed first flight-feather. Their feet certainly appear to have been yellowish horn-colour, but that characteristic would be accounted for by their comparative youth. It would be very interesting if some one, with the opportunity of doing so, would shoot and preserve a series of birds of this migratory form, and would carefully record the weight, and the coloration of the bill and feet in each individual.

It is well known that in certain parts of the Grampians, in Scotland, and elsewhere, coveys of partridges which have been bred comparatively high up on the mountains move down to the low ground in winter, while there are also many moorland partridges which never visit the arable lands, but remain on the lower moors and heaths all the year round. It is by no means uncommon to fall in with an isolated covey or two of these birds on the edges of a grouse-moor. Such hill-birds are, as a rule, smaller and more brightly coloured than the low-ground birds and, when handled, seem to be very much lighter in weight than examples from the southern counties of England. When measured, however, the differences in the length of the wing are comparatively trifling, but the average weight of the hill-birds is considerably less.

In the Proceedings of the Fourth International Ornithological Congress 1905 (pp. 494-512), Dr Louis Bureau has published an elaborate account of the somewhat isolated race of partridges inhabiting the higher parts of the mountains of Northern Spain and the Pyrenees (4,000 to 10,000 feet). As already mentioned above, these have been distinguished as Perdix charrela by Seoane, and as $P$. hispaniensis by Reichenow. The male is said to have transverse buff bars on the median wing-coverts, as in the female of the common partridge; and the latter is said to be distinguished by having the upperparts and chest marked with yellowish-white ovate 


\section{THE GUN AT HOME AND ABROAD}

spots; but such markings, as already pointed out, are characteristic of all hen birds in the breeding-season, from May till August or September. Dr Bureau was not aware of this fact when he wrote his paper. Up to the present time comparatively few examples of the so-called $P$.charrela have been examined and, as in the case of the migratory form $P$. damascena mentioned above, a series of well-prepared specimens is required to confirm the differences which are said to be characteristic of the race.

Distribution in the British Isles.-In England the partridge is generally distributed, and it is also abundant in many parts of Scotland. In Ireland its numbers are said to be steadily diminishing, and in some parts it has entirely disappeared.

Food.-The diet of the partridge is very varied, but consists principally of tender shoots and leaves of various weeds and clovers, grass-seeds, grain and berries, as well as beetles and other insects, grubs, ants' pupæ and small molluscs. Birds inhabiting the edges of the moorlands also eat shoots of heather.

Flight.-The flight of the partridge is remarkably strong and swift. It rises with a loud whirring sound, made by the rapid beats of its short rounded wings, and, when clean moulted, is soon under way, and travelling at a great pace. It glides along with outstretched wings, skimming over the hedges and trees, altering its course, and varying its pace, with the greatest ease and quickness. During a long flight, which often covers a mile or more, the pace is maintained by a few rapid wing-beats and intervals of gliding with out-stretched wings. The legs are always fully extended beneath the tail in flight, and are only brought forward when the bird is on the point of settling on the ground.

Breeding habits. - The partridge is strictly monogamous, and in this country generally pairs very early in the year. If the season is open and mild, paired birds may be seen in the south of England towards the end of January, during the last days of the shooting season, and the coveys have all broken up by the end of February or early in March.

It is a distinctly gregarious bird, except during the pairing and nesting season, when fighting takes place, not only between the cocks for the possession of the hens, but also between the latter themselves, and the pairs often unite in driving off other pairs which have encroached too near the site selected for their nest. In early spring the cocks may constantly be seen chasing one another over the ploughed fields and grasslands, sparring, springing up into the air, and striking at one another 
5

in

디 르

01

$=-$

E

$<2$

ค. ญ

7

怘

$\sum_{0}$

0 ت

$\frac{0}{\pi}$ 


\section{GOMMON PARTRIDGE}

with their beaks and wings, in much the same fashion as the red grouse does. The battles are, however, seldom protracted or very serious in their results, for the weaker bird soon retires from the combat. It is a pleasing sight to watch the pairs of birds through a good glass as they move about the nearly bare fields of early wheat, the cocks frequently standing up to utter their well-known call, kir-r-rik as a challenge to rivals. In March the pairs select a suitable nesting-site and, having chosen it, settle down in the immediate neighbourhood. The partridge is, however, by no means an early breeder, and eggs are seldom laid before the end of April or the beginning of May; most of the eggs being hatched in the latter half of June. If the nest is destroyed after incubation has commenced, the partridge seldom nests a second time; but if the hen bird has not begun to sit, a second and smaller clutch of from six to ten eggs is often laid.

Nest.-Except in very rare instances, the nest is placed on the ground, and consists of a slight hollow lined with dry grasses and dead leaves. The site chosen varies very much, but perhaps the most favourite situation for a nest is the bottom of some dense hedgerow, amongst coarse grass and vegetation, in young plantations of spruce-fir and larch, amongst gorse-bushes and broom; often in growing corn, clover, and in grassfields, or amongst heather. Sometimes an exposed situation close to a path is chosen, but the nest is generally so well hidden that it escapes detection. Nests are sometimes found in very curious places, the tops of haystacks, bean-stacks, and other situations at a height from the ground being occasionally resorted to.

Eggs.-The eggs, which are of a pointed oval shape, and pale olive-brown colour, measure about $1 \cdot 4$ inch by $1 \cdot 1$ inch. They are usually from ten to twenty in number, and though as many as thirty-six have been found in one nest, they were no doubt laid by more than one hen.

Incubation lasts from twenty-one to twenty-three days.

General habits.-The female sits very closely on her eggs, and trusting, no doubt, to the protective coloration of her plumage, which harmonizes so well with her surroundings, frequently succeeds in avoiding detection. Like other game-birds the partridge, when sitting on her nest, gives forth no scent; and this power of being voluntarily able to suppress her natural odour usually saves her from her many four-footed enemies. At the same time it should be mentioned that this retention of scent ceases when the eggs are on the point of hatching, and it is then that so many sitting birds are taken off their nests by foxes. 


\section{THE GUN AT HOME AND ABROAD}

The hen partridge is a most excellent mother, and in very wet cold weather, such as too frequently occurs in the British Isles in June, often pays the penalty of her devotion, being found dead on her nest. The cock bird remains in close proximity to the nest, and mounts guard over his sitting mate, driving off any intruder, and showing a bold front to prowling cats and other vermin. When hatched, the young are very carefully tended by both parents, the hen uttering a soft clucking note as she leads her chicks after the cock bird in search of food. On the approach of danger the old birds will attack or lead off their enemy by feigning a broken wing while the young scatter and seek safety by hiding in the nearest covert.

For the first five or six weeks of their lives the young live almost exclusively on insect-food, especially on ants and their pupa.

By the end of September they are usually fully grown, and as the season advances the coveys unite and form packs, which feed and roost together. An open spot in a field is the usual roosting-place, the birds crouching close together on the ground. Some say they all face outwards to guard against a possible attack, others assert that they all face inwards, a most unlikely theory. It seems much more probable that they all face the wind ; for such is the universal custom of all birds.*

The early morning and afternoon are the principal feeding times of the partridge during the summer and autumn months; during the rest of the day the coveys hide themselves in cover, basking on sunny banks, or dust themselves on some convenient sandy spot and preen their feathers. During the winter and spring months they are far more active during the day, and may be seen feeding at all hours.

The average weight of a cock partridge in good condition is about thirteen ounces, and the hen about twelve ounces, but much heavier birds have been noted by Mr G. E. Lodge, who has paid special attention to the matter of weights, and he tells me that cocks of seventeen ounces are not uncommon in north Norfolk, and hens of sixteen ounces, while in one instance a young hen bird of the year, shot in January, weighed seventeen ounces. $\downarrow$

The partridge has many enemies. Stoats, weasels, and rats steal the eggs and kill the young. Hedgehogs also are said to take the eggs, though this has been denied. Foxes, prowling dogs, and cats account for a good

\footnotetext{
*It is evident that they all face outreards, because the droppings are always found in a mass in the centre instead of in a circle round the covey as would otherwise he the case. - Ed.

†This increase in weight was attrihuted by the shooting tenant on the land referred to, the late Mr T. J. Mann, to the fact of his having introduced fresh blood by turning out a number of Hungarian partridges. - Ed.
} 


\section{GOMMON PARTRIDGE}

many birds, and the first named especially have a reprehensible way of taking sitting hens off their nests. Hawks, especially sparrow-hawks, are sometimes troublesome, and carry off a number of the chicks. Rooks, crows, jackdaws and magpies steal numbers of eggs, but the jay is comparatively harmless, and usually confines its attentions to the eggs of passerine birds, such as thrushes and blackbirds.

Diseases.-Partridges suffer from various diseases, but the most common is that known as gapes, a parasitic worm which attacks the windpipe, and frequently causes great mortality among the young birds. Like the young of grouse, pheasants, fowls, etc., they also suffer from the ravages of Coccidiosis, which frequently kills numbers of young birds especially among those reared by hand.

W. R. OGILVIE-GRANT. 


\section{RED-LEGGED PARTRIDGE \\ CACCABIS RUFA \\ (Plates XIX-XXI)}

Tetrao rufus, Linn., Syst. Nat., i, p. 276 (1766).

Perdix rubra, Gould, Birds Europe, iv, pl. 260 (1837).

Caccabis rufa, Dresser, Birds Europe, vii, p. 103, pl. 471, fig. 1 (1875); Saunders, ed. Yarrell, Brit. Birds iii, p. 115 (1882); Lilford, Col. Fig. Brit. Birds, pt. viii (1891); OgilvieGrant, Cat. Birds Brit. Mus., xxii, p. 118 (1893); id., Handbook Game Birds, i, p. 96, pl. x (1895); Irby, Orn. Gibraltar, p. 237 (1895); Saunders, Ill. Man. Brit. Birds, p. 503 (1899); Millais, Nat. Hist. Brit. Game Birds, p. 126, 2 pls. (1909).

Perdix rufa, Seebohm, Hist. Brit. Birds, ii, p. 457 (1884).

Caccabis rufa hispanica, Seoane. Mém. Soc. Zool. France, vii, p. 93 (1894).

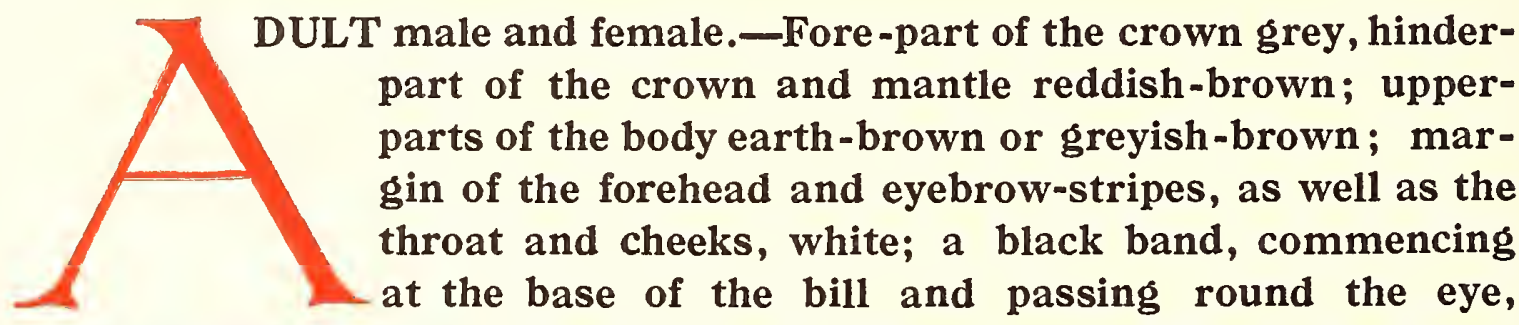
surrounds the throat; chest and neck rufous, the feathers of the chest, as well as those of the sides and back of the neck, margined on either web with black, and tipped or barred with white, giving these parts a black-spotted appearance; breast bluish-grey; feathers of the sides and flanks bluish-grey, tipped with dark chestnut, and barred across the middle with white and black; rest of the underparts rich buff. Outer tail-feathers dark chestnut. The bare skin round the eye red; the bill, legs and feet, bright coral-red. The legs of the male are armed with one or sometimes two pairs of blunt, wart-like knobs.

Dimensions. - Male, total length 13.5 inches; wing 6.2 inches; tail $3 \cdot 7$ inches; tarsus 1.7 inch. Female, total length 13.0 inches; wing 6.0 inches; tail 3.6 inches; tarsus $1 \cdot 6$ inch. (Plate XIX.)

Young birds shot in September which have partly assumed the adult plumage, but still retain the barred scapulars and inner secondary quills of the first plumage, are often mistaken for hybrids between the red-legged and common partridge. The first flight-feather, which is pointed, is dark brown, with a buff spot at the tip (fig. 1).

Young in first plumage. - Grown and back of the neck 148

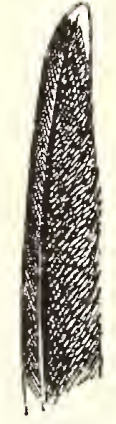

Fig. 1.

Fig. 1. End of first fight-feather of young in first autumn-plumage, showing buff spot at tip.

Fig. 2. End of first fiight-feather of adult. 


\section{RED-LEGGED PARTRIDGE}

brownish-buff ; upperparts dull earthy-brown, most of the feathers with a black bar and white triangular spot at the extremity. Quills dark brown, mottled and notched with black and buff on the outer web. Tail-feathers reddish-brown, slightly vermiculated with black, and tipped with white. Sides of the head, throat and rest of the neck white; chest brownish, spotted with white; remainder of the underparts greyish-white. (Plate XX.)

Nestling.-Crown and back of the neck reddish-brown, back reddishbrown, finely mottled with black, and with three whitish bands, one down the spinal tract, and one on either side. Wings very similarly marked. Sides of the face, throat, and rest of the neck whitish, without any of the black markings characteristic of the young of the common partridge. Rest of the underparts whitish-buff. (Plate XX.)

Variations in colour.-Among red-legged partridges variations in plumage are not very common, but a few remarkable forms have come under our notice, and two of the most striking have been figured by Mr G. E. Lodge on the accompanying plate. (Plate XXI.)

In the first the blue-grey colour of the breast extends over the whole of the upperparts, the rufous pigment in the feathers being nearly absent, a point which is especially noticeable on the tips of the flank feathers, which are white.

The most extraordinary variety, however, that we have ever examined, is that shown in the second figure. It has the fore-part of the head, eyebrow-stripes, cheeks and throat black; the rest of the head, mantle, breast, and flanks dull vinous-red, with the exception of a few white feathers on the middle of the breast; and the abdomen, thighs, and under tail-coverts are dull greyish-brown, with the exception of a few buff feathers on the middle of the belly. The tail-feathers are dull greyish-brown, like the lower back, rump and wings.

Partially white examples are also met with. In the most complete the plumage is white, with the exception of the top of the head and earcoverts, which are normally coloured; the spotting on the sides of the neck is present, but paler; the mantle is washed with light red, and the flanks are barred with chestnut at the tips of the feathers.

Another specimen is normally coloured, but the greater part of the back, rump, wing-coverts, some of the secondary quills and the thighs are white. In a third the plumage is normal, but there is a large horse-shoe-shaped mark of white on the breast, very similar to that found in some examples of the grey partridge. 


\section{THE GUN AT HOME AND ABROAD}

General distribution.-The red-legged or French partridge is a native of south-western Europe, ranging northwards into Belgium and Switzerland, westwards to north and central Italy, and southwards to Spain and Portugal, where a rather darker and more richly coloured form is found and has been separated by Seoane as Caccabis hispanica.

It is found in the Balearic Islands, Elba and Corsica. In Madeira, Gran Canaria in the Canary Islands, and in the Azores it has long since been introduced by early settlers, and the Iberian origin of the birds is still evidenced by their darker coloured plumage.

Distribution in the British Isles. - In England it was first introduced about 1770, when numbers of eggs were imported from the Continent and hatched out under domestic fowls on two estates in Suffolk. Subsequently other lots of eggs were brought over, and the species soon established itself in East Anglia, and spread westwards along both sides of the Thames valley. It has also been introduced into various parts of the Midlands and has wandered to Yorkshire and elsewhere, but is most numerous in Lincolnshire, Cambridgeshire, Norfolk, Suffolk, Essex, and all the home counties. Attempts to introduce the red-legged partridge into Scotland, the Orkneys, and Ireland have hitherto proved unsuccessful, but in parts of Wales recent attempts appear to have met with some measure of success.*

Dr N. F. Ticehurst, who has gone very carefully into the early history of the red-legged partridge in Kent, is convinced that occasional birds or coveys "wander across" from the Continent. It may be so ; but we agree with Professor Newton and others in thinking that the birds which have been observed arriving in Kent and elsewhere in an exhausted condition, have probably been driven out to sea by shooting parties on some other part of the English coast.

Allied species.-The handsome Barbary partridge (C. petrosa), a southern representative which inhabits north-west Africa, has been introduced from Morocco to the Rock of Gibraltar, and probably also to Sardinia, as well as to Tenerife, Gomera and Lanzarote, in the Canary Islands, where it is common. It is easily recognized by having the top of the head dark chestnut and a wide chestnut collar spotted with white bordering the sides and front of the neck. To the East the present species is represented by the larger rock red-legged partridge (C. saxatilis),

\footnotetext{
* In Scotland the red-legged partridge has been met with near Aberdeen, and in Wigtonshire in December, 1892, where, according to Sir Herbert Maxwell, some had been previously turned out; in Morayshire in December, 1891, and September, 1892, near Findhorn, where four pairs were liberated by Capt. Brander-Dunbar, and in Forfarshire, November, 1898. (A mn. Scot. Nat. Hist. 1900, p. 50).-Ed.
}

150 


\section{RED-LEGGED PARTRIDGE}

which inhabits the stony hill-sides of the mountains of Southern Europe, the Eastern Pyrenees, Alps, Carpathians, Apennines and Balkans, and is also met with in Sicily. It is distinguished by having the white throat bordered by a plain black band, as in its close ally the chukor (C. chukar) of Asia, and it differs only from that still more eastern form in having the lores or patches of feathers in front of the eyes black, whereas in the latter they are white. The chukor is very widely distributed, extending in the west to the Ionian Islands, and possibly to the mainland of Greece, in the east to China, in the north to Turkestan and Mongolia, and in the south to the Persian Gulf and the southern ranges of the Himalaya. In the island of St Helena it has long been introduced and flourishes. It is a wonderfully hardy species, and appears to be equally indifferent to the influences of climate and to the physical features of the country which it inhabits. The late Mr Allan Hume, the well-known author of the "Game-Birds of India," writing of the species, says : "The chukor may be found in different localities, from sea-level, as in Southern Sind and Baluchistan, to an elevation of at least $\mathbf{1 6 , 0 0 0}$ feet, as in Ladak and Tibet. It will be found in comparatively well-wooded, watered and cultivated hills, as throughout the lower, southern and outer ranges of the Himalaya; in absolute deserts like those of Ladak and the Karakorum plateaux; or in utterly barren and rocky ranges, like the Mekran and Arabian coasts, where the abomination of desolation seems to reign enshrined. In one place it faces a noonday temperature of $150^{\circ} \mathrm{F}$., in another braves a cold about daybreak little above zero; here it thrives when the annual rainfall exceeds 100 inches, and there flourishes where it is practically nil. But all these differences of physical environment affect appreciably the size and colour of the species."

The chukor might probably be introduced with success into parts of the British Isles, and the experiment would certainly be worth attempting.

Yet another closely allied species is Prjevalsky's red-legged partridge (C. magna), met with in the rocky mountains of South Koko-nor, Northern Tibet and the Tsaidam Plains.

Lastly, mention must be made of the very distinct black-headed species ( $C$. melanocephala), which inhabits south-western Arabia and ranges southwards to the neighbourhood of Aden. It is much the largest species of the genus, and is easily recognized from all its allies by its black crown and grey outer tail-feathers, as well as the general slatygrey colour of its plumage. 


\section{THE GUN AT HOME AND ABROAD}

The common red-legged partridge is a remarkably handsome species, and, as in other members of the group, the sexes are similar in plumage, and only to be distinguished externally by the larger size of the males, and by the blunt knobs on their legs.

Food.-It feeds chiefly on young shoots and leaves of various plants, seeds and insects, the latter forming an important part of its diet during the summer-months. In autumn and winter it picks up quantities of grass in addition to its other food.

Flight.-Like its allies, it is an inveterate runner, generally trusting to the swiftness of its feet to escape from approaching danger, and seldom taking wing unless hard pressed or suddenly disturbed. Once on the wing, however, its flight is fairly rapid and straight, and for this reason it affords capital sport when driven; but if shot over dogs or walked up in cover, its cursorial habits are very trying to the temper. Not only does it generally refuse to rise until it has reached the further end of the field, and is probably out of shot, but it disturbs and puts up any covey of grey partridges it may chance to meet with on its course.

Breeding habits.-Like the grey partridge, the red-leg is strictly monogamous, and becomes more quarrelsome and addicted to fighting in spring, and there can be no doubt that the two species frequently indulge in fierce combats during the pairing-season. By many the red-leg is believed to drive off the smaller species, and for that reason is regarded with disfavour; all the evidence, however, seems to show that the grey partridge is not only perfectly able to hold its own, but is generally victorious, when it comes to a fight. Sometimes pairs of the two species are anxious to occupy the same nesting-site, and if they disagree the red-legs generally find the place too hot to hold them. This is, however, by no means always the case, for their nests are often to be seen in close proximity, and eggs of both species are not infrequently to be found in the same nest.

Nest.-The nesting-habits of the red-leg are much like those of the grey partridge. The nest is usually a slight hollow scraped in the ground among grass and herbage growing at the bottom of some hedge or young plantation-growing crops are also resorted to, and sometimes the tops of stacks.

Eggs.-The eggs, which vary from ten to eighteen in number, are laid towards the end of April, or early in May, and are easily recognized. They are typically of a regular oval form, but pyriform eggs are of frequent occurrence. The shell is thick and finely mottled all over; and the colour 
A.

Z

ن

$\sum_{0} \frac{\pi}{\Xi}$

岂

.

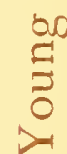




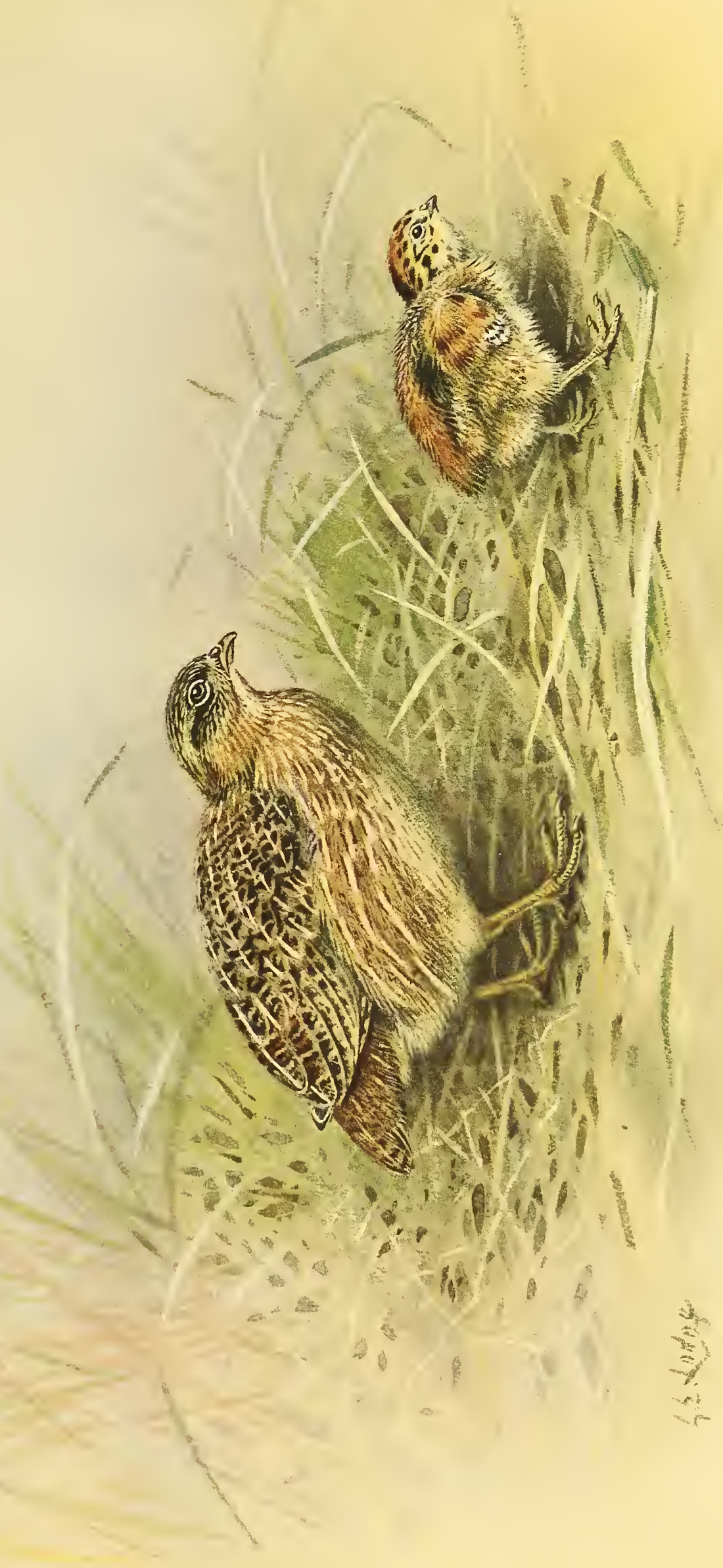




\section{.}




\section{RED-LEGGED PARTRIDGE}

is creamy-buff or stone-colour, spotted or blotched with purplish-, reddishor yellowish-brown. They measure about 1.55 inch by 1.2 inch.

An interval of several days often elapses between the laying of each egg. The young are able to follow their parents soon after they are hatched, and even in their earliest stages of down, are easily distinguishable from the young of the grey partridge.

General habits.-They are nervous, active birds, and generally on the move, except when resting and dusting themselves on some dry sunny spot, or when feeding undisturbed. On the slightest alarm they commence running with neck erect and fully extended, and with all the feathers tightly drawn in to the body. Seen thus, they look very much smaller; and when feeding and at their ease, with all their feathers comfortably puffed out, they seem nearly twice the size.

When driven, red-legs immediately commence to run, soon becoming scattered in all directions, and, when they rise, often come singly or in pairs to the guns. It is this habit, combined with their straighter and steadier flight, which renders them more easy to kill than the grey birds. Their powers of endurance are decidedly inferior to those of their smaller ally, for after one or two long flights they become exhausted and are unable to rise again. They then try to escape by running before the beaters, and hide themselves in the bottom of some hedge or among any convenient cover, where they are often caught by the dogs at the end of the drive. Not infrequently they seek shelter in a convenient rabbit-burrow, and a keeper has been known to take as many as three birds from a hole down which they had scurried.

In very wet weather the plumage of the red-leg becomes soaked much sooner than that of the grey partridge, and the bird's feet get so clogged, especially on a clay soil, that they are often unable to rise, and soon tire when they attempt to escape by running. A clay soil is often fatal to the young birds, for the lumps adhering to their toes become so dry and hard that they cannot be got rid of, and the birds being almost unable to move, soon perish.

The red-legged partridge is very partial to rough hill-sides, the edges of young plantations, and to heaths and commons as well as long grass or rushes. When flushed it not infrequently perches on the branch of a neighbouring tree, and the male, especially in spring, may often be seen on some tree or stack. His call is a frequently-repeated chuck-er-ra-kae, and both sexes utter a clucking note when running. 


\section{PARTRIDGE REARING}

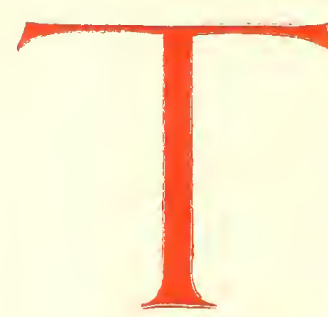

HOSE who are fortunate enough to own or lease a partridge shooting naturally take the greatest interest in the success of the nesting and hatching operations. Most partridges' nests are hatched off a week before, or after Midsummer day; they must have fine weather in June and July, or all is over for that season. Many are the anxious inquiries during the latter part of June, when a series of untimely thunderstorms cause as much concern to the future host as they do to the farmer who is hard at work saving his hay. A bad partridge year often means a disastrous hay and corn harvest.

Some people may think the statement that partridges should be looked upon as the farmer's friends rather a doubtful one, as in the early spring, when insect life above ground is practically non-existent, and there is little other food on which they can subsist, they certainly do use the young seed-grass fields a good deal, and select the heart of the young clover plants, occasionally doing an appreciable amount of damage.

They also frequently do harm by pulling up the barley when first sprouting, but this cuts both ways, for they destroy an immense number of wireworms at the same time. Seed can be dressed with a preparation of tar, which, though harmless to them, the birds will not touch.

This damage can be easily prevented if the owner or lessee will give orders to his keepers to scatter a few handfuls of dari and small corn under the sunny side of the hedges and dusting places, especially in hard weather.

It is wonderful how quickly partridges will discover these feeding places; by carrying out this not very expensive plan, any friction that may have arisen with the farming tenant is likely to disappear. There is another advantage in thus feeding in hard weather, it tends to keep the breeding stock healthy and strong, and they will not be tempted to wander away over boundary fences.

That partridges do move considerable distances in search of food, the following instance will show. A few seasons ago, on the estate of Mr Pearson Gregory, of Harlexton Manor, Lincolnshire, a cock partridge with some white on the wing, could be easily recognized at a distance; this bird, with his family, was observed two years running to shift his quarters for nearly two miles each autumn, though he invariably returned for mating and nesting in the following spring.

154 


\section{PARTRIDGE REARING}

We all know how some fields, especially seeds, hold unusual numbers of birds late in the season, they have evidently gathered in these places because of the abundance of food, and when any particular field is exhausted as regards the food supply, they shift elsewhere, perhaps over the boundary to ground which may prove more permanently attractive to them. The farmer will very likely say, "Why, my seeds be all eaten up with they partridges; they be like a flock of starlings, and I shan't have a seed left." All this can be prevented by the hand-feeding recommended above. Much of the damage to seed fields attributed to partridges is caused by the large flocks of wood pigeons who are the real culprits. When first hatched there is no ripe corn of any sort for them to feed on, so that they cannot do much harm to the corn crops.

For several years the writer has annually reared a covey of partridges which have been cut out of young grass, or have met with some other untoward disaster; these eggs having been hatched off by a bantam, the covey has been given the run of the garden, and very tame and bold they soon became. From close observation of these young birds I am certain that they live almost entirely, during the first six weeks of their life, on minute insects; they spread out in line and carefully examine every blade of grass or vegetable leaf as the case may be for any insect, no matter how small, and the excitement over a spider, or a daddy longlegs, is something prodigious, two or three eagerly chasing it, very often jumping up some distance to secure the prize.

It is, of course, very difficult to prove that the wild coveys feed to the same extent on insect food, but it is practically certain that this is the case, for the fact that a spell of cold dry weather, when insect life becomes very scarce, has a disastrous effect on the young coveys, goes far to prove how dependent they are on this food for their living. Think, then, of the myriads of aphides, beetles, daddy longlegs, wireworms, and other pests of the farmer that even one covey must rid the ground of in the course of two or three months!

When the young have reached the age of six weeks they greedily devour the juicy leaves of various weeds, together with their seeds; here again they must be of great assistance to the farmer. It is only after the corn is cut and carried that they get much of the scattered grain which would otherwise be wasted; and in September and October, when the insect life is at its greatest development, they will still be hard at work assisting the farmer in keeping them within reasonable bounds. One reason why part- 
THE GUN AT HOME AND ABROAD

ridges have decreased on some of the light lands of the Eastern Counties may be because the farmers no longer "clay" them as they used to do when corn really paid. Now this land is too light, and consequently lacks insect life. It is a well-known fact that the better and higher the farming, the stronger the stock of partridges the land will carry, provided it is arable.

Of late years it has become a growing custom to place a chicken hut, with from twenty to sixty cocks and hens, on the various stubbles directly harvest is over. The poultry very soon clear the fields of any grain there may be left, and they also, of course, consume the greater part of the insect population, thus shortening the food supply of the partridges. In addition to this poultry do considerable damage to the fences, scratching out great gaps, and if anyone will take the trouble to examine the inside of these chicken huts, he will find that they are, as a rule, in a most filthy condition, the nesting boxes full of mouldy hay, swarming with fleas and vermin, the floors covered with rotting poultry dung; this is bound to foul the ground, and very likely will spread disease amongst the poultry, which will speedily be communicated to partridges and pheasants in the surrounding fields. Now, it is a question whether these poultry houses pay their owners in the long run, except in a small way; it is therefore well worth the while of any owner or lessee to approach the tenants on the subject of what profit they expect to make. In many cases a five pound note, or less, will cause a farm to be cleared of all these poultry houses to the advantage of the tenant, the partridges, the owner, and his friends who come to shoot with him; whilst the extra number of partridges shot, plus the sport they will afford, should amply repay the expenditure thus incurred. Many landlords stipulate in their leases that fowl-houses are not allowed on the land; there can then be no trouble, though perhaps they may get a few pounds less rent.

Early nesting pairs are often tempted to choose that fatal spot a lucerne, sainfoin, or young-grass field, which will very likely mean the destruction of their eggs or young later on. These disasters may be partly prevented if a pointer or setter be run frequently over the young-grass fields in the month of April and early May; the old birds very soon fight shy of nesting in such disturbed ground, and will seek safer quarters in the neighbouring hedgerows or rough brakes.

On an estate that is well supplied with belts, rough ground, or still better, a high bank running for miles, like the Roman dyke in the Six 156 


\section{PARTRIDGE REARING}

Mile Bottom country in Cambridgeshire, the nests are less likely to be destroyed, either by grass cutting operations or the poaching practices of rooks, jackdaws and carrion crows.

At Sandringham and Welbeck "remises" have been formed on the Hungarian system, for the purpose of giving quiet feeding and nesting places, and these have proved very successful. In other places, where the owners have not cared to go to the expense of making "remises," certain corners of badly shaped fields (for agricultural purposes) have been taken out of cultivation, the rough, natural grasses allowed to spring up, broom and sunflowers sown, thereby producing quiet corners to which birds can retire when the surrounding fields are much disturbed by the ordinary routine work of the farm; this is greatly appreciated by them. Where this plan is carried out care must, of course, be taken that the thistle heads are cut before they seed, otherwise they would become a nuisance to the surrounding farmers.

Narrow paths should be cut the last week in March or first week in April, as English partridges prefer, as a rule, to nest near the edge of thick covert; this will also make it easier for the keeper to find and watch the nests; if the country is a dry one, it would be advisable to place a drinking water pan in one of the paths. A permanent basin one and a half yards in diameter can be made for about twelve shillings, with clay bottom; once filled it will keep full, but must be cleaned out now and then. Properly made, such basins will last for years.

Where the land is heavy, and "driving" is possible, red-legged partridges will flourish, and should be encouraged; they will very likely save the situation in a moderate season, as they nest in belts, on old haystacks, and even in low trees, frequently hatching and bringing up their families through a wet season that has played havoc with the English cousins.

It was formerly held by some that the red-legged birds fought and drove away the English, but this is not the case; many instances have been known in which red-legs have laid in English partridge's nests, and the latter birds have eventually hatched them off.

A sprinkling of red-legs on a driving beat is an advantage in two ways: for instance, supposing a root field to have been stocked with English partridges, they are liable to alight and run together and get up in one great pack directly the drivers enter the field. This will mean that a very small proportion will be shot as they dash over the guns; whereas, if there are 


\section{THE GUN AT HOME AND ABROAD}

a few red-legs mixed up with them, whose nature when disturbed is to run away from danger and rise independently, by doing this they will cause many of the English birds to run and scatter likewise, and they are more likely to come over the guns in small lots.

Again, the red-leg, as a rule, rises singly, and flies straight, and perhaps not quite so fast as the English bird; the consequence is that many a gun who is possibly a little bit off colour or not quite on the spot, regains his confidence by killing neatly three or four red-legs in succession. Success in shooting is more a matter of confidence than anything else.

With regard to the question of soil most suitable for red-legs, Mr Heatley Noble, who is an authority, states that in his experience, he finds that light land is best, and that they do not flourish anywhere so well as on the light lands of Suffolk and Norfolk. Yet on certain heavy land in Lincoln redlegs always seem to thrive.

Where the fields are small, and walking up or shooting over dogs is the order of the day, French partridges are a nuisance. They demoralize the dogs-and run to the hedges, whence they refuse to budge.

In cases such as this, it would be well worth an owner's while to exchange red-leg eggs for English ones with any friend who lives in a driving country.

In order to obtain satisfactory results with partridges the following conditions are absolutely necessary:

(1) A sufficiency of ground, well cultivated, and soil not too heavy.

(2) A good healthy stock.

(3) A good understanding between the keepers and the tenants and their labourers.

(4) A keen and energetic staff of keepers.

(5) A favourable nesting and hatching season.

In the writer's opinion 1200 acres, lying compactly, is the smallest extent of ground on which it would be worth while trying to get up a stock of partridges. Anything smaller than this would give considerable trouble with boundary birds, at any rate on a windy day.

Of course there are exceptions to every rule, and a notable one is that ably explained by Mr F. E. Fryer. See "The Country Life Library" (Shooting, vol. i, pp. 130-159).

Therefore, provided the estate is of not less than 1200 acres, fairly flat or undulating, and most of it consisting of arable land, there is 158 


\section{PARTRIDGE REARING}

no reason why, with careful management and good keepering, a satisfactory result should not be obtained, both by walking up or driving. Of course the larger the area the easier it will be to plan the beats, the direction and strength of the wind not being quite so important a factor. Where the soil is light and fields large, one man can look after 2000 acres of partridge ground, and this may be divided into two beats. Where the soil is heavy, the fields small, 1200 acres is about as much as one man can look after properly, and this acreage may be divided into two beats. If fences are scarce or bad, it is wise to plant belts of gorse, broom, and larch. These will come in very useful for nesting purposes, and when they have grown up, of course they will be splendid to drive over.

In counties such as certain parts of Kent, where fences are almost non-existent, the best plan is to put up hurdles, permanently if possible, in the form of a wide $\mathrm{V}$ reversed, filling up the interstices with bracken, reeds, or gorse, being careful not to make these "hides" too high. Many a short or moderate-sized man has found it impossible to shoot over these improvised shelters, they should therefore be not much over four feet in height. A man can then sit on his shooting seat well out of sight of an approaching covey until it is within range, and then rise quietly and get off both barrels in front. In many cases, in my experience, the hurdle butts have been made so thick and high that it has been almost impossible to see over them, or to shoot with any sort of comfort; the consequence has been that the guns have been obliged to look round the corner, and show themselves to coveys coming at an angle, very likely turning them back over the drivers' heads.

(2) A good healthy stock is, of course, most important. It is not a wise plan to give a jubilee year, i.e., not to touch the ground at all in a bad season-by this means too many old birds are left, and it is well known that old birds require larger areas of ground for nesting operations than do young pairs. It would therefore be better in a really bad year either to walk the ground over in the first week of September with some active and reliable guns, killing only the old birds as they rise out of the roots or other covert, leaving what young birds there are to pack together and form a good healthy mixed-up breeding stock for the following season. Or, if this cannot be done, to drive the ground as early as possible, and ask the guns to confine their attentions to pairs, and threes, or fours, which will generally consist of old birds. If this latter plan be carried out, and birds are fairly numerous, it would be advisable to have one or two 


\section{THE GUN AT HOME AND ABROAD}

return drives; the season being early, the young birds would not get up after one or two drives, and this would make it all the easier to pick up the old stagers.

As Mr Alington states in his book on partridges, what you want to get hold of is the really old barren pairs and old cocks; for a partridge of two years will both mate earlier, lay a stronger clutch of eggs, and presumably have more experience in looking after her family, than when one year old. It is, as a rule, after the age of two years that they gradually become less prolific and more quarrelsome, as is the case in other species.

Capt. George Taylor, of Pickenham, Norfolk, who, besides being the fortunate owner of an excellent partridge manor, is a close observer of their home life, sends me the following interesting story:

"Some seasons ago my head keeper observed a pair of partridges nesting in a small paddock close to his house, and within quite a short distance of the dogs tethered to their kennels ; they frequently came and fed with his poultry. From the situation of the nest it was probably the same pair each year. They hatched out a good covey of about twenty young birds. The cock bird had met with some accident in his youth, and always walked with a limp, and could be easily recognized. The following year the same cock nested in the same paddock and again hatched out a fine covey. The following season apparently the same pair carried out the same tactics for the third time, and brought off a strong covey. They occupied ground that was practically never driven."

With regard to the amount of stock required on a beat, this, of course, varies in different counties; where foxes abound, many nests and sitting birds will be destroyed, and therefore a larger stock will be necessary than in a non-foxhunting country. But one point must always be borne in mind, the ground will only carry a certain number of partridges; if this maximum be exceeded, the surplus will be certain to move off to your neighbour's land, especially if the food supply be short. The hand feeding, before recommended, will prevent this to a certain extent, but there is always a point where the balance of Nature will assert itself. The more arable land there is, the better for the stock.

A rough calculation may be made as follows. Taking a beat at from 700 to 800 acres, every year on February 1 the keeper of the beat should be able to vouch for 140 pairs being on his ground; or, say, one pair to five acres. In an ordinary good year coveys average all round about 160 


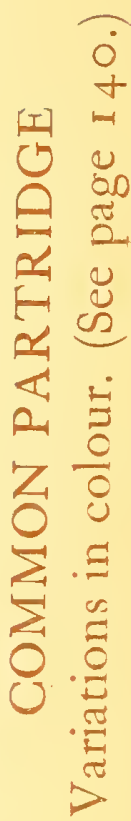




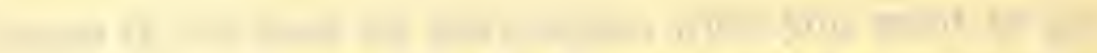

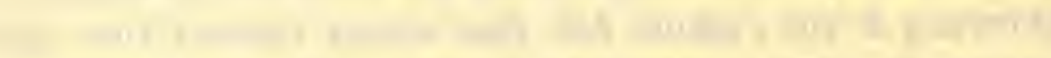

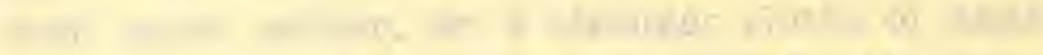

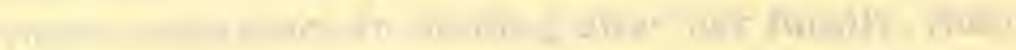
I.

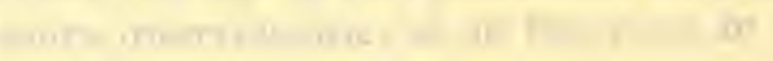

The aning of 0 (n)

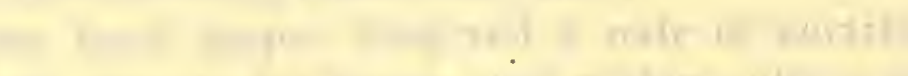




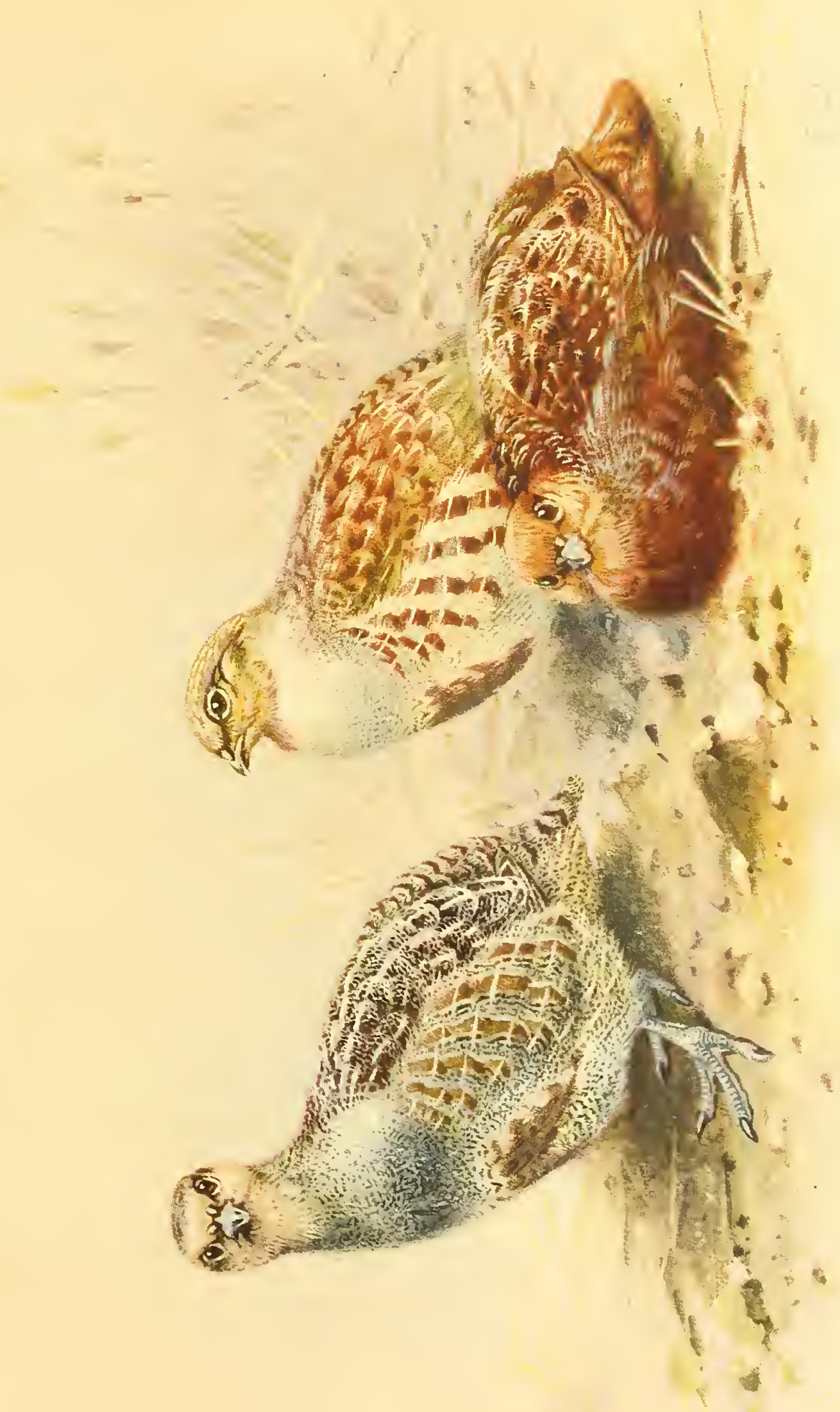




\section{PARTRIDGE REARING}

six young birds to a covey. If you reckon that 20 per cent of your nests may meet with accidents of various kinds, and that some birds will be unpaired, or meet with fatal accidents during the pairing season, this would leave 110 coveys of eight birds each; i.e., 880 birds on the beat. The first time over, with luck, you should get 500 birds, leaving 380 on the beat. Some of these will be badly pricked and die, others will fall a prey to vermin - cats, foxes, etc. This should leave about 150 brace for the next season.

As a rule where more than 200 brace are killed in the day, except in a bumper year, the beat is considerably larger than 700 acres. As to the number of birds the ground will carry, Mr Heatley Noble writes: "I believe that far more birds can be kept to the acre round Newmarket than in any other part of these Isles. Look at Dalham, Denham, and Chippenham ; on the last-named, when our late King was shooting there, they once killed 400 brace in four hours. The property was small, and they shot it many times, never trying for a big bag, or leaving a very large stock. Then again look what they used to do at Six Mile Bottom, and will again if they only get a decent season or two. On the other hand, look at a certain property in Hampshire. If I remember right the first year they knew of 160 nests, and killed some 800 brace, since then (and before the bad years) they have known of 400 nests, hatched off well, no foxes to speak of, or vermin, but the bag was hardly larger." He adds: "No beat of 700 acres can stand a second shoot if the birds are properly brought to six good guns, and the weather is all right. They are flattened out, and only a stock is left."

(3) A good understanding between keepers, tenants, and labourers is absolutely necessary. Without it, no matter how heavy a stock may be left, the results are sure to be disappointing. A dissatisfied tenant can do much harm by letting his dogs run loose all over the farm during the nesting season, or by the late cutting and cleaning of certain favourite hedges and ditches. Whilst the labourer who is hostile, even if he or his wife do not actually take the eggs or put other people in the way of finding them, may easily put his foot in the nests and destroy many of them.

A wise master, therefore, will cultivate the co-operation of the tenant by asking him to come out and see the sport and stay to lunch when his farm is shot over, giving him an adequate present of game in proportion to his sport, and doing anything else in his power to assist the tenants. 
THE GUN AT HOME AND ABROAD

A couple of rabbits at Christmas time, and a reward for news of nests laid in dangerous places, or of any egging visitors, will keep the labourers on the side of the game preserver. The keeper also can keep on the right side of the tenants by being civil and obliging to all, helping to prevent damage done by rabbits, and repairing any gaps in fences that the beaters may have made when crossing the land.

A good keeper should trap hard throughout the year; and it is advisable when partridges are a special object, to have certain men who can give their whole time to the partridge ground, and not be lured away by the fatal fascinations of the pheasant-rearing field. I am inclined to think that each keeper of a partridge beat should be provided with a map, on which every nest should be marked and numbered; in addition to this he should note the date of laying, number of eggs, and date of sitting.* This will facilitate the changing of eggs from different beats or nests; and will enable the "chipped egg" system to be carried out with success.

In a fox-hunting country objections have been made to this, as it is held by some that the path to the nest, which is necessarily made by such constant visits, will sooner or later be discovered by the foxes, and much damage may be done.

To prevent foxes attacking sitting birds is a difficult problem. In the early part of the sitting the hens give out little scent, but the last day or so, when perhaps some of the chicks are hatched, the bird does not sit quite so tight, and that seems to be the most dangerous time. Several plans have been tried, amongst others a small flag a yard or so away from the nest, a few pieces of loose old iron dropped close to the nest, which an approaching fox would most likely suspect to be a trap.

On an estate in Norfolk where foxes abound a sort of glorified cage of large meshed wire netting is put over each nest to protect the sitting bird, but all these plans have the disadvantage that, even if they are successful in scaring away a fox or marauding dog, they make known the position of every nest to any two-legged fox there may be about and will entail an enormous amount of watching. This summer, 1912, a fox took eight sitting birds in one night, all of which were wired in. In one case he jumped over the wire and got the eggs as well.

An old keeper who was very successful with his partridge nests in a

*Mr Alington gives an excellent example of how these maps with their accompanying memoranda may be kept. 162 


\section{PARTRIDGE REARING}

certain fox-hunting country gave me the following simple recipe, which he declared never failed:

" Every morning, when I be going my rounds, I puts a wad of cotton wool under each arm - and when I comes to a nest which I think Mr Fox is likely to visit-I just plucks a bit of the wool from under my arm and puts it down to windward, and no fox won't come near that nest for two days."

In regard to the chipped egg system, should the nests be situated near a footpath or in a dangerous spot, it is a very good plan, after the bird has laid at least five eggs, to substitute some artificial eggs for the real ones.

The best of these artificial eggs, so far as my experience goes, are made by Mr G. Malden, and are so exactly like the natural egg that even rats and crows have been taken in.

The real eggs should be put under light hens or bantams until they chip, and may then be placed in lots of twenty-four in those nests in which the birds are sitting on the sham eggs-the latter, of course, being removed. This should not be done unless the bird has been sitting at least ten days, otherwise they are likely to desert. Should a nest be made in a very dangerous place, it is advisable to remove the eggs each day after the first five have been laid, substituting sham eggs, until the whole clutch has been laid; this may be ascertained by the fact that the bird will leave them uncovered when away at feed, just before she begins to sit. The nest should then be destroyed, and the pair will most likely make a new nest in a safer place, and lay from eight to ten eggs. It is very rare indeed for a partridge to make a new nest and lay a second clutch of eggs if she has once sat on her first lot. The process of sitting is so exhausting to the parent bird, that she has little inclination or strength to begin again.

Whilst on the subject of nesting, the following further observations by Capt. G. Taylor, of Pickenham, will be of interest:

"I said I would send you some facts about partridges. In 1906 I was out with one of my keepers, looking for partridge nests. In the morning

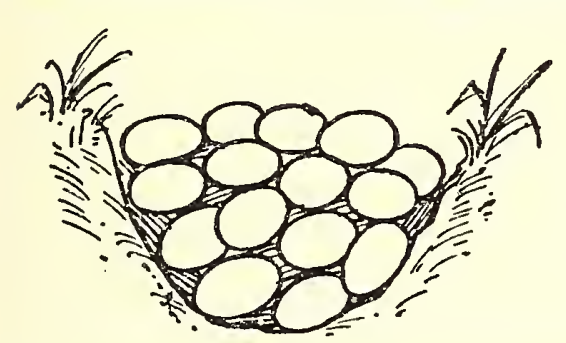
we found a nest with five partridge eggs, one pheasant's egg, and one lark's egg ! A few days later, on the same beat, we found a partridge sitting on sixteen partridge eggs and thirteen pheasant's eggs, four layers deep in the nest, and hopelessly mixed up. We took away all the pheasant's eggs, but she deserted, and all were found to be spoilt. I had a partridge's nest spoilt by a rabbit 


\section{THE GUN AT HOME AND ABROAD}

insisting on using it as a seat. I have known a partridge sit on an empty nest for a week; and another hatched twenty-eight out of twenty-nine eggs laid in her nest, the twenty-ninth being unfertile."

To return to the subject of stock. As a rule hand-reared birds, at any rate in large numbers, are unsatisfactory. Unless there is a large natural supply of ants' eggs and insect food they are difficult to rear, a very large percentage get trodden on by the hens, or die from other causes. Those that survive have no fixed home, they pack together, wander all over the place, and when the nesting season comes round they are probably not such good parents as the naturally reared wild birds are, as they have not had the experience, first of their parents' lessons in looking out for danger, or learning to shift for themselves in the matter of food when quite young. If the "chipped egg" system is found impossible to carry out, I am inclined to think that the best alternative plan is to hatch those eggs that are cut out or laid in dangerous places under bantams in lots of fourteen, and turn them down when four or five days old in the standing corn with their foster parents. The result will be that many will join the neighbouring wild coveys, or be adopted by barren pairs, whilst the foster parents, if they escape the attention of foxes or vermin, on finding themselves deserted-will make their way to the nearest farm.

Mr Alington says, and with reason, that when hunting for partridge nests, the keeper should begin his work as soon after daybreak as possible and finish this work not later than 10.30 a.m., for after that hour birds will begin to lay; he also mentions the interesting fact that they lay later each day, i.e., supposing the first egg was laid at 10.30 a.m., the second would be laid about $11 \mathrm{a} . \mathrm{m}$., and so on. The period of incubation is about twenty-four days.

Supposing the breeding stock to have sunk almost to vanishing point, or from the want of change of blood, those birds that are left have diminished in size and stamina, it is absolutely necessary to import fresh blood, and probably new and more energetic keepers.

On a certain estate in the West of England a few years ago, the partridges had so deteriorated from continuous in-breeding that they were scarcely larger than blackbirds, the coveys being equally small in numbers.

In such a case, it is almost imperative to take one of these courses: to import Hungarian partridges or Hungarian eggs, or to write round to all one's friends who happen to own a partridge shooting, and ask them for a sitting or two of eggs.

164. 


\section{PARTRIDGE REARING}

To take the importation of Hungarian adult birds first. There is a great difference of opinion as to how these birds should be turned down, grave doubts having been expressed whether Hungarians do not sometimes bring with them disease in some form or other. Having had considerable experience in the importation of them, I venture to give my opinion for what it may be worth. If you have made up your mind to take this step, go to a trustworthy importer. There are several who advertise, or who can be communicated with through game protection societies.

Kill down as many of your old birds as you can very early in the season, and import the fresh stock early in October, whilst there is still plenty of food to be found in the fields.

On arrival, look them over very carefully, and knock on the head any that appear to be unhealthy or diseased. This will save money in the end.

Place these imported birds in enclosures twenty yards square by four feet high in lots of from fifteen to twenty brace, dotted about on various parts of the ground. The sides of these enclosures should be of string netting, so that the birds will not injure themselves by beating against them.

Some covert of boughs should be placed inside so that the birds may hide themselves, and there should be a heap of gravel grit and a pan of clean water. Feed them regularly morning and evening with dari, small corn, and if possible ants' eggs, so that they may regain their strength after their long journey.

In ten days or so lift up one side of the netting, the birds will gradually find their way out, and will settle down in the immediate neighbourhood of their original feeding place. Of course it is advisable to scatter a little food near where the enclosure was during the winter. This will help to keep the visitors from wandering. If on the other hand the birds are turned out immediately on arrival, they will be weak and starving, and will be set upon by any native birds that may be in the neighbourhood, and be either driven off the ground or killed.

If turned down in the middle of January they will be probably too late for pairing with the native birds that year; whereas if turned out by the end of October they will have had time to familiarize themselves with their new surroundings, and very likely have found English mates. Some people think that the Hungarian cross tends to weaken the English breed, as the former are not accustomed to our fogs and damp climate, whilst our home-bred birds have gradually become acclimatized to the damp ; but this is not the experience of many importers. 


\section{THE GUN AT HOME AND ABROAD}

Of course it is fatal to shoot a single partridge on any ground where you have recently turned out a batch of Hungarians. A kind host who had just turned out several brace of Hungarians planned a drive on the way to one of the coverts after lunch, with the disastrous result that three brace of his newly imported twelve-shillings-a-brace birds were added to the bag!

Hungarian eggs do not pay to import. They are generally stale from having taken some time to collect; added to this the long journey by rail and sea does not improve their condition. If sixty per cent hatch it is rather above the average, and those that do hatch produce such weakly chicks that a very large number die in spite of endless trouble taken by the keepers who look after them; forty to forty-five per cent turned into the fields may be considered a good average, and these birds will probably not be constitutionally strong.

With reference to Hungarian eggs $\mathrm{Mr} \mathrm{H}$. Noble writes: "I quite agree; $T$. T. once bought 500 Hungarian eggs, and reared one bird, it cost $£ 25$ ! I must say I have heard of some good results. When the eggs arrive they should be laid in trays flat, and each egg turned right over four times in forty-eight hours; in any case they should never be sat on until they have rested at least that time. The reason is, the yolk gets badly shaken, and by the vibration on the journey is apt to get out of place. If sat on in this condition the egg cannot hatch, but it may recover with rest.

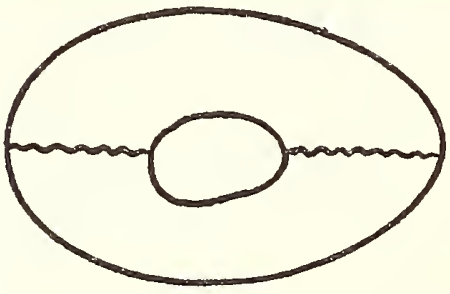

"Normally, the yolk is held in its place by two sort of spiral springs of elastic substance; this stretches, and sometimes snaps, when the yolk falls to the side, and the egg is spoilt. Sometimes the springy membranes only stretch, and regain their position by rest."

When importing Hungarian eggs it is advisable to test them before sitting. I have known a keeper who, when unpacking some eggs, inadvertently knocked one off the kitchen table on to the floor; much to his astonishment the egg did not break, and on examination he found it was a hard boiled one of the previous year! On examining the rest he found many similar specimens. In order to avoid such imposition, importers should be very careful with whom they deal. There are plenty of trustworthy men; but the local egg gatherer of Hungary has evidently learnt certain tricks of the trade which may cause disappointment if not detected. 


\section{PARTRIDGE REARING}

Borrowing eggs from one's friends is the last resource, and is not a very satisiactory one. Few owners, and no keepers, care to give away their partridge eggs, but if two or three hundred can be obtained in this way, and they are fresh, they may be put in the wild nests and allowed to take their chance, but the following season there should be very light shooting.

All these expensive and laborious methods may be prevented by judicious changing of eggs from one nest to another, and from different beats. Or still better by exchanging every year a certain number of eggs with friends. Even then each keeper is apt to think he has been done by the other, and that the eggs he sent away were far better than those he has received in exchange.

(4) Keen and energetic keepers are very necessary. It is hardly fair to expect a man to look after a large stretch of partridge ground and at the same time take his share of work in the pheasant-rearing field; he will be in the same predicament as the man who tries to serve two masters.

If a keeper is to be successful with partridges he must get round his beat every morning to visit his nests. He must also visit his traps daily, and keep them going all the year. In addition to this he should be present when certain fields of young grass are cut, in case nests are cut out. He must also make it his business to be on good terms with both tenants and labourers on his beat. He should know if any of the latter are inclined to egging.

A single barrelled Zeiss field-glass is of the greatest use to a keeper. It will save him an enormous amount of walking, and stalking suspicious looking people, and the fact that it is possible to be recognized and sworn to at the distance of over half a mile will often prove a wholesome deterrent to any man or woman who may think of looking for nests or snares.

As already remarked, the keeper of the beat should know, as far as possible, every nest on it, and its history from the time the first egg is laid, until it is hatched out. It will then be possible for him to save many a nest that has met with some disaster, and to prevent a hedgehog, an old buck rat, or other vermin committing great depredation in any particular spot.

(5) Last, and by no means least, there must be a favourable nesting and hatching season. Since 1906 the seasons have been disastrous, in the Eastern Counties especially. A cold spring will delay nesting operations, it will also delay the growth in hedge-rows, and render what eggs are laid likely to fall a prey to rooks, jackdaws, and carrion crows. Therefore a fairly warm May and June, with occasional showers, are most desirable. 
THE GUN AT HOME AND ABROAD

The majority of partridges hatch off about June 21, and at that time it is most important that the weather should be warm, a few showers (not heavy thunderstorms) will do more good than harm, as they will promote insect life.

The partridge is a very devoted mother. Many have been found dead on their eggs after a long spell of cold and very wet weather, having sacrificed themselves in the hope of rearing their broods. They also display great courage and resource if disturbed either on their nest or with their young.

$\mathrm{Mr} \mathrm{H}$. Noble writes: "We had a case here of interest, the keeper heard a partridge cock making an awful row-on looking about he saw a cat advancing to a nest he knew of; before he could shoot the beast she had sprung at the sitting bird, just missed her, but pulled out her tail. The cat was shot. In an hour's time the hen was back on her nest, minus her tail."

Of late years many partridges, both old and young, have died all through August and September in a most mysterious and heartbreaking way. No satisfactory explanation has been given of this. It is not always from gapes, but prevails if the season be a dry one. It is probable that the enormous numbers of poultry in the fields have a good deal to say to this, for reasons mentioned earlier in this article.

In 1910 several old birds were picked up dead the last week in September which seemed to be in fairly good condition, except that their feathers were dark, and the back of the head bald and rather raw.

An irreverent sportsman suggested that they had died from old age, having been spared for several successive seasons. But there is something really wrong in the way that old and young die quite late in the season, and it might be worth the while of those who are interested in partridges to follow the example of the owners of grouse moors, and get a competent committee appointed to look into the matter and report.

ARTHUR ACLAND HOOD. 
1 ह

된 $\frac{0}{\tilde{\pi}}$ 
$\frac{1}{\ddots}$

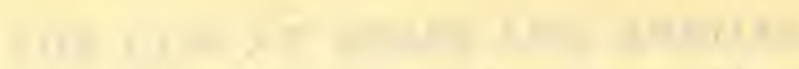

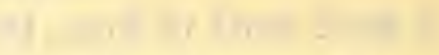

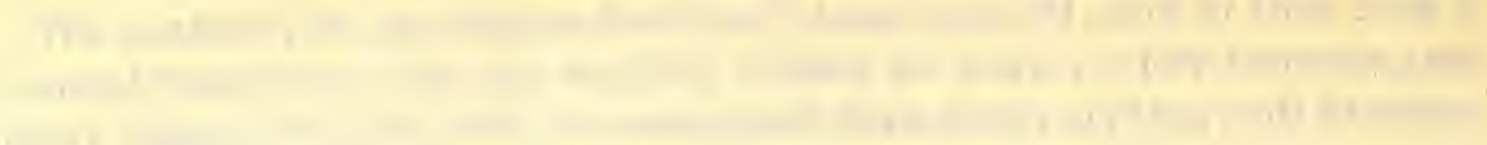

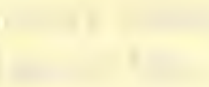

6he in it 1

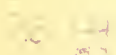

t.

$16 \quad 2$

.

$-i n$

ᄀ.

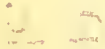

$3:$

- 4

5

$\therefore$

$\sum_{i=1}$ 


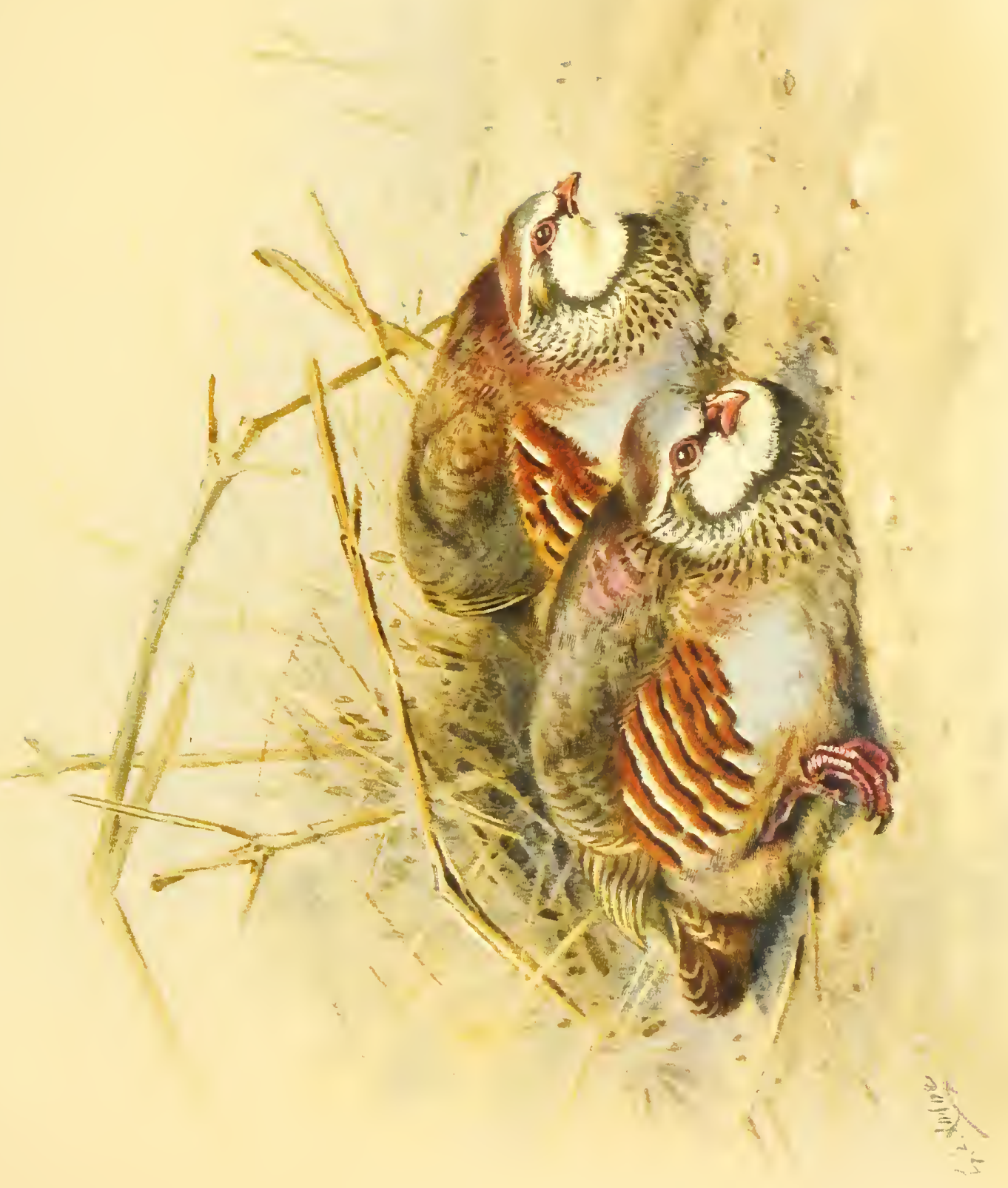




\section{PARTRIDGE SHOOTING}

HOOTING partridges over dogs is very nearly an extinct sport in the British Isles. High farming has led to fields being increased in size, the stubbles close cropped by machine mowers, and the grass lands drained, so that there is little or no covert to encourage birds to lie to dogs. There are nevertheless a few favoured localities where the fields are rough, with stretches of marsh land here and there, where it is still possible to use a pointer or setter with success.

Nothing is prettier than to watch a brace of good pointers quartering their ground at an easy gallop, each stanchly backing the other when a point is obtained.

When walking up birds, where the party is a small one, coveys scarce, and an occasional large field of roots is met with, it will save a great deal of time to run a pointer over it, and go straight for the covey or few scattered birds that may have been driven in.

At the present day, if the fields and property are too small, or the ground too hilly for driving, the only alternative is to walk the birds up. This, besides being good exercise and sport for the matured sportsman, is excellent training for the tyro. It teaches him to carry his gun properly, to keep his eyes and ears open for signals; it also teaches him more or less the habits of the partridge, and when and where they are likely to be found, and lastly, it gives him an opportunity of appreciating the beauties of retriever work, for which he will not have so good an opportunity if he only takes part in driving.

A beat should be kept for walking or driving; no ground will stand both. It is not only poor fun for the guns who are asked to take part in driving a beat, to know that the cream has already been taken off it in September, but it is also bad for the stock.

On some estates there may be certain stretches of ground which it is impossible to drive satisfactorily; these should be kept entirely for walking up early in the season, the more open portions being reserved for driving in October and November.

Not that I am by any means opposed to walking up - but I maintain that where driving is possible, better sport is afforded those who are lucky enough to be asked to take part in it, for the reason that the birds are older and stronger on the wing, and the shots are more difficult, and at the same time it is better for the stock and for the labourers employed as drivers. 


\section{THE GUN AT HOME AND ABROAD}

Where the fields are small, two guns, accompanied by four or five keepers and beaters, may have excellent sport walking up, but it is most important, especially in a hilly country, or where fences are thick, to have a couple of active young men, who can climb trees, to serve as markers. These men should know the beat well, and take up their position in trees within sight of the guns and in the direction to which the beat is advancing. Each man should be provided with a whistle and a stout stick with a hook at one end to hang on the branches, and a small red flag.

A system of signals must be established between the markers and the guns, so that they may readily give information of any birds that have been disturbed, and which they have been able to mark.

For instance, a single prolonged note on the whistle, may mean a covey marked; two whistles, several coveys; three whistles, several scattered birds.

When the guns are getting within range of him, the marker should give a low whistle and show his flag, in order that they may know his whereabouts, otherwise accidents may occur through the marker not being seen amongst the branches. By this means birds which have disappeared from the shooter's sight will be more easily found, much time will be saved, and many pricked and towered birds will be recovered.

When birds have been marked into a hedge, one gun will take each side, with a beater next the hedge, a good spaniel or steady retriever working the lee side; it is by no means so easy as one would think to make a certainty of birds that pop out on your side and dash over the fence almost before you can get your gun up.

By trying to pick out the old birds as often as possible (this is fairly easy early in September), a great deal of good will be done for the stock.

It is as well to remember that partridges do not naturally lie in swedes, clover, or any other thick covert, with the exception of mangel or white turnips, which they sometimes go to during the heat of the day. Therefore all stubbles and grass fields must be walked in. If the weather is wet, they will not stay long in any thick covert, nor will they after four 0 'clock in the afternoon, as they will be wanting to get back to the stubbles for the evening feed.

In walking up it is important to bear two or three principles in mind. 
PARTRIDGE SHOOTING

Strict silence should be the rule. Nothing frightens partridges, or indeed any other wild animals, so much as the human voice, therefore everything

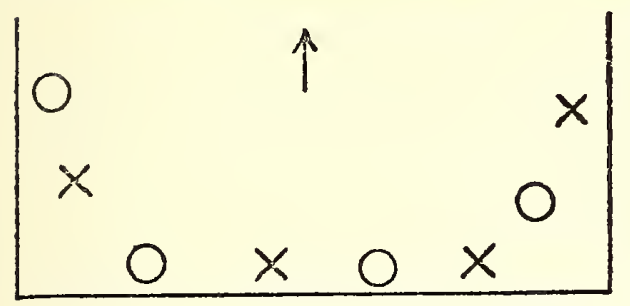
should be done, as much as possible, by means of signals, preceded by a low whistle from the leader of the party.

When walking a field one flank, and generally both, should be in front of the centre. This will prevent birds breaking out at the sides.

If it be desired to drive birds in any particular direction, say to the right, the left flank should be more advanced than usual, and the leading man on that flank should have a gun.

Great care should be taken to walk out all the corners of each field, and to make good the ground close to the fences-if this is neglected many coveys will be missed, for they love to dust themselves under the lee of a fence. When beating a root field, the

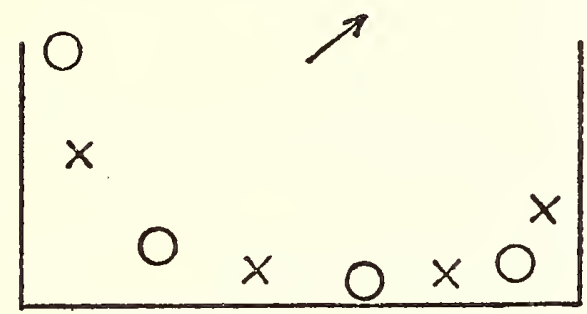
guns should walk, if possible, across the drills, otherwise the birds will run down them to the end of the field, and get up in a pack and disappear over the hedge, very often out of shot.

When shooting in potatoes or roots, especially if the covert be thick, we all know how tedious, and sometimes exasperating, is the long wait caused by looking for six or seven birds that may have been knocked down at the same time. It very often happens that most of the retrievers are either young and wild, or old and deaf, and what with the ground being thoroughly fouled by well meaning but too eager beaters, and the scent being bad, endless noise and confusion ensue, birds rise wild all over the place, and the rest of the field is disturbed. To prevent this as much as possible, a beater or keeper should be told off to each gun, and it should be his business to mark accurately the first bird that his gun shoots, while the gun himself should be able to mark the second bird.

Sir Ralph Payne-Gallwey, in his "Letters to Young Shooters," makes an excellent suggestion as regards assisting this operation of picking up.

He advises that each beater should carry two or three small wands, and when he has reached the spot where he has marked a bird fall, if he cannot see it at once, he should place the wand in the ground, and stand 
THE GUN AT HOME AND ABROAD

still and not foul the scent. Should any still be lost, after a fairly long search, it will assist matters greatly if one keeper with a steady retriever, or still better a brace, be left behind to hunt the ground thoroughly, whilst the remainder of the party continue their advance. Many an old keeper who is practically past his work for night watching and the heavier duties, is invaluable if employed in this way.

It is always advisable to walk slow through covert of any sort, and to remember that the most likely spot for birds to surprise you is when close to the hedge at the end of a field, especially if you have been obliged to walk down the drills. Where fields are very large and the party consists of six or seven guns and a good many keepers and beaters, half-mooning is sometimes resorted to.

But this is an operation which must be carried out with great accuracy; and if there is an excitable gun in the party, it is perhaps wiser not to try it.

Supposing a field of roots has been filled with birds, if approached in the ordinary way they would probably run together and get up very wild in one great pack. Half-mooning may circumvent this. The flank guns advancing very quietly under either hedge, when

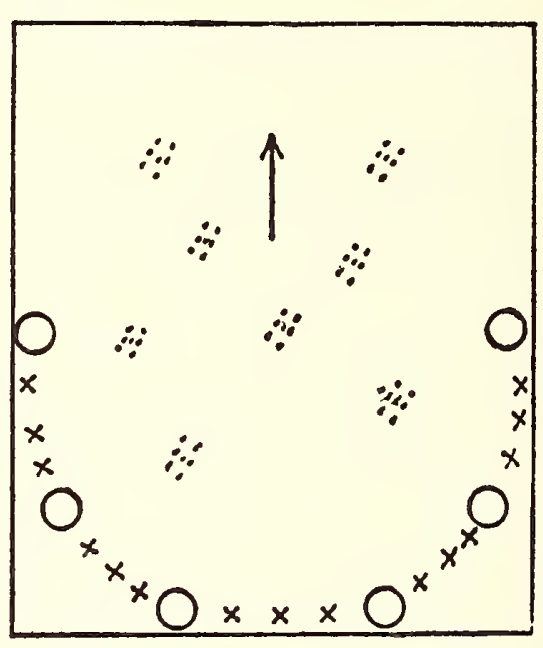

Half-mooning.-First stage. they have gone some distance, a beater on either side will start, and so on until by the time the flanking guns have

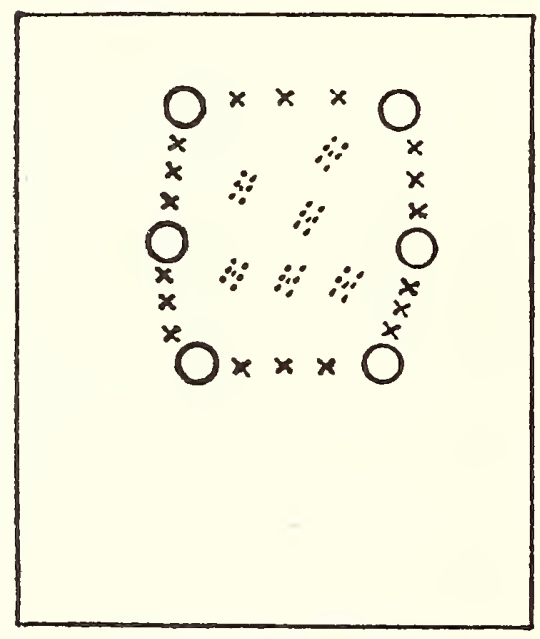

Half-mooning.-Second stage. 172 reached half way up the field the centre gun may start. The partridges will hear the slight noise on their flanks and gather towards the middle of the field, by that time the flank guns will have reached the top hedge and have turned inwards, the partridges there being aware that they are surrounded, will get up in small lots and swing back over the guns in all directions-but, as a rule, it is the centre guns that get the cream of the sport.

Guns stand fast and the beaters draw inwards.

When the circle is complete, great care must 


\section{PARTRIDGE SHOOTING}

be exercised in shooting only at birds which are either high over head or have passed on. If the covert be thick, a great deal of time will be taken in the pick up, and the chances are that many will be lost. The late Lord Leicester was a master of the art of half-mooning, and in fact of everything connected with shooting. He kept his party in great order, and woe betide the gun or beater who was out of place.

In the opinion of many this is the cream of the sport. To enjoy it at its best, the estate must be large, the fences good, and the stock abundant. But excellent sport may be enjoyed on small beats, when the skilful generalship entailed by consideration of wind and boundaries makes up for the smaller size of the bag.

That driving does good for the partridges on an estate is an acknowledged fact; but it must be carried out in moderation to suit the seasons and the numbers of birds on the property.

Provided two lots of beaters are used, the weather fine, and the guns above the average, each being accompanied by a loader, it is only in a very good year indeed that a beat will stand a second day's regular driving, though, of course, when covert shooting, it will vary the entertainment and improve the day's sport to include one or two drives between the coverts, and that should do no appreciable harm to the stock.

It all depends on what the host desires. He may be a very busy man, with many interests and other shooting engagements, which will only enable him to go over his ground properly once. In a case like this he naturally wishes to realize to the very best what is on the beat. He will therefore pick his team of guns carefully, and shoot late in October or early November, when his partridges will be at their strongest, and will have everything planned to make the best of that particular beat or series of beats.

Equinoctial gales or rain may spoil the best laid plans, and it may be necessary to go over the beats or some of them again, much to the advantage of those who are asked to the "second time over." On the other hand, the host may be a man of great hospitality, with few temptations to leave home, who loves to see his old friends round him, and wants to make his shooting go as far as possible. Where this is the case, the driving party will generally consist of a small number of guns-four or five-with only one gun each, and one set of drivers. Excellent sport will be enjoyed, the beat will stand a similar attack later on, and by running two beats into one, quite a good third day may be obtained. 
THE GUN AT HOME AND ABROAD

Whether the result aimed at be a "big" or a "moderate" bag, to bring off a successful day's driving means a lot of work and thinking out on the part of the host and his head keeper. He must first go over the ground beforehand, satisfy himself what number of birds there are, study the position of the root fields and other covert, and arrange his plan of campaign; not too rigidly, as the wind may change and necessitate a complete alteration of plans at the last moment. At least it should do so.

It is curious how seldom the direction of the wind is taken into consideration. Time after time attempts are made to bring fresh birds from their own ground and against a strong head wind that are bound to be failures.

I remember one particular day on a beat which carried a very fine stock; there was a certain field out of which, when in roots, was provided a splendid drive over a valley, with a return drive from the opposite side. On the occasion in question it was desired to fill this field, and three drives in succession were taken all against a very strong gale, with that object in view, but with the result that covey after covey after topping the hedge behind which the guns were posted, broke back over the drivers' heads, scarcely a bird going in the required direction. The host was in low spirits and said: "What on earth are we to do?" It was suggested that we might walk about a mile and a half to the up-wind end of the beat, and have a succession of down-wind drives till lunch, and then walk back again and repeat the operation.

This scheme was carried out, with the result that we had a clinking 190-brace day, nearly all down-wind drives, the partridges coming like bullets, and giving the most sporting shots.

The late Lord Leicester, when he desired to push birds against a strong wind, always had a blank drive, i.e., the guns did not line the fence, but sat under one at right angles some distance off. It was a very effective manœuvre, and a most interesting sight to see packs, coveys, and single birds making their way in the teeth of a full gale back to their own ground, and incidentally, leading many others with them.

Partridges always like to return to their original ground as soon as possible. It is seldom that they will take more than two flights straight away; when flushed on the third occasion they almost invariably either go straight back over the drivers' heads, or else swing out over the flankers, and then turn homewards. It is therefore not the slightest use having too long drives. How often have we heard a keeper say at the end 174 


\section{PARTRIDGE SHOOTING}

of one of these very long drives: "I can't make these birds out, they won't drive. Why a sight more birds broke back over our heads than went over the guns:" the reason, of course, being that they declined to be pushed any further from their homes.

Of course late in the season, with a gale behind them, they will, especially if packed, fly a mile or more; but early in the season, i.e., up to the middle of October, the shorter the drives are in reason the better.

It sometimes happens that there is a covert very inconveniently placed in the middle of a beat, into which many coveys will disappear; and the keeper, though he may particularly wish to bring off a drive in that direction, is afraid to do so, for fear of losing all his birds in the wood. This may be easily prevented, provided the covert be not a very wide one, by lining the guns quietly under the near side and close to the fence. Owing to the background of trees, the partridges will not see them until it is too late; they will then rise thoroughly frightened, and most likely fly clean over the wood to the desired ground on the other side.

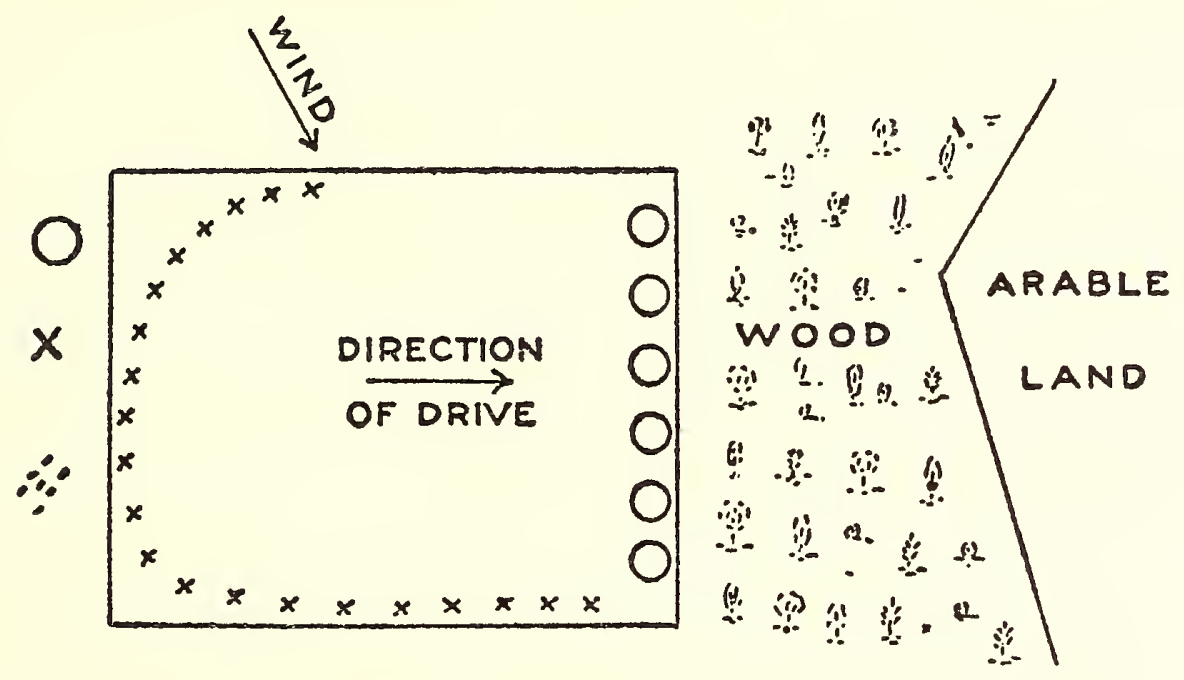

When arranging the different drives, it will save a great deal of time and much unnecessary talking if the position of each gun be marked out by a withy placed in the ground, this will ensure the line being straight and the guns a proper distance from the fence and from each other.

Some men are always keen to be looking over the fence if it be a low one, thus showing themselves to every bird in the next field directly they fire, and very likely spoiling the drive. If a fence be so low that it is easy to shoot over, it is far better, especially if it is likely to be an up-wind drive, 


\section{THE GUN AT HOME AND ABROAD}

to arrange hurdle hides, as before described, from fifteen to twenty yards behind the low fence, than in the fence itself Should there be a cross fence running at right angles to that in which the guns stand and a continuation of it, a place should always be marked out for a gun on the far side, as this is a very favourite line for the birds to take.

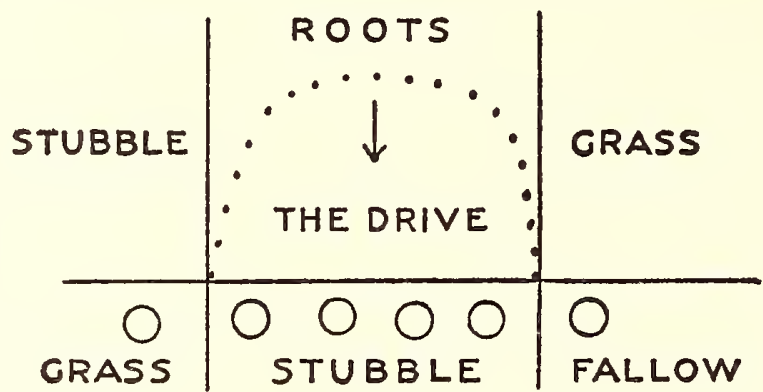

These withys can be placed on different sides of a field in order to arrange for alternative drives should there be a change of wind.

As a rule thirty yards is quite far enough between guns. A covey that flies between two guns is then well within reach of both, whilst should a covey come straight for a gun, his shooting will cause them to scatter, and very likely afford chances to the men on either side of him.

It is most important to shoot at birds as they top the hedge in front, and not wait till they have passed the line; to begin with they are much easier when they are flying at you than when they have passed, and you will have more time to change guns; if pricked, they are not so likely to be injured in the ovaries, whilst by scattering the coveys you assist the sport of your friends on either side, and at the same time probably increase the size of the bag.

With regard to the question of noise; nothing is more irritating than the man who never knows what his number or place is for the next drive, and goes about asking every one in a loud and querulous voice: "What's my number this time?" Again sometimes one hears an animated conversation being carried on between one of the guns and the tenant of the beat as to the late harvest, the prospects for the future, what is the price of wool, wheat, barley, and a hundred and one other things at the local market -this thirst for knowledge would be excellent and tactful at any other time, but not whilst the drive is in progress. Nothing will disturb birds in front more than this otherwise harmless chattering, especially if there is a breath of wind blowing towards the drivers. 


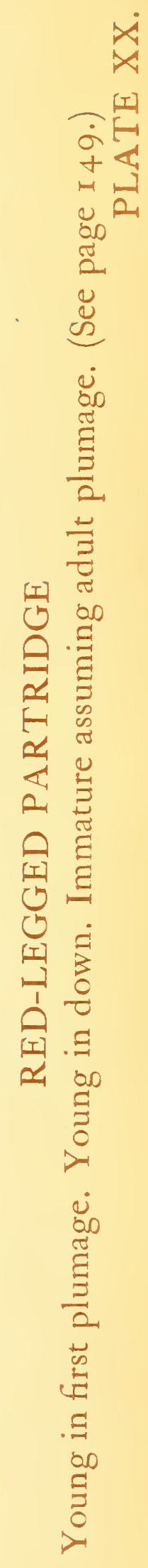




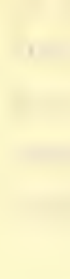




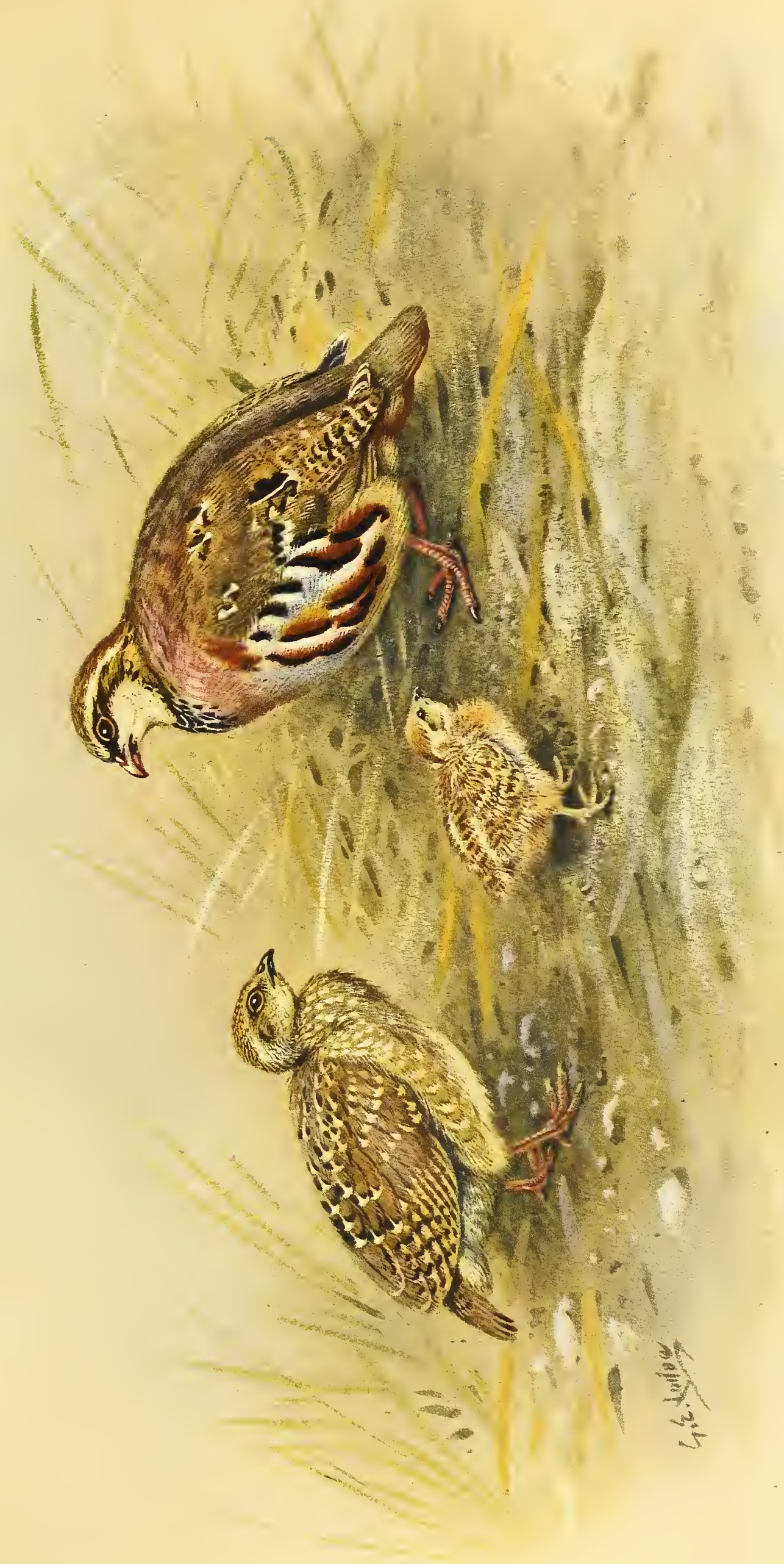




\section{PARTRIDGE SHOOTING}

It is also very important when going to one's place not to show oneself more than possible over a low fence.

To return to the planning of a day's driving. The size of the beat will, to a great extent, govern the strategy. If it be a small beat of 500 or 600 acres, it will be possible and wise to go over the whole ground before lunch, and repeat the operation in the afternoon, those birds that have been disturbed and broken up in the morning will have run out on to the stubbles and be re-found in smaller coveys and single birds.

As a rule one can never do much good with fresh unbroken masses of partridges after three o'clock, whilst two or three drives off favourite barley stubbles late in the afternoon, where the ground has perhaps already been gone over twice, are often very productive.

The keeper should let the tenants know beforehand the day which has been selected to shoot over their holdings, and make arrangements to engage as many of his farm hands as possible. This will benefit the host, as the fields will not be so much disturbed by farm work. The tenant farmer will very likely take care that his sheep are put on the grass fields for the day-and he will come out to look on, and stay to lunch, taking as keen an interest in the sport as any one of the party.

At the same time the labourers will have a pleasant change from the rather monotonous round of farm work, and should they have a good lunch and go home with a couple of rabbits or their equivalent in cash, plus their ordinary day's wages, they will be more likely to take an interest in game preserving and shooting generally, than if they were not considered at all. It is a thoughtful act on the part of the master to provide ginger beer, cider, or shandy-gaff for the drivers about 4 p.m. This will be much appreciated, and will freshen them up wonderfully, especially if the weather be hot or the going heavy.

When the actual day of shooting arrives, it is much better to make an early start. No sportsman worthy of the name minds breakfasting early; if it be November the days are short, and it is a great pity to have the last drives in the dusk when birds and neighbouring guns are difficult to see; it is also rather heartbreaking for the keeper of the beat, who may see the whole of his year's work spoilt by this pandering to the over-luxurious tastes of his master's guests.

When drawing for places the question is often asked: "How many do we move up ?" Very often the answer has not been thought out. As a matter of fact if the number of guns is an even one, i.e., four, six, or 
THE GUN AT HOME AND ABROAD

eight, the guns should move up one place, and if uneven they should move up two places after each drive. This will ensure each gun having a run of all the numbers, and where there are several return drives this is sometimes important, in order to equalize the chances.

Where there are only a few drivers, two intelligent mounted grooms will be of great assistance in getting round large stubbles, or bringing in birds that have broken out some considerable distance.

Each gun should remember what birds he has knocked down, in order that he may know what he has got to pick up; when they are retrieved they should be placed near his stick for convenience of collecting after each drive, and being checked by the man with the game cart. If this is not done it sometimes happens that several are left on the ground to rot.

Here, again, an old, or for that matter a young keeper with a brace of retrieving spaniels will be invaluable to hunt the ground thoroughly and look for any birds that may not have been found by the guns; quite independently of the humane side of the question, if there are many rats, hooded crows, or even pigs about, it will often be too late to search the ground on the following day, for in many cases only the stripped and mangled carcasses will be found. An intelligent keeper or two lying in a fence out of shot and out of sight behind the guns, will assist greatly in recovering towered or pricked birds that might otherwise be lost.

The practice of keepers and spectators sitting under the hedge in front of the guns is a very dangerous one, no matter how high the hedge may be, it very often puts a man quite off his shooting, he has so many additional dangerous angles to bear in mind. (See fig. below.) It is not so much those who are sitting in his immediate front who are in danger from him, but those farther away down the hedge to his right or left.

All lookers on should sit on one flank or the other in line, or on the ground behind the guns.

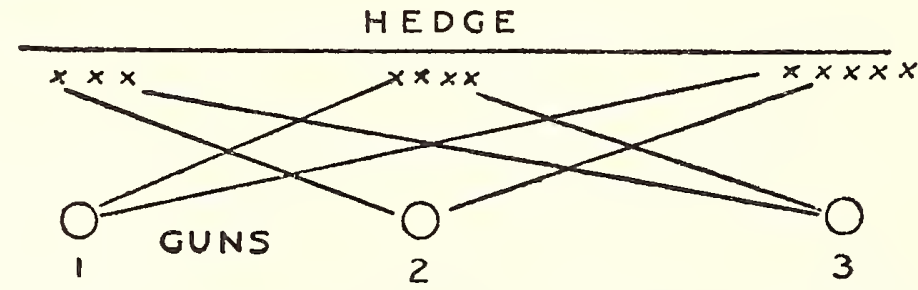

From this sketch it will be readily seen what a number of extremely dangerous angles there are, when spectators sit in front of the guns. 


\section{PARTRIDGE SHOOTING}

The host will save his guests much trouble, and himself perhaps a certain amount of strong language and shouting, if he will tell them before

HEDGE

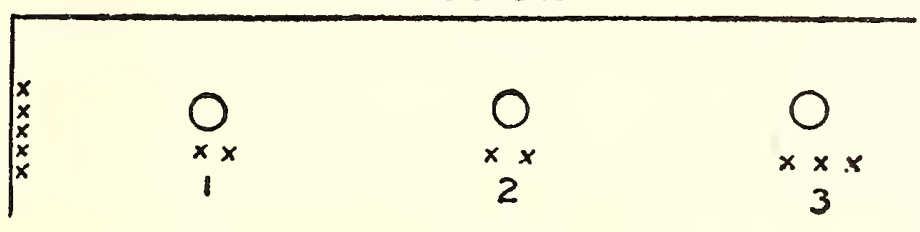

the drive commences, in which direction the next drive will be. They will then know which end of the field to make for when they have picked up their birds.

The drivers will generally approach the guns in a slight curve, both flanks being forward, in order to try and force the birds over the centre of the line. If there be a side wind, of course the beaters on the down-wind side should be considerably advanced. In the latter case, the outside gun should be rather down-

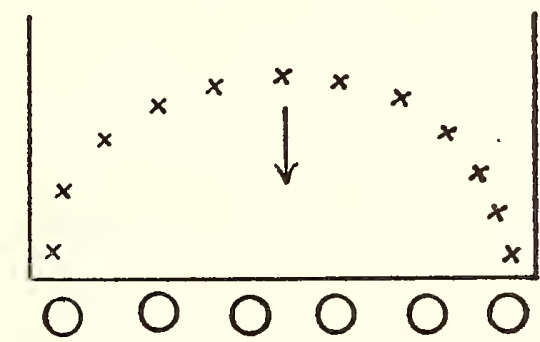
wind of the drive, as some birds are sure to break out. If it is a case of a

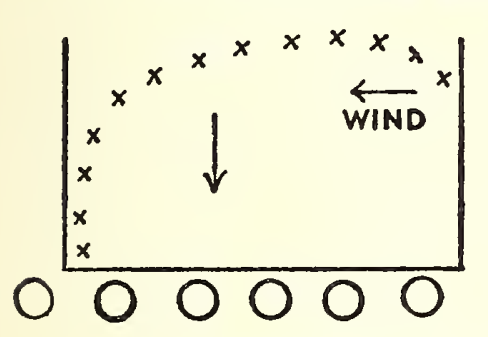
still day, or a down-wind drive pure and simple, the drivers should not come in front of the flank guns, unless it is desired to turn them in a particular direction. This "flanking in" is often carried to excess, and unless the wind is very strong, there is no reason why any gun should be flanked out.

I have often seen the two outside guns rendered quite useless by the flankers coming right across them. This means that where there are six guns out, the party is virtually reduced to four on many occasions, and this must not only be detrimental to the bag, but it spoils the sport of those who happen to be the flank guns on these occasions.

No noise of any sort should be permitted; if partridges mean to go back, no amount of shouting or flag waving will stop them; in fact, it will only make them fly higher and further, and very likely drive them off the beat.

It is a good plan to provide whistles for the centre keeper and one on each flank. These whistles should be in different keys. When a covey rises on the right of the beaters, the keeper on that side will blow his whistle, and the guns opposite that end will be on the qui vive. Should a covey 


\section{THE GUN AT HOME AND ABROAD}

rise in the middle of the field the head keeper will blow his whistle, and so on. This only applies when the fields to be driven are large. Where they are small, one man with a whistle is sufficient, and by blowing once for the right, twice for the centre, and three times for the left, the same object is attained.

In a country where the fences are high, the flankers should carry their flags on long wands, so that the partridges may see them before topping the side fences. These flankers should be selected from the more experienced and intelligent men, otherwise much harm may be done by continually flicking the flags to and fro. This terrifies partridges so much that they will lie like stones, or creep into hedges and remain there for the rest of the day.

It is a pleasant custom at many places for the guns to subscribe a small sum each for the benefit of the drivers if they have done their work well. These little acts tend to cement the good understanding between employers and employed.

When the beat is a large one, and the fields of great size, there will probably be a field in the centre with good fences, which may be chosen as the point d'appui for nearly all the drives. This was the principle that used to be carried out with great success by the late Lord Leicester at Holkham. The first two drives of the day were down-wind, and having collected a large number on perhaps the lower half of the beat, the remaining drives were nearly all carried out to the common centre. Occasionally it happened that large numbers broke out or back, and then it was necessary to go back after lunch and again bring in the hinterland of the morning, in order to replenish the centre. These first drives were rather nerve shattering to a new-comer, as one stood under a hedge on a bitterly cold December morning, with fingers so cold that the trigger could hardly be felt. Suddenly one would hear a covey get up in the distance off the frozen ground, soon followed by many more, and in a moment or two, with a thundering roar, from 300 to 500 partridges would burst over the guns at fifty miles an hour. It was only the most level-headed who could fix attention on particular birds and get off all their barrels with any sort of success.

By the last few drives of the day the big packs were, as a rule, broken up, and they came in small lots or singly, getting such a hammering that the beat could never stand a second dose, even in the very best years. 


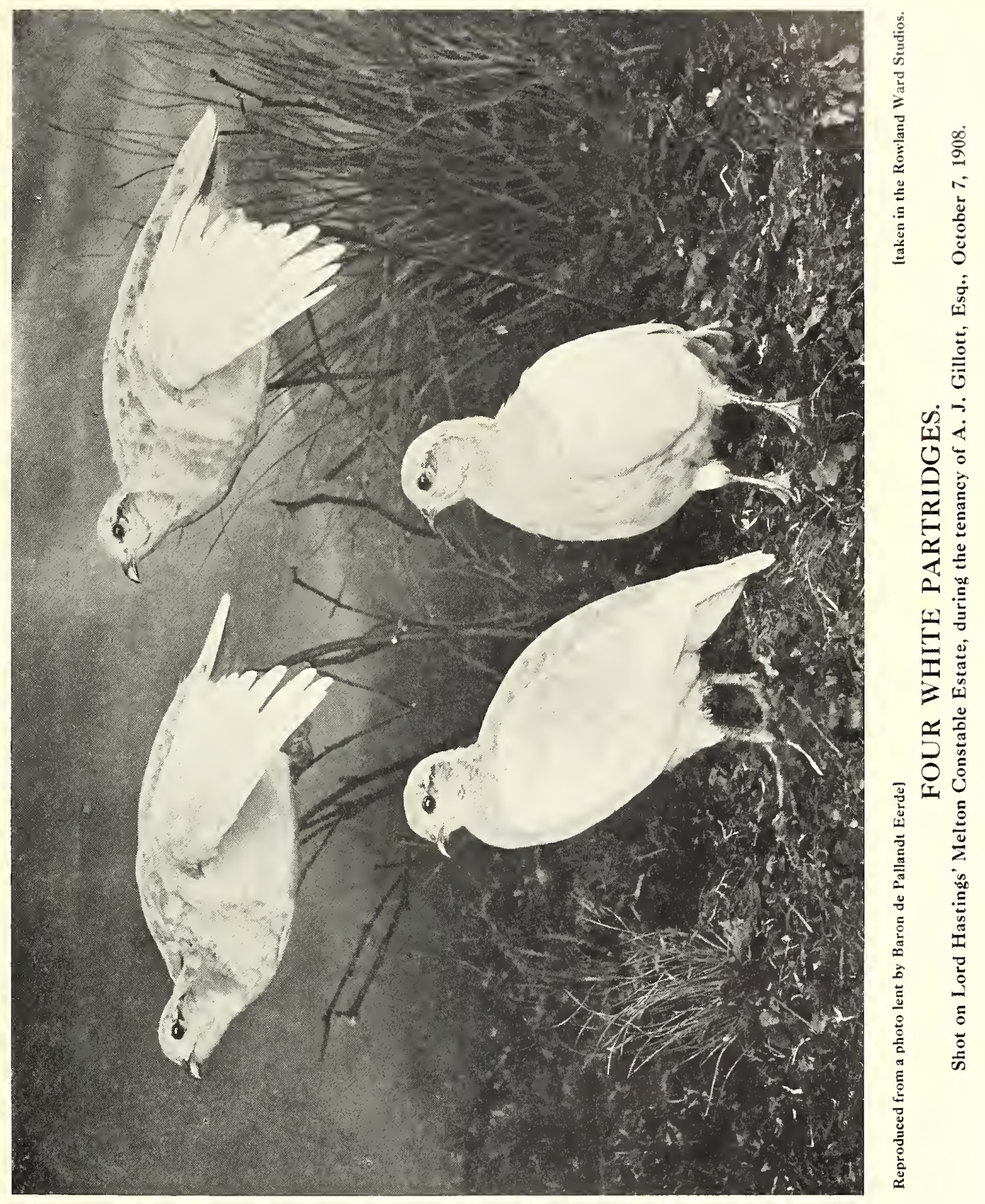





\section{PARTRIDGE SHOOTING}

Owing to the lateness of the season they were so strong on the wing that they never seemed to get tired, and few indeed were the "sitters" one got in a day's driving at Holkham.

When beats are once mapped out, it is advisable to stick closely to them, never mind how tempting it may be to follow a big lot that have broken out just over the boundary hedge. It is fairer to the keeper of the next beat not to poach in any way on his domain, and if by any chance one or two big lots do escape unshot at from a large area of ground, they will make a real good healthy stock for next season, and one need not mind pitching into those that remain pretty severely.

If a host finds that his stock is thinner than he thought, it is easy to save them either by letting the drivers walk through the roots and other covert quickly, when many birds will be walked over or get up and go back, or else to take care that they are not flanked in too severely, in which case many will break out to the flanks, unshot at.

When driving late in the season, roots are generally scarce, and what there are have little or no "top" on them, and therefore afford little cover. When this is the case a good rough fallow is the best place for breaking up big lots and eventually providing a good drive.

For the first drive of the day it is often the custom to walk in a good deal of land before the arrival of the guns, in the hope of providing a good start. In a case like this, two things must be borne in mind, if the weather be wet the partridges will be wanting to be out of the roots almost as soon as they have been driven in; therefore this driving in should only be done at the last possible moment. As the first drive should always be, if possible, down wind, some of the fields that lay down wind of the first field should be walked in, and the birds there will fly straight back to their original ground and give a lead to any other coveys that may have been put in from the up-wind end of the field. In order to keep birds in the roots "stops" are sometimes placed to prevent them running out. Of course these stops must be some distance back from the actual field.

Directly the guns have taken up their stands, the host can give the signal to start the drivers by blowing one or two notes on the little horns that are supplied for this purpose. If there is a gale of wind, or the drivers are a long way off, it is advisable to precede the horn by a very quick double shot, some one of the driving party is sure to hear this and pass the word along to the head man.

Half the fun of shooting small game is the possession of a good retriever. 
THE GUN AT HOME AND ABROAD

For driving purposes it will save a good deal of anxiety to peg a dog who shows any tendency to run in during the drive. He will soon recognize that it is no use trying to run in, and will sit quietly marking every bird as it falls. Some dogs, however, are so keen that they keep up a continual whining accompaniment to their master's performances; this is maddening to the gun himself and also to his neighbours. If a dog will not break himself of this habit the best thing to do is either to give him to an under keeper or turn him into a house dog-but as a rule age brings experience, and they soon learn to be quiet.

Labradors are all the fashion now, but, in my humble opinion, they are so often hard-mouthed, or develop such bad tempers, that for practical working I prefer a cross between a retriever and a spaniel, or if it is desired to have an easier broken dog, a retriever and a setter cross, picking out the puppies that are of uniform colour.

The spaniel cross is a splendid one, though such dogs are difficult to break from fur, their spaniel blood making them keen to hunt anything. On the other hand they never seem to tire; after the longest day they will retrieve and hunt just as busily as when they started.

Another important thing to enable a man thoroughly to enjoy a day's driving and do his best in the actual shooting, is the knowledge that his loader is safe, quick, and keen.

A great deal depends on the way he hands you your second gun, and, of course, much also depends on his quickness in loading, and his ability to get out of your way when you swing round to shoot at birds that have passed the line. Every new man ought to be taught in the offseason how to clean and look properly after the guns in his charge, and practice loading till he has got into his master's ways. One of the best means of doing this after he has been properly grounded is to take him to a shooting school three or four times, and give him half an hour's practice in loading for you whilst you get your muscles and eye in at clay pigeons.

A good loader may be also a great help in picking up after a drive, having first taken care to see that both guns are unloaded, and placed in a position where they cannot be knocked down.

ARTHUR AGLAND HOOD. 


\section{SOME NOTABLE BAGS}

\section{SANDRINGHAM}

B

$Y$ the gracious permission of His Majesty I am enabled to give a selection of some of the best partridge days at Sandringham, which will give an idea of the results of good management.

In connection with these excellent days' sport it should be borne in mind that on no occasion was there any attempt made to create a record, or any special selection of guns.

On November 10, 1905, only eleven drives were taken, and the last three drives yielded 641 partridges. Unfortunately his present Majesty was absent in India.

Date $\begin{gathered}\text { No. of } \\ \text { Guns }\end{gathered} \quad$ Beat $\quad$ Pheasants Partridges Hares Rabbits Pigeon Various $\begin{gathered}\text { Daily } \\ \text { Totals }\end{gathered}$

Nov. 10.9 . Flitcham and Appleton

Farms . . . . . $190.689 .29,2 \cdot 1 \cdot 1.912$

Nov. 11 . 9 . Shernbourne Fields and

Partridge Cover •. 94 . 826 . 64 . 3 . 0 . $\quad 2 \quad 989$

Nov. 10 . Shernbourne and Eleven

Acres..... . 282 . 766 . 183 . 6 . 1 - 0 . 1,238

Nov. 10 . Shernbourne and Eleven

$$
\text { Acres . . . . . } 317 \text {. } 1,342 \text {. } 101 \text {. } 5 \text {. } 5 \text {. } 5 \text {. } 0 \text {. } 1,770
$$

Nov. 6 . 9 Shernbourne and Eleven

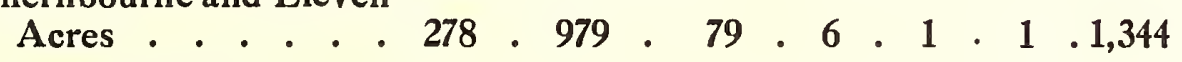

Dec. 5.9. Flitcham and Captain's

$$
\text { Close .. . . . } 499,717,150,7 \cdot 0 \cdot 2 \quad 1,365
$$

On the dates mentioned the guns were the following :

Nov. 10, 1897.-H.R.H. the Prince of Wales (His late Majesty King Edward), the Duke of Saxe-Coburg and Gotha, the Duke of Sutherland, the Earl of Lathom, the Earl of Albemarle, the Earl of Rosebery, the Earl of Clarendon, the Right Hon. Henry Chaplin, and Colonel Arthur Davidson. Weather: Fine.

Nov. 11, 1897.-Same guns. Weather: Foggy at the start in the morning, and again in the afternoon, preventing at least one drive.

Nov. 10, 1904.-His late Majesty King Edward, H.R.H. the Prince of Wales, the Duke of Richmond, the Marquis du Lau, the Marquis de Breteuil, the Right Hon. Henry Chaplin, Hon. Geo. Keppel, Major-Gen. Sir Albert Williams, and Mr George West. Weather: Fine. 


\section{THE GUN AT HOME AND ABROAD}

Nov. 10, 1905.-His late Majesty King Edward, Prince Kinsky, the Duke of Alba, the Duke of Marlborough, the Earl of Rosebery, Viscount Falmouth, Lord Brooke, Lord Lovat, and the Hon. George Keppel. Weather: Fine.

Nov. 6, 1906.-His late Majesty King Edward, H.R.H. the Prince of Wales, H.R.H. Prince Philip of Coburg, H.S.H. Prince Trautmansdorff, H.S.H. Prince Löwenstein, the Earl of Granard, Viscount Coke, the Hon. George Keppel, and the Hon. H. Stonor. Weather: Fine.

Dec. 5, 1906.-His late Majesty King Edward, H.M. the King of Norway, H.R.H. the Prince of Wales, the Earl of Gosford, Earl de Grey, Monsieur S. Poklewski, the Rt. Hon. H. Chaplin, Mr A. Sassoon, and the Hon. J. Ward. Weather: Fine.

\section{HOLKHAM}

The writer was one of the fortunate members of the party who at Holkham in November, 1905, enjoyed the best week's partridge driving on record. The late Lord Leicester was then alive, and although a great invalid, his indomitable sporting spirit overcame all difficulties. He came out every day in a victoria, to superintend the operations, and no man more thoroughly enjoyed the sport. The beats were large, the drives long, at that time of year there was very little covert, and, as a matter of fact, nearly every drive consisted of a big stretch of barley stubble, young grass, fresh sown wheat, and bare fallow, with an occasional piece of roots.

On the "big day," there was a light breeze, hard frost, and very bright sun, which was dead in our eyes for several of the drives.

On the third day at Wighton, some very big lots broke out, just over the boundary hedge of the beat for that particular day and were not brought in. If they had been, in all probability the bag that day would have been as good as the first.

\begin{tabular}{|c|c|c|c|c|c|c|c|}
\hline & Beat & Pheasant & ts Partridges & Hares & Rabbits & 3 Various & \\
\hline & & . 10 & & & . 2 & & \\
\hline & and Egmore & 30 & & 40 & 3 & - & \\
\hline & $\mathbf{W i}$ & 8 & 1,294 & 21 & 1 & - & \\
\hline ov. Iu & Branthill and Crabb. & 29 & 754 & 36 & 2 & - & \\
\hline
\end{tabular}

Guns : Lord Coke, Col the Hon. W. Coke, Prince F. Dhuleep Singh, Hon. C. Willoughby, Col Custance, C.B., Mr W. Forbes, Mr W. Barry, and Major Acland Hood.

There were twenty drives-all long ones-which shows how well and quickly the beaters (of whom there were two lots), must have got round.

184 


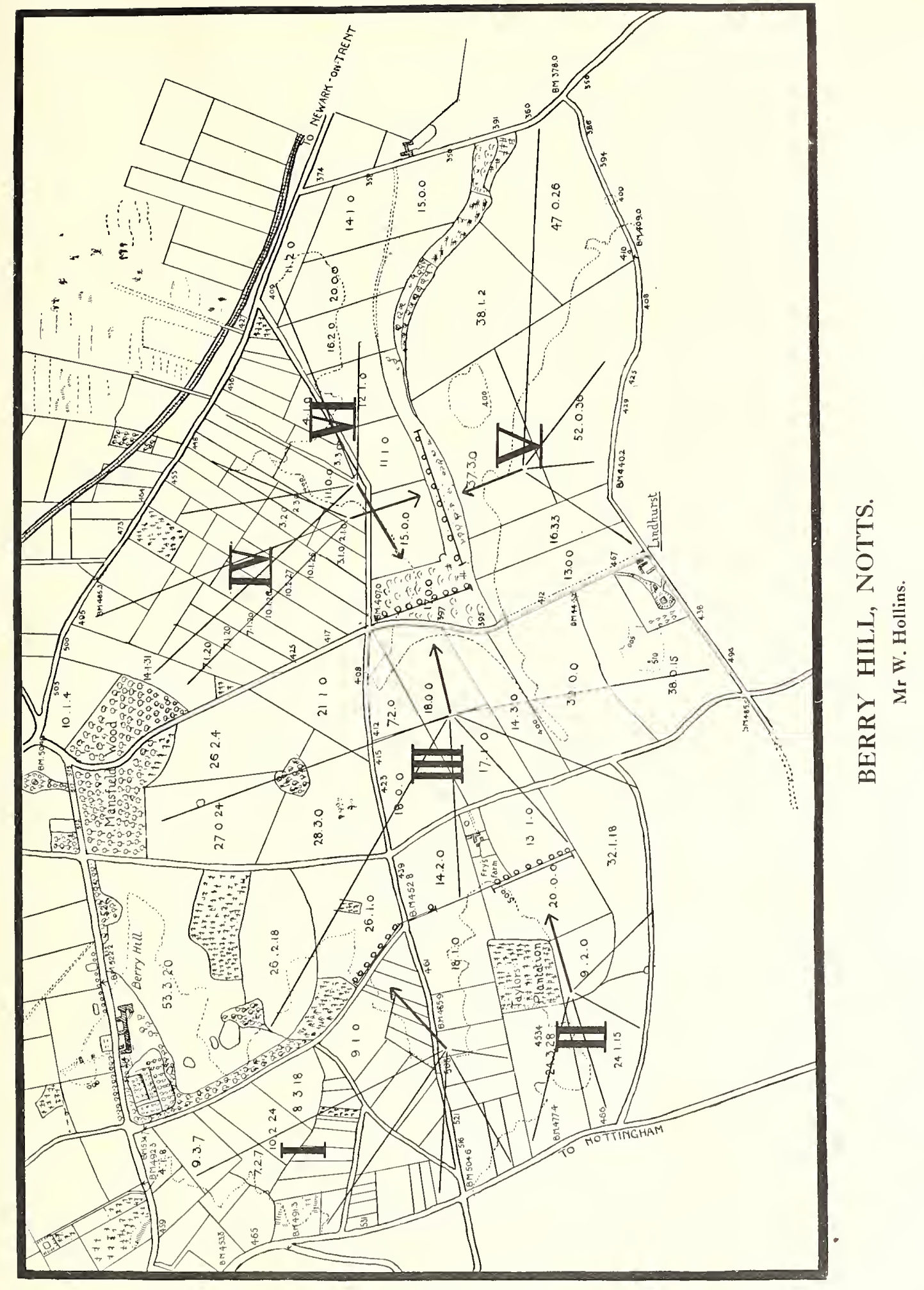





\section{SOME NOTABLE BAGS}

The following is a list of birds picked up after each drive. Of course a few more were found far away behind, and not counted at the time, and with those that were found on the following day, make up the total; $47,46,79,168,88,102,74,132,41,112,71,136,42,27,111,66,37,92$, $80,45-1,596$.

\section{BERRY HILL, NOTTS.}

Mr W. Hollins has kindly sent us a map of his best beat, showing the different drives, which will readily explain the plan adopted.

The result shows what may be done by good management, and the judicious introduction of Hungarian partridges. With reference to the latter Mr Hollins says: "Before Hungarians were turned down here seventeen years ago, we used to think we had a good day if we shot forty brace with four guns walking early in September. I first of all turned down Hungarians in 1895, and have had a good stock ever since.

"The Berry Hill beat consists of 1,292 acres; without doubt, on October 10, 1906, if we had started shooting at 9.30, and I had had two distinct lots of drivers, we should have shot 1,000 brace, as I could easily have got three, or possibly four more drives into the day. I did not kill any more birds after the 'big day' on that beat, and owing to bad seasons have done nothing very remarkable since. I farm all the ground except about 160 acres on the Berry Hill beat."

Date Pheasants Partridges Hares Rabbits Various Total

Oct. 9, 1906 . - . 442 . - 2 - - 444

Oct. $10 \quad 19 \cdot 1,504 \cdot 3 \cdot 10 \cdot 2 \cdot 1,538$

Oct. 11 - - $671 \cdot 3 \cdot 2 \cdot-.676$

Guns : Capt. W. H. Thomasson, Lord Savile, Mr F. H. Oates, Mr W. C. Oates, Sir G. E. Paget, Mr F. E. Seely, Mr J. Whitaker and Mr W. Hollins.

On Oct. 10 there were only eleven drives. The pick-up looks large, but many birds fell in thick stuff and were most difficult to find.

\begin{tabular}{|c|c|c|c|c|}
\hline lst & rive & •• & . & \\
\hline 2nd & , & & 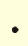 & \\
\hline $3 r d$ & " & & • & \\
\hline 4th & " & • & . & - \\
\hline 5th & ," & $\cdot$ & . & \\
\hline $6 \mathrm{th}$ & ", & 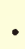 & . & \\
\hline 7 th & ", & & . & . \\
\hline
\end{tabular}

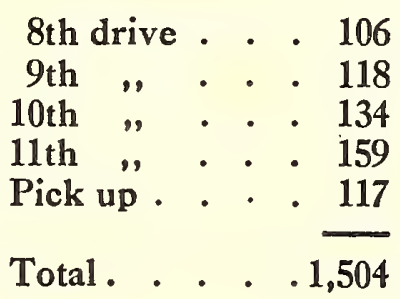




\section{EUSTON}

Mr Pearson Gregory, who for years rented the Duke of Grafton's estate at Euston, has very kindly sent the following particulars of best mixed days in various years. The chief point about the shooting on this estate is that, besides plenty of partridges, a very large number of field-bred pheasants come over the guns, flying beautifully, and varying the sport.

\begin{tabular}{|c|c|c|c|c|}
\hline \multirow{3}{*}{1897.} & & Pheasant & Partridges & Hares \\
\hline & Oct. 27 & . 270 & . 448 & 76 \\
\hline & Oct. 28 & 330 & 626 & 136 \\
\hline \multirow[t]{2}{*}{1898.} & Nov. 1 & 289 & 509 & 70 \\
\hline & Nov. 4 & 380 & 615 & 168 \\
\hline \multirow[t]{3}{*}{1899.} & Oct. 17 & 210 & 348 & 45 \\
\hline & Oct. 31 & . 259 & 402 & 98 \\
\hline & Nov. 2 & 304 & 503 & 97 \\
\hline \multirow[t]{3}{*}{1900.} & Oct. 11 & 244 & 269 & 40 \\
\hline & Oct. 30 & 238 & 337 & 42 \\
\hline & Oct. 31 & 194 & 541 & 171 \\
\hline \multirow[t]{3}{*}{1901.} & Oct. 18 & 240 & 280 & not given \\
\hline & Oct. 29 & . 307 & 551 & , , \\
\hline & Oct. 30 & . 423 & . 517 & \\
\hline \multirow[t]{2}{*}{1902.} & Oct. 29 & - 213 & - 512 & 121 \\
\hline & & & & \\
\hline
\end{tabular}

$$
\begin{aligned}
& \text { 1903. Pheasants Partridges Hares } \\
& \text { 1904. Oct } 19 \cdot 340 \cdot 373 \text {. not given } \\
& 328 \cdot 563 \cdot \text {. } \\
& \text { Nov. } 2 \cdot 282 \cdot 714: 115 \\
& \text { 1905. Oct. } 17 \text {. } 267 \text {. } 638 \text {. not given } \\
& \text { Nov. } 1 \div 627 \text {. } 604 \div 101 \\
& \text { Nov. } 2 \text { - } 150 \text {. } 542 \text {. } 106 \\
& \text { 1906. Oct. } 31 \text {, } 228 \text {. } 346 \text {. not given } \\
& \text { Nov. } 1 \text { - } 154 \text {. } 362 \text {. , } \\
& \text { 1907. Oct. } 29 \text {. } 191 \text {. } 459 \text {. , } \\
& \text { 1908. Nov. } 3 \text { • } 277 \text { • } 457 \text { • ,, } \\
& \text { Nov. } 5 \text {. } 266 \text {. } 369 \text {. , } \\
& \text { 1909. Nov. } 2 \text {. } 240 \text {. } 251 \text {. , } \\
& \text { 1910. Nov. } 1 \text { - } 315 \text {. } 203 \text {. ", } \\
& \text { Nov. } 2 \text {. } 244 \text {. } 210 \text {. , }
\end{aligned}
$$

The object at Euston has been to have a succession of good weeks, rather than a few enormous bags. The beat for each day is always strictly adhered to, and they are not of very large extent.

The best weeks for partridges were the following :

$$
\begin{aligned}
& \text { 1896. Nov. 3-6 353, 635, 615, } 458 \text { birds. Total for the year, } 6,162 \\
& \text { 1898. Oct. 11-14 317, 457, 535, } 389 \text {," } \\
& \text {, Nov. 2-5. 509, 265, 615, } 760 \quad \text { ", , , , , } \quad 5,171 \\
& \text { 1902. Oct. } 28-31 \quad 516,512,511,509 \quad, \quad \text {, } \quad \text {, } \quad \text {, } \quad 4,812 \\
& \text { 1904. Sept. 27-30 384, 336, 804, } 234
\end{aligned}
$$

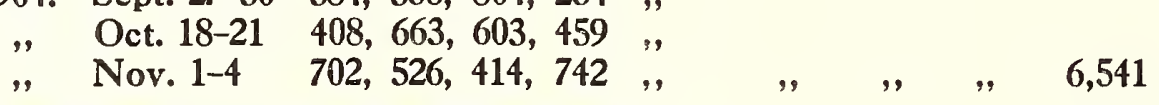

$$
\begin{aligned}
& \text { 1905. Oct. } 17-20 \quad 638,566,383,318 \text {, } \\
& \text { " } \begin{array}{lllll}
\text { Oct. } 31 & \text { No } 3
\end{array}
\end{aligned}
$$

Since 1905 the seasons have been very bad, but bags of over 200 brace in the day have frequently been made. 


\section{SOME NOTABLE BAGS}

THE GRANGE, ALRESFORD

This estate of Lord Ashburton's, in Hampshire, is reputed to afford, perhaps, the finest partridge shooting in England. It was here that $\mathrm{Mr}$ Archie Wortley's picture of "Partridge Driving" was painted in a field called Newland Glade, and it was in this field in 1887 that 1,000 partridges were killed without ever going out of it; the drives being towards this common centre.

Lord Ashburton writes: "There were, as you probably know, no imported birds, Hungarian or others, no bought eggs or hand-reared birds-the bags were the result of a good season. ... These last two years have been disastrous, but I think I have a good useful stock left."

1887. Oct. 18 . New House . . . 1,344 partridges.

Oct. 19 . Itchen Down . . . 1,093 ",

Oct. 20 . Totford . . . . . 732 ,"

Oct. 21 . Swarraton . . . . 940 ",

Guns : H.R.H. the Duke of Cambridge, the Duke of Roxburgh, Lord Walsingham, Mr A. H. Wood, Col the Hon. E. Digby, Capt. Mildmay, and the Hon. F. Baring.

Another week the same year, on different beats, produced 2,604 partridges in the four days. Total bag for the year a little over 9,000 birds.

1897. Nov. 2 . Itchen New House . 1,374 partridges . 30 drives.

Nov. 3 . No shooting, wet.

Nov. 4 . Chilton Valley . . . 1,461 " 25 "

Nov. 5 . Dunridge . . . . 691 " 16 "

Guns: Prince Victor Dhuleep Singh, Lord Pembroke, Lord Lathom, Lord Walsingham, Lord Newport and Lord Ashburton.

Very strong wind each day; on the last day could not go out till 12.

On four other days that year 2,071 partridges were killed.

Total bag for the year 6,000 partridges.

\section{HONINGHAM, NORFOLK}

On this estate of Sir Ailwyn Fellowes there are five beats, and in 1905 the owner had the best of the many good weeks his friends have enjoyed there.

In this part of Norfolk the fields are not so large as in the north-western part of the county, and the beats are smaller, seldom averaging much over 600 acres. The weather was splendid, and so was the show of birds. 


\begin{tabular}{|c|c|c|c|c|c|c|}
\hline \multirow{4}{*}{1905.} & Date & Beat & Partridges & Hares & & s Vari \\
\hline & Sept. 26 & Honingham & & 1 &. & \\
\hline & Sept. 27 & of & . 703 & - & 2 & 1 \\
\hline & Sept & . & 680 & & 2 & 2 \\
\hline
\end{tabular}

Guns: Lord Albemarle, Mr R. Rimington Wilson, Col Hon. F. De Moleyns, Mr Heatley Noble and Major Acland Hood.

Sir Ailwyn Fellowes did not shoot, as he prefers to manage the driving which goes like clockwork. In addition to the above Col Custance, C.B., Mr E. G. Buxton, and Mr W. Barry each shot on one day.

In the early nineties anything over 100 brace per day was considered very good. This shows what good management will do.

\section{MOULTON PADDOCKS}

We now come to a case of successful tactics, on a small extent of most excellent ground, where Mr F. E. R. Fryer is a past master of the art of preserving, planning, and realizing his partridges.

He writes: "In 1870 Moulton Paddocks consisted of 300 acres only. My father and self got 80 brace on September the first that year; and 507 birds in the season-all walking up.

"In 1872. The best day (same guns) 75 brace; season's bag 682 partridges-all walking up.

"In 1877. The extent was increased to 505 acres, and then we began driving-but we could not shoot till well into October on account of having to shoot the pheasants first, and it appears by the game book that it nearly always blew a gale.

"In 1877. 765 partridges were killed during the season. Best day 65 brace, driving, on October 17.

"In 1881. 676 partridges were killed; 75 brace on October 19 and 71 brace on January 25 (1882), five guns. This year the total bag was 3,024 head, including 241 hares.

"In 1882. 724 partridges were killed; 95 brace in a gale of wind on October 19-best day.

"In 1883. 749 partridges killed during season. October 17 and 18, 91 brace and 82 brace (five guns), both days very high wind. Total bag 3,274 head, including 332 hares.

"In 1884. Total bag 701 partridges. Best days, September 27, 145 brace to five guns; and September 29, 81 brace to five guns."

188 


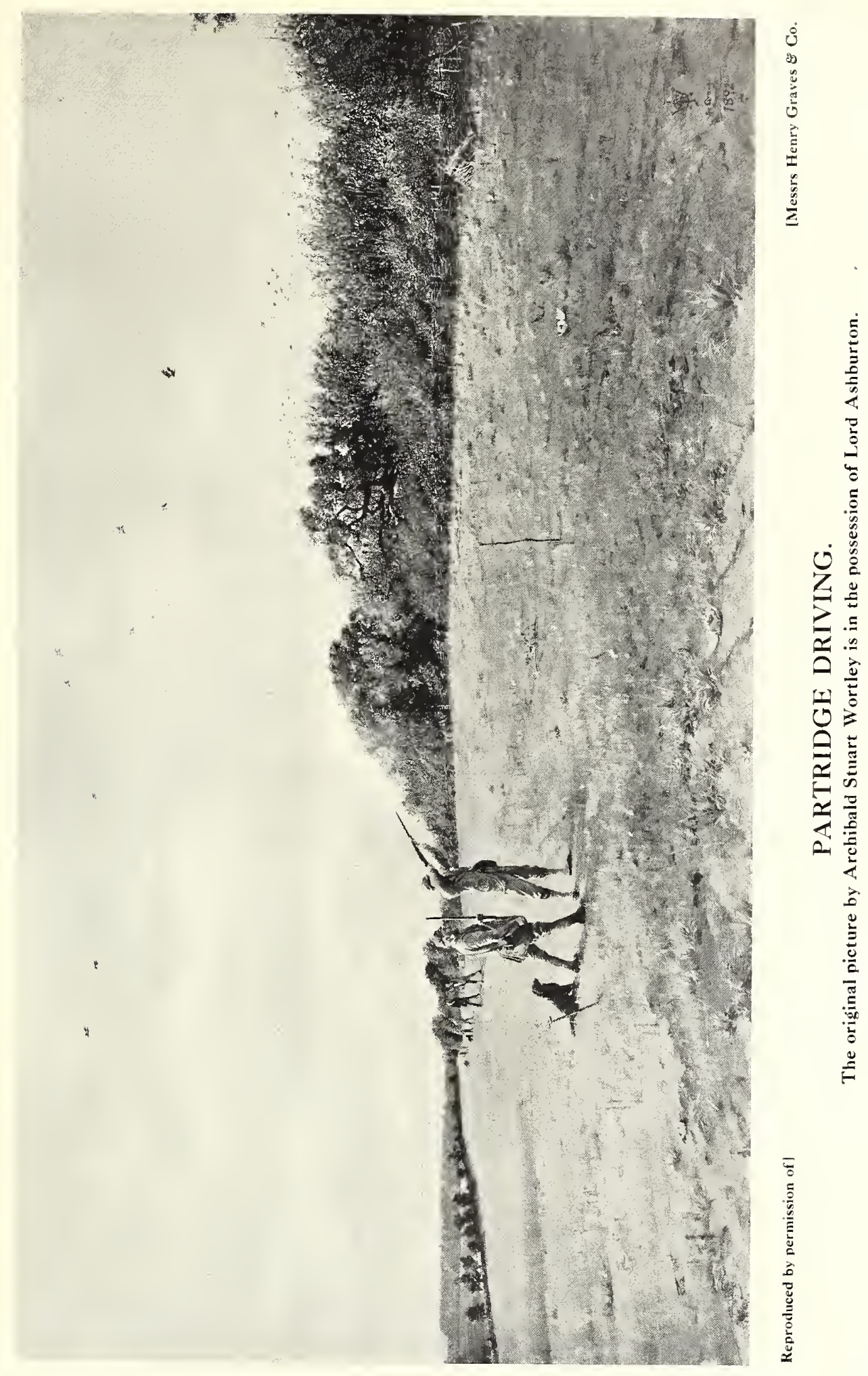





\section{SOME NOTABLE BAGS}

PICKENHAM HALL

Capt. G. W. Taylor has kindly furnished the following details of a good day's shooting on his estate :

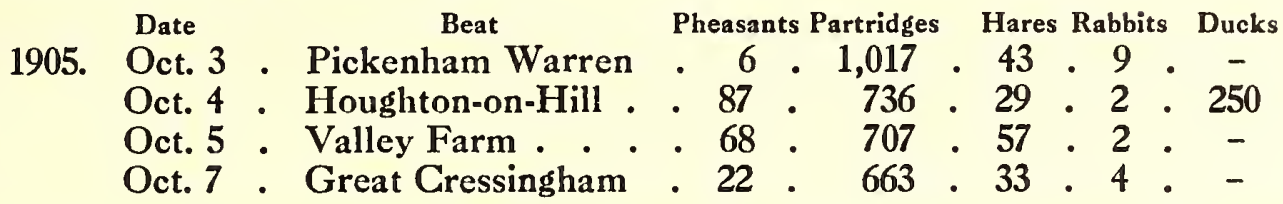

Guns : Lord Deerhurst, Lord Chelsea, Hon. P. Thelhusson, Mr G. Sloane Stanley and Capt. G. W. Taylor.

Lord Wilton shot two drives on October 3, but damaged his arm, and was unable to shoot the remainder of the week, his place being taken on October 7 by Mr W. Johnson.

This is a wonderful good week, especially considering the number of guns.

\section{ORWELL PARK, IPSWICH}

On this typical Suffolk shooting, belonging to Capt. E. Pretyman, M.P., the following is reported as the best week for many years :

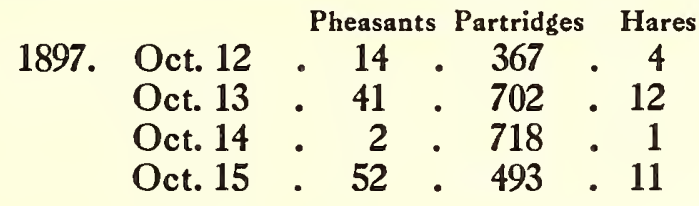

Only one lot of drivers on the last day.

Guns : Lord Ashburton, Hon. O. Molyneux, Mr A. Stuart Wortley, Mr R. H. Rimington Wilson, Mr W. J. Beart, and Sir J. Rowley. On the last three days Sir J. Rowley left and Capt. Pretyman took his place.

\section{STRATTON PARK, MICHELDEVER}

On this estate there are now only three beats, one of which principally consists of grass. The owner, Lord Northbrook, says : "I think we began driving regularly about 1881 or 1882 : we got up to

100 brace in the day in 1884.

$150 \quad " \quad " \quad 1892$.

$200 \quad " \quad$ " 1895.
300 brace in the day in 1897.

$400 \quad " \quad$ " 1906.

$500 \quad " \quad$ " 1908.

Concerning the last mentioned, he adds : "I don't expect ever to have such a good year again." 


\section{THE GUN AT HOME AND ABROAD}

1908. Pheasants Partridges Hares

Oct. 14 : Little Farms : $15: 353: 4$

Oct. 15 . Burrough . . . 10 . 602 . 1

Guns : H.R.H. Prince Arthur of Connaught on October 13 and 15, Lord Ilchester, Lord Chesterfield, Lord Falconer, Lord Willoughby De Eresby, Mr Wilfred Ashley and Lord Northbrook.

\section{WELBECK ABBEY}

This well-known estate of the Duke of Portland furnishes a good instance of the success which has attended the judicious introduction of Hungarian partridges, combined with excellent management, as the following annual returns will show :

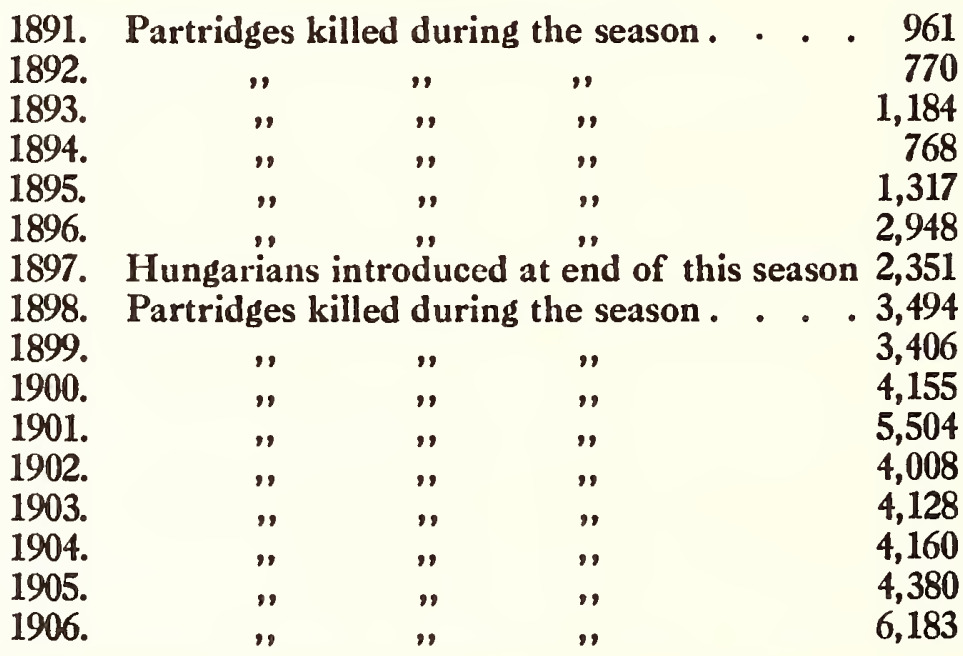

Since 1906 each season has been more unfavourable than the last, but there is a good stock left, and given a couple of good years, everything will be right again.

The following is the best week at Welbeck-and a splendid one it was :

$$
\begin{aligned}
& \text { Rabbits } \& \\
& \text { 1906. Oct. Clipstone I } .73 .900 .6 .7 \\
& \text { Blue Barn . . } 239 \text { • 1,467 . } 11 \text {. } 12 \\
& \text { Clipstone II : } 34 \text {. } 773: 1: 3
\end{aligned}
$$

Guns : The Duke of Portland, Lord H. Bentinck, Col Hon. H. Legge, Lord Dudley, Hon. J. Ward, Mr G. Holford, Mr H. Lindsay and Capt H. Heathcoat Amory. 
SOME NOTABLE BAGS

The Duke of Portland has kindly allowed us to reproduce a plan of one of his "remises." There are many foxes on this estate, and "remises" afford protection for nesting purposes.

PLAN OF A "REMISE" AT WELBECK.

Scale about 100 yards to the inch.

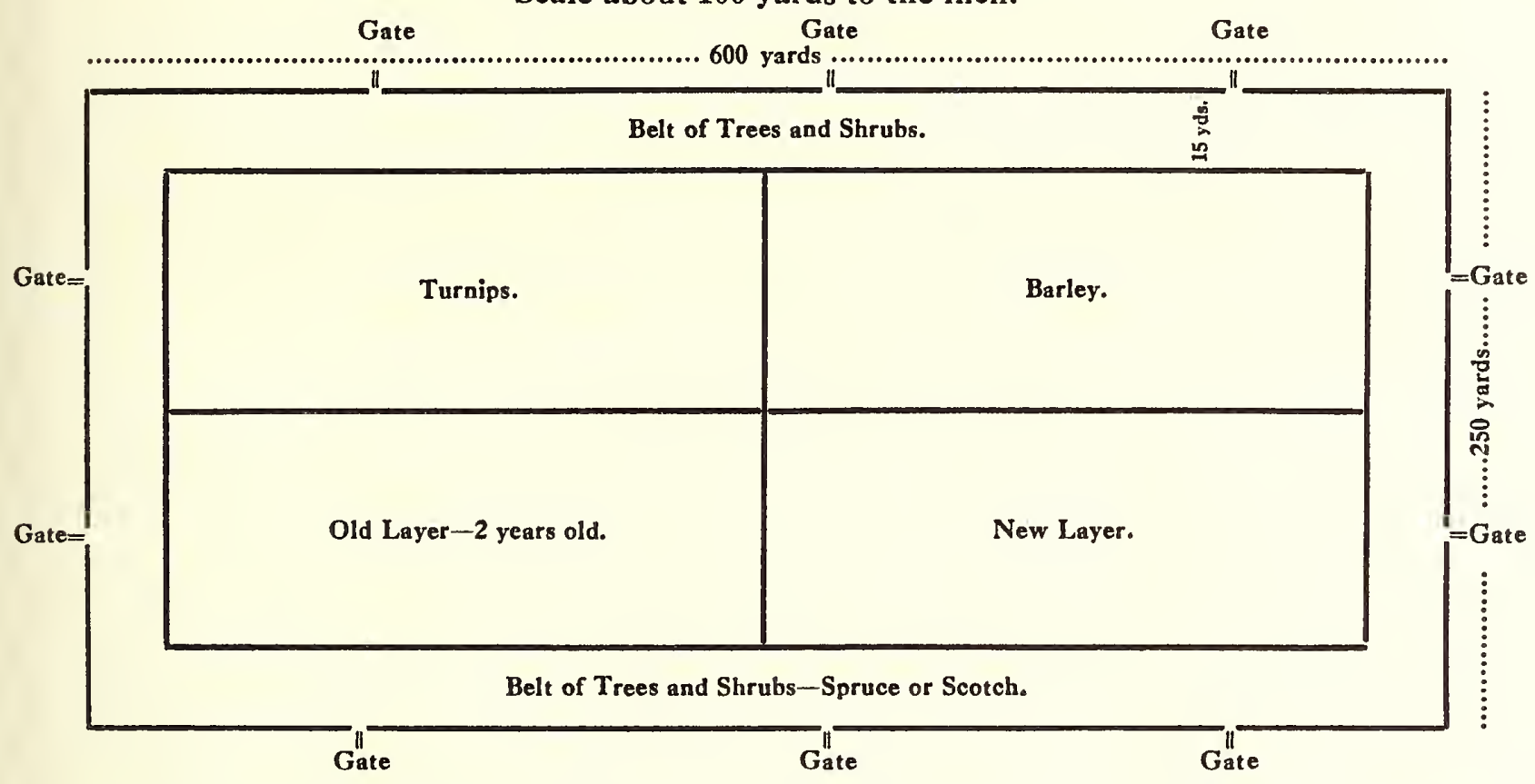

Must be cropped in rotation. Wire fencing $6 \mathrm{ft}$. to $8 \mathrm{ft}$., large mesh at bottom, $4 \mathrm{in}$. to $5 \mathrm{in}$.

The whole extent of this remise is about 11 acres. Usual size 4 or 5 acres.

\section{WESTACRE, NORFOLK}

This estate affords a good example of the association of foxes and partridges. The owner, Mr Birkbeck, is a keen preserver of foxes for the West Norfolk Hunt, and puts wire cages over the nests to protect them from the attentions of the old foxes in the nesting season. There are several beats on the estate, the best being Gayton Thorpe. On October 17, 1904, 860 partridges were shot in a very high wind, from the wrong direction. Mr Birkbeck says with regard to that day : "I never saw so many birds here as there were in the first field, which also included a brace of foxes, but the wind played havoc with the bag!

"The following year, 1905, with fewer birds we killed 908 on the same beat. We have also killed 800 partridges in a day on the Walton beat." 
In 1905 the guns were: Mr S. Gurney Buxton, Mr O. S. Curtis, Lord Cranworth, Hon. J. Dawnay, Mr R. H. Rimington Wilson, Mr A. C. Fountaine, Mr R. Heywood, and the host, Mr H. Birkbeck.

\section{WITCHINGHAM, NORFOLK}

On this estate belonging to $\mathrm{Mr} \mathrm{W}$. Barry we have an excellent example of the reward which attends good keepering and intelligent supervision. Before Mr Barry bought this property, a few years ago, the best day was about seventy-eight brace. Mr Barry determined to give up rearing pheasants, and to concentrate his keepers' work on vermin killing and looking after the partridges' nests, changing the eggs, etc. At the end of four years the following result was obtained :

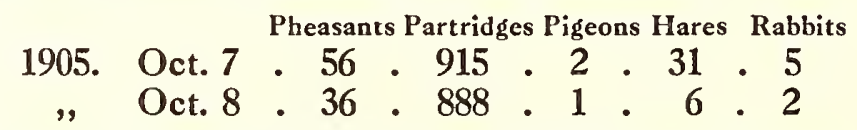

Guns : Lord Ernest Hamilton, Lord Elphinstone, Mr J. D. Cobbold, Mr J. F. Mason, Capt. G. Tryon, Sir Ailwyn Fellowes and Mr W. Barry.

The above are a few instances in various counties of the success which attends careful preservation. There are of course many other places where equal success has been or is being attained; notably in Scotland where, on the Duke of Roxburgh's estate, an average of 220 brace per day has been obtained. In Somersetshire, which is not generally considered a partridge country, Lord St. Audries has killed over 500 brace in three days' driving, and about the same number walking up on the outside beats, where the fields are too small for driving purposes.

A. ACLAND HOOD. 


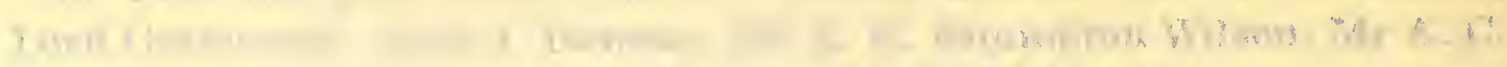

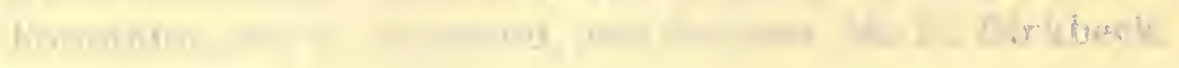

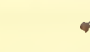

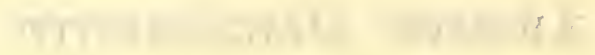

\section{$10, n=0.90$}

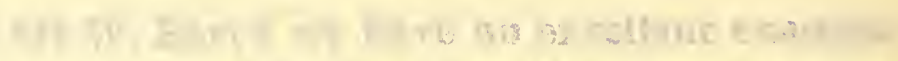

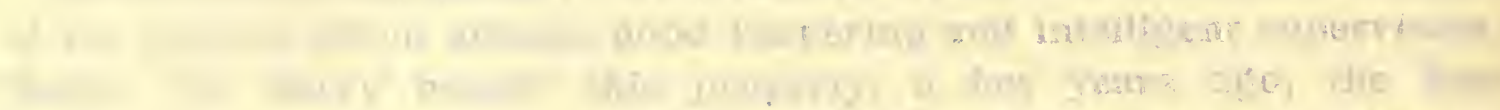

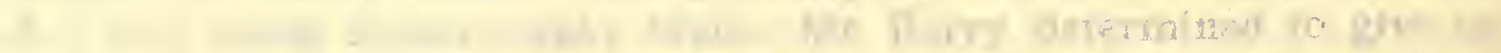

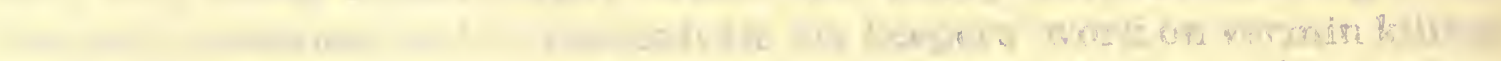

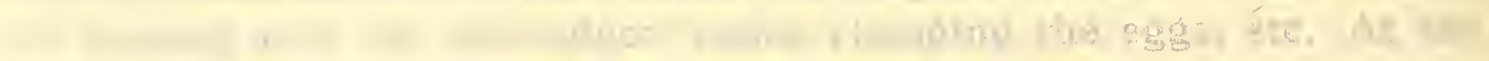

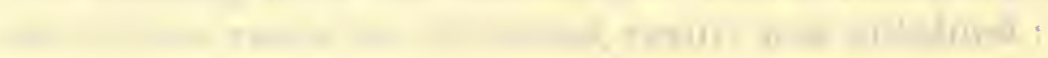

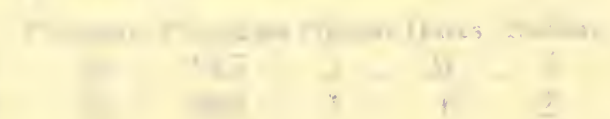

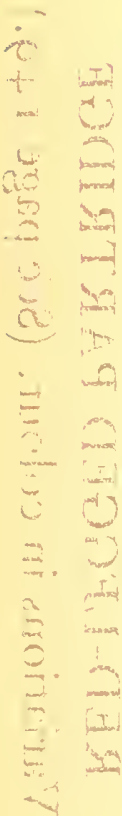

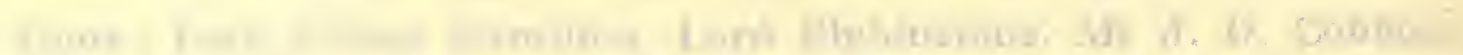

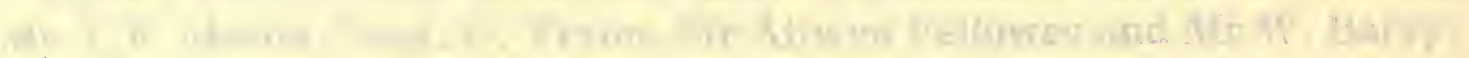

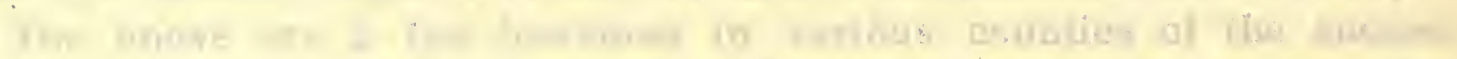

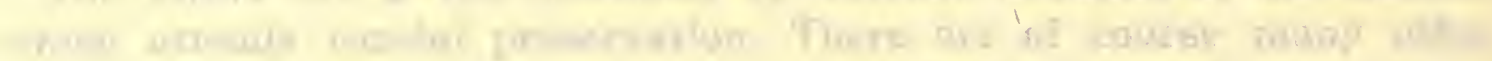

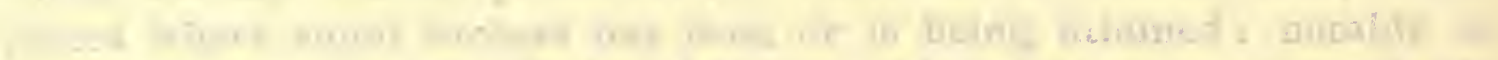

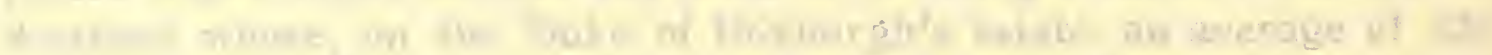
1.

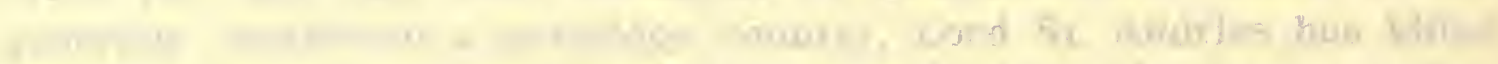

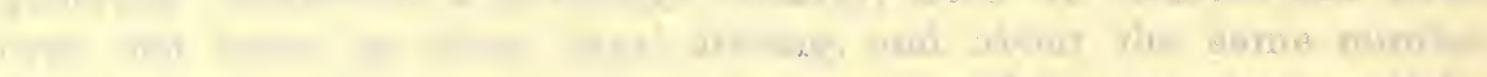
the

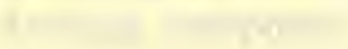




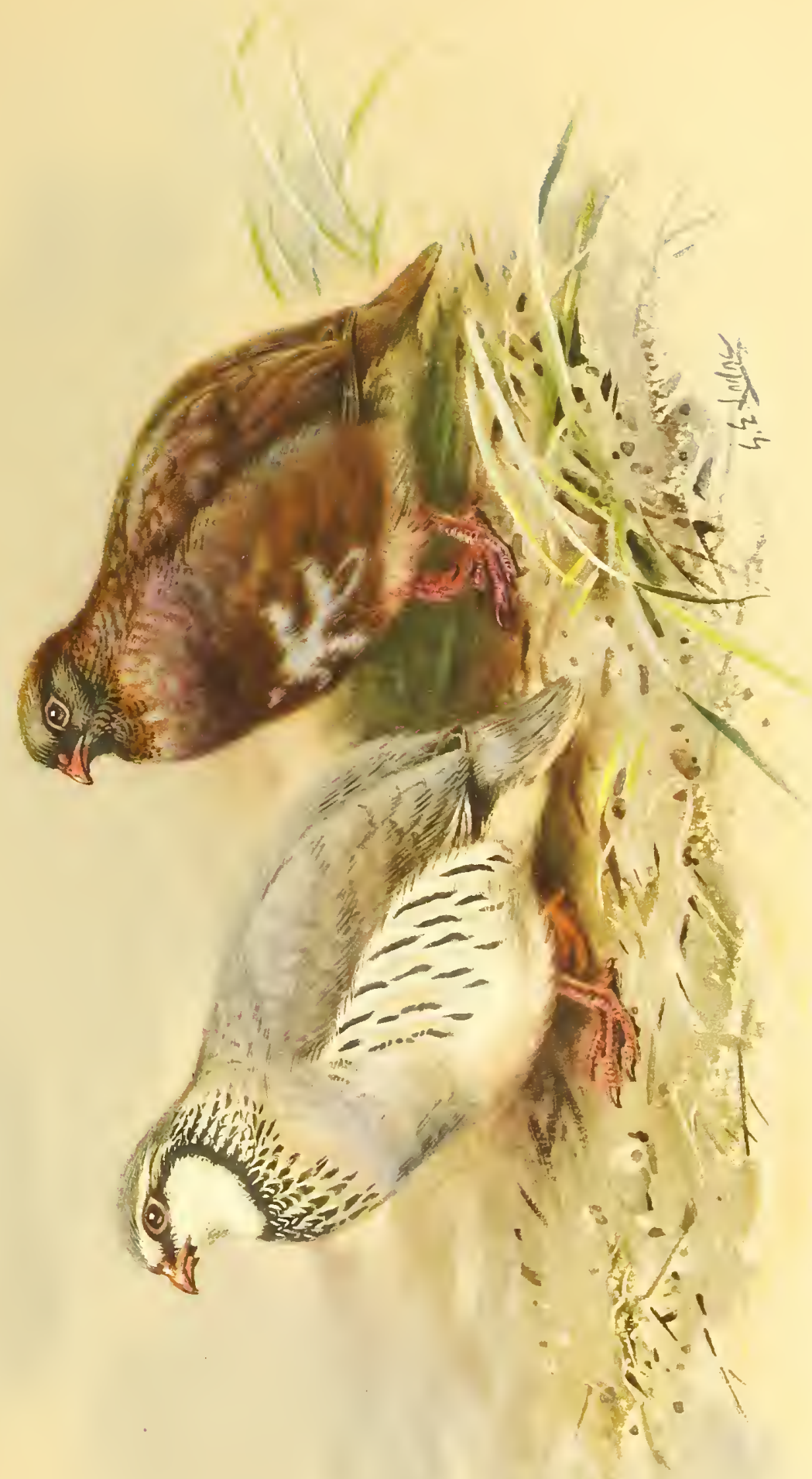





\section{QUAIL \\ COTURNIX COTURNIX \\ (Plate XXII)}

Tetrao coturnix, Linn., Syst. Nat., i, p. 278 (1766).

Coturnix communis, Bonn., Dresser, Birds Europe, vii, p. 143, pl. 476 (1878) ; Hume \& Marshall, Game Birds Ind., ii, p. 133, pl. (1879); Legge, Birds Ceylon, iii, p. 756 (1880); Saunders, ed. Yarrell, Brit. Birds, iii, p. 123 (1882) ; Seebohm, Hist. Brit. Birds, ii, p. 462 (1884); Lilford, Col. Fig. Brit. Birds, pt. xxvi (1893); Saunders, Ill.Man.Brit. Birds, p. 505 (1899). Coturnix dactylisonans, Temm.; Gould, Birds Europe, iv, pl. 263 (1837).

Coturnix coturnix, Ogilvie-Grant, Ann. and Mag. Nat. Hist. (6), x, p. 166 (1892); id., Cat. Birds Brit. Mus., xxii, p. 231 (1893); id., Handbook Game Birds, i, p. 180 (1895) ; Millais, Nat. Hist. Brit. Game Birds, p. 130, pl. (1909). [N.B. The male bird figured is Coturnix africana, the South African form.]

DULT male.-Feathers of the crown black, tipped with
reddish-brown, a pale whitish-buff stripe down the
middle of the head, and one above each eye, extending
from the bill to the neck; mantle sandy or reddish-
brown, each feather with a wide buff black-edged shaft-
stripe tapering to a point, and a black bar or blotch on one or both webs; shoulder-feathers, back, rump and upper tail-coverts very similar to the mantle, but the ground-colour is generally blacker, with narrow V-shaped bars of rufous-buff, and the buff shaft-stripes are wider and confined to a line of feathers down each side of the spine, forming a regular pattern. Quills blackish, barred and mottled with buff, the primaries on the outer web only. Sides of the head, chin, and throat, white; a reddish or brownish band extends from the bill to the ear-coverts, and a black anchor-shaped mark extends from the chin down the middle of the throat, the arms curving upwards to the ear-coverts. Chest rufousbuff, with pale shafts; remainder of the underparts paler; the sides and flanks reddish-buff, more or less spotted with black, and with wide white black-edged shaft-stripes. Tail-feathers black, barred with buff and tipped with whitish. Total length $6 \cdot 7$ inches; wing 4.2 inches; tail 1.5 inch; tarsus 1.0 inch. (Plate XXII.)

Adult female.-Differs from the male in having no black band down the middle of the throat, only the arms of the anchor-like mark being somewhat imperfectly represented, and the chest is more or less thickly spotted with black. The plumage of the female does not appear to differ in the breeding-season, but is paler and more worn. (Plate XXII.)

Young males in first plumage resemble the female, but the chest has only a few black spots. 


\section{THE GUN AT HOME AND ABROAD}

Young in down.-Crown rufous - buff, with two parallel, well - defined blackish bands extending from behind the forehead to the occiput; upperparts buff, with three parallel black bands, one from the nape to the tail, and one on each side of the body; wings buff, mottled with rufous, and blackish. Sides of the head and underparts pale yellowish-white, with one or two rather indistinct blackish spots behind the eye and behind the ear. (In the nestling of the common partridge the cheeks and sides of the face are conspicuously spotted with black.) Bill, dull orange-red.

QUAIL (Coturnix coturnix).

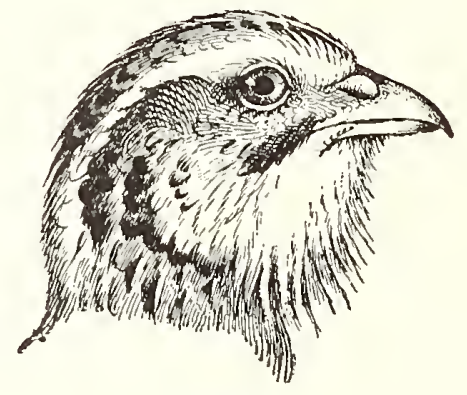

Fig. 1.

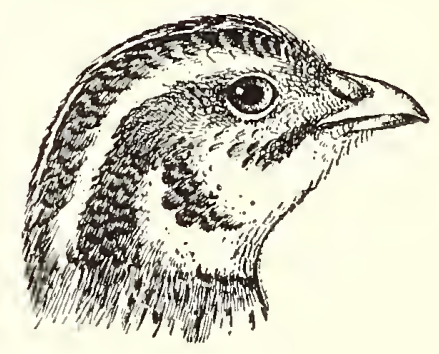

Fig. 2.
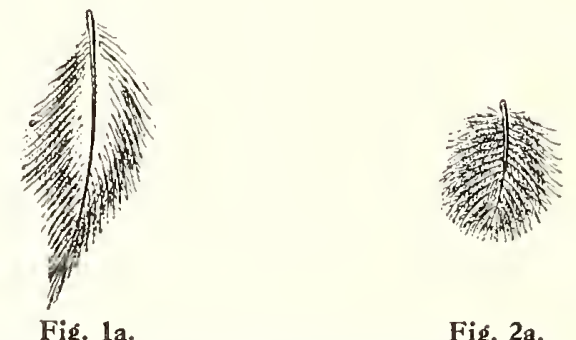

Fig. 2a.

Figs. 1 and la. Head of Female Japanese Quail ( $C$. japonica), showing lanceolate feathers on throat.

Figs. 2 and 2a. Head of Female Migratory Quail ( $C$. coturnix), showing short rounded feathers on throat.

In the first plumage the feathers of the upperparts are much like those of the adult female, but the markings on the wing-coverts take more the form of black spots; the feathers on the sides of the breast and belly are white, with conspicuous white shaft-stripes and rounded black markings, giving these parts a spotted appearance.

The male described above is a typical example of the quail, commonly known as the migratory quail of Europe, which has the throat pure white, with a black anchor-shaped mark down the middle. As considerable variation is to be found in the coloration of the chin and throat and their black markings, it may be as well to give here the substance of the remarks which I have already published on this subject. The migratory quail 


\section{QUAIL}

has been constantly confused with two more or less resident local forms, Coturnix africana, found in South Africa, and the islands off the coast both in the Southern Pacific and Atlantic Oceans, and C. japonica from North-eastern Asia, China and Japan. The former is a smaller and more richly coloured form of $C$. Coturnix, but the latter is a distinct and well characterized species.

The male of $C$. africana has the chin and throat bright chestnut, usually with a well-defined black anchor-shaped mark on the throat, and the mantle, chest, and sides of the body are more or less strongly washed with rufous.

The female differs from that of the common quail chiefly in size, but is also more richly coloured on the sides and flanks. Both on the wing and when handled $C$. africana is a strikingly smaller bird than the common quail, a fact which is very apparent when both birds are flushed in the same field.

The male of the Japanese quail has the chin and throat dull brick-red, devoid of any black markings, and the margins of the flank-feathers are mostly rufous, and much less spotted with black.

The female is readily distinguished from that of the migratory bird (figs. 2 and $2 a$ ) by having the feathers on the chin and sides of the throat elongate and lanceolate (figs. 1 and 1a), and of much the same structure as those found in the bearded partridge (Perdix daurica) inhabiting North-eastern and Central Asia. The migratory quail, wandering over an immensely wide range, visits the countries inhabited by both these resident forms, and unquestionably interbreeds with them, with the result that hybrids in intermediate plumage are not uncommon.

Among European examples of the migratory quail, the males often have the throat partially rufous, and are no doubt the offspring of birds which have paired with $C$. africana.

Equally among Central Asiatic examples of the migratory quail the males often show the influence of a union with $C$. japonica, the hybrids having the throat brick-red, or partially so, with a black anchor-shaped mark more or less developed. These hybrid forms seem to be mostly met with in Eastern Siberia, Ghina and Japan, but specimens have also been procured in North-east India and Burma. Indian examples of the migratory quail are, generally speaking, very pure bred, and seldom show any trace of rufous on the sides of the head and throat, which are white, with black markings. Some few, however, have the throat more or less rufous, as in the South African form, C. africana, and are probably 
THE GUN AT HOME AND ABROAD

birds which during the spring migration from Africa to Europe and Western Asia have been driven eastwards to India.

Colour variations.-A curious variety or semi-melanistic form of the migratory quail has been met with in South Spain in the marshy neighbourhood of Valencia. In the male the general colour of the upperparts is black, with narrow buff or rufous cross-bars; the pattern formed by the wide golden-buff shaft-streaks on the feathers of the mantle and on either side of the body is normal; the greater part of the sides of the head, chin, and throat are black, interspersed here and there with a few white feathers; the chest-feathers are mottled with black, and the feathers of the sides and flanks are black, dotted with rufous, and with a wide white shaft-stripe down the middle. In the female all the underparts are suffused with smoky-brown. These curious specimens, which formed part of Lord Tweeddale's collection, were procured by the late Mr Howard Saunders, and are preserved in the Natural History Museum. Grey and white varieties are also sometimes met with.

Distribution. -The quail has a very wide range, extending over the greater part of Europe, Asia, and North Africa. In summer it is met with as far north as the Faeroes, and in Scandinavia and Russia up to about $65^{\circ} \mathrm{N}$. latitude, but is more abundant southwards in Central Europe. In autumn immense numbers visit the countries bordering the Mediterranean, but the majority pass on southwards, many visiting North Africa and wandering to the Madeira, the Canaries, Azores and probably to South Africa. Across Siberia, south of about $60^{\circ} \mathrm{N}$. latitude, its range extends to Japan, and it is a common summer-visitor to Persia, Afghanistan, Turkestan and North China, vast numbers wintering in India and South China. In its migrations from Central Asia to India the quail crosses the Karakorum (16,000 feet), and other high ranges of the Himalaya. Many also arrive in Sind and Guzerat from the west, moving southwards from Persia, Baluchistan and other northern latitudes. The migratory habits of this species are well-known, but though, on the approach of cold weather, the majority of the birds-to be numbered in countless hosts-shift their quarters in September and the early part of October and move southwards, in many places, in more southern latitudes, a certain number remain and spend the winter where they have been bred. The return journey in spring commences about the middle of March, and continues till the end of May.

During the height of the spring migration between about April 20 and 196 


\section{QUAIL}

May 10 quails pass in countless numbers, but of late years they have diminished considerably. The migration appears to take place entirely during the night and early morning, and ceases at daybreak, when the birds settle down for the day.

The number of migrants varies greatly in different years; their movements being largely, if not entirely, regulated by the prevailing winds, the food supply, and the seasonal conditions of the countries which they visit.

Distribution in the British Isles.-The quail is now principally a springvisitor, and leaves us early in October, but in mild winters a few often remain in the west and south-west of England and in Ireland. Though formerly a partial resident in Ireland, its numbers seem to have steadily decreased during the latter half of the last century for no apparent reason. As Saunders concisely puts it: "In England before drainage and high cultivation had broken up the coarse, tussocky land in which the quail delighted, it was far more plentiful than it is at present, particularly in Hertfordshire, Cambridgeshire, Suffolk, Norfolk, Lincolnshire, Lancashire, etc., but from time to time unusual influxes take place. One of these extended, in 1870, from East Anglia to Cardigan, Pembroke, and Cornwall; in 1885 a remarkable increase was noticed on the high ground along the north side of the valley of the Thames and as far as the Severn; while in 1892 there was a marked accession, and a still larger immigration in 1903. Northward, the quail gradually becomes less numerous, yet nests have been found in Scotland as far as Caithness, Sutherland, the Orkneys, and the Shetlands, several times in the Outer Hebrides, and not infrequently in the south-west of the main land."

The cause of the comparative scarcity of the quail, especially in this country, is no doubt largely due to the wholesale netting of the birds in the Mediterranean countries during the spring migration, to meet the enormous demands in the markets which supply the great cities of Europe. At that season quails are generally in poor condition, and unfit for the table, but the captured millions are crowded together in long narrow darkened cages, where they cannot see to fight with one another, and those that survive, about one-third, are readily fattened on millet and hemp-seed, etc., for the market.

At the International Sports Congress, held at Vienna in 1910, a formal resolution was passed to the following effect:

The Second International Sporting Congress recognizes the desirability that quail shooting should be closed in all States at a season as 


\section{THE GUN AT HOME AND ABROAD}

near as possible to the time when these birds migrate to Europe, and that during the close season all trade in, and transport of, quail shall be forbidden. The Congress further recognizes it to be desirable that an International Convention should suppress all shooting of woodcock between February 1 and October 1 , and that in all countries signatory of the Convention, the sale, purchase, transport, and transit of woodcock should be forbidden from February 1 onwards. The Congress recognizes it to be desirable that an International Conference should meet as early as possible to discuss and settle the text of an International Convention in order that effective protection may be assured to migratory gamebirds, by the adoption of equivalent measures in all countries. This International Convention would then be laid before the various Governments for their ratification and adhesion.

In a letter to the "Field" of October 1, 1910, Mr F. C. Selous has embodied the careful account of Count Clary, President of the St Hubert Club of France, on the destruction of quails.

Count Clary writes: "Quails were formerly very abundant in France, Belgium, and Germany. For some years past, however, they have been diminishing in numbers to such an extent that their complete disappearance is to be feared. In France this diminution is estimated as at least two-thirds (of the original stock). In Belgium quails are scarcely seen any longer, yet these birds are very prolific, and were formerly plentiful in that country. What, then, are the reasons for this disquieting decrease in their numbers? These must be looked for on the coasts of the Mediterranean, in Morocco, Tripoli, Egypt, Sicily, and Italy, where thousands, nay millions, of quails are caught alive during the periods of migration, in enormous nets. In Belgium alone 400,000 of these quails are eaten every year, whilst in England the consumption is even greater, and formerly the single port of Marseilles received annually as many as $1,500,000$ quails. These quails, put on board of steamships in batches of 70,80 , or 100,000 at a time, are carried over sea to the great Mediterranean ports, such as Marseilles or Genoa, or even directly to England. In the month of October the provision dealers commence to receive their supplies of quails, some of which they sell during the shooting season, but the greater part of which they reserve for sale during close time.

"These quails are kept in crates, and after having been fattened, are sold gradually at a high price during the season, when the sale of other game-birds is no longer legal.

198 
THE QUAIL

"The mortality amongst the birds thus carried from Africa to Europe is terrible, for less than 40 per cent survive the voyage, and the total captures of quails are amply sufficient to explain their decrease in Europe.

"The day can be foreseen, perhaps it is not far distant, when this species will have completely disappeared, unless international action at once prompts the enactment of the most energetic measures to put an end to a trade which is as immoral as it is scandalous!"

Count Clary proceeds to give a detailed account of the laws which have already been enacted in various European countries for the protection of quails. To its lasting honour be it said, the Swiss Government was the first to attempt to bring about international co-operation with this object for, as long ago as 1896, after having first assured itself of the goodwill of Austria-Hungary, the Government of France was asked "if it would not consent, in the general interest, to put an absolute interdict on the unholy traffic in quails during the close season." These negotiations, however, fell through.

In the following year, 1897, a proposal was made to France by Germany that these two powers should make joint representations to Great Britain with a view to the protection of quails, by forbidding their importation and sale in all three countries during the close season for other gamebirds. The British Foreign Office, however, declined to subscribe to the agreement. Various other negotiations between different countries have since taken place, and the present position in Europe appears to be this: In France, Germany, Austria-Hungary, and Switzerland the open season for quail shooting lasts from August 15 to October 15, and during the remaining ten months of the year, in the above - mentioned countries, it is not only illegal to shoot or capture these birds, but their importation from other countries during the same time is also strictly forbidden. In addition to this, the French have made the netting of quails by the natives of Algeria and Tunis illegal, and-so Count Clary informed me-this prohibition has put an end to this destructive industry in these territories.

It now only remains for Great Britain, Belgium, and Italy to cooperate with France and those other powers which have already taken measures for the protection of quails, and if only such an international agreement could be brought about, these handsome little game-birds would not only be saved from extinction, but would in all probability in a few years' time again become as plentiful as they once used to be, for they are very prolific if left unmolested during the nesting season. 


\section{THE GUN AT HOME AND ABROAD}

At the present time more quails are probably netted in Egypt than elsewhere, and the majority are shipped to Marseilles. In addition to the long nets stretched across the line of passage, numbers are taken at night with the aid of a landing net and a flaming torch stuck in the man's hat, when, the birds being dazed with the light, make no attempt to escape.

It is greatly to be hoped that some international action may be taken without delay to limit the wholesale extermination which at present exists.

Allied species. - Of the allied species I have already mentioned the small resident chestnut-throated form, $C$. africana, found in South Africa and in the islands off the African coast, including the Azores; also the Eastern Asiatic, $C$. japonica, with a brick-red throat, met with in Manchuria, South-east Mongolia, China, and Japan. In addition to these there is the well-known Indian and Burmese species, $C$. coromandelica, commonly known as the black-breasted or rain-quail, the chestnut-breasted $C$. delegorguei, peculiar to Africa; the Australian quail, $C$. pectoralis, found in Australia and Tasmania, which has been introduced into New Zealand to take the place of $C$. novce-zealandice, now extinct. The latter species, the largest of the group, was a common bird in the middle of the last century; in 1848 as many as forty-three brace were killed in a day's shooting, but it has long since entirely disappeared, and is now one of the rarest species in collections.

Food.-Seeds of various kinds of grasses and weeds, such as chickweed and plantain, form the principal food of the quail, but it also feeds on all kinds of grain and millet. In their season small berries are also eaten, likewise slugs and insects, especially small beetles, bugs and ants. Like other game-birds, it swallows a considerable quantity of quartz and sand to aid digestion.

Flight.-As is indicated by the pointed shape of the wing with the outer flight-feathers longest, the quail is capable of protracted flight during its extensive migratory movements. Generally, however, it is extremely reluctant to rise, and prefers to escape by running, or squatting in thick cover. Once on the wing it flies fast and straight with rapid wing-beats, seldom rising more than a few feet above the ground. After scurrying along for a hundred yards or so, it sails and pitches, dropping quickly back to cover. To flush the bird a second or third time, even with the aid of a good dog, is an extremely difficult task, and it will sometimes allow itself to be caught sooner than rise.

Breeding habits. - In the pairing season in March and April quails love 200 
QUAIL

to frequent the fields of young corn, lupins, peas, etc., and in countries where they are plentiful, their well-known and unmistakable call may be heard on all sides, though the birds themselves are seldom seen unless they are flushed with the aid of a dog. The male utters a triple note, low and soft, but penetrating, which may be described by the syllables whiter-wit, imitated by the words "wet my lips." It is repeated many times in succession, and the female replies with a soft low call like whin, whiu. On taking wing, when suddenly disturbed, the birds also utter a shrill alarm note.

As a rule the quail is monogamous, but the males are said sometimes to mate with more than one female, probably in localities where there is a preponderance of the latter sex. The males are exceptionally pugnacious, and fight very fiercely with one another during the breeding season, the battles often terminating in the death of one of the combatants, or in both birds fighting till they are utterly exhausted and incapable of further effort. In India the sport of quail-fighting is a favourite pastime among the natives, and considerable sums are staked on the prowess of the captive birds.

Nest.-The nesting season does not usually commence until May, when a shallow depression is scraped in the ground in the middle of a corn-field, grass-field, or sometimes in a rough open common, and lined with a few bits of dry grass or dead herbage.

Eggs.-The number of eggs laid varies greatly, from eight to twelve is probably the average number, but as few as six and as many as twenty are sometimes found. They are usually of a broad oval shape, but sometimes pointed, and have little gloss. The ground-colour is yellowish-buff, the whole shell being thickly covered with reddish-brown, or sometimes olive-brown markings, which either take the form of small spots, or blotches of various sizes. The eggs, which are usually laid between March and June, according to locality, are very handsome, and measure about $1 \cdot 2$ inch by $\cdot 9$ inch.

The period of incubation lasts about three weeks, two broods being sometimes reared in a season. The male does not appear to take any part in the incubation, but both parents usually accompany the brood. The young are able to run and follow their parents soon after they are hatched, and soon learn to pick up their own food.

General habits. -The broods or "bevies" of quail do not remain with their parents after they are able to care for themselves, and the family DD 


\section{THE GUN AT HOME AND ABROAD}

parties soon become broken up, and separate, the various members leading a more or less solitary and independent existence till the autumn migration commences.

An attempt was made some thirty years ago in Morayshire to increase the number of quail, which sometimes occur there in small numbers, by importing a large number of eggs and hatching them under bantam hens. Though a considerable number were successfully reared, all disappeared in the autumn, and apparently did not help to increase the stock in the subsequent year.

The habits of the quail are in many ways very similar to those of the partridge; they feed chiefly, and are most active, in the morning and evening, remaining more or less quiescent during the middle of the day, especially in warm weather, when they sun themselves and indulge in a dust-bath like other game-birds. At such times they are most unwilling to rise. They are entirely terrestrial in their habits, and never perch on trees.

As soon as the breeding-season is over quails become more or less solitary in their habits, and are never found in coveys like partridges. Though comparatively rare in this country, they are often overlooked owing to their skulking habits and disinclination to rise, but their presence may always be detected by those familiar with their unmistakable call.

When on migration quails may be often met with in the early morning in large flocks or packs, before they have scattered and settled down for the day. At such times the birds are very restless, and on rising, often fly far, but as the day advances they lie very close, and may be almost trodden on before they take wing.

W. R. OGILVIE-GRANT. 


\section{QUAIL SHOOTING}

LTHOUGH quail are not included in the list of game as defined by section 2 of the principal Game Act $(1 \& 2$ Will. 4, cap. 32), a game licence is nevertheless necessary for shooting them. This is required by the Game Licences Act, 1860 (23 \& 24 Vict., cap. 90, sec. 4), which provides that every person who shall kill, take, or pursue, or use any dog, gun, net, or other engine for killing, taking, or pursuing any game, or any woodcock, snipe, quail, or landrail, shall take out a proper "licence to kill game" under this Act. There is a general impression that any of these birds may be shot by the holder of a ten shilling licence, but for the reason above given this is not the case.

The question then arises where and when are quail now to be met with in the British Islands, a question not so easily answered. This little bird is a summer-visitor, arriving in April and departing in October, and between those two months it used to be commonly distributed throughout the country, nesting after the manner of a little partridge. As its habit is to lay a large number of egis-from eight to ten, or twelve-it is reasonable to suppose that during the summer months a considerable number ought to be reared annually, and this, in fact, was formerly the case, especially in the eastern counties, where the light, dry soil and the wide extent of unreclaimed land admirably suited its requirements. In the Cambridgeshire fens and rough lands, also, quails used to breed commonly, and the London market was supplied mainly from that district, as well as from Norfolk and Essex. I remember that "in the seventies" quails were plentiful around Newmarket and Cherry Hinton. They were formerly far more numerous in Norfolk than at present, showing a preference for sandy soils, and according to Messrs Gurney and Fisher, it was " not unusual for a sportsman to kill, on light lands early in the month of September, three or four brace of these birds in a day." When Stevenson published the first volume of his "Birds of Norfolk" in 1866, he remarked that "the great stronghold of this species in Norfolk during the summer months was in the rough fens of the south western district, in the neighbourhood of Feltwell, where Mr Clough Newcome found them so plentiful that from ten to twelve couple might be shot in a day."

Dr Churchill Babington, who published his " Catalogue of the Birds of Suffolk" in 1886, enumerates under the head of Quail a great many locali - 
ties where this bird was formerly to be found, adding the remark that "it has now for a long time been everywhere scarce."

In the hot dry summer of 1870 quail were reported to be plentiful in north Lincolnshire. In one instance three brace were killed in a day by one gun, and eight brace by another sportsman on a farm near Caistor, where two or three large bevies occurred, doubtless bred there.* The former abundance of the quail in Essex is vouched for by Jesse, who, in his "Scenes and Tales of Country Life" (p. 267), observes: "In one district in Essex numerous eggs have been found during the mowing season, and as many as sixty couple have been killed in the course of a few days' shooting on one manor in that county." In Kent the quail is reported to be less common now than twenty years ago. $\mathrm{Mr}$ Ticehurst was informed by a resident in that county that until twenty years ago he used to meet with quail every year in autumn. He frequently shot five or six in a day, and found them particularly abundant on the high ground overlooking Romney Marsh. $\uparrow$

In some years quail are much commoner than in others, as in 1870, when they were observed to be plentiful in Surrey, as they were in other counties. Mr Bucknill, in his "Birds of Surrey" (1900), mentions several instances of nests having been found. In the late "sixties" and during the "seventies" I used to shoot a good deal in West Sussex, where my father resided; and in the month of September both quail and landrail were often added to the bag of partridges. We generally found them in dry clover, and on the edges of stubbles, as well as in rough meadows that had been grazed by cattle, where common weeds like dock, plantain, sorrel, and chickweed were running to seed, and provided the birds with plenty of food. Such fields would attract them still were they to reach that part of the country in such numbers as they used to do. On the Warren farm near Brighton in September, 1896, Mr H. R. Spooner shot five quail, and $\mathrm{Mr}$ Beard, the Master of the Brookside Harriers, previously killed three couple there. In Hampshire, in the neighbourhood of Selborne, Gilbert White remarked that "there are few quail, because they more affect open fields than enclosures." But he was familiar with the bird's call-whit-iu-whit-and has referred to it in his "Naturalist's Summer Evening Walk." He was aware also of its migratory habits, and in his thirteenth letter to Pennant, remarked that "Quails crowd to our southern

* Cordeaux, Birds of the Humber District (1872), p. 83.

$\dagger$ Ticehurst, Birds of Kent (1909), p. 392.

204 


\section{QUAIL SHOOTING}

coast, and are often killed in numbers by people that go on purpose."* But that is now a thing of the past. Nor is it worth while to examine in detail the present status of the quail in other English counties; it being the general opinion of sportsmen that these birds are not nearly so common in September as they used to be.

With a view to remedying this general scarcity of quail a few landowners turned out imported birds obtained from London poulterers. The late Mr Borrer, of Cowfold, near Horsham, wrote: "Many years ago my father-in-law turned down several dozen on a farm not far from the downs, but never afterwards fell in with one of them." In the same county, at Middlehurst, Mr Malcolm Burr reported in 1892 that a number of quails had been turned out in fields close to his house, with the only result, so far as he was aware, that one of them was subsequently killed by a reaping machine. Similar experiments have been made in other parts of the country. Many years ago the late Mr Robert Mitford, of Hampstead, turned out a number of bought quails to the north of London in the expectation that some of them might breed, and provide some shooting in the autumn, but he was disappointed.

Years ago Ireland was reckoned almost as good a country for quail as it has always been for snipe, and they were often to be found on the cultivated patches of the peasantry as well as on the edges of the bogs, as I know from experience in Kildare and Wicklow. But quail have been annually becoming scarcer for a long time past, and, in fact, were reported to have become practically extinct in 1892 . Such at least was the opinion of a good observer in Ireland, Mr G. B. Moffat, who published an interesting article on the quail in Ireland in the "Irish Naturalist" for 1896.

Curiously enough in 1892 quails began to reappear, and in 1893 and 1896 there were some notable visitations. In each of those years there was very little rainfall in Ireland, and Mr Moffat wondered whether the drought had anything to do with their unexpected appearance, though it seemed to him " more probable that the consequent sparseness of vegetation in their continental resorts might at such times drive the birds further afield in search of localities where covert and food are more attainable." Mr Ussher, commenting on this article a few years later, pertinently inquired whether the particular seasons referred to partook of the same dry character throughout Western Europe, for "the causes of an unusual

\footnotetext{
* Col Hawker certainly did not find many quails in Hampshire in his day, for in the course of fifty years he shot no more than fifty-eight. See The Diary of Col Peter Hawker (1893), vol. ii, p. 356.
}

$\dagger$ Borrer, Birds of Sussex, p. 188. 


\section{THE GUN AT HOME AND ABROAD}

migration are rather to be sought for in the countries from which it originates than in those to which it is directed."**

Speculating on the causes likely to account for the noticeable decrease of quail in Norfolk, Stevenson suggested that it might be due to the cultiva tion of what was formerly rough ground, and that such local changes, the commencement of which was contemporaneous with the earliest records of the diminution of quails in this country, may have had no little influence in rendering them so scarce as summer residents. "At the same time," he adds, "it is quite possible that the numbers annually visiting our shores from the continent may have also diminished considerably of late years; and that, too, from causes which European ornithologists would be better able to explain than ourselves." It is curious that in this expression of opinion Stevenson missed the true interpretation of the decrease. There can be no doubt of the correctness of Mr Ussher's view when he states that the cause must be looked for in the country from which the birds come, rather than in that which they are expected to visit. And, sure enough, the explanation is forthcoming. It is briefly this. The annual northward migration in spring, when the birds quit their winter quarters in thousands, and cross the Mediterranean into Europe, would result, if they were unmolested, in large numbers becoming scattered all over Europe, including the British Islands, where they would breed and rear their broods in the proportion of eight or ten young ones to every pair; in this way providing excellent sport for shooters of every nationality. But unfortunately they are met all along the Mediterranean coast by the opposing flight nets of those who make a living by netting them in hundreds-nay, in thousands-for the market. The result is that the vast majority of the migrating birds never reach us, while those that manage to escape the nets are too few in number to populate the countries they contrive to reach. It is in this way, it seems to me, that the notable decrease of quail in this country, and elsewhere in Europe, is to be explained.

From a consideration of the foregoing remarks, it will be apparent that "a day's quail shooting" is not to be had in the British Islands, and a sportsman desirous of bagging more than two or three couple in the course of a day's partridge shooting in September must turn his attention to foreign countries in pursuit of them.

As to the best countries to visit for quail shooting, it may be said that

${ }^{*}$ Ussher and Warren, The Birds of Ireland (1900), p. 235.

206 


\section{QUAIL SHOOTING}

Spain and Portugal, which are very accessible from England, claim the first attention; Morocco, Algeria, and Egypt come next; France, AustriaHungary, Italy, Turkey, the Balkan States, Roumania and Greece all afford good quail shooting at the proper season; and finally, after Egypt and the Nile country, India, and perhaps Ceylon, offer the best sport to be obtained with this little game bird.

It may be well to take a glance at the different countries in which quail are to be met with, including some further north than those above-mentioned, in order that the reader may know what to expect in making choice of his field of operations in one or other of three continents. Let us begin with the north of Europe :

SCANDINAVIA.-No one would go specially to Sweden or Norway for the purpose of getting good quail shooting, although in Sweden this bird is found sparingly up to about $59^{\circ} \mathrm{N}$. 1at., according to Wheelwright ("The Old Bushman") who resided long in that country.*

Saunders says of the quail, "a summer visitant in no great abundance in Scandinavia and Russia up to about $65^{\circ} \mathrm{N}$. lat., becoming more common in Denmark and northern Germany.' $\dagger$

Lloyd found it rare in the vicinity of Ronnum, and also in the west of Sweden, but in certain localities near the east coast and in Scania it was not uncommon at the proper season, the shooting being over pointers.

Count Eric von Rosen, writing from Rockelsbad, Sparreholm, August 29, 1912, says : "That quails are of very uncertain appearance in Sweden, being found occasionally in districts where they have not been met with for many years previously. They occur in the following provinces: Skane, Halland, Öland, and more rarely in Wester Götland, Öster Götland and Würmland, and have been found breeding near the town of Hernosand $63^{\circ} 30$, and in the north of Jemtland up to $64^{\circ} . "$ He adds that the quail is so rarely shot that it hardly deserves to be called a Swedish game-bird, and it is not specially protected. The shooting season for partridge and willow-grouse or ryper is from September 1 to November 1.

In Norway quails in some years are not uncommonly met with, as in Upper Tellemarken, and even in the neighbourhood of Christiania, preferring the open country and wide tracts of arable land. In the Danish Islands also it is said to be fairly numerous between May and October.

\footnotetext{
*Ten Years in Sweden, p. 350.

† Manual of British Birds, 2nd Ed., p. 125.

†ame-birds and Wildfowl of Sweden and Norway, p. 177.
} 
THE GUN AT HOME AND ABROAD

DENMARK.-There is very little game in Denmark, and no pheasants except in the royal preserves. Partridges are not uncommon, and the law protects them between February 1 and September 12. Quail are not specially mentioned, and unless they fall into the same category as partridges, are probably shootable at any time between the date of their casual arrival in spring and the departure of the survivors in autumn.

BELGIUM and HOLLAND. - In these countries the same causes are in operation which have led to a decrease of quails in the British Islands. The spring migration, which should provide a large influx of birds for the breeding season, is ruined by the netting which goes on along the shores of the Mediterranean, and the majority of the quail which would spread over both these countries, never reach their destination.

GERMANY.-The spring shooting in which German sportsmen are wont to indulge, without any regard to the disastrous consequences of killing birds which have arrived for the purpose of increasing their species, must inevitably lead to a diminution of the stock of both woodcock and quail. So that here again an English sportsman in search of quail is likely to be disappointed.

The cost of a game licence in Germany is 3 marks, in Hanover 6 marks, and in Hesse 9 marks. Unenclosed properties of less than 200 acres do not entitle their owners to kill the game thereon. The shooting belongs to the commune in which the land is situated, and under certain restrictions is available to the public.

The close time for partridge and quail is from December 1 to August 31 , and the penalty for shooting them between those dates is two thalers or six shillings.

SWITZERLAND.-As in other countries of Central Europe, quails are becoming scarcer in Switzerland every year, owing to the same cause, the stoppage of the migrating flocks when crossing the Mediterranean. It is satisfactory, however, to know that an association of Swiss sportsmen has taken the matter up, and international arrangements are being made between Switzerland and neighbouring states to stop the transport of quails from Southern Europe. With the exception of quail, which are shot in September, the only other game bird is the grey partridge (Perdix cinerea), which has been introduced in various parts of the plains.*

${ }^{*}$ Dr Eugene Pitard, Sport in Europe, p. 347.

208 
$\cdots$
$\cdots$
$\cdots$
$\cdots$

7)

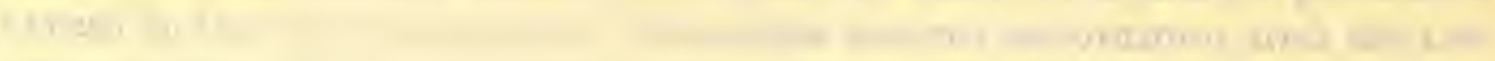

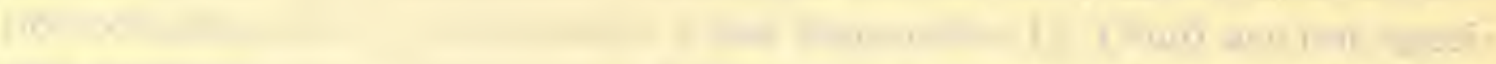

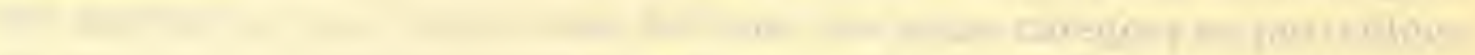

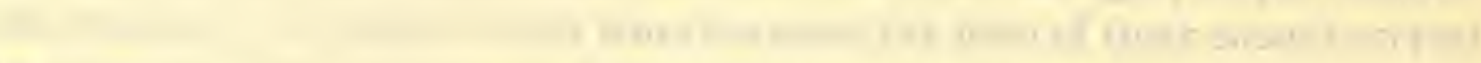

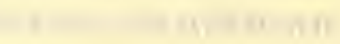

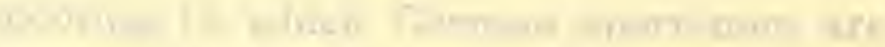
Why

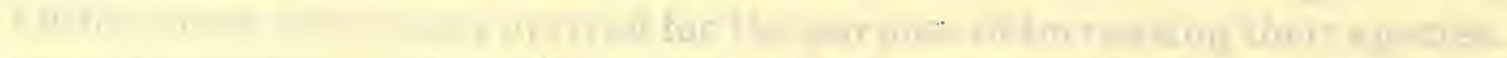

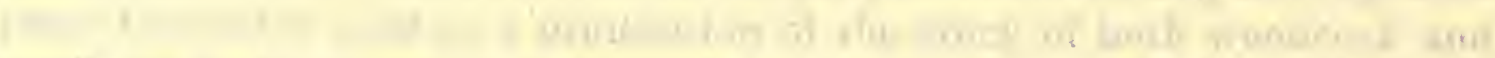

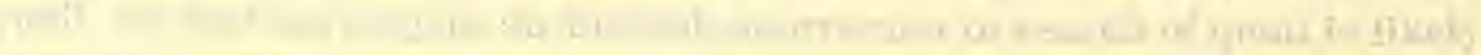

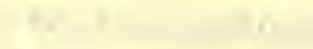

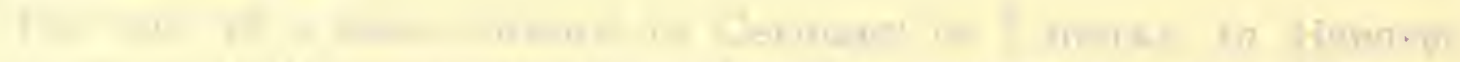
| th

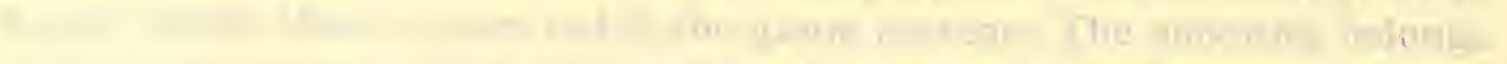
Where-

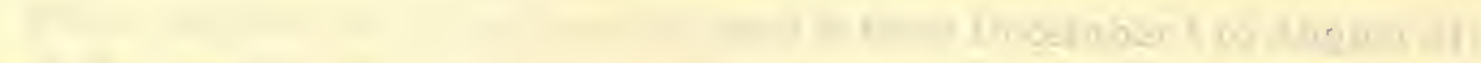

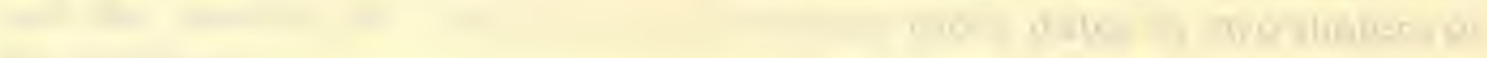

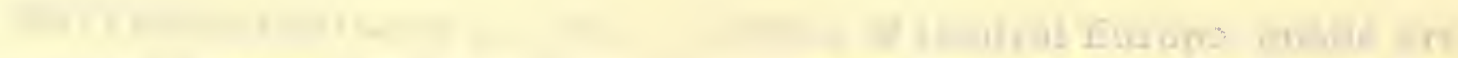

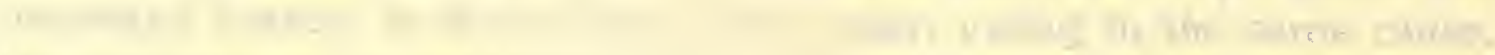

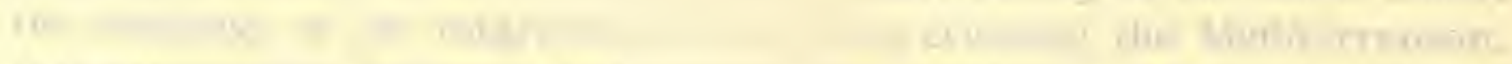

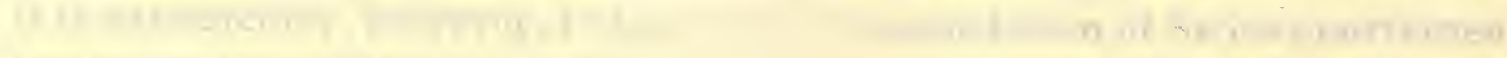

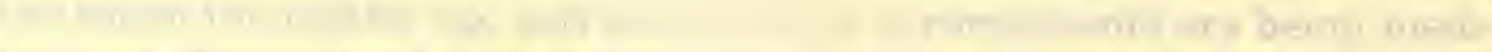
1

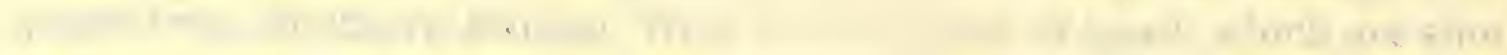

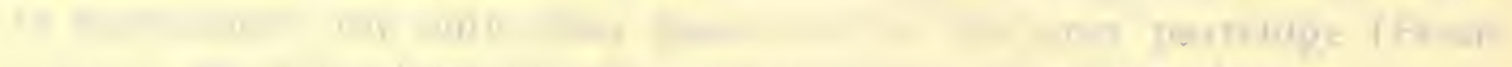

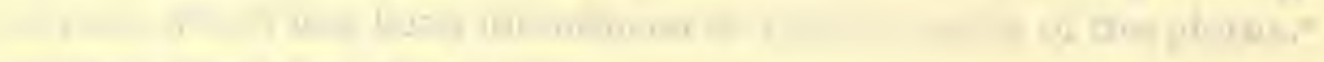




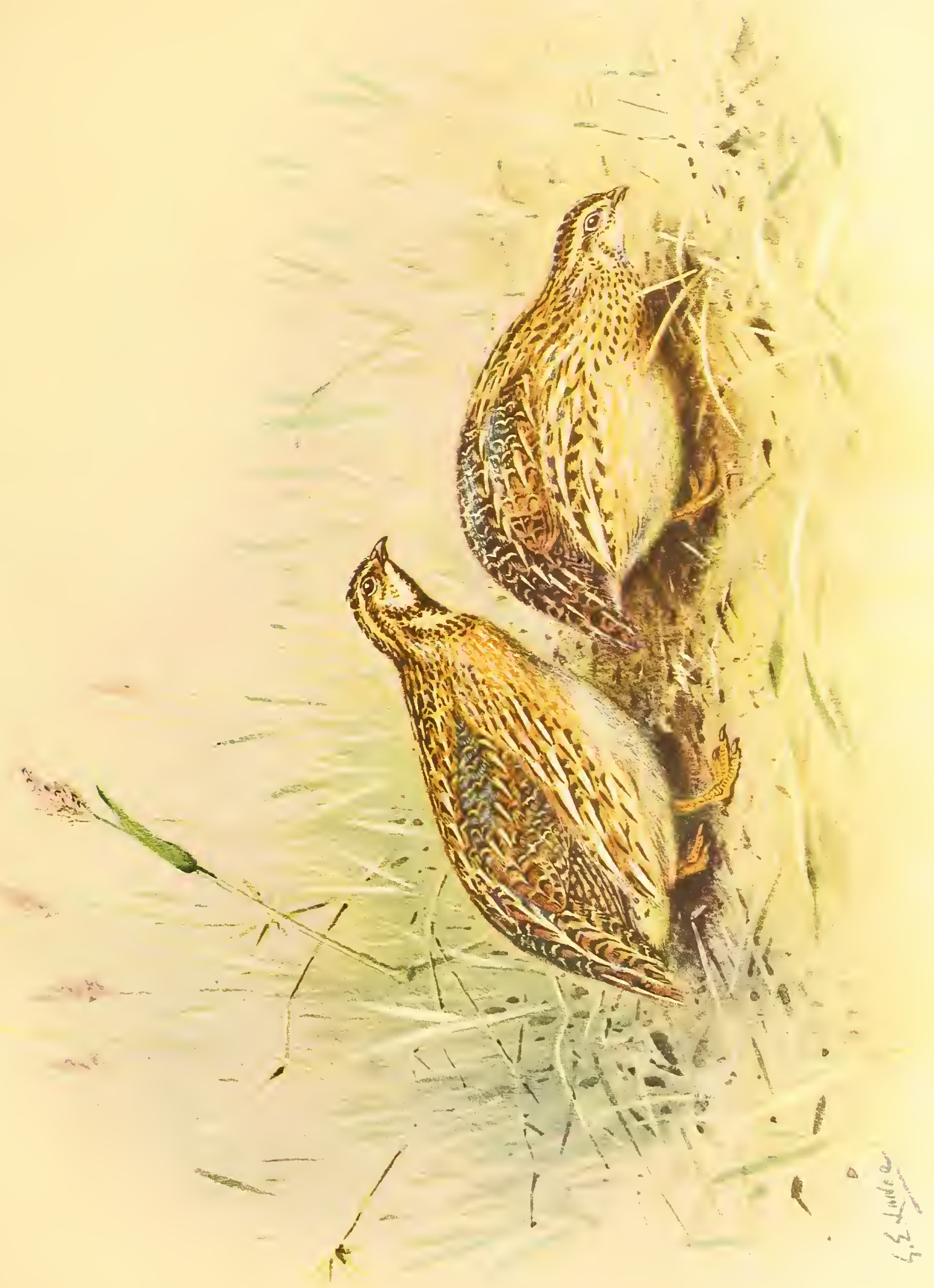





\section{QUAIL SHOOTING}

FRANCE.-Before the spread of railways gave facilities for the sale of game, and encouraged poaching, no country in Europe was better stocked with game than France. At the present day every holder of a licence costing 27f., is at liberty to shoot on all lands on which the sporting rights are not reserved by the owners, and even they are not always able to reserve their rights. All attempts at prohibiting shooting have been useless, the peasants regarding it as a right. Migratory birds like quail, woodcock, and woodpigeons fall to the gunners, two-thirds of whom care little for sport, and use destructive nets to capture them for the market. This is especially the case around Arcachon, in the Gironde, and in the Landes, where hundreds of birds of all kinds are captured in this way. Everywhere, indeed from north to south, there is an organized slaughter of game throughout the year. In Central France the prefects authorize the use of nets even at night, ostensibly to catch larks, but with the result that numbers of partridges and quails are also taken. In Brittany these birds have all become very scarce. Woodcocks arrive in the autumn, but their haunts are then covered with snares of all kinds, which capture both woodcocks and snipe. Only in the neighbourhood of Paris, in Central France, Normandy, and one or two departments in the north, is the country still stocked with game, but the best sporting estates are in the hands of wealthy owners, who preserve chiefly partridges and pheasants. At the present day, therefore, sportsmen in search of quail, unless they happen to be guests of resident landowners, are not likely to meet with much success in France.*

SPAIN.-In this country, where the quail arrive about the end of March and beginning of April, leaving in the last fortnight of September, some good bags are made by those who know just where to go for them. Mr Abel Chapman has put the case concisely when he says that "though not strictly marsh birds, quails at times abound amongst the moist rushy prairies both of Spain and Portugal, and hardly a hillock of drier ground or patch of maize stubble but will yield a brace or two. The largest bag recorded in our game book is fifty-two brace in a day, but this has been, and easily might be, exceeded. At certain passage-periods the Andalusian vegas simply swarm with quail, and at such times, with dogs well entered to this game, very large bags might be secured by anyone specially follow-

\footnotetext{
* M. Paul Caillard in Sport in Europe (1901), p. 123.

†Chapman, Wild Spain (1893), p. 419. 
ing them." He adds that "one afternoon when returning from snipe shooting, we fell in with an entrada of quail in a belt of dry rush and sedges and bagged twenty-seven and a half couple in less than an hour, when daylight and cartridges ran short."

On another page, referring to the delta of the Guadalquivir, and especially those parts known as the Isla Mayor, and Isla Menor, so-called "islands" formed by the triple channel of that great river, he observes : "These islands comprise vast areas of level pasturage, in winter bare of herbage, almost dry mud, but by April knee deep in richest grass and vegetation resonant with the whit-tu-sohit of unnumbered quail."

The dry plateaux on the north of the Laguna de Janda-an inland sea of yellow muddy water surrounded by sedge and cane brake, a well-known haunt of wildfowl in winter-are a notable resort of little bustard, and large bags of quail and golden plover are there at times secured. But this is well-known ground, and has been described by others.

The Duke of Frias writes,* "Quail cross from Morocco in April for breeding quarters, and quail shooting opens in most provinces on August 1, but in Burgos, Soria, and Valladolid not until August 10. The birds are shot over dogs in the stubble and pastures, and great bags are sometimes made. I recollect a party of five guns getting in one day, near Siguenza, no less than 490 brace. Burgos, Soria, Segovia and Old Castilla are undoubtedly the finest localities for quail in Spain. It is a curious fact, and one perhaps worth recording, that a good quail season in Spain depends largely on the energy with which the Governor of the Province of Cadiz prevents the netting of the weary birds on their first arrival on the coast. Properly protected for a day or two until they recover, the quail soon spread over the country.

PORTUGAL.-The Rev. A. C. Smith, in his "Spring Tour in Portugal," tells us that quail in that country are excessively abundant, and that the markets are always glutted with them. This is to be expected where every man's hand is against them, and where nets as well as guns are employed for their destruction. There are no proper game laws in Portugal, the Administrative Corporations being merely empowered by the Civil Code (art. 334) to regulate the seasons for shooting; the result being that the close season varies in different provinces, and even in different districts of the same province.

*Sport in Europe (1901), p. 326. 


\section{QUAIL SHOOTING}

It appears from an article on "Sport in Portugal," by Count d'Arnoso, forming a chapter in a larger work,* that a gun licence costs very little (7s. to 8s. a year), and in many places is not enforced, so that shooting is within reach of all. Such a licence is valid for the whole country, and must be taken out in the district in which the applicant resides. In the Lezirias do Tejo and Sado, and in the country near Estarreja, great numbers of quail (codorniz) are shot at the end of April and during May and again in August and September, when a good gun may bag from eighty to one hundred birds in a day. In some parts of the country, says Count d'Arnoso, quail remain all the winter, principally in the Alemtejo. $t$

Col Hawker, in his immortal "Instructions to Young Sportsmen," incidentally mentions that quail (in his day) were so plentiful on the left bank of the Tagus, that many of the officers, indifferent shots, while in winter quarters at Vallada, thought nothing of going over and returning to dinner with ten or twelve couple, although with every disadvantage in point of guns and ammunition.

AZORES. - In the cultivated lands on all the islands quail are plentiful, and may be found even in the gardens. Mr F. D. Godman, in his "Natural History of the Azores" (p. 32), states that they are not migratory there and have two and sometimes three nests in the year. He adds: "They afford excellent sport; on one occasion a Portuguese gentleman and I killed 157 in a few hours." The Azores, it may be observed, mark the westernmost limit of this bird's geographical distribution.

AUSTRIA-HUNGARY.-Quail arrive in numbers in April, and are scattered over the country throughout the summer. The shooting season begins in August, and during that month and September good bags may be made. An English naturalist and sportsman, Mr Charles Danford, for many years resident in Transylvania, informs us that in the meadows in the valleys there quail are quite common from April to September. His account of the birds of Transylvania, published in "The Ibis" for 1875 , is well worth referring to, especially for the remarks on game and wildfowl.

RUSSIA.-There is no shooting to be had in Russia without the written permission of the owner of the land, and shooting of every kind, either on

*Sport in Europe, pp. 241.42.

$\dagger$ This also is the case in England as well as in Ireland, where every winter a few quails are reported to have been met with by snipe shooters. 
THE GUN AT HOME AND ABROAD

private land or on Crown lands, is prohibited between March 1 and June 29 (St Peter's Day). In the governments of St Petersburg, Novgorod and Pskoff the close time extends to July 15 , but exception is made in the case of Capercaillie and Black-game which may be shot in the spring just before the breeding season. Licences are granted by the department of the official who corresponds to the German "Ober-Jagermeister," and the penalty for shooting without one is a fine which if not paid may result in the confiscation of gun and dogs. Quail shooting is more or less confined to the South of Russia.

ROUMANIA.-The quail is perhaps the most widely distributed game bird on the plains of Roumania, and is shot only over dogs, chiefly in the millet fields, or on the stubbles just after harvest. In good years, and on well-chosen ground during August and September, a good shot would have no difficulty in bagiging his fifty brace a day. For such sport, however, a good dog is needed-one that can bear both heat and thirst-and English pointers have been found to be the best for this work.*

DALMATIA.-The Crown Prince Rudolf, describing the result of a few weeks spent on the coasts of Dalmatia and Istria, with excursions into the Herzegovina, says: "Quails were often observed in Lacroma from the 10th to the end of March," the period of his visit. He found no more until April 17, in a field of oats in that island. In the neighbourhood of Trebinje the flight of quail is often so large that very good shooting may be obtained. $\uparrow$

ITALY.- In the months of April and May, when the quail arrive so exhausted by their passage over the Mediterranean that they are barely able to make the land, special trains take crowds of shooters from Rome to the seashore to meet the tired birds, which are thereupon slaughtered by hundreds in the land which they had hoped to make their summer home, while even greater destruction is effected by the nets spread to intercept them on landing.

Count Scheibler reports that there is not the necessary protection for the breeding of game in Italy that would encourage the landowners to preserve it on their farms. Not only is there a lack of control during the breeding season on the part of the police, but the laws regulating exclusive

\footnotetext{
*Prince Nicolas Ghika, Sport in Europe, p. 271.

† Crown Prince Rudolf, Sport and Ornithology (1889), p. 632.

212
} 


\section{QUAIL SHOOTING}

shooting rights on one's own property vary in different parts of the country and are difficult to enforce. Consequently shooting is limited in Italy, and to English sportsmen would not prove very attractive. The cost of a game licence in Italy varies in different parts of the kingdom, but on the average is equivalent to about $10 \mathrm{f}$.

On the Island of Capri, opposite Naples, quail used to be captured in great numbers, and furnished the chief revenue of the Neapolitan bishop of the diocese. The Bishop having jurisdiction in the Lipari Islands also derives an income from a tax on quails imported from those islands.

SICILY and MALTA.-During the periods of migration in spring and autumn there is a fair sprinkling of quail and snipe, but there are always too many guns out to make it worth while for any but residents to go in pursuit of the birds that temporarily visit these islands. The cost of a shooting licence is equivalent to about 7 francs. With regard to the arrival and departure of quail in Malta, some very interesting observations by Leith Adams will be found in his " Notes of a Naturalist in the Nile Valley and Malta" (pp.98-100). They are too long to be quoted here but will well repay perusal. Several pages also on quail shooting in Sicily and Malta will be found in Col Hamilton's " Reminiscences of an old Sportsman," Vol. I, pp. 166-170.

SARDINIA.-There are always a few quail to be found after the northward migration in April and May, and again on the return passage in autumn, but sportsmen who visit Sardinia are chiefly those who are in quest of larger game, and carry a rifle in preference to a gun.

TURKEY.-Smart, in his "Travels in Turkey," states that in the vicinity of Constantinople the sun is sometimes nearly obscured by the prodigious flights of quail, which alight on the coasts of the Black Sea near the Bosphorus, and are taken in hundreds in nets spread along the shore. Leith Adams was informed in Turkey that quail are common in vetch-fields in July and also in November, which shows some discrepancy in their migrations in the extreme eastern as compared with the central and western portions of the Mediterranean basin. But he had noticed that fields of vetches were particularly attractive to these birds, and that at whatever time of year any vetches were raised the quail would be sure to be found there in abundance, even after the majority have pushed onwards to distant countries.*

* Notes of a Naturalist in the Nile Valley and Malta, p. 100. 


\section{THE GUN AT HOME AND ABROAD}

Mr Hulme Beaman reports that Constantinople itself affords excellent sport in the immediate neighbourhood. At the end of August the southward flight of quail begins, and in a good year great numbers are killed. Their favourite ground is San Stefano, about an hour by train from the capital. The fields are parched and almost bare, but every little tuft of grass, or furrow, seems to shelter a bird. Kilios, on the Black Sea, is the only other spot which provides anything like the same number of quail, being apparently the point of arrival, as San Stefano is the point of departure. The natives there seldom use a gun, but take numbers of quail with trained sparrowhawks, as they do also with nets. An English sportsman, therefore, sojourning at Constantinople might find it worth while to take a gun to either of the two places named. About fifty miles lower down the Marmora than San Stefano is the village of Herekly, which is also much favoured by quail.

THE BALKAN STATES.-The most sporting districts in Servia are those of Nisch and Krushevatz. Quail especially are very plentiful, and there is also some snipe shooting. Montenegro is a stiff and rocky country, but harbours partridge, quail and woodcock, the last named bird affording very good sport near Cettinje and Podgoritza.

Mr Hulme Beaman states that there are no Customs dues in Montenegro, and sportsmen are free to bring in what they wish.

Albania, although properly speaking part of Turkey, may be conveniently grouped with the Balkan States. There is very pretty mixed shooting along the whole coast, consisting of partridges, pheasants, snipe, duck, quail, and, in October, November and December, the best of woodcock shooting. Sportsmen usually confine their attention to the country about Alessio and Butrinto, or other spots opposite Corfu, but the whole seaboard affords splendid chances, especially at the mouths of the rivers and along the course of the Skumbi to Elbassan. Scutari also is a capital centre, there being plenty of sport to be obtained within half an hour of the town, with lots of snipe and woodcock within easy distance in November and December.

In Bulgaria a stranger will require several days in which to procure his shooting licence, as the game laws have been revised and are strictly enforced. Before obtaining it he will have to find two sureties and to fulfil several tedious formalities. But there is no difficulty in importing guns and ammunition, the best route being viâ Bourges. Sofia is the capital 


\section{QUAIL SHOOTING}

and in the country all round there quails breed in large numbers, and in the early autumn it is easy to bag fifty in a day. For this information acknowledgment should be made to Mr Hulme Beaman, whose close acquaintance with the Balkan States, and particularly Bulgaria, qualify him to speak with authority on the sport to be obtained there.

GREEGE.-The opri $\xi$ of Aristotle, known to the Greek peasants and sportsmen of the present day as ortuki, arrives in great numbers in the month of March, and again in August and September, being a migratory bird at those periods of the year. The few pairs that stay to breed begin nesting in May, and some even remain during the winter. Great numbers are caught by the peasantry in nets, and when salted and packed form a lucrative article of commerce.* M. de Heldreich, a resident of Athens, informed me during my visit to that city that thousands of these little birds are sent away annually packed in barrels, after being plucked, drawn and flattened between layers of sea-salt. In this condition they may be preserved for a long time, being taken out and washed when required for roasting.

According to the late Lord Lilford a few quails remain the whole year in Corfu and Epirus; but great numbers arrive every year in April and remain for a few days. On the little island of Fano, especially, they sometimes at that season alight in incredible numbers, often remaining only for a single night. "Occasionally" (he writes) "I have met with good sport at quails in the maize fields of Epirus in September. These were chiefly young birds that had been bred in the country. A few are always to be found in winter on the grassy hills of the mainland opposite to Corfu, particularly on those near the little harbour of Pagania.' +

CYPRUS.-According to the latest information on the subject; the quail is a regular visitor in some numbers to Gyprus on its spring and autumn migrations. A few remain to breed, and some spend the winter in the island. In some years very fair sport can be obtained during the autumn, whilst in others these little birds are noticeable. Mr J. A. Bucknill states that during his residence in the island the best bag reported to him was ten-and-a-half couple shot by two English sportsmen, Messrs

* Heldreich, Faune de Gréce, p. 49.

† Notes on European Ornithology, p. 31.

‡ Bucknill, The Ornithology of Cyprus, in The Ibis for July, 1910. 


\section{THE GUN AT HOME AND ABROAD}

Greenwood and Baxendale. This was at Papho, on October 11, 1908. Another sportsman killed nine to his own gun at Famagusta, January 10, 1909.

MOROCCO._On the Moorish side of the Straits of Gibraltar quail are very abundant at the time of their passage in spring and autumn; crossing over to Europe during March and April, and returning in October and November, remaining much longer in the South of Spain in autumn than they do in other European countries bordering on the Mediterranean.* A sportsman visiting Tangier, Ceuta, Tetuan, or Fez, and making excursions in the neighbourhood would be sure to get some quail shooting in those months.

The Moorish name for the quail is summin, and the Spanish and Portuguese name codorniz.

For further information see Tyrwhitt Drake on "The Birds of Tangier and Eastern Morocco," published in "The Ibis," 1867 and 1869.

ALGERIA AND THE SAHARA.-The reader who may be desirous of information on the subject of quails as well as sandgrouse, red-legged partridges and other game to be met with in these countries could not do better than turn to the late Canon Tristram's entertaining volume, "The Great Sahara," a work which, though published many years ago, conveys an excellent description of the country and the sport which may be obtained there. The quail, of course, is well known there as a bird of passage migrating in large flocks, and is known to the Arabs as mell'houa (op. cit. p. 400). For further information the reader may be referred to Mr J. H. Gurney's "Journal in the Algerian Sahara," which forms a chapter in his "Rambles of a Naturalist," 1876, pp. 21-62. He mentions that on one day in the neigh bourhood of Algiers a keen sportsman shot ten brace of quail in a few hours, and mentions that at Lake Alloula, within two days' journey of Algiers, capital sport may be had with duck, geese and snipe. Two guns in a few hours got $\mathbf{4 0}$ couple of snipe there.

EGYPT AND THE NILE VALLEY.-So many travellers and sportsmen have visited Cairo and made the usual Nile tour, that the sport to be obtained in Egypt with the gun, made known through the books they have published, must by this time be tolerably familiar to all interested in

"Irby, Ornithology of the Straits of Gibraltar.

216 


\section{QUAIL SHOOTING}

the subject. To name only a few of such books will perhaps be sufficient, as the reader may readily refer to them. At the head of the list may be placed the late Capt. Shelley's handsome volume with coloured plates, "The Birds of Egypt," which is said to be now rather a scarce book. This is not to be wondered at, for the information it conveys is very accurate, and the coloured plates very attractive. Then there is Leith Adams's " Naturalist in the Nile Valley," already quoted ; Gurney's "Six Months' Bird Collecting in Egypt," forming a chapter in his " Rambles of a Naturalist" ; Charles Whymper's "Egyptian Birds," illustrated by himself with charming coloured plates-one of them being a quail on the wing, and lastly a pretty little volume for the pocket by Lady William Cecil, published in 1904, with tinted plates, entitled, "Bird Notes from the Nile." From two of these only a few lines may be here quoted, to convey some idea of the "bags" of quail that may be made in Egypt. Mr Gurney says (op. cit. p. 184) : "I never attempted to make any great bag, but I have frequently shot ten brace. The biggest bag I heard of was twenty brace to one gun, or rather to one sportsman with two guns, at Cairo." Mr Whymper states on the authority of a friend, Mr Burnett Stewart (op. cit. p. 106), that on one occasion two guns obtained 252 quail in a day at Ayat, fifty miles south of Cairo.

The best time to shoot quails is in the morning and evening, and ripe barley or strips of lentils are the best places in which to look for them.

GAPE GOLONY.-Before quitting the subject of quail shooting in Africa it should be noted that the migrations of this little bird are most extensive, and that on its southward journey in autumn it actually reaches Cape Colony, whence after spending the winter (i.e., the South African summer) it returns northward again the following spring. It reaches the Cape about the last fortnight in August, and for some time afterwards may be said to swarm there, more particularly in the Eastern Province. A friend of Mr F. H. Guillemard informed him that he had shot over 100 brace in a day near the Kowie River. During a "year of plenty" the late E. L. Layard, an old friend of the writer, while resident at Cape Town bagged forty brace in a day and lost many more. Mr Walter James Pike, writing from Port Elizabeth in December, 1905, remarked, "We are glad to get fifty brace after a hard day's walk with two guns." At the same time he forwarded particulars of a remarkable bag of quails made at Port Elizabeth by a party of eight guns at the beginning of December, and which totalled 


\section{THE GUN AT HOME AND ABROAD}

2,049 birds. This bag was made in twelve-and-a-half hours distributed over four days, though on the average three guns were shooting at a time. The following are the individual scores made by the different members of the party :-Mr W. Armstrong, 282 brace; Mr H. Parker, 224! brace; Mr Walter Pike, 137 brace; Mr T. B. Parker, 1341 brace;

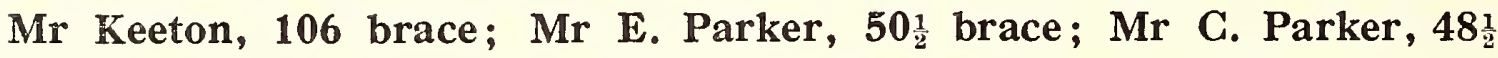
brace; Mr $\mathrm{R}$. Irving, $41 \frac{1}{2}$ brace. This report, which was published in the "Cape Argus" in December, 1905, shows not only the skill of the sportsmen concerned, but the extraordinary abundance of quail at the time and place mentioned. There was a wonderful influx of quails into Mashonaland in 1901 and 1902, an account of which was published by Mr Tredgold in the "Proceedings of the Rhodesia Scientific Association."

ARABIA AND PALESTINE.-During the course of his travels in the Holy Land Canon Tristram constantly met with quails. The plain outside Jaffa (he says) abounded with larks and quails, and in many parts of the country along the banks of the Jordan both quails and francolins were lieard calling incessantly in the marsh and beanfields. He followed the left bank of the Jordan for miles, putting up herons, spurwing plover and quails continually.*

The Grown Prince Rudolf, also, on his way to Jericho, found plenty of shooting in the Jordan Valley, where the bag consisted of red-legged partridges (chukor), Hey's partridge, snipe and quails.

PERSIA.-The status of the quail in Persia is pretty much what it is in India. There are plenty of them at certain seasons and in haunts that are congenial to them, but as most English sportsmen who visit that country go there for much larger game-wild sheep and ibex-such small quarry as the quail is usually left to the native falconers and their sparrowhawks, and to the bird catchers, who take them in nets with the aid of a quail pipe. One of these pipes is now before me as I write, given to me years ago by Mr Sydney Churchill when acting as Oriental Secretary at the British Legation at Teheran. It would cause too much of a digression however, to describe its ingenious construction and the ingenious method of using it, and the reader must be content to be told that if so disposed he may shoot plenty of quails in Persia, as well as partridges, sandgrouse and bustard.

* Tristram, The Land of Israel; a journal of travels in Palestine (1876), pp. 398, 423, 447. 


\section{QUAIL SHOOTING}

INDIA.-The European quail is found throughout India in considerable numbers during the cold weather, most of them migrating during the rains and breeding elsewhere ; but a few remain to breed in various parts of the country, especially towards the west and north-west, as well as in Rajpootana and Bundelkund. It is less numerous towards the south of India than further north. In some localities and in certain seasons it occurs in great profusion in long grass, cornfields and fields of pulse, affording excellent sport with the gun, fifty couple being not unfrequently bagged by one gun in a morning's shooting in the North-west Provinces. In parts of Bengal, also, quails are numerous. Jerdon heard of seventyfive couple being killed by two guns.

Blanford states* that quail arrive in Northern India from Central Asia in September, but are not usually seen in the Deccan or Bengal before October. Occasionally some, even large parties, arrive in Sind, Cutch and Guzerat from the latter end of August till December, coming from seaward, probably from Arabia. The majority, as a rule, leave the North of India in December and January for the South, returning, and at times abounding, in the ripening wheat and barley fields of the North-west Provinces, Sind, and the Punjab in March and April, and finally migrating northward in the latter month or May. A few, however, remain to breed in India, and nests have been taken not only in Northern India, but also at Purneah in Bengal, Hoshangabad in the Central Provinces, and even Satara, in the Bombay Deccan.

Dr Leith Adams, in his entertaining volume "Wanderings of a Naturalist in India," writing on quails, makes the following observation :"Proceeding northwards from Wazeerabad, we entered a district more or less uncultivated, and often covered for miles with tall scrubby jungle, where the sportsman might pick up a few quails at almost any season of the year. ... From the great numbers met with in the fields during the ripening of the grain, and their sudden disappearance afterwards, it is generally supposed they migrate, and in certain situations this may doubtless be the case; but I am inclined to believe that in general they disperse themselves over the jungles of the north-west, and congregate when the wheat and barley are beginning to ripen." $\phi$

BURMA.-Blyth has recorded the occurrence of the quail in Burma

* Fauna of British India (Birds) vol. iv, p. 115.

$\uparrow$ See also Journ. Asiatic Soc. Bengal (1875), p. 151. 
and Arakan, but without any comment on its distribution and numbers. A fuller account is given by Oates in "Birds of Burma" (1883), as well as in his "Manual of the Game Birds of India " (1898). In the latter work he states (p. 81): "The most eastern locality from which I have seen the common quail-' grey quail,' as it is called in India-is Cachar, and I now very much doubt if it occurs in Burma, and especially Lower Burma, as was believed to be the case when I wrote 'The Birds of British Burma.' Major Wardlaw Ramsay's specimen from Karennee turns out to be the Japanese quail, and mistakes may have occurred with regard to the other reported instances of its occurrence in Burma. There are many sportsmen in Burma now, but $I$ have not heard of anyone meeting with the 'grey quail' in recent years, even in the northernmost parts of Upper Burma."

Colonel Le Mesurier has described the native methods of catching quails in the standing crops of barley in Kandahar, the majority of which are taken to market, the stronger cock birds being selected and reserved for fighting purposes, quail fighting being a favourite pastime in that country.*

Jerdon describes an ingenious mode of catching quails in Nepal, and Macpherson, in his "History of Fowling" (1897), has a chapter on "Quail Catching in the East" (pp. 382-388), which is very entertaining and instructive.

GEYLON.-Quails are constantly put up by sportsmen in the plains and glades, and other dry grass lands in the low country, but they are not often fired at for the reason that cartridges are rarely loaded with the proper small shot. They generally rise almost at one's feet and fly only a short distance, or run a few yards along the path, and at such range a charge of ordinary snipe shot is likely to blow so small a bird to bits. If they are known to be fairly plentiful in any old chena or abandoned field, it might be worth while to load a few cartridges specially with No. 10 shot and a small charge of powder, and to go after them, for they are capital eating. They are, however, scarcely worth considering amongst the game birds of Ceylon. $\dagger$ It is, perhaps, for this reason that in the Ordinance enacted by the Governor of Ceylon "to prevent the wanton destruction of birds, beasts and fishes not indigenous to this colony"

"Kandahur in 1879, pp. 180-181, and Game, Shore, and Water Birds of India (1904), pp. 74.95.

$\dagger$ Clark, Sport in the Low Country of Ceylon (1901), p. 78.

220 


\section{QUAIL SHOOTING}

the quail is not included, the only game birds protected being pheasants, partridges, francolin* and sandgrouse.

Mr. H. Storey, Secretary of the Ceylon Game Protection Society, identifies three species of quail in the island. Writing in 1907, $\uparrow$ he enumer ates the black-breasted bustard quail, coming first as the one most commonly met with, though plentiful in only a few parts of Ceylon, frequenting open grassy or weed-grown country from an elevation of about 2,000 feet to sea level; difficult to flush without a dog, but flying with a "whirr" at great speed for about fifty yards, to settle with extraordinary suddenness. He adds that abandoned dry grain clearings are favourite resorts. Next there is the Chinese quail (Coturnix chinensis), the eastern representative of our common quail (Coturnix communis) and not unlike it in appearance; an autumn migrant to be found chiefly in the low country of the west in damp spots and grassy hollows in the jungle. Finally there is the jungle bush-quail (Perdicula asiatica), a larger bird, about an inchand-a-half longer, and stouter in proportion, to be met with only in the low country of the Eastern Province.

It is curious that Sir Emerson Tennent, in his "Natural History of Ceylon," so full of information on other subjects, makes no mention of partridge or quail further than to say (p. 265) that " partridges and quails are to be had at all times," a statement which in regard to the latter bird is not quite exact.

It will be seen from the foregoing statistics that the common European quail (Coturnix communis) has a most extensive geographical distribution over three continents. In addition to this, experiments have been made to introduce it into parts of the United States, where large consignments have been set at liberty. In the State of Vermont, for example, in the neighbourhood of Rutland, no fewer than 6,000 quails were liberated in the course of two years, communis is a migratory species, the wisdom of such experiments may be questioned, and they have been adversely criticized even by American writers. Messrs Sandys and Van Dyke, for example, in their "Upland Game Birds," write as follows :- "Although the common quail of Europe, Asia and Africa is not indigenous in North America, a determined but

\footnotetext{
* The Francolin (Francolinus pictus) is to be met with on some of the lower hills of the central provinces, west and south of Newara Elia. Blanford, Fauna of British India (Birds), vol. iv, p. 137, and Baker, With Rifle and Hound in Ceylon (1854), p. 387.

†Hunting and Shooting in Ceylon (1907), p. 66.

I See The Zoologist, 1878, p. 390, and Dr C. H. Merriam's Report on Quail, Bulletin U.S. Dept. Agriculture (1905).
} 
THE GUN AT HOME AND ABROAD

misguided attempt was made some years ago to introduce it. Sportsmen in various parts of the States heard of the possibility of adding to their game list, and money for the purpose was speedily forthcoming. The original importations were released at various points in the northern States and Canada early in spring; the promoters of the experiment believing that the birds would breed there, and that their progeny would follow their natural instinct by moving southward at the approach of cold weather, and return to their birthplace in the following spring. Theoretically this seemed sound reasoning, but practically the experiment turned out a failure."*

The comprehensive title of the present work has made it necessary to consider the birds included in it in their haunts abroad as well as at home, and from the fact of the remarkably wide geographical distribution of the quail, it so happens that the smallest of them all-with the exception, perhaps, of the jack snipe-has taken us further away from home than any other bird on the list.

J. E. HARTING.

* Sandys and Van Dyke, Upiand Game Birds (1902). 


\section{WOODCOCK}

\section{SCOLOPAX RUSTICULA}

(Plate XXIII)

Scolopax rusticola, Linn. Syst. Nat., i, p. 243 (1766); Gould, Birds Europe, v, pl. 319 (1837); Dresser, Birds Europe, vii, p. 615, pl. 540 (1877) ; Hume and Marshall, Game Birds Ind., iii, p. 309, pl. (1880); Seebohm, Hist. Brit. Birds, iii, p. 231 (1885).

Rusticola sylvestris, Macgillivray. Man. Brit. Birds, ii, p. 105 (1842).

Scolopax rusticula, Saunders, ed. Yarrell, Brit. Birds, iii, p. 320 (1883); Lilford, Col. Fig. Brit. Birds, pt. vii (1888) ; pt. xiv (1890). Sharpe, Cat. Birds Brit. Mus., xxiv, p. 671 (1896); Saunders, Ill. Man. Brit. Birds, p. 569 (1899); Oates, Man. Game Birds Ind., ii, p. 428 (1899); Ogilvie-Grant, Country Life, 1910, p. 69.

Walsingham and Payne-Gallwey, "Badminton Library," Marsh and Moor. The Woodcock, p. 112 (1886).

Shaw and Ussher, "Fur, Feather, and Fin Series," Snipe and Woodcock (1904).

DULT male and female.-General colour of the upperparts mottled with rufous, black, buff and grey, the groundcolour being rufous, coarsely marked with black crosslines and blotches, with grey or buff tips to many of the feathers, forming spots or bands, especially down the sides of the interscapular region and scapulars; lower back, rump, and upper tail-coverts light chestnut, with narrow blackish crossbars. Quills dark brown, notched with rufous; the outer web of the first long primary quill being either margined or notched with pale buff, a purely individual character found in both adult and young birds (figs. 1 and 2). Tail-feathers black, notched with chestnut on the outer webs, and broadly tipped with smoky-grey above and silvery white below, the grey portion

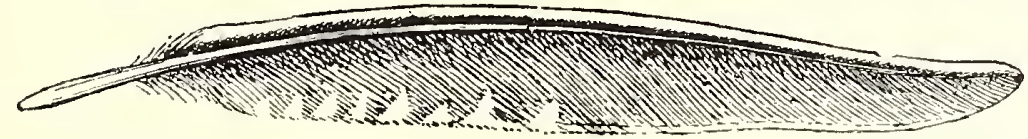

Fig. 1. First long flight-feather of adult Woodcock showing outer web margined with buff.

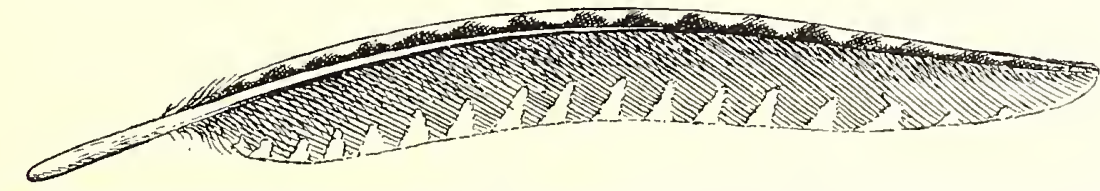

Fig. 2. First long flight-feather of adult Woodcock showing outer web notched with pale buff.

being divided from the black portion by a narrow buff line. Forehead, ashy grey; lores, sides of the head and chin, as well as the upper part of the throat, white; a brownish-black band from the base of the mandible to the eye; crown black, barred with rufous, with three or four whitish-buff 
THE GUN AT HOME AND ABROAD

cross-bands; rest of the underparts pale buff, barred with brown. Iris dark brown; bill dusky brown; livid or pale flesh-colour at the base of the lower mandible; feet greyish.

Adult male.-Total length about 15 inches; bill, from feathers on forehead to tip, about $2 \cdot 85$ to 3.0 inches; wing 7.5 inches; tail 3.5 inches; tarsus $1 \cdot 55$ inch.

Adult female. - The bill is usually longer than in the male, 3.0 to 3.3 inches; while the other measurements are usually less; wing $7 \cdot 3$ inches; tail 2.9 inches; tarsus 1.4 inch. The female may almost always be recognized by the longer bill, the only reliable external character for distinguishing the sexes.

The young bird in first autumn-plumage. -Differs from the adult in being smaller and darker above, and in having the feathers of the back and scapulars less distinctly tipped with cream-colour or buff, never with grey; no subterminal buff line between the dark smoky grey tip and the black portion of the tail-feathers;* the outer web of the first long primary quill usually edged with buff or sometimes partially notched towards the tip of the feather, rarely toothed with buff throughout. The first character has generally been attributed to very old birds, the last mentioned to birds of the year.

Young in down.-Whitish-buff, widely striped and mottled with chestnut above; a wide chestnut band extending from the base of the bill to the rump, darkest on the crown and back; one or two transverse buff bands across the crown between the eyes indicating the markings of the adult; a dark chestnut band from the gape to the eye, and thence extending down the side of the neck to the shoulder; wings mixed with chestnut; a light chestnut band on each side of the back, divided from the darker median band by a pale buff area; underparts buff; a rather distinct chestnut band across the throat, and a less marked band at the base of the neck; thighs and flanks blotched with pale chestnut.

The following notes, recently contributed by the writer to "Country Life" (with photographs of the first primary quill-feathers taken from old and young woodcocks), are here reproduced by the kind permission of the proprietors.

"How to distinguish the male from the female woodcock, and the old birds from birds of the year by their plumage, are questions which have long puzzled both naturalists and sportsmen; certain characters to be

${ }^{*}$ Seebohm states that the buff line is characteristic of young birds of the year, but this is certainly an error. 224 


\section{WOODGOGK}

found in the markings of the feathers have been indicated as diagnostic, but all these I have proved to be absolutely valueless.

"In 1873, Gould ('Birds of Great Britain,' iv, p. 77) expressed his views on the subject as follows : 'Some sportsmen assert that they can distinguish the sexes by an examination of the outer primary, and affirm that those birds which have the external margin of that feather plain or devoid of tooth-like markings are males, and those in which it exists are females. But they are absent in both sexes of very old birds; for I have wings of females in my collection in which the outer margin of the first primary is totally devoid of the toothed character. When the young woodcock assumes his first primaries, which he does at the age of two or three weeks, the outer feather is strongly marked; and I have frequently seen specimens with the outer primary toothed for half its length, and the other part plain.'

"It will thus be seen that, though Gould did not believe that there was any sexual distinction to be found in the plumage, he implies that the woodcocks with tooth-like markings on the outer web of the first long flight-feather are the young birds of the year; that these tooth-like markings gradually disappear with age-i.e., at the second and subsequent autumn moults, when the flight-feathers are shed; and that the birds with a narrow whitish-buff border to the outer web of the first long flightfeather are 'very old birds,' more than two years old. This statement has been generally accepted as correct, and has been copied and recopied by various authors, even by that most careful writer, Howard Saunders, who in 1899 writes as follows ('Ill. Man. Brit. Birds,' p. 570): 'In the young birds the outer webs of all the primaries show distinct fulvous notches; in the adult there are hardly any such markings on the first and second webs.' The investigations which I have undertaken during the last few years have clearly proved the entire fallacy of this theory.

"On the higher parts of the islands of the Azores the woodcock is a very common bird, and during the five months I spent there, from February to June, 1903, I shot and examined a very large number of these birds, many of which were breeding. These exhibited all varieties of markings on the first long flight-feather, some, both males and females, having a narrow border of creamy-white along the margin of the outer web (fig. 1), while others had well-defined tooth-like buff markings along the whole of the outer web (fig. 2), and examples in every intermediate stage were also observed. Subsequently Mr E. G. B. Meade-Waldo, who was 


\section{THE GUN AT HOME AND ABROAD}

much interested in the matter, sent me the first long flight-feathers taken from four undoubtedly young woodcocks, which he had shot in Kent in August and September, 1908. These equally displayed great variety in their markings, one having an almost entire buff margin to the outer web of the first flight-feather, while in the others it was partially toothed on the terminal half, but in no two was it alike. This clearly proved that woodcocks with the tooth-like markings all along the outer web of the first flight-feather were not necessarily young birds. To throw further light on the matter, I sought help from Sir Richard Graham of Netherby, where numbers of woodcocks are known to breed annually, and he very kindly sent me eleven young birds in various stages of plumage, the flight-feathers in all being only partially grown. These, like the young birds from Kent, showed every variety of marking, but the majority (like Gould's very old birds) had a more or less entire buff border to the first flight-feather, and in one only was it toothed throughout. This entirely upsets Gould's theory, as many of the birds which he considered to be fully adult (on account of the entire buff margin on the outer web of the first long flight-feathers) were no doubt birds of the year. My investigations have clearly proved that it is impossible to distinguish between the plumage of the male and female woodcock, or between old birds and young birds of the year, when once the latter have fully developed their flight-feathers.

' Seebohm ('Hist. Brit. Birds,' iii, p. 236) distinguishes the young from the old bird as follows: 'Young in first plumage very closely resemble adults, but the bold pale spots on the upperparts are much less conspicuous, being smaller and chestnut-buff. The most striking difference is to be found in the tail-feathers, in which the grey tips on the upper surface have buff bases, and the chestnut spots on the margins of the outer webs are lengthened into bars reaching to the shaft. Birds of the year are intermediate in these respects between adults and young in first plumage.' These differences are individual, and do not appear to have any significance whatever.

"Lastly, the width of the barring on the underparts has been suggested as a distinctive character, but, like those already mentioned, it appears to be purely an individual one.

"The woodcock is more or less dimorphic in plumage-i.e., two more or less distinct phases of plumage are found; some birds have the general colour of the upperparts greyer, while in others it is richer and more 


\section{WOODCOCK}

rufous. The grey phase and the rufous phase occur in both sexes alike, in fully adult birds; but, as far as my experience goes, the grey phase is never found among young birds, which are always more or less rufous. These represent what is often described by sportsmen as the smaller rufous 'species' of woodcock. Though a careful examination of the plumage of the woodcock has not led to the discovery of any character by which the sexes may be recognized externally, it has suggested another point of a much more interesting nature, and to this I especially wish to draw attention. Of the sixty odd birds examined by myself in the Azores, only four proved to be females. At the time I attributed this partly to the fact that the birds were procured between the months of February and June, when many were breeding, and partly because the majority were shot when 'rôding,' as their peculiar evening flight is called. But this explanation does not apply to the eleven young birds sent from Cumber land, only one of which proved, on dissection, to be a female. The remark able preponderance of males seems to me to suggest very clearly, what I had already suspected, that in the woodcock, as in the cuckoo (Cuculus canorus), the males are far more numerous than the females. It was with a view to testing and obtaining further information on this most interesting point that $I$ have already brought this matter before the members of the British Ornithologists' Club, and I hope that those who have an opportunity of doing so will endeavour to furnish us with further statistics. The obvious and easy method of proving or disproving this question would be to sacrifice a limited number of broods of young woodcocks, so as to ascertain the sex of the four individuals in each family party. In districts where the woodcock breeds numerously, a few lots of young birds might surely be spared for such a purpose. The birds might be caught and for warded while still young, as the sex, even in downy young, can easily be ascertained by careful dissection."

Up to the present time the question as to the possible preponderance of males remains unanswered. We read that the male woodcock is generally to be found in close proximity to the female with nest or young, but such has never been my experience, either in Scotland or abroad, the young being invariably accompanied by a single bird, and two which were shot proved, on dissection, to be females.

The woodcock is a very highly specialized bird, and among its more striking peculiarities may be noted:

(1) The bill, which is a wonderfully constructed organ of touch, and 
THE GUN AT HOME AND ABROAD

probably also, to some extent at least, of smell; its structure will be further alluded to under the heading "Food."

(2) The position of the large eye, which is situated so far back in the head, that to enable the bird to see in front of it, it is obliged to fly with the bill pointing more or less downwards. In daylight the powers of vision are probably less keen than they are at night, for woodcock, suddenly startled, have been known to fly against trees and such-like obstacles, and to stun or even kill themselves.

(3) The remarkable position of the ear, which is situated beneath the eye, and near the anterior corner of it. In the opinion of Mr W. P. Pycraft the unusual position of the ear in the Scolopacida is due to a shortening of the base of the skull, which has had the effect of drawing downwards and forwards the hinder portion of the skull, and with it the aperture of the ear. ("Ibis," 1908, pp. 551-558).

Variations in plumage.-Variations in plumage among woodcocks are by no means uncommon. White or partially white birds are not infrequently met with, also smoky-brown (like the dark variety of the snipe known as Sabine's snipe), pale buff, cream-coloured or light ash-coloured individuals with the dark markings present, but much paler than in the normally coloured woodcock. A very handsome bird in the Natural History Museum has the ground -colour of the wings, back and tail-feathers silverygrey, barred with pale rufous and black, and the primary quills white. Birds with a great deal of black in the plumage also occur; in fact, the range of variation to be found is very great indeed.

In the Azores the writer obtained a nearly white specimen under rather curious circumstances. While waiting at night to get a shot at a large owl, which frequented the neighbourhood of our camp on the island of San Jorge, a white object was seen moving on the ground, and at the first glance mistaken for a piece of paper blown along by the wind. It proved, however, to be a fine variety of the woodcock engaged in making its evening meal, and its skin is now preserved in Mr Walter Rothschild's splendid collection at Tring.

General distribution. - The woodcock is peculiar to the north-eastern hemisphere, and is widely distributed over Europe and the greater part of Asia, ranging southwards in winter to North Africa, while in the higher wooded parts of the Azores, Madeira, and the Canaries it is resident. In the Faeroes it has once been obtained; while in Newfoundland, and on the Atlantic shores of the United States it occurs as an accidental straggler. 


\section{WOODCOCK}

In the north-western portion of its range it is found in the breeding season as far north, in Scandinavia, as the Arctic Circle (lat. 66 $2^{\circ}$ ), and up to about lat. $65^{\circ}$ in western Russia; but eastwards its northern limits are less extended, and in Siberia it is not met with much beyond $60^{\circ}$ north latitude. Southwards it is a common breeding-species in the higher wooded grounds of the Azores, Madeira and the Canaries, and a limited number breed in Europe as far south as the Pyrenees, central Italy, Transylvania, the Balkans and the Caucasus; while in Asia, though the breeding-range does not extend so far south, it nests in Kashmir and the Himalaya above 10,000 feet, and also on Fujiyama, the great volcano on the island of Hondo, Japan. It will thus be seen that the breeding-range of the woodcock may, roughly speaking, be included within four lines drawn from the Canaries to the Arctic Circle in Norway, thence across Europe and Asia to the sea of Okhotsk, southwards to Japan, and back through the Himalaya to the Canaries. Outside these limits it ranges southwards in winter, and is found in vast numbers on both sides of the basin of the Mediterranean, occurring in Africa as far south as the Atlas Mountains, and even beyond them, also in Persia, India, Ceylon, Burma, and South China.

The woodcock leaves the Mediterranean basin towards the end of February and the beginning of March, and the bulk of the birds gradually move northwards during the latter month, and arrive in their more northern breeding-grounds early in April. It returns to the Mediterranean basin between the latter half of October and the end of November. Further east the dates of its spring - and autumn-movements are almost synchronous with the western, and it is found in Persia, India, Ceylon, Burma and Southern China from October till the end of February.

Allied forms. - Apart from the various species of snipes, which many ornithologists regard as congeneric with the woodcocks, the latter have few close allies, all characterized by having the tail-feathers tipped with silvery-white below. In the mountains of Java and north-western New Guinea a much darker plumaged species (Scolopax saturata) is met with, and is easily distinguished from the common species by having the forehead barred with buff and black, and the abdomen white instead of buff, very heavily barred with blackish. It is possible that a larger series of these rare birds than is at present available, may show that the Javan bird is distinct from that found in the Arfak Mountains in North-western New Guinea, in which case the former would bear the name of $S$. saturata 


\section{THE GUN AT HOME AND ABROAD}

Horsfield, and the latter that of $S$. rosenbergi, Schlegel. In the Obi Islands and possibly also in the Island of Ternate, both of which form part of the Molucca group, a different and very handsomely plumaged black and buff species, Neoscolopax rochussenii, occurs, characterized by having the legs bare above the tarsal joint, as in most snipes, not feathered as in Scolopax. Lastly, in North America a smaller species, Philohela minor, is found, having the three long outer flight-feathers attenuated to a remarkable degree, and the underparts nearly uniform buff, without transverse bars of black. This species has never, so far as is known, been recorded as a straggler to Europe, though h, as already stated, the common woodcock occasionally reaches the shores of North America.

Distribution in the British Isles. - In the British Isles the woodcock is resident, breeding in many suitable localities, and appears to have done so in greatly increasing numbers during the last twenty or thirty years. In Scotland it now nests in most wooded districts, but more commonly in England and Ireland. At Alnwick Park, in Northumberland, and Netherby, in Cumberland, many broods are annually reared, also in the southern counties of England. In Ireland it breeds in every county, and in some of the large coverts the birds are reported to be more numerous during the summer-months than they are in winter.

During the late autumn- and winter-months the numbers are vastly increased by hordes of migrants from Northern Europe, and at that season many of the islands off the north and west coasts of Scotland, and suitable parts of the mainland, especially in Ireland, abound with birds moving southwards in search of more open feeding-grounds. The annual " flights " usually begin about the middle of October, and the return migration northwards reaches our islands in the middle of March, but the movements of the woodcock, like those of other wading-birds, depend greatly on the mildness or severity of the seasons, and vary somewhat from year to year. There is a popular belief that our home-bred woodcocks leave this country early in autumn before the northern migrants arrive, but all the evidence seems to show that this is not really the case. In autumn the birds are going through their annual moult, and, though no longer to be met with in their usual haunts, are no doubt merely hiding themselves and lurking in out of the way places till such time as their flight-feathers have been renewed. This is proved by the fact that many of the birds marked in spring by placing metal rings on their legs have been shot in the same county in autumn. It is very unlikely that the woodcock is exceptional 230 


\section{WOODCOCK}

in its migrations, for, as Seebohm has pointed out, it is certainly not a gipsy migrant, but has a regular winter-home, to which it constantly returns year after year. The rule among regular migrants is unquestionably that whenever the breeding-range overlaps the winter-range, the birds in the overlapping districts are residents, those breeding further north only passing through the intervening district on migration to winter further south. Another argument against the supposed migration of resident birds is the fact that nests with eggs are not infrequently found in mild seasons in the British Isles in March, when the spring migration from the Continent is only commencing.

Food.-Earth-worms, slugs, fresh -water molluscs, and insects of various kinds are the principal articles of food, but vegetable matter is sometimes found in the stomach, and tender shoots of heather are said to be eaten occasionally. Mr Hugh Wormald, who has kept both woodcock and snipe in captivity writes, "I could never get my woodcock or snipe to eat anything but live food; they would sometimes pick up a root of some waterplant (which must have felt very like a worm !) but they always discarded it." Earth-worms form the woodcock's staple article of diet, and the number required to satisfy its voracious appetite is almost incredible. The bill of the woodcock, which is about three inches in length, is specially adapted by Nature to enable the bird to discover and capture its prey. The upper mandible is abundantly provided with rows of nerve-cells, which culminate in a subterminal mass in the swollen cushion-like extremity of the bill, and render that organ extraordinarily sensitive to touch, and no doubt also, though in a less degree, to smell. The upper mandible terminates in a sharp, slightly curved nail, about one-tenth of an inch longer than the lower mandible. This highly organized bill is used as a probe, and is thrust into the mud or soft-soil in search of earth-worms, which are unerringly detected, seized, and withdrawn. The ground where woodcocks have been probing may always be recognized by the round holes all over the surface, larger than those made by the snipe. Water of some sort in the immediate vicinity of the feeding-ground is an essential, for all the Scolopacide require to wash the bill frequently when feeding.

In hard weather, when the usual feeding-grounds in the marshes and water-meadows are frozen, and its favourite earth-worms are unattainable, the woodcock betakes itself to the warmer and more sheltered parts of the woods and to ditches, where it searches for insects and small 


\section{THE GUN A'T HOME AND ABROAD}

mollusca among the dead leaves. At such times it also consumes a certain amount of vegetable matter to allay the pangs of hunger.

Normally, the woodcock is nocturnal in its habits, leaving the shelter of the woods for its feeding-grounds shortly before dusk and returning at dawn to rest in some sheltered spot, but when food is scarce, and it has been unable to satisfy its abnormally large appetite, it also feeds to some extent during the day in the neighbourhood of its restingplace. In such times of stress it rapidly loses weight and becomes a mere skeleton.

Weight.-The average weight of a good plump woodcock is about twelve ounces; smaller birds weigh about eleven ounces, and very large ones as much as sixteen ounces, though the latter are exceptional. Occasionally one hears of even heavier birds being killed, and Yarrell records a giant woodcock, killed in 1801, which was said to have weighed no less than twenty-seven ounces! It seems certain, however, that a mistake must have been made; it is probable that " seventeen ounces" should be substituted for "twenty-seven ounces." The greatest weight is usually attained about the end of November, but this entirely depends on the season and on the quantity of food obtainable. After a period of frost the weight may fall as low as eight ounces, but usually before this happens the birds continue their southward movement to open feedinggrounds.

There is a popular belief that woodcock lose weight during migration, and that when they first land on our east coast in the autumn they are very thin, owing to the want of food during the crossing. As the crossing is usually accomplished in a couple of hours it is impossible for the birds to lose flesh to any appreciable extent, and their poor condition when they arrive is no doubt accounted for by severe weather encountered in the north before migration. Mr Victor Ames informs me that on October 20, 1890, he shot fourteen woodcocks which had come across the sea and that their average weight was eleven ounces, all being plump and in good condition. The woodcock swallows a large amount of grit and sand to aid its extremely rapid digestion, which, coupled with its enormous appetite, enables the bird to put on flesh very quickly in times of plenty. Thus, birds which during a short spell of cold become so reduced that they are not worth shooting, with the return of mild weather, as rapidly resume their former condition and plumpness.

$\operatorname{Mr} \mathbb{E}$. J. Mann has kindly furnished me with the following record of the 232 


\section{WOODCOCK}

weights of woodcock shot on various days in four seasons on Sir Edward Mann's shootings in Norfolk :

1908-1909.

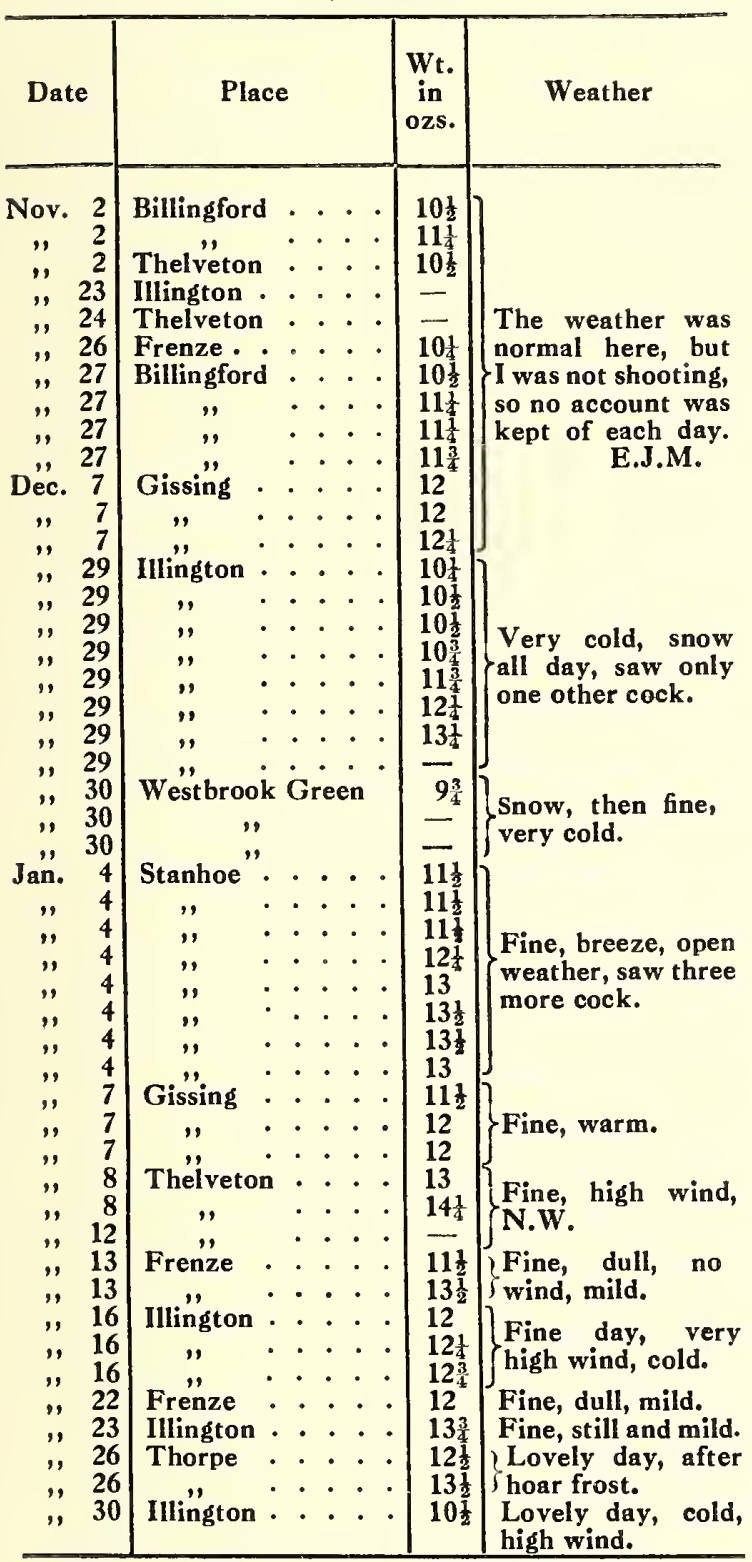

48 Woodcocks, 6 not weighed. 42 Woodcocks, 11.89 average.
1909.1910 .

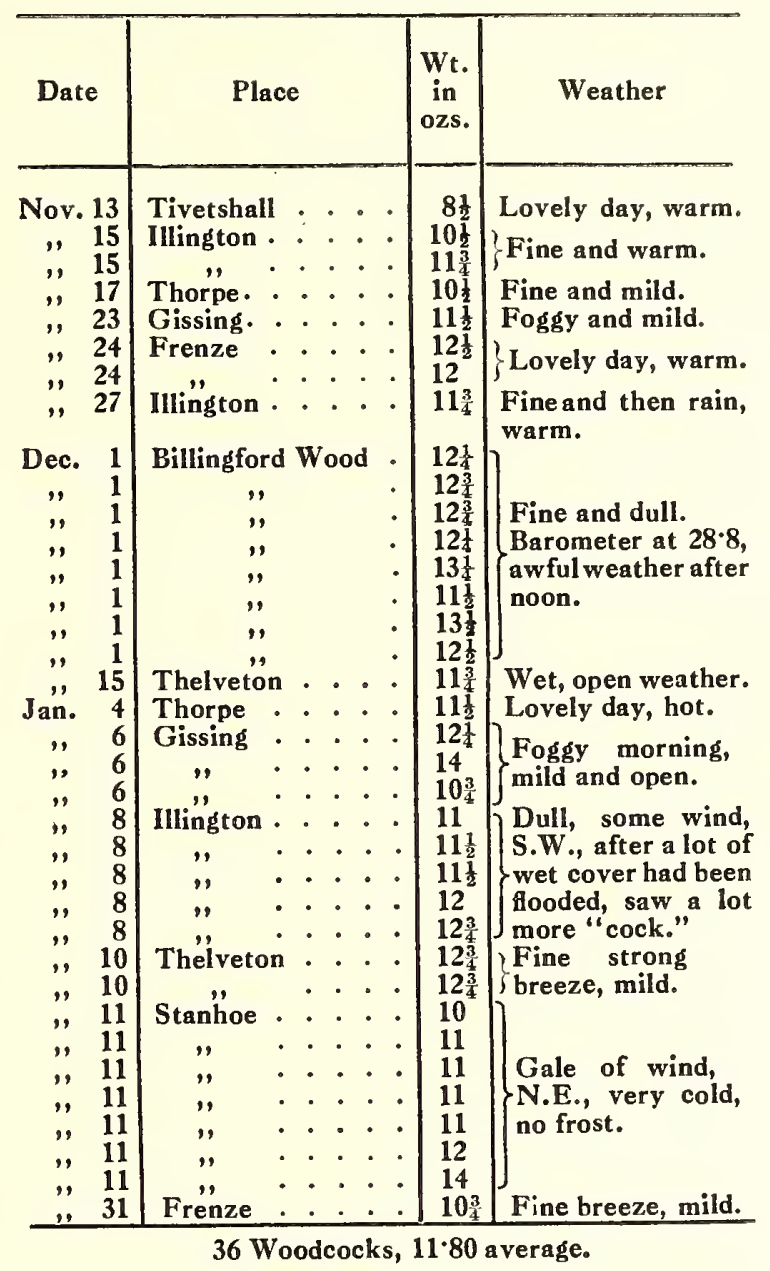


THE GUN AT HOME AND ABROAD

1910.1911.

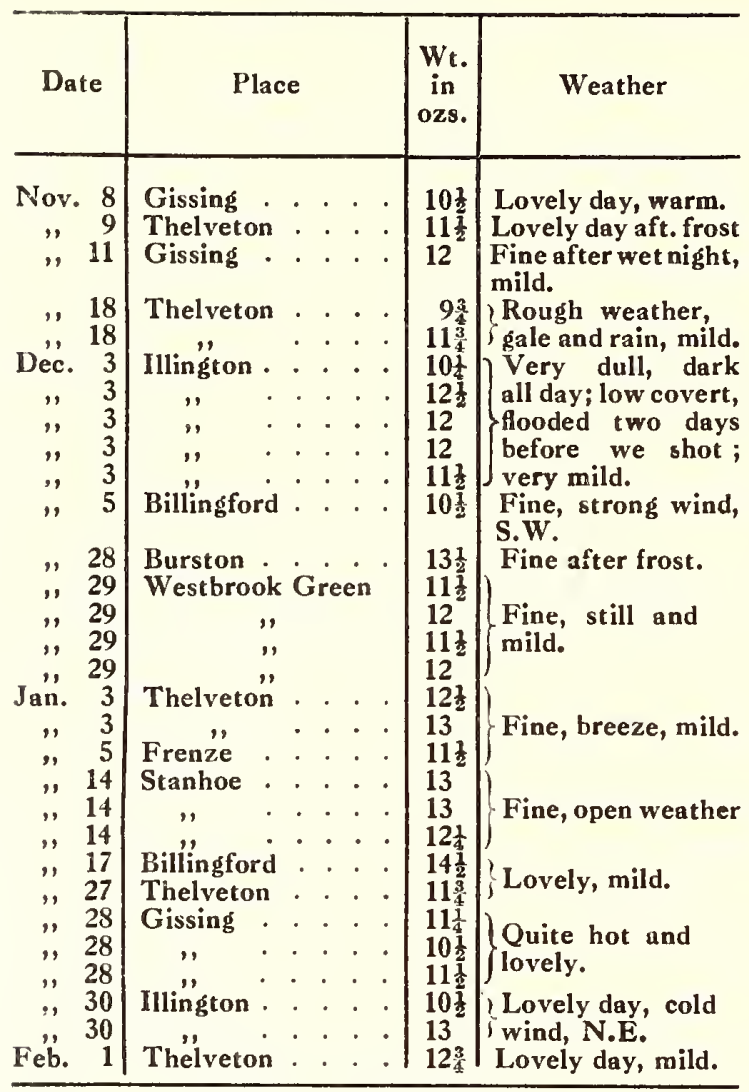

30 Woodcocks, $11 \cdot 83$ average.
1911-1912.

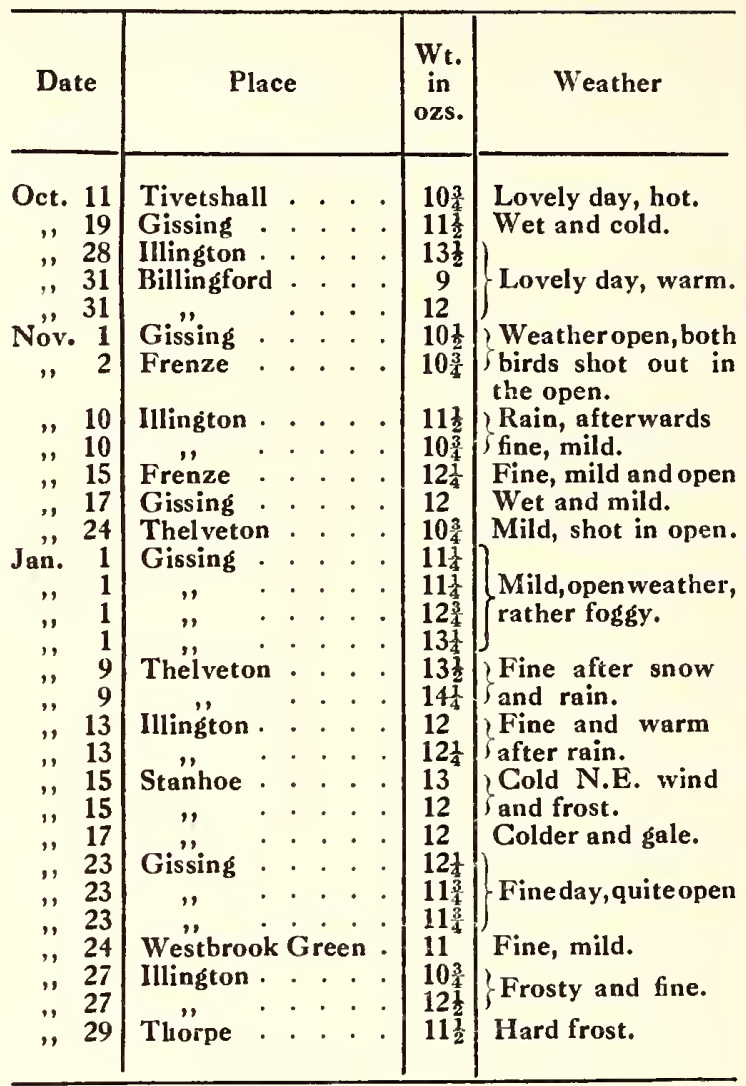

30 Woodcocks, $11 \cdot 80$ average.

Flight.-The feeding-grounds are often situated a long way from the coverts specially favoured by woodcocks, and shortly before dusk the birds may be seen leaving the wood singly, but always by the same route, and fiying swiftly to their marshy destination. On rising from their " seat" in the wood they make for the nearest glade or ride, flying low until they reach the open, when they shoot up to a height of twenty or thirty feet, and travel at a great pace straight to the feeding-ground. Personally, I have never seen them leaving the marshes at dawn, but in doing so they are said to wheel round for a short time, often making a peculiar call; then, after mounting to a considerable height, they take a direct line for the covert in which they have found a temporary resting-place.

As might be expected from the shape of the wings and the great development of the pectoral muscies, the woodcock is capable of very rapid and protracted flight; and one can hardiy believe that the birds one sees in the spring and early summer flapping slowly through the air when 


\section{WOODGOCK}

" rôding," or the birds which are flushed in the morning after a heavy gorge of worms overnight, when they flap along almost like short-eared owls, can be really the same dashing woodcocks one meets with at other times.

When food is scarce the birds are active enough, and rising sharply, twist swiftly through the trees in a fashion that admits of no hesitancy on the part of the shooter. Flight is performed with the wings bent, and with regular, not very swift, wing-beats. The bill is pointed downwards, and the legs, as is usual among all the wading-tribe, are fully extended behind the tail. The angle at which the bill is held during flight is no doubt a matter of necessity; for the eye is placed so abnormally far back in the head that the birds are incapable of seeing what is in front when the bill is pointing forward.

Migration.-The pace at which woodcocks can travel on migration must be very great indeed, and probably enables them to compass the long distance between Scandinavia and the East coast of Scotland in a couple of hours, or less under favourable conditions. Migration, which normally follows the usual westerly route, always takes place at night, the birds starting at dusk and arriving at their destination long before dawn, except when their movements have been delayed by unfavourable weather and gales which have driven them out of their course. They fly at a great height, and, like all other migrants, prefer a side wind when making their journey; also greater numbers arrive on thick misty nights than in clear weather. The inherited instinct which enables them to find their way in thick weather and guides them to the same destination year by year is truly marvellous. Many perish during their bi-annual flights, when overtaken by contrary gales, as is proved by the numbers of drowned birds seen off the west coast of Ireland. Like other migrants, too, many kill themselves against the lighthouses. The birds are often so utterly exhausted on arrival at the coast that they are scarcely able to rise again.

In a letter published in the "Evening Standard and St James's Gazette," March 13, 1912, a correspondent furnishes the following interesting details, which we quote in full, of the havoc wrought by some of the French lighthouses : " Everybody knows what a powerful attraction lighthouses have for birds, and how the one on Heligoland especially is the centre in migration times in spring and autumn of vast swarms of birds, many of whom, half-blinded by the light, dash themselves against the glass or the masonry and perish. The extent of this slaughter is for 


\section{THE GUN AT HOME AND ABROAD}

the first time emphasized and insisted upon by a correspondent of the 'Liberté,' who has taken great pains to get at the truth, deriving his facts from numerous eye-witnesses. The 'engines of destruction' are the lighthouses provided with electric light.

"The first offender is the lighthouse on the Pointe de Penmarch, in Brittany, which has a revolving light of thirty million candle-power. Visiting this on November 10 last year, and again on the 12th, the observer saw tens of thousands of birds whirling round, and it seemed to him that the light shot out a perfect hail of electric sparks amongst the migrants. However that may be, next morning he was present while the dead bodies were being collected. They are dispatched every day to Paris by train, and the ' catch,' he was told, often comprised from 2,000 to 4,000 victims; one morning alone there had been more than 500 woodcocks in the 'bag.' As for what he himself actually saw on the two mornings he was present at the collection of the victims, there were only a score of woodcocks the first morning, but on the second the ground was littered with from 600 to 1,000 victims, chiefly blackbirds, ducks, woodcocks, thrushes, and golden plovers. Western Brittany used to be a favourite haunt for woodcock, but every year now the number grows smaller, thanks to the slaughter at the lighthouses.

"The second offender is the lighthouse on Belle Ile, off the South Coast of Brittany. On two dark nights at the end of last November, with an east wind blowing, this light caused the death of 3,200 birds, including curlews, thrushes, snipes, starlings, over 100 woodcocks, and some sparrows and quails.

" Thirdly, the Pilier Lighthouse kills every season some 700 woodcocks.

"An old sportsman of Normandy declares that round the lighthouse of Barfleur last November there were picked up in the course of four nights 10,000 birds of all sorts, including 1,800 woodcocks.

"Be it remarked that these figures only refer to four out of the many lighthouses round the French coast. It is impossible, of course, to interfere with these strong lights and the protection they give to shipping, but could not a means be found of preventing their blinding effect on birds ? The St Hubert Club is already moving in the matter, and has offered a handsome prize to the inventor who shall devise a plan for protecting birds against the fascination that takes hold of them when they find themselves in the beams of the electric light.

"Two projects out of many submitted seem to give the required solu236 


\section{WOODGOGK}

tion. The first is based on a bird's well-known dislike for any unfamiliar noise. So the Chinese protect their tame pigeons from birds of prey by attaching to their tail-feathers little wooden whistles that sound when the pigeon takes to flight. If the lighthouses were provided with a siren that sounded continuously on dark nights, the birds might avoid them. The second idea is to light the walls with acetylene lamps, to prevent the birds dashing against them."

The birds are often so exhausted on arrival at the coast that they are scarcely able to rise again. Two lads, both of whom could shoot well, were given permission to kill rabbits on the Elginshire coast, and happened on a great flight of woodcock which had come in after a stormy crossing. The birds, which had taken refuge in the gorse-bushes fringing the cliffs, were only able to fly feebly, and nearly two hundred were killed in two days. On the third day almost all the survivors had passed on, and only six were shot. Writing from Norfolk, Mr Victor Ames observes that if flushed on the morning after arrival in a covert near the sea, the woodcocks merely fly out on to the grass and run about wagging their heads, and get back into the thicket on the first opportunity, being very difficult to flush a second time. The woodcocks, like their close allies the snipes, are solitary in their habits, and though large numbers often leave the shores of their northern breeding-haunts simultaneously and cross the seas together, they are not truly gregarious, but merely obeying a common impulse which prompts each individual to start at a certain time and follow the same route followed by its ancestors. On arrival at their destination the birds almost immediately scatter and resume their normal solitary existence, each woodcock taking up his abode in some particular spot until a further move becomes imperative, when all the scattered individuals disappear with one accord.

Breeding habits. - The woodcock is a very early breeder, and the pairingseason generally begins towards the end of February, but varies according to the mildness or severity of the weather. At that season the males become very active during the daytime, and when courting the females strut round with the feathers of the head and neck puffed out, the wings drooped, and the tail spread out like a fan. When the females begin to sit-in mild springs they sometimes do so as early as March, but usually not until April-the males commence their early morning and evening flights known as " rôding." When indulging in this curious habit they fly slowly along about thirty feet from the ground with the feathers of the head 


\section{THE GUN AT HOME AND ABROAD}

and neck much puffed out, every few minutes giving vent to their peculiar cry, which consists of a whistling note like pist, followed by three deep guttural croaks, ork, ork, ork. The flight, which lasts about twenty or thirty minutes, generally follows a triangular course, the same bird often passing several times over almost precisely the same spot.

A few years ago the writer spent five months camping in the Azores, where the woodcock is an extremely common bird on the higher grounds of some of the islands, and had exceptional opportunities of studying its habits and of obtaining a large series of specimens, the sex in every instance being carefully determined. On the island of San Jorge they were especially numerous, and during the month of May a dozen or more might be seen on the wing any evening going through their strange performance. There being no law to prevent it, the Portuguese shoot the woodcock when "rôding" all through the breeding-season, and considering the way the birds are constantly persecuted, it is astonishing that they should be so numerous. In former times our ancestors used to set their nets called "cock shuts" and catch the flighting males; and in many parts of the continent it is still a common practice to shoot them during their love-flight. Our hut on San Jorge was situated on the high ground amongst patches of giant heath, broom, and other bushes, and many woodcocks nesting in the neighbouring coverts passed over our camp during their evening flight. At sunset a male and female were sometimes seen to rise together from a patch of broom; the latter uttering a shrill whistle, would make straight for her feeding-ground leaving the male to continue his solemn evening flight. On one or two occasions two males were seen to meet in their rôding, and chase one another along the hill-side, their slow, straight and measured flight suddenly changing to one of twisting lightning speed.

The rôding of the woodcock is evidently analogous to the "bleating" of the common snipe, but while the former produces the sounds with his throat, the latter drums with the outer tail-feathers; also, both male and female snipe drum at the moments when they make their downward slanting flights, whereas only the male woodcock utters the peculiar call described above during his rôding.

Nesting.-The nest of the woodcock is a very simple affair, being merely a depression in the ground, lined with dead grass and leaves. The spot selected is generally among gorse, broom, bracken and such-like cover; often in fir-woods, among long heather, or in oak-woods and other coverts 


\section{WOODCOGK}

with plenty of undergrowth and fern. The nest is generally sheltered but is often placed in a quite open spot in a wood.

$E g g s .-T h e$ number of eggs laid is always four. It has been stated that three are generally laid, but this is no doubt an error, and the clutches seen were probably incomplete. The eggs are of a broad oval or slightly pyriform shape, and vary in colour from greyish-white to brownishbuff, spotted with reddish-brown and ash-grey or lilac-grey. The markings are generally most numerous round the broad end, and sometimes form a well-marked cap. The average measurements are $1 \cdot 75$ by $1 \cdot 3$ inches. Incubation lasts twenty-one days, or occasionally one or two days longer.

The female sits very closely, and will generally allow one to approach very near without taking flight, trusting to her beautiful mixed plumage, so like her surroundings, to shield her from observation. When at last she knows that she has been discovered-her great black eye being often the cause of her undoing-she rises from her nest, and after flying a little way, begins fluttering along the ground, endeavouring to draw the intruder away from her nest by feigning a broken wing.

As is the case with all young waders, the young are able to run soon after they are hatched. They are very lovely little birds in their richly marked chestnut and buff downy plumage, and are most carefully tended by their mother. We have on several occasions, both at home and abroad, suddenly come across a female woodcock accompanied by very small young, with their quills just beginning to grow. The mother fiies off a yard or two and then flutters away along the ground in an apparently totally disabled condition, while the young run with outstretched wings displaying the blue sheaths of the half-grown quills, and looking like tiny ostriches as they scatter in all directions. They are so nimble that they are difficult to catch, and when once they have squatted it is almost impossible to distinguish them from their surroundings. When the female wishes to remove her young from one place to another, or from the wood where they have been bred, to the feeding ground, she picks them up one at a time with her feet and flies off with them. In rising, the bill is probably momentarily used to assist in keeping the young pressed close to her breast, but this point has never been satisfactorily settled. When in the act of being carried, the legs of the young one hang down below the mother, and are very noticeable as they become longer. In the New Forest the late Duke of Beaufort had the unusual good fortune to come across a female woodcock watering three young ones at a rivulet, 
THE GUN AT HOME AND ABROAD

and to see her pick up one in each foot and fly off with them. He then hid and saw her return in a few minutes and pick up the remaining bird, also in her foot.

The mode in which the young are carried has given rise to much discussion, and some say that the mother carries the young between the thighs. No doubt this is true, but she also grasps them with her toes, and the legs which have been observed hanging down as she flies off, are not hers, but those of the young bird.

That woodcocks carry their young is now a well ascertained fact, though there are still many who are sceptical on the subject. It is certain that the mode of carrying varies, and as it is chiefly done at dusk, or early dawn, when the light is bad, accurate observations are difficult. The best chance of observing is when the bird is disturbed with her brood in the daytime, but possibly on such occasions of hurry, abnormal methods are resorted to. That they will sometimes carry large young birds able to fly has been ascertained by Mr W. H. St Quintin on two occasions. When shooting a rather open birchwood at Invershin, on August 30,1882, he came across a late brood of woodcocks, and shot an old woodcock carrying a young bird, and another of the young birds with his second barrel. He afterwards shot the young bird which the old one had been carrying, and which his retriever had tried, but failed, to catch. The young were fledged, but somewhat undersized, and he recollects well seeing the young bird between the parent's legs as he fired.

It is not known for certain whether the woodcock nests twice in a season. It may be that some birds do so, but it is more likely that those with late broods met with in August and September have lost their first set of eggs and nested a second time.

General habits.-One of the chief characteristics of the woodcock is its nocturnal habits, which have already been referred to. During the day it retires to some dry and sheltered spot in the woods or on some hill-side covered with bracken and broom, where, if undisturbed, it remains till dusk. The birds display extraordinary partiality for certain woods, and shun others which appear equally suited to their needs. Why this should be so it is impossible to say, but it is a well-known fact that certain places are a sure find for " 'cock" if there are any in the neighbourhood, and that if the occupant of any particular spot is killed, its place is nearly sure to be filled almost immediately by another bird. Mr Hugh Wormald, who has had special opportunities of studying the 240 


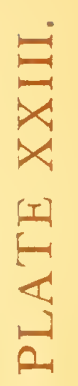

$\dot{n}$

N

()

80

苑

\&

ن

约

$\bigcirc$

○ํํㅇ

$B$ 


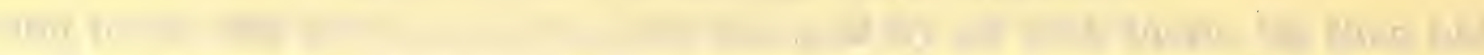

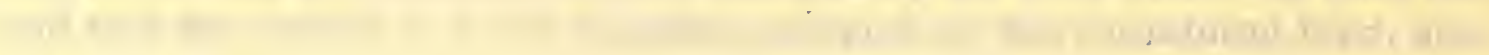

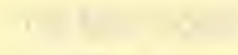

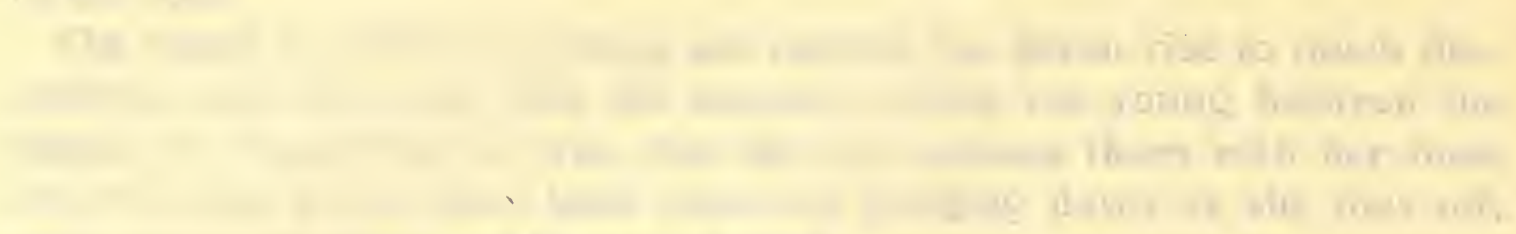
ran

-

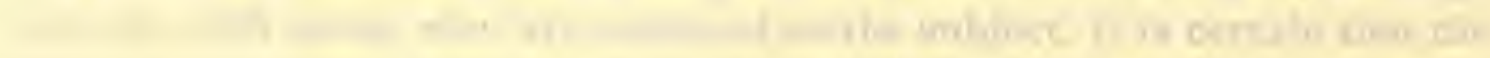

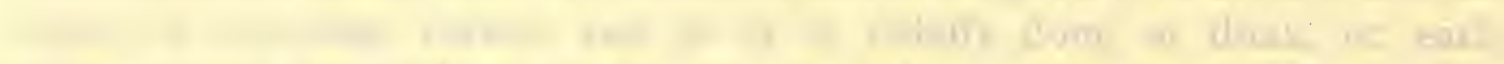

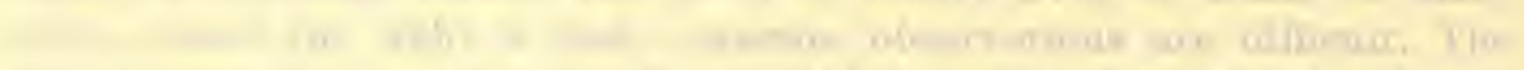

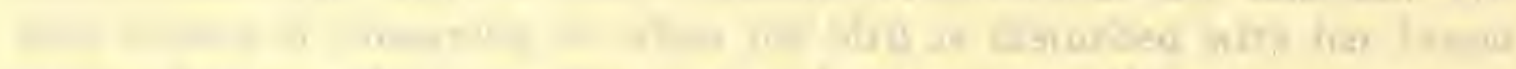

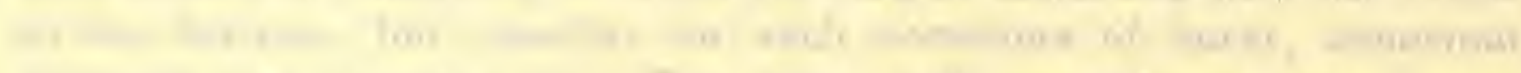

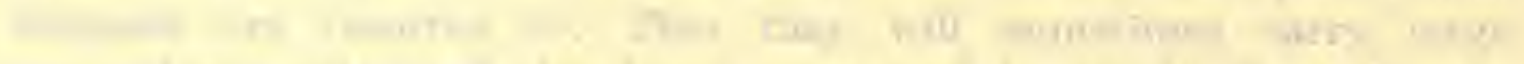

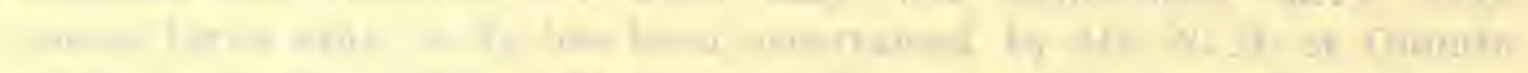

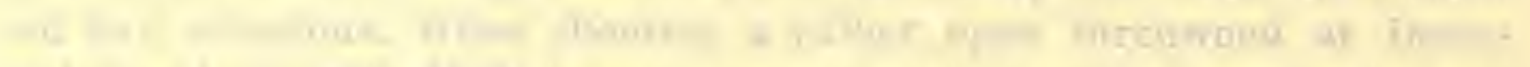
Folin wh

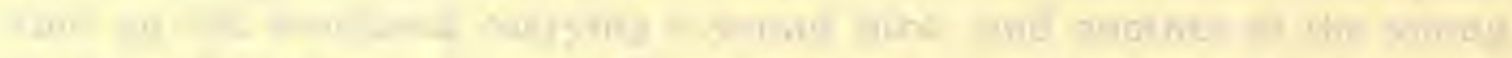

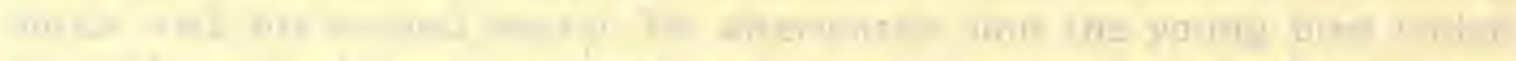

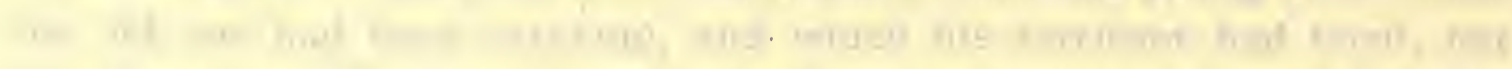

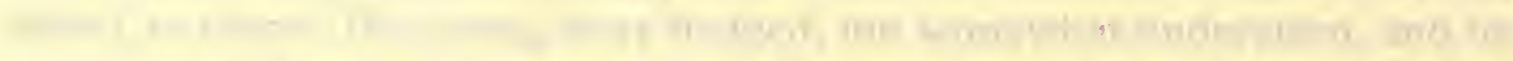

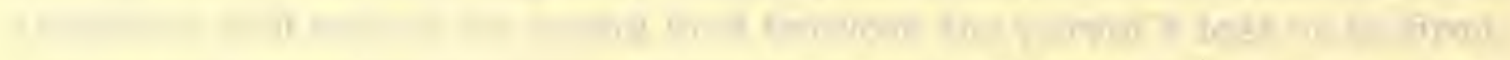

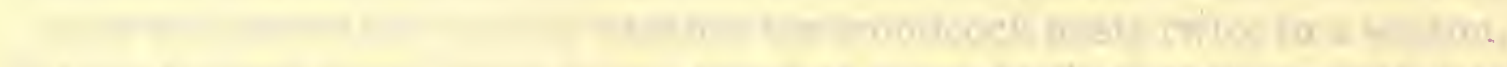

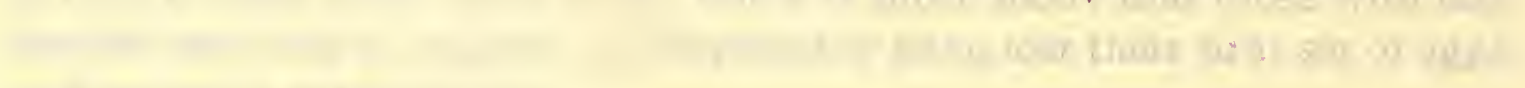

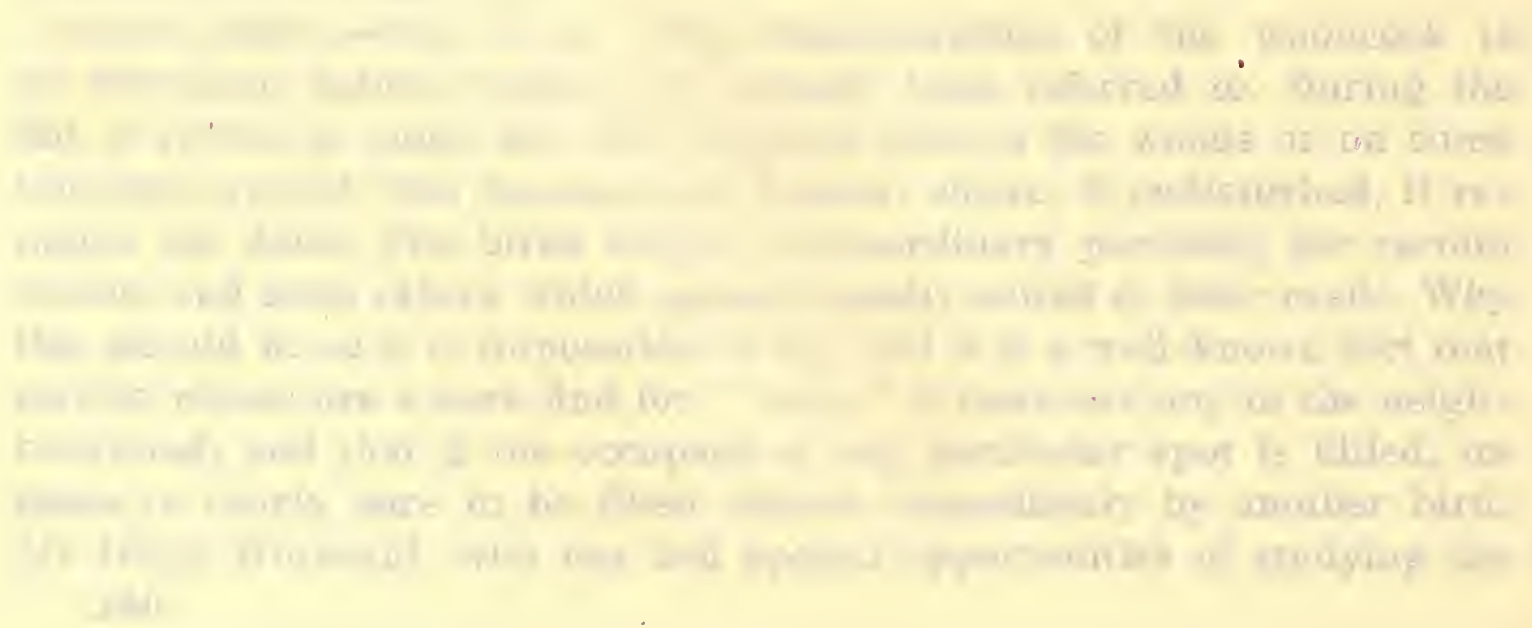




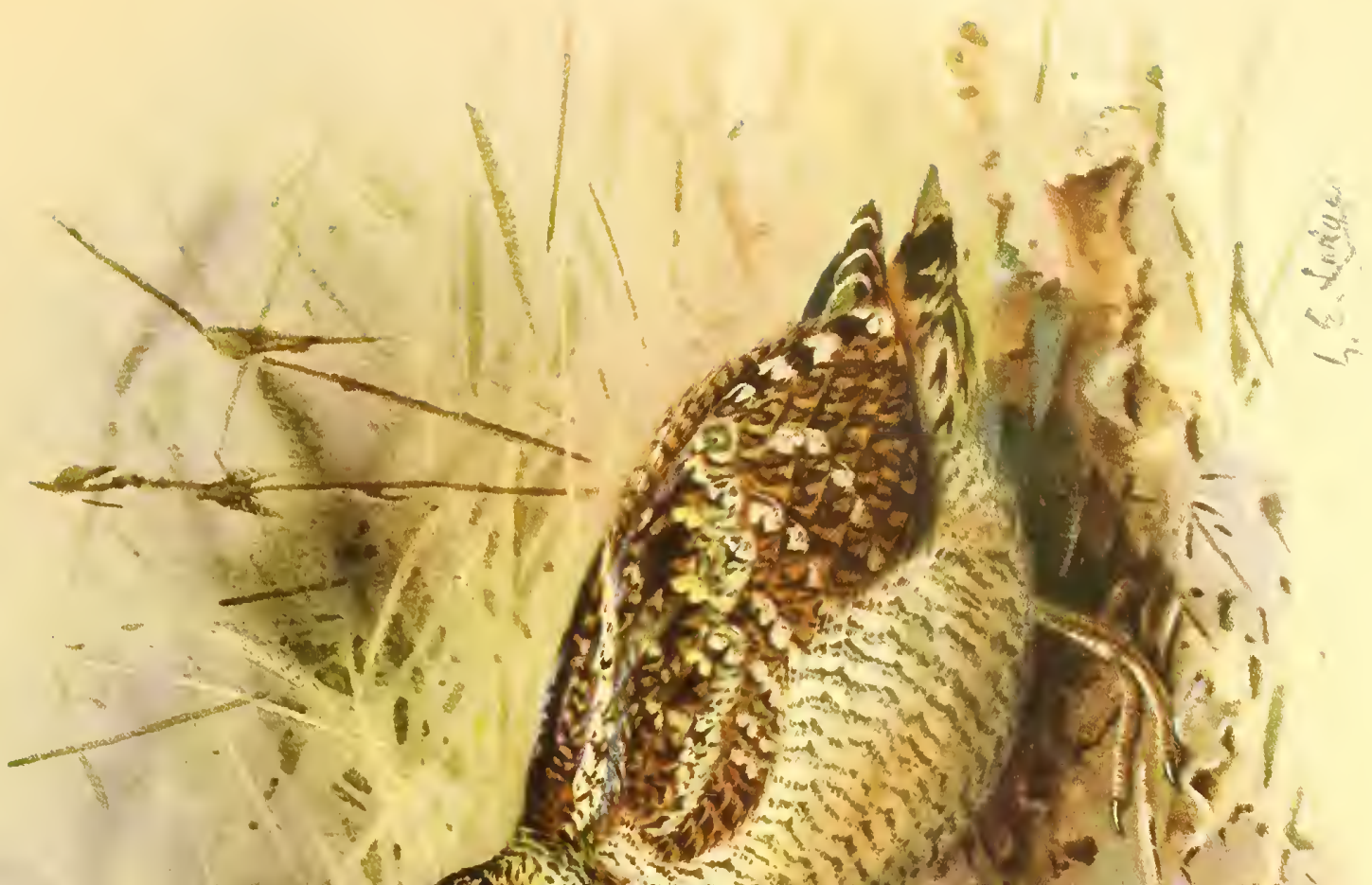

1. 1 (f)
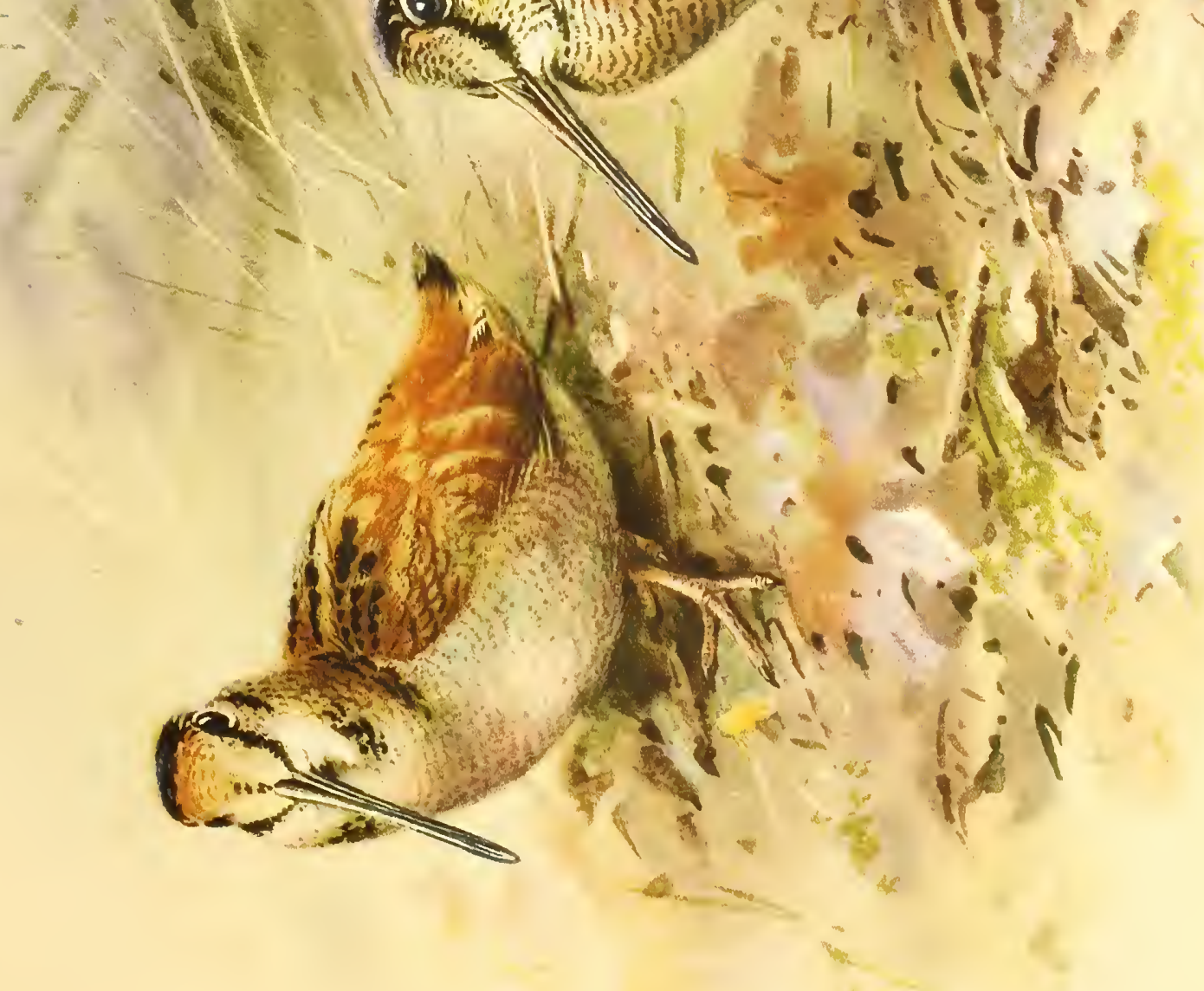



\section{WOODCOCK}

habits of woodcock in captivity, writes: "When at rest the woodcock sits with its tail cocked up. When first settling to rest the bird sits down rather suddenly and throws the tail right back so that it almost touches the back of the head; it then settles down comfortably, with the tail raised.

"The woodcock is full of play, and often squats down with its tail well up and fully expanded and its wings drooped; it then jumps from side to side." It is very solitary in its habits, and though in coverts where "cock" are abundant, two or three may sometimes be flushed from the same patch of brambles and bracken, their close proximity does not seem to indicate any inclination to sociability, but is due to some attractive quality of the cover. In this country the woodcock, as a rule, rises sharply enough when disturbed, but the birds which visit India in the cold season appear to be much tamer and more sluggish in their habits, being loth to rise, and anxious to settle again after flying a few yards. The same want of dash is observed in the common snipe met with in the East, and there can be no doubt that the bird twists much less when it rises, and is much easier to shoot, in a warmer climate.

All the woodcocks met with in India, Ceylon, and probably most of those which visit Burma during the cold season, are presumably natives of the Himalaya. According to Hume, they are distinctly lighter in weight than the birds of Central and Northern Asia or those met with in Europe; seldom exceeding twelve ounces. In measurements, however, they do not differ, and it will be seen by referring to the tables given above that the average weight of birds killed in Britain is under twelve ounces, eleven ounces being the ordinary weight of birds in good condition. When leaving a covert for their evening feed, woodcocks have a curious habit of making their exit by some particular opening in the wood, each individual following the same recognized route, quite independently of its fellows. Possibly the feeding-grounds all lie in the same direction, and the birds having a keen-set appetite after their day's fast, take the shortest road to reach their destination. Professor Victor Fatio, an eminent Swiss ornithologist, has published a remarkable account of the means said to be employed by wounded woodcocks of staunching their wounds and binding up their broken limbs.

The following translation appeared in the volume of Snipe and Woodcock in the "Fur, Feather and Fin Series," p. 176, and is so extraordinary, that it is reproduced here :

"Monsieur Victor Fatio relates that when shooting woodcocks (Scolapax 
rusticula) he had often noticed that this bird, when wounded, manages to make for himself, with the aid of his beak and feathers, a very ingenious dressing; whichever the case may be, he knows exactly how to apply a plaster to a bleeding wound, or to fix a solid ligature round a broken limb. He shot, one day, one of these birds which had an old wound on its breast, and which was covered by a large plaster composed of small, downy feathers plucked from different parts of its body and fixed firmly on the wound by the dry blood. Another time he found another plaster made in exactly the same way on a bird's back. Twice he found woodcocks which had ligatures of feathers tied and twisted round the part where the bone had been fractured. In one case the right leg, just above the cartilage, was strongly, but quite recently bound round with feathers, which the bird had taken from its back and breast. In the other case the cartilage itself, which was almost completely healed, still had the band that had maintained it in position. The most curious and at the same time the most unfortunate case was that of a woodcock which had both of its legs fractured by shot, and which was only picked up the following day. The poor bird had put feather plasters and bandages round both its legs, using one bandage only for one leg, and that was broken in two different places; but as it was obliged to operate in a most awkward position, and deprived of the use of its claws, it was unable to get rid of some feathers that had stuck and curled round the end of its beak, and which were causing it to die of hunger.

"Although its wounds were splendidly dressed, and although it was still able to fly, it was terribly thin. This indisputable proof of the intelligence of a bird which has always been considered rather stupid, because people have put a wrong interpretation on its name,* appears sufficiently interesting to be inscribed in the annals of biology."

It seems highly improbable that any woodcock deliberately binds up its wounds, and we do not for a moment believe that it really does so. The feathers and mud adhering to old wounds are no doubt purely accidental, and are not deliberately placed there by the bird; also, the supposed ligatures of feathers round a broken leg might easily become twisted round the limb when the bird is crawling wounded along the ground.

In confinement, woodcocks make interesting pets, becoming very tame, and display the same love of warmth shown by the snipe.

W. R. OGILVIE-GRANT.

* In France the woodcock is called grand bec, while the same term is used to designate a stupid person.

242 


\section{WOODCOCK SHOOTING}

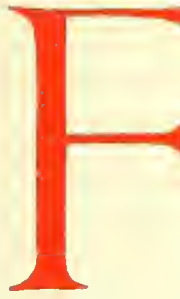

ROM the great size of its wings in comparison to its weight the woodcock is a strong flyer, and can get up "full steam ahead" perhaps quicker than any other bird. This great power of flight enables it to turn quickly amongst the branches, dart in and out, and swoop down a narrow glade; therefore when shooting in covert, especially when it first rises, there is no time to lose, and one is rather apt to shoot in too much of a hurry. But once fairly started, or when flushed in the open, it flies as a rule rather heavily, and affords an easy looking shot, though this is not always the case. I have known them fly, even in the open, more like snipe, especially after a dark and cloudy night when they may not have been able to get their proper amount of food.

The woodcock, like the snipe, is principally a night feeder; it loves to lie in the warmth and dry during the day, and to sally forth about dusk, just about the time the lighthouses begin to glimmer along the coast, flying or "rôding" as it is called, down the same glade every evening to some bog or running stream well provided with springs, feeding greedily all night, only returning to rest and shelter just at daybreak. By watching the various " rôding " paths of a covert it is quite possible to estimate whether they are "in" or not, and in what numbers. When they first arrive, should there be any heathery moorlands or red-bogs, as they are called in Ireland, the 'cock will spread about in the open, very often lying just outside the edge of the coverts, and it is only after the first fall of snow, or still better, driving hail, that they leave the open and take up their winter quarters in the more sheltered coverts.

That there are certain specially favourite coverts for 'cock throughout Great Britain and Ireland is well known, and it is practically certain that should they survive the dangers of a shooting season, they will, in a great number of cases, return to the same neighbourhood, and very likely to the actual covert in the following winter. A fact which goes far to support the above theory is that in Lord Ardilaun's famous covert of Ballykine, county Galway, whenever for some reason or another the coverts have not been shot in any particular year, the following season has invariably provided a record day.

As to what constitutes a good 'cock covert, there are three indispensable requirements :

(1) Good feeding ground in the neighbourhood, i.e., bogs and springs 


\section{THE GUN AT HOME AND ABROAD}

where plentiful supplies of worms and aquatic insects can be readily obtained.

(2) Warmth and shelter; the model covert should have every sort of shelter, including hollies, laurels, bracken, young larch, heather, gorse (which is a favourite in very hard weather), oak scrub, and hazel of different ages of growth, and the underwood should be kept properly thinned and not allowed to grow too high. Rhododendrons are also favoured by woodcocks. In addition to the above, if the covert springs from limestone rocks, these will be found to provide warmth and shelter in their crannies, and comparative dryness in wet weather, which will be much appreciated. I have often seen woodcocks issuing apparently from the bowels of the earth when crossing certain almost bare stretches of limestone rocks in Ireland.

(3) A third and very important desideratum for a good woodcock wood is quiet. Having been feeding all night, they like to rest in peace and quiet during the day, and resent being continually disturbed by a lot of pheasants constantly moving about, or even rabbits, not to mention a keeper whistling up his pheasants several times a day for their food. In the returns which Lord Hastings has kindly sent, one of his coverts, Swanton Wood, used to be famous for woodcocks, but when pheasants were turned down in large numbers the 'cock, to a great extent, deserted it, and it is only in recent years, when pheasants have not been so much encouraged in this particular wood, that they have returned to their old haunts.*

Again, to quote Ballykine, which is, taking it all round, far and away the best " "cock" covert in the British Isles, pheasants are treated almost as vermin there, and Lord Ardilaun has always been very particular about keeping his coverts as quiet as possible during the winter months.

An old keeper at Markree, in the West of Ireland, told me that there had never been so many 'cock in the great covert there since the practice of grazing cattle all round the outside in the early autumn had been given up, after which the outskirts were kept quiet.

The West of England used to be famous for woodcocks; in Scott's " British Field Sports" (1828) it is stated: "The neighbourhood of Torrington, Devon, used to be celebrated for them early in the nineteenth century. One dealer supplying them to London to the value of nearly two thousand

* This applies also to Boconnoch, Mr Bevill Fortescue's property in Cornwall, where, in 1865, they killed 203 wood. cocks. But at the present time, 1911-12, partly owing to pheasants being reared in much greater numbers, and partly, no doubt, to an indifferent season, only 50 or so have been killed. 


\section{WOODCOCK SHOOTING}

pounds in one season. The majority of these were caught in horsehair springes and by glade or 'flight' nets, hoisted by pulleys to the trees along their flighting paths. The Exeter coach sometimes carried up 30 dozen per week; price at particular seasons as high as $16 \mathrm{~s}$. a couple!"

Many of the southern lines of migration cross to Wales and Ireland via Devon and Cornwall-Lundy Island being frequently used as a resting place. On one occasion, in the early seventies of the last century, over forty were shot in one day on this small island by a sportsman who happened to be there just at the time of migration.

With regard to the actual shooting of woodcock, it is the usual practice in Ireland and those favoured localities in England and Scotland where they are known, or expected to be plentiful, to use No. 7 or 8 shot. It is a soft bird not heavily feathered, and this size of shot gives good results up to say forty-five to fifty yards, beyond which one ought not to shoot at them. The pattern is close, and the penetration quite sufficient for the purpose; at anything over thirty yards a larger size shot is apt to give rather too open a pattern, and it is as well to remember that if only winged, a woodcock will run a considerable distance.

Many retrievers dislike the scent, and so, if the bird is not killed, there is a good chance of its being lost.

When beating for woodcock in the open, on the red bogs of Ireland or the heathery bottoms in Scotland, the guns can walk in line; should there be a wood on one flank it is a good plan for the gun on that side to keep well ahead of the line, as they are sometimes inclined to rise wild and make straight for the covert.

When seeking them in coverts, especially if wide and straggling, and scantily provided with paths, as they very often are, five guns are, in my opinion, the model number. You can then have one forward on each side, a gun in the centre and one on each flank, these three being in line with the beaters. This enables every one to shoot towards the centre of the covert, whereas if there be a forward gun going up the middle ride, though that gun will probably get more shooting than any of the others, he will be either masking the fire of his friends, or running a considerable risk of being peppered. The forward guns will get the easiest shots if they know the game, as they will push well ahead, very likely disturbing 'cocks which may be lying on the edge of the covert as they move on, and when they have at length got to some open space, it is advisable to stand still, with the attention towards the beaters. When nearing the end of a 


\section{THE GUN AT HOME AND ABROAD}

covert the forward guns should push round the end and head the corners, many birds will try and slip out whilst the beaters are still far away, or dashing round the corner of the wood will drop in the outside ditch.

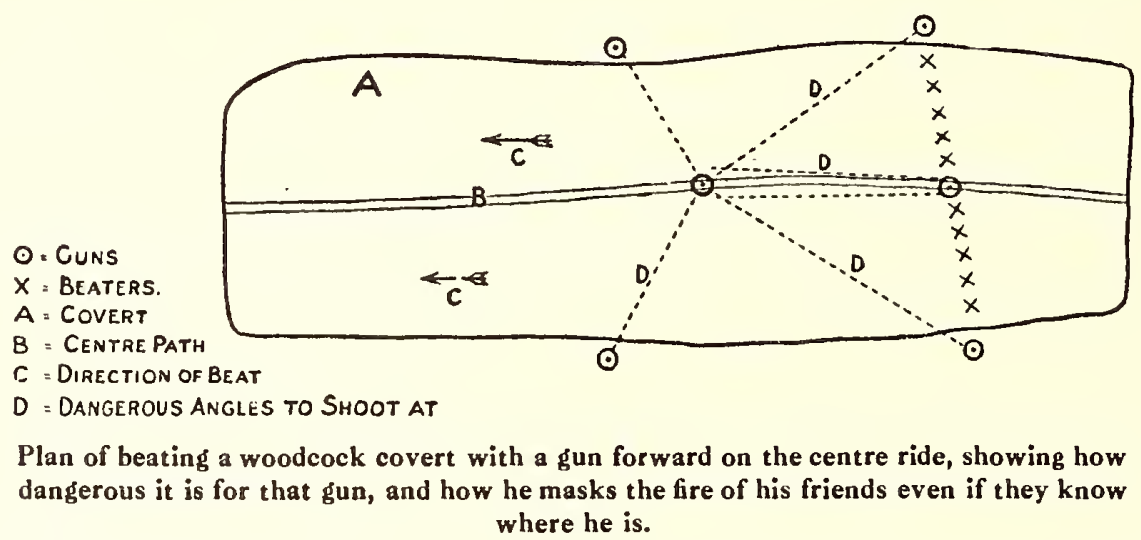

Any bird that does break covert should be watched, especially if the surrounding country be open, as it will very likely make a big circle and come back to the wood which is still being beaten, or else pitch in some neighbouring ditch, where, if carefully marked, it can be shot when the beat is finished.

The guns in line should always be on the look out for close lying birds that do not rise until the beaters are on or past them, and then nip back ; it is not always easy to decide in the momentary chance offered whether such a bird is a safe shot or not. A good general rule is that if you can see daylight beneath the bird, i.e., between it and the tops of the underwood or young trees, it is safe to shoot at. Again, when nearing the end of a wood, the guns in line should stand fast till the cry "all out" is heard, as the 'cock are more likely than ever to dash back at this time.

If the woods are very large and wide, two or three woodcock paths should be cut parallel to the line of advance, so that more than three guns can walk in line; if this is not done many birds will escape unshot at between the guns, and where this plan is adopted of course more friends can be provided with sport. But in any case it is advisable not to have a forward gun in the centre. It is a most tantalizing thing for the gun with the beaters to see 'cock after 'cock get up close to him and fly so near the line of the man in front that he dare not fire.

Supposing that the wood be a hanging one on the side of a hill, with possibly a fringe of heather or straggling gorse bushes on the outside, 246 


\section{WOODCOCK SHOOTING}

three or four men should be made to walk this carefully, especially if it faces south and the day is bright, as it is almost always a very favourite spot for birds to lie, except in the hardest weather.

When a beat is finished, and all the "'cock" collected, they should be carefully looked over in order to see if any have labels on their legs. Many owners of coverts have of late years marked young birds, and it is a matter of great interest to them to hear of any cases of marked birds being found; in addition to this it is useful to the naturalist in proving their lines of migration.

When walking along a woodcock path one may often observe, especially under holly bushes or warm sunny spots, the leaves scratched up and the marks of a woodcock's bill thrust here and there into the moss; it is almost a certainty that the bird is not far off, having run into some neighbouring shelter, and an easy shot will very likely be offered to the man who uses his eyes.

Again, when the cry of "cock forward" is heard, the woodcock, after being flushed, and flying in and out of the trees, will very likely swoop down a path and fly straight for the forward gun's head; if he stands quite still he is almost certain to get an easy chance as the 'cock suddenly perceives him and flies upwards to right or left.

Perhaps the 'greatest charm in woodcock shooting is the fact of the uncertainty. They may not be "in " on the particular day when the covert is shot, and one never knows when a chance may occur. We remember on one occasion the guns and beaters were all standing round a small line of dead 'cock at the end of a ride in a certain wood, when all of a sudden a gasping exclamation came from one of the beaters, and looking up a shadow flitted over the party, one of whom luckily had his gun loaded and brought down a woodcock; as he was being congratulated on his readiness there was a shout, and another 'cock dashed over; again he successfully annexed it, amidst laughter and cheers, and almost at the same moment still a third 'cock dashed over the same line of flight. This bird was saluted by the combined fire of the party, who were by this time prepared for any emergency.

It afterwards transpired that two "stops " who were being sent forward to the next beat had flushed these three birds in the outside ditch of the covert as they were going to their places.

Close time. - The writer would suggest to the powers that be, that the close time for woodcocks should commence on February 2. By that date 
THE GUN AT HOME AND ABROAD

they have already paired, or soon will be, and if left unmolested would probably breed in far greater numbers than is now the case.

Ways of cooking a Woodcock:

(1) Roasted lightly when quite fresh, i.e., the day it is shot.

(2) Hang it for a week, with trail removed, then shoot another 'cock and put the fresh trail inside the one that has been hung.

(3) Cut its head off and bake it in a dumpling; this is an old fashioned receipt, but excellent.

(4) Woodcock pie ; the birds must be boned, and all the trails put in the pie. Few are worthy of this dish, and fewer get the opportunity to appreciate its excellence.

It is the almost universal custom, in England at any rate, to pull a woodcock's legs, in order to extract the sinews, which would otherwise make the thigh tough; this rather spoils the appearance of the birds, and the same end may be effected by pulling the middle toe, to which the said sinew is attached. The same remark applies to pheasants; one of the most intelligent gourmets we know always pulls the sinews from those hen pheasants that he selects for his own consumption.

Many friends and acquaintances who are the happy possessors of good 'cock coverts, having kindly sent their experiences of different kinds, they are here given in alphabetical order.

\section{ASHFORD, CO. GALWAY}

Lord Ardilaun, who is the owner of Ashford-undoubtedly the best woodcock estate in the British Isles-has kindly sent some notes with regard to his bags of woodcock. Before mentioning them it may be of interest to give a short description of this bird's model winter home.

Situated on the shores of Lough Corrib, the estate extends to Lough Mask, the country principally consists of limestone rocks, with patches of grass and cultivated land cropping up here and there. Along the shores of both loughs are several bogs, which give good feeding ground, whilst there is a great extent of covert, some of it old hazel, and much of it larch in different stages of growth; the latter has been all planted by the present owner. On the south and west sides the high rocky mountains and numerous small bogs of Joyce's country and Mayo afford extensive feeding ground in the early autumn, and it is only when these hills are covered with snow, or lashed by hail storms, that the woodcocks in large numbers seek the shelter of the coverts below them. 


\section{WOODGOGK SHOOTING}

There are several beats on the estate, which are only shot once a year, as a rule the end of January; the most famous being Ballykine and Toberbearogue, which come into the same day. Ross Hill-Cong rocks and Pigeon Hole-Doon, which is some twelve miles away, at the far end of Lough Corrib. Each has its distinctive features. At Ross Hill nearly the whole morning is taken up in beating two islands in Lough Mask, two guns generally guarding the outside flank in boats. When the water is rough it is an exciting experience, and most difficult to shoot at all, to say nothing of shooting successíully.

Doon, which is generally best in very hard weather, is an old larch wood on the side of a steep hill, with very old and deep heather for undercovert. Birds flushed near the top dart straight down hill towards the guns below, and then turn sharply, and apparently fly straight for the next man's head, twisting and turning in every direction, and affording perhaps the most difficult chances one gets at Ashford.

The best beat of all is Ballykine, as the record will show. Ballykine itself is an old wood, consisting principally of hazel, with a few hollies and a little bracken, all springing from the limestone rocks. Being an old demesne, it is surrounded by a high wall, and no doubt it is this wall which has made it such a favourite with the 'cock, as it is so perfectly undisturbed. The first beat in Ballykine proper is the best, and we have known fifty-eight 'cock killed in this one long strip, one gun being fortunate enough to annex sixteen birds. There is another covert called Toberbearogue, which is shot the same day, a very long larch covert, perhaps eighteen years old, and of late years this has proved almost as productive as Ballykine itself.

His Majesty, when Prince of Wales, stayed with Lord Ardilaun and shot these coverts in 1905, and though it was not a first-class year, 470 'cock were killed in the week-181 being the yield of Ballykine, on which day His Majesty shot over forty 'cock to his own gun.

The beaters, who are always good, outdid themselves this particular week, keeping a perfect line through the thickest covert, and no day was too long for them.

Just to show the sporting capabilities of Ashford, at the end of this week His Majesty went out after snipe with another gun, and had a model mixed bag : two pheasants, one rabbit, four woodcocks, eighty-four snipe, four ducks, five teal and one pigeon.

As before mentioned, whenever from any cause the coverts have not 


\section{THE GUN AT HOME AND ABROAD}

been shot the previous year, the succeeding one has always produced a record day, and very often a record week.

1887. Jan. - . Ballykine . 6 guns . $72 \frac{1}{2}$ couple of woodcock (145 birds). During 4 days, 277 woodcock.

1890. Jan. 29 . Ballykine . 7 guns . 911 couple of woodcock (183 birds). During 4 days, 300 woodcock.

1891. Jan. 19 . Ballykine . 7 guns - 104! couple of woodcock (209 birds). During 6 days, 494 woodcock.

1895. Jan. 25 . Ballykine . 7 guns . 1021 couple of woodcock (205 birds). During 6 days, 508 woodcock.

1899. Jan. 28 . Ballykine . 7 guns . 84 couple of woodcock (168 birds). During week, 400 woodcock.

1900. Jan. 29 . Ballykine . 7 guns 70 couple of woodcock ( 140 birds). During 4 days, 273 woodcock.

1904. Feb. 1 . Ballykine . 7 guns . $105_{2}^{1}$ couple of woodcock (211 birds). During 6 days, 544 woodcock.

1905. Jan. 25 . Ballykine . 7 guns . $90 \frac{1}{2}$ couple of woodcock (181 birds). During 5 days, 448 woodcock.

1907. Jan. 26 . Ballykine . 6 guns . $71 \frac{1}{2}$ couple of woodcock (143 birds). During 6 days, 443 woodcock.

1910. Jan. 28 . Ballykine . 6 guns . 114 couple of woodcock (228 birds). During 5 days, 587 woodcock.

Number of woodcock shot during shooting week at Ashford from 1878 :

\begin{tabular}{|c|c|c|}
\hline 1878 & . 320 & odcock \\
\hline 1879 & 350 & \\
\hline 1880 & . 335 & , \\
\hline 1881 & 87 & ", \\
\hline 1884 & 196 & ", \\
\hline 1885 & 280 & ," \\
\hline 1886 & 301 & ", \\
\hline 1887 & 277 & ", \\
\hline 1888 & 235 & ", \\
\hline 1890 & 300 & ," \\
\hline 189 & 494 & ", \\
\hline 189 & 369 & ", \\
\hline 189. & 273 & ", \\
\hline & 508 & ," \\
\hline
\end{tabular}

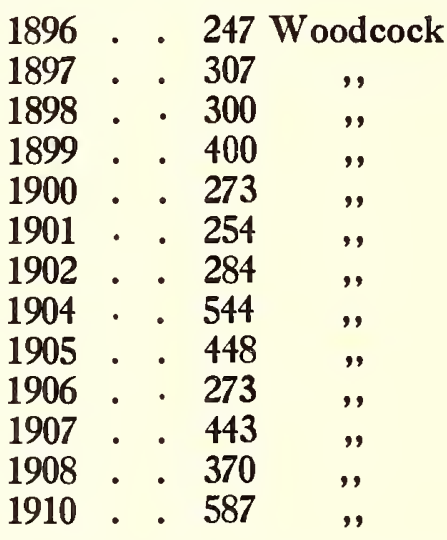

The week has consisted of from four to six days, and there has been no shooting before or after the week.

\section{ALNWICK, NORTHUMBERLAND}

Lord William Percy has kindly sent complete particulars up to date of the result of the marking of young woodcocks since 1891 on the Duke of Northumberland's estate at Alnwick Castle, Northumberland, and 250 


\section{WOODGOCK SHOOTING}

in his accompanying letter he says: "This list of marked birds includes only such as I have been able to authenticate by actually obtaining the ring; and $I$ have not included a good many heard of through such channels as game dealers' shops. On the whole it always seems to me that the percentage of marked birds that have been heard of again is extraordinarily high, considering the large number that undoubtedly die in a dry summer, and the fact that a certain number of marked birds are shot by people who do not think it worth the trouble to inquire where they come from.

"There are two points with regard to this record that I should like to mention :

"(1) That, practically speaking, no Alnwick marked 'cock have been got north of here; i.e., that these birds are breeding in the northernmost part of the range of these individual woodcock.

"(2) That a considerable number of home-bred woodcock are absolutely stationary, as they are to be found here in every month from September to February. I mean the birds bred here.

"Advent of foreigners. This generally occurs between November 5 and November 12, and that flight is almost always succeeded by a larger one about the end of the month. I once saw them come the second week in January.

"Nesting. The number of nests is certainly increasing year by year, and I feel sure it would do so more rapidly if the close time began February 1, as I feel confident that most of the woodcock shot in North umberland in February would nest here if left alone. The number of nests now is about $\mathbf{1 0 0}$ in the park here. Some years when there have been a great number of nests, we have been unlucky in catching the young ones.

"We generally shoot about 150 here every season, but they are hardly ever shot by anyone except myself, and I am rarely here at the right time."

"The following are the best bags :-

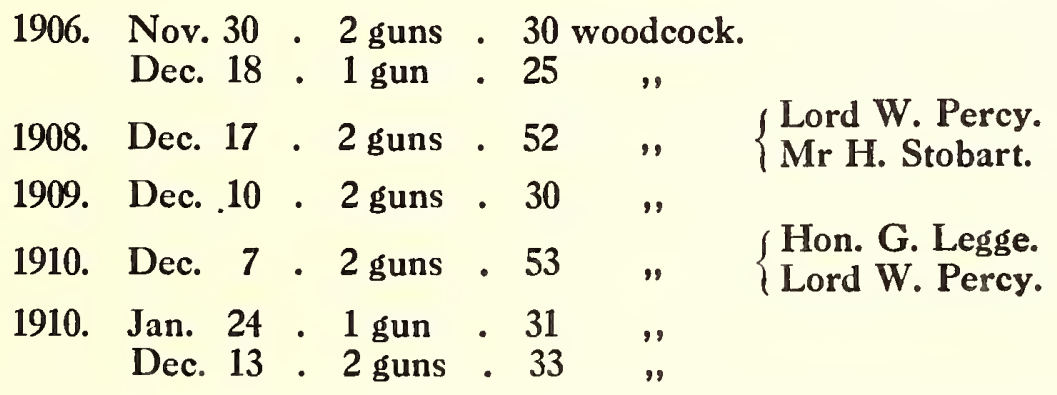


THE GUN AT HOME AND ABROAD

WOODCOCKS MARKED AT ALNWICK FROM 1891 TO 1911.

\begin{tabular}{c|c|c|cc}
\hline Year & $\begin{array}{r}\text { No. } \\
\text { Marked }\end{array}$ & $\begin{array}{c}\text { No. re. } \\
\text { toveded } \\
\text { to date }\end{array}$ & \multicolumn{1}{|c}{ When and Where Killed } \\
\hline 1891 & 6 & 3 & $\begin{array}{l}\text { Nov., 1891, Northumberland } \\
\text { Oct., 1892, } \\
\text { Dec., 1892, }\end{array}$ \\
\hline 1892 \\
1894
\end{tabular}

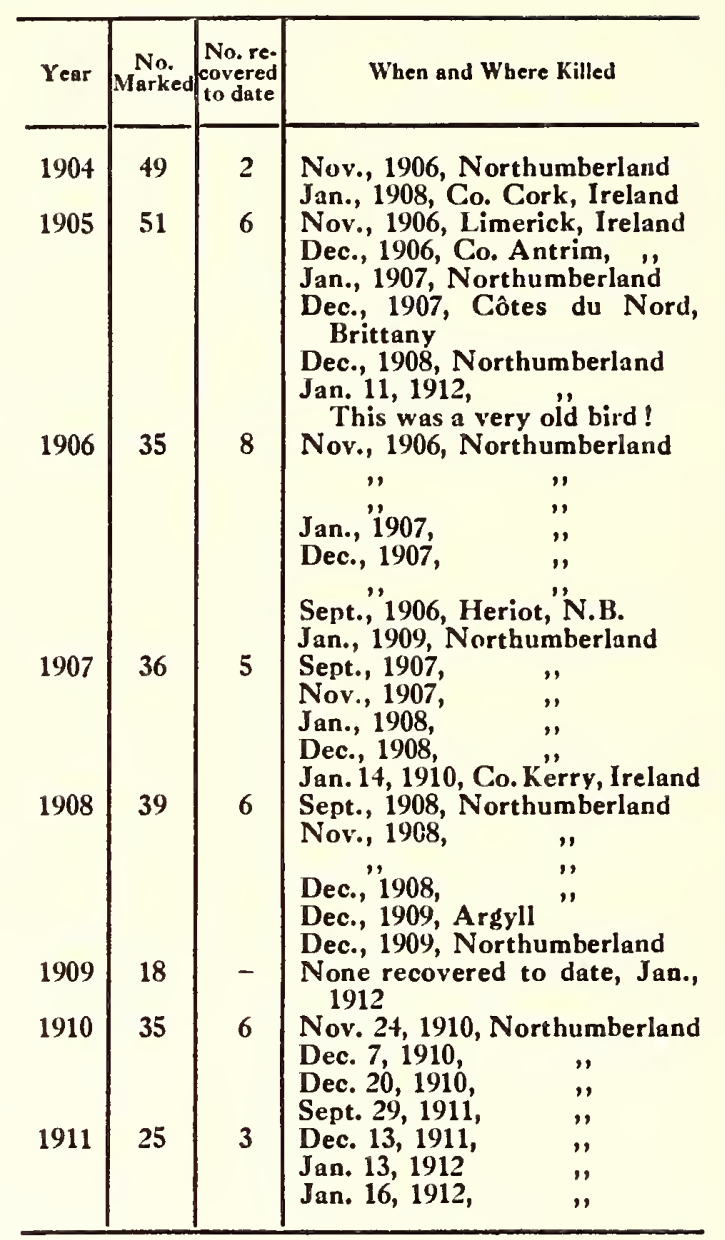

\section{BARONSCOURT, GO. TYRONE}

Mr R. Taylor, head keeper to the Duke of Abercorn, writes as follows :

"The marking of young woodcocks was begun at Baronscourt in the year 1905. The earliest date we have put rings on is April 6, and the latest July 18. When gathering pheasants' eggs in the latter end of April and beginning of May we see young woodcocks on the wing, and a lot of old birds sitting. The distinguishing mark on the ring affixed to the young bird's leg is B. C., and the date. The following is a record of woodcocks ringed at Baronscourt, and of birds shot with the rings on them : 


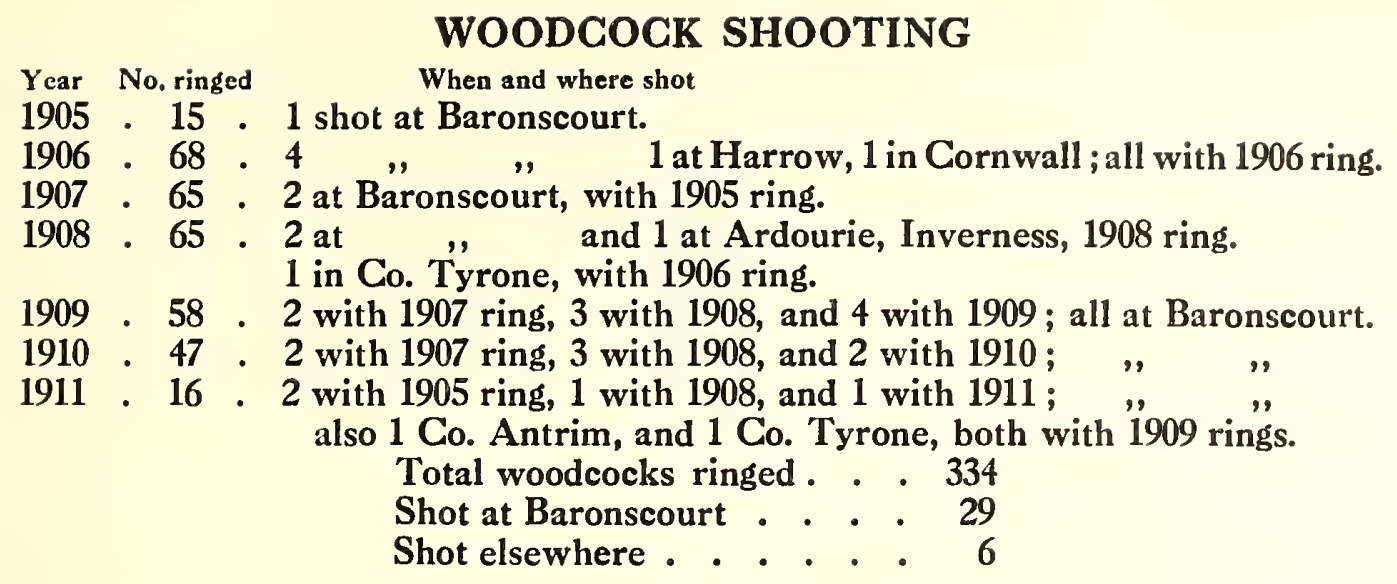

"A great many woodcocks are seen flying about here in June and July, but towards the end of the latter month they begin to leave the place, and during the month of August and September very few are to be seen. The first flight generally reaches us about the second week in November.

"Woodcocks, as a rule, are very fond of a shrub, at the edge of which they are able to sit perfectly concealed, and yet in a position to spring into instant flight if disturbed; laurels permit of this, but rhododendrons are too close and matted. In rough weather we find the birds amongst the laurels, but in open and mild weather they like the heather fringing the edge of the coverts. The following is a list of woodcocks shot on this estate since 1905 :

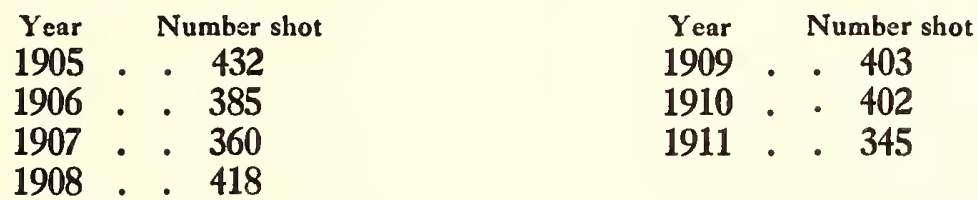

"Some years aǵo I had a tame woodcock, it was picked up when about ten days old. I put it in a 'foster-mother,' which was kept at a comfortable temperature, and therein it did very well. For the first few days it had to be fed by hand, and worms comprised its chief diet, but it soon began to pick them up on its own account, and from that moment its progress was speedy. Worms being scarce one day, it was offered bread and milk, this it became very fond of, and appeared to prefer it to all other food. This woodcock was kept in the open, and it had the liberty of two runs connected with the 'foster-mother.' From the bottom of one of these runs several inches of soil were removed, and the space filled in with loose sand ; this run was its favourite resort, as worms were buried, and it used to bore for them. A small dish of water was kept beside it, 


\section{THE GUN AT HOME AND ABROAD}

and when boring for worms it continually washed its beak. At night the bird was closed in. When released in the morning its pleasure was testified by a slight cry. Worms it had a difficulty in picking up if lying on the surface, apparently because of the shortness of its lower mandible; it was very fond of the fire, and appeared very happy when basking in its warmth. It came to an unfortunate end, being strangled by a piece of wire."

\section{EDEN VALE, CO. GLARE}

Mr Richard Stackpoole writes as follows: "Woodcocks do not breed in county Clare in any number. I have heard of occasional nests being found, and have seen one or two couples in the woods here in April and May, but not sufficient to warrant my saying that their nesting here is at all common.

"The flights arrive generally with the full moon in October and November; I have been told that sometimes when the birds have first arrived they have been killed with sticks on the sea shore, being so tired that they were quite unable to rise. Where these flights come from seems very doubtful; if they come by sea, what brings them round to the west of Ireland, when they could easily land on another part of the coast, without reaching the state of exhaustion which they are in when they arrive? I have heard it suggested that they fly across Ireland and are only stopped by the Atlantic. If this is so one would think that in the case of very tired birds (as they undoubtedly are at times), that they would settle on the east coast instead. The fact remains, however, that the great majority of the flights arrive on the west coast and spread inland from there. I have seen new arrivals, i.e., tired birds as early as the first week in October. My woodcock coverts consist of hazel and blackthorn bushes, with occasional trees of oak and ash; these grow among limestone rocks, where, with the exception of occasional grass patches, there is hardly any earth, except in the fissures of the rock. I have noticed hazel leaves freshly turned over in the daytime, but except what they can find among these, the 'cock have no feeding in the coverts, and we generally find them among the bare patches of rock. That they like absolute quiet is certain; in one of my coverts I allowed the rabbits to increase, with the result that for a couple of seasons I had hardly any 'cock in it. When I killed down the rabbits they returned to it again. When the undercovert gets too high and bare underneath, woodcocks will not stay in it. Since 1902 254 


\section{WOODCOCK SHOOTING}

my coverts have been regularly cut; this makes the hazel break low and grow bushy, with the result that the bags have considerably increased. These used to average twenty or thirty 'cock for the first time over, but since the coverts have been cut they have considerably increased, as the following list will show":

\begin{tabular}{|c|c|c|c|c|}
\hline Year & & First Time & Season & Remarks \\
\hline 1903 & Eden Vale & . 54 . & 102 & The coverts were put in proper \\
\hline 1904 & , & 56 & 102 & order in 1900 . Before that year \\
\hline 1905 & ," & 67 & 110 & the bag was from 20 to 30 first \\
\hline 1906 & ,, & 73 & 135 & time over. \\
\hline 1907 & , & 52 & 84 & \\
\hline 1908 & ," & 43 & 111 & \\
\hline 1909 & ,, & 82 & 142 & \\
\hline 1910 & ," & . 67 & 112 & \\
\hline 1911 & , & . 46 & 46 & $\begin{array}{l}\text { The worst year we have had, the } \\
\text { weather being too mild. }\end{array}$ \\
\hline
\end{tabular}

\section{GLENSTAL, GO. LIMERICK}

Sir Charles Barrington, of Glenstal, sends the following interesting letter, dated February 4, 1912 :

"Woodcock begin to appear here in numbers at the end of October and the beginning of November, but, all the same, a few come dribbling in from the end of September, and I am unable to see here any difference between what are said to be foreign birds and our own that have bred here. In fact, there is no difference, but when some one picks up and feels a bird that is thin, he says it is a foreigner.

"I think our home-bred birds do not go away to any great distance, but only just move about locally as the food supply varies-of course this only refers to Glenstal, and not to other places further north.

"I have seen them feeding on the lawn here just at dusk, sometimes almost standing on their heads, with the bill right down in the ground after a worm (I suppose), but generally getting the worms with a side thrust; after every five or six efforts they take an easy and shake themselves up and settle their feathers, and then at it again until successful. I could never see them get the worm, they are so quick.

"Colour. I have never seen a white or black one, but have seen a buffcoloured specimen and a curious light-coloured one, which was shot here.

" Nesting. The 'cock nest here, I may say in great numbers; I have seen as many as twenty flying about here on a fine summer evening. They began breeding round Glenstal seriously about 1870 ; before that we used to have 


\section{THE GUN AT HOME AND ABROAD}

only an odd nest or so, which was always looked upon as a considerable rarity, and talked about. I have seen two nests within a yard of each other, and close to this house; I showed them to a friend who was staying here, four egiss in each nest, and they are very fertile, as I have only once found a bad egg in all the nests I have seen.

"They breed again in July, and I have often seen young birds in August. I had nine young marked some years ago. Two were shot the same year here, and one was found dead six years afterwards and brought to me. I stopped marking them, as I think it does harm to the young birds, and causes injury and death. The following are the bags made on my best beat, Flavin, since :

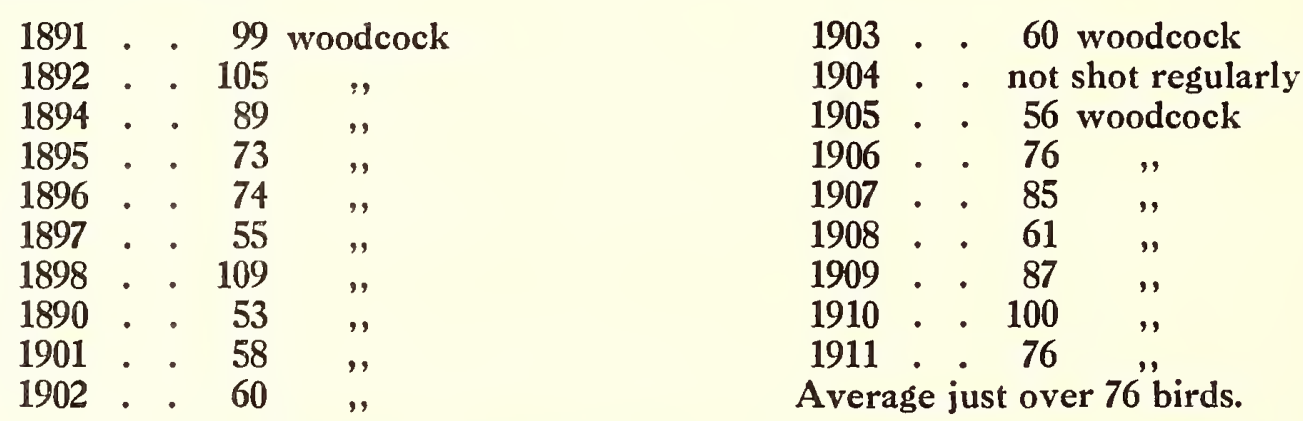

"I have another beat, Bobermanshill, where we average about fifty per day."

\section{MUCKROSS, KILLARNEY}

Lord Ardilaun has kindly sent the following interesting extract from a letter of Lord Wemyss referring to a wonderful week he had at Muckross, Killarney, in January, 1863 :

"And now as to the 'cack,' as the Irish beater, the best of his kind, pronounces the word. These were muzzle-loading days, and I shot with two Boss 12 bores, my servant loading for me. In the course of the eight consecutive days I bagged 245. My smallest day, the first, 18 . My best, on Thomies Beat, 53, and if I had worked as hard and as carefully after I had got $\mathbf{5 0}$ as I did before, I am sure that I should have made up at least 60 . The total bag for five guns was 620 ."

\section{THE ISLAND OF ISLAY}

Mr Hugh Morrison, who owns about half of this isiand, writes :

"For the last few years I have only shot my coverts once, formerly I used to shoot them twice. There is no doubt that more woodcocks breed 256 


\section{WOODGOCK SHOOTING}

in Islay than formerly, and, in my opinion, there are more birds about than there were fifteen or twenty years ago. We have never marked any young woodcock, so I cannot say for certain whether the birds bred there are those that we shot. My keepers always say that our home-bred birds leave in July. With regard to the bags, I have generally shot the coverts with four guns and the glens with two. The best show of woodcock I have ever seen on the island was in January, 1909, when we killed an average of fifty-seven 'cock per day for five days.

"Bags for the last twelve years:

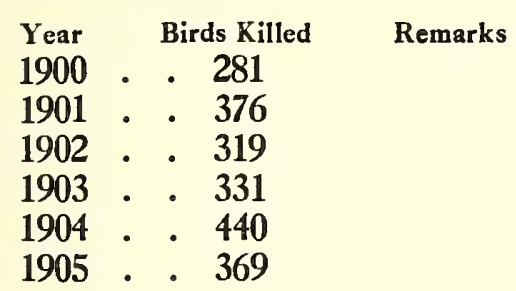

\begin{tabular}{|c|c|c|}
\hline & Birds Kille & ed $\quad$ Remarks \\
\hline 1906 & . 545 & Best day 60 coch \\
\hline 1907 & . 224 & \\
\hline 190 & . 348 & \\
\hline 90 & . 520 & 3 days of $60 \mathrm{coc}$ \\
\hline 191 & . 242 & \\
\hline & . 230 & \\
\hline
\end{tabular}

"For comparison with former years, woodcock shot round Ardenserney Cottage by P. Mackenzie, keeper to the late Mr Campbell, of Islay. This is on the other half of the island:

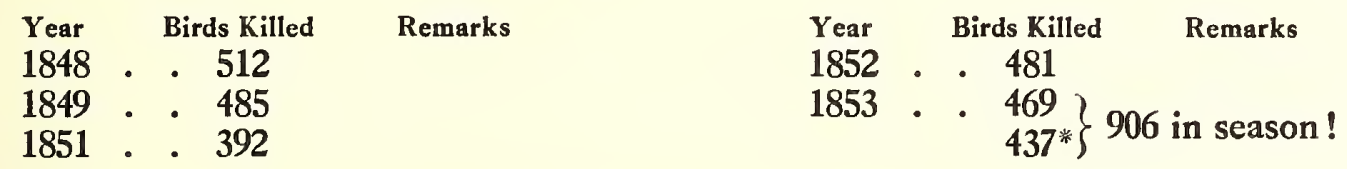

"Nests have been found in Islay as early as March 10, and as late as July. Breeding increases yearly. We find that an extra dry season affects woodcock and snipe just as frost would do, as it sends the worms down, and there is a scarcity of food.

"Date of arrival of the foreigners, about October 20. They come with a full moon, and whilst the moon lasts. They are tamer when they first arrive.

"Mackenzie, the head keeper, shot a pied woodcock in 1897. This is the only one he has ever seen or heard of. The breast, wings, and back of wings were pied. It was shot in Sorn Glen.

"In open weather they feed at night; but in severe frosty weather they feed during the day.

"In 1895, during very severe frosty weather, the first birds to suffer were the curlews; they were nearly exterminated.

* Same year, killed by Mr Campbell, of Islay, and his friends. 


\section{THE GUN AT HOME AND ABROAD}

"The next were the woodcock, snipe and mallard, all of which died in large numbers. The choughs also suffered severely.

"In 1880, the head keeper, Peter Mackenzie, at Kildalton, Islay, shot in one day with a 20-bore Joe Manton muzzle loader, forty-four woodcock.

"On February 6, 1902, at Gearach, Ben Sart á Inhill, I fell in with a flight of 'cock, and shot forty-six in a snowstorm to my own gun.

"I thoroughly agree with your view as to the close season beginning on February 2. If not shot after that date they would breed in greater numbers in this country than at present.

"January 22, 1909, is the last date on which woodcocks were shot on this estate by keepers; this has made some considerable difference in the total bags."

\section{LANARTH, GORNWALL}

Mr P. D. Williams, of Lanarth, writes under date February, 1912 :

"We usually kill more woodcocks in a day than our neighbours for several reasons: firstly we have distinct geographical advantages; secondly we have no pheasant feeding in the best woodcock coverts, and consequently very few pheasants; and thirdly we keep the coverts quite quiet, except for one day's shooting, between October 1 and April 1.

"As to your questions, I enclose the card of the 'woodcock day' for each of the past eight years. In 1908 I was laid up with a broken leg, which made a difference in placing the guns, and there was a severe storm, which was also against a bag. In 1909 the country was so dry that we lost our woodcocks; they shifted, which was not surprising, as we had only .40 in. rain between October 29 and November 26, the dates when we usually collect our birds.

\begin{tabular}{|c|c|c|c|c|c|c|c|c|}
\hline $\begin{array}{l}\text { Year } \\
1904 \\
1905 \\
1906\end{array}$ & 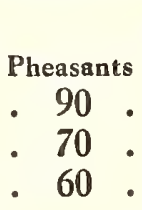 & $\begin{array}{c}\text { Wood- } \\
\text { cock } \\
55 \\
58 \\
63\end{array}$ & $\begin{array}{c}\text { Snipe } \\
. \quad 9 \\
. \quad 6 \\
. \quad 3\end{array}$ & $\begin{array}{c}\text { Wild- } \\
\text { fowl } \\
4 \\
4 \\
1 \\
-\end{array}$ & $\begin{array}{c}\text { Wild } \\
\text { Pigeon } \\
\cdot \quad 9 \\
\cdot \quad 2 \\
\cdot \quad 1\end{array}$ & 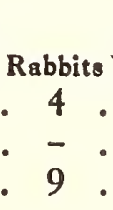 & $\begin{array}{c}\text { Various } \\
- \\
- \\
-\end{array}$ & Remarks \\
\hline 1907 & 51 & 95 & 5 & - & 8 & 6 & 3 & $\begin{array}{l}\text { About } 150 \text { seen. } 4 \text { guns killed } \\
104 \text { snipe the following day. }\end{array}$ \\
\hline 1908 & 94 & 43 & 3 & 1 & - 8 & 4 & - & $\begin{array}{l}\text { A very rough day, or more } \\
\text { would have been killed. }\end{array}$ \\
\hline 1909 & 50 & 54 & 1 & - & 3 & 5 & 1 & Too dry. \\
\hline 1910 & . 48 & 81 & 6 & 1 & - 5 & 8 & - & $\begin{array}{l}\text { We consider that we moved } \\
\text { between } 140 \text { and } 150 \text { birds. }\end{array}$ \\
\hline 1911 & 52 & 63 & 5 & 4 & 1 & 2 & - & $\begin{array}{l}\text { We moved about } 120 \text { different } \\
\text { birds. Six guns each day. }\end{array}$ \\
\hline
\end{tabular}




\section{WOODGOGK SHOOTING}

"As to the arrival, about October 15 to 25 we get a few birds, very few, but the first, these are generally the big chestnut coloured birds, and we think they are bred in England or Scotland. About November 1 to November 7 we usually get a nice sprinkling, say 25 per cent of our crop; November 23 to November 29 we should get our best flight, 50 per cent, and for this we prefer S.E. wind, foggy weather, and morning moon.

"In 1910, three guns killed thirty-six woodcocks on November 26. After December 1 we get a few stragglers in, but I think these are coming to our coverts from the hedgerows and outsides. Still, in a dry autumn, or with unfavourable weather earlier in the season, we sometimes build up a nice stock between December 1 and December 12. I have seen a few arrive in January, but this is not usual, and occurs only in severe winters, and these arrivals are usually noticed in the big woodlands.

"Breeding. An old history of Cornwall* gives an illustration of a young bird hatched from a woodcock's egg; the nest was found in a West Cornwall parish, but I have never heard of any other nest at this end of the country. In the past summer we saw a bird once or twice in June or July, but I think it was a cripple that could not migrate.

"Best time to shoot. We usually shoot about December 12 , which I consider the best time. Some years we lose our birds after they have arrived owing to a dry November, or a very big storm, but this only occurs once in five years at the most. We watch the 'rôding' of our woodcock pretty closely through November and December, so know their numbers fairly well before we shoot. The largest number we ever saw rôding in one evening at one place was December 7, 1907, when we saw twenty-nine. We have frequently heard the birds squeal when rôding, and of course at other times ; 442 woodcock were killed in the Scilly Isles in 1878-9-but they have never done much in a day there-thirty-nine being, I believe, their best.

"I know two instances of woodcock being killed at one shot in Cornwall, one by Mr W. F. Gordon Gregor, at Trewithan, in or about 1840; he fired at a 'cock alighting, and found two dead ones, the bird he aimed at was probably joining the other. Mr Gregor always used a single barrel gun, having lost one thumb. The other instance was Mr Christopher Popham, at Clowance; he shot one 'cock and the other fell some five yards further on.

\footnotetext{
*Borlase's Natural History of Cornwall, 1758, page 245, records a nest found in the neighbourhood of Penzance in the summer of 1755 . There were two eggs, one being broken the other was put under a pigeon, and a young woodcock hatched out, which is figured on plate xxiv, fig. xii, page 239.
} 


\section{THE GUN AT HOME AND ABROAD}

"A well-known Gornish gunner, Mr F. G. Emys, told me he kept a record of what 'cock he killed individually between 1859 and 1891, and the score was 2,051 . He was the most accurate man I ever met, and I am quite sure that he would never count any bird that anyone else had a share in."

\section{MELTON GONSTABLE, NORFOLK}

Lord Hastings writes that he has unfortunately mislaid the old game book which gives the great day in Swanton Wood, when 105 were shot, probably in 1872 .

He has kindly sent a list of totals since 1877 , from which we have extracted the bags for the best years in Swanton Wood, and the best days of the good years.

N.B.-The bags in Swanton Wood, which is very large, are the results of more than one day's shooting in each season:

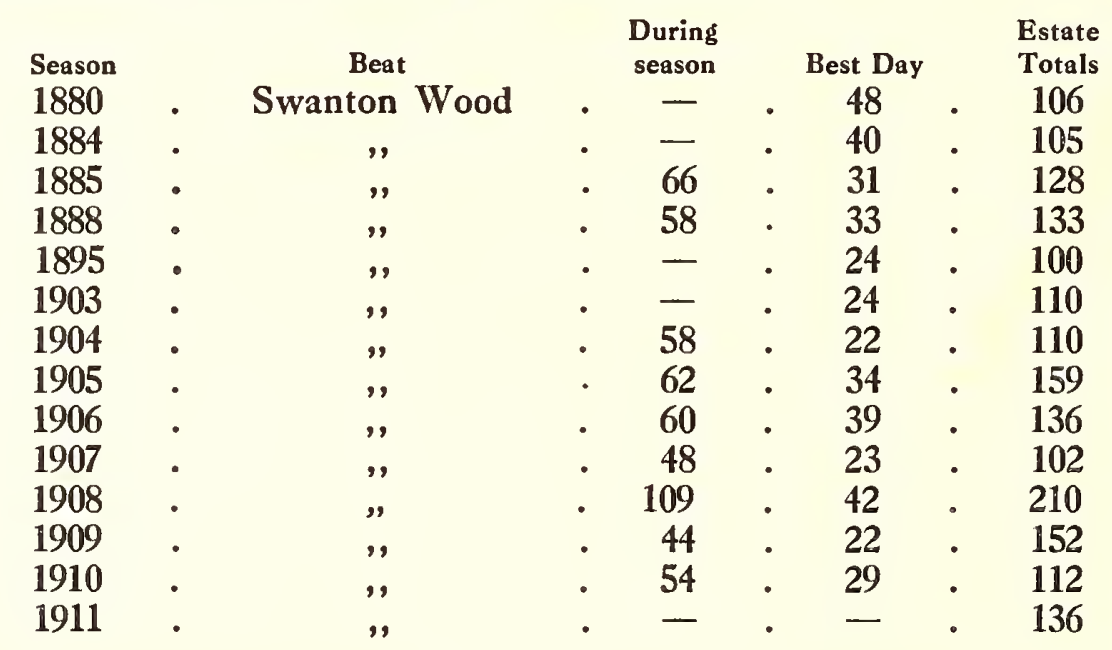

The best week's shooting was in 1908, December 1, 2, 3, 4, when 103 woodcocks were shot and 2,500 pheasants.

Melton being close to the east coast of Norfolk, affords a resting place for the earliest migratory 'cock ; the first fiights generally arrive early in October.

ARTHUR AGLAND HOOD. 


\section{COMMON SNIPE}

\section{GALLINAGO GALLINAGO}

(Plate XXIV)

Scolopax gallinago, Linn., Syst. Nat., i, p. 244 (1766) ; Gould, Birds Europe, v, pl. 321, fig. 2 (1837); Seebohm, Hist. Brit. Birds, iii, p. 241 (1885); Lilford, Col. Fig. Brit. Birds, pt. xxxi (1895).

Gallinago scolopacina, Bonap.; Gould, Birds Great Brit., iv, pl. 79 (1863).

Gallinago coelestis, Frenzel ; Dresser, Birds Europe, vii, p. 641, pls. 542-543(1880); Hume and Marshall, Game Birds Ind., iii, p. 359, pl. (1880); Saunders, ed. Yarrell, Brit. Birds, iii, p. 342 (1883); id., Ill. Man. Brit. Birds, p. 573 (1899).

Gallinago gallinago, Oates, Man. Game Birds Ind., ii, p. 455 (1899); Sharpe, Cat. Birds Brit. Mus., xxiv, p. 633 (1896).

Payne-Gallwey, in "Badminton Library," Moor and Marsh, The Snipe, p. 134 (1886).

Shaw \& Ussher, in "Fur, Feather and Fin Series," Snipe and Woodcock, p. 3 (1904).

To the Dark variety chiefly met with in the British Isles, and known as Sabine's Snipe, the following are the principal references :-

Scolopax sabinii, Vigors, Trans. Linn. Soc., XIV, p. 557, pl. (1825) ; Gould, Birds Europe, v, pl. 321, fig. 1 (1837); Lilford, Col. Fig. Brit. Birds, pt. xxvi (1893).

Gallinago coelestis, var. sabinii, Barrett-Hamilton, Irish Nat., iv, p. 12 (1895).

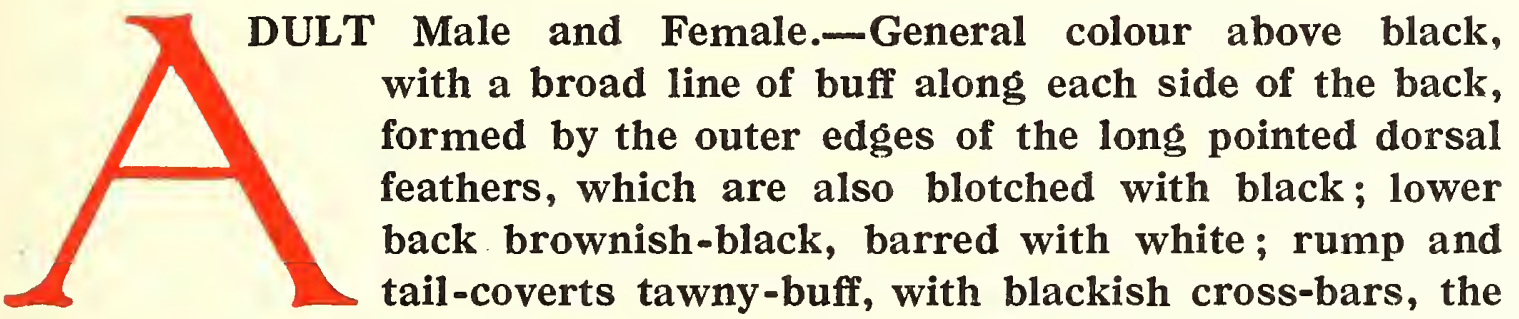
longer coverts tipped with white; shoulder-feathers (scapulars) black, margined with buff, and irregularly barred with rufous. Quills blackish, the outer quill whitish along the outer web, the short outer secondaries, primary coverts and bastard wing black, tipped with white, the secondaries conspicuously so, the long innermost secondaries dark smoky grey, barred with black and rufous-buff. Tail-feathers fourteen (occasionally sixteen) in number, with the terminal portion light chestnut tipped with white, separated by a black band, and the basal portion mostly black; outer pair regularly barred with blackish. (Fig. 1.) Grown of the head black, with a pale buff band down the middle, and wide buff-coloured eyebrow-stripes extending from the lores to the occiput; a broad black streak from the nostril to the eye; sides of the head whitish, with a dark streak across the ear-coverts; chin white, throat and chest sandy-brown, with blackish spots and bars, breast and abdomen pure white, sides conspicuously barred with blackish; axillary plumes usually white, barred with 


\section{THE GUN AT HOME AND ABROAD}

black, but occasionally pure white, especially in Asiatic birds. Iris hazel; bill dark brown, paler at the base and darker at the tip; legs and toes greenish-grey.

Male. -Total length 11 inches; bill from the feathers on the forehead to the tip $2 \cdot 6$ inches to $2 \cdot 8$ inches; wing $5 \cdot 2$ inches; tail $2 \cdot 3$ inches; tarsus $1 \cdot 2$ inch.

Female. - Similar to the male, but rather larger.

Young in first autumn-plumage. -Differs from the adult in being more rufous, especially on the throat and neck. The black markings on the back are more broken up and mottled with rufous bars; the pale buff bands along the back formed by the outer webs of the elongate dorsal feathers and scapulars are not so wide, and the lower back is blackish, and lacks the white bars on the tips of the feathers found in the adult.

Young in down.-Dark orange-chestnut, mottled with black and frosted with white above. A black band at the base of the bill, a second across the crown between the eyes, and short black bands from the bill to the eye and on the cheelss. The white downy plumes are mostly arranged in bands across the head, cheeks, neck and down the back.

Variations in plumage.-Light-coloured, buff, and partly or entirely white specimens are occasionally met with, and are sometimes very handsome birds; but by far the most curious and interesting variety is the dark form known as Sabine's snipe. It has the general colour above black, barred with rufous and the underparts evenly barred with rufous and black. The buff stripes down the back and scapulars, so characteristic of the ordinary snipe, are entirely absent, also the white outer web of the first flight-feathers. This description refers to typical examples, but other forms occur which are intermediate between Sabine's and the ordinarily coloured snipe. Almost all the examples of Sabine's snipe known, nearly sixty in number, have been killed in the British Isles.

General distribution.-The range of the common snipe is even more extensive than that of the woodcock; not only is it met with in the breeding-season further north in Europe and Asia, being found up to about $70^{\circ}$ north latitude, but extends to Iceland, the Faroes and South Greenland. Its southern breeding-range is chiefly confined to mountain-ranges, and includes the southern slopes of the Alps, the marshes of Northern Italy and South Russia and, further east, Turkestan, the lofty table-lands of Yarkand and South-east Mongolia. That the species occasionally remains to breed in the Azores is certain, for on the high ground on the Island of Flores I shot 262 


\section{COMMON SNIPE}

a female on April 16 containing large eggs, one almost ready to be laid. It is also said to nest occasionally in North-west Africa, which seems highly probable. A few pairs occasionally remain to breed in favourable localities in India.

In winter it migrates further south, and is found over a considerable portion of North Africa as far as Senegambia on the west, and the Southern Sudan and Abyssinia in the east; it is also common in Southern Arabia, the Island of Socotra, South Persia, India, Ceylon, China, and the Malay countries as far as the Philippine Islands and Moluccas. To the eastern part of North America it is an occasional visitor, and has occurred in the Island of Bermuda.

Allied species.-In North America the common snipe is represented by Wilson's snipe (Gallinago delicatula), a nearly allied species, which breeds from the Northern United States northwards up to the Arctic Gircle. It winters in the Southern States, Bermuda, and the West Indies, and extends sparingly to the northern parts of South America, while stragglers have been met with as far south as Rio de Janeiro. The American bird may usually be distinguished by having sixteen tail-feathers; the long axillary feathers below the wing are always transversely barred with black and white, and, the black bars being usually the wider, they may be described as black, barred with white; the breast is barred with blackish. All these characters are, however, occasionally to be found in the common snipe, and individual examples are occasionally killed in Europe and Asia which seem to be referable to Wilson's snipe.

Besides the two species already mentioned, twenty different kinds of snipes are known, the genus being nearly cosmopolitan in its range. Eleven are confined to the Old World and the remaining nine are peculiar to South America. The snipes may be divided into two sections : the " pintailed" and the "fan-tailed," the latter group including the common and Wilson's snipes, already mentioned.

The pin-tailed section includes only one species, the common pin-tail ( $G$. stenura), a remarkable bird, much like the common snipe in size and general appearance, but with twenty-six tail-feathers, of which the eight outer pairs are greatly attenuated. The outermost pairs are about onetenth of an inch wide at the base, and less than half that width at the tip, which is slightly lobate.

The pin-tail snipe breeds in Eastern Siberia, east of the Yenesei Valley, and ranges southwards to India, Ceylon, and Socotra. 


\section{THE GUN AT HOME AND ABROAD}

Of the fan-tailed snipes the great or double snipe, often called the solitary snipe (G. major), breeds in Northern Europe and Asia as far east as the valley of the Yenesei, and ranges south in winter to South Africa. It has the outer tail-feathers white, with a few black bars at the base of the outer web. As a winter-visitor to these islands in small numbers, it is well known, and is specially referred to elsewhere. G. nigripennis, a very dark bird, with the ground-colour of the upperparts mostly black, and the three outer pairs of tail-feathers nearly pure white, the outer pair often entirely so, is peculiar to Africa, and $G$. macrodactyla, with a very long bill, measuring more than three and a half inches, is confined to Madagascar.

Swinhoe's snipe (G. megala), with twenty tail-feathers, the outer pairs being much narrower, inhabits Eastern Siberia, and ranges south in winter to China, Japan, the Philippines, Borneo, and the Moluccas. The three following species possess eighteen tail-feathers, the outer pairs, as in G. megala, being much narrower and rather stiff. G. australis breeds in Japan and winters in Australia and Tasmania. The Eastern solitary snipe ( $G$. solitaria), a large and remarkably handsome species, inhabits Eastern Asia down to the Himalaya, and has occurred in Southern India, and the wood-snipe ( $G$. nemoricola), a very dark coloured bird, is peculiar to the Indian Peninsula, Assam and Burma.

Three very interesting small species of snipes, with very limited powers of flight, are met with on the islands off New Zealand: G. aucklandica, on the Auckland and Antipodes Islands; a dark form, G. huegeli, on the Snares Islands; and G. pusilla on the Ghatham Islands. The latter is the smallest species of snipe known, and has a wing-measurement of less than four inches.

South America is particularly rich in snipes, and no fewer than nine different species are found in that vast continent. Some of them are, comparatively speaking, very large birds, especially $G$. gigantea, from Brazil and Paraguay, and G. undulata, from Guiana, both of which have a wing measurement of 6.5 inches. The former is the largest of all the snipes, measuring a foot and a half from the tip of the bill to the end of the tail, and has a very long bill, more than five inches in length. The latter belongs to the same group as the common and Wilson's snipes, but is a very much larger bird.

Two of the species, G. frenata and G. paraguaice, of the same size as the common snipe, have a very wide distribution, and are found over a large 264 
part of South America; but the remainder appear to be comparatively local in their distribution; G. nobilis, G. jamesoni, and $G$. imperialis being only known from the north-west, and inhabiting Colombia, Ecuador, or Bolivia; while $G$. andina inhabits Peru; and G. stricklandi ranges from Chile to the Straits of Magellan.

Distribution in the British Isles.-The common snipe is resident in the British Isles, and breeds wherever marshy ground suitable to its habits is to be found. In England it is most abundant in the eastern counties of Lincolnshire, Cambridgeshire, Norfolk, Suffolk, and Essex, also in some parts of Wales; it is likewise common on the moorlands and marshes of Scotland; but it is most plentiful in Ireland, where the extensive bogs provide a large area of ground eminently suited to its tastes. The number of snipe that breed in these islands is, however, small compared with the vast numbers of migrants which annually visit our shores in October and November, and usually remain till March, when the majority return to more northern latitudes to breed. The migration takes place at night, generally with an east or north-east wind, the birds usually travelling singly or in pairs, more rarely in small parties of half a dozen or so. At such times many are killed by striking against the lanterns of the lighthouses.

The migratory movement, as in the case of the woodcock, etc., is largely dependent on weather, the first arrivals appearing towards the end of September. The numbers increase during the first half of October, and the migration reaches its height during the last half of that month, and is continued, with gradually diminishing numbers, till the beginning of December. The dates of arrival are, however, very variable, and are largely governed by early or late frosts and snows. Between the middle of February and the early part of March the majority of snipes leave Great Britain and return to the more northern breeding-grounds, but it is certain that, as in the case of the woodcock, the number of birds remaining to breed in our islands is steadily increasing, and has been largely augmented during recent years.

Food.-Like woodcocks, snipes subsist mainly on earth-worms, all kinds, except the brandling, being equally acceptable as food. These are obtained by probing in the soft earth in the same manner as the woodcock. As has been proved by the study of birds in captivity, a snipe is capable of consuming in an evening an amount of worms equal to at least twice its own weight. It is also partial to the grubs of the 


\section{THE GUN AT HOME AND ABROAD}

daddy long-legs, and to small molluscs, and will pick up small insects of all sorts and kinds when not engaged in the more serious task of worm-hunting. Mr Hugh Wormald has published a delightful account of the habits of a tame snipe hatched by him in an incubator. The bird was unable to detect a worm placed right under it; but if placed two or three inches in front, it would catch sight of it at once, walk up to it, feel about with its bill till it touched it, and then instantly swallow it. This clearly shows the sensibility of the bill. Mr Wormald's snipe fed at intervals throughout the whole day and night, and eat a large quantity of grit and small pebbles, which could be heard grinding in its gizzard quite distinctly at a distance of several feet, especially immediately after feeding; the gizzard was heard to grind twelve times to the minute. The digestion was wonderfully rapid, so much so that he does not think a worm remained in the bird for more than ten minutes. Its hearing was very acute, and it was observed to listen like a thrush, then drive its bill into the turf and bring out a worm, which it sucked down with no apparent exertion. The bird did not throw back its head, as one constantly sees depicted, but rather stretched out its neck, the bill pointing downwards. If the worm was too large to be swallowed whole, it was hammered and pinched until broken up, when the pieces were swallowed separately. Another writer in the "Field," also describing the habits of a tame snipe, says that except when very hungry, it generally washed each worm before eating it. After carefully cleaning a worm the bird would disable it by pinching it all over with the tip of its bill, and then, taking it by the middle, suck it down doubled up.

It has often been stated that snipe will eat vegetable matter, but the observations made on birds in captivity seem to prove conclusively that this is a mistake, and that any such matter found in the bird is swallowed accidentally, either in or with the insects and worms it eats. Snipe in captivity can be taught to eat various kinds of animal food, such as bits of raw flesh, strips of raw tripe, and even bread and milk, but to keep the bird in health, worms should be added to this diet.

Flight.-The flight of a snipe is very swift, and when getting up speed on first rising, the bird has a curious way of twisting from side to side. This habit, commonly seen in the birds inhabiting colder climates, is much less conspicuous or absent in those met with in warm countries, such as India. The sportsman accustomed to shoot snipe in the British Isles, 


\section{COMMON SNIPE}

when first visiting the East will be surprised at the ease with which he can kill a right and left time after time, but the fact is that the birds really twist and fly more slowly in a warm climate, and are infinitely easier to shoot. There is a popular belief that the snipe, when rising, uses its bill like a jumping pole to assist it in springing from the ground; but, as Mr Shaw has pointed out, this supposed habit can be explained in a very simple and natural manner. Snipe are sometimes suddenly disturbed when feeding with the bill thrust deep into the ground, and acting under the impulse of sudden fear, spring into the air without first withdrawing the bill. Thus a bird may sometimes be seen as it were balanced for a second or two on its bill before it is able to free itself. Occasionally the bill is so firmly buried in the earth that in attempting to rise the bird turns a complete somersault.

Under this heading must be included the remarkable habit of the common snipe, and many of its allies, of executing aerial evolutions and "bleating" or "drumming" during the breeding-season. In early summer the male (and sometimes also the female) may often be seen circling round high over the breeding-ground for long periods, sometimes mounting to such a height that it appears a mere speck in the sky. Every few minutes it darts obliquely downwards with half-closed wings and widely extended tail, then shoots up again and regains its former elevation. At each downward rush a strange bleating sound is produced by the rush of wind meeting the stiffly extended outer pair of tailfeathers, and causing their peculiarly constructed inner webs to vibrate.

The "bleating" or "drumming" of the snipe is a subject on which much has been written, and about which there has been, and still is, much difference of opinion. Many still maintain that the sound proceeds from the throat; others are equally positive that it is produced by the wings, or by the contact of the tips of the wing-feathers with the outer feathers of the tail ; but it has now been conclusively proved that the outer pair of tail-feathers, and to a less degree the next or sixth pair, produce the intense vibrating sound which resembles the bleating of a sheep or goat. During the headlong stoop, when alone the sound is heard, the two outermost tail-feathers are held out rigidly, well beyond the remaining twelve, by means of a small muscle attached to them.

The assertion that the "bleating" is produced by the tail-feathers was first made by Meves, of Stockholm, in 1856, when he was led to experi - 


\section{THE GUN AT HOME AND ABROAD}

ment with the tail of the snipe, and found that he was able to reproduce the sound mechanically. More recently, in 1907, Dr P. H. Bahr made a close examination of the subject, and the results of his investigations were published in the "Bulletin of the British Ornithologists' Club" xix, pp. 72-73. By fastening the outer tail-feathers firmly into a cork, and moving the apparatus rapidly through the air, he was able to produce exactly the familiar bleating sound made by the common snipe, and also to show that most of the other species are equally capable of producing sounds of varying intensity. It was shown that in the common snipe the inner web of the outermost pair of tail-feathers is the main sound-producer, and that the narrow outer web can be cut off without altering the sound, also, that when the rami of the inner web are disarranged, no sound is produced. If the feathers are exposed to the resistance of the air with the outer web towards it, the inner web vibrates so rapidly that its edge becomes invisible, and when travelling at a rate of twenty miles an hour the low humming sound is produced. Microscopically, the outer pair of musical feathers are differentiated by possessing no fewer than eight hamuli or hooklets which hook over the inturned edges of the proximal radii or barbules, and thus keep the rami or barbs taut, like the strings of a harp. In the other feathers of the tail only five hamuli occur on each radius.

It is certain that the female "bleats" as well as the male, for this fact has been noted in the field by trustworthy observers, and the outer tail-feathers, on examination, are found to possess the same peculiar properties in both sexes. As to the female "bleating," a fact of which I am well assured from personal observation, it may be interesting to refer to the account given by Mr F. Boyes, of Beverley, in "The Field" of July 9, 1898. He visited a very small strip of bog, and almost immediately flushed the cock bird, which commenced to "drum" above and around him. In a short time he flushed the hen off her nest containing three eggs, and as she left it she dropped the fourth egg, which was broken in its fall. The bird, in continuing its flight, struck itself against some posts and rails, and fell stunned to the ground, but soon recovered and flew away. He marked it, and afterwards flushed it again. All this time the male was "drumming" overhead, and no other snipes were in the neighbourhood. The female now joined in the "drumming," and the two continued to "drum" for some time. Eventually both alighted on the tops of posts and allowed Mr Boyes to 


\section{COMMON SNIPE}

walk quite close to them, nodding their heads at him all the while. In this instance, at any rate, there could be no doubt whatever that both male and female were "drumming," for he walked over the small strip of bog again and again without flushing any other snipe.

The curious habit of perching on trees and fences during the breeding-season is worthy of special note. Messrs Seebohm and HarvieBrown during their journey in Siberia have furnished some interesting notes on this subject which will bear repeating: "We were not a little surprised when we first became acquainted with the arboreal habits of the snipe at Habarika, and saw one of these birds perched, seventy feet from the ground, on the topmost upright twig of a bare larch, where one would have thought it could scarcely find sufficient foothold. With its head lower than its body and tail, it sat there uttering at intervals the curious double 'clucking' note, tjick-tjuck, tjick-tjuck, whilst others of the same species were 'drumming' high in the air over the marsh. To put it all beyond a doubt, Harvie-Brown shot one in this peculiar position."

Breeding habits.-The pairing-time of the snipe varies much according to locality and season. In Britain, if the winter is exceptionally mild, the birds may commence to mate in February, but the usual time is the end of March. In Europe nesting usually begins about the middle of April, but fresh eggs may be found from the end of March till the middle of May. In high altitudes and high latitudes the date is considerably later; for example, in Kashmir the birds do not apparently begin to lay till May, and in the Arctic regions not until the middle of June.

The breeding-note or love-song of the snipe, chick-a, chick-a, or tink-a, tink $\bullet a$, rapidly repeated several times, is uttered both on the ground and on the wing, and must not be confused with the "bleating" sound produced by the tail-feathers when the bird is on its downward flight, and at no other time.

Nesting.-The nest, a mere depression in the ground lined with dry grass, is usually placed in a bunch of rushes or among coarse grass and heather, in or near swampy ground, where the birds are in the habit of feeding. In one instance $I$ have seen two nests situated in the same clump of herbage, so close to one another that they were only divided by a thin fringe of rushes. One nest contained three eggs, the other two, clearly indicating that they were the property of two pairs. 


\section{THE GUN AT HOME AND ABROAD}

Eggs.-The eggs, almost invariably four in number, are nearly always pyriform in shape, rarely more or less oval. Like those of all waders, they are neatly arranged with the smaller ends together in the middle of the nest, so as to be covered in the smallest possible space. The groundcolour varies from pale greenish to buff or brownish-olive of various shades, marked with large spots and blotches of dark brown or chocolate-brown, and underlying purplish-grey. The markings are usually most numerous about the larger end, often confluent, forming an irregular cap, and are usually disposed obliquely from left to right. The average dimensions are 1.6 in. by 1.1 in.

The period of incubation lasts about sixteen days, and it seems probable that two broods are occasionally reared in a season, for young snipe have been found as late as the middle of August. It is not known if the male bird takes any part in the duties of incubation, but there seems to be a general consensus of opinion that he does not.

The beautiful little downy nestlings are able to leave the nest soon after they are hatched, and are extremely active in their movements. It seems possible that they are sometimes carried by the female on her back in moments of danger, for I was told by a trustworthy and observant keeper in Sutherland that he had actually seen this take place within a few yards of him. He suddenly came on a female snipe accompanied by nestlings, and saw her deliberately squat down while one of the nestlings mounted on her back, and she then flew slowly off with it. Such an instance may be exceptional, and I have never heard of a similar case, but as the man who actually saw it was a trustworthy witness, it seems worthy of record.

General habits.-Bogs and marshes, the rushy margins of streams, lakes and ponds, water-meadows and sewage-farms, in fact any spot where there is soft soil in the vicinity of water, will hold snipe. Sometimes they are met with in grass-fields and on ploughed lands, or again in turnip or potato-fields, and in all sorts of unexpected places which at first sight seem quite unsuited to their tastes, but they are never found far from water, which is essential to their mode of life, not only for drinking purposes, but for the frequent washing of the bill when feeding. In this respect they resemble the woodcock. The snipe cannot probe for worms in ground which is submerged, and, consequently, a very slight increase in water may cause places which a few days previously were full of birds to be entirely deserted. This, no doubt, is the secret of their apparently 270 


\section{COMMON SNIPE}

capricious movements, for a snipe cannot stand in more than two inches of water, much less obtain a living, when the bogs and marshes are all submerged. The snipe is almost entirely a ground-bird, and its curious habit, already referred to, of perching on trees and posts during the breeding-season, common to many other waders, such as the redshanks and sandpipers, is not observed at other times of the year.

As a rule the snipe is a very solitary bird, and though hundreds may be met with in the same bog, they usually lead an entirely independent existence. Occasionally, however, all the snipe in a district seem to pack, and gather in large "wisps"; at such times they are usually very wild and unapproachable, and, rising en masse, scatter in all directions. At other times, when a number of snipe are found concentrated in some favourite spot, they will act in an entirely different manner, rising singly or in pairs. The weather-conditions have no doubt much to do with this diversity of habit, and influence their actions, as in the case of grouse and other wildfowl. Wet and stormy weather will always render them wild and unsettled. When frost sets in the birds leave the more open feeding-grounds and repair to the margins of streams, or any open water; when these become frozen, the majority migrate to more favourable districts.

The seashore and mud-flats have but small attraction for snipe, and they are rarely found there, their haunts and feeding-grounds being the same both in winter and summer. Mr Wormald, who has had exceptional opportunities of observing snipe in captivity, says that they are full of play. They often squat down with the tail well up and fully expanded and the wings drooped, and then jump from side to side. On bright sunny mornings they are sometimes very active, and will romp almost like young partridges. The late Duke of Beaufort stated that the snipe, when resting, invariably sits on its shanks, with its back to the wind, its bill pointing downwards, and pressed close against its breast, and that it shelters itself behind its raised and fully expanded fan-like tail. This action is so different from what has been observed in other birds, that I think the snipe referred to by his Grace must have been at play, as described above. As all birds invariably sit facing the wind, I cannot believe that snipe normally sit with their backs to it, and no other observer, so far as I am aware, has noted this peculiarity.

When rising, the snipe utters a harsh note, sounding like "scape," 
THE GUN AT HOME AND ABROAD

repeated several times. This is quite distinct from the note, chich-a, uttered during the breeding-season, and referred to above.

Like the woodcock, the snipe rapidly loses weight in hard frost, and as rapidly regains it on the return of mild weather. The average weight of a snipe is about four ounces, but in times of plenty many birds may be shot which average five ounces, and individuals weighing as much as eight ounces have sometimes been killed.

W. R. OGILVIE-GRANT. 


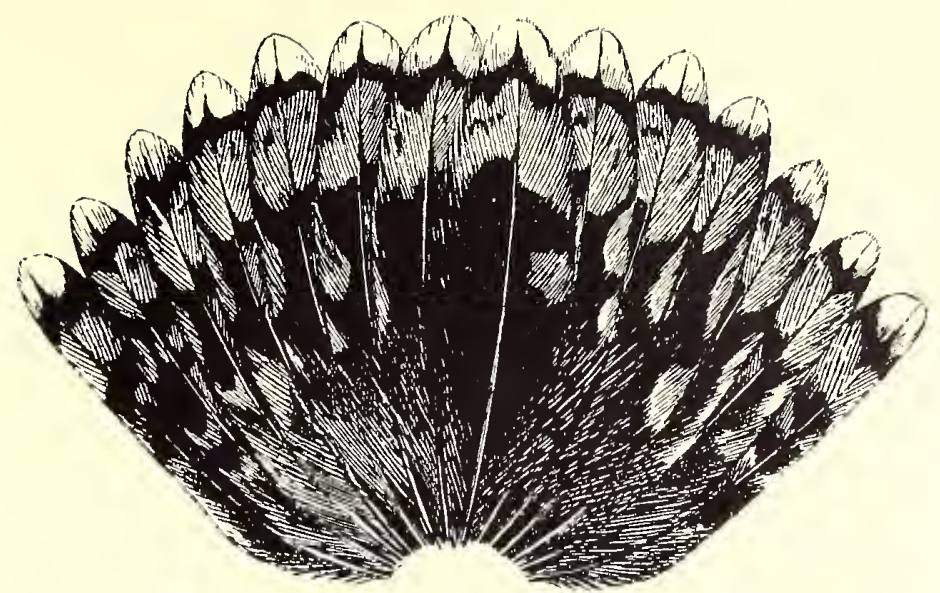

Fig. 1. Tail of Common Snipe (Gallinago gallinago) with 14 feathers.

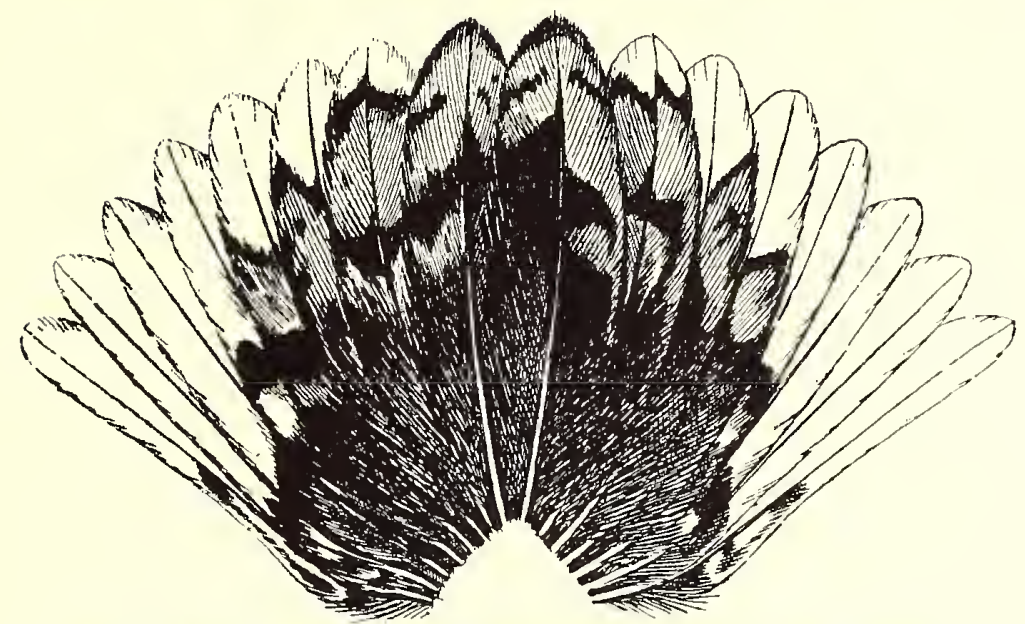

Fig. 2. Tail of Great or Double Snipe (Gallinago major) with 16 feathers.

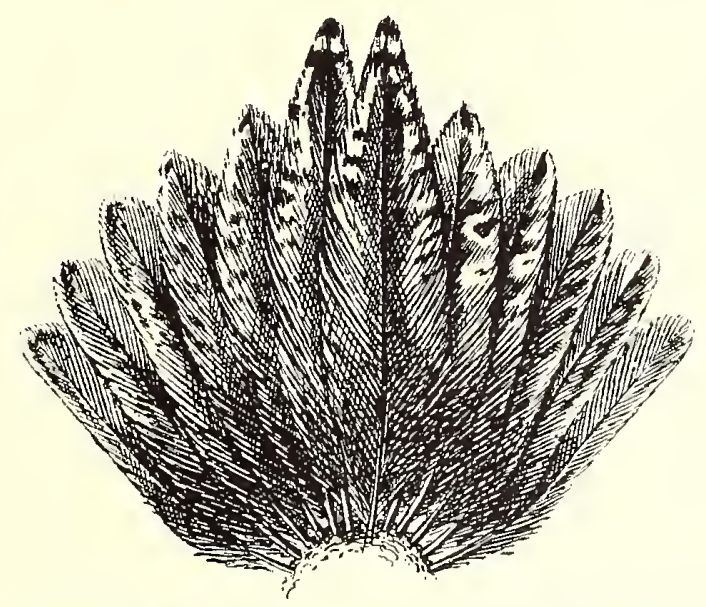

Fig. 3. Tail of Jack Snipe (Limnocryptes gallinula) with 12 feathers. 


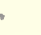




\section{GREAT OR DOUBLE SNIPE}

\section{GALLINAGO MAJOR}

Scolopax major, Gmel. Syst. Nat., i, p. 661 (1788) ; Gould, Birds Europe, v, pl. 320 (1837); Seebohm, Hist. Brit. Birds, III, p. 237 (1885) ; Lilford, Col. Fig. Brit. Birds, pt. xxviii (1894).

Gallinago major, Gould, Birds Great Brit., iv, pl. 78 (1863); Dresser, Birds Europe, vii, p. 631, pl. 541 (1876); Saunders, ed. Yarrell, Brit. Birds, iii, p. 336 (1883) ; Sharpe, Cat. Birds Brit. Mus., XXIV, p. 626 (1896) ; Saunders, Ill. Man. Brit. Birds, p. 571 (1899).

Shaw, in "Fur, Feather and Fin Series"; Snipe and Woodcock, p. 11 (1904).

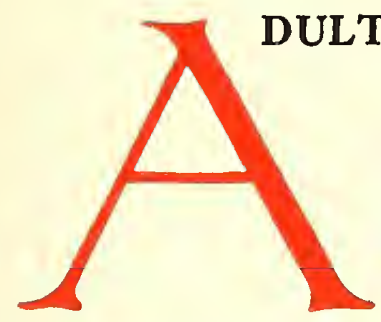

DULT male and female.-Very similar to the common snipe in colour and markings, but larger, and distinguished by the following characters: The white tips to the wing-coverts are much more conspicuous, the breast and flanks are more profusely barred with black; and the four outer tail-feathers on each side are mostly pure white, with only a few black bars or markings near the base. This last character is a very simple means of distinction (p. 272, fig. 2).

Total length 11.0 inches; bill from the feathers on the forehead to the tip about $2 \cdot 5$ inches; wing 5.5 inches; tail $2 \cdot 0$ inches; tarsus 1.4 inch.

General distribution.-The breeding-range of the great snipe extends from the lowlands and fells of Scandinavia across Northern Europe and Asia to the valley of the Yenesei in Siberia. In Western Europe it is met with in summer up to $71^{\circ}$ north latitude, but eastwards, in Siberia, its northern range does not appear to extend beyond $66 \frac{1}{2}^{\circ}$. In autumn it migrates southwards to the basin of the Mediterranean and Africa, many birds passing on to winter in Cape Colony. The birds breeding in Siberia pass through Turkestan and take a south-westerly course through Persia, the Caucasus, and North-East Africa, while many follow an easterly route to more southern latitudes. As a migrant to the British Isles, though an annual visitor, the great snipe is, comparatively speaking, a rare bird, but it is no doubt often overlooked on account of its general close resemblance to larger examples of the common species. Its large size, more heavily barred underparts, and tail composed of sixteen feathers, with the outer ones nearly pure white are, however, characters which render it easily distinguishable.

Those which visit this country are, of course, stragglers from the main body moving southwards through Western Europe to the Mediterranean basin and Africa. The majority are said to be young birds of the year, 


\section{THE GUN AT HOME AND ABROAD}

but I do not know that there is any good reason for this belief, for many adult birds have been obtained. They begin to arrive in the latter part of August, and stragglers continue to come till November, but the majority seem to be met with in September and the early part of October. They probably do not remain long in Britain, but after resting for a while continue their journey southwards. In the west the return migration takes place late in April, the birds arriving at their breeding-grounds in Scandinavia about the middle of May, but, the shooting season being over, few examples have been recorded, and consequently much less is known of the spring-movements in our islands.

In the eastern part of its range the return migration seems to commence earlier than in the west, the birds appearing in the Ionian Islands towards the end of March, but they do not reach their breeding-grounds in Siberia till the first week in June, being among the latest migrants to reach the Arctic Gircle. Exceptionally large examples of the common snipe, which rarely weigh as much as eight ounces, are sometimes mistaken for the great snipe, the average weight of which is eight ounces, while in rare instances birds of ten ounces have been obtained.

Distribution in the British Isles. - The great snipe has never been known to breed in the British Isles. As a visitor it is now perhaps most common in the eastern counties of England, though occasionally killed in all parts of our islands, but from notes written by Major Walker, and recorded by Mr Shaw in the volume on Snipe and Woodcock in the Fur and Feather series, it would seem that this species was much more numerous in Wexford more than half a century ago, and that three or four were sometimes killed during a day's snipe-shooting.

Flight.-When flushed its flight is slow and straight, and on rising it does not twist like the common snipe. It does not fly far, and, like the jack snipe, soon drops after covering a distance of perhaps a hundred yards.

Food.-The food consists chiefly of worms, small field slugs, and the larvæe of insects, especially crane-flies, and according to Professor Collett, of Christiania, small stones are swallowed.

Breeding habits.-Unlike the common snipe, the great snipe, though it makes short flights when displaying in the breeding-season, does not "drum," its outer tail-feathers, as has been proved by the experiments of Dr Bahr, being incapable of producing any sound. It has, however, some peculiar habits which demand notice.

274 


\section{GREAT OR DOUBLE SNIPE}

Seebohm, who had many opportunities of observing this bird in Siberia, writes as follows: "In the pairing-season the males are gregarious, and have a sort of 'lek,' like that of the ruff, or of many species of grouse. Late one evening as Harvie-Brown and I were drifting down the Petchora, we came upon a large party of these birds, making curious noises with their bills, in the long grass on the banks of the river. Sometimes as many as half a dozen were on the wing at once, but their flights were very short, and we succeeded in shooting ten of them, which all proved to be males. I saw the same remarkable performance in Siberia, where they were very common in the valley of the Koorayika, and soon after their arrival I used sometimes to watch them in the evenings through my binocular. With a little caution I found it very easy to get near them, and frequently, as I sat partially concealed between a couple of willow bushes, I was able to turn my glass on two or three pairs of these birds all within fifteen or twenty yards of me. They had one very curious habit which I noted : they used to stretch out their necks, throw back the head almost upside down, and open and shut their beaks rapidly, uttering a curious noise like that produced by running the finger along the edge of a comb. This was sometimes preceded by a short flight, or by the spreading of the wings and tail. I have never heard the great snipe utter any other call or alarm-note. During the breeding-season it is not at all shy, and allows of a near approach ; and when resting it almost permits itself to be trodden upon before rising, which it does with a whirr of the wings, like that of a grouse, buit not so loud. . . .

"On the ground it is a very comical looking object : plump, short-legged, it shuffles about, half walking, half running, its bill always depressed, and, however intent it may be on feeding, it is ever on the watch for danger, and always tries to keep behind a bunch of rushes or a clump of sedge. It hides in the long coarse grass on the banks of rivers and lakes during the day, and comes out on the open in the evening, if there be any evening where it happens to live, to feed on worms and various small insects."

Dr P. H. Bahr, who has made a special study of the breeding-habits of the snipe, in comparing the display of this species with that of the jack snipe, has made the following remarks : "We have records, made by such excellent observers as Professor Collett, that the great snipe (Gallinago major), though an allied species, has an entirely different nuptial display. The males, it is said, meet together on common ground, and there, in much the same manner as the blackcock, display before 
THE GUN AT HOME AND ABROAD

the hens. The chief point about this display is that the tail is spread out like a fan and moved up and down, as if the bird was anxious to do something with its tail, but did not quite know how to set about it. In this wise the pure white outer tail-feathers are shown to the admiring gaze of the opposite sex. In view of the fact that the performance takes place on the ground, and that there are no specialized structures, in either the wing or the tail, which could possibly serve as musical instruments, we are forced to conclude that the sounds made by this snipe too, must be vocal in origin. It has always seemed to me a remarkable thing that some of the Scolopacine should have such specialized musical instruments in their wings or tail, and that others, although in form and anatomical features apparently so closely allied, should have to depend upon their vocal organs for giving vent to their feelings during the breeding-season." [cf. Bull. Brit. Orn. Club, xxix, p. 79 (1912)].

Nest and eggs.-The nest is usually placed among long grass or in the middle of a tuft of rushes, and is a mere depression in the ground lined with moss and dead grass. The full complement of eggs is four. They are of a pyriform or sometimes oval shape, longer and considerably wider than those of the common snipe, and have the ground-colour pale greyishbuff or brownish-buff, sometimes faintly tinged with green. The bold blotches and spots of rich Vandyke-brown or pale brown, and the underlying markings of purplish-grey are mostly distributed round the larger end, where they are often confluent, a nd are generally obliquely directed from left to right. The average dimensions are $1.8 \mathrm{in.} \mathrm{by} 1.27 \mathrm{in}$.

General habits.-The great snipe is usually found in drier situations than those inhabited by the common snipe, and it may be met with in grass- or clover-fields or among potato- and turnip-fields, as well as in heather, and in Corfu commonly in currant plantations. As a rule it is found singly, or at most, in pairs, and is a very silent bird, uttering no cry as it rises somewhat heavily from the ground.

W. R. OGILVIE-GRANT. 


\section{JACK SNIPE \\ LIMNOCRYPTES GALLINULA}

(Plate XXIV)

Scolopax gallinula, Linn., Syst. Nat., i, p. 244 (1766) ; Gould, Birds Europe, v, pl. 322 (1837) ; Hewitson, Eggs Brit. Birds, ii, p. 355 (1856) ; Seebohm, Hist. Brit. Birds, iii, p. 247 (1885); Lilford, Col. Fig. Brit. Birds, pt. xxx (1895).

Limnocryptes gallinula, Gould, Birds Gt. Brit., iv, pl. 80 (1865) ; Sharpe, Cat. Birds Brit. Mus., xxiv, p. 665 (1896); Oates, Man. Game Birds Ind., ii, p. 477 (1899); Pycraft, Bull. Brit. Orn. Club, xxix, p. 77 (1912).

Gallinago gallinula, Dresser, Birds Europe, vii, p. 653 ; pl. 544 (1877) ; Hume \& Marshall, Game Birds Ind., iii, p. 373 (1880) ; Saunders, ed. Yarrell, Brit. Birds, iii, p. 351 (1883); id. Ill. Man. Brit. Birds, p. 575 (1899).

Jack Snipe, Shaw in Fur, Feather and Fin Series, Snipe and Woodcock, p. 15 (1904).

DULT male.-General colour above, black, glossed with green
and purple and with a few rufous markings on the
back. The long feathers on the sides of the back with
the outer webs rich buff, forming a broad longitudinal
stripe on either side; scapulars very similarly marked;
lower back and rump black, many of the feathers narrowly margined with white; wing-coverts and quills mostly brownishblack, the coverts margined with pale rufous; the pointed outer secondary quills broadly tipped with white, and the long inner secondaries marked with black and buff; the tail, composed of twelve feathers, pointed and uniform dusky brown, with pale rufous margins (p. 272, fig. 3). Top of the head black, mottled with rufous, no pale band down the middle of the crown, which is bounded on either side by a well-defined buff superciliary stripe extending from the lores to the back of the head, and bordered internally with black; a broad black band extending from the base of the bill to the ear-coverts, and a second narrower black band across the cheek; remaining portions of the sides of the head white; back and sides of the neck dull rufous, slightly mottled with white and blackish; fore-neck and sides of the body pale rufous-brown, spotted and streaked with black; rest of the underparts pure white, with a few brown mottlings; under wing-coverts and axillaries white, irregularly barred with brown.

Iris dark brown; bill black at the tip, greenish towards the base, legs and toes pale olive-green.

Total length $7 \cdot 5$ inches; bill from the feathers on the forehead to the tip 1.6 inch; wing 4.3 inches; tail 1.8 inch; tarsus 0.8 inch.

Adult female.-Similar to the male in plumage, but slightly smaller. 


\section{THE GUN AT HOME AND ABROAD}

Young in down.-According to Seebohm, closely resembles that of the common snipe. I have never examined a specimen.

Variations in colour.-Abnormally coloured examples of the jack snipe are very uncommon, but a melanism comparable to the dark form of the common species known as Sabine's snipe has been met with.

General distribution.-In summer the range of the jack snipe extends irregularly across Northern Europe and Asia from the Atlantic to the Pacific Oceans, and it is most numerous to the north of the Arctic Circle. It breeds on the Dovrefjeld, above the limits of forest growth, and on the tundras of Lapland and Western Russia, as far south as St Petersburg. To the east of Archangel it appears to be uncommon, and Seebohm did not find it nesting either on the Petchora or on the Yenesei.

Eastwards, however, it breeds as far north as $70^{\circ} \mathrm{N}$. lat., south of the Taimyr Peninsula, and probabiy also in north-eastern Siberia. South of about $60^{\circ} \mathrm{N}$. lat. it must be regarded as a migrant, and in autumn visits the Mediterranean and Africa north of the Sahara, from Morocco to Egypt, as well as Persia, Afghanistan, India, Ceylon and Burma. It has also occurred frequently during the cold season in Japan, and has been obtained once in Formosa in the month of December.

The jack snipe has no very close ally, and though in general outward appearance it resembles the true snipe, it possesses a number of peculiar structural characters which seem fully to entitle it to generic distinction. These are internally the peculiar structure of the syrinx, described below; the presence of four notches in the posterior margin of the sternum; and externally, the structure of the tail, which is composed of twelve pointed feathers, nearly uniform in colour, and the purple and green gloss on the feathers of the back and shoulders.

At a meeting of the British Ornithologists' Club, held on February 14, 1912, Mr W. P. Pycraft gave a brief description of the syrinx of the jack snipe, comparing it with that of the common snipe and the woodcock.

He showed that the syrinx of the jack snipe (fig. 1, p. 279) differed not only from that of its immediate allies, but from all other members of the plover-tribe hitherto described. As in the snipe and woodcock, the syringeal chamber was formed by a fusion of the four hindmost tracheal rings, though in the jack snipe the lower ends of the rings remained more or less cartilaginous, forming a subcrescentic plate of cartilage in the middle line of the ventral aspect of the chamber. Closely attached by fibrous tissue to the hinder korder of the syringeal chamber was a semi-ring, which 278 


\section{JAGK SNIPE}

seemed to have been derived from the tracheal, not the bronchial series of rings, and which, so far as Mr Pycraft could make out, was met with in no other bird. He said that in the accompanying figure this semi-ring, for the sake of clearness, had been made to appear as if widely separated from the syrinx (fig. 1, S.-f.s.r.). The lower third of this peculiar semiring was cartilaginous, and was attached by a bundle of short fibrous threads to a lingulate plate of cartilage, which in turn was attached to the inferior end of the first bronchial ring (fig. 1, B.r.I.). What part this peculiar semi-ring and its accessory lingulate cartilage played in the production of the remarkable sounds which the jack snipe was known to produce, was a matter for further discovery. The identity of the first bronchial ring was established by the insertion of the intrinsic muscle, which was of the normal type.

If the syrinx of the common snipe (fig. 2) were contrasted with that of the jack snipe on the one hand and that of the woodcock (fig. 3 ) on the other, it would be found to hold an intermediate position between the two, in so far as the expansion of the syringeal chamber was concerned; but the hindmost of the fused rings was wider than in either of the contrasted forms, and was produced further backwards, giving a more pronounced $V$-shape to this end of the trachea. The intercalary syringeal semi-ring (fig. 1, S.-f.s.r.) and its accessory plate of cartilage were wanting.

Fig. 1.

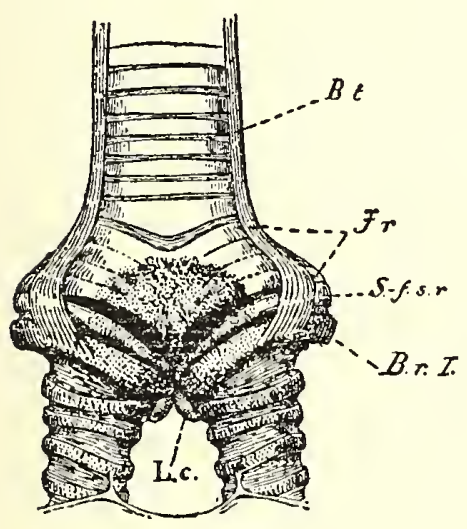

Syrinx of Jack Snipe (Limnocryptes gallinula).
Fig. 2.

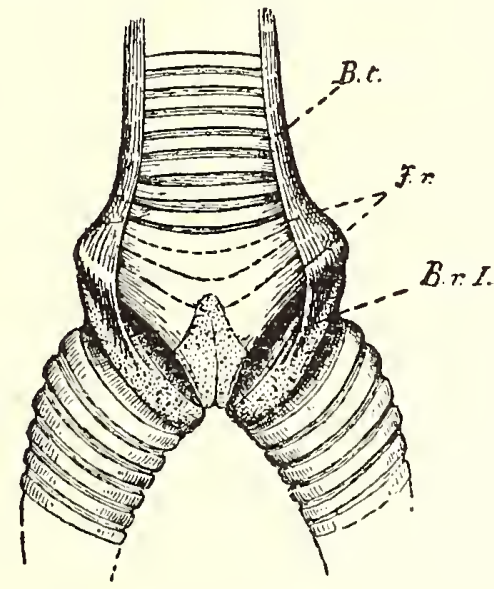

Syrinx of Common Snipe (Gallinago gallinago).
Fig. 3.

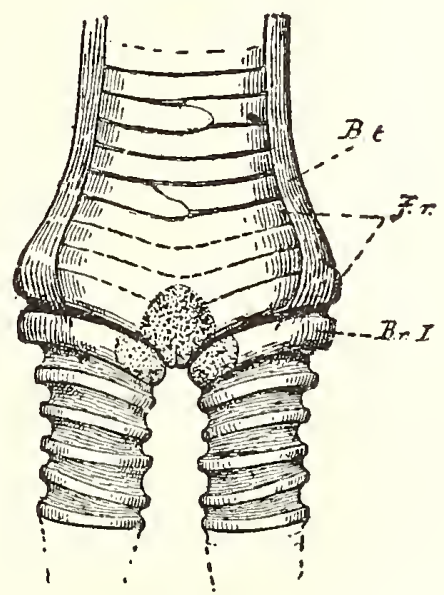

Syrinx of Woodcock (Scolopax rusticulo).

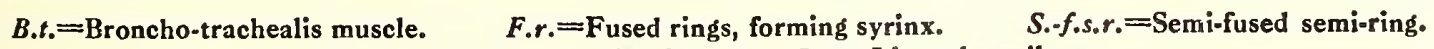
B.r.I. $=$ First bronchial ring. $\quad$ L.c. $=$ Lingual cartilage. 
In the woodcock the syringeal box was less expanded than in the jack and common snipes, but it was similarly composed of four fused rings. The most striking feature of this syrinx was the degenerate condition of the intrinsic muscles (fig. 3, B.t.), which appeared to terminate on the hinder border of the syrinx. As a matter of fact, however, a number of fine tendinous fibres would be found to run to the normal point of insertion in the middle of the first bronchial semi-ring.

Dr P. H. Bahr, who was present at the meeting, made the following remarks : "The interesting discoveries of Mr Pycraft have added another to the list of specialized structures for which the Scolopacina are remarkable. To my mind, the fact that the syrinx of the jack snipe is provided with an intercalary bar of cartilage, as Mr Pycraft has already pointed out, explains a great deal.

"During the course of a number of experiments which I published in 1907, I experimented with both the primary wing-feathers and the rectrices of the jack snipe, but was not able to produce any characteristic sound with either of them. Wolley has stated, and the accuracy of his statements are proverbial, that in Lapland this snipe while soaring, at a great height over its breeding-grounds, makes a sound comparable to that of a horse galloping over a hard road. We have now, in view of Mr Pycraft's interesting discovery, some reason to believe that the origin of this sound is vocal."

Distribution in the British Isles.-In this country the jack snipe makes its appearance between the middle of September and the middle of October, and departs towards the end of March or the beginning of April; to the east, in India, it arrives in certain localities as early as the end of August, and remains till April. It should, however, be noted that stragglers occasionally reach this country some weeks before the general migration commences, and that individual birds have been known to remain throughout the summer, although they have never been proved to breed in any part of the United Kingdom. During the colder months of the year it is generally distributed over the same ground as the common snipe and, like that bird, shows a marked preference for certain localities; but is generally much less numerous, and though on occasions many more jacks than full snipe may be killed in a day, such instances are quite exceptional, and as a rule the latter outnumber the former, by about twenty to one.

Food.-In the matter of food the jack snipe is partly a vegetarian. 280 


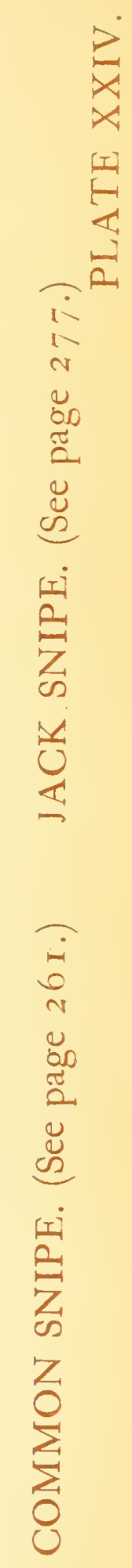




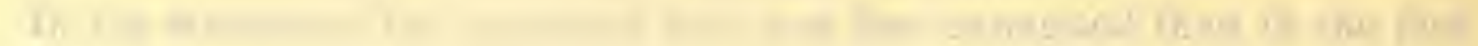
maty I 1,

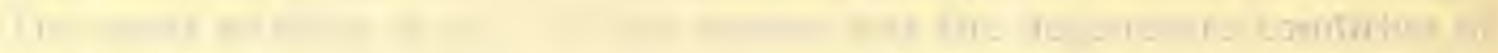

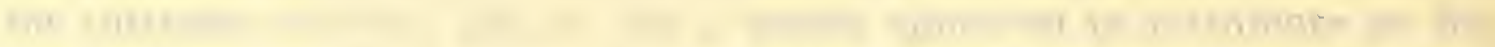

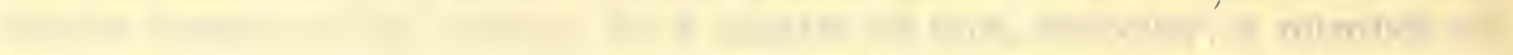
W. 25. han

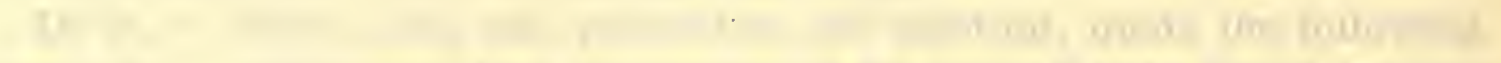

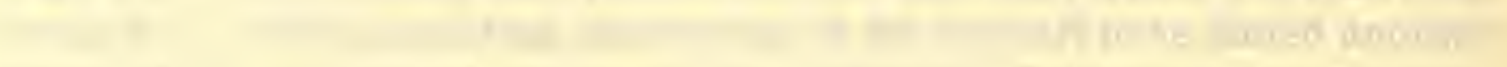

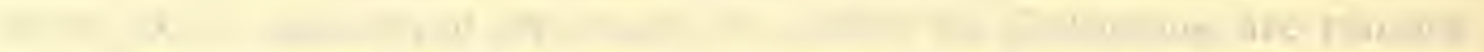

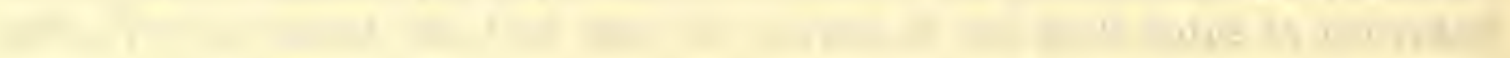

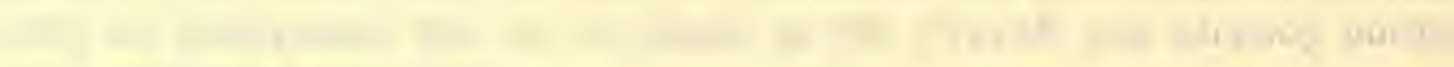

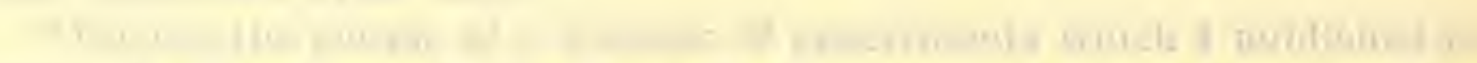

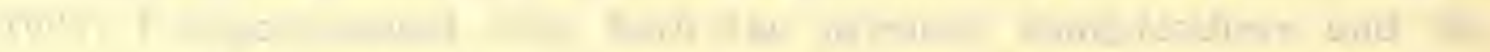

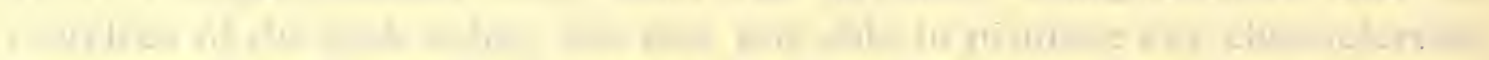

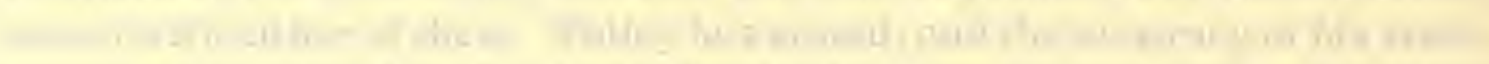

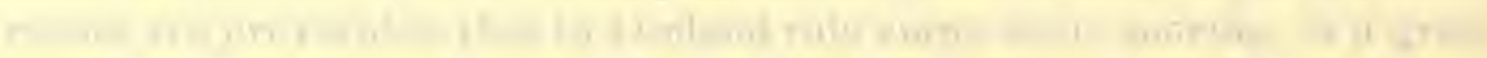

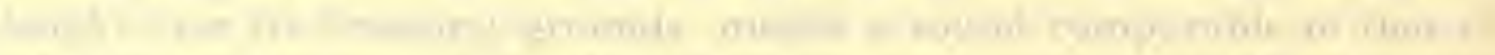

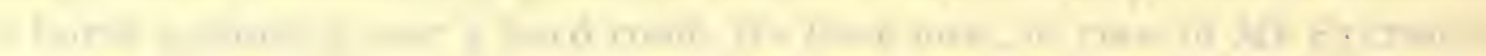

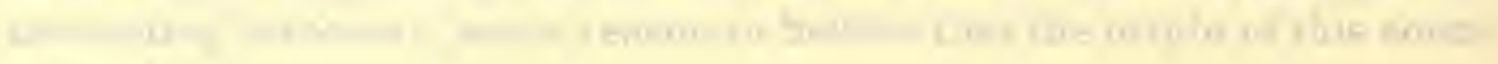

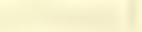




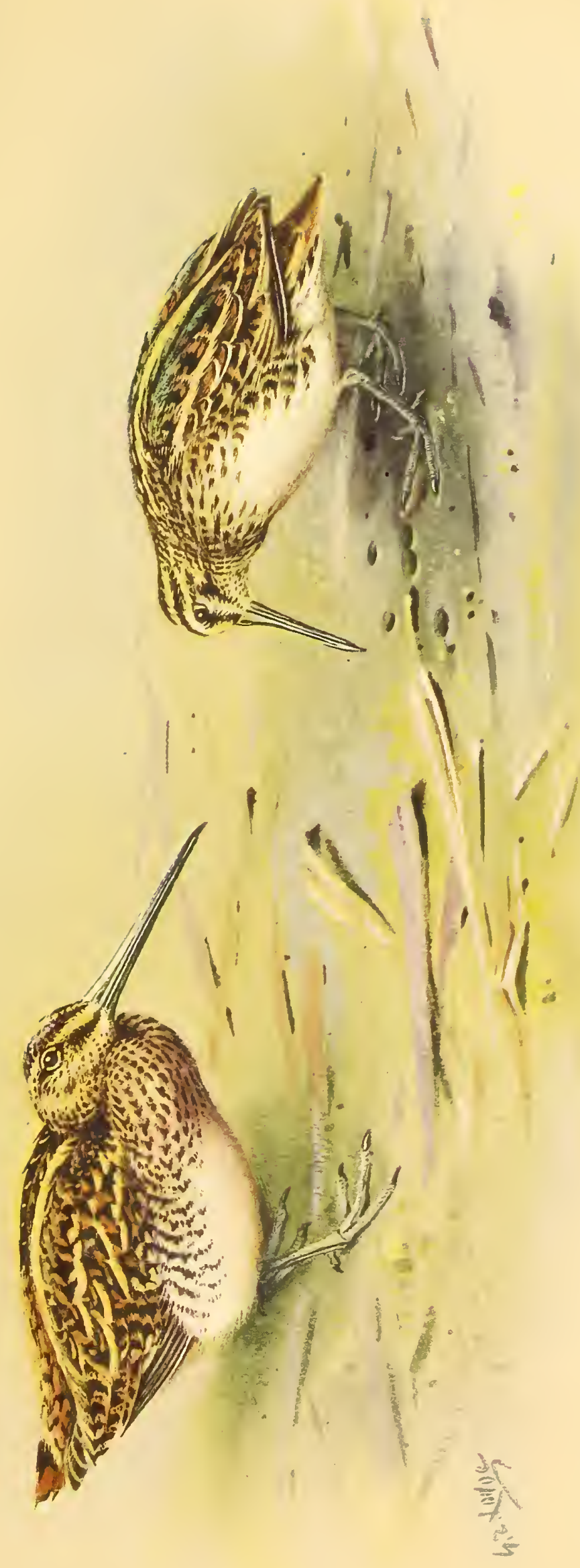




\section{JAGK SNIPE}

While eating worms, grubs, and small molluses like its larger ally, and occasionally minute insects, it normally adds a certain amount of vegetable matter to its diet. In times of stress, when the ground is frost-bound and the supply of animal-food is much reduced, it subsists almost entirely on grasses, moss, seeds, and other herbage, and is able to maintain its ordinary plump condition, when the full snipe is reduced almost to a skeleton. The average weight is about two ounces; but individuals vary from little more than one ounce to two and a half ounces.

Flight.-The leisurely and comparatively feeble flight of the jack snipe when flushed would scarcely lead one to suppose that it is capable of long and protracted migrations; but that this is so is proved by its annual spring- and autumn-movements. When disturbed, it flits slowly and silently away for about a hundred yards or less, sometimes twisting when it starts, and then drops suddenly to the ground as if shot. It never makes a long flight, and appears to have very little fear of man, for it often allows itself to be almost trodden on before it will rise. It is an extraordinarily phlegmatic bird during the day time, and is always difficult to flush a second time.

Breeding habits.-In the nesting-season the jack snipe entirely changes its usual sluggish habits, and may then be seen gliding at a wild pace and at a great elevation over the marshes of Lapland and Finland. Wolley, who in June, 1853, was the first to obtain trustworthy information as to its nesting-habits, says that during its aerial evolutions it produces an extraordinary sound, which he likens to the noise made by a horse canter ing in the distance over a hard, hollow road; it comes, he says, in fours, with a similar cadence, and is a clear, yet hollow, sound. It has been proved that the outer tail-feathers of the jack snipe are not specially developed to form musical instruments, like those of the common snipe, and are incapable of producing any sound; there can therefore be very little doubt that the cantering sound described by Wolley issues from the bird's throat, and is directly connected with the peculiar structure of the syrinx already explained. Wolley found the birds so tame on the nest that one allowed him to touch it with his hand before rising, and another only got up when he was within six inches of it.

Nest.-The nests found by Wolley in the great marsh of Muonioniska, in Lapland, were all alike in structure, loosely made of little pieces of grass and equisetum not woven together, with a few old leaves of the dwarf birch. They were placed in a dry sedgy or grassy spot close to more open swamp. 


\section{THE GUN AT HOME AND ABROAD}

Eggs. - The eggs are very large for the size of the bird, and resemble those of the common snipe so closely that it is difficult to give any character by which they may with certainty be distinguished. They are however, slightly smaller, and average about 1.55 in. in length by $1.09 \mathrm{in.}$ in breadth.

General habits.-The jack snipe is even more solitary in its habits than its larger ally, and never gathers in "wisps" like that bird, for though a number may be found occupying some specially attractive spot, each seems to lead an entirely independent existence. It is seldom wild and unapproachable ; on the contrary, it usually lies so closely that, without a good dog, many are walked over. So loth is the jack snipe to rise, that when a dog is pointing, it may sometimes be caught in a landing net, or even with the hand, and a marked down bird is so averse to rise a second time that it will almost allow itself to be walked on. As already remarked, when flushed during the day time its flight is usually short and much feebler than that of the common snipe, and its curious habit of dropping suddenly to the ground as if shot often raises false hopes in the breast of the unsophisticated sportsman. It seems to have little instinctive fear of man; and though so sluggish in its movements during the day, is active enough at night. Its leisurely flight is executed in silence, and it seldom, if ever, utters any sound as it rises noiselessly and flits away. In Upper India we are told that the jack snipe sometimes outnumbers the other snipes, but, as in the west, it is seldom that any considerable number of these birds can be bagged in the course of a day's shooting, and Oates says that in Upper Burma, where it is fairly common, half a dozen may occasionally be killed in a day.

W. R. OGILVIE-GRANT. 


\section{SNIPE SHOOTING}

NIPE are justly regarded as true denizens of the wild, for like the wind they come and go whither they list-the antithesis of hand-reared game-birds. And yet no one with an intimate knowledge of life in the country does not know at least one spot where a snipe may constantly be found in close proximity to human habitations. I am writing in a city of more than $\mathbf{8 0 , 0 0 0}$ inhabitants, and yet within two gun-shots from my window is a small pond daily in the winter time frequented by snipe. Being never shot at, they get very tame, and it is most interesting to watch all their little ways, with the help of a pair of field-glasses.

A notable instance of tameness took place last summer at Howsham Hall, in Yorkshire, the romantic residence of Major and Mrs Raitt, when on going into the kitchen garden one day, a brood of young snipe were seen waddling with unduly long legs along the gravel walk, having been just hatched in the asparagus bed! As the garden is surrounded by exceptionally high walls, and was daily visited by dogs and cats, it seems strange that it should have been selected as a nesting-site, and still more wonderful that the eggs should have been successfully hatched.

Lucky is the owner who has several snipe haunts on his estate, if he is fond of shooting, for he need not lay his gun aside until March, when the close time for pheasants and partridges is ushered in on February 1. Yet how often an "improving" landlord or agent will spend money in draining some miry spot beloved of snipe, trying to convert it into indifferent farming land, and spoiling his sport at the same time! He is quite oblivious, too, that snipe shooting is a valuable asset, which will oft-times induce a hesitating tenant to hire a shooting, which would otherwise be rejected. There are sure to be plenty of miry places which snipe never frequent, and on which the owner can spend his money in draining if so inclined. The writer has known a case where an owner borrowed. money at 5 per cent to drain an extensive and excellent snipe marsh, and as the cost came to $£ 80$ per acre, the estate was saddled with a debt of $£ 4$ an acre for interest in perpetuity. To meet this amount the land was let at first at $£ 1$ per acre! But this was soon reduced to $15 \mathrm{~s}$., and now there has been again a further reduction, while the snipe shooting, of course, has disappeared. Verb. sap.!

Snipe breed commonly in these Isles, but migrate from where they are bred towards the end of September, and at the beginning of October 
they may often be found in turnip and potato fields if the weather is wet. After the middle of October foreign snipe begin to appear on our shores, the bulk of them reaching their haunts during the last week in October and the first week in November, after which a few continue to arrive throughout the month. By the system of attaching a marked and registered ring to young snipe, which has been done with success to young woodcock during recent years, much information is likely to be gained as to the lines of their migration. Even when arrived at their favourite haunts they are very uncertain in their movements, here to-day and gone to-morrow, and much affected in their choice of feeding ground by the age of the moon, especially in the vicinity of moors and bogs. After a light night, too, they lie better the next day, having been able to feed to repletion, but after a dark night, when they have been restricted in finding food, they are busy feeding during the early part of the following day, and are much more likely to be restless, and observe from afar the approach of the shooter.

In every locality there are certain spots where there is invariably a snipe to be found, frequently within a yard or two of the same tuft of rushes, and as often as the occupant is shot another takes its place, in a similar manner as trout take up favourite haunts in a stream directly they become vacant. Such places should always be visited, and anyone knowing the locality well can often save both time and trouble by going from one favourite spot to another.

During hard frosts they frequent tidal estuaries, and sometimes congregate there in immense numbers. On January 26, 1907, the writer when travelling by train in the midst of a very hard frost, had the fortune to observe such a gathering of snipe alongside the Humber, and thus recorded the circumstance in his diary.

"The tide was at its highest, and quantities of snipe were seen feeding close by the train. They kept rising into the air, a dozen at a time, as each wavelet reached them, and then alighting again ran along, prodding their bills into the mud of the estuary, until the next wavelet arrived. The constant rising, almost like a flock of starlings when feeding, was curious to watch, whilst many waded in the water where it was shallow, feeding all the time. There must have been hundreds of snipe, for they appeared in equally great numbers for fully a mile. Then not one was to be seen, so there must needs have been some peculiar food at that particular place, which had tempted them to collect in such crowds."

284 


\section{SNIPE SHOOTING}

It is not unlikely these birds had come from the contiguous warp-lands which were then mostly frozen, and which attract large numbers of snipe throughout the winter.*

It is remarkable how the colour-scheme of the back of a snipe assimilates with the surroundings of withered grass and rushes, and how difficult even a dead bird is to see when it lies back uppermost. The buff markings and dark streaks so coincide with the colour of the stalks and dark shadows, that even practised eyes may be some time in noticing the little form, lying prostrate and fully exposed, without any artifice of concealment; whilst a live bird, squatting close in some little hollow in the ground, is seldom seen unless the point of the bill attracts the eye.

Like the woodcock, snipe possess the little pin-feather at the extremity of each wing, but whilst those of the former used to be in great request by water-colour painters, when a very fine and thin line was needed in a picture, those of the snipe were seldom requisitioned, either because they were deemed too small to be of use, or because their existence was unrecognized. For miniature painting they appear to be eminently suitable.

When in pursuit of snipe over a large extent of bog or mountain, but little sport will be obtained without the aid of a setter which is staunch on snipe, and keen as well. Though these birds have a very strong scent it is distasteful to most dogs, and many will not acknowledge it at all, while few will eat the flesh of either snipe or woodcock. But some setters love to hunt for snipe, and are invaluable to anyone who is fond of snipe shooting, and has to seek them over a large area. When snipe lie well numbers of birds will be passed over, which would be found by a good dog; and on the other hand when snipe are wild, oft-times one will lie to the point of a dog ranging rather far ahead, and then, crouching low down, will not observe the approach of the shooter, but would have risen far out of shot if its attention had not been concentrated upon the dog. Setters are usually better suited for this work than pointers, for they are generally hardier, and can stand the wet, with more impunity from rheumatic ailments. The Irish red setter has deservedly a great reputation, but other breeds of setters are often as good, and some of the best the writer has used have been black-and-tan Gordon setters.

The surest way of inducing a dog to be keen after snipe is to take him as a puppy, at the very beginning, to likely places for finding a snipe,

* This observation is entirely at variance with what has been observed by others; snipe being very rarely found on tidal mud-flats, and then only singly or in twos and threes; certainly not in such numbers as here indicated. It is more likely that the birds referred to were sandpipers of some kind.-Ed. 


\section{THE GUN AT HOME AND ABROAD}

and allow him to find a few if possible before he sees any other kind of game. Dogs are generally most keen after the kind of winged game at which they were first entered and encouraged to hunt for, and they will remember this all their lives. This distaste for snipe is shared also by many retrievers, and the usefulness and value of an otherwise good dog is frequently lessened by its absolute refusal to pick up a snipe when it has fallen into a thick tangle of rushes, with just enough vigour left to hide itself from view.

Though many a snipe is shot during grouse-driving, it is only on very few estates where driving snipe is regularly practised, the chief reason being that they are not easy to drive except under especially favourable circumstances. Occasionally some favourite haunt is so placed that the occupants can be driven over a high hedge or other convenient place of concealment for the guns; or the latter may be posted between two favourite bogs in the line of flight which is usually followed; or again on a bog, which lends itself to the purpose, butts or hiding places may be arranged, somewhere in the centre. Luck must always be a considerable element in the matter of success, but good management is also very important. The judicious placing of flankers is generally very necessary, and these should be posted well away (where the snipe cannot fail to observe them before they are flushed), and with flags to wave continually when the birds are on the wing. It should be remembered that snipe do not usually fly so high, or take such long flights, on a perfectly calm day as they do when it is rough, and therefore if it is quite possible to select your own time, a quiet day should be your choice. In boisterous weather snipe are very apt to soar high at once and fly away out of ken. The drivers should go slowly and search every likely spot, for frequently snipe lie so closely they may be easily passed by; and it is well for the men to be accompanied by a steady old setter or retriever used to snipe, who will not miss a bird if allowed to hunt within close range, and especially will put up any close-lying jack snipe.

Driven snipe are not difficult to kill after they have flown a short distance, for they soon give up the zigzag flight, so puzzling to many a man when walking them up, good as he may be at other game. The drivers should not be further apart than twenty yards or so if the covert is good; and a little talking is advantageous rather than otherwise, for birds which get up at a distance are very likely to go forward, while those not flushed till the line has reached them are quite likely to break back. 


\section{SNIPE SHOOTING}

When walking up snipe it is usually recommended they should be approached down-wind if possible, yet experience teaches it is a more deadly plan to proceed across the wind, for then the zigzag course, so baffling when a snipe first commences its flight, ceases to offer any difficulty. Going down-wind answers well on a day when snipe rise a little into the air and hang for a moment, showing the white underparts of the plumage, and if that moment can be seized, the mark offered is quite an easy one. But sometimes the snipe dart off in a different fashion, and, commencing at once to twist, require a skilful shot to bring them down. Very apt are they to essay this trick when thoroughly alarmed after watching the approach of the shooter, and a frightened snipe, flinging itself downhill, with a wind behind it, is one of the most difficult shots any game-bird can present. If approached up-wind snipe are apt to fly so low they only just skim over the ground, and when flying thus over withered grass and rushes they are difficult to see clearly enough to bring the gun to bear upon them, for their zigzag course is apt to be displayed at the same time in their best and most tortuous manner. It is when meeting the wind that they can employ their long wings to the best advantage. The twisting flight does not, however, last very long, and the bird soon settles down to a more uniform course, so that on days when snipe are lying well, getting up close to the shooter, and flying at a moderate speed, it often happens that by waiting a second or two before firing, a snipe has ceased its erratic flight and then affords a steady and easy shot.

There is a knack in shooting snipe, and plenty of practice will usually develop it. As the bird soon commences to rise, often imperceptibly, it is necessary to aim well above it, when flying away from the shooter. The size of shot generally considered the most suitable for snipe shooting is No. 8; the gun must be a light one; and the wrists and forearm should be supple and elastic, for no one with stiff, wooden wrists can follow the twisting of a snipe, or ever become a notable snipe-shot.

The little jack snipe is a winter visitor to our shores, and has never been proved to breed in this country. Its tameness is remarkable, for it usually lies till it is almost trodden upon, and even after being fired at will pitch again almost within shot. Sometimes, however, it may be termed actually wild! It is easily recognized by having a smaller bill in proportion to its size than the ordinary snipe; and by the central stripe on the top of the head being dark, with light-coloured ones out- 


\section{THE GUN AT HOME AND ABROAD}

side it, whereas with the ordinary snipe these markings are exactly reversed. The tail has but twelve feathers instead of fourteen as in the common snipe; and when it is flushed it rises silently, without the peculiar cry of "scape" with which the full snipe heralds its flight. Its weight averages but two ounces, or half the weight of its larger relative.

The great, or solitary snipe, is an annual visitor in early autumn, and as becomes its extra size, it flaunts two more feathers in its tail, that is, sixteen. It is curious that the number of tail-feathers should increase in regular gradation from the little jack snipe up to the great snipe!

A handsome specimen of the great snipe was shot by Mr Wilfrid Stanyforth on September 16, 1911, at Stangfoot, Arkengarthdale, Yorkshire, which is the first that has been recorded in that county for several years.* It has been well set up by Allen, of York, the peculiar markings on the wing coverts, the barred underparts, and the white outside tailfeathers being conspicuously displayed, which, once seen, will enable anyone to distinguish this species at a glance.

\section{R. F. MEYSEY-THOMPSON.}

\footnotetext{
- The communicated and recorded occurrences of the great snipe in Yorkshire number upwards of sixty, and are too numerous to mention in detail. Mr. T. H. Nelson, in his Birds of Yorkshire, 1907, states (vol. ii, p. 602) that eighteen have been shot in the North Riding, seventeen in the East Riding, and in the West Riding twenty-nine.-Ed.
} 


\section{WILD FOWL}

$O$ give in a single chapter a really complete account of all the swans, geese, ducks and mergansers to be met with in British waters would obviously be an impossible task and quite beyond the scope of the present work. I have therefore only aimed at supplying such information as may be of interest to sportsmen and to those who are desirous of identifying the members of the duck-tribe which they are likely to meet with in a wild state. Descriptions of the plumage of the adult male and female of each species are given in detail, likewise their general distribution abroad and in the British Isles, together with some particulars as to their nidification, food and general habits. As a further aid to identification I have drawn up a general key to all the species on the British list, which, as far as I am aware, has never before been attempted. The characters employed have been carefully selected, and it is hoped that any person making use of the key will be able to name examples of any species, either male or female, without much trouble or difficulty.

To those who have never tried to use a key it may at first sight appear a very involved and complicated affair, but if properly constructed it should be easily read, and should prove most valuable in facilitating identification. Several of my friends with no special knowledge of ducks have been kind enough to test the present key, selecting the more obscure looking females of the sea-ducks, which are generally considered the least easy to name. As in every instance they were successful in correctly determining the species it is hoped that others will find this part of the work equally useful.

In using a key it is all-important to pay attention to the lettering in front of the various headings, and to remember that if the characters given in " $A$ " do not fit the specimen to be named those under " $B$ " or " $C$ " must be tried.

Let us suppose that a grey lag-goose has been shot, and that it is desired to name it quickly with as little trouble as possible. With the bird on the table before one, one takes the key and reads the first general heading "I," which does not agree, while the characters given under "II " do so perfectly. Following on, one finds the character of the hind toe given in " $C$ " also agrees, likewise those given under " $c$," " $a^{1} "$ " $a^{2}$," and " $a$," but not under " $a^{4} "$; so one tries " $b^{4}$," which again agrees, and thus easily arrives at the fact that the bird is a grey lag-goose. 


\section{STRUCTURAL CHARACTERS OF GEESE AND DUCKS USED IN THE KEY TO THE SPECIES.}

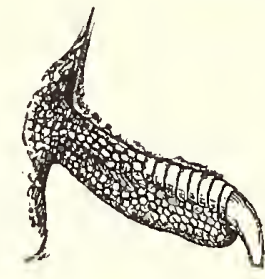

Fig. 1.

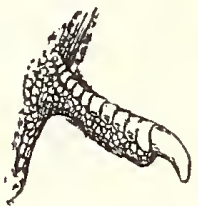

Fig. 2.

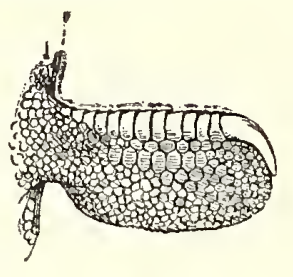

Fig. 3.

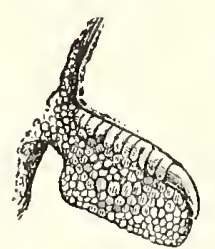

Fig. 4.

Figs. 1 and 2. Hind toe narrowly lobed.-1, Grey Lag-Goose; 2, Mallard.

Figs. 3 and 4. Hind toe widely lobed.-3, Common Scoter; 4, Goosander.

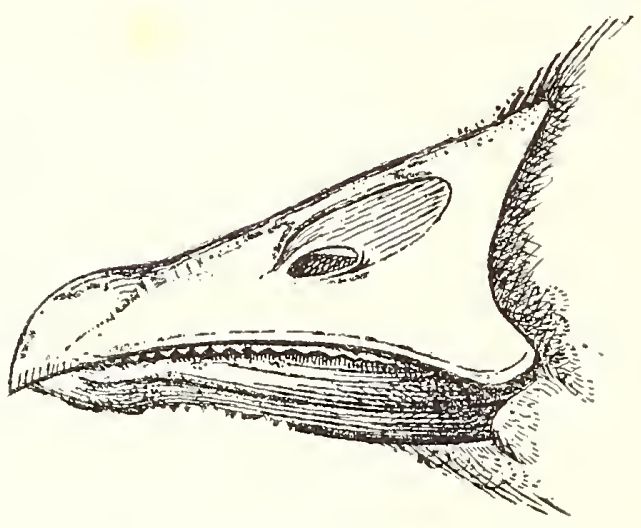

Fig. 5.

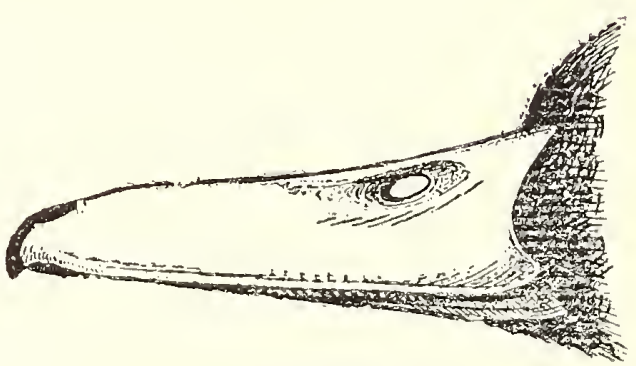

Fig. 6.

Fig. 5. Bill of Grey Lag-Goose : the depth at the base more than half the total length.

Fig. 6. Bill of Mallard: the depth at the base less than half the total length.

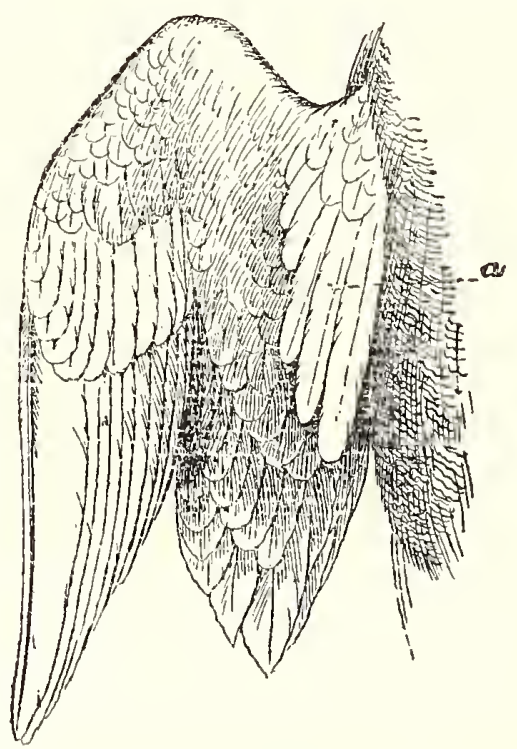

Fig. 7. Wing of Duck, showing (a) Axillary plumes, 


\section{WILD FOWL}

\section{KEY TO THE SPEGIES OF SWANS, GEESE, DUGKS AND MERGANSERS TO BE MET WITH IN THE BRITISH ISLES.*}

I. Neck very long, as long or even longer than the body; entire plumage white; size very large; wing over 20 inches . . .

$A$. No knob at the base of the bill.

$a$. Black on the apical portion of the bill does not extend nearly to the forehead and on the sides reaches only half way to the gape: larger; bill $4 \cdot 2$ inches; wing $25^{\circ} 0$ inches. Female smaller

b. Black on the apical portion of the bill extends towards the forehead and backwards to the gape: smaller; bill $3 \cdot 8$ inches; wing 21.0 inches. Female smaller . . . . . . . . .

$B$. A prominent knob at the base of the bill; bill $4 \cdot 2$ inches; wing $27 \cdot 0$ inches. Female smaller; knob less developed.

II. Neck moderate, much shorter than the body, entire plumage

Swans: Cygnus

Whooper:

Cygnus cygnus, p. 302.

Bewick's Swan:

C. bewicki, p. 303 .

Mute Swan: C. olor, p. 305 . never white, the primary quills at least being always black; wing less than 20 inches.

C. Hind toe narrowly lobed. (See Figs. 1 and 2.)

c. Size larger, wing 13 to 19 inches; bill rather short and thick, the depth at the base being more than half the total length. (See Fig. 5.)

$a^{1}$. Teeth in the upper mandible conspicuous when the bill is closed and viewed from the side; feet pink or orange. $a^{2}$. Plumage of the body not white; mostly grey and brown sometimes mixed with black . . . . . $a^{3}$. No white on the forehead, or only a very narrow line at the base of the bill.

$a^{4}$. Head brown.

$a^{5}$. Bill about $2 \cdot 5$ inches in length, with the nail and basal part black, and the middle portion orange; feet orange; size larger; wing $19 \cdot 0$ inches. Female smaller . .

$b^{5}$. Bill about 1.9 inch in length, with the

Bean-Goose:

A. fabalis, p. 312 . nail and basal part black, and the middle portion pink; feet pink; size smaller; wing $17 \cdot 0$ inches. Female smaller . . Pink-footed Goose :

$b^{4}$. Head brownish-grey; bill about $2 \cdot 4$ inches A. brachyrhynchus, p. 314 . in length, with the nail white and the remaining portion flesh-colour or orange; legs pink; wing 17.5 inches. Female smaller. .

$b^{3}$. Forehead conspicuously white.

Grey Geese: Anser

Grey Lag-Goose:

A. anser, p. 307.

$c^{4}$. Larger; bill about $2 \cdot 0$ inches in length ; wing 15.5 inches. Female smaller . . White-fronted Goose:

A. albifrons, $p .309$.

* N.B. - The length of the bill is always measured from the feathering on the forehead to the tip. The length of the wing is measured from the bend to the tip of the longest flight-feather. 
THE GUN AT HOME AND ABROAD

$d^{4}$. Smaller; bill about 1.3 inch in length;

wing 14.5 inches. Female smaller . . . Lesser White-fronted

Goose: A. finmarchicus, p. 311.

$b^{2}$. Plumage of the body white, primary flight-feathers

black . . . . . . . . . . . . Snow-Geese : Chen

$c^{3}$. Smaller; bill 1.95 to $2 \cdot 3$ inches in length . . Snow-Goose:

C. hyperboreus 0 and 9 , p. 315 .

$b^{1}$. Teeth in the upper mandible not visible when the bill

is closed and viewed from the side; feet always black. Brent Geese : Branta

$c^{2}$. Chest black or grey.

$e^{3}$. Chest grey; head and neck black; throat white, extending upwards on the cheek to behind the

ear-coverts . . . . . . . . Canada Goose :

B. canadensis o and $\uparrow, p .322$.

$f^{3}$. Chest black.

$e^{4}$. Head and neck black, with an irregular white patch on each side of the neck.

$c^{5}$. Underparts greyish.white (light form)

$d^{5}$. Underparts dark grey or brownish (dark form)

Brent Goose:

$f^{4}$. Head white, hinder part of the crown and neck black; belly pure white . . . . .

$d^{2}$. Chest deep chestnut; head black and white with a large chestnut patch on either side, behind the eye . . . . . . . . . . . . . . . .

$d$. Size smaller; wing 7 to 11 inches ( 12 to 14 inches in the Sheld. Ducks); bill long, and depressed towards the tip, the depth at the base being half, or less than half the total length. (See Fig. 6.)

$c^{1}$. Wing more than 8.0 inches in length.

$e^{2}$. Under tail-coverts $u n$ iform chestnut, buff or whitishbuff, never spotted with black . . . . . . . $g^{3}$. Plumage of the body reddish-chestnut; size larger; wing $14 \cdot 0$ inches.

$\mathrm{g}^{4}$. A narrow black collar round the neck from about March to November.

$h^{4}$. No black collar round the neck . . . .

$h^{3}$. Plumage of the body white, chestnut and black; size smaller; wing 12 to 13 inches.

$i^{4}$. A knob at the base of the bill

$j^{4}$. No pronounced knob at the base of the bill

Sheld-Ducks : Tadorna

Ruddy Sheld-Duck:

T. casarca ठ , p. 325.

Ruddy Sheld-Duck :

T. casarca,+ . 325 .

Sheld-Duck :

T. tadorna ठ , p. 324.

Sheld-Duck:

T. tadorna \&, p. 324. 


\section{WILD FOWL}

$f^{2}$. Under tail-coverts black, or whitish spotted with black or brown.

$i^{3}$. Bill conspicuously spatulate, being nearly twice as wide towards the tip, as it is at the base, sides of the upper mandible provided with long comblike lamellæ . . . . . . . . . . . .

$k^{4}$. Under tail-coverts black; wing-coverts slate-blue ; lower breast and belly chestnut

$l^{4}$. Under tail-coverts whitish, spotted with brownish-black; general colour above blackish, edged with brownish-buff, below buff, mottled with blackish . . . . .

$j^{3}$. Bill about the same width at the tip as it is at the base.

$m^{4}$. Under tail-coverts black. (Males.)

$e^{5}$. Rump black.

$a^{6}$. Head and neck metallic green; lesserand median wing-coverts pale greyish - brown; wing - speculum purplish-blue, margined above and below with black and white . .

$b^{6}$. Head and neck whitish-buff, finely spotted with black; lesser and median wing-coverts largely chestnut, forming a conspicuous patch; wingspeculum black and white . . .

$f^{j}$. Rump finely vermiculated with black and white.

$c^{6}$. Bill $2 \cdot 0$ inches; lesser and median wing-coverts brownish-grey; wingspeculum dull purplish-bronze edged with pale rufous above and with black and white below . .

$d^{6}$. Bill about 1.5 inch; lesser and median wing-coverts mostly white; wing - speculum dark green, bordered above and below with black. $a^{7}$. Head and neck chestnut, forepart of the crown buff . . Wigeon:

Mareca penelope ð, p. 335.

$b^{\prime}$. Head and neck whitish-buff, conspicuously dotted with black on the sides; entire crown uniform whitish-buff, surrounded posteriorly by a wide green band commencing behind the eye.
Shovelers: Spatula

Shoveler: S. clypeata ठ, p. 327 .

Shoveler: S. clypeata $\&$, p. 327 .

Mallard: Anas boscas ठै, p. 329 .

Gadwall : Chaulelasmus streperus $\sigma^{t}, p .331$.

Pintail : Dafila acuta ${ }^{\star}$, p.333.

M. americana $\delta, p .337$.

293
American Wigeon: 


\section{THE GUN AT HOME AND ABROAD}

\section{$n^{4}$. Under tail-coverts white, spotted with}

black or brown (Females.)

$g^{5}$. Bill $1{ }^{\circ} 6$ to $2 \cdot 1$ inches; breast white, spotted or mottled with brownish.

$e^{6}$. Under wing-coverts and axillaries

(See Fig. 7) pure white.

$c^{7}$. Bill 2'1 inches; wing-speculum deep purplish-blue bordered above and below with black and white . . . . .

$d^{\prime}$. Bill $1^{\circ} 6$ inch; wing-speculum black and white
Mallard: Anas boscas $q$ p. 329 .

Gadwall: Chaulelasmus streperus $\&, p .331$.

$f^{6}$. Under wing-coverts and axillaries mottled with brown and white; bill 2.0 inches; wing-speculum brownish-black mottled with rufous or brown and edged with white

$h^{5}$. Bill 1.5 inch or less; breast and belly pure white.

$g^{6}$. Ground colour of head and neck rufous; axillaries mottled with white and brownish-grey; wingspeculum black, mottled with grey, narrowly margined above and below with white . . . . .

Wiǵcon:
Mareca penelope $\uparrow, ~ \not ึ .335$.

$h^{6}$. Ground-colour of head and neck whitish; axillaries pure white, wing - speculum black, narrowly margined above and below with white . . . . . . . .

$d^{1}$. Wing less than $8^{\circ} 0$ inches in length.

American Wigeon:

M. americana $\uparrow, p .337$.

$g^{2}$. Under tail-coverts black.

$k^{3}$. Head and neck chestnut, with a wide metallic green band behind the eye; lesser and median wing-coverts brownish-grey.

$0^{4}$. Feathers on the sides of the chest narrowly banded with black and white; outer scapulars white, obliquely edged with black .

\section{Common Teal:}

Querquedula crecca ठే, p. 338.

$p^{4}$. Vermiculated feathers on the sides of the chest with a wide subterminal white bar, forming a conspicuous white band above the shoulder; outer scapulars grey, the outermost only edged with black . . 


\section{WILD FOWL}

$l^{3}$. Head and neck dark sooty-grey, crown black; a wide crescent-shaped white band in front of the eye; lesser and median wing-coverts greyish. blue . . . . . . . . . . . . American Blue-winged

$h^{2}$. Under tail-coverts white, spotted with brownish T’eal: Q. discors ðे, p. 341 . or blackish.

$m^{3}$. Sides of the head dull reddish-brown, finely streaked with white; crown and throat black; wide white bands from behind the eyes uniting on the nape . . . . . . . . . . .

$n^{3}$. Sides of the head whitish dotted with brown;

Garganey:

Q. querquedula $\precsim$, p. 343. crown sooty-brown, or brown mottled with black; throat white.

$q^{4}$. Lesser and median wing-coverts brownishgrey.

$i^{5}$. Wing-speculum brilliant deep metallic green and black.

$i^{6}$. Edged internally with white, tinged with rufous . . . . . . .

Common Teal:

Q. crecca $\uparrow, p .338$.

$j^{6}$. Edged internally with rufous . . American Teal:

Q. carolinensis \&, p. 340 .

$j^{5}$. Wing-speculum dark brown, slightly tinged with metallic green, edged above and below with white . . . .

Garganey:

Q. querquedula,+ , 343 .

$r^{4}$. Lesser and median wing-coverts slate-blue American Blue-winged

D. Hind toe widely lobed. (See Figs. 3 and 4.)

Teal: Q. discors $q, p .341$.

$e$. Bill broad and flattened or moderately so, at least 0.4 inch wide at the tip which is not conspicuously hooked; and is never lengthened and cylindrical.

$e^{1}$. Head and neck uniform black, or uniform deep chestnut, or black glossed with purple and green and patterned with white, sometimes also white with grey, brown, or sea-green : the areas of colour being always very sharply defined. (Males.)

$i^{2}$. Plumage black, or almost entirely black, with some white on the head or wings.

$o^{3}$. No white on the secondary-quills; wing about $9 \cdot 0$ inches.

$s^{4}$. Head and neck uniform black like the rest of the plumage; terminal portion of the first primary greatly attenuated . . . . Common Scoter: 


\title{
THE GUN AT HOME AND ABROAD
}

$t^{4}$. Head and neck black with a large white spot between the eyes, and an elongate white patch down the back of the neck; terminal portion of first primary only slightly attenuated . . . . . . . . .

$p^{3}$. Secondary-quills mostly white forming a marked speculum; a small white patch below the eye; wing about $10^{\circ} 5$ inches . . . . . .

$j^{2}$. Plumage not entirely black.

\author{
Surf-Scoter: \\ E. perspicillata ऊ, p. 347
}

$q^{3}$. Head variously patterned with black or purplish-black and white (grey and dull sea-green being also sometimes present).

$u^{4}$. Breast and belly black.

$k^{5}$. No elevated knob at the base of the olive-green bill; crown of the head black, with a whitish band down the posterior half; occiput and nape dull sea-green; cheeks and throat white; sickle-shaped inner secondaries white like the scapulars

\author{
Velvet-Scoter : \\ CE. fusca ${ }^{7}$, p. 348.
}

l. An elevated knob at the base of the orange-coloured bill; top of the head and nape pale grey; cheeks partly sea. green; throat white with a strongly. marked V-shaped black mark; sickleshaped inner secondaries black like the scapulars . . . . . . . .

Common Eider: Soma. teria mollissima $\sigma^{\star}, p .350$.

$v^{4}$. Breast rufous-buff, shading into brownishblack on the belly; head white; chin and throat black; a dull sea-green patch in front of each eye and a similarly coloured band across the occiput, terminating at each end in a black spot; curved inner secondaries and scapulars with the inner web white and the outer metallic purplish-black . . . . . Steller's Eider:

\author{
King-Eider: \\ S. spectabilis ðँ,p. 352.
}

$w^{4}$. Breast and belly dark slate-grey with a dark chestnut patch on either side of the latter; head and neck greyish-black shading into black on the throat; a black band from the base of the bill to the occiput, margined anteriorly with white and posteriorly with chestnut; forepart of the cheeks, rounded ear-spots and a band along each side of the neck pure white 


\section{WILD FOWL}

$x^{4}$. Breast dark sooty-brown; belly white; crown and throat white; forepart of face and cheeks pale brownish-grey; hind part of cheeks and sides of neck deep sooty-brown; middle tail-feathers greatlyelongated; about $9 \cdot 5$ inches . . . . . . . . . . .

$y^{4}$. Breast and belly pure white.

Long-tailed Duck:

Harelda glacialis ð , p. 357.

$m^{5}$. Larger; wing about 8.5 to 9.0 inches.

$k^{6}$. Head and neck metallic greenish. black, with a rounded oval white patch at the base of the bill. . .

$l^{6}$. Head and neck metallic purplish. Clangula clangula ð,, \$. $35 \%$. black, with a large triangular white patch at the base of the bill. .

$n^{5}$. Smaller; wing about 6.5 inches; head

Barrow's Golden-eye :

C. islandica ð,, .361 . and neck bluish-green shading into purple and bronze on the crown, throat and neck; hinder part of the head from behind the eyes and nape, white .

$r^{3}$. Head chestnut.

$z^{4}$. A conspicuous cinnamon-rufous crest; bill red; underparts blackish; back earthybrown; wing 100 inches . . . . . . .

$a^{4}$. No crest; bill not red.

$0^{5}$. Chest blackish; breast, belly and back whitish finely vermiculated with blackish; wing 8.5 inches . . . . .

$\boldsymbol{p}^{5}$. Chest chestnut; breast and belly white; back dark-brown slightly vermiculated with rufous; wing about $7 \cdot 5$ inches.

$s^{3}$. Head black, glossed with green or purplish.

$\beta^{4}$. Chest chestnut; breast and belly white; back dark-brown, tinged with rufous .

$\gamma^{4}$. Chest black; breast and belly white.

$q^{5}$. Back white, rather coarsely vermicu-

lated with black . . . . .

$r^{5}$. Back practically uniform black and glossy.

$m^{6}$. No conspicuous crest of long loose feathers; a chestnut ring at the base of the foreneck . . .

Buffel-headed Duck:

C. albeola ð, p. 362 .

Red-crested Pochard:

Netta rufina ð, p. 364.

Common Pochard:

Nyroca ferina ð, p. 366.

Ferruginous Duck, or White-eyed Pochard:

N. nyroca ठे, p. 368 .

Baer's Pochard:

N. baeri $\precsim, p .370$.

Scaup-Duck:

N. marila $\delta, p .371$.

Ring-necked Duck:

$N$. collaris $\precsim, p .373$. 


\section{THE GUN AT HOME AND ABROAD}

$n^{6}$. A conspicuous crest of long loose feathers (about 2.5 inches in length); no ring at the base of the neck . . . . . . . . . Tufted Duck:

Fuligula fuligula ð,, . 374 .

$f^{1}$. Head and neck brownish-black, dull rusty-red, buff, or some paler shade of colour; if patterned with white markings these are not very sharply defined. (Females.)

$k^{2}$. Axillary plumes dark smoky-brown (in Clangula albeola only the longer axillary-plumes are smoky. brown, the shorter ones being white or partially white; the species may however always be recognized by its small size; wing $60^{\circ}$ inches). (See .Fig. 7.)

$t^{3}$. Breast and belly brown, mottled with white.

$\delta^{4}$. Wing $8^{\circ} 5$ to 9.5 inches; bill 1.5 to 1.75 inch.

$s^{5}$. No white on the secondary-quills; wing 8.5 inches.

$o^{6}$. No rounded swelling on the base of the upper mandible; crown brownish-black; lores and ear. coverts brownish; terminal portion of the first primary much attenuated

$\boldsymbol{p}^{6}$. A rounded swelling on the base of Common Scoter :

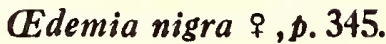
the upper mandible; crown brownish-black; lores and ear-coverts white; terminal portion of the first primary only slightly attenuated .

$t^{5}$. Secondary-quills mostly white; wing $9{ }^{\circ} 5$ inches; crown brown like the neck; lores and ear-coverts whitish .

$$
\begin{aligned}
& \text { Velvet-Scoter: } \\
& \text { CE. fusca } \uparrow, \text {,p. } 348 .
\end{aligned}
$$

$\epsilon^{4}$. Wing 7.5 inches: bill about 1.0 inch in length; top of the head brown like the neck;

lores and ear-coverts whitish . . . Harlequin Duck: His.

$u^{3}$. Breast and belly pure white. trionicus histrionicus $\$$, p. 355.

$\xi^{4}$. Secondaries brown not forming a distinct wing-speculum . . . . . . . . Long-tailed Duck:

Harelda glacialis , , p. 357.

$\eta^{4}$. Secondaries mostly or partly white, form. ing a distinct wing-speculum.

$u^{5}$. Wing $8 \cdot 0$ to $9^{\circ} 0$ inches; head and neck uniform brown.

$q^{6}$. Wing $8^{\circ} 0$ inches; depth of bill at the base about 0.7 inch . . . Golden-eye: 


\section{WILD FOWL}

$r^{6}$. Wing $9 \cdot 0$ inches; depth of bill at the base about 10 inch . . . .

$v^{5}$. Wing $6^{\circ} 0$ inches; head and neck brown with a large white patch on the ear. coverts and posterior part of the head

$l^{2}$. Axillary plumes white (slightly mottled with dusky in Somateria mollissima). (See Fig. 7.)

$v^{3}$. Feathers of the mantle black, widely edged with rufous-buff or chestnut.

$\theta^{4}$. Wing-speculum blackish, narrowly bordered above and below with white.

$w^{5}$. Feathering on the sides of the face extending far beyond that on the forehead; wing $11^{\circ} 0$ inches . . . . . Common Eider :

Somateria mollissima q, p. 350 .

$x^{5}$. Feathering on the forehead extending much beyond the feathering on the sides of the face; wing $10^{\circ} 0$ inches . .

$\imath^{4}$. Wing-speculum deep greenish-blue, widely edged above and below with white; feathering on the sides of the face and forehead about equal . . . . . . Steller's Eider:

Heniconetta stelleri $q, p .354$.

$w^{3}$. Feathers of the mantle uniform brown.

$\kappa^{4}$. Size larger; wing about $10^{\circ} 0$ inches; inner primaries dull whitish very distinctly tipped with dark brown; secondaries similar, forming a soiled-white speculum . . . .

$\lambda^{4}$. Size smaller; wing $7^{\circ} 0$ to $8^{\circ} 0$ inches.

\section{King Eider :}

S. spectabilis $\uparrow$, p. 352 .

Red-crested Pochard:

Netta rufina,$+ p .364$.

$y^{5}$. Wing-speculum grey.

$s^{6}$. Back black finely vermiculated with white. . . . . . Common Pochard;

Nyroca ferina $q, p .366$.

$t^{6}$. Back uniform dark brown . . . Ring-necked Pochard:

$z^{5}$. Wing-speculum pure white.

N. collaris,$+ p .373$.

$u^{6}$. No distinct crest.

$e^{7}$. Head and neck dull rusty-red; rest of the underparts rufous mottled with white; wing $7 \cdot 0$ inches. . . . . . . .

Ferruginous Duck, or White-eyed Pochard:

N. nyroca $q, p .368$. 


\title{
THE GUN AT HOME AND ABROAD
}

\author{
$f^{7}$. Head and neck brownish- \\ black tinged with rufous on the \\ sides; chest chestnut; breast \\ and belly: white; wing $7 \cdot 3$ \\ inches . . . . . . \\ $g^{7}$. Head, neck and chest brown; \\ lores whitish; breast and belly \\ pure white; wing 8.0 inches \\ $v^{6}$. A distinct crest of loose feathers \\ Baer's Pochard: \\ N. baeri $q$, p. 370 . \\ about $1^{\circ} 5$ inch in length; head, neck \\ and chest brown; breast and belly \\ pure white; wing 7.5 inches . \\ Scaup-Duck : \\ N. marila,+ , .371 . \\ Tufted Duck:

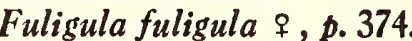

$f$. Bill lengthened, cylindrical and strongly toothed, not exceeding 0.3 inch in width at the tip, which is strongly hooked. $g^{\prime}$. Head black, glossed with greenish; or black and white.

(Males.)

$m^{2}$. Size larger; wing $9^{\circ} 0$ to $11^{\circ} 0$ inches; head and neck

black, strongly glossed with green.

$x^{3}$. Occipital crest shorter, about $1 \cdot 3$ inch in length; chest white; rump grey; size larger; wing $11^{\circ} 0$ inches . . . . . . . . . . Goosander:

$y^{3}$. Feathers of the occipital crest very long and

Mergus merganser o , p. 376. narrow, about 3.5 inches in length; chest pale rufous spotted with black; rump with fine wavy black and white bars . . . . . . Red-breasted Mergan.

$n^{2}$. Size smaller; wing 7 to 8 inches long; head and

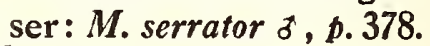
neck black and white.

$z^{3}$. Head and neck mostly white, with a moderate occipital crest of black and white feathers about 1.5 inch in length; a large black patch on the forepart of the face, including the eye; wing 7.5 inches; bill $1 \cdot 2$ inch . . . . . . . . .

$a^{3}$. Head and neck mostly black, with a high com. pressed and elevated crest consisting mostly of white plumes, tipped with black; wing about $7 \cdot 75$ inches; bill $1 \% 6$ inch . . . . . . .

$h^{1}$. Head and nape rufous, or rufous-brown, chin and Smew : M. albellus ð, p. 380 . throat white or whitish. (Females.)

$0^{2}$. Size larger; wing 8.5 to 9.5 inches.

$\beta^{3}$. Head and neck chestnut; chin and throat pure white and sharply defined; occipital crest long and full, about 3.0 inches in length; wing 9.5 inches

Goosander:

Hooded Merganser :

Lophodytes cucullatus ${ }^{\circ}$, p. 382. 


\section{WILD FOWL}

$\gamma^{3}$. Crown reddish-brown, shading into rufous on the sides of the head and neck, inclining to whitish on the chin, throat and foreneck; occipital crest short, less than 1.5 inch in length; wing 8.5 inches . . . . . . . .

$p^{2}$. Size smaller; wing 6.5 to $7 \cdot 5$ inches.

Red-breasted Merganser: $M$. serrator $\&, p .378$.

$\delta^{3}$. Top and sides of the head and back of the neck brownish-chestnut; chin, throat and foreneck pure white; crest very slightly developed about 0.8 inch in length; bill 1.1 inch; wing 6.75 inches

$\epsilon^{3}$. Top and sides of the head and neck brownish Smew: M. albellus \&, p. 380 . with a long compressed and erect rufous crest, nearly two inches in height; chin and throat pure white; bill $1^{\circ} 6$ inch; wing $7 \cdot 5$ inches . .

Hooded Merganser:

Lophodytes cucullatus $\&$, p.382.

\section{SWANS}

HREE species of swans are met with in Western Europe and the British Isles.

They are easily recognized by their large size and very long neck, as long or even longer than the body. The plumage of the adults is entirely white; pale brown in young birds. They differ from both the geese and ducks in having the space in front of the eyes entirely bare of feathers, and from the former in their shorter leg, which is never as long as the middle toe. Their movements when walking are very awkward, but on the water they are extremely graceful birds. Their food is chiefly obtained in the water, and for this purpose they immerse their long necks, elevating the hinder part of the body like the geese and surface-feeding ducks. They are incapable of diving. Their flight is strong and rapid, the neck being fully extended, and when migrating they usually fly at a great height.

The sexes are alike in plumage, but the male is usually somewhat larger and heavier than the female. They moult once a year, in the autumn. 


\section{THE GUN AT HOME AND ABROAD}

\section{WHOOPER SWAN}

\section{CYGNUS CYGNUS}

(Plate XXVII, Fig. 2)

Cygnus ferus, Gould, Birds Europe, v, pl. 355 (1837).

Cygnus musicus, Dresser, Birds Europe, vi, p. 433, pl. 419, fig. 4 (1880); Lilford, Col. Fig. Brit. Birds, part xxv, pl. (1893); Salvadori, Cat. Birds Brit. Mus., xxvii, p. 26 (1895); Saunders, Ill. Man. Brit. Birds, p. 413 (1899).

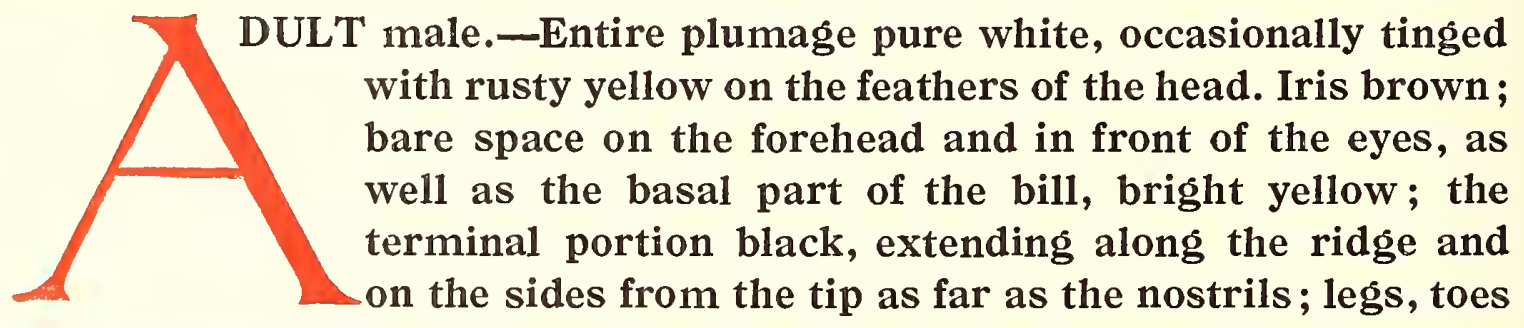

and their membranes, black. Total length about 60 inches; bill $4 \cdot 2$ inches; wing $25^{\circ} 0$ inches; tail 7 inches; tarsus $4^{\circ} 6$ inches.

Adult female-Similar to the male, but smaller. Total length about 55 inches; bill $4 \cdot 1$ inches; wing 22.5 inches; tail 6.7 inches; tarsus $4 \cdot 2$ inches.

Young in first autumn-plumage. - Greyish-brown, paler on the underparts. Basal portion of the bill flesh-colour, terminal portion black; feet dull flesh-colour.

Young in down. - Nearly white, somewhat ashy on the crown and back. Bill flesh-colour, tip blackish, nail whitish.

General distribution.-The whooper breeds in Iceland, Northern Europe and Northern Asia, extending eastwards to Kamchatka and the Commander Islands in Bering Sea. In winter it migrates southwards to Central and Southern Europe, Central Asia, China and Japan. In severe winters it is met with in North Africa, on the large lakes of Algeria and in Lower Egypt; also in Palestine.

Distribution in the British Isles.-To the British Islands it is now only a winter-visitor, its numbers varying according to the mildness or severity of the weather prevailing in Northern Europe. It appears regularly on the coasts of Scotland and the adjacent islands towards the end of October, and November, and frequents the estuaries and lochs, individuals sometimes remaining until May. In severe weather it is often common on the shores of England and Wales, but it is only an irregular winter-visitor to Ireland, where the smaller Bewick's swan is far more numerous. 302 


\section{WILD FOWL}

Formerly it used to nest in the Orkney Islands, on the islets in Loch Stenness in the Mainland.

Nest and eggs.-The nest, a large structure of dead herbage, is generally placed on an island in a delta or lake, and concealed among the dense willow-scrub. The eggs, which vary in number from four to seven, are yellowish-white or creamy-buff, and measure about $4 \cdot 4$ by $2 \cdot 8$ inches. Incubation lasts from five to six weeks.

In the adult the trachea is less lengthened than in Bewick's swan, and the loop curving forwards enters a cavity in the keel of the sternum for a distance of about three or four inches only, never extending to the hinder part. The call is a loud, trumpet-like sound-whoop, whoop-whoop, whoop -often uttered during flight.

The food consists of roots and stems of aquatic plants and grass. The whooper is a very shy bird. Both on the water and on the wing its movements are very graceful and powerful, but on land it is somewhat awkward and ungainly. When swimming the neck is usually held erect, but when walking the head is lowered over the back. The weight of an adult male is about $22 \mathrm{lbs}$.

\section{BEWICK'S SWAN \\ CYGNUS BEWICKI \\ (Plate XXVII, Fig. 3)}

Cygnus bewicki, Gould, Birds Europe, v, pl. 356 (1837); Dresser, Birds Europe, vi, p. 441, pl. 419, fig. 3 (1880) ; Hume \& Marshall, Game Birds Ind., iii, p. 51, pl. 6 (1880) ; Lilford, Col. Fig. Brit. Birds, part xxv, pl. (1893) ; Salvadori, Cat. Birds Brit. Mus., xxvii, p. 29 (1895) ; Saunders, Ill. Man. Brit. Birds, p. 415 (1899).

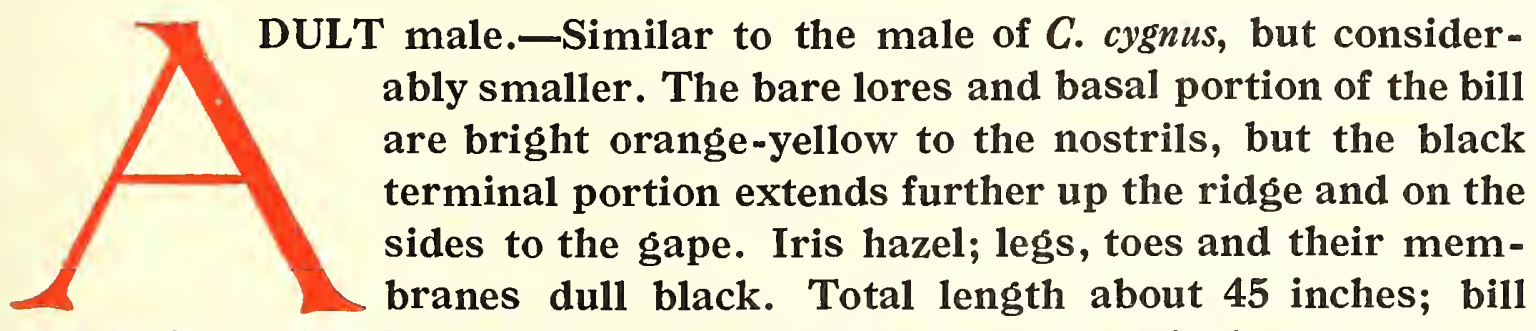

3.8 inches; wing 21.0 inches; tail 6.6 inches; tarsus $4 \cdot 1$ inches.

Adult female.-Similar to the male, but smaller. Total length about 40 inches; bill 3.4 inches; wing $20^{\circ} 0$ inches; tail 6.2 inches; tarsus $4 \cdot 0$ inches. 


\section{THE GUN AT HOME AND ABROAD}

Young in first autumn-plumage. - Head brownish-grey; the upperparts white tinged with greyish; rest of the plumage white. Bill, from the bare forehead to the nostrils, pinkish-white; ridge mottled with pinkishbrown, yellowish along the middle, tips of both mandibles and edges of the upper, blackish ; feet and toes yellowish-white, with dark edges to the scales.

Young in down.-White with a slight shade of dusky on the crown and upperparts; bill flesh-colour, edged with black; nail whitish; feet pinkish.

General distribution.-The breeding-range of Bewick's swan is more northerly and easterly than that of the whooper, and includes North Russia from the White Sea eastwards, Kolguev, Novaya Zemlia and Arctic Asia as far east as the delta of the Lena; from thence eastwards its place is taken by a larger, broader-billed form, which has been separated under the name Cygnus jankowskii by $\mathrm{Mr}$ S. N. Alphéraky. In winter it migrates southwards to Western and Central Europe, the Caspian Sea, China and Japan. It is sometimes found in severe weather as far south as the Mediterranean, and appears to occur accidentally on the great lakes of Algeria.

Distribution in the British Isles. -To the British Isles it is a regular wintervisitor. In Scotland, especially in the Outer Hebrides, it is sometimes very numerous; also in the north and west of Ireland, where it is far more abundant than the whooper, and sometimes seen in vast flocks. In England and Wales it is often met with during severe weather, but is distinctly rarer than the whooper.

Nest and eggs. -The nest is like that of the whooper, but the eggs are somewhat smaller, the average measurements being $4 \cdot 0$ by $2 \cdot 6$ inches. Incubation probably lasts from five to six weeks, as in the allied species.

The trachea is even more lengthened than in the whooper, and the loop extending laterally in a cavity in the keel of the sternum reaches nearly to the posterior extremity of that bone. The call is very different from that of the whooper, and resembles the syllable tong repeated several times.

The food, general habits, etc., of Bewick's swan are very similar to those of the whooper. The weight is about $13 \mathrm{lbs}$. 


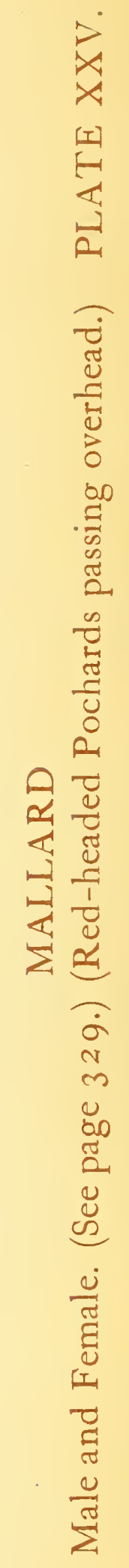



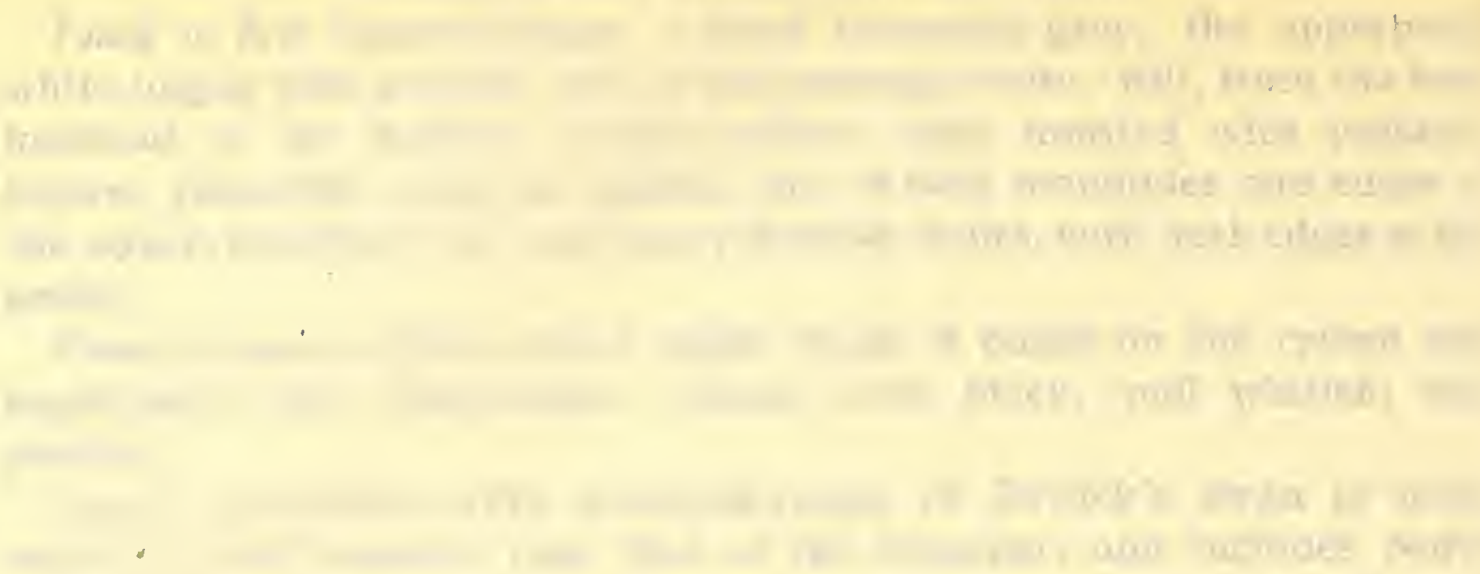

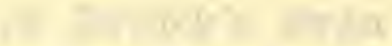

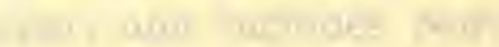

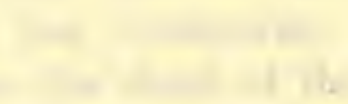

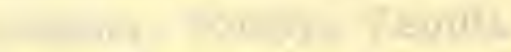

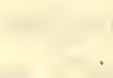

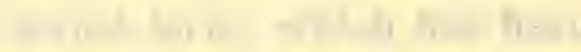
A 1
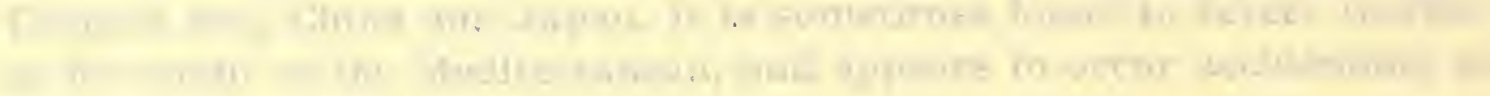

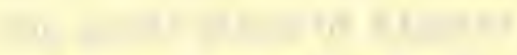

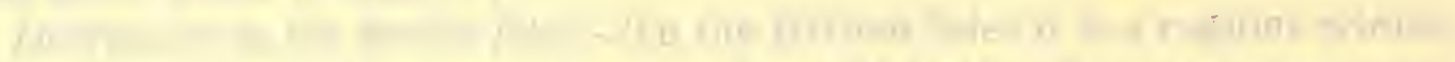
a

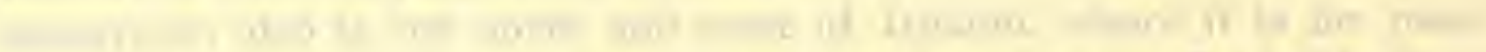
that

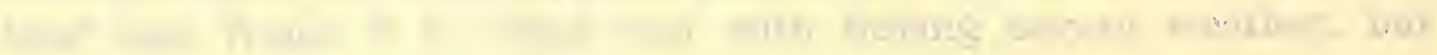

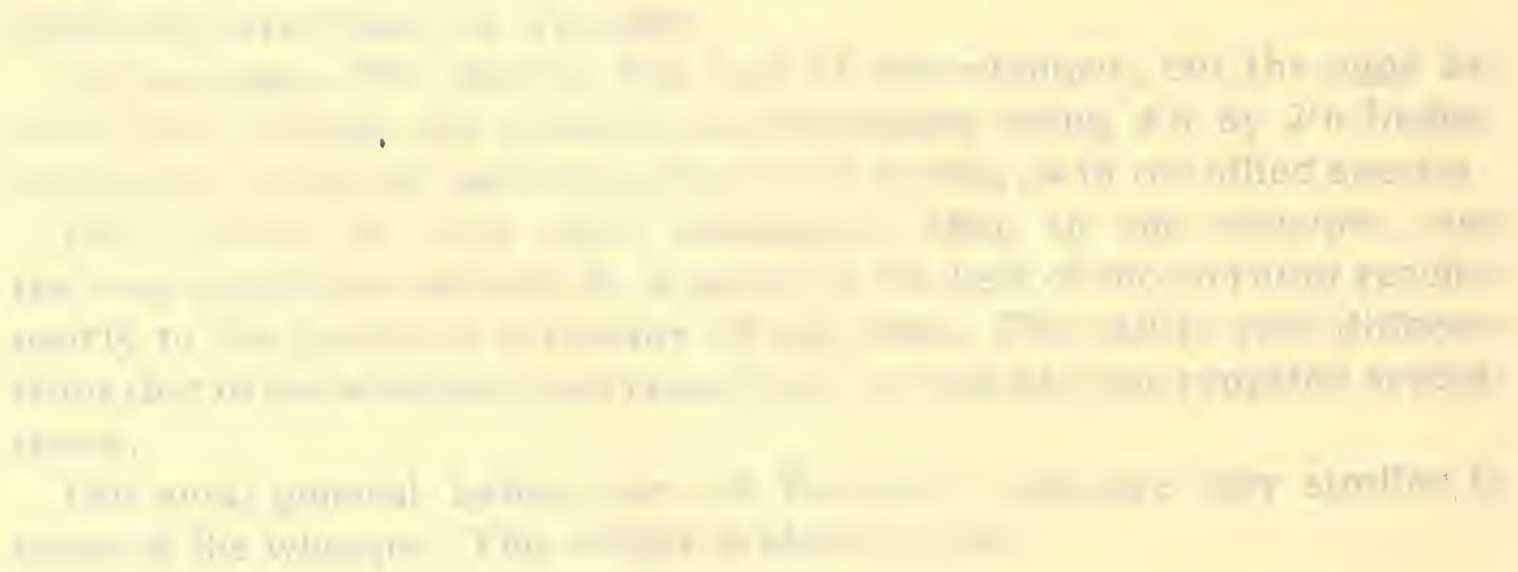




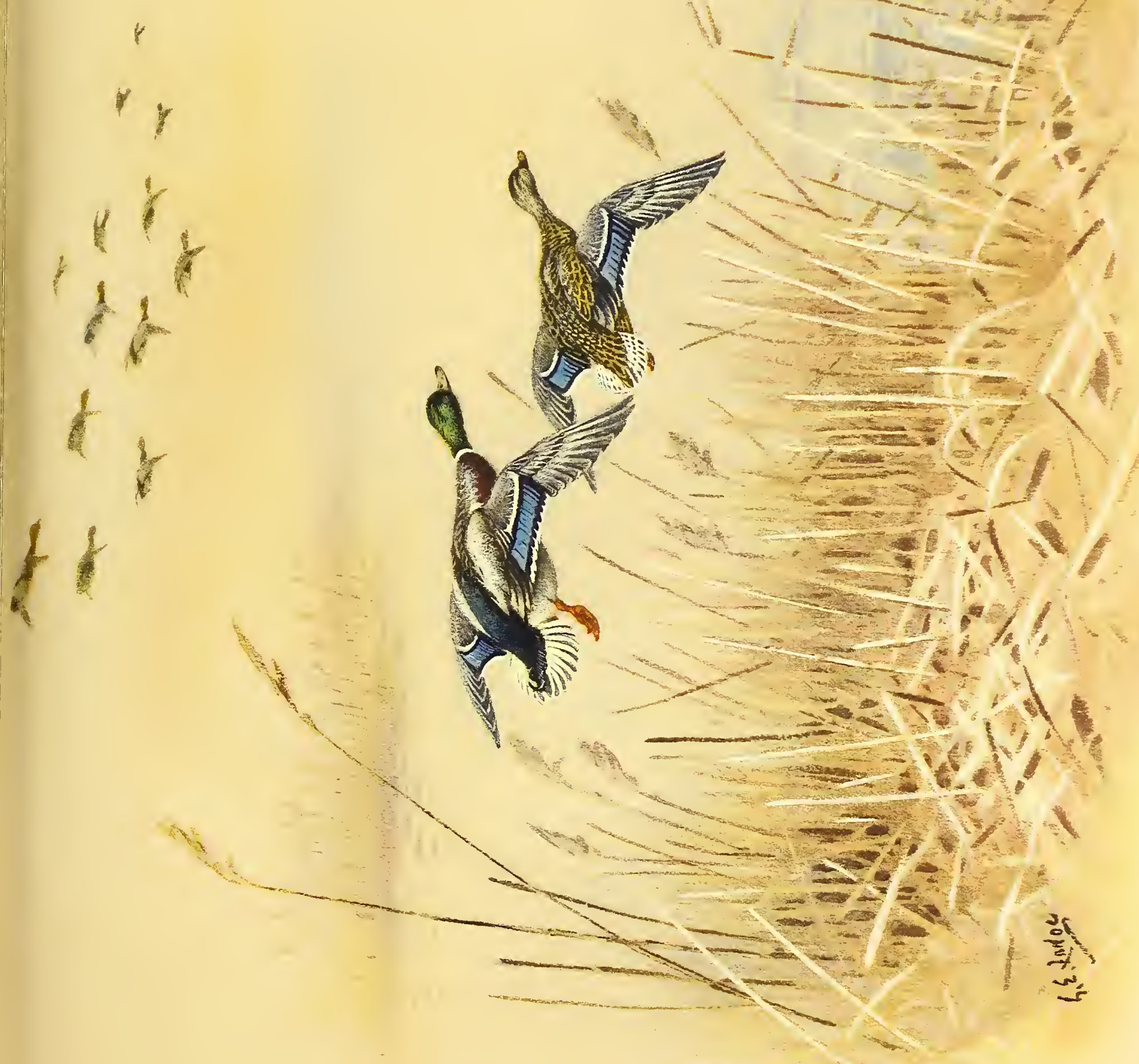



WILD FOWL

\section{MUTE SWAN}

\section{CYGNUS OLOR}

(Plate XXVII, Fig. 1)

Cygnus mansuetus, Gould, Birds Europe, v, p. 354 (1837).

Cygnus immutabilis, Dresser, Birds Europe, vi, p. 429, pl. 419, figs. 1 and 2 (1880).

Cygnus olor, Dresser, Birds Europe, vi, p. 419, pls. 418, 419, figs. 5 and 6 (1880); Hume \& Marshall, Game Birds Ind., iii, p. 41, pl. 5, fig. 2 (1880); Salvadori, Cat. Birds Brit. Mus., xxvii, p. 35 (1895); Lilford, Col. Fig. Brit. Birds, part xxxv, pl. (1897); Saunders, Ill. Man. Brit. Birds, p. 417 (1899).

DULT male.-Plumage pure white. The bill orange-red, only the nail, nostrils, lores and swollen tubercle at the base being black. Iris dark hazel. Legs, feet and membranes black. Total length about 60 inches; bill $4 \cdot 2$ inches; wing $27^{\circ} 0$ inches; tail 8.5 inches; tarsus 4.9 inches.

Adult female.-Similar to the male, but smaller, and the tubercle at the base of the bill not nearly so large.

Young in first autumn-plumage.-Brownish-grey above, paler below. Bill dull leaden-grey, with the nostrils and the basal marginal band black.

Young in down.-Usually sooty-grey above, paler below, but sometimes almost or entirely white. Bill very dark leaden-grey; nail black; legs dull blackish-grey.

General distribution.-The mute swan breeds in Southern Scandinavia, Denmark, North Germany, Central and Southern Russia, and on the Lower Danube; also commonly in the neighbourhood of the Black and Caspian Seas, and eastwards in Turkestan and Mongolia. In winter it is found in the Basin of the Mediterranean and migrates to North Africa, where it is a regular visitor to the lakes of Algeria and Egypt, and occasionally wanders to North-west India.

Distribution in the British Isles.-In the British Isles it was originally introduced and is now generally distributed in a semi-domesticated condition.

Nest and eggs. - The nest, like that of the other swans, is a large structure of dead reeds and aquatic herbage. The number of eggs laid varies according to the age of the female, younger birds laying clutches of from three to five eggs, while older birds lay as many as ten or twelve. The eggs are greyish-green, and measure about 4.0 by 2.9 inches. The period of incubation varies from 35 to 39 days. 


\section{THE GUN AT HOME AND ABROAD}

In the mute swan the trachea is shorter than in the species already mentioned, and does not enter a cavity in the keel of the sternum, but on reaching the intra-furcular space forms a slight curve outwards before entering the thorax. It has a loud and trumpet-like note, uttered chiefly in the breeding-season, and makes a hissing sound when approached too closely; but at other times it is a very silent bird. The food consists chiefly of water-plants, aquatic insects and grain, etc. Unlike the whooper and Bewick's swans, the present species does not carry its head erect when swimming, the neck being held in a graceful curve. The weight is about 24 lbs.

The so-called Polish swan (Cygnus immutabilis, Yarrell) is now generally admitted by ornithologists to be a mere variety as regards the colour of the young, which are said to be white. White cygnets are not infrequently seen amongst broods of darker birds, and none of the characters attributed to the Polish swan are constant.

\section{GEESE}

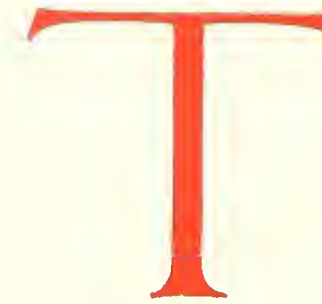

HE geese to be met with in Western Europe and the British Isles belong to three well-defined groups or genera-the grey geese, snow-geese and Brent geese. In all the hind toe is very narrowly lobed (see fig. 1, p. 290), and the bill is rather short and thick, the depth at the base being more than half the total length measured from the feathering on the forehead to the tip (see fig. 5, p. 290), while in the surface-feeding ducks with the hind toe narrowly lobed, the depth at the base of the bill is less than half the total length. The legs are longer than in the ducks, and are placed further forward, consequently geese are able to walk and run with much greater ease and grace. The sexes are alike in plumage, the male (gander) being usually larger and heavier than the female (goose). In all the species under consideration the upper tail-coverts are white. They have only one moult in the year, in autumn.

1. -The grey geese may always be recognized by their greyish-brown plumage and by their entirely orange, or partly orange or pink, bill, and by their light-coloured orange or pink legs. The bill is furnished with strong serrations or "teeth," those in the upper mandible being conspicuous when the bill is closed and viewed from the side, and more adapted for cropping grass, etc., than for sifting water and mud. They feed mostly 306 


\section{WILD FOWL}

during the day, on grass, clover, etc., and some of the species are partial to grain. At night they resort to some sand-bank or other place difficult of access. They are gregarious birds, and when making long flights usually assume a wedge-shaped formation, whence the term " a skein of geese."

2.-The snow-geese may be easily recognized by their white plumage, only the flight-feathers and their coverts being black. The bill and legs are red in the adult, greyish-black in the immature, which has the upperparts brownish-grey and the underparts greyish-white. The teeth in the upper mandible are strongly developed and plainly visible when the bill is closed and viewed from the side. They are rare stragglers to Western Europe and the British Isles.

3.-The Brent geese have the bill and legs black. The bill is less strongly serrated than in the grey geese and snow-geese, and the "teeth" in the upper mandible are not visible when the bill is closed and viewed from the side.

The food varies in the different species, the Bernacle feeding at night on grass pastures near the sea, while the Brent feeds chiefly by day on the ooze and in shallow waters, searching for aquatic plants and seaware below the surface.

\section{GREY LAG-GOOSE \\ ANSER ANSER}

Anser ferus, Gould, Birds Europe, v, pl. 347 (1837); Salvadori, Cat. Birds Brit. Mus., xxvii, p. 89 (1895).

Anser cinereus, Dresser, Birds Europe, vi, p. 355, pl. 411 (1878); Hume \& Marshall, Game Birds Ind., iii, p. 55, pl. vii (1880) ; Lilford, Col. Fig. Brit. Birds, part xxvi, pl. (1893) ; Saunders, Ill. Man. Brit. Birds, p. 397 (1899).

Anser rubrirostris, Salvadori, Cat. Birds Brit. Mus., xxvii, p. 91 (1895).

Anser anser, Alphéraky, Geese of Europe, p. 24, pls. iii and xxii (1905).

DULT male.-Head light brownish-grey, a little darker on the crown and paler on the sides of the head and throat; back of the neck ash-brown, fore-neck greyer, the feathers of the upper part arranged in rows with furrows between; back, scapulars and longer outer secondaries, as well as the sides and flanks, ash-brown, greyish towards the base, and with light greyish-brown edges; lower back and 


\section{THE GUN AT HOME AND ABROAD}

rump grey; upper and under tail-coverts white; chest and rest of the underparts pale brownish-grey shading into white towards the base of the abdomen and vent; over the breast and abdomen are scattered numerous dark ash-brown feathers, forming irregular bars or patches, a character which increases with age; thighs pale grey; outer wingcoverts pale grey, the greater ones paler than the lesser and median; middle wing-coverts ash-brown with pale edges, like the back; outer secondary and inner primary quills brownish-black, outer primary quills ash-grey except at the tip, which is brownish-black; all the shafts of the quills white; under wing-coverts and axillaries very pale grey; middle pairs of tail-feathers ash-brown tipped with white, ranging to uniform white on the outermost pair. Iris brown; bill orange or pale flesh-colour; nail yellowish-white; legs, toes and membranes flesh-colour.

Total length about 38 inches; bill 2.4 inches; wing 17.5 inches; tail $5 \cdot 3$ inches; tarsus $3 \cdot 4$ inches.

Adult female.-Similar to the male, but generally smaller and lighter in weight. Wing about 16 inches.

General distribution.-The breeding-range of the grey lag-goose extends from Iceland in the west to the Ussuri district and Kamchatka in the east. In North Europe and in Western Siberia it is found, even beyond the Arctic Circle, along the Obi Valley; but to the east of about $80^{\circ} \mathrm{E}$. long. its northern range declines, and does not seem to extend beyond $56^{\circ} \mathrm{N}$. lat. Its southern breeding limit is difficult to define, but seems to include the northern shores of the Mediterranean from South Spain eastwards, Transcaucasia, Persia, Turkestan, Eastern Turkestan and probably Ghina, though at the present time it is only recorded from there as a winter-visitor. On migration enormous numbers visit Southern Spain, and many cross to North Africa and are found in Tangier, Algeria and North Tunis. It is likewise plentiful in the cold season in North and Gentral India and China as far south as Canton.

Distribution in the British Isles.-In the north of Scotland the grey laggoose is resident and breeds in Caithness, Sutherland and Ross-shire, and on the Outer and some of the Inner Hebrides. In winter its numbers are greatly increased, and it is then more generally distributed, but is comparatively rare on the east side. To the Shetland and Orkney Islands it is an accidental visitor. To England and Wales it is a winter-visitor only, and comparatively rare and irregular, especially in the south and west. In most parts of Ireland it is scarce, but some numbers visit the 308 


\title{
WILD FOWL
}

southern and western counties. Formerly the grey lag-goose bred in the fens of Cambridgeshire and Lincolnshire, but it ceased to do so in the beginning of last century.

Nest and eggs.-The nest, usually situated among coarse grass or long heather, is a fairly large structure made of dead grass, reeds, sedges, moss, etc., and is lined after the eggs are laid with down plucked from the breast of the female. In this country five or six eggs are usually laid about the middle of April, but more than twice that number are occasionally to be found. They are yellowish-white, and measure about $3 \cdot 4$ by $2 \cdot 3$ inches.

The weight of adult birds varies from 8 to $10 \mathrm{lbs}$, , but heavier birds are occasionally met with.

\section{WHITE-FRONTED GOOSE}

\author{
ANSER ALBIFRONS \\ (Plate XXVII, Fig. 4)
}

Anser albifrons, Gould, Birds Europe, v, pl. 349 (1837); Dresser, Birds Europe, vi, p. 375, pl. 414 (1878); Hume \& Marshall, Game Birds Ind., iii, p. 73, pl. x (1880); Lilford, Col. Fig. Brit. Birds, part x, pl. (1889); Salvadori, Cat. Birds Brit. Mus., xxvii, p. 92 (1895); Saunders, Ill. Man. Brit. Birds, p. 399 (1899); Alphéraky, Geese of Europe, p. 42, pls. iv and xxii (1905).

DULT male.-Forehead and feathers at the base of the upper mandible, white, bordered posteriorly with black, which is continued over the chin; head, neck, back, scapulars, long outer secondaries, sides and flanks, ash-brown, the three last-named with pale brownish-grey edges; lower back and rump dark brownish-black; upper and under tail-coverts white; chest pale greyish-brown; breast and belly brownishwhite, more or less heavily marked with patches and bars of black, the amount of black varying according to age, and sometimes covering the greater part of the breast and belly in very old ganders; lower abdomen and vent white; thighs ash-brown; the wings like those of the grey lag-goose, but the outer wing-coverts and quills of a darker and more leaden-grey; under wing-coverts and axillaries dark smoky-grey; all the tail-feathers brownish-black tipped with white. Iris dark brown; bill orange-yellow, nail white; legs, toes and membranes orange, nails 
THE GUN AT HOME AND ABROAD

white. Total length about 27 inches; bill $2 \cdot 0$ inches; wing $15 \cdot 5$ inches; tail 4.8 inches; tarsus 2.9 inches.

Adult female.-Similar to the male, but generally smaller, and with less black on the breast and belly. Wing about 14.5 inches.

General distribution. - The white-fronted goose breeds in the most northerly tundra, and has been met with in limited numbers in Finland and, apparently, in Lapland, in the Kola Peninsula round Varanger Fjord, in Novaya Zemlia, Kolguev, the Obi basin, Yenesei, Taimyr Peninsula, and eastwards over the extreme north of Siberia and the islands along the whole shore of the Arctic Ocean. It also breeds in Iceland and Greenland. On migration it is met with throughout Europe, southwards to the Mediterranean basin, and vast numbers occur in winter in Egypt, the Black and Caspian Seas, North India, China, Corea and Japan. In Arctic North America a slightly different form with a rather larger bill, known as Anser gambeli, is met with, and winters as far south as Mexico and Cuba. It seems doubtful if the American bird is really separable from A. albifrons: Mr Alphéraky does not consider it to be so.

Distribution in the British Isles. - To the British Isles the white-fronted goose is a winter-visitor only. In Great Britain it is generally scarce on the east coast, except near the Moray Firth, but on the west and south, though local in its distribution, it is often numerous. It is often plentiful in the Shetlands, common in the Orkneys, sparingly met with in the Outer Hebrides, but common in Islay. In Ireland it is abundant and widely distributed, being much the commonest species of grey goose.

Nest and eggs. - The nest is said to be placed as a rule on a grassy hillock in a depression on the summit, and has the usual thick lining of down after the eggs are laid. These are usually from five to seven in number, but smaller sets of four and probably also larger clutches are to be found. They are creamy-white, the average measurements being $3 \cdot 2$ by $2 \cdot 1$ inches. The eggs are laid in the latter part of May and in June.

The weight of adult birds is about $5 \frac{1}{2}$ to $6 \frac{1}{2} 1 \mathrm{bs}$. 


\section{LESSER WHITE-FRONTED GOOSE}

\section{ANSER FINMARCHICUS}

Anser finmarchicus, Gunner, Leemii de Lappon. Comm. notis, p. 264 (1767); Alphéraky, Geese of Europe, p. 59, pls. v, vi and xxii (1905).

Anser erythropus, Dresser, Birds Europe, vi, p. 383 (1879); Hume \& Marshall, Game Birds Ind., iii, p. 77, pl. xi (1880); Salvadori, Cat. Birds Brit. Mus., xxvii, p. 97 (1895).

DULT male.-Very similar to the white-fronted goose, but easily distinguished by its smaller size and much shorter bill, and by having the white on the forehead (in adults at least) much more extensive, reaching to a line drawn between the posterior margins of the eyes. Iris dark brown; bill orange, nail whitish; legs, toes and membranes orange-yellow. Total length about 21 inches; bill $1 \cdot 3$ inches; wing 14.5 inches; tail 4.0 inches; tarsus 2.5 inches.

Adult female.-Similar to the male, but rather smaller. Wing $13 \cdot 7$ inches.

General distribution.-The lesser white-fronted goose has been generally confused with its larger but perfectly distinct ally $A$. albifrons. It is known to nest in Lapland and the Kanin Peninsula, and though not at present known to breed in Kolguev, certainly does so in Novaya Zemlia. It appears also to inhabit the whole tundra of Northern Siberia in suitable localities, from the Yenesei eastwards to Kamchatka. Its winter-range is very difficult to define, but it appears to occur sparingly or rarely over the whole of Western Europe in the late autumn and winter as far south as Southern Spain. In Northern and Eastern Europe it is often seen in considerable numbers, and vast flocks have been observed in autumn near Taganrog, on the Sea of Azov; it is a winter-visitor to Turkey and Greece. It no doubt also visits the Black Sea, and has been found in North Egypt. To the Caspian Sea it is a numerous winter-visitor, and is met with eastwards in Persia, India, South China and Japan, while it is very common on Lake Baikal and in other parts of Northern Asia. The present species, as already stated, has been so constantly coniused with its larger ally that it has been found impossible to trace its range with any certainty.

Distribution in the British Isles.-The lesser white-fronted goose is a rare straggler to the British Isles, and has only been recorded from Northumberland, Yorkshire, Norfolk, and possibly the Solway district. 


\section{THE GUN AT HOME AND ABROAD}

Nest and eggs.-The nidification is similar to that of the white-fronted goose, but the eggs are somewhat smaller and average about 3.0 inches by 1.95 inches. The eggs are laid in the end of May and in the early part of June.

The weight does not appear to have been recorded, but is much less than that of the white-fronted goose, probably about 4 lbs.

\section{BEAN-GOOSE ANSER FABALIS}

Anser segetum, Gould, Birds Europe, v, pl. 348 (1837) ; Dresser, Birds Europe, vi, p. 363, pl. 412 (1879); Hume \& Marshall, Game Birds Ind., iii, p. 67, pl. viii (1880); Lilford, Col. Fig. Brit. Birds, part xxvi, pl. (1893); Saunders, Ill. Man. Brit. Birds, p. 401 (1899).

Anser fabalis, Salvadori, Cat. Birds Brit. Mus., xxvii, p. 99 (1895).

Melanonyx segetum, Alphéraky, Geese of Europe, p. 110, pl. xi and xxiii (1905).

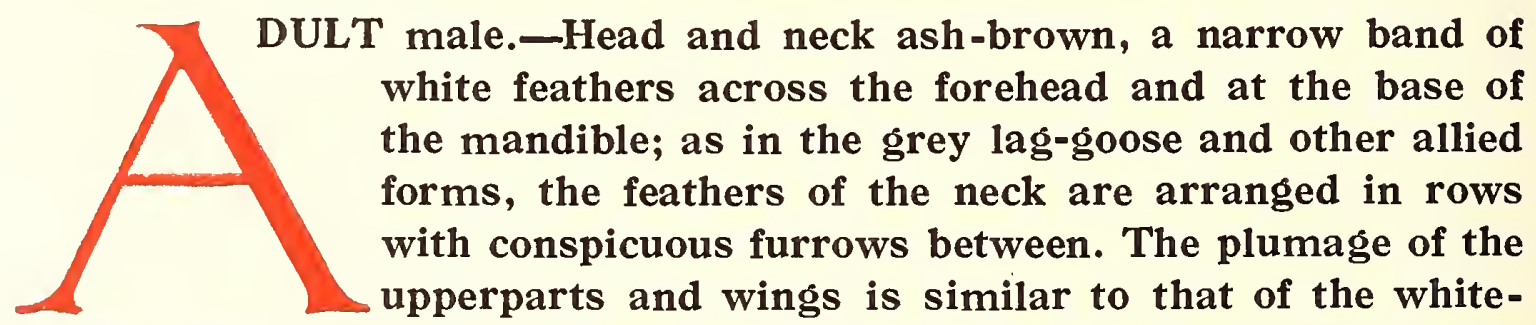

fronted goose, including the dark ash-brown of the back, etc., and the dark leaden-grey of the outer wing-coverts and quills. The breast and belly are uniform greyish-white, devoid of any black patches or bands. Iris dark brown; bill with the nail, edges and basal part black, the intermediate portion orange; legs and toes orange, claws black. Total length about 32 inches; bill $2 \cdot 5$ inches; wing $19 \cdot 0$ inches; tail 5.3 inches; tarsus $3 \cdot 4$ inches.

Adult female.-Similar to the male but smaller. Wing about $16 \cdot 5$ inches.

General distribution.-The typical bean-goose breeds in Kolguev and Novaya Zemtia and in North-eastern Russia, but in Finland and Lapland it appears to be met with on passage only. Eastwards of the Petchora its breeding-range probably extends to the Yenesei, and on migration it can be traced as far as Lake Baikal, but beyond that its existence is doubtful, and its place appears to be taken by the more Eastern thickbilled species Anser serrirostris. In winter the bean-goose is found over the greater part of Europe and Western Asia. 


\section{WILD FOWL}

It is asserted that another form, known as the yellow-billed bean-goose (Anser arvensis) [cf. Alphéraky, "Geese of Europe," p. 94, pls. ix and xxii (1905)] occurs, together with $A$. fabalis, and is far more common in Western Europe, including the British Isles, than the latter species. At present, however, the distribution of the two forms, if there really are two, is so involved and shrouded in uncertainty that it is outside the scope of the present work to deal with this interesting matter. A. arvensis is said to be characterized by having the upper mandible orange-yellow with the exception of the nail and a black band extending from the forehead down the ridge of the culmen as far as the nostrils, whereas in $A$. fabalis the basal three-fifths of the upper mandible and the nail are black with an orange-yellow subterminal band.

It is a subject of great interest to naturalists and worthy of the special attention of sportsmen, who could greatly assist in elucidating the question by forwarding examples of bean-geese for examination to the Natural History Museum, Cromwell Road, London.

Distribution in the British Isles.-The bean-goose is a winter-visitor to the British Isles, but is much less abundant than some of its allies, and is commoner on the west coast of Great Britain than it is on the east. It is scarce in the north of Scotland and some of the inner islands, almost unknown in the Outer Hebrides, while in the Orkney and Shetland Islands its occurrence requires confirmation. In Ireland it is often numer ous in the midland and western counties, especially in severe winters, but rare in the south.

Nest and eggs. - The nest of the bean-goose is a slight hollow in the ground lined with dead grass and moss, and thickly lined with light grey down after the eggs have been laid in May or June. The eggs vary in number from three to five, but no doubt larger clutches are sometimes found. They are creamy-white, and average about $3 \cdot 2$ by $2 \cdot 2$ inches.

Adult birds weigh from $7 \frac{1}{2}$ to $8 \mathrm{lbs}$.

Allied forms.-The Siberian bean-goose (Anser serrirostris) is characterized chiefly by its massive bill $-2 \cdot 4$ to $2 \cdot 7$ inches in length. It occurs in North and North-east Asia from the Taimyr Peninsula eastwards, wintering in Corea, China and Japan.

Yet another supposed form of the thick-billed bean-goose is Anser mentalis, from North Manchuria, the Commander Islands and Japan. It appears to be a very large form close to $A$. serrirostris, but the white patch on chin of the type specimen from Japan, according to Alphéraky, is not a 


\section{THE GUN AT HOME AND ABROAD}

constant character, and it seems possible, even probable, that it is founded on very old and unusually large examples of $A$. serrirostris.

Middendorff's bean-goose (Anser middendorfi) seems to be distinguished from its allies by having the head and neck golden-buff or rufous instead of chocolate-brown, and inhabits North-eastern Siberia from the Taimyr Peninsula to Kamchatka and the Commander Islands. It has a longer (2.9 to 3.25 inches) and less thick bill than $A$. middendorffi, but like that species has the basal three-fifths and nail black and the subterminal portion orange-yellow.

\section{PINK-FOOTED GOOSE}

\section{ANSER BRACHYRHYNCHUS}

Anser brachyrhynchus, Dresser, Birds Europe, vi, p. 369, pl. 413 (1878); Hume \& Marshall, Game Birds Ind., iii, p. 71, pl. 9 (1880); Lilford, Col. Fig. Brit. Birds, part xxv, pl. (1893); Salvadori, Cat. Birds Brit. Mus., xxvii, p. 103 (1895); Saunders, Ill. Man. Brit. Birds, p. 403 (1899).

Melanonyx brachyrhynchus, Alphéraky, Geese of Europe, p. 87, pls. viii and xxiv (1905).

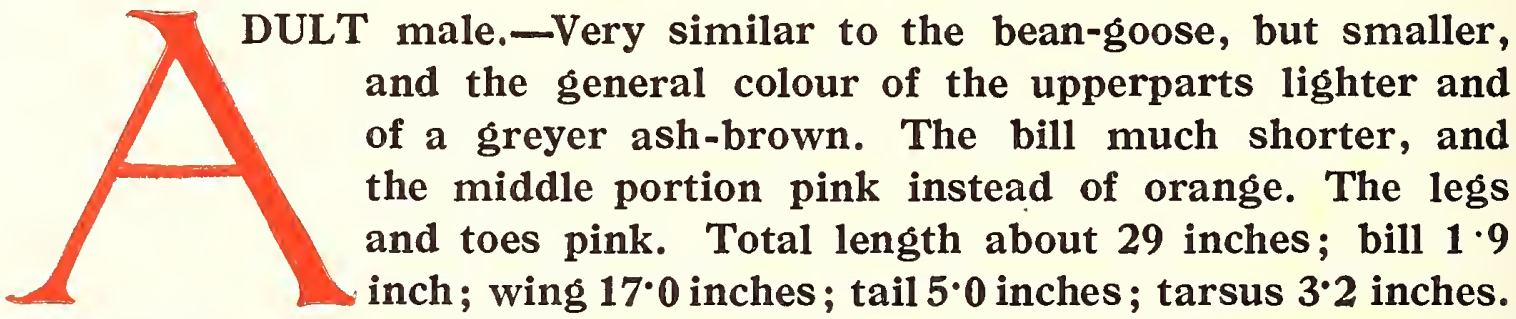

Adult female.-Similar to the male, but smaller. Wing about $16 \cdot 0$ inches.

General distribution.-The pink-footed goose breeds in Spitzbergen and probably also in Franz Josef Land and Iceland. On passage it winters in North-western Europe, and is a casual visitor to Scandinavia, North Germany, Holland, Belgium and France, and seems occasionally to stray southwards along the Atlantic seaboard to Spain and Portugal.

Distribution in the British Isles. - In the British Isles the pink-footed goose winters regularly in large numbers, being most numerous on the east coast and less common on the south and west. In the Shetland Islands it appears to be unknown ; in the Orkneys and in the North of Scotland it is rarely met with, and its occurrence in the Outer Hebrides is doubtful, while to Ireland it appears to be an accidental straggler. 
WILD FOWL

Nest and eggs.-The nest is similar to that of the bean-goose. Three eggs taken by Mr A. Trevor-Battye in Spitzbergen on the 26th of June were slightly incubated. They are yellowish-white, and the average measurements are $3 \cdot 3$ by $2 \cdot 15$ inches. Another clutch of five eggs was taken by H. Stjernspetz on Spitzbergen on the 15th of June.

The weight of adult birds varies from $5 \frac{1}{2}$ to $7 \mathrm{lbs}$.

Allied form.- In Kolguev and Novaya Zemlia, a larger form known as Sushkin's goose ( $A$ nser neglectus) replaces the pink-footed goose as a breeding species. It winters in Eastern Europe, being common on migration in the Ufa Government of East Russia: it is also met with in Persia, and appears to be almost certainly the form which has been met with in India.

\section{SNOW-GOOSE}

\section{CHEN HYPERBOREUS}

(Plate XXVII, Fig. 5)

Anser hyperboreus, Gould, Birds Europe, v, pl. 346 (1837).

Chen hyperboreus, Dresser, Birds Europe, vi, p. 413, pl. 417, fig. i (1873) ; Lilford, Col. Fig. Brit. Birds, part xxvi (1893); Salvadori, Cat. Birds Brit. Mus., xxvii, p. 84 (1895); Saunders, Ill. Man. Brit. Birds, p. 405 (1899); Alphéraky, Geese of Europe, p. 12, pls. i and xxii (1905).

DUL'T male.-Uniform pure white; primary quills black, becoming ash-grey towards the base; primary coverts paler grey. Iris dark brown; bill purplish-red, the nail whitish and the edge black; feet purple or orangered. Total length about 27 inches; bill $2 \cdot 1$ inches; wing $16 \cdot 5$ inches; tail $5 \cdot 3$ inches; tarsus 3.0 inches.

Adult female.-Similar to the male; usually a little smaller.

General distribution.-The snow-goose probably nests in the Arctic regions of Eastern Asia from the Lena eastwards, and in Western North America from the Mackenzie River east to Melville Island. In winter it migrates southwards to Japan, while some small proportion move westwards and have been observed from time to time in many parts of North -western Europe and southwards in Greece and the Caspian, which is said to be visited regularly in winter. In North America it visits the whole of the western parts between the Pacific Ocean and the Valley 
THE GUN AT HOME AND ABROAD

of the Mississippi, and extends southwards to Lower California and Mexico. It is generally rare in the Eastern United States.

Distribution in the British Isles.-To the British Isles it is a rare wintervisitor, and from time to time in exceptionally severe winters small numbers, and even flocks, have been seen in Great Britain from the Solway southwards; also in Ireland, and a few have been killed.

\section{GREATER SNOW-GOOSE}

\section{CHEN NIVALIS}

Chen nivalis, Salvadori, Cat. Birds Brit. Mus., xxvii, p. 86 (1895).

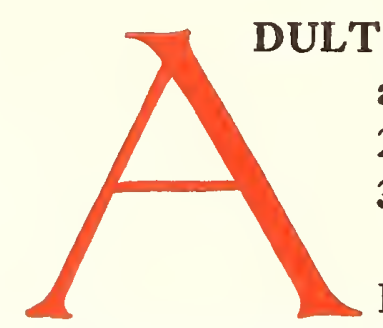

T male.-Similar to the snow-goose, but larger and with a longer bill. Total length 33 to 36 inches; bill $2 \cdot 6$ to $2 \cdot 7$ inches; wing $17 \cdot 5$ inches; tail 6.0 inches; tarsus $3 \cdot 2$ to $3 \cdot 5$ inches.

This is merely a larger form of the snow-goose, and that its claims to distinction from $C$. hyperboreus are not yet satisfactorily established.

General distribution.-The greater snow-goose breeds in Greenland and in the eastern part of Arctic North America. In winter it is found in the Eastern United States from the Mississippi to the Atlantic Ocean, extending southwards to Florida and Porto Rico.

Distribution in the British Isles.-A single example was obtained in Ireland, at Belmullet, Co. Mayo, in October, 1886. 


\title{
WILD FOWL \\ BRENT GOOSE
}

\author{
BRANTA BERNICLA \\ (Plate XXVII, Fig. 7)
}

Anser brenta, Gould, Birds Europe, v, pl. 352 (1837).

Bernicla brenta, Dresser, Birds Europe, vi, p. 389, pl. 415, fig. 2 (1877); Lilford, Col. Fig. Brit. Birds, part xxiv, pl. (1893); Saunders, Ill. Man. Brit. Birds, p. 411 (1899).

Branta bernicla, Salvadori, Cat. Birds Brit. Mus., xxvii, p. 119 (1895); Alphéraky, Geese of Europe, p. 150, pls. xvi and xxiv (1905).

DULT male.-Head, neck, upper mantle and upper breast black, sharply defined from the brownish-grey colour of the rest of the upper-and underparts*; an oblique patch of white on each side of the neck; feathers of the rump considerably lengthened; upper and under tailcoverts white; sides and flanks tipped with whitish and

forming a series of bars; thighs dark grey; quills black, wing-coverts grey; tail black; axillaries dark smoky-grey. Iris dark brown; bill, legs and toes black with an olive-green tinge on the tarsal joint and toes. Total length about 24 inches; bill 1.4 inch; wing $13^{\circ} 0$ inches; tail $3 \cdot 8$ inches; tarsus $2 \cdot 4$ inches.

Adult female.-Similar to the male, but rather smaller; wing about $12 \cdot 0$ inches.

General distribution.-The breeding-range of the Brent goose lies to the north of the Arctic Circle, in Kolguev, Novaya Zemlia, Franz Josef Land and Spitzbergen. It is not known to breed on the mainland of European Russia, but it probably does so on the tundra of the Kaninsk Peninsula and Yalmal. Eastwards it has been found nesting near the mouth of the Yenesei and on the Taimyr Peninsula, but beyond that point its range is uncertain, and its place is taken by the black Brent (Branta nigricans) with a complete white collar on the neck and a black belly, which breeds from the Lena eastwards to Bering Strait and in Western North America. In winter the Brent migrates to the Faeroe Islands, and vast numbers are met with on the shores of Western Europe, Scandinavia, North Germany, Denmark, Holland, Belgium and Northern France, and sometimes as

\footnotetext{
"Obs, - In the light-bellied form (B. glaucogaster) which inhabits Greenland and Arctic America all the feathers of the breast and upper belly are tipped with whitish, giving these parts a much lighter and distinctly mottled appearance, and the white on the lower belly extends further up towards the breast. This form is often met with in British waters among flocks of Brent.
} 


\section{THE GUN AT HOME AND ABROAD}

far south as the Atlantic coast of Morocco. It is also found in parts of the Mediterranean basin and in Lower Egypt, and very probably visits the Black Sea, though on the Caspian it is unknown.

Distribution in the British Isles.-To the British Isles it is a numerous and regular, but late, winter-visitor all along the east coast of Great Britain from the Shetland and Orkney Islands southwards and along the south coast of England. In the Hebrides and on the western shores it is much less numerous and more irregular; but in Ireland it is very common, vast numbers frequenting many parts of the shores and estuaries. It is very rarely met with on inland waters unless wounded.

Allied form.-In North-eastern North America and in Greenland a paler-breasted form of the Brent goose, known as Branta bernicla glaucogaster [cf. Alphéraky, "Geese of Europe," p. 158, pl. xvii (1905)] is met with and has been recorded from Kolguev, Novaya Zemlia and the Taimyr Peninsula. It very closely resembles the common Brent, and differs only in having the underparts paler and greyer. It has been met with at various times in the British Isles, occurring with flocks of the common darkbreasted Brent on the east coast, mostly to the north of the Humber. According to $\mathrm{Mr}$ Abel Chapman it seems to be more abundant on the Northumberland coast than the darker bird, and the same seems to be true about the south-east coast of Ireland. The distribution of this palebreasted form is at present very imperfectly known, but it seems probable that it is merely a lighter coloured phase, which is the prevalent form in Arctic America and Greenland. Mr Trevor-Battye appears to have found it breeding in Kolguev along with the common Brent, and to have examined intermediate forms between the light and the dark-breasted races. Those who have opportunities of shooting large numbers of Brent in the winter months would do well to look carefully for examples of the lightbreasted forms and to forward them to the Natural History Museum, London, S.W., where, strange as it may seem, the series of Brent, of the dark form especially, is very poorly represented. 


\section{WILD FOWL \\ BLACK BRENT GOOSE}

\section{BRANTA NIGRICANS}

Branta nigricans, Salvadori, Cat. Birds Brit. Mus., xxvii, p. 123 (1895).

Branta bernicla nigricans, Alphéraky, Geese of Europe, p. 162, pl. xviii (1905).

DULT male.-Similar to the Brent goose, but with a conspicuous white collar interrupted on the nape only, and formed by the white patches on the sides of the neck meeting together in front; abdomen almost as black as the breast. Iris dark brown; bill and feet black. Total length about 27 inches; bill $1 \cdot 3$ inch; wing 13.5 inches; tail 3.8 inches; tarsus 2.4 inches.

Adult female.-Similar to the male, but rather smaller. Wing, $13 \cdot 0$ inches.

General distribution.-The breeding-range of the black Brent goose extends through the Arctic Zone of North Asia from the Lena to Bering Strait, and thence eastwards into the Arctic portion of North America. In the cold weather it migrates southwards along the east coast of Asia and the adjacent islands to Japan, and along the west coast of North America to Lower California.

According to Prof. Menzbier this species occurs on migration with flocks of the common Brent in East Russia.

In the British Isles it is said to have been obtained on several occasions, but whether these specimens were really referable to $B$. nigricans with a white collar surrounding the neck, or were merely unusually darkbellied examples of the common Brent, seems at present uncertain. In any case its occurrence must be regarded as by no means proven. 


\title{
BARNACLE-GOOSE
}

\author{
BRANTA LEUCOPSIS
}

(Plate XXVII, Fig. 8)

Anser leucopsis, Gould, Birds Europe, v, pl. 350 (1837).

Bernicla leucopsis, Dresser, Birds Europe, vi, p. 397, pl. 415, fig. 1 (1878) ; Lilford, Col. Fig. Brit. Birds, part xi, pl. (1889) ; Saunders, Ill. Man. Brit. Birds, p. 409 (1899).

Branta leucopsis, Salvadori, Cat. Birds Brit. Mus., xxvii, p. 117 (1895).

Leucopareia leucopsis, Alphéraky, Geese of Europe, p. 171, pls. xx and xxiv (1905).

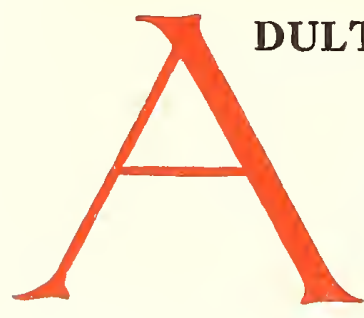

T male.-Front of the head, cheeks and throat white; a line of black from the bill to the eye; hinder part of the crown, neck, back, rump and chest black; upper tail-coverts white; sides and flanks pale grey tipped with white; thighs black edged with white; rest of the underparts pure white; scapulars, lesser, median and greater secondary wing-coverts grey, tipped with black and edged with white; greater primary coverts and quills grey with dark tips; axillaries pale grey. Iris dark brown; bill, legs and toes black. Total length about 27 inches; bill 1.3 inch; wing $16^{\circ} 0$ inches; tail 5.0 inches; tarsus $2 \cdot 8$ inches.

Adult female.-Rather smaller than the male. Wing, about $15^{\circ} 0$ inches.

General distribution. - The breeding-range of the Bernacle-goose is still very imperfectly known, but it has been found nesting in Eastern Greenland in Scoresby Land, above $70^{\circ} \mathrm{N}$. latitude, in Spitzbergen and in limited numbers in the Lofoden Islands. It probably also nests in Iceland, Kolguev, Novaya Zemlia, Franz Josef Land and North-western Siberia as far east as the Taimyr Peninsula. On migration it is an autumn-visitor to South Greenland, Iceland, the Faeroes, the North Sea and Baltic, and to the north-western coasts of Europe generally, Scandinavia, Russia, Denmark, etc. It is sometimes met with in Southern Spain and Italy, and has been known to wander to Mogador and the Azores, where an example killed on the Furnas Lake, San Miguel, is preserved in the Ponta Delgada Museum; while individuals have occurred in North America, in Hudson's Bay and in several of the Eastern United States.

Distribution in the British Isles.-In the British Isles it is a regular autumn-visitor to the Shetlands and Orkneys, but does not appear to winter in the former islands. Though met with sparingly on the east 320 
WILD FOWL

and south coasts of Great Britain, especially when the weather on the continent is severe, it is more common on the west, and is most numerous in the Outer and Inner Hebrides and west coast of Scotland; likewise in the Solway district, Cumberland and Lancashire. To Ireland it is a regular winter-visitor, rather abundant in the north and north-west, and in Dundalk Bay in the east, but rare in the south.

\section{RED-BREASTED GOOSE}

\section{BRANTA RUFICOLLIS}

(Plate XXVII, Fig. 9)

Anser ruficollis, Gould, Birds Europe, v, pl. 351 (1837).

Bernicla ruficollis, Dresser, Birds Europe, vi, p. 403, pl. 416 (1876); Lilford, Col. Fig. Brit. Birds, part xxi, pl. (1892); Saunders, Ill. Man. Brit. Birds, p. 407 (1899).

Branta ruficollis, Salvadori, Cat. Birds Brit. Mus., xxvii, p. 124 (1895).

Rufibranta ruficollis, Alphéraky, Geese of Europe, p. 140, pls. xv and xxiv (1905).

DULT male.-Crown and hind-neck black, that colour extending through the eye to the chin and throat, and leaving a large round white patch between the eye and the base of the bill; a large quadrangular patch of chestnut margined with white covers the side of the head and neck, one angle extending nearly to the eye; fore-neck and chest rich chestnut margined all round with a border of black and white, which extends across the mantle; back, rump and scapulars black; upper tail-coverts white; breast black, the bases of the feathers white; belly and under tail-coverts white; sides, flanks and thighs white, barred with black at the tips of the feathers; wings black, the greater secondary and median wing-coverts tipped with white; axillaries very dark smokygrey. Iris hazel; bill, legs and feet dark brown, almost black. Total length about 22 inches; bill 1.0 inch; wing 13.5 inches; tail 4.0 inches; tarsus $2 \cdot 4$ inches.

Adult female.-Similar to the male, but slightly smaller; wing $\mathbf{1 2 \cdot 0}$ inches.

General distribution.-The red-breasted goose nests in the tundra of Western Siberia from the Obi to the Yenesei, at no great distance from the coast, and is not known to occur much to the east of the Taimyr Peninsula. 
It is also reported to breed on Lake Ukanskoe, in Russian Lapland (H. J. Pearson, "Ibis," 1896, p. 210), and if this statement is confirmed its breeding-range extends much further west than is at present supposed. The frequent visits of this species in winter to Western Europe seem to indicate the possibility of a more western breeding-range. On migration enormous numbers visit the Caspian and Aral seas, also parts of Persia, travelling through South Russia, the Kirghiz Steppes and Turkestan. As a straggler it sometimes occurs in Egypt and possibly in Algeria.

Distribution in the British Isles. - The red-breasted goose is a very rare straggler to the British Isles, but has been procured in Northumberland, Yorkshire, Norfolk, Essex, Devon and Gloucestershire, while other occurrences have been reported on more or less doubtful evidence.

\section{CANADA GOOSE}

\section{BRANTA CANADENSIS}

(Plate XXVII, Fig. 6)

Branta canadensis, Salvadori, Cat. Birds Brit. Mus., xxvii, p. 112 (1895).

Bernicla canadensis, Saunders, Ill. Man. Brit. Birds, p. 412 (1899).

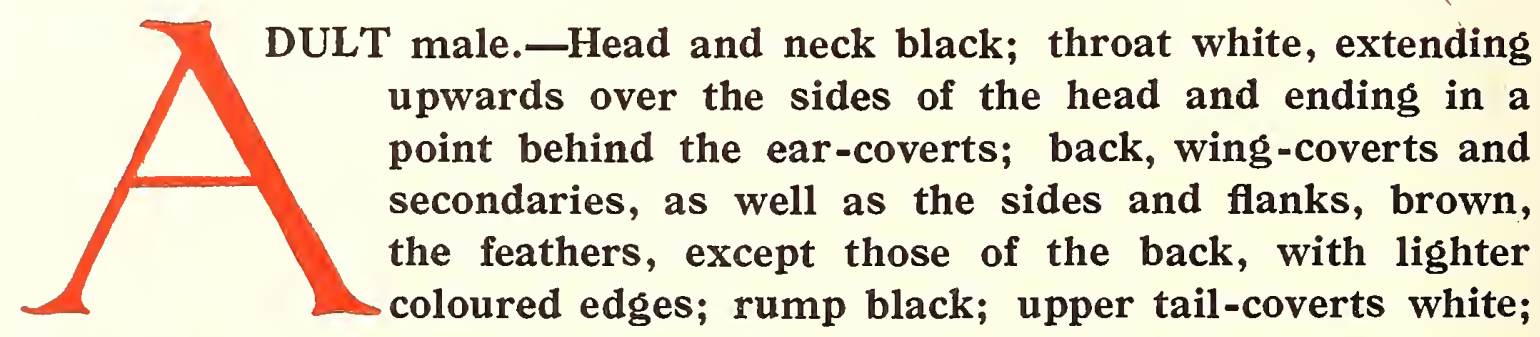

lower part of the neck pale greyish-white, shading into brownish-white on the breast and upper belly, and gradually fading into white on the lower parts of the abdomen and under tail-coverts; primary quills and tailfeathers black, the former greyish towards the base and on the coverts; axillaries light smoky-greyish-brown. Iris dark brown; bill black; legs and toes dark lead-colour, membranes almost black. Total length about 40 inches; bill $2 \cdot 6$ inches; wing 20.0 inches; tail $6 \cdot 0$ inches; tarsus $3 \cdot 3$ inches.

Adult female.-Similar to the male, but rather smaller; wing about $18^{\circ} 0$ inches.

322 


\section{WILD FOWL}

General distribution.-The Canada goose breeds from Arctic North America southwards to the Northern United States, migrating in winter to Mexico, Texas and Florida, and occasionally to Bermuda and Jamaica. In the British Isles it has been domesticated for more than two centuries, and in many parts birds are occasionally shot. For this reason it has been included among the British geese, but there is no evidence to show that wild American birds have ever visited this country.

\section{THE SURFACE-FEEDING DUCKS}

HE surface-feeding ducks are characterized by having the hind toe narrowly lobed (see fig. 2, p. 290), and the bill lengthened and depressed towards the tip, the depth at the base being half, or less than half, the total length measured from the feathering on the forehead to the tip (see fig. 6, p. 290). They may be divided into two groups, the sheld-ducks and the true ducks.

The former are distinguished by having the plumage almost alike in both sexes, and by their longer legs, which enable them to walk with greater ease, and by their uniform chestnut, buff or whitish-buff under tail-coverts, which are never spotted with brown or black.

In the true ducks the plumage is entirely different in the two sexes during the greater part of the year, except when the male assumes the eclipse-plumage after the breeding-season; the legs are shorter and the under tail-coverts are black, or whitish spotted with brown or black. All the males, except the garganey, have the under tail-coverts black, but in that species they resemble those of the females, which are whitish spotted with brown or black. 


\section{SHELD-DUCK}

\section{TADORNA TADORNA}

(Plate XXVIII, Fig. 1)

Tadorna vulpanser, Gould, Birds Europe, v, pl. 357 (1837).

Tadorna cornuta, Dresser, Birds Europe, vi, p. 451, pl. 420 (1878); Hume \& Marshall, Game Birds Ind., iii, p. 135, pl. 18 (1880); Lilford, Col. Fig. Brit. Birds, part xxvi, pl. (1893); Salvadori, Cat. Birds Brit. Mus., xxvii, p. 171 (1895); Saunders, Ill. Man. Brit. Birds, p. 419 (1899).

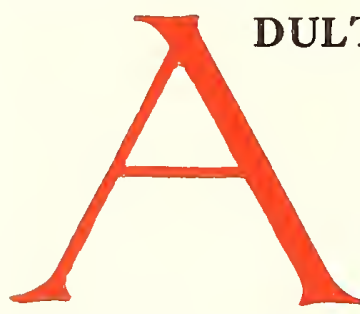

DULT male.-Head and upper half of the neck black, glossed with dull green and dull purplish; round the lower neck a broad white collar; a broad band of bright chestnut across the upper back and upper breast; outer scapulars black, inner ones white; a wide black band down the middle of the breast and belly; under tail-coverts uniform rufous-buff; rest of the plumage of the body, including the wingcoverts and axillaries, pure white; primary quills and their coverts black; the secondaries with the outer web bronze-green, forming a speculum; longest inner secondaries rich chestnut on the outer web, white on the inner web, with a black band along the shaft. Tail-feathers white, tipped with black. Iris brown; bill and swollen knob at the base bright red; legs, toes and membranes pinkish-flesh-colour. Total length about 22 inches; bill $2 \cdot 1$ inches; wing $13 \cdot 0$ inches; tail $4 \cdot 2$ inches; tarsus $2 \cdot 1$ inches.

Adult female. - Similar to the male, but rather smaller and less brightly coloured, the chestnut feathers of the mantle being paler, generally more or less vermiculated with blackish; and the black scapulars slightly freckled with rufous-buff. No swollen knob at the base of the bill. Total length about 20 inches; bill 1.9 inches; wing 12.0 inches; tail 4.0 inches; tarsus $2 \cdot 0$ inches.

General distribution.-In Western Europe the sheld-duck breeds from about $\mathbf{7 0}^{\circ} \mathrm{N}$. latitude in Norway, southwards to France and Spain; also in the Ural Mountains up to about $56^{\circ}$. In the basins of the Black and Caspian Seas it is resident, but over the rest of Europe, along the basin of the Mediterranean and in North Africa it is chiefly known as a wintervisitor. It occasionally visits the Faeroes and has been met with in Iceland. Eastwards it breeds on the salt steppes of Southern Siberia, and in Central Asia on the salt lakes of Turkestan and Mongolia, and ranges to Japan; while in winter it visits North India, South China and Formosa.

Distribution in the British Isles.-In the British Isles it is resident and 324 


\section{WILD FOWL}

generally distributed, being abundant in suitable localities along the coasts, but it is less numerous in the south of England. In the Shetland Islands it is scarce, and it seems doubtful if it has ever bred there. On the east coast of Scotland it is especially plentiful, its numbers being largely increased in winter by flocks from the Continent.

In Western Europe the sheld-duck is almost exclusively a marine species, though it frequently visits the small lochs near the coast.

Nest and eggs.-The nest, generally to be found among sand-hills or near the shore, is placed in a rabbit-burrow at a distance varying from a few feet to several yards from the entrance. Sometimes the burrow is excavated by the birds themselves. The nest is made of dry bents, grass, etc., thickly lined with down from the breast of the female. From seven to twelve cream-coloured eggs, measuring about $2 \cdot 75$ by 1.9 inches, are laid in May, and incubation lasts from twenty-eight to thirty days. The male takes no part in hatching the eggs, but remains in the neighbourhood in company with other drakes of his kind.

This species is commonly known as the "burrow-duck," on account of its curious nesting-habits. The flesh is dark in colour, and has an unpleasant flavour. The food consists of small molluscs, crustaceans, marine insects, and sea-weed, which are mostly picked up between the tides.

\section{RUDDY SHELD-DUCK}

TADORNA CASARCA

(Plate XXVIII, Fig. 2)

Tadorna rutila, Gould, Birds Europe, v, pl. 358 (1837).

Tadorna casarca, Dresser, Birds Europe, vi, p. 461, pl. 421 (1875); Lilford, Col. Fig. Brit. Birds, part xx, pl. (1891) ; Saunders, Ill. Man. Brit. Birds, p. 421 (1899); Ogilvie, Zoologist, p. 392 (1892).

Casarca rutila, Hume \& Marshall, Game Birds Ind., iii, p. 123, pl. 17 (1880) ; Salvadori, Cat. Birds Brit. Mus., xxvii, p. 177 (1895).

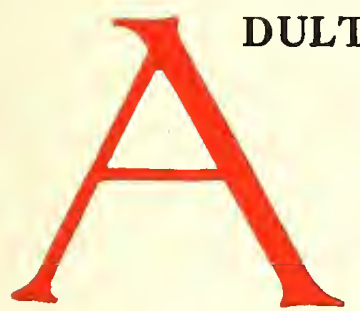

DULT male.-Head, cheeks and chin whitish-buff, shading into orange-brown at the base of the neck, which is surrounded by a narrow, somewhat ill-defined black ring during part of the year; back, scapulars, breast and underparts orange-brown or foxy-red, chestnut on the belly and under tail-coverts; lower back and rump fulvous and greyish, vermiculated with blackish; upper tail-coverts, 


\section{THE GUN AT HOME AND ABROAD}

tail, primary quills and their coverts black; wing-coverts white; secondary quills bronze-green on the outer web, forming a speculum; long inner secondaries pale fulvous shading into foxy-red on the outer web. Axillaries and under wing-coverts pure white. Iris hazel; bill, legs and feet blackish. Total length 24 inches; bill $1.8 \mathrm{inch}$; wing $14 \cdot 0$ inches; tail $4 \cdot 8$ inches; tarsus $2 \cdot 5$ inches.

Adult female. - Similar to the male, but the head is generally rather whiter, and the narrow black collar round the neck is wanting at all seasons. Total length 23 inches; bill 1.6 inch; wing $13 \cdot 2$ inches; tail $4 \cdot 8$ inches; tarsus $2 \cdot 4$ inches.

General distribution.-The distribution of this species in Europe is more southern than that of the common sheld-duck, but in Asia it extends to about $55^{\circ} \mathrm{N}$. latitude. It breeds in small numbers in Southern Spain, but is otherwise rare in South Europe, west of the Adriatic. In Southeastern Europe it becomes more plentiful, in Macedonia, the Danube and Black Sea districts and South Russia. In Asia it breeds in Persia and Turkestan; also in the elevated central parts of Tibet and Mongolia up to an altitude of 16,000 feet, ranging as far north as Lake Baikal and the Amur Valley, and through China to Japan. In winter it visits India in large numbers, and is commonly known as the "Brahminy" duck; also South China and Formosa. It is resident in North Africa from Morocco to Egypt.

Distribution in the British Isles.-To Western Europe it is merely an occasional wanderer, sometimes visiting the British Isles. The most notable occasion was between June and September, 1892, during the great drought in Southern Europe, when many, including flocks of from ten to twenty individuals, were observed on the coasts of Great Britain and in Ireland. During that great emigration some found their way to Iceland and even to Greenland, and stragglers were recorded in North Europe from Norway, Sweden, etc.

Nest and eggs.-The nest, though sometimes placed in a burrow in the ground, is found in very varied situations, such as clefts in rocks, hollow trees, among growing corn, etc. Like that of the common species, it is thickly lined with down. The eggs are laid about the end of April or early in May, and the number in a clutch varies from nine to sixteen. They are indistinguishable from those of the common sheld-duck. Incubation lasts about thirty days. The ruddy sheld-duck is more partial to fresh water than $T$. tadorna, and like the grey geese feeds largely on young corn, grass, etc., as well as crustaceans and molluscs. 


\section{WILD FOWL \\ SHOVELER}

SPATULA CLYPEATA

(Plate XXVIII, Figs. 3 and 3a)

Rhynchaspsis clypeata, Gould, Birds Europe, v, pl. 360 (1837).

Spatula clypeata, Dresser, Birds Europe, vi, p. 497, pl. 425 (1873); Hume \& Marshall, Game Birds Ind., iii, p. 141, pl. 19 (1880); Salvadori, Cat.Birds Brit. Mus., xxvii, p. 306 (1895); Saunders, Ill. Man. Brit. Birds, p. 427 (1899); Millais, Surface-feeding Ducks, p. 58, pls. xxixxviii (1902).

Anas clypeata, Lilford, Col. Fig. Brit. Birds, part x, pl. (1889).

DULT male.-Head and upper half of the neck dark glossy green shading into purple, except on the crown, lores and throat, which are brownish-black, devoid of gloss; lower neck, chest and anterior scapulars white; middle of the hind-neck and back dark brown edged with brownish; rump and upper tail-coverts black glossed with green; wing-coverts and outer webs of the longer scapulars bluishgrey, inner scapulars black with white shaft-streaks; outer webs of the secondaries glossy-green, forming a speculum which is edged internally with white, formed by the tips of the greater wing-coverts; primary quills ashy-brown; breast and belly chestnut; the longer flankfeathers buff towards the tip and vermiculated with black; under tailcoverts black, more or less glossed with green; under wing-coverts and axillaries pure white; middle tail-feathers blackish, outer pairs nearly pure white, intermediate pairs more or less mottled with brownishblack. Iris yellow; bill lead-colour; feet reddish-orange. Total length about 19 inches; bill 2.65 inches; wing about 9.5 inches; tail 3.5 inches; tarsus $1 \cdot 4$ inch.

Adult male in eclipse-plumage (30th August).-General colour of the crown and upperparts uniform dark brown, only the scapulars being margined with pale rufous-buff; sides of the head and neck marked as in the female, rest of the underparts also very similar to those of the female, but the feathers are more strongly marked with blackish; wings as in the adult male.

Adult female.-General colour of the upperparts brownish-black, each feather margined with pale rufous-buff; lower back blackish, irregularly marked and mottled with buff; throat pale rufous-buff almost devoid of markings; head, neck and underparts pale rufous-buff, streaked on 


\section{THE GUN AT HOME AND ABROAD}

the crown and spotted on the sides of the head and fore-neck with blackish; rest of the underparts blackish-grey widely margined with pale rufousbuff, giving these parts a mottled or coarsely spotted appearance; under tail-coverts pale reddish-buff, spotted and marked with blackish; wings much like those of the male, but the wing-coverts are greyer, the green speculum on the secondaries less bright, and the longer scapulars devoid of blue-grey on the outer web. Iris light hazel; bill brown; feet dull orange. Total length about 18 inches; bill 2.4 inches; wing 8.5 inches; tail 3.0 inches; tarsus 1.4 inch.

General distribution.-The Shoveler inhabits the greater part of the northern hemisphere, and during the summer-months its range is circumpolar. Its breeding-range is a very wide one; in Europe it is seldom found further north than the Arctic Circle, but from thence southwards to North Africa it is more or less universally distributed in suitable localities, and is said to be resident in the highlands of Abyssinia. Across Asia, south of about $68^{\circ} \mathrm{N}$. latitude, it extends to the Pacific. In winter the numbers in the Mediterranean basin are greatly increased by migrants from the north, and its movements extend to the Canary Islands, Senegambia and Somaliland, while it has even been recorded from the Cape. It is also found in Arabia, Persia, India, Ceylon, South China, Japan, Formosa and the Hawaiian Islands. In North America it is widely distributed, and breeds from Alaska southwards to the Southern States, wintering in the West Indies, Panama and Colombia.

Distribution in the British Isles.-To the British Isles the shoveler is chiefly a winter-visitor, but it is also resident and breeds in many parts. Since the Act for the Preservation of Wildfowl was passed in 1876, the number of pairs which remain to breed has steadily increased, and at the present time it nests in varying numbers from the Orkney Islands southwards. In Ireland it breeds plentifully in many counties and in increasing numbers.

Nest and eggs.-The nest is placed among heather or rough grass, usually near fresh water, and is made of dead grass, lined with down from the breast of the female. The eggs, from eight to fourteen in number, are laid between the end of April and June, according to locality; they vary from whitish-buff to pale greenish-buff, and measure about $2 \cdot 2$ by 1.5 inches. Incubation lasts from twenty-one to twenty-three days.

The food consists of grasses, weeds, worms, molluscs, aquatic insects, etc., and the flesh is usually excellent. 
WILD FOWL

\section{MALLARD OR COMMON WILD DUCK}

\section{ANAS BOSCAS}

(Plate XXV)

Anas boschas, Gould, Birds Europe, v, pl. 361 (1837); Dresser, Birds Europe, vi, p. 469, pl. 422 (1873).

Anas boscas, Hume \& Marshall, Game Birds Ind., iii, p. 151, pl. 21 (1880) ; Lilford, Col. Fig. Brit. Birds, part viii, pl. (1888) ; Salvadori, Cat. Birds Brit. Mus., xxvii, p. 189 (1895); Saunders, Ill. Man. Brit. Birds, p. 423 (1899); Millais, Surface-feeding Ducks, p. 1, pls. i-xi (1902).

DULT male.-Head and neck rich glossy green, shading into
purple, and bordered below by a white ring interrupted
behind; mantle greyish-brown, scapulars grey, both being
finely vermiculated with brown; lower back, rump and
upper tail-coverts black; wings ashy-brown, the outer
webs of the secondaries glossed with green and purple, forming a speculum bordered with black and white bands formed by the tips of the secondary quills and the greater coverts ; base of the foreneck and chest deep chestnut-brown; breast and belly white, finely ver miculated with brown; under tail-coverts black; under wing-coverts and axillaries pure white; four middle pairs of tail-feathers black glossed with purplish-green and recurved, the remaining pairs pale grey, edged and mottled with whitish. Iris brown; bill yellowish-green, nail black, base of the under mandible reddish-yellow; legs and feet reddishorange. Total length about 22 inches; bill 2.2 inches; wing 10.5 inches; tail $3 \cdot 8$ inches; tarsus $1 \cdot 8$ inch.

Adult male in eclipse-plumage (middle of June to September). - Like the adult female, but somewhat darker. The crown blackish; the dark blackishbrown feathers of the back margined with rufous; the feathers of the breast and sides with blackish middles and rusty-red edges, especially on the chest; and the rump and upper tail-coverts black, glossed with dark green. The bill dull olive-green.

Adult female. - General colour above dark brown, each feather being margined with brownish-buff; underparts, including the under tailcoverts, buff streaked with dark brown, except on the chin and throat; long feathers of the sides and flanks with a brown shaft-stripe and submarginal band ; wings as in the male. Total length about 20 inches; bill $2 \cdot 1$ inches; wing 10.3 inches; tail 3.5 inches; tarsus 1.6 inch. 
THE GUN AT HOME AND ABROAD

General distribution. - The mallard, or common wild duck, is to be found over the greater part of the northern hemisphere; throughout Europe it is generally distributed, and breeds in suitable localities from the Arctic Circle southwards to the Mediterranean and North Africa. It occurs in Madeira, the Canaries and Azores, and a few pairs remain to nest in the last-named group. In Asia it occurs from Turkestan to China and Japan, and breeds as far south as Kashmir, visiting India and Burma in winter. It is abundant in Iceland in summer. In North America it nests from Alaska to Greenland southwards, and in winter is found as far south as Mexico, and in Central America as far as Panama. The Greenland birds have recently been separated, but the differences ascribed to them appear to be extremely doubtful and are probably due to age, younger female birds having the underparts much more heavily spotted than the adults.

Distribution in the British Isles.-In the British Isles the mallard is resident and generally distributed, but the numbers that breed are few compared with the hosts that annually visit this country from the Continent during the winter-months.

Nest and eggs.-The nest, of grass and leaves lined with down, is usually placed on the ground among long grass, bushes or heather near a lake, river or stream: many other situations are also resorted to, such as hollow trees many feet from the ground, the tops of pollard willows, and old nests of other birds-wood-pigeons, rooks, crows, etc.-are sometimes utilized. The eggs, which are laid between the end of March and the middle of May, vary in number from eight to twelve; they are pale greyish-green or yellowish-green, more rarely cream-colour, and measure about $2 \cdot 25$ by $1 \cdot 6$ inches. Incubation lasts from twenty-six to twenty-eight days.

The mallard is omnivorous and is principally a night-feeder; its flesh is excellent.

In a wild state the mallard is generally monogamous, and sometimes inter-breeds with the pintail, more rarely with the wigeon and gadwall, the offspring being fertile. 


\section{WILD FOWL \\ GADWALL \\ CHAULELASMUS STREPERUS}

(Plate XXVIII, Fig. 4)

Chauliodes strepera, Gould, Birds Europe, v, pl. 366 (1837).

Chaulelasmus streperus, Dresser, Birds Europe, vi, p. 487, pl. 424 (1873); Hume \& Marshall, Game Birds Ind., iii, p. 181, pl. 24 (1880); Salvadori, Cat. Birds Brit. Mus., xxvii, p. 221 (1895).

Anas strepera, Lilford, Col. Fig. Brit. Birds, part xv, pl. (1890); Saunders, Ill. Man. Brit. Birds, p. 425 (1899); Millais, Surface-feeding Ducks, p. 29, pls. xii, xiii (1902).

DULT male.-Crown of the head dark brown mottled with dull rufous, rest of the head and neck whitish-buff thickly speckled with brown; feathers of the mantle black with white wavy bars; lower back, rump and upper tailcoverts black; inner scapulars ashy-brown margined with pale rufous-buff; wings ash-brown, most of the median wing-coverts dark chestnut; innermost greater secondarycoverts black; median secondaries black on the outer web, innermost ones pure white, forming a black and white speculum when the wing is closed; feathers of the chest white and black with a submarginal white band, giving these parts a scaled appearance; sides and fianks black, finely waved with white; breast and belly mostly white in the middle and vermiculated towards the sides with greyish-brown; under tailcoverts black; under wing-coverts and axillaries white; tail-feathers grey, edged with whitish, and the outer pairs indistinctly mottled with buff towards the end of the outer web. Iris dark hazel; bill lead-colour; legs, toes and membranes dull orange. Total length about 21 inches; bill 1.7 inch; wing $10 \cdot 7$ inches; tail $3 \cdot 7$ inches; tarsus $1 \cdot 5$ inch.

Adult male in eclipse-plumage. - Very similar in plumage to the adult female, but easily distinguished by the dark chestnut wing-coverts.

Adult female. - General colour of the plumage much like that of the female mallard, but the wing-speculum is black and white, much as in the male, though none of the secondaries are black on the outer web, all being grey except the two innermost ones, which are whitish. The chin and throat are spotted with dark brown like the rest of the head, and the underparts, including the under tail-coverts are more finely and distinctly spotted with brown; under wing-coverts and axillaries white; the much narrower and shorter bill is also a character by which the 


\section{THE GUN AT HOME AND ABROAD}

present species may be easily distinguished at a glance from the female mallard. Total length about 19.5 inches; bill 1.5 inch; wing 9.5 inches; tail $3 \cdot 4$ inches; tarsus $1 \cdot 5$ inch.

General distribution.-The gadwall is found throughout the greater part of the northern hemisphere, but does not extend into the Arctic regions. It breeds in small numbers in Iceland, and in Europe from Southern Sweden, the Baltic Provinces and Russia (extending, according to Saunders, as far north as Archangel) southwards in suitable localities to Spain and the northern shores of the Black Sea. In Asia it extends eastwards through Southern Siberia south of about $60^{\circ} \mathrm{N}$. latitude to the Pacific, and southwards to the Caspian and North Turkestan. In winter it visits the basin of the Mediterranean and the inland waters of North Africa, following the Nile Valley into Nubia and Abyssinia. From October till April it is one of the most plentiful ducks in North India, but is less numerous in China and Japan. In North America it is generally distributed in the breeding-season over the Northern United States, and winters in the Southern States, Mexico and the West Indies.

Distribution in the British Isles.-Though a somewhat scarce wintervisitor to the British Isles, the gadwall is resident in some parts, breeding in considerable numbers in Norfolk and Suffolk, and of late years in two localities in the south of Scotland. The nesting of this species in Norfolk commenced in the middle of last century, when a pair of pinioned gadwalls induced wild birds to remain and breed. Though a comparatively scarce and uncertain winter-visitor in most other parts, it is tolerably numerous in the Hebrides, and is said to be abundant in Tiree. It is rare in the west of England and Wales, and uncommon in the east. In Ireland it is irregularly distributed, but is probably more numerous than is supposed.

Nest and eggs. - The nest is much like that of the mallard; the eggs, from eight to thirteen in number, vary from cream-colour to greyishgreen, and measure about $2 \cdot 15$ by 1.5 inches. They are laid in May and June.

The gadwall is chiefly a night-feeder, and subsists largely on grain and vegetable matter: its flesh is excellent. It prefers fresh-water lakes which afford plenty of covert, and owing to its retiring habits is often overlooked. 



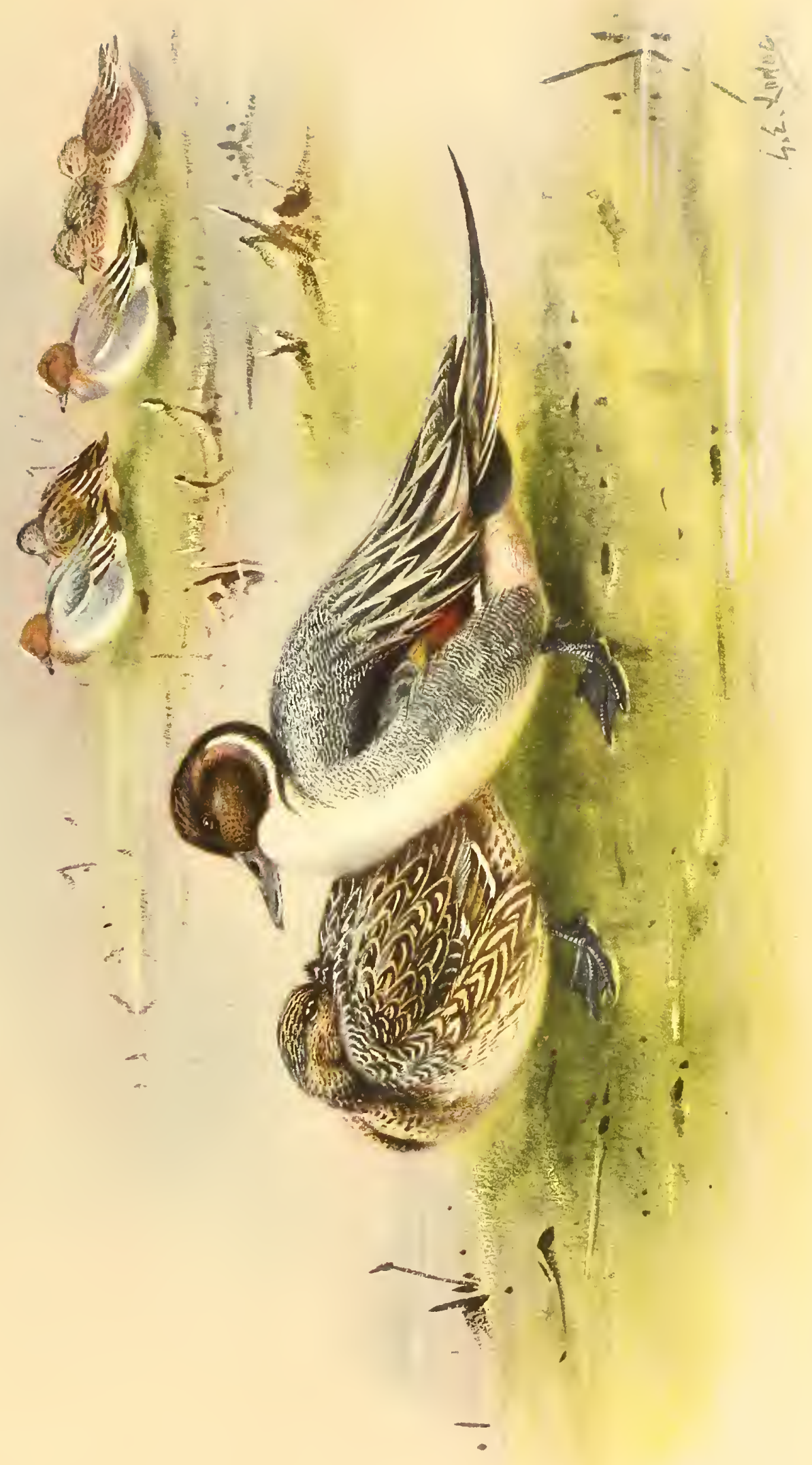





\section{WILD FOWL}

\section{PINTAIL}

DAFILA ACUTA

(Plates XXVI and XXVIII, Fig. 7)

Dafila caudacuta, Gould, Birds Europe, v, pl. 365 (1837).

Dafila acuta, Dresser, Birds Europe, vi, p. 531, pls. 430, 431 (1873) ; Hume \& Marshall, Game Birds Ind., iii, p. 189, pl. 25 (1880); Salvadori, Cat. Birds Brit. Mus., xxvii, p. 270 (1895) ; Saunders, Ill. Man. Brit. Birds, p. 429 (1899); Millais, Surface-feeding Ducks, p. 92 , pls. xxxvii-xli (1902).

Anas acuta, Lilford, Col. Fig. Brit. Birds, part xiii, pl. (1890).

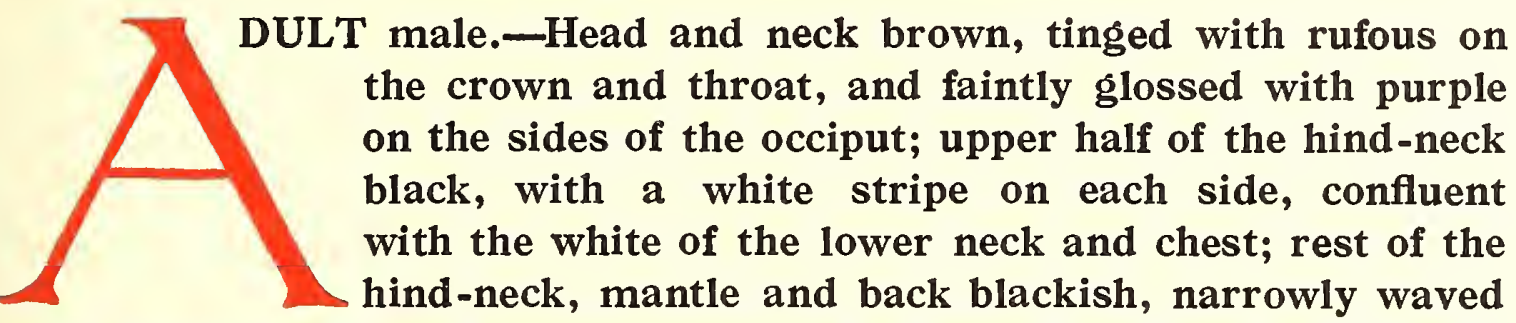

with white; long inner secondary quills and scapulars black, edged with grey more or less mottled with brown; wings ashy-grey; outer webs of the median and inner secondaries dull bronze-purple shading into green and forming a speculum, which is edged with black and white externally and pale chestnut internally, the latter band being formed by the tips of the greater secondary-coverts; sides and flanks with narrow wavy bars of dark brown and white; under tail-coverts black edged externally with white; a white patch on each side of the rump; under wing-coverts mostly ash-grey; axillaries white, mottled with grey; middle tail-feathers black, much lengthened and pointed, the outer pairs grey, edged with whitish. Iris dark brown; bill black, dull leaden-blue on the sides; feet greyish-black. Total length about 25 inches; bill 2.0 inches; wing 10.5 inches; tail 6.8 inches; tarsus $1 \cdot 6$ inch.

Adult male in eclipse-plumage.-Resembles the adult female, but may be distinguished by the metallic green alar speculum, and by being darker and richer in colour.

Adult female.-General colour above, including the sides and flanks, dusky greyish-brown, varied with irregular bars of yellowish-white or pale ochraceous; head and neck pale buff, narrowly streaked with dark brown, and becoming nearly uniform white on the chin and throat; wings ashy-brown, all the feathers being narrowly edged, and the secondaries tipped with white; rest of the underparts dull white, more or less 


\section{THE GUN AT HOME AND ABROAD}

streaked on the abdomen and under tail-coverts with brown; under wing-coverts and axillaries ashy-brown mottled with white. Total length about 19 inches; bill 1.9 inch; wing 9.5 inches; tail 4.0 inches; tarsus $1 \cdot 5$ inch.

General distribution.-The pintail inhabits the greater part of the northern hemisphere, and in the summer its range is circumpolar. It breeds in Iceland, the Faeroe Islands and the northern parts of Europe about as far south as $50^{\circ} \mathrm{N}$. latitude, also in some numbers in Southern Spain and France, in the Rhone delta. In Asia it ranges to the Pacific, and it has been found nesting on the Yenesei as far north as $72^{\circ}$. In winter numbers migrate to Northern Africa, including Egypt and Southern Abyssinia; also Asia Minor, Persia, India, Ceylon, Burma, China, Japan and Borneo. It also occurs in the Hawaiian Islands and Laysan. In North America it is met with in Alaska up to $72^{\circ}$, and extends eastwards to Labrador; while in winter it is found as far south as the West lndies and Panama.

Distribution in the British Isles.-To the British Isles it is chiefly a winter-visitor, between September and April, but from time to time a few have remained to nest in Scotland, and possibly in Ireland. In recent years a small number have bred annually in the Orkney Islands and on Loch Leven in Fife, and their numbers seem to be increasing, thanks to the protection which has now been afforded them.

Nest and eggs. - The nest is placed in a clump of rough grass not far from fresh water, and is made of dried grass, etc., and thickly lined with down. The eggs are laid between May and June, according to locality; in Orkney well-grown broods of young may be seen early in June, but in North Russia, etc., the first eggs appear to be laid about that date. They vary in number from seven to ten, and in colour from greenish-buff to greyish-green, the average measurements being about $2 \cdot 1$ by $1 \cdot 5$ inches. Incubation lasts about twenty-four days.

The food consists chiefly of fresh-water plants, insects and small molluscs, and the flesh is particularly excellent.

Though the pintail is a fresh-water duck during the summer, in many parts it resorts to salt water during the winter months. At that season large flocks may be seen composed entirely of drakes, a peculiarity almost confined to this species. It is constantly to be found in company with flocks of wigeon, and has often been known to pair with that species and with the mallard, the offspring being perfectly fertile. 


\section{WIGEON}

\section{MARECA PENELOPE}

\section{(Plate XXVIII, Fig. 5)}

Mareca penelope, Gould, Birds Europe, v, pl. 359 (1837); Dresser, Birds Europe, vi, p. 541, pls. 432, 433 (1876) ; Hume \& Marshall, Game Birds Ind., iii, p. 197, pl. 26 (1880) ; Lilford, Col. Fig. Brit. Birds, part xv, pl. (1890); Salvadori, Cat. Birds Brit.Mus., xxvii, p. 227 (1895); Saunders, Ill. Man. Brit. Birds, p. 437 (1899); Millais, Surface-feeding Ducks, p. 38, pls. xivxix (1902).

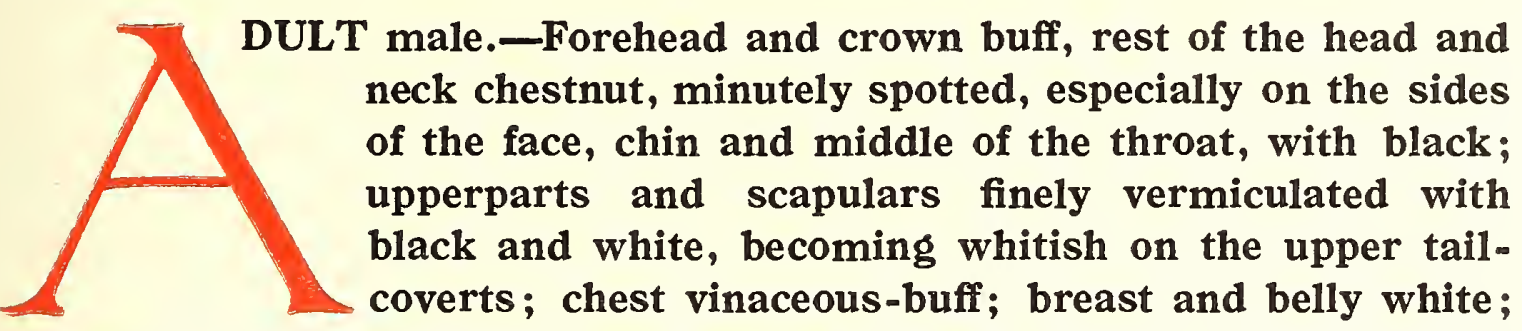
under tail-coverts black; wing-coverts mostly white; primary quills and their coverts brownish-black, secondaries similar, but mostly black and metallic green on the outer web, the latter colour forming a speculum, bordered internally by a black band formed by the tips of the greater secondary-coverts; the outermost of the long innermost secondaries have the outer web white; in the rest the outer web is black, narrowly edged with white; under wing-coverts grey, finely vermiculated with white; axillaries white, slightly mottled with grey; tail dark grey, the outer feathers edged with whitish. Iris dark brown; bill bluish lead-colour tipped with black; legs and toes dark brown. Total length about 19.5 inches; bill 1.5 inch; wing 10.5 inches; tail 4.5 inches; tarsus 1.6 inch.

Adult male in eclipse-plumage.-Entire head and neck chestnut, spotted with black; "rest of the upperparts black, barred with rufous; chest, sides and flanks dull chestnut, the first named more or less barred with black; under tail-coverts white, barred with black.

Adult female.-General colour above brown, the mantle barred with rufous-buff, the scapulars margined with the same colour, and the lower back and rump edged with whitish; top of the head and nape black, irregu larly barred with pale rufous; the sides of the head, throat and fore-neck whitish-buff, thickly spotted with black; chest and flank-feathers pale reddish-brown; breast and belly white; under tail-coverts white, barred with black; wings brownish-black, most of the coverts and secondaries 


\section{THE GUN AT HOME AND ABROAD}

tipped with white; under wing-coverts pale greyish-brown, edged with whitish; axillaries mottled with the same colours; tail like that of the male. Total length about 17.5 inches; bill 1.3 inch; wing 9.5 inches; tail 3.7 inches; tarsus 1.5 inch.

General distribution.-The wigeon is widely distributed over Europe and Asia, breeding in the more northerly parts of its range up to about $70^{\circ} \mathrm{N}$. latitude. It nests in Iceland, the Faeroes, abundantly in Scandinavia, Finland and North Russia, also in the islands of Kolguev and Waigats, and in decreasing numbers in Denmark, Holland and North Germany, while eggs have been taken in France and on the lower valley of the Danube. In Asia its breeding range extends from about $71^{\circ}$ south to about $51^{\circ}$, nests having been found in the Baikal basin. During October and November it passes through Central Europe and visits the whole of Southern Europe and North Africa as far south as Abyssinia, while stragglers reach Greenland, the Atlantic coasts of North America, especially Virginia and North and South Carolina, also Madeira and the Azores. Eastwards on migration it passes through Turkestan and Mongolia, wintering in Persia, India, Burma, China, Japan and even the Sunda Islands, and it has been recorded from the Marshall Islands. Some cross Bering Sea to the Aleutian Islands and Alaska, and the wigeon is not uncommon on the coast of California.

Distribution in the British Isles. - In the British Isles, though the countless numbers of wigeon seen on the coasts in autumn and winter are visitors only, a considerable number remain to breed in the Shetland and Orkney Islands and in many parts of Scotland, also occasionally in the north of England and Wales. In Ireland there is no actual proof of its having bred, but it is possible that a few pairs may nest there.

Nest and eggs.-The nest is usually placed near water among coarse grass, rushes or heather, and is composed of dead grass, thickly lined with down from the breast of the female. The eggs, generally from seven to ten in number, laid in May and June, are cream-colour, sometimes faintly tinged with green, and measure about $2 \cdot 1$ by $1 \cdot 4$ inches. Incubation lasts from twenty-four to twenty-five days.

The food in the early part of the autumn consists chiefly of aquatic plants, insects and molluscs, which are consumed by day, but in winter the wigeon becomes nocturnal and feeds largely on Zostera marina. The flesh is excellent. It has been known to breed with the mallard, pintail, gadwall and teal. 


\title{
WILD FOWL
}

The peculiar whistling note of the male-whee-you-is worthy of mention, as it is unlike the note of any other British species. It is a very gregarious bird, and collects in enormous flocks.

\section{AMERICAN WIGEON}

\author{
MARECA AMERICANA \\ (Plate XXVIII, Fig. 6)
}

Anas americana, Audubon, Orn. Biogr., iv, p. 337, pl. 345 (1838).

Mareca americana, Salvadori, Cat. Birds Brit. Mus., xxvii, p. 233 (1895); Lilford, Col. Fig. Brit. Birds, part xxxiii, pl. (1896) ; Saunders, Ill. Man. Brit. Birds, p. 439 (1899) ; Millais, Surface-feeding Ducks, p. 55, pl. xx (1902).

DULT male.-Forehead and the top of the head white, tinged with buff; sides of the head and neck similar, but thickly speckled with black; behind the eyes a wide band of metallic-green bordering the hinder-part of the crown; upperparts and scapulars rufous-grey, with fine wavy black lines; rump and upper tail-coverts greyer, the longer upper tail-coverts black on the outer web; chest, sides and flanks vinaceous, the latter narrowly banded with black; breast and belly pure white; under tail-coverts black; wing like that of $M$. penelope, but the outermost of the long inner secondaries (the 5th) has the outer web grey instead of white; tail much like that of $M$. penelope. Iris brown; bill light greyish-blue, tip black; legs and feet light-bluish. Total length about 20 inches; bill 1.5 inch; wing 10.5 inches; tail 4.0 inches; tarsus 1.8 inch.

Adult male in eclipse-plumage.-Head and neck very similar to those of the adult female, whitish-buff, spotted all over with black, darkest on the crown and occiput, where the markings are larger and take the form of irregular bars; back and scapulars dark brown, widely margined with chestnut and barred with pale rufous; chest and sides dull chestnut, the former barred with blackish; under tail-coverts whitish, barred with brown, tinged with rufous.

Adult female.-Very similar to the female of $M$. penelope, but the ground colour of the head and neck much whiter, the speculum formed by the outer webs of the secondaries uniform brownish-black, not mottled 


\section{THE GUN AT HOME AND ABROAD}

with grey; the outermost of the long inner secondaries (the 5th) with the outer web grey instead of brownish; the axillaries pure white. Total length about 18 inches; bill 1.4 inch; wing 9.5 inches; tail 3.8 inches; tarsus 1.5 inch.

General distribution.-This North American species breeds from Alaska eastwards to Hudson's Bay, and southwards to Utah, Colorado, and Wisconsin, migrating south in winter to Mexico, Central America and the West Indies. It has also been obtained in the Hawaiian Islands.

Distribution in the British Isles.-To the British Isles it is a very rare straggler, and there are only one or two authentic records of its occurrence. It has also been obtained in France, the Azores (a male, Sete Cidades, San Miguel) and on Bering Island. Its reported breeding in Iceland is extremely doubtful.

It is said to nest on high, dry ground among trees and bushes, some distance from water. The eggs, from seven to ten in number, are like those of the wigeon.

\section{COMMON TEAL \\ QUERQUEDULA CRECCA}

(Plate XXVIII, Fig. 8)

Querquedula crecca, Gould, Birds Europe, v, pl. 362 (1837); Dresser, Birds Europe, vi, p. 507, pl. 426 (1871) ; Hume \& Marshall, Game-Birds Ind., iii, p. 205, pl. 27 (1880).

Nettion crecca, Salvadori, Cat. Birds Brit. Mus., xxvii, p. 243 (1895) ; Saunders, Ill. Man. Brit. Birds, p. 431 (1899); Millais, Surface-feeding Ducks, p. 79, pls. xxxi-xxxv (1902).

Anas crecca, Lilford, Col. Fig. Brit. Birds, part viii, pl. (1888).

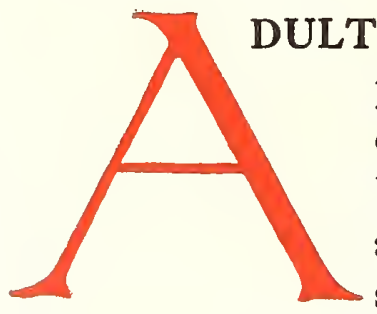

male.-Head and neck chestnut, a metallic green and purple band down each side of the head between the eye and the nape, which is velvety-black; a narrow buff line commencing behind the gape passes upwards above the eye; chin blackish; back, inner scapulars, outer scapulars buff, edged on the outer web with black; lower back, rump, upper tail-coverts and tail dark ashy-brown, the two last named with light margins; breast and belly white, the former with round black spots; under tail-coverts black, the lateral ones buff with a band of black 338 


\section{WILD FOWL}

at the base formed by the black tips of the shorter feathers; wing-coverts, primary quills and long inner secondary quills dark ashy-grey; outer webs of the outer secondaries black, tipped with white, the median ones green, forming a black and green speculum bordered externally with white and internally with white, tinged with rufous; outer under wing coverts grey, edged with white; axillaries pure white. Iris hazel; bill black; legs, toes and membranes brownish-grey. Total length about 14.5 inches; bill $1.5 \mathrm{inch}$; wing 7.2 inches; tail 2.7 inches; tarsus $1 \cdot 2$ inch.

Adult male in eclipse-plumage. - Very similar to the female.

Adult female.-General colour above brownish-black, the feathers with paler margins and rufous-buff bars; top of the head blackish, streaked with rufous-buff; sides of the head and neck whitish, thickly spotted with brown, a line of dusky feathers behind the eye; chin and throat whitish; underparts whitish, tinged with rufous on the chest and mottled on the breast and sides with dusky middles; under tail-coverts white, spotted with brownish-black; wings and tail like those of the male. Total length 13.5 inches; bill 1.4 inch; wing $7 \cdot 1$ inches; tail $2 \cdot 5$ inches; tarsus $1 \cdot 1$ inch.

General distribution.-The teal, the smallest of our British ducks, is widely distributed over Europe and Asia, breeding plentifully over the more northern parts of its range in the Palæarctic region, including Iceland and the Faeroes, up to about $70^{\circ} \mathrm{N}$. latitude, and in gradually decreas ing numbers southward to the Mediterranean, and even in the Azores, where it has been found nesting about the large lakes in San Miguel. In Asia it likewise nests in great numbers north of the Arctic Circle, and in diminishing numbers in Turkestan, Mongolia and the valley of the Amur. In winter it is abundant over the Continent wherever open water is to be found; also North Africa, some extending as far south as Madeira and the Canary Islands, as well as the highlands of Abyssinia. Eastward it ranges to Persia, Sokotra, India, Ceylon, Burma, China and Japan. In North America it has been procured in Alaska in summer, and may possibly breed there, while to the east coast and to Greenland it is an occasional straggler.

Distribution in the British Isles.-In the British Isles it is resident, and breeds from the Shetlands, Orkneys and Outer Hebrides southwards, being most plentiful in the north, fairly common in the north and east of England and in Wales, and least numerous in the midland and southern 


\section{THE GUN AT HOME AND ABROAD}

counties of England. In Ireland it is universally distributed, and nests in every county. In winter, from September onwards, its numbers are vastly increased by visitors from Europe.

Nest and eggs.-The nest is usually placed among rough grass, heather and low bushes in the vicinity of water, and is made of dead grass, leaves, etc., lined with blackish down. From eight to fourteen creamywhite or pale buff eggs, often with a tinge of green, are laid in May or June, according to locality, and measure about 1.8 by 1.3 inches.

The teal frequents fresh water, and feeds on the seeds of aquatic plants, grain, worms, slugs and insects; its flesh is much esteemed as food.

\section{AMERICAN TEAL \\ QUERQUEDULA CAROLINENSIS}

Nettion carolinense, Salvadori, Cat. Birds Brit. Mus., xxvii, p. 250 (1895); Saunders, Ill. Man. Brit. Birds, p. 433 (1899); Millais, Surface-feeding Ducks, p. 89, pl. xxxvi (1902).

Anas carolinensis, Lilford, Col. Fig. Brit. Birds, part xxxv, pl. (1897).

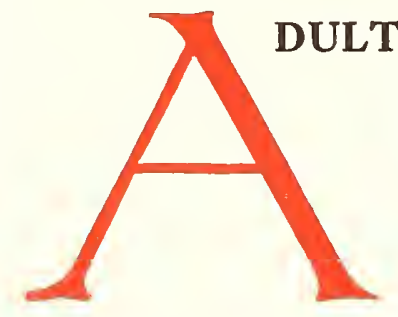

male.-Similar to the male of $Q$. crecca, but the light band ascending from the gape and passing over the eye is nearly obsolete; the scapulars are uniform slategrey with no whitish-buff on the outer ones; there is a broad whitish band on each side of the breast above the shoulder, and the speculum is edged internally with chestnut. Total length about 14.5 inches; bill 1.5 inch; wing $7 \cdot 2$ inches; tail $3 \cdot 0$ inches; tarsus $1 \cdot 2$ inch.

Adult male in eclipse-plumage.-Very similar to the female.

Adult female.-Similar to the female of $Q$. crecca, but the wing-speculum is edged internally with rufous, as in the male. Total length about 13.5 inches; bill 1.4 inch; wing 6.8 inches; tail 2.5 inches; tarsus $1 \cdot 2$ inch.

General distribution.-The American teal replaces the common teal in North America, where it is generally distributed over the northern portions in summer, from the Arctic regions of Alaska to Greenland. It is resident in the Aleutian Islands, and in winter its migrations extend 340 


\section{WILD FOWL}

to Mexico, Central America and the West Indies. It has been recorded from Bermuda, and is an accidental wanderer to the Hawaiian Islands.

Distribution in the British Isles.-To the British Isles it is only a very occasional straggler, and has been met with three times, in Yorkshire, Devon and Hants respectively, the last mentioned record being somewhat doubtful.

The nesting-habits, eggs, food, etc., are much the same as those of the common teal.

\section{AMERICAN BLUE-WINGED TEAL QUERQUEDULA DISCORS}

(Plate XXVIII, Fig. 9)

Querquedula discors, Salvadori, Cat. Birds Brit. Mus., xxvii, p. 299 (1895) ; Saunders, Ill. Man. Brit. Birds, p. 434 (1899); Millais, Surface-feeding Ducks, p. 76 (1902).

Anas discors, Lilford, Col. Fig. Brit. Birds, part xxxv, pl. (1897).

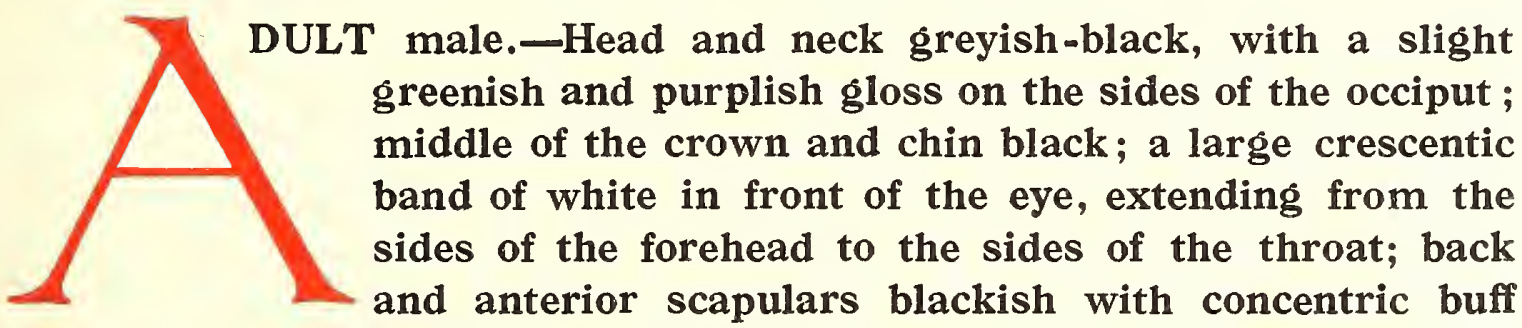
bars; longer scapulars black with buff shaft-streaks, the two outermost ones with the outer web pale greyish-blue; lower back, rump, upper tail-coverts and tail brownish-black glossed with green, with paler margins; chest, sides, flanks and belly pale rufous-white spotted with black, the longer flank-feathers regularly barred; breast darker and barred with blackish; under tail-coverts black; primaries and their coverts brownish-black; lesser wing-coverts pale greyish-blue; greater secondary-coverts black, widely tipped with white; outer secondaries glossy green on the outer web, tipped with black, narrowly margined with white, and forming a distinct speculum; long inner secondaries black with pale buff shafts like most of the longer scapulars; under wing-coverts and axillaries, except along the edge of the wing, pure white. Iris brown; bill black; feet yellowish. Total length about 14.5 inches; bill $1 \cdot 6$ inch; wing $7 \cdot 5$ inches; tail $2 \cdot 8$ inches; tarsus $1 \cdot 3$ inch. 
THE GUN AT HOME AND ABROAD

Adult male in eclipse-plumage. - Very similar to the adult female, but easily distinguished by the rich green speculum and brighter grey-blue wing-coverts.

Adult female.-Upperparts dark brown, the feathers with pale edges; sides of the head and neck nearly white, minutely streaked and spotted with blackish, the markings being most dense behind the eye, where they form a dusky stripe; lores, chin and throat white; underparts white with dusky blackish-brown middles to the feathers, giving these parts a heavily mottled appearance; under tail-coverts white spotted with brownish; lesser and median wing-coverts pale greyish-blue; greater secondary-coverts brownish with white tips; outer secondaries slightly glossed with greenish, forming an indistinct speculum; inner under wing-coverts and axillaries pure white. Total length about 14.5 inches; bill 1.5 inch; wing $7 \cdot 1$ inches; tail 2.6 inches; tarsus 1.2 inch.

General distribution.-This species is a native of North America, south of about $60^{\circ} \mathrm{N}$. latitude, and is met with chiefly east of the Rocky Mountains. It breeds from Labrador and the Valley of the Saskatchewan southwards in suitable localities to Florida and Western Mexico, wintering in the Southern States, Central America, the West Indies, and extending to North-western South America, Colombia, Ecuador and Peru.

Distribution in the British Isles. - To the British Isles the American blue-winged teal is a very rare wanderer, and three female examples only have been obtained, in Dumfries, Cheshire and co. Cork respectively.

Its mode of nesting, and pale cream-coloured eggs, measuring about 1.8 by 1.3 inches, and likewise its habits, do not seem to differ much from those of its allies. 


\section{WILD FOWL \\ GARGANEY \\ QUERQUEDULA QUERQUEDULA}

(Plate XXVIII, Fig. 10)

Querquedula circia, Gould, Birds Europe, v, pl. 364 (1837); Dresser, Birds Europe, vi, p. 513, pl. 427 (1871) ; Hume \& Marshall, Game Birds Ind., iii, p. 215, pl. 28 (1880); Salva. dori, Cat. Birds Brit. Mus., xxvii, p. 293 (1895); Saunders, Ill. Man. Brit. Birds, p. 435 (1899); Millais, Surface-feeding Ducks, p. 71, pls. xxix-xxx (1902).

Anas circia, Lilford, Col. Fig. Brit. Birds, part xiii, pl. (1890).

DULT male.-Crown and occiput brownish-black, with dis-
tinct white shaft-stripes on the forehead, bordered on
each side by a broad white band commencing in front
of the eye and uniting on the occiput; chin and middle
of the throat dull black; sides of the head and rest of
the neck dull rufous-brown, finely streaked with white; mantle and upper tail-coverts black, barred with concentric lines or bars of rufous-buff; back and rump blackish, edged with greyish-olive; longer scapulars black glossed with dull green, with white shaft-streaks and pale grey inner webs; chest and breast barred with buff and black like the mantle; sides and flanks white, narrowly barred with black, and the longer feathers tipped with grey; belly white, freckled with blackish; under tail-coverts white, spotted with brown; primaries and their coverts dark brown, the latter whitish-grey on the outer web; lesser and median wing-coverts brownish-grey; greater secondary coverts brown, widely tipped with white; outer secondaries brown glossed with dull green, widely tipped with white, forming a distinct speculum; long inner secondaries brown, axillaries pure white. Iris hazel; bill black; legs, toes and membranes greyish-brown. Total length about 14.5 inches; bill 1.6 inch; wing $7 \cdot 5$ inches; tail $2 \cdot 7$ inches; tarsus $1 \cdot 2$ inch.

Adult male in eclipse-plumage.-Similar to the adult female, but easily distinguished by the rich green speculum and blue-grey wing-coverts.

Adult female.-Upperparts dark brown, the feathers with pale edges; sides of the head and neck nearly white, streaked with dark brown, most dense behind the eye, where they form a dusky stripe; post superciliary streak, lores, chin and throat mostly pure white; underparts pure white, with brownish middles to the feathers, giving a mottled appearance most conspicuous on the chest, sides and belly; wings much as in the 


\section{THE GUN AT HOME AND ABROAD}

male, but the lesser wing-coverts are brown, tinged with greyish. Total length about 14 inches; bill $1 \cdot 4$ inch; wing $7 \cdot 1$ inches; tail $2 \cdot 7$ inches; tarsus $1 \cdot 2$ inch.

General distribution.-The garganey is met with throughout the greater part of Europe and Asia, and in winter visits the northern and tropical portions of Africa. It is a common breeding species in Europe from Denmark, South Sweden, Finland and North Russia southwards, especially in the east, being much scarcer and less regular in the Iberian Peninsula than it is in the Black Sea district. In Asia its summer-range extends eastwards to Kamchatka, and from about $60^{\circ} \mathrm{N}$. latitude southwards to the Himalaya. In winter the birds breeding in the more northern districts move southwards, and the garganey is then far more abundant in the south, and visits North Africa, wandering as far south as Uganda; eastwards it ranges to Palestine, Arabia, and Persia, is very common in India and Ceylon, and visits China, Japan, the Philippines, Borneo and the Moluccas.

Distribution in the British Isles. - The garganey is chiefly a springvisitor to the British Isles, but also visits our shores, though less frequently, in autumn; while in exceptional instances individuals have been known to pass the winter in this country. It breeds regularly, but in small numbers, in some of the south-eastern counties of England, from Norfolk southwards to Kent, and used to breed regularly in Northumberland before Prestwick Car was drained; it has occasionally done so during recent years in Durham, Yorkshire, Hants and Somerset. In Scotland, the West of England and Wales, and in Ireland, it is irregularly and comparatively rarely met with; in the Shetland and Orkney Islands and in the Outer Hebrides its occurrence is doubtful.

Nest and eggs. - Its nesting-habits, and eggs, laid in the end of April and May, do not differ from those of the common teal. Incubation lasts from twenty-one to twenty-two days.

Its food seems to consist of small fishes, molluscs and aquatic insects, with some vegetable matter, and its flesh is not considered particularly good for the table. 


\section{WILD FOWL DIVING-DUGKS}

HE diving-ducks are easily distinguished from the surfacefeeding species (p. 323) by having the hind toe widely lobed (see fig. 3, p. 290). The bill is broad and flattened, or moderately so, and is at least 0.4 of an inch wide at the tip, which is not conspicuously hooked. The legs are shorter and placed further back on the body, and the feet are larger, which assists the birds in swimming and diving, but renders their gait on land very awkward. The plumage in the two sexes is different during the greater part of the year, except when the males assume the eclipse-plumage after the breeding-season, when in some species they resemble the females.

\section{COMMON SCOTER}

CEDEMIA NIGRA

(Plate XXIX, Fig. 1)

Oidemia nigra, Gould, Birds Europe, v, pl. 378 (1837).

AEdemia nigra, Dresser, Birds Europe, vi, p. 663, pl. 449 (1877); Lilford, Col. Fig. Brit. Birds, part xxii, pl. (1892); Salvadori, Cat. Birds Brit. Mus., xxvii, p. 401 (1895) ; Saunders, III. Man. Brit. Birds, p. 465 (1899).

DULT male.-Entire plumage velvety-black, with a slight
purplish gloss on the head and neck; breast and belly
duller, more smoky-black; inner webs of the primary
quills, except the tips, whitish-brown; the terminal half
of the first primary greatly attenuated, the second less
so, and the third, fourth and fifth slightly. Iris darkbrown; bill black, except a yellow patch on the culmen surrounding the nostrils; base swollen on either side; legs and feet brownish-black, webs darker. Total length about 20 inches; culmen $1.8 \mathrm{inch}$; wing 9.0 inches; tail $3 \cdot 7$ inches; tarsus $1 \cdot 7$ inch.

Adult female. - Above dark brown, darkest on the top of the head; paler on the cheeks, throat and underparts, which are largely brownishwhite, somewhat mottled with brown on the breast; no white on the secondary quills, but the inner webs of the primaries are paler, as in the 


\section{THE GUN AT HOME AND ABROAD}

male, the first being, however, much less abruptly attenuated; axillaries dark smoky-brown; bill black without any distinct swelling at the base. Total length about 18 inches; culmen $1.7 \mathrm{inch}$; wing 8.5 inches; tail 3.4 inches; tarsus $1 \cdot 7$ inch.

General distribution.-The breeding-range of the scoter extends from Iceland through North Europe and Asia as far east as the Taimyr Peninsula in Western Siberia, and from about $74^{\circ} \mathrm{N}$. latitude southwards to the Arctic Circle. It is reported to have bred in Spitzbergen in 1905. In winter it is a very common species on the Atlantic shores of Europe, and wanders southwards to the Azores, the coast of North-west Africa, and visits the Mediterranean; it is met with on the Caspian Sea and also off the coast of Palestine.

Distribution in the British Isles. - In the British Isles it breeds in small numbers in the more northern counties of Scotland, and is reported to have nested in the Inner Hebrides, on the Island of Tiree, in 1897, and on a lough in Ireland of recent years. It is a very plentiful winter-visitor to our coasts, especially the east coast of Great Britain, but is less numerous on the west. Round the north of Ireland it is also plentiful, but on the southern and western shores it is seldom found. In spring the majority of adult birds depart to the north of Europe, but a number of immature birds remain about our coast throughout the summer.

Nest and eggs. - The nest, usually made of moss and girass, with a lining of down, is placed on an island in a fresh-water loch, or among heather in the vicinity. The eggs, from six to nine in number, are laid early in June, and vary in colour from greyish-brown to light brownish cream-colour. They measure about $2 \cdot 55$ by $1 \cdot 75$ inches.

The food consists principally of molluscs, which are obtained by diving, and the flesh is coarse and oily.

The scoter is an expert diver, like the rest of its allies, and can remain for a considerable time under water. It is one of the commonest of our sea-ducks, and may often be seen in winter in the North Sea in very large flocks containing thousands of birds. Except during the breeding-season it rarely visits inland waters unless wounded or driven inland by severe storms.

Allied form.-In North America the scoter is represented by a slightly different form, $\mathscr{E}$. americana, which differs only in the colour of the bill, the basal half of the mandible, including the whole of the swollen knob at the base, being yellow, shading into orange-scarlet on the sides. 


\section{WILD FOWL SURF-SCOTER}

\section{CEDEMIA PERSPICILLATA}

(Plate XXIX, Fig. 3)

Oidemia perspicillata, Gould, Birds Europe, v, pl. 376 (1837).

Gedemia perspicillata, Dresser, Birds Europe, vi, p. 669, pl. 450 (1877) ; Salvadori, Cat. Birds Brit. Mus., xxvii, p. 412 (1895) ; Lilford, Col. Fig. Brit. Birds, part xxxi, pl. (1895) ; Saunders, Ill. Man. Brit. Birds, p. 469 (1899).

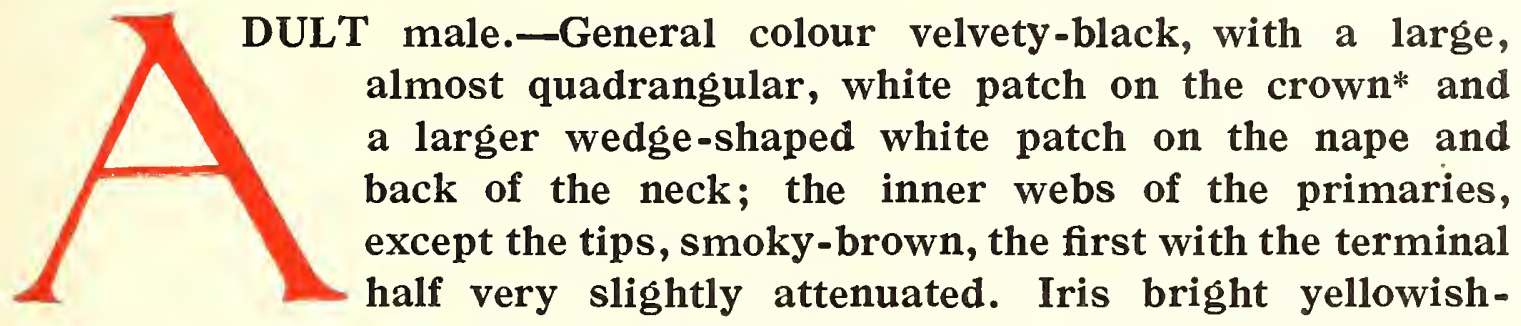
white; upper part of bill at the base, including the nostrils, dull crimson, shading into scarlet on the anterior part of the culmen; nail cadmium. yellow; on the swollen basal part of the side a nearly square black patch, bordered posteriorly with crimson and above with orange; beneath and in front as far as the anterior edge of the nostril white, the remaining portion to the nail pure orange; outer side of tarsus and toes, except the inner toe, crimson; the inner side and both sides of the inner toe orangechrome, blackish about the joints, webs black. Total length about 21 inches; bill 1.4 inch; wing 9.2 inches; tail 3.5 inches; tarsus 1.75 inch.

Adult female. - General colour above brown, whitish on the lores and ear-coverts; the feathers of the back usually with paler margins; the underparts paler brown mottled with white, especially on the middle of the breast and belly; vent and under tail-coverts uniform dark brown. Iris yellowish-white; bill greenish-black, a swelling on the basal part of the side as in the male, but much less developed; feet yellowish-orange, webs greyish-black. Total length about 16 inches; bill 1.5 inch; wing $8 \cdot 6$ inches; tail $2 \cdot 8$ inches; tarsus $1 \cdot 5$ inch.

General distribution.-The surf-scoter is a native of North America, ranging during the summer months from the Atlantic to the Pacific, and from about $70^{\circ}$ down to about $48^{\circ} \mathrm{N}$. latitude. In winter it visits the shores of the Great Lakes, and wanders southwards along the coasts to Lower California on the west and to Florida on the east, being occasionally

*The white patch on the crown is occasionally absent in examples which appear to be fully adult. 


\section{THE GUN AT HOME AND ABROAD}

met with in some of the central states, the Bermudas and Jamaica; it is also believed to breed on the shores of Bering Sea, and is said to be a straggler to North-east Siberia and to Greenland; while eastwards it has been occasionally met with in Western Europe from Scandinavia and Finland as far south as the north coast of France.

Distribution in the British Isles.-To the British Isles it is a rare wanderer during the colder months of the year, and seems to be most frequent in the Orkney Islands, where quite a number have been observed and six obtained from time to time. As might be expected, most of the other records are from Ireland and the western and southern shores of Great Britain, but one example at least has been obtained in the Firth of Forth.

Nest and eggs.-The nesting-habits of this species are very similar to those of the common scoter, and the eggs, which measure about $2 \cdot 25$ by $1^{\cdot} \cdot 6$ inches, are laid towards the end of June.

As its name implies, this species is quite at home among the surf, to which it is specially partial, feeding on small molluscs, which are obtained by diving.

\section{VELVET-SCOTER}

\section{CEDEMIA FUSCA}

(Plate XXIX, Fig. 2)

Oidemia fusca, Gould, Birds Europe, v, pl. 377 (1837).

Edemia fusca, Dresser, Birds Europe, vi, p. 657, pl. 448 (1877) ; Lilford, Col. Fig. Brit. Birds, part xxii, pl. (1892) ; Salvadori, Cat. Birds Brit. Mus., xxvii, p. 406 (1895); Saunders, Ill. Man. Brit. Birds, p. 467 (1899).

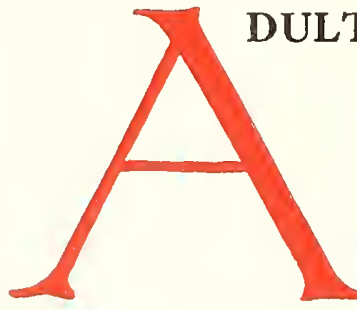

DULT male.-General colour velvety-black; a small white patch beneath and behind the eye; secondary quills and the tips of the greater secondary coverts white; inner webs of the primary quills, except towards the tips, brownish; the quills, though sharply pointed, are not attenuated. Iris white; bill orange-red, with the basal portion of the culmen as far as the nostrils, the posterior border and edges black; legs and toes scarlet, membranes and joints blackish. 


\section{WILD FOWL}

Total length about 22 inches; bill 1.8 inch; wing 10.5 inches; tail 3.5 inches; tarsus 1.9 inch.

Adult female.-General colour of the head, neck and upperparts brown; lores and ear-coverts whitish; secondaries and tips of the greater secondary coverts white; breast and underparts lighter greyish-brown, mottled with whitish. Iris brown; bill brown; legs and feet paler than in the male. Total length about 20 inches; bill 1.6 inch; wing 9.5 inches; tail $2 \cdot 8$ inches; tarsus $1 \cdot 8$ inch.

General distribution.-The velvet-scoter breeds in Northern Europe and Asia at least as far east as the mouth of the Yenesei in Western Siberia. It is commonly met with on the lakes in Scandinavia and North Russia, and is said to breed as far south as Podolia in South Russia, in $48^{\circ} \mathrm{N}$. latitude. In winter it visits the coasts of Western Europe, the Mediter ranean, Black and Caspian Seas, and is occasionally met with off Algeria and in Tunisia.

Distribution in the British Isles.-To the British Isles it is a regular but not very numerous winter-visitor, being most often met with off the east and south coasts of Great Britain. It is common in the Orkney Islands, and small flocks of non-breeding (?) male birds may be seen there and on the east coast of Scotland throughout the summer. It is rare in the Shet lands, and uncommon in the Outer Hebrides, while in Ireland, though not infrequently met with off the northern and eastern coasts, it is almost unknown on the west. To the Faeroes it is an accidental visitor, and has been recorded from Greenland.

Nest and eggs. - Its breeding-habits are much like those of the common scoter, and its eggs, laid rather late in June to July, are similar, but somewhat larger, measuring about $2 \cdot 75$ by $1 \cdot 85$ inches.

One or more pairs of the velvet-scoter are often to be seen in winter in company with large flocks of the common species. The food is similar, and the flesh equally rank.

Allied forms.-In North America it is represented by an allied form, $G$. deglandi, with the base of the bill much higher, the feathering more extended, and the flanks olive-brown; while in East Siberia, China and Japan its place is taken by $\mathscr{E}$. carbo, with a larger and more swollen knob at the base of the bill. 


\section{SOMATERIA MOLLISSIMA}

(Plate XXIX, Fig. 4)

Somateria mollissima, Gould, Birds Europe, v, pl. 374 (1837) ; Dresser, Birds Europe, vi, p. 629, pl. 445 (1871); Lilford, Col. Fig. Brit. Birds, part xxii, pl. (1892); Salvadori, Cat. Birds Brit. Mus., xxvii, p. 425 (1895) ; Saunders, Ill. Man. Brit. Birds, p. 459 (1899).

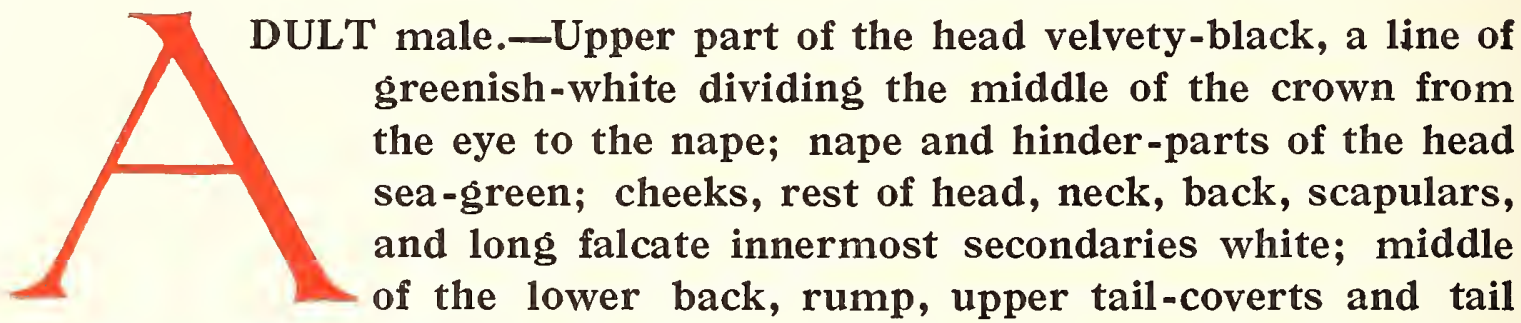

black; chest pale vinaceous-white; rest of the underparts black; primary and secondary quills black, the innermost primaries and their coverts tipped with white; secondary coverts mostly white tipped with black; under wing-coverts and axillaries white. Iris brown; bill dull olive-green, almost olive in old birds, nail brownish-white; feet light olive-green, claws brownish-black. Total length about 24 inches; bill $2 \cdot 2$ inches; wing 11.5 inches; tail 4.0 inches; tarsus 2.0 inches.

Adult male in eclipse-plumage.-Resembles the immature male about the head, neck and chest, which are brown spotted with black; but in the rest of the plumage of the back a good deal of the white is retained, including the long falcate inner secondaries; the breast and rest of the underparts remain black and unchanged.

Adult female.-General plumage pale rufous-brown, the head and neckwith narrow streaks of black, darkest on the crown; upper chest and breast banded with black and rufous-brown, almost uniform brownish-black on the lower breast and belly, the black bands on the back being broader; greater secondary coverts and secondaries dark brown tipped with white, forming two white alar bars; under wing-coverts brownish; axillaries white, somewhat mottled with greyish. Total length about 23 inches; bill $2 \cdot 2$ inches; wing $11^{\circ} 0$ inches; tail 3.8 inches; tarsus $2{ }^{\circ} 0$ inches.

General distribution.-The eider duck inhabits the northern parts of Europe and Western Asia, and has been met with as far east as the Taimyr Peninsula. Its breeding-range includes the Faeroe Islands, Iceland, Jan Mayen, Spitzbergen, Franz Josef Land and Novaya Zemlia; also Norway 350 


\section{WILD FOWL}

to the mouth of the Yenesei, where it is rare, and not actually known to breed, and southwards to the North Friesian Islands. In winter it is found on the coasts of Europe, and sometimes visits parts of the Mediterranean, even wandering to the Azores. It is occasionally found on inland waters.

Distribution in the British Isles.-In the northern parts of the British Isles the eider is a well known resident species, especially in the Shetland and Orkney Islands, where immense numbers nest, and in the Outer and Inner Hebrides; also in suitable localities down the east coast of Scotland to Northumberland and the Farne Islands, and on the west coast to Argyllshire. In winter the number of birds is greatly increased by migrants from the north of Europe, and many visit the eastern shores, but on the west and south coasts of England and Wales the eider is not common, and only occasionally wanders to Ireland.

Nest and eggs.-The nest is placed in tufts of coarse grass or among heather, and in localities where the birds are much disturbed may be found on the moors several miles from water. It is usually made of dead grass with a dense lining of beautiful down, which is gradually added after the eggs have been laid. These vary in number from five to eight, and in colour from greenish-grey to deep green. They measure about 3.0 by 2.0 inches. They are laid in May and June, and incubation lasts from 27 to 28 days. When disturbed the duck evacuates a stinking green liquid over her eggss.

The food consists of seaweed, mussels, which are sometimes swallowed whole, and crustaceans, and the flesh is very coarse and generally regarded as unfit for food. For this reason the bird is seldom shot, and though in most places where it breeds the eggs are regularly collected and eaten by the natives, the bird seems to be increasing.

Allied forms.-In Greenland and eastern North America the eider is represented by a very closely allied form, $S$. borealis, said to be distinguished by having an orange-yellow bill and by slight differences in the plumage.

In Southern Labrador and the north -east coast of North America from Maine to Newfoundland $S$. dresseri is found, and has the bare space near the base of the bill rounded instead of narrow and more or less pointed.

In Western North America and North-eastern Asia another near ally, known as $S . v$-nigrum, is met with, the male having a v-shaped black mark on the throat, as in the male of the king-eider. 
Male examples of the common eider sometimes show an indistinct $v$-shaped black mark on the throat, and these have been mistaken for examples of $S$. $v$-nigrum.

$S$. dresseri has been obtained once off the coast of Holland by the late Mr T. M. Pike.

\section{KING-EIDER \\ SOMATERIA SPECTABILIS \\ (Plate XXIX, Fig. 5)}

Somateria spectabilis, Gould, Birds Europe, v, pl. 375 (1837); Dresser, Birds Europe, vi, p. 643, pl. 446 (1877); Salvadori, Cat. Birds Brit. Mus., xxvii, p. 432 (1895); Lilford, Col. Fig. Brit. Birds, part Xxx, pl. (1895) ; Saunders, Ill. Man. Brit. Birds, p. 461 (1899).

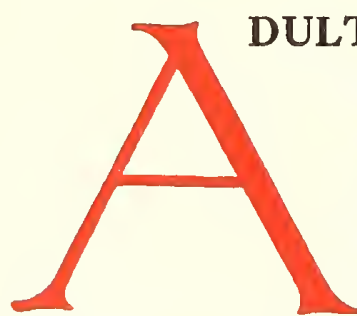

male.-Top of the head and nape French grey; forehead and feathers surrounding the base of the bill and eye-spot black; cheeks pale sea-green, darkest above; throat, neck, upper back and a large patch on each side of the rump white; on the throat a v-shaped black mark pointing towards the chin; chest isabelline-

buff; rest of the plumage of the body, including the scapulars, black; most of the lesser and median wing-coverts white; quills, including the long sickle-shaped inner secondaries, black; under wing-coverts brown; axillaries white. Iris yellow; bill reddish-orange, with the base of the upper mandible much elevated and compressed and forming a sort of shield on either side; legs and feet orange-red, with the membranes somewhat darker. Total length about 24 inches; bill $1 \cdot 3$ inch; wing 11.0 inches; tail 3.5 inches; tarsus $2 \cdot 0$ inches.

Adult male in eclipse-plumage. - Head and neck brown spotted with black, paler on the chin and throat; chest brown, barred with black, and with whitish middles to the feathers, giving a mottled appearance; a line of feathers down each side of the mantle and most of the lesser and median wing-coverts white, remainder of the plumage brownish-black.

Adult female.-Resembles the adult female of $S$. mollissima, but is smaller and more ruddy. It may be easily distinguished by having the feathering on the forehead extending forward to the nostrils, whereas 352 


$$
\begin{aligned}
& 1 \\
& d \\
& 4
\end{aligned}
$$





\section{WILD FOWL}

in the common eider it only reaches half way. Breast and abdomen more uniform smoky-brown than in the common eider, and with scarcely a trace of black cross-bars. Under wing-coverts brown and white; axillaries pure white. Iris dull yellow; bill greenish-brown; feet dull ochre. Total length about 21 inches; bill 1.2 inch; wing $10 \cdot 0$ inches; tail $3 \cdot 0$ inches; tarsus $1 \cdot 7$ inch.

General distribution.-The king-eider is an Arctic species nearly circumpolar in its distribution. It breeds in Kolguev, Spitzbergen and Novaya Zemlia, and along the Arctic shores of Asia to Bering Sea; thence eastwards across Arctic North America to Greenland, where it has been found up to $81^{\circ}$ north latitude. In winter it visits Iceland, the Faeroes and the coast of Norway, and occurs, but rarely, on the shores of Denmark, Holland and the Baltic, while individual stragglers have been met with much further south, even near Venice. In America it has occurred as far south as California on the west and Georgia on the east coast; also in Iowa.

Distribution in the British Isles.-To the British Isles it must be regarded as a very rare straggler, though a considerable number have been obtained from time to time in the Shetland and Orkney Islands and on the more northern parts of the coast of Great Britain, especially at the Farne Islands; also a few on the north-east coast of Ireland.

Nest and eggs.-The nesting-habits resemble those of the common eider, and the eggs are very similar but somewhat smaller, measuring about $2 \cdot 7$ by $1 \cdot 75$ inches.

The food is much the same as that of the common eider. 


\section{STELLER'S EIDER \\ HENICONETTA STELLERI \\ (Plate XXIX, Fig. 6)}

Fuligula dispar, Gould, Birds Europe, v, pl. 372 (1837).

Eniconetta stelleri, Gould, Birds Gt. Brit., v, pl. 25 (1863).

Somateria stelleri, Dresser, Birds Europe, vi, p. 649, pl. 447 (1871); Lilford, Col. Fig. Brit. Birds, part xxxi, pl. (1895); Saunders, Ill. Man. Brit. Birds, p. 463 (1899).

Heniconetta stelleri, Salvadori, Cat. Birds Brit. Mus., xxvii, p. 419 (1895).

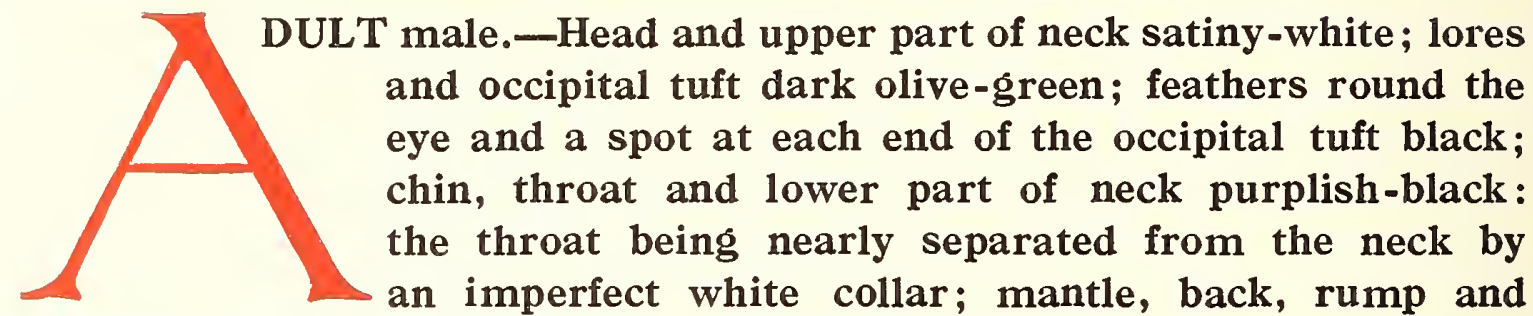

upper tail-coverts black with a purplish gloss; chest, breast and flanks pale cinnamon-brown, shading into blackish-brown on the middle of the breast and belly, paler on the flanks, the longer feathers being nearly white; a black spot on each side of the breast, scapulars and curled inner secondaries, with the inner web white and the outer web metallic purplishblack; outer secondaries very similar, but less glossy and tipped with white; primary-quills brownish-black; lesser and median wing-coverts white; under wing-coverts and axillaries white. Iris dark brown; bill lead colour, horny-white at the tip; feet and toes dark lead-colour; webs blackish-grey. Total length about 19 inches; bill $1.5 \mathrm{inch}$; wing 8.5 inches; tail 3.5 inches; tarsus 1.5 inch.

Adult male in eclipse-plumage.-Has not been examined.

Adult female.-General colour very dark brown, barred with rufous on the head, neck and mantle, and with deep chestnut on the chest; rest of the upperparts nearly black, with indistinct rufous bars on the lower back; breast and rest of underparts uniform shining brownish-black, inclining to dull reddish-brown on the sides and flanks; long curled inner secondaries metallic purplish-black on the outer web, smoky-brown on the inner web, and whitish down the middle; rest of the secondaries metallic-purple on the outer web and widely tipped with white, forming a distinct purple speculum widely bordered with white, the interior one formed by the tips of the greater secondary-coverts; inner under wingcoverts and axillaries pure white. Total length about 19 inches; bill 1.5 inch; wing 8.5 inches; tail 3.5 inches; tarsus 1.5 inch. 


\section{WILD FOWL}

General distribution.-Steller's eider inhabits the Arctic and sub-Arctic coasts of the Northern Hemisphere, and breeds in the Arctic portions of the coasts of Siberia from the Taimyr Peninsula eastwards to Alaska and the Aleutian Islands. It is also believed to breed at Varanger Fjord, though this has recently been denied. In winter it ranges to Northern Europe, regularly visiting the coast of Norway, and in the Baltic it is sometimes not uncommon, while several have been obtained off Heligoland and Denmark. In the east it is rather numerous on the coasts of Kamchatka, and is met with in the Kurile Islands, Aleutian Islands, and sometimes in Greenland, and has once been obtained as far south as Quebec.

Distribution in the British Isles.-It has been obtained twice only in the British Isles, on the Yorkshire and Norfolk coasts respectively.

Nest and eggs.-The nesting-habits and food are like those of the common eider. The eggs are said to be from seven to nine in number, and are of a pale greenish-grey colour, measuring $2 \cdot 35$ by 1.6 inches.

This species is said to be found in winter in small flocks, and to frequent deep clear sea-water. It is not known to associate with other ducks, but occasionally a solitary king-eider may be seen keeping company with a flock.

\section{HARLEQUIN-DUCK}

\section{HISTRIONICUS HISTRIONICUS}

(Plate XXIX, Fig. 10)

Clangula histrionica, Gould, Birds Europe, v, pl. 381 (1837).

Cosmonetta histrionica, Dresser, Birds Europe, vi, p. 609, pl. 442 (1877); Salvadori, Cat. Birds Brit. Mus., xxvii, p. 395 (1895) ; Lilford, Col. Fig. Brit. Birds, part xxx, pl. (1895); Saunders, Ill. Man. Brit. Birds, p. 457 (1899); Ogilvie-Grant, Bull. B.O.C., xxvii, p. 38 (1911).

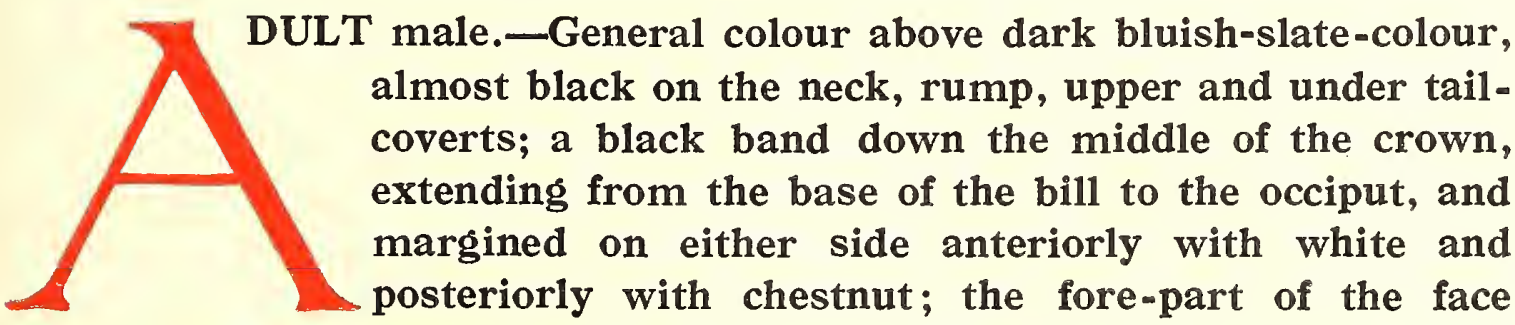
before the eye, ear-spot and a band on the side of the neck white; at the base of the neck a white collar margined with black and incomplete on the nape; on the sides of the breast a crescentic white band margined 
on either side with black; a white band along the middle of the scapulars, breast and belly greyish-brown; flanks chestnut; a white spot at the base of the under tail-coverts; wings dark slaty-grey; secondaries dark metallic-purplish-blue, forming a speculum; innermost secondaries mostly white on the outer web; some of the greater secondary coverts and median coverts with a sub-apical white spot; under wing-coverts smoky-grey; axillaries ash-brown. Iris dark brown; bill deep lead-blue, the nail lighter; legs brown, webs blackish. Total length about 17 inches; bill $1 \cdot 2$ inch; wing $7 \cdot 7$ inches; tail $4 \cdot 0$ inches; tarsus $1 \cdot 6$ inch.

Adult male in eclipse-plumage (August).-Head and neck sooty-black, all the ornamental markings having disappeared except the white ear-spot and the white patches which lie between the base of the bill and the eyes, but all the feathers are fringed with sooty-black; the black-and-white collar round the neck and the black-and-white crescentic patches on the sides of the breast, as well as the chestnut sides and flanks, are wanting, and the long scapulars are uniform sooty-brown. The adult male in eclipseplumage may be distinguished at a glance from the immature male by the colour of the breast and belly, which in the former are dark slaty-grey, in the latter whitish spotted with brown.

Adult female.-General colour of the upperparts and chest dark ashbrown; an ill-defined whitish patch in front of and below the eyes, a more defined white spot on the ear-coverts; feathers of the breast and belly brown with a wide, subterminal white band, giving these parts a mottled white and brown appearance; flanks, under wing-coverts and axillaries lighter ash-brown. Total length about 16.5 inches; bill $1 \cdot 0$ inch; wing $7 \cdot 5$ inches; tail $3 \cdot 6$ inches; tarsus $1 \cdot 4$ inch.

General distribution.-The harlequin-duck inhabits the greater part of the Northern Hemisphere, and breeds over a large part of its range except in North Europe. It nests in Iceland, and is reported to do so in the Ural; while east of the Lena it is met with from Lake Baikal through the Valley of the Amur and Stanovoi Mountains to Kamchatka. In North America it is found from Alaska to Greenland up to about $70^{\circ}$ north latitude on the east coast, and southwards in the mountains of Central California and Colorado to about $40^{\circ}$, also in Newfoundland. In winter it visits the Kurile Islands and Japan, also California and the United States south to about $37^{\circ}$. In Iceland it appears to be resident. It very rarely visits north-western Europe, but occasional wanderers have been obtained in Sweden and on the Swiss Lakes. 


\section{WILD FOWL}

Distribution in the British Isles.-To the British Isles it is a very rare straggler, but several well authenticated instances of its occurrence are on record in Yorkshire and the Farne Islands.

Nest and eggs.-The harlequin-duck places its nest close to the water's edge, a rapid stream being preferred; sometimes under the shelter of such plants as the wild angelica, at others in holes in the banks sheltered by herbage. The nests appear to contain comparatively little down. The eggs, about seven or eight in number, are laid very late in June and July; they are cream-coloured, and measure about $2 \cdot 3$ by $1 \cdot 7$ inches.

The food consists of molluses, crustaceans and marine and freshwater insects, especially the larvæ of mayflies. This duck is a very strong swimmer, and is perfectly at home among rapids which few other birds would care to frequent.

\section{LONG-TAILED DUCK}

\section{HARELDA GLACIALIS}

(Plate XXIX, Fig. 11)

Harelda glacialis, Gould, Birds Europe, v, pl. 382 (1837) ; Dresser, Birds Europe, vi. p. 617, pls. 443, 444 (1875) ; Salvadori, Cat. Birds Brit. Mus., xxvii, p. 389 (1895) ; Lilford, Col. Fig. Brit. Birds, part xxx, pl. (1895) ; Saunders, Ill. Man. Brit. Birds, p. 455 (1899).

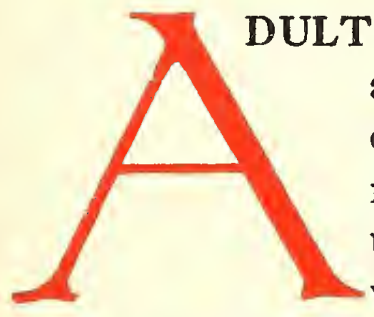

male.-Head, neck and upper mantle white; forehead and sides of the head pale smoky-grey; on each side of the neck an oval patch of dark brown inclining to rufous-brown on the lower margin; back, rump, upper tail-coverts and wings brownish-black, the outer webs of the innermost secondaries inclining to chestnut; breast lighter, dark ash-brown; belly and under tail-coverts white; long pointed scapulars and flanks very pale grey; under wing-coverts and axillaries ash-brown; very long middle pair of tail-feathers black, second pair nearly so but edged with white, ranging to pure white on the outer pairs. Iris reddish-brown; nail and basal part of bill greyishblack, intermediate part pinkish-orange; legs and feet lead-blue, joints blackish. Total length about 22 inches; bill $1 \cdot 2$ inch; wing $8 \cdot 6$ inches; tail (middle pair of rectrices) $9 \cdot 0$ inches; tarsus $1 \cdot 35$ inch. 


\section{THE GUN AT HOME AND ABROAD}

Adult male in eclipse-plumage (June to August). - Sides of the fore-part of the head whitish and grey; rest of the head, neck and upper breast dark brown; base of the nape, upper back and scapulars the same, but each widely margined with rufous and chestnut; remainder of the plumage unchanged.

Adult female.-Forehead, crown, hinder part of the sides of the face, chin and middle of the throat dark brown; fore-part of the face, sides of the throat and ring round the neck white; upperparts dark brown with broad rufous margins to the feathers; upper part of the chest pale rufous, rest of the underparts white; wings as in the male; under wing-coverts and axillaries ash-brown; middle tail-feathers dark brown, ranging to nearly white on the outer pairs. Total length about 15 inches; bill $1 \cdot 15$ inch; wing $8 \cdot 0$ inches; tail 2.6 inches; tarsus 1.4 inch.

General distribution.-The long-tailed duck is a circumpolar species breeding throughout the Northern Hemisphere. It nests in the Faeroe Islands, Iceland, Jan Mayen, Spitzbergen, and Novaya Zemlia; also in Northern Scandinavia south to $60^{\circ}$ north latitude, North Russia, Siberia, Arctic America and Greenland southwards to the Mackenzie River and Ungava. In winter it is found in Southern Europe, its range extending to about $40^{\circ}$, and visits the Adriatic, Black and Caspian Seas; in Asia it is found in Japan and North China, and in America it extends to the Northern States and the Great Lakes; rarely to California, Texas and Florida.

Distribution in the British Isles.-To the British Isles it is mostly a winter-visitor, but a small number appear to be resident in the Shetland and Orkney Islands, and nests have been recorded from these groups on several occasions. In winter it is a regular and numerous visitor to the east coast of Great Britain, and also to the West of Scotland, including the Outer and Inner Hebrides; but on the west and south coasts of England it is generally much less frequent. To Ireland it is a less regular visitor, and is most often to be met with on the north and west coasts.

Nest and eggs.-The nest, usually placed among low bushes, grass and other herbage near fresh water, is made of dry grass and thickly lined with brownish-black down. From six to eight eggs are laid in June and July; they are pale greyish-green, inclining at times to buff, and measure about $2 \cdot 1$ by $1 \cdot 5$ inches.

The food consists of small molluscs, crustaceans and insects, also, in summer, of various aquatic plants. 


\section{GOLDEN-EYE}

\section{CLANGULA CLANGULA}

(Plate XXIX, Fig. 7)

Clangula vulgaris, Gould, Birds Europe, v, pl. 379 (1837).

Clangula glaucion, Dresser, Birds Europe, vi, p. 595, pl. 440 (1875) ; Hume \& Marshall, Game Birds Ind., iii, p. 285, pl. 38 (1880); Salvadori, Cat. Birds Brit. Mus., xxvii, p. 376 (1895) ; Saunders, Ill. Man. Brit. Birds, p. 451 (1899).

Fuligula clangula, Lilford, Col. Fig. Brit. Birds, part xi, pl. (1889).

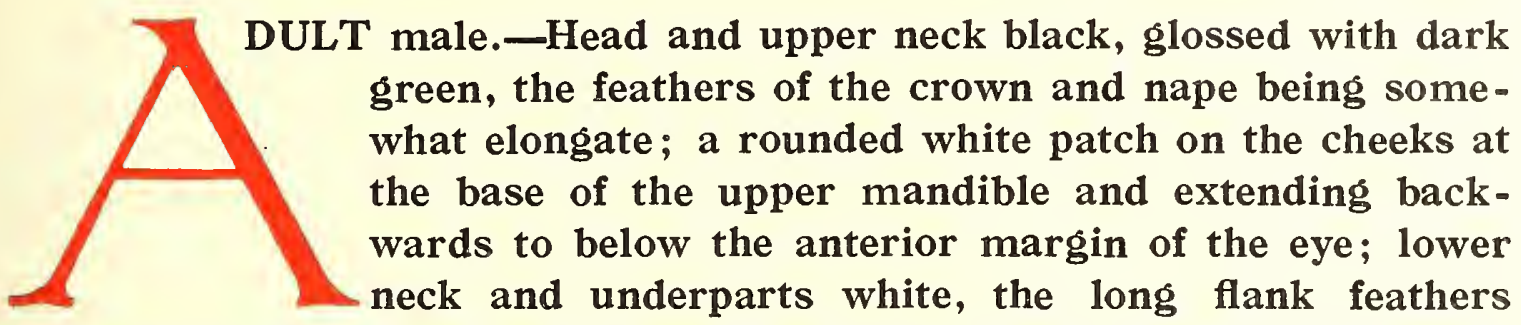
edged with black; back, rump and upper tail-coverts black; inner scapulars black, the outer ones white, edged with black; wings black, with a large white patch in the middle formed by the wing-coverts and outer secondaries; under wing-coverts and axillaries dark smoky-brown; tail rather darker. Iris golden-yellow; bill bluish-black; feet orangeyellow, webs dusky. Total length about $17 \cdot 5$ inches; bill $1 \cdot 3$ inch, depth at base, 0.9 inch; wing 8.5 inches; tail 3.6 inches; tarsus 1.5 inch.

Adult male in eclipse-plumage.-Resembles the adult female, but retains the black and white wing of the adult male.

Adult female.-Head and upper neck brown; a white collar round the lower neck, becoming indistinct on the nape; upper parts blackish, the mantle, scapulars and lesser wing-coverts edged with grey; feathers of the chest, sides and flanks grey, edged with whitish ; rest of the underparts white; median wing-coverts brown, tipped with white; inner greater secondary coverts white, tipped with brown; median secondaries white, the rest of the wings and tail brownish-black; under wing-coverts and axillaries smoky-brown. Iris golden-yellow; basal two-thirds of the bill and the nail brownish-black, subterminal portion yellow; feet orangeyellow, webs dusky. Total length about 16 inches; bill $1 \cdot 25$ inch; wing 8. 0 inches; tail $3 \cdot 3$ inches; tarsus 1.4 inch.

General distribution. - The golden-eye inhabits the Northern Hemisphere, breeding in the Arctic and sub-Arctic regions. In Europe it is 


\section{THE GUN AT HOME AND ABROAD}

found plentifully in Scandinavia up to $70^{\circ} \mathrm{N}$. latitude, and thence across Russia and throughout Siberia; while southwards it is met with sparingly in North Germany and in Russia south to about $58^{\circ}$. In winter it visits the rest of Europe, and in severe seasons reaches North Africa and the Western Mediterranean; also the Black and Caspian Seas, Asia Minor, Persia, Upper India, China and Japan. In North America it breeds from Alaska to Ungava and Newfoundland, and southwards to Montana and New York, and ranges south in winter to Mexico, Florida and Cuba. The American bird has been separated as $C$. americana, on account of its slightly larger size.

Distribution in the British Isles. - To the coasts of the British Isles this duck is a regular visitor, generally distributed during the colder months from October onwards, and immature birds sometimes remain till May. It frequents lakes, rivers and tidal estuaries, females and immature birds being much more commonly met with than adult males.

Nest and eggs. - The golden-eye nests in hollow trees, often in old nesting-holes of the black woodpecker, and deposits its eggs on woodchips. The down is pale lavender-grey with paler centres. It seems to prefer the vicinity of running water in choosing a nesting site. The eggs, laid in May and June, are from ten to twelve or more in number, and vary in colour from deep green to greyish-green. They measure about $2 \cdot 3$ inches by $1 \cdot 65$ inches.

Like its allies, this species is an expert diver, and feeds on various aquatic plants, "sea-grass," molluscs, insects, and crustaceans, and occasionally on small fishes. Its flight is very noisy, hence its name of "Rattle-wing" or "Whistler."

Wild hybrids between this species and the smew and hooded merganser are known to occur. 


\section{WILD FOWL \\ BARROW'S GOLDEN-EYE}

\section{CLANGULA ISLANDICA}

(Plate XXIX, Fig. 8)

Clangula barrovii, Gould, Birds Europe, v, pl. 380 (1837).

Clangula islandica, Dresser, Birds Europe, vi, p. 603, pl. 441 (1878); Salvadori, Cat. Birds Brit. Mus., xxvii, p. 383 (1895).

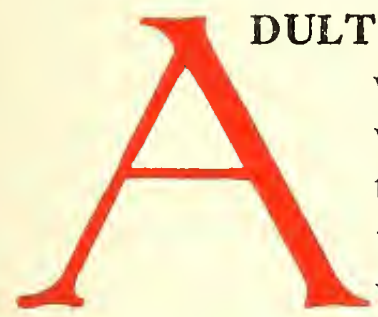

male.-Head and upper part of neck black, glossed with purple; at the base of the bill a crescent-shaped white patch extending from the gape to the side of the forehead; lower part of the neck and underparts white, the feathers of the sides and flanks widely tipped with black; back, rump, upper tail-coverts, and tail black; scapulars white on the inner web, black on the outer web, the black portion produced into a point, and extending considerably beyond the white portion; wings black, a long white patch in the middle formed by the median coverts, and a second outer patch formed by the median secondary quills and the tips of their greater coverts; under wing-coverts and axillaries dark smoky-brown. Iris bright yellow; bill dark plumbeous; legs and toes yellow, webs dusky. Total length about 20 inches; bill $1 \cdot 35$ inch, depth at base $1 \cdot 1$ inch; wing $9 \cdot 2$ inches; tail 3.5 inches; tarsus $1 \cdot 6$ inch.

Adult male in eclipse-plumage.-Probably resembles the female, but retains the black and white wing characteristic of the adult male.

Adult female.-Similar to the female of $C$. glaucion, but larger, and with the grey of the chest, sides and flanks browner, and with less conspicuous markings. Total length about 18 inches; bill 1.35 inch; wing 8.9 inches; tail $3 \cdot 0$ inches; tarsus $1 \cdot 6$ inch.

General distribution.-Barrow's golden-eye breeds in the northern parts of North America, from Alaska to Ungava and southwards to Oregon, Colorado and Quebec, also in Iceland, but rarely visits Greenland. In winter it ranges southwards to California, Utah, Illinois and New York, and occasionally strays to North-western Europe. An immature male, which has been referred to this species, was shot by Mr F. M. Ogilvie on the Alde, Suffolk, on February 1, 1908 (cf. Bull. Brit. Orn. Club, xxiii, p. 63). This is the only record.

Nest and eggs.-Like the common golden-eye, this species breeds in hollow trees, but where they are not obtainable, it conceals its nest in 


\section{THE GUN AT HOME AND ABROAD}

crevices in rocks or in holes in turf-walls. The eggs are larger than those of the common species, but otherwise do not differ from them, the average measurements being about $2 \cdot 45$ by $1 \cdot 8$ inches.

\section{BUFFEL-HEADED DUCK \\ CLANGULA ALBEOLA}

(Plate XXIX, Fig. 9)

Fuligula albeola, Audubon, Birds Amer., vi, 369, pl. 408 (1843).

Clangula albeola, Dresser, Birds Europe, vi, p. 589, pl. 439 (1877); Lilford, Col. Fig. Brit. Birds, part xxx, pl. (1895); Salvadori, Cat. Birds Brit. Mus., xxvii, p. 385 (1895) ; Saunders, Ill. Man. Brit. Birds, p. 453 (1899).

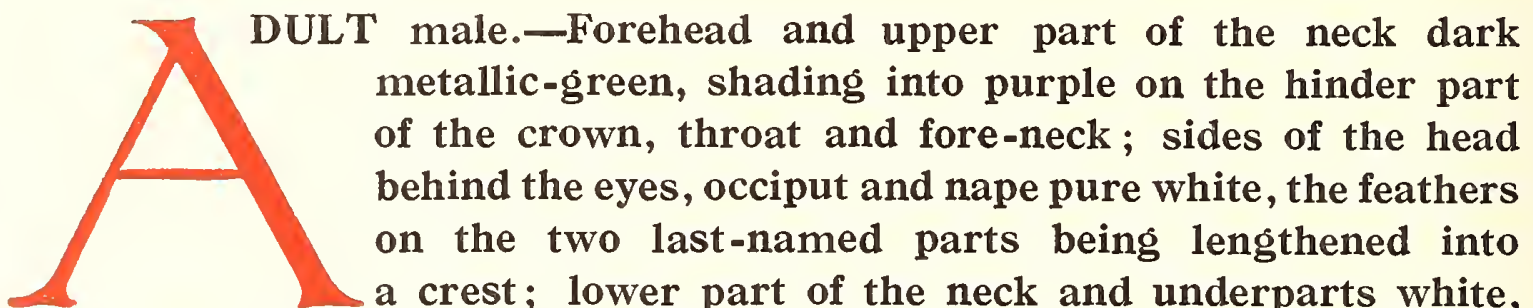
the breast and belly with indistinct dusky middles to the feathers and the long flank-feathers narrowly edged above with black; back and rump black; upper tail-coverts grey; scapulars black, the shorter outer ones white, edged with black; wings black, with a large white patch formed by the median and greater secondary coverts, and the median secondary quills; least wing-coverts black, fringed with white; under wing-coverts light ash, edged with whitish; axillaries sooty-brown, mostly tipped with white; tail-feathers dark grey, the outermost pair margined externally with whitish. Iris dark brown; bill bluish-black; legs and toes yellowishpink, the webs and joints darker. Total length about $14 \cdot 5$ inches; bill $1 \cdot 1$ inch; wing $6 \cdot 5$ inches; tail $3 \cdot 0$ inches; tarsus $1 \cdot 3$ inch.

Adult male in eclipse-plumage.-Probably resembles the female, but retains the black and white wings of the adult male. No specimens in this plumage have been examined.

Adult female.-Head and neck brown, with an oblique white patch across the hinder part of the cheeks and ear-coverts; upperparts brownishblack, the feathers of the back indistinctly edged with greyish; underparts white; sides, flanks and under tail-coverts smoky-grey; wings 


\section{WILD FOWL}

brownish-black, the median secondaries and their greater-coverts white; axillaries parti-coloured, the shorter plumes being white and the longer smoky-brown. Iris dark brown; bill dusky, inclining to grey at the tip and along the commissure; legs and toes pale pinkish-lilac, the webs and joints darker. Total length 13 inches; bill $1 \cdot 1$ inch; wing $6 \cdot 0$ inches; tail $2 \cdot 3$ inches; tarsus $1 \cdot 2$ inch.

General distribution.-The buffel-headed duck inhabits North America, breeding as far north as Alaska, and as far south as Montana and Ontario, about $45^{\circ} \mathrm{N}$. latitude. In winter it ranges southwards to Lower California and Mexico on the west, and to Florida and the West Indies on the east, and occasionally to the Bermudas. On the Asiatic side it has been obtained as a straggler in the Commander Islands and Hawaii, while to the east it has been met with in Greenland, Newfoundland, and Nova Scotia, but has not been obtained in North-Western Europe.

Distribution in the British "Isles.-To the British Isles it is a very rare wanderer, and only two or three authentic instances of its occurrence are on record. One was killed at Yarmouth in the winter of 1830 , a second in Yorkshire in the winter of 1864-5, and possibly a third in Aberdeenshire in January, 1865.

Nest and eggs.-Like the other species of the genus the buffel-headed duck nests in holes in trees, laying its eggs on the rotten wood and covering them with a plentiful supply of down. The eggs, laid between the end of May and July, and from eight to ten in number, are greenish-white, and measure about $2 \cdot 0$ by $1 \cdot 5$ inches.

This duck is a most expert diver, and by this means obtains molluscs and crustaceans on the coast; but it also feeds on worms, snails and aquatic plants. On account of its extreme fatness this species is com monly known in North America as "Butter-ball," its thick coating of adipose enabling it to withstand great cold, and to remain in waters covered with floating ice. 


\section{THE GUN AT HOME AND ABROAD \\ RED-CRESTED POCHARD}

NETTA RUFINA

(Plate XXX, Fig. 1)

Fuligula rufina, Gould, Birds Europe, v, pl. 369 (1837) ; Dresser, Birds Europe, vi, p. 559, p!. 435 (1873) ; Hume \& Marshall, Game Birds Ind., iii, p. 253, pl. 34 (1880); Lilford, Col. Fig. Brit. Birds, part x, pl. (1889).

Netta rufina, Salvadori, Cat. Birds Brit. Mus., xxvii, p. 328 (1895) ; Saunders, Ill. Man. Brit. Birds, p. 441 (1899).

DULT male.-Forehead, sides of the head, throat, and
fore-part of the upper neck glossy vinaceous chestnut;
crown and occiput rufous-buff, the feathers much
lengthened, and forming a conspicuous crest; nape,
lower neck and chest black, shading into blackish-
brown on the breast and belly, a large white patch on each side of the belly bordered above with vermiculated black and white feathers; upper feathers of the sides and flanks light dun-brown; a partiy concealed white patch on each side of the mantle; back and scapulars light earthy-brown, darker on the lower back and rump; marginal wingcoverts white; median and greater wing-coverts and long inner secondary quills grey; shorter outer secondary and inner primary quills white, with a subterminal or terminal blackish band; long outer primary quills brownish-black, with the greater part of the inner web white towards the margin (this pattern of the primaries being very remarkable among ducks); under wing-coverts and axillaries white; tail greyish-brown, the outer feathers paler. Iris reddish-brown; bill crimson-scarlet, the nail paler; legs and toes scarlet, the joints and membranes blackish. Total length about 21 inches; bill 1.9 inch; wing 10.0 inches; tail 3.5 inches; tarsus $1 \cdot 8$ inch.

Adult male in eclipse-plumage (July).-Very similar to the female, but retaining the plumage on the wings of the adult male.

Adult female.-General colour light earthy-brown above, greyish-brown below; apper part of the head, including the ocular region, brown; sides of the head and throat greyish-white; lower back dark sooty-brown; feathers of the chest and rest of the underparts pale brown, with greyishwhite tips, producing a mottled appearance; under tail-coverts white; upper feathers of the sides and flanks light brown; wings much like those 


\section{WILD FOWL}

of the male, but the marginal coverts are not pure white, and the median and greater coverts are browner, less grey; the longest axillary plumes slightly tipped with brown. Iris light reddish-brown; bill and legs dull red. Total length about 20.5 inches; bill 1.9 inch; wing 10.0 inches; tail 3.0 inches; tarsus 1.7 inch.

General distribution.-The red-crested pochard breeds in the central and southern parts of Europe, from South Germany to Spain and the delta of the Rhone eastwards, being abundant in the Danube Valley and parts of Southern Russia; in Asia it is met with in summer from Northern Persia to Eastern Turkestan. Southwards it nests in North Africa, north of the Sahara, frequenting the fresh-water lakes and marshes; but appears to be rare in Egypt. In winter it inhabits the basins of the Mediterranean, Black and Caspian Seas, ranging to India, where it is plentiful in the northern parts, but somewhat scarce in the south, though probably extending to Ceylon, and occasionally to Western China. It has been known to wander accidentally to North Europe and the Eastern United States. North of about $50^{\circ} \mathrm{N}$. latitude it is an accidental visitor in Western Europe to Pomerania, the Baltic Provinces, Denmark, Belgium, etc., and to the British Isles.

Distribution in the British Isles.-All the examples but one met with in this country have been procured in autumn and winter, chiefly on the east and south coasts of England, while individuals have occurred in Pembrokeshire, Westmoreland, Argyleshire, and co. Kerry.

Nest and eggs. - The nest seems to be generally placed in marshy ground, near water, in dense herbage, and is thickly lined with down. The eggs, laid between April and June, are from seven to ten in number, of a greyish-green or pea-green colour, and measuring about $2 \cdot 3$ by $1 \cdot 65$ inches.

The food consists of water-weeds, obtained by diving, small fish, insects, etc., and the flesh is highly esteemed, but, as is the case with most ducks, it varies in quality, and depends largely on the locality the birds are frequenting, and the nature of their food. 


\title{
COMMON POCHARD
}

\author{
NYROCA FERINA
}

(Plate XXX, Fig. 2.)

Fuligula ferina, Gould, Birds Europe, v, pl. 367 (1837) ; Dresser, Birds Europe, vi, p. 551, pl. 434 (1878) ; Hume \& Marshall, Game Birds Ind., iii, p. 247, pl. 33 (1880) ; Lilford, Col. Fig. Brit. Birds, part xiii, pl. (1890); Saunders, Ill. Man. Brit. Birds, p. 443 (1899).

Nyroca ferina, Salvadori, Cat. Birds Brit. Mus., xxvii, p. 335 (1895).

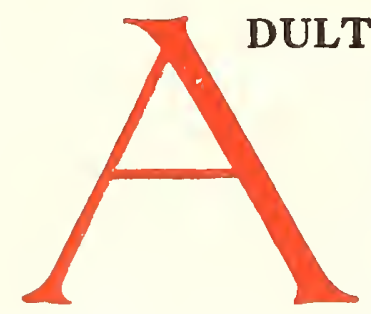

T male.-Head and neck chestnut; upper mantle and chest black; back, wings, sides and flanks greyish -white, finely vermiculated with black; lower back darker, shading into black on the rump and upper and under tail coverts; upper breast black, the feathers fringed with sandy-white; lower breast and upper part of the abdomen

greyish-white, faintly vermiculated with blackish, much paler than the upperparts; lower abdomen darker and more densely vermiculated with dusky, several of the longer outer secondaries mostly grey, edged on the outer web with black; inner ones white, mottled with greyish and tipped with white; shorter inner primary quills grey, tipped with blackish; longer quills more smoky-brown, with the outer webs and tips blackish; axillaries pure white; tail dark grey. Iris yellow; bill black at the base and tip, the intermediate portion dull light blue; legs and toes dark lead-blue, webs blackish. Total length about 18 inches; bill 1.9 inch; wing 8.5 inches; tail $2 \cdot 2$ inches; tarsus $1 \cdot 5$ inch.

Adult male in eclipse-plumage.-Resembles the female very closely.

Adult female.-Head and neck dull reddish-brown, paler on the foreneck, and shading into whitish on the chin and throat; upper mantle and chest browner; back, scapulars, sides and flanks whitish, vermiculated with blackish-brown; rump and upper tail-coverts black; upper breast brown, the feathers tipped with white, and showing the dark bases; lower breast and belly similar, but with wider white tips, which for the most part mask the greyish-brown bases; lower belly and under tailcoverts smoky-brown, finely vermiculated with whitish; secondary quills and wing-coverts grey without whitish vermiculations; primary quills as in the male; axillaries white; tail blackish. Iris brown; bill duller than in the male; legs dark leaden-grey. Total length about 18 inches; bill $1 \cdot 8$ inch; wing $8 \cdot 1$ inches; tail $2 \cdot 1$ inches; tarsus $1 \cdot 5$ :inch. 
WILD FOWL

General distribution.-The common pochard inhabits the greater part of Europe and Asia, wandering to Iceland and the Faeroe Islands, but does not extend far north. It breeds in the sub-Arctic portions from Scandinavia, where it is comparatively scarce, and North Russia southwards throughout the rest of Europe in suitable places. Eastwards through temperate Asia it is found in summer as far north as Lake Baikal. In winter it migrates to the Mediterranean and North Africa, and is more or less abundant on the coasts and inland waters from Morocco to Egypt. Thence eastwards it occurs from the Red Sea to China and Japan, being found in all parts of the Indian peninsula, north of about $15^{\circ} \mathrm{N}$. latitude, but is comparatively rare in the south.

Distribution in the British Isles.-In the British Isles, though chiefly a winter-visitor between October and April, many pairs remain to breed, and, owing to the protection now afforded them, seem to be increasing in numbers. In Scotland it is pretty generally distributed in summer from the Orkneys southwards, but is said to be a winter-visitor only to the Shetlands, and rarely nests in the Outer Hebrides or in Ireland. In England it has nested in many counties, but chiefly along the east and south coasts.

Nest and eggs. - The nest, placed among rushes, sedges and coarse grass near the margins of fresh-water lakes and pools, is made of dead grass, and lined with down after incubation has commenced. From seven to ten or more eggs are laid in May; they are of a greenish -drab or greyish green colour, and measure about $2 \cdot 3$ by 1.65 inches.

The pochard is an expert diver, and much of its food consists of weeds obtained below the surface of inland waters, but when at sea it feeds on crustaceans and molluscs, which spoil the excellent quality of its flesh for the table.

Allied form. - In America the pochard is represented by a nearly allied form, $N$. americana, which has no black at the base of the bill, a greyer back and purer white abdomen. 


\title{
FERRUGINOUS DUGK OR WESTERN WHITE-EYED POCHARD. \\ NYROCA NYROCA
}

\author{
(Plate XXX, Fig. 3)
}

Fuligula leucophthalma, Gould, Birds Europe, v, pl. 368 (1837).

Nyroca ferruginea, Dresser, Birds Europe, vi, p. 581, pl. 438 (1872).

Fuligula nyroca, Hume \& Marshall, Game Birds Ind., iii, p. 263, pl. 35 (1880) ; Lilford, Col. Fig. Brit. Birds, part xiv, pl. (1890); Saunders, Ill. Man. Brit. Birds, p. 445 (1899).

Nyroca africana, Salvadori, Cat. Birds Brit. Mus., xxvii, p. 345 (1895).

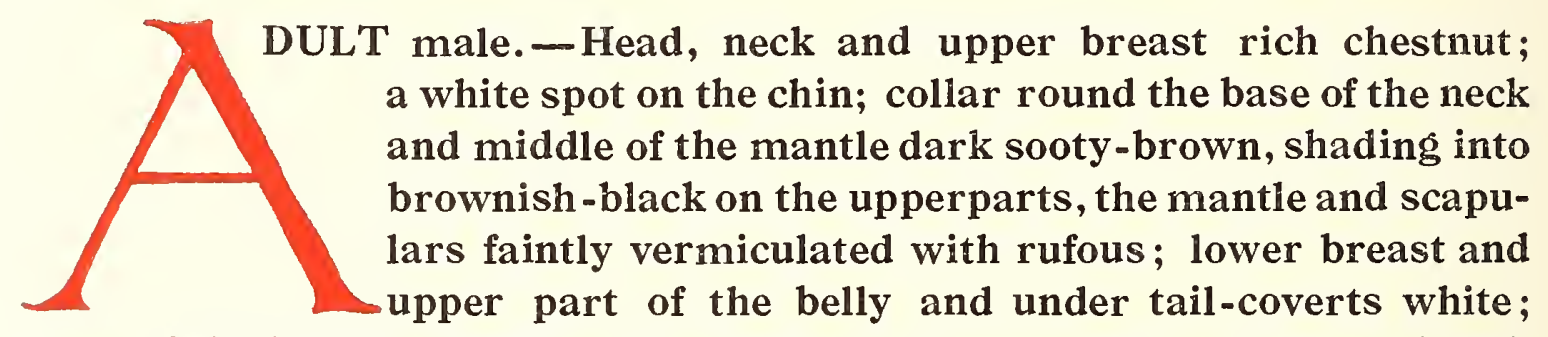

base of the belly and thighs smoky-brown, indistinctly vermiculated with whitish; sides and fianks reddish-brown and dun-colour; wing-coverts and long inner secondary quills brownish-black, the latter glossed with dull oily-green on the outer web, and edged with black; inner secondary and primary quills white, tipped with dark brown; long outer primaries, with the outer webs and tips, brownish-black, and the rest of the inner web white; axillaries white, slightly vermiculated with brown at the extremity; tail brownish-black. Iris white; bill, legs, etc., dark bluish-black. Total length about 16 inches; bill 1.5 inch; wing $7 \cdot 3$ inches; tail $2 \cdot 3$ inches; tarsus $1 \cdot 2$ inch.

Adult female. - Differs from the male in having the head, neck, and upper breast dull reddish-brown, a white spot on the chin; upperparts blackish-brown, without vermiculations, almost black on the rump, the feathers of the mantle and scapulars with pale rufous-buff margins; the upper breast-feathers tipped with whitish, and not clearly defined from the lower breast, which, with the abdomen and under tail-coverts, are less pure white and mottled with rufous where the bases of the feathers are visible; lower part of the abdomen and thighs light reddish-brown; sides and flanks dun-brown; wings and tail as in the male. Iris white; bill horn-black; legs and toes French grey, mottled with dusky at the joints and on the webs. Total length about $15 \cdot 5$ inches; bill $1.6 \mathrm{inch}$; wing $7 \cdot 2$ inches; tail $2 \cdot 2$ inches; tarsus $1 \cdot 3$ inch.

368 
WILD FOWL

General distribution.-The ferruginous duck inhabits Central, Southern and Eastern Europe, Western Asia as far east as Kashmir, and North Africa. It breeds from Holland southwards to Spain, and thence east wards to the Volga. In Western Asia it nests in the temperate and elevated regions as far east as Kashmir, and is reported to have been met with in the valley of the Obi as far north as the Arctic Circle, but this statement seems to require confirmation.

In North Africa it breeds plentifully in Morocco, also in Algeria and Tunis, its numbers being greatly increased in winter, when it is common in Egypt and Abyssinia, and ranges eastwards to India as far as the longi tude of Calcutta, and southwards to about the $14^{\circ} \mathrm{N}$. latitude.

This species has been constantly confused with its more eastern ally, $N$. baeri, which inhabits Eastern Siberia, China and Japan, and also visits India in winter.

Distribution in the British Isles. - To the British Isles the ferruginous duck is a somewhat rare wanderer, and has been met with principally in the eastern and southern counties of England, though a few have been obtained in the west, and in Scotland as far north as the Tay; also in Ireland.

Nest and eggs.-The nest is placed among rushes and other covert near the water, and is made of dry water-plants, lined with brownish-white down after the eggs are laid. These, from seven to fourteen in number, vary from cream-colour to pale buff, frequently with a greenish tinge, and measure about $2 \cdot 1$ by $1 \cdot 5$ inches. Incubation lasts from twenty-two to twenty-three days.

This duck frequents reedy pools with plenty of covert, and is a most expert diver. Its food consists not only of water-plants, but of insects, crustaceans and small molluscs, and its flesh varies in quality according to the food eaten. 


\section{BAER'S POCHARD OR EASTERN WHITE- EYED POGHARD NYROCA BAERI}

Nyroca baeri, Salvadori, Cat. Birds Brit. Mus., xxvii, p. 344 (1895).

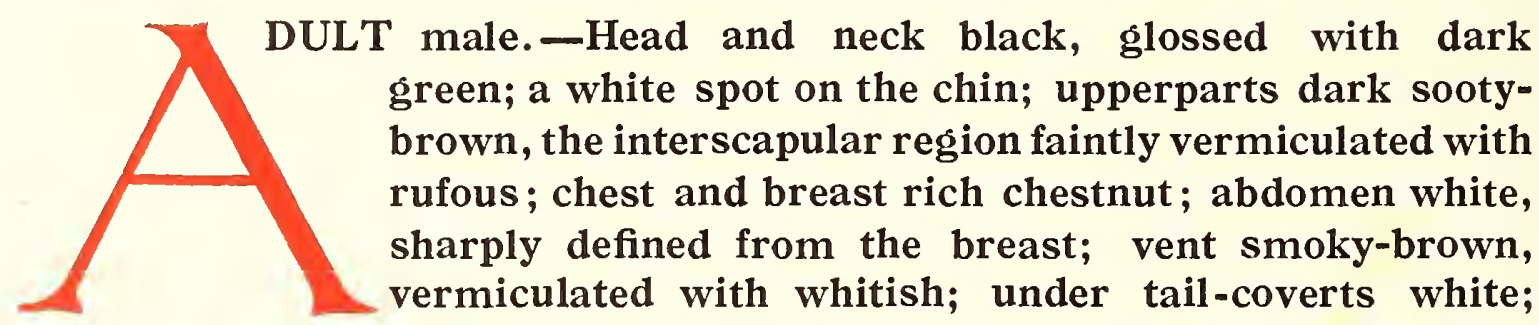

sides and flanks reddish-brown; wings dark brown; the longer outer secondary quills glossed with dull oily-green; inner secondaries white, tipped with black, glossed with oily-green; shorter inner primary quills white, tipped with dark brown; longer outer quills brownish-black on the outer webs and tips, whitish on the inner webs; axillaries white, slightly vermiculated with dusky at the tip; tail blackish-brown. Iris white or pale yellow; bill bluish, with the base and nail black; legs and feet lead-grey, with the joints dusky. Total length about 18 inches; bill $1 \cdot 8$ inch; wing $8 \cdot 3$ inches; tail $2 \cdot 4$ inches; tarsus $1 \cdot 4$ inch.

Adult female.-Very similar to the male, but the head and neck are browner, and have very little gloss, and there is a dull chestnut patch at the base of the bill; the upper breast is duller chestnut. Iris white; bill black, with a bluish-grey band across it; legs and feet plumbeous. Total length about $17 \cdot 5$ inches; bill $1 \cdot 7$ inch; wing $7 \cdot 8$ inches; tail $2 \cdot 3$ inches; tarsus $1 \cdot 3$ inch.

General distribution.-Baer's pochard is the eastern representative of the ferruginous duck, with which it has been frequently confused, though really a very distinct species.

It breeds in Eastern Siberia and Kamchatka, ranging in winter to India, Burma, Ghina and Japan, even visiting the Waigiu Islands to the west of New Guinea.

A male, shot on the Tring Reservoirs in Hertfordshire, on November 5, 1901, was believed to be a wild bird, but the evidence in support of this seems scarcely sufficient. It must, however, be noted that at the time this specimen was obtained, the only examples of Baer's pochard known to exist in this country were four pinioned birds in the Zoological Gardens at Regent's Park.

370 


\section{WILD FOWL \\ SCAUP-DUCK}

\section{NYROCA MARILA}

(Plate XXX, Fig. 4)

Fuligula marila, Gould, Birds Europe, v, pl. 371 (1837) ; Dresser, Birds Europe, vi, p. 565, pl. 436 (1878); Hume \& Marshall, Game Birds Ind., iii, p. 271, pl. 36 (1880); Lilford, Col. Fig. Brit. Birds, part xv, pl. (1890) ; Salvadori, Cat. Birds Brit. Mus., xxvii, p. 355 (1895); Saunders, Ill. Man. Brit. Birds, p. 449 (1899).

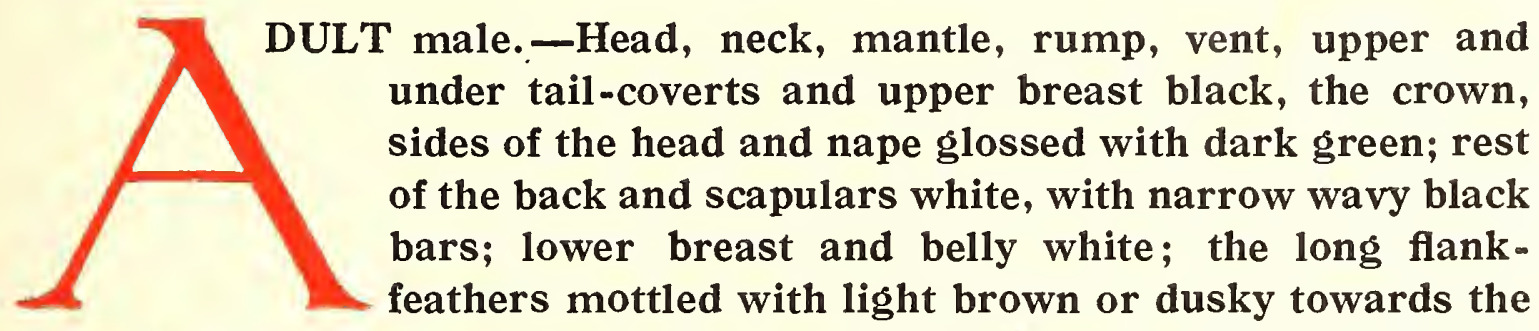
tips; wing-coverts blackish, finely vermiculated with white; long innermost secondary quills black glossed on the outer web with dull oil-green; outer secondaries white tipped with black; short inner primary quills, whitish on the outer web, smoky-brown on the inner web, and tipped with blackish; long outer primaries brownish-black, lighter on the inner web; axillary plumes white, slightly vermiculated with dusky towards the tips of the longest feathers; tail brownish-black. Iris yellow; bill and legs light lead-grey; nail on the bill and webs of the toes blackish. Total length about 18 inches; bill $1 \cdot 75$ inch; wing $9 \cdot 0$ inches; tail $2 \cdot 3$ inches; tarsus $1 \cdot 55$ inch.

Adult male in eclipse-plumage-Closely resembles the adult female; but the wings are darker, as in the adult male with vermiculated coverts and dull oil-green inner secondary quills.

Adult female.-General colour of the head, neck, upperparts and chest brown; darker on the back and wings, and shading into blackish on the lower back and rump; slightly vermiculated with whitish on the mantle; a large oval patch of white on the face at the base of the bill; chin also whitish; upper breast, lower belly, and under tail-coverts smokybrown, barred and mottled with white; lower breast and upper part of abdomen white; sides and flanks reddish-brown; the wings much like those of the male, but browner, the wing-coverts almost uniform dark brown, with scarcely a trace of whitish vermiculations, and the long inner secondary quills brown, without any oil-green gloss; axillaries pure white; 
tail dark sooty-brown. Iris yellow; bill black; feet dingy olive, the toes more yellow, especially along the edges of the webs, which are black; joints blackish. Total length about 17 inches; bill $1 \cdot 7$ inch; wing $8 \cdot 3$ inches; tail $2 \cdot 1$ inches; tarsus $1 \cdot 4$ inch.

General distribution.-The scaup-duck inhabits the greater part of the northern hemisphere, ranging in summer up to $70^{\circ} \mathrm{N}$. lat. Its breedingrange includes the Faeroe Islands, Iceland, and Northern Europe and Asia, from Scandinavia across Arctic Russia and Siberia to Bering Sea; while in North America it is found from the Pacific to the Atlantic coasts, from the Aleutian Islands southwards to North Dakota, Ontario and the Magdalen Islands north of about $49^{\circ} \mathrm{N}$. lat.

In winter it is met with as far south as the Mediterranean, being generally more numerous in the eastern parts, and in North Africa on the lakes of Algeria, and probably also of Tunisia, but apparently not in Abyssinia, as has been stated by Seebohm. It occurs on the Black and Caspian Seas, and rarely in Northern India; while eastwards it visits China, Japan and Formosa; and, in America, Mexico, Central America, and the West Indies.

Distribution in the British Isles.-To the British Isles the scaup-duck is chiefly a winter-visitor, making its appearance on our coasts in October, and remaining till spring. Of recent years, however, a few pairs have been known to remain and breed in the north of Scotland and in the Outer Hebrides.

Nest and eggs.-It is essentially a maritime species, except in the breeding-season, when it comes inland to nest among rough grass, bilberries, etc., in the vicinity of water. The nest is generally well hidden and placed in a hole lined with dry sedge and grass and, after the eggs are laid, with down. The eggs, from six to eleven in number, vary in colour from greenish-drab to greenish-grey, and measure about $2 \cdot 35$ inches by 1.65 inches. The scaup is an expert diver, and obtains much of its food under water; this consists chiefly of molluscs, crustaceans, and the larvæ of insects, together with some vegetable matter. The flesh is strong and unpalatable.

Allied form.-In America a very similar but smaller species, $N$. affinis, also occurs, the male being distinguished, among other characters, by having the head and neck glossed with purple instead of green. 


\section{WILD FOWL RING-NEGKED DUCK}

\section{NYROCA COLLARIS}

Fuligula collaris, Salvadori, Cat. Birds Brit. Mus., xxvii, p. 370 (1895).

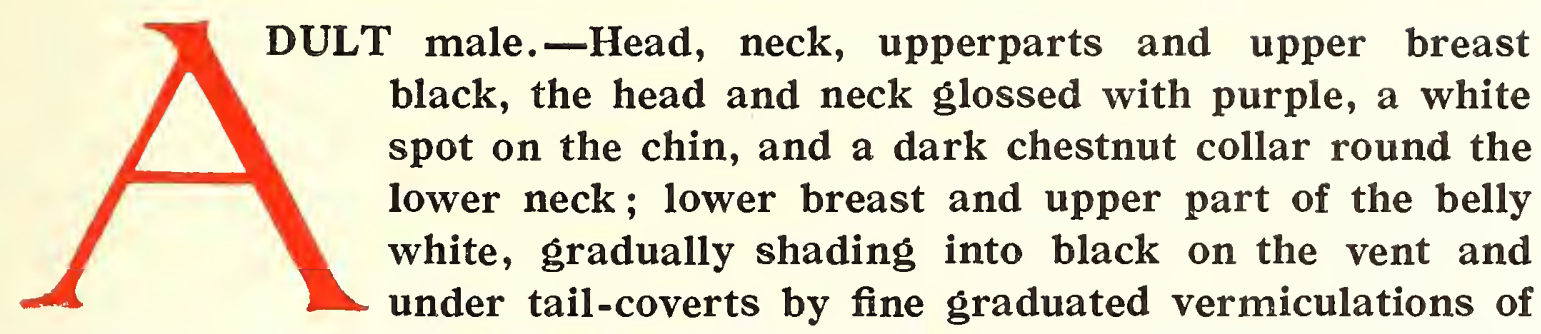
white and dusky; sides and flanks white finely vermiculated with black; upper wing-coverts dark sooty-brown tinged with greyish, long inner secondary quills glossed with dull bluish-green; rest of the secondaries with the outer web grey, blackish towards the tip, the median quills being edged with white; short inner primary quills very similar, but of a more smoky-grey; long outer primaries blackish, smoky on the inner web; axillaries white, slightly freckled towards the tips of the plumes with blackish; tail dark sooty-brown. Iris bright yellow; bill lead-colour, with a narrow basal and a broad subterminal band of bluish-white, tip black; legs and feet pale slate-colour. Total length about 17 inches; bill $1 \cdot 9$ inch; wing $7 \cdot 8$ inches; tail $2 \cdot 3$ inches; tarsus $1 \cdot 4 \mathrm{inch}$.

Adult male in eclipse-plumage.-Probably resembles the female very closely, the wings in the two sexes being much alike. No specimen has been examined.

Adult female.-General colour of the head, neck, upperparts and chest brown, much darker sooty-brown on the back and wings; the front of the face behind the bill, as well as the chin and upper throat, white; fore-neck and chest mottled with whitish; breast and belly pale greyishbrown tipped with pure white, giving these parts a mottled appearance and shading into darker smoky-brown on the vent; sides and flanks warm dun-colour or reddish-brown; wings very similar to those of the adult male; axillaries pure white. Iris yellow; bands on the bill narrower and less distinct than in the male; feet slate-colour. Total length about 17 inch; bill $1 \cdot 8$ inch; wing $7 \cdot 2$ inches; tail $2 \cdot 1$ inches; tarsus $1 \cdot 3$ inch.

General distribution.-The ring-necked duck inhabits North America, and breeds from the southern parts of British Columbia to Lake Winnipeg 
and southwards to Northern California, North Dakota and Lake Michigan. In winter it ranges southwards to Mexico, Guatemala and the West Indies.

This species was first described by Donovan [cf. "Brit. Birds", vi, pl. 147 (1809)] from a specimen found in Leadenhall Market, and which was said to have been taken in Lincolnshire. It seems fairly certain that this unknown species could not have been imported to England, and that the bird must have been a wild example. I have therefore included it in my list of British birds, and cannot understand why it should hitherto have been omitted. My much valued friend, the late Mr Howard Saunders, had overlooked it until I called his attention to Donovan's work. Species with far less claim than the ring-necked duck have been admitted to the British list.

\section{TUFTED DUCK}

\section{FULIGULA FULIGULA}

(Plate XXX, Fig. 5)

Fuligula cristata, Gould, Birds Europe, v, pl. 370 (1837) ; Dresser, Birds Europe, vi, p. 573, pl. 437 (1879) ; Hume \& Marshall, Game Birds Ind., iii, p. 277, pl. 37 (1880); Lilford, Col. Fig. Brit. Birds, part xiii, pl. (1890); Saunders, IIl. Man. Brit. Birds, p. 447 (1899).

Fuligula fuligula, Salvadori, Cat. Birds, Brit. Mus., xxvii, p. 363 (1895).

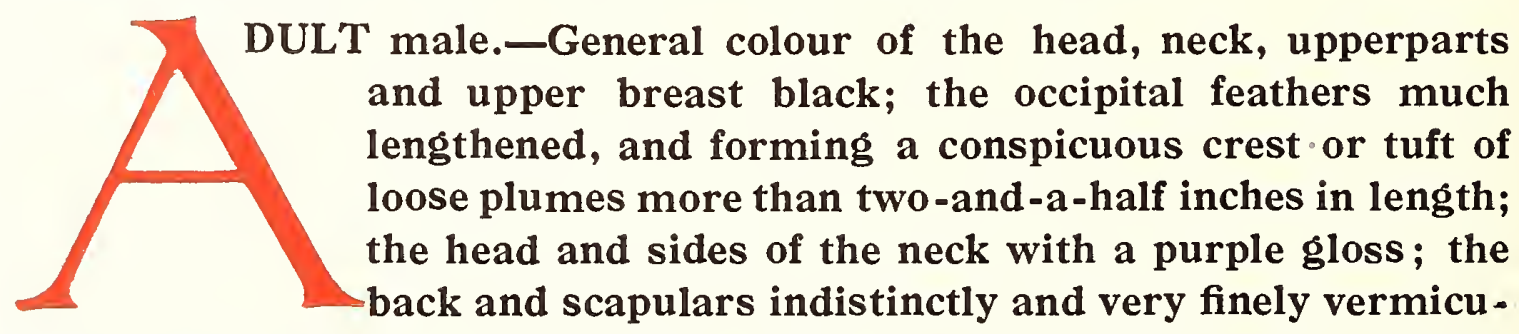
lated with whitish; lower breast, belly, sides and flank white; thighs, vent and under tail-coverts black; wings black, the inner primary and outer secondary quills partly white, or white tipped with black, the long inner secondaries glossed with dark greenish; outer primary quills blackish on the outer web and tip, brownish on the inner web, and shading into white towards the margin; axillary plumes white; tail black. Iris golden-yellow; bill bluish-grey with a black nail; legs and toes slateblue, webs black. Total length about 16 inches; bill $1 \cdot 6$ inch; wing $7 \cdot 5$ inches; tail $2 \cdot 3$ inches; tarsus $1 \cdot 4$ inch.

374 
WILD FOWL

Adult male in eclipse-plumage (August).-Very similar to the female.

Adult female.-General colour of the head, neck, upperparts and chest dark brown; the occipital crest shorter than in the male; feathers of the upper breast brown edged with white; rest of the underparts white; sides and flanks smoky-brown slightly vermiculated; axillaries white. Total length about $16 \cdot 5$ inches; bill $1 \cdot 6$ inch; wing $7 \cdot 3$ inches; tail $2 \cdot 3$ inches; tarsus $1 \cdot 4$ inch.

General distribution.-The tufted-duck is widely distributed over Europe and Asia, ranging to North Africa in winter. It breeds in the Faeroe Islands and in Norway, but is not very common there; eastwards in Sweden, Finland and Russia it is more plentiful, and nests from far beyond the Arctic Gircle southwards to about $50^{\circ} \mathrm{N}$. latitude. In Asia it is found in summer up to $70^{\circ}$, and extends to Eastern Siberia and Kamchatka. In winter it ranges over South Europe to North Africa as far as Abyssinia, where a few are said to breed on the elevated lakes; thence eastwards to India, Ghina and Japan, occasionally wandering to the Philippines, Borneo, and even to the Pelew and Marianne Islands in the Western Pacific.

Distribution in the British Isles.-At the present time it nests throughout the British Isles, having greatly increased as a breeding-species during the last twenty years. In the colder months large numbers visit the low coasts and inland waters, and are often found in company with flocks of other diving-ducks.

Nest and eggs.-The nest is usually placed in a tuft of grass or sedge, and is made of dry grass lined with down. From eight to thirteen greenish buff eggs are laid towards the end of May or early in June, and measure about $2 \cdot 3$ by $1 \cdot 5$ inches. Incubation lasts from twenty-five to twenty-seven days.

The food consists of aquatic plants and various kinds of animal food, most of which is obtained by diving; as a rule the flesh is indifferent eating. 


\section{MERGANSERS}

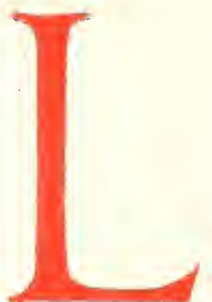

IKE the diving-ducks, the mergansers have the hind toe very widely lobed (see fig. 4, p. 290). The bill is narrow, lengthened, cylindrical, and strongly toothed, not exceeding 0.3 of an inch in width at the tip, which is strongly hooked. The legs are placed very far back, enabling the birds to dive and swim with ease, but rendering their gait on land very awkward. The plumage in the two sexes is different during the greater part of the year, except when the adult male assumes the eclipse-plumage after the breeding-season.

\section{GOOSANDER}

\section{MERGUS MERGANSER}

(Plate XXX, Figs. 7 and 7a)

Mergus merganser, Gould, Birds Europe, v, pl. 384 (1837) ; Dresser, Birds Europe, vi, p. 685, pl. 452 (1875); Hume \& Marshall, Game Birds Ind., iii, p. 299, pl. 40 (1880); Lilford, Col. Fig. Brit. Birds, part xxiii, pl. (1893); Saunders, Ill. Man. Brit. Birds, p. 471 (1899).

Merganser castor, Salvadori, Cat. Birds Brit. Mus., xxvii, p. 472 (1895).

DULT male.-Head and upper part of the neck black, glossed
with oil-green on the top of the head and back of the
neck; the occipital feathers considerably lengthened but
not forming a conspicuous crest except when erected;
lower half of the neck, upper mantle and outer scapulars
white; upper back and long inner scapulars deep black; lower back, rump, median upper tail-coverts and tail ashy-grey; the shorter lateral rump-feathers and coverts white, finely vermiculated with black; breast and abdomen white, more or less tinged with salmonpink (most conspicuous when the bird is freshly killed); lesser and median wing-coverts white; greater secondary coverts widely tipped with white; median and long outer secondary quills white, the latter edged with black; inner secondary and primary quills brownish-black, the former whitish on the inner web; axillaries white. Iris deep red or reddish-brown; bill vermilion-red, the ridge of the upper mandible and the nail blackish; 

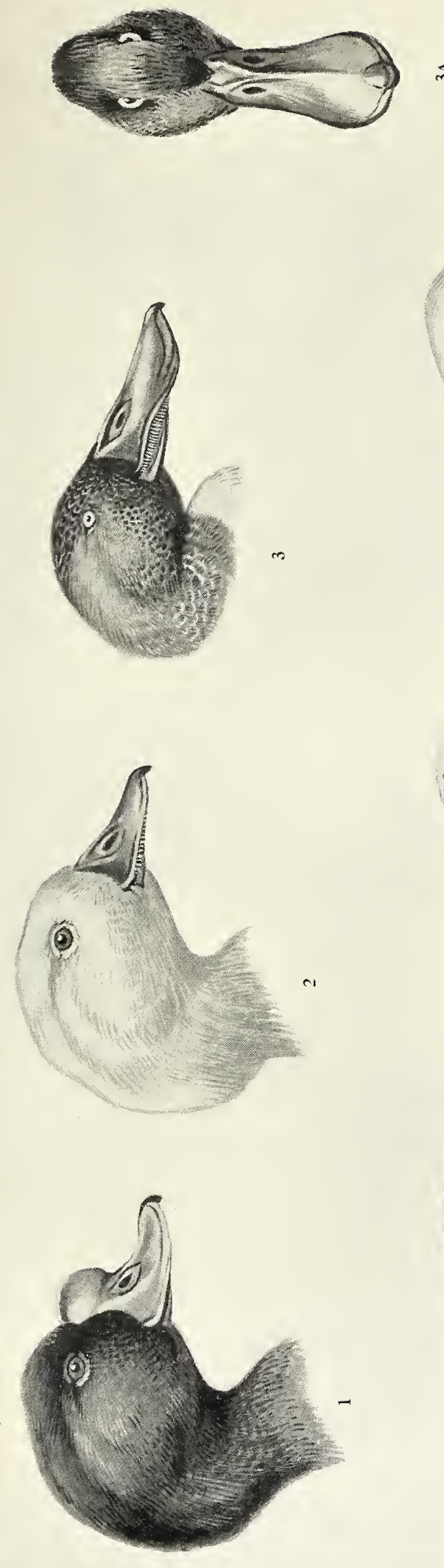
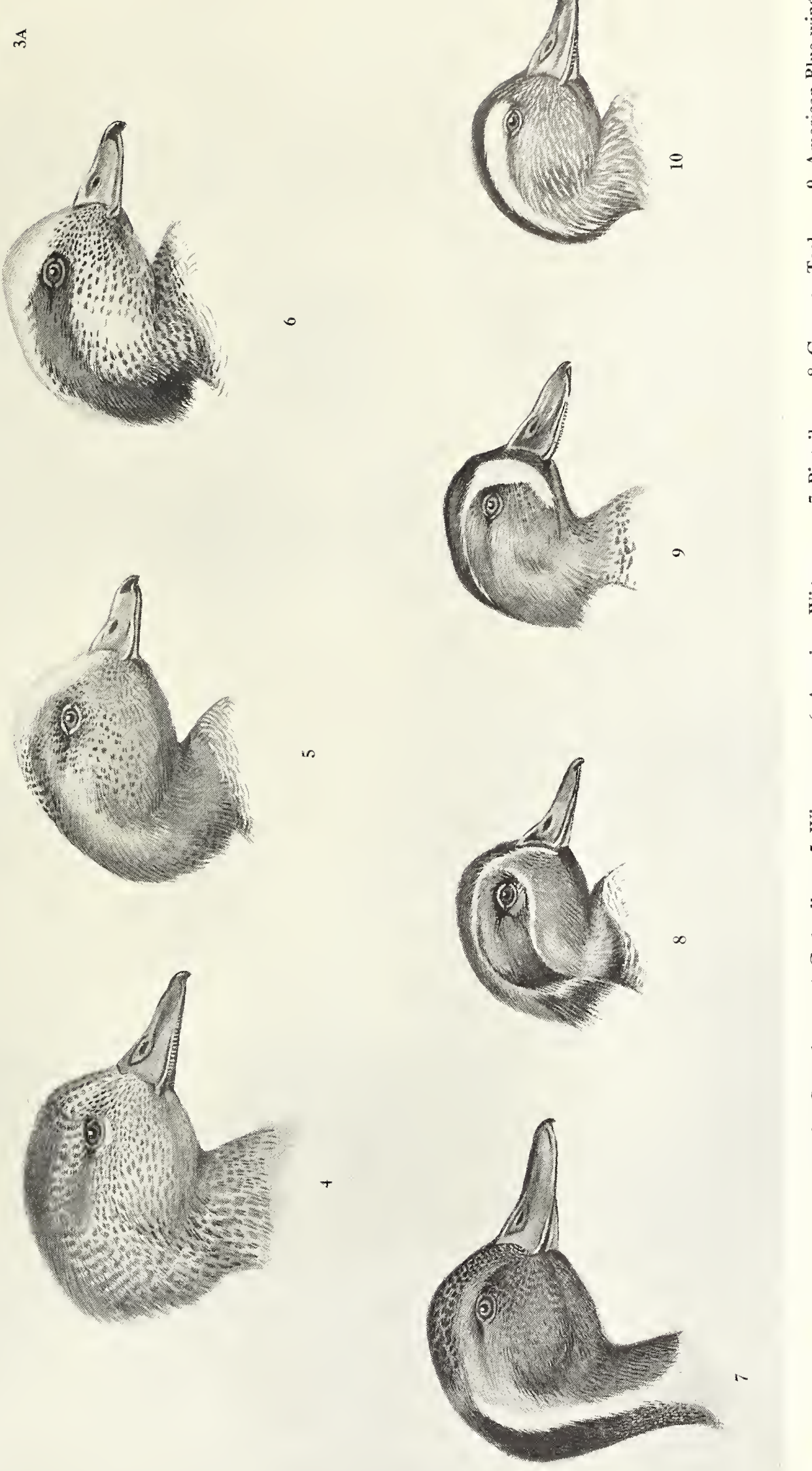

WILD FOWL

feet and toes vermilion-red. Total length about 26 inches; bill $2 \cdot 4$ inches; wing $11 \cdot 5$ inches; tail $4 \cdot 3$ inches; tarsus $2 \cdot 1$ inches.

Adult male in eclipse-plumage.-Closely resembles the adult female.

Adult female.-Head and upper neck reddish-chestnut, browner on the crown and occiput, the feathers being much elongated and forming a conspicuous crest; chin and upper part of the throat white; back of the neck grey, the feathers edged with whitish; rest of the upperparts, including the inner secondary quills, scapulars and wing-coverts ash-grey; median secondaries white tipped with black, their greater coverts black with a wide subterminal white band; inner secondary and primary quills and their coverts black; rest of the lower neck and underparts white; sides and flanks grey tipped with whitish; axillaries pure white. The colours of the iris, bill, legs and toes are similar to those of the male, but less bright. Total length about 22 inches; bill $1 \cdot 9$ inch; wing $9 \cdot 8$ inches; tail $4 \cdot 0$ inches; tarsus $1 \cdot 8$ inch.

General distribution.-The goosander inhabits the northern and central parts of Europe and Northern Asia. Its breeding-range includes Iceland, Scandinavia, Finland and North Russia southwards to Denmark, East Germany, the Swiss Lakes, the Central Volga districts and the Ural. Eastwards it ranges across Siberia to Kamchatka. In winter it is met with in Southern Spain, sparingly in the Mediterranean basin, except in the Adriatic, while in the Black Sea it is common. It is rare on the African coasts, but has occasionally been met with in Morocco, Algeria and Tunis. It is not met with in Central Asia or India, where a very closely allied form takes its place, but winters in China and Japan.

Distribution in the British Isles.-Though chiefly a winter-visitor to the British Isles a number nest in various localities in Scotland. In the Shetlands, Orkneys and Outer Hebrides it is seldom met with, and is neither a regular nor common winter-visitor on the south coasts of England, Wales and Ireland, but elsewhere it is fairly common in the estuaries and inland waters.

Nest and eggs.-The goosander breeds very early in the year, towards the end of April or early in May. The site selected is usually a hollow tree by the side of a loch, but sometimes a hole under the roots or a sheltered ledge of rock are made use of. The hole is lined plentifully with greyish-white down, and from eight to thirteen dark cream-coloured eggs are laid, measuring about 2.7 by 1.8 inches. Incubation lasts about twenty-eight days. 
THE GUN AT HOME AND ABROAD

The goosander is a most expert diver, and its food consists almost entirely of fish.

Allied forms.-In Central Asia and India this species is represented by a closely allied but smaller form, $M$. comatus, the male of which is distinguished by having broader black edges to the long innermost secondary quills.

Another very handsome allied species inhabits South China, and is known as M. squamatus.

In America the representative species is $M$. americanus, the male of which has a black bar across the base of the greater wing-coverts.

\section{RED-BREASTED MERGANSER}

\section{MERGUS SERRATOR \\ (Plate XXX, Figs. 6 and 6a)}

Mergus serrator, Gould, Birds Europe, v, pl. 385 (1837) ; Dresser, Birds Europe, vi, p. 693, pl. 453 (1874); Hume \& Marshall, Game Birds Ind., iii, p. 305 (1880); Lilford, Col. Fig. Brit. Birds, part xxi, pl. (1892) ; Saunders, Ill. Man. Brit. Birds, p. 473 (1899).

Merganser serrator, Salvadori, Cat. Birds Brit. Mus., xxvii, p. 479 (1895).

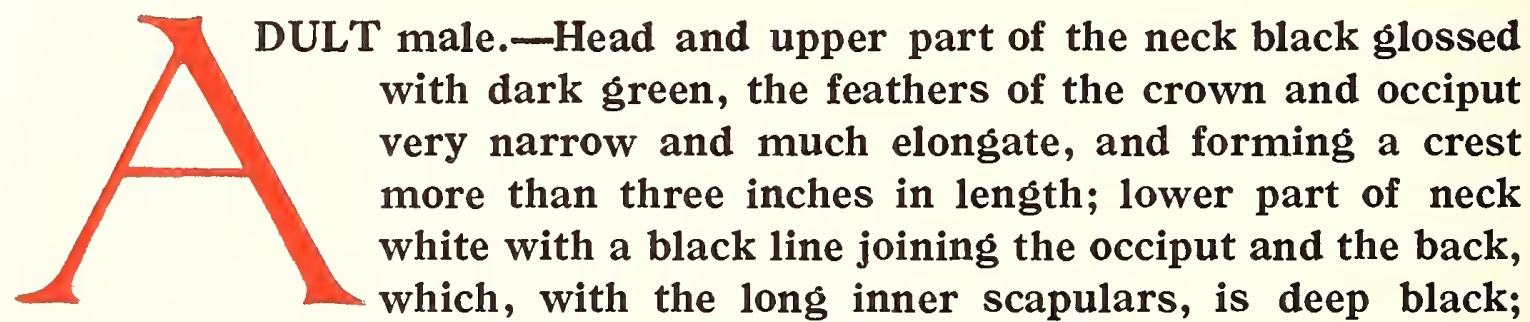
outer scapulars white; sides of the mantle and chest pale rufous spotted with black; lower back and rump, as well as the sides of the breast and flanks, with narrow wavy bars of black and white; upper tail-coverts and tail nearly uniform grey; breast, belly and under tail-coverts white; on the sides of the breast a conspicuous patch of black feathers with the central part white; lesser wing-coverts greyish ash-brown; median coverts white; long outer secondaries white margined with black; median secondary quills white with the basal part blackish, greater coverts similarly marked, the exposed black basal parts forming two conspicuous black bands across the white ground-colour of the wing; innermost 378 


\section{WILD FOWL}

secondaries, primaries and their coverts brownish-black; axillaries white. Iris bright red; bill bright vermilion, the nail and ridge dusky; legs and toes bright vermilion. Total length about 23 inches; bill $2 \cdot 2$ inches; wing $10^{\cdot} \cdot 0$ inches; tail 3.5 inches; tarsus $1 \cdot 75$ inch.

Adult male in eclipse-plumage.-Resembles the adult female.

Adult female.-Top of the head and nape ash-brown, shading into light rufous on the sides of the head, and into whitish on the chin and throat; the occipital feathers narrow and considerably lengthened, forming a crest more than one inch in length; feathers of the back and scapulars, as well as the sides of the breast and flanks, ash-brown with grey margins; tail ash-brown; breast and rest of the underparts white, the under tail-coverts mixed with pale brown. The wings differ from those of the male in having the median wing-coverts greyish ash-brown, like the lesser coverts, and all the inner secondary quills brownish-black; axillaries white. The colours of the iris, bill and legs are similar to those of the male, but not so bright. Total length about 18.5 inches; bill $2 \cdot 1$ inches; wing 8.8 inches; tail 2.8 inches; tarsus 1.6 inch.

General distribution. - The merganser inhabits the northern parts of the Northern Hemisphere, and breeds over a large part of its range. It nests in Greenland, Iceland, the Faeroes, Scandinavia, North Russia, the Baltic and Northern Siberia. In winter it is generally distributed southwards, and visits North Africa, the Black and Caspian Seas, Persia, North India, China and Japan. In India it has only been twice observed, but no doubt the majority of visitors pass unnoticed, as they frequent the coasts. In North America it breeds from Alaska eastwards to Greenland, and southwards to about $45^{\circ} \mathrm{N}$. latitude; while in winter it ranges to Lower California and Florida, and occasionally to Bermuda and Cuba; also to the Hawaiian Islands.

Distribution in the British Isles.-In the British Isles it is resident in Scotland, and breeds in numbers on the lochs and along the coasts, especially in the northern and western counties; also in the Shetlands, Orkneys and Hebrides. It nests also in many parts of Ireland, on the large loughs and along the sea-board. In winter it is generally distributed about the coasts and is everywhere common.

Nest and eggs.-The nest is placed in heather, rough grass, etc., sometimes in a hole, and is made of dry grass plentifully lined with light brown down after the eggs have been laid. About ten or twelve eggs are laid, in May or early in June, and vary in colour from brownish-cream. 
colour to drab with a greenish tinge; they measure about 2.6 by 1.7 inches. Incubation lasts from twenty-six to twenty-eight days.

The merganser is an expert diver, and feeds almost exclusively on fish, especially small trout and salmon-fry. Its flesh is unfit for the table, but it is constantly shot on account of the damage it does in the rivers.

\section{SMEW \\ MERGUS ALBELLUS \\ (Plate XXX, Figs. 9 and 9a)}

Mergus albellus, Gould, Birds Europe, v, pl. 387 (1837) ; Dresser, Birds Europe, vi, p. 699, pls. 454, 455 (1874) ; Lilford, Col. Fig. Brit. Birds, part xix, pl. (1891) ; Salvadori, Cat. Birds Brit. Mus., xxvii, p. 464 (1895); Saunders, Ill. Man. Brit. Pirds, p. 475 (1899).

Mergellus albellus, Hume \& Marshall, Game Birds Ind., iii, p. 293, pl. 39 (1880).

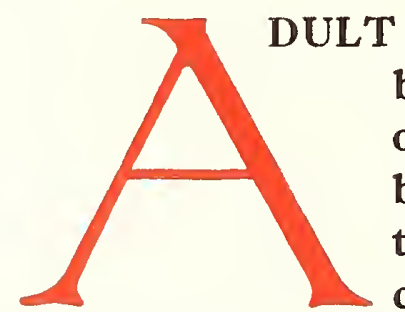
bill, including the eye, black; lower part of the white occipital crest, which is about an inch-and-a-half in length, black glossed with green; back and rump black; upper tail-coverts grey with pale edges; tail dark grey; two crescentic black bands on the sides of the breast; sides and flanks greyish-white with narrow wavy black lines; lesser wingcoverts blackish, median white; long outer secondary quills dark grey, followed by one with the outer web white edged with black; remaining secondaries and their greater coverts black tipped with white, the tips forming two white bands across a black ground; primary quills and their coverts brownish-black; axillaries white. Iris in very old birds bluish-white, usually reddish-brown; bill bluish lead-colour; legs and toes plumbeous, webs darker. Total length about 17 inches; bill $1 \cdot 2$ inch; wing $7 \cdot 5$ inches; tail $2 \cdot 8$ inches; tarsus $1 \cdot 2$ inch.

Adult male in eclipse-plumage.-Resembles the female.

Adult female.-Upperparts and sides of the head and nape chestnutbrown with a blackish patch on the lores; the rest of the upperparts, including the tail, dark brownish-grey, lighter on the scapulars; chin, throat and fore-neck white; chest pale grey; breast and rest of underparts white; sides and flanks ashy-grey; wings much like those of the 


\section{WILD FOWL}

male but browner. Iris brown; bill greyish-black; legs and toes as in the male. Total length about 16 inches; bill $1 \cdot 1$ inch; wing $7 \cdot 0$ inches; tail $2 \cdot 7$ inches; tarsus $1 \cdot 2$ inch.

General distribution.-The smew inhabits the northern portions of Europe and Asia. Its breeding-range extends from Finnish Lapland and the northern portion of the Baltic across Northern Russia to the Ural Mountains, and thence eastwards across Siberia to Bering Sea up to the limit of the forest-growth. In winter it is occasionally met with on the coast of Norway, and extends along the Atlantic coast of Europe southwards to Morocco; it also visits the Swiss Lakes, Mediterranean, Black and Caspian Seas, Northern India, China, Japan and the Commander Islands. It has occurred accidentally in the northern part of North America.

Distribution in the British Isles.-To the British Isles it is a wintervisitor, and while in the Shetlands and Outer Hebrides it is scarce, it is not uncommon in the Orkney Islands and along the east coast of Great Britain; less numerous on the south, and scarce on the west, except on some of the Inner Hebrides. To Ireland it appears to be a regular annual visitor, but is always somewhat rare. The birds seen in this country are generally females and immature, the adult males being seldom met with near the shore except in severe weather.

Nests and eggs.-Very little is known about the breeding-habits of the smew, but, like its allies, it places its eggs in holes in hollow trees with a lining of white down. The eggs, from six to nine in number, are of a pale cream-colour, and measure about $2 \cdot 0$ by $1 \cdot 45$ inches. The eggs are laid in June.

The food consists of fish and small crustaceans, which the bird obtains by diving. 


\title{
THE GUN AT HOME AND ABROAD
}

\section{HOODED MERGANSER}

\author{
LOPHODYTES CUCULLATUS
}

(Plate XXX, Figs. 8 and 8a)

Mergus cucullatus, Gould, Birds Europe, v, pl. 386 (1837) ; Lilford, Col. Fig. Brit. Birds, part xxxi, pl. (1895); Saunders, Ill. Man. Brit. Birds, p. 477 (1899).

Lophodytes cucullatus, Salvadori, Cat. Birds Brit. Mus., xxvii, p. 468 (1895).

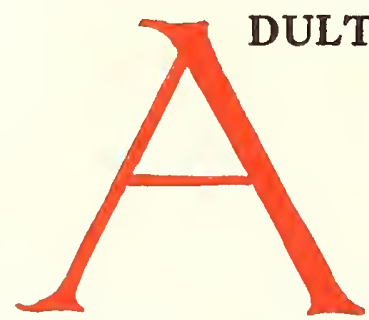

male.-Head and neck black, becoming sooty-black on the forepart of the crown; the feathers of the hinder part of the crown and occiput much lengthened, and forming a full compressed semicircular crest, the posterior half of which is white edged with black; back, rump and upper tail-coverts brownish-black; scapulars

deep black; base of the fore-neck, breast and belly white; on the sides of the breast two pairs of crescentic black bands descend from the mantle, the upper pair being indistinctly united across the chest; sides and flanks greyish-rufous narrowly barred with wavy blackish cross-lines; under tail-coverts brownish-grey mottled with light sandy-white; lesser wingcoverts blackish, median grey; long curved outer secondary quills black with a wide white shaft-stripe; rest of the secondaries brownish-black, the median ones with the terminal half of the outer web widely edged with white; greater secondary coverts black tipped with white, the black bases of the secondary quills and their coverts forming a double black band across a white ground; outer webs and tips of the primary quills brownish-black, the rest of the inner webs greyish-brown; axillaries white. Iris bright yellow; bill black; legs and toes yellowish-brown. Total length about 19 inches; bill $1 \cdot 6$ inch; wing $7 \cdot 8$ inches; tail $3 \cdot 6$ inches; tarsus $1 \cdot 3$ inch.

Adult male in eclipse-plumage.-Similar to the adult female, but with the throat and middle of the fore-neck blackish.

Adult female.-Head, neck and upper part of the chest greyish-brown; the feathers of the occiput brownish-rufous and much lengthened, forming an erect compressed crest; chin and throat white; upperparts as well as the sides and flanks, dark brown with paler margins to the feathers; rest of the underparts white; under tail-coverts spotted and mottled with dark brown; the wings differ from those of the male in having all the wing-coverts dark brown and the inner secondaries much less lengthened 382 


\section{WILD FOWL}

and curved; axillaries white. Iris hazel; bill black edged with orange, lower mandible orange; legs and feet dusky. Total length about 18 inches; bill 1.5 inch; wing $7 \cdot 5$ inches; tail $3 \cdot 5$ inches; tarsus $1 \cdot 25$ inch.

General distribution. - The hooded merganser is a native of North America, and breeds from British Columbia, Ungava and Newfoundland southwards to New Mexico, Louisiana and Central Florida. In winter it visits Lower California, Mexico and the West Indies. It has been recorded from Alaska and Bermuda.

Distribution in the British Isles.-To the British Isles it is a very rare wanderer, and only four fully authenticated instances of its occurrence are on record, though others have been reported. Seven of the records are from Ireland, one from North Wales, and one from Norfolk.

Nest and eggs.-Like its allies, it invariably nests in hollow trees, the down surrounding the eggs being dark-coloured and not white. The eggs, five to eight in number, are of a creamy-white or pale cream-colour, and measure about $2 \cdot 2$ by $1 \cdot 7$ inches. Incubation is said to last thirty-one days.

This species feeds on fish, and seems to frequent fresh-water ponds in summer and the sea-coast in winter.

W. R. OGILVIE-GRANT. 


\section{WILDFOWL AND WILDFOWLING}

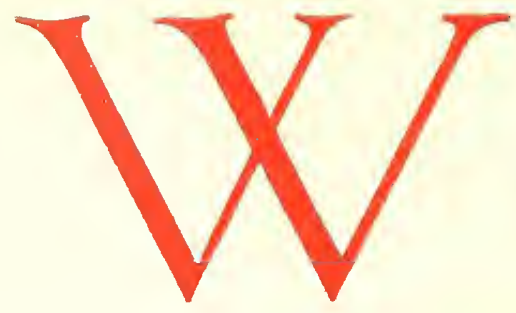

ILDFOWL-which term, for the present, may be restricted to wild geese and ducks-comprise a very large proportion of the most valuable species of the bird-world both as regards the sport they afford, and their edible excellence.

Wildfowling, by its nature, is always uncertain, always difficult; it commonly involves the endurance of considerable discomfort, if not of hardship; and not seldom of actual danger. These are presumably the reasons that condemn the pursuit of wildfowl in the eyes of the vast majority. But they are also the reasons that entrance and inflame the enthusiasm of an inspired minority. Beyond all doubt or denial, wildfowling promises no sort of ideal for the easygoing, nor for the lazy, the old, or infirm in health. But the other sort-the young and fiery; those who love difficulties and adventures, who seek danger, and ensue it-what of them? They have latterly found a better field for their energies than British wildfowling, even at its best, afforded. The sort that, thirty or forty years ago, revelled in laborious days and nights afloat on our British coasts, counting no cost, and amply repaid by a scant and fortuitous reward in wigeon and wild geese-these men now seek lions and elephants in Equatoria, moose and cariboo in Alaska, big game and adventure in a hundred far away hunting-fields. Be the cause as indicated, or otherwise, the outstanding fact remains beyond question-that amateur wildfowling on our British coasts is all but neglected at the present day.

To write on wildfowling in such circumstances is not an encouraging task, and I should never have attempted doing so but for the too flattering desire of the publishers of this work.

Colonel Hawker's classic writings of a century ago stimulated an interest in this difficult pursuit that has never entirely died away. Since his day, a dozen other wildfowlers, not one of whom, including myself, would presume to compare with "the Colonel," have had recourse to print; but none of these efforts have availed to dispel the prevalent apathy, not to say antipathy, displayed towards an avocation that is worshipped only by a few, and condemmed by all the rest as "only fit for fishermen"! It verily seems that the more the art of wildfowling is expounded in print, the less it is pursued in practice. As I have said, the enterprising section of the present generation have preferred to seek adventure abroad, and they 384 


\section{WILDFOWL AND WILDFOWLING}

were right. For the pursuit of wildfowling afloat has fallen from its former standard. The glamour has faded. Hard and uncertain of success as this sport ever was, it is now tenfold harder and more uncertain still. The cause of this deterioration I have already indicated in my "Art of Wildfowling," and need not recapitulate.

I recently found among some MS. notes by my late brother, Alfred Crawhall Ghapman, the following appreciation of wildfowling:

"This pursuit has one superlative attraction-that the prolonged suspense and excitement enjoyed while manœuvring, and finally drawingin upon the fowl, resembles nothing else that $I$ have experienced in other forms of sport with gun, rod, or rifle. As to the shot itself-well, the strain on the nervous system in trying to assure the fullest effect, after all the labours undergone to secure it, is sometimes almost too poignant ! Still, the joys of success, however scarce, with these terribly wild creatures, and the inward sense of having overmastered difficulties that approximate to impossibilities, are one's sufficient reward.

"Another supreme point in its favour is the charming variety in seagame, many of them objects lovely in themselves-perfect pictures of pure bright colour as you lift them off the waves. Many, moreover, are but little known, or at least less familiar than any other British birds. On the other hand, it is certainly the hardest work that men pursue for pleasure. You lie prostrate on your chest, sometimes for hours, and a gunning-punt provides the most comfortless of couches.* Your weight resting on your elbows, knees or hips, those prominent parts should be constructed of steel instead of flesh and bone. Then the prone position necessitates a very awkward angle of the neck in order to keep the eyes bearing horizontally-the neck-muscles should be of whipcord!

"The fowler is for ever scheming, devising, contriving to outwit his wary quarry; yet, in the majority of cases, the fowl have it pretty nearly their own way. There is no certainty. You may have 5,000 geese before your eyes day after day; yet, after a fortnight's chasing, may not have secured a score!

"Again, to the purely amateur fowler, who only perhaps spends a dozen or a score of days afloat each winter, the chances are that he will strike ' the most favourable circumstances' about once in ten years!

"Those who are not more or less inured to really hard work; careless of

\footnotetext{
* On one occasion when the author had brought down an armful of oat-straw to lie on throughout a bitterly cold winter's night afloat, his puntsman scornfully remarked: "You must be one of them hot-house plants !"

DDD 


\section{THE GUN AT HOME AND ABROAD}

cold, wet and disappointment, and as used to knocks, bumps, jars and boatwork generally, as a deep-sea fisherınan, will probably find a few days at a time suffice.

"The risks and hardships, the frequent failures and disappointments -all these adverse circumstances one can tell. The joys of success, the fascination of a suspense prolonged over pregnant minutes worth inonths of humdrum life-these are things that cannot be told in terms. Until realized in actual practice, the fowler's triumph will never be fully appreciated. A similar remark may be applied to other things; but to none, within ny experience, in similar degree."

An amusing illustration of the divergence of tastes in this regard is afforded by the writings of "The Old Shekary" (the late Major H. A. Leveson), one of the toughest and hardest-bitten sportsmen that ever lived; but who, nevertheless, condemned wildfowling by reason of its "uncertainties, hardships and exposure." Although throughout his life he had sought every kind of adventure and danger, yet of puntgunning he writes: "He must be an enthusiast indeed who systematically pursues wildfowl by night as a diversion, since there is no sport so precarious or more calculated to test the endurance, the patience, and the constitution." Even when the aspiring fowler was (as "The Old Shekary" recommends) "ensconced in a large punt provided with air-chambers to avoid the risk of sinking, with plenty of waterproof rugs, an inflatable air-bed, and a good-sized keg of eau-de-vie "' (!) -and I know not what besides, our author concluded that "le jeu ne vaut pas la chandelle," and apostrophizes his experience afloat in a final sentence : "I do not like to make a tuil of a pleasure, and could not again be tempted to face a nor'-wester aboard a gunning-punt on a dirty cold winter's night, even were I sure of bagging a ton weight of wild ducks ; mais chacun à son goût."

The entire change of scene and surroundings form, in my view, no mean asset. Wildfowling, in a general way, follows after game-shooting. After months spent on the wild moorland-always beautiful, but somewhat bleak and inhospitable by November-and after almost a satiety of dripping woods and cleughs, then a sort of rapture surges in the fowler's breast when he finds himself once more by the blue salt sea and all it imports. Yesterday's leagues of rolling brown heather are exchanged to-day for vast prospect over level oozes and savannas dotted with halftide banks gorgeous in many-hued marine plant-life; here the marsh386 
WILDFOWL AND WILDFOWLING

samphire and laver, the sea-wrack or emerald-green zostera replace russet fern, moss and sphagnum. Not a tree nor a bush grows within view, nor can a hill be descried, save dimly in farthest distance. Note that there is no "scenery" where wildfowl gather. The fowler's whole environment is transformed as completely as though he had changed his world. But the charm of the sea-that is, of those desolate places by the sea-is a subtle sentiment undefinable by words of mine. The ceaseless ebb and flow, with its effects-altering every hour, and twice a day varying the life-conditions of a thousand living organismsis a commonplace only to the callous.

Beyond all is the novelty - the grace, the beauty and the variety - of the fresh forms of bird-life by which the wanderer now finds himself surrounded. Close at hand the glistening sands are ornamented by groups of sedate sea-gulls, each figure exquisitely mirrored on the moist surface beneath. Along the shore course tiny waders, hundreds of them, nimble as frightened mice, some venturing breast-deep in miniature wavelets to secure an escaping zoophite. Beyond, where sand-worms have dotted the ooze with countless castings, probe curlews and redshanks; while further away, hosts of chattering godwits mark afar the unwelcome intrusion.

Such sights and sounds as these, remember, greet you from the very outset-they are there to charm eye and ear while launching the gunningpunt hard by your cottage door. They are but everyday incidents of the fowler's surroundings.

But now we are afloat. The trim craft shoots ahead across rippled shallows, crystal-clear, and the salt spray leaps and dances around her sharp bows and surges along the rounded decks. Within an hour's time, or maybe two, we get within touch of true wildfowl, and witness spectacles of wild bird-life that few, very few birdlovers have yet enjoyed. I emphasize this fact since, numerous as are naturalists - and wildfowlers hardly less so-yet the combination of the two characters is strangely rare. Of all our many keen ornithologists, I cannot call to mind a dozen who have ever spent a winter's day afloat in a gunning-punt. Yet those craft appear to offer the only available means to study wildfowl in actual life. Nor can I remember a dozen wildfowlers who have ever taken a living scientific interest in the beautiful creatures whose pursuit they love. Among those rare exceptions there occur to mind the late E. T. Booth, whose "Rough Notes" 


\section{THE GUN AT HOME AND ABROAD}

on wildfowl and fine collection of British birds at Brighton are well known; there is the veteran, Mr J. E. Harting, whose "Hints on Shore-Shooting" long ago inflamed many a youthful enthusiast. I remember therein a picture of grey plovers in their summer-plumage that aroused in me a sort of waking dream for years. Then there is Mr J. G. Millais, who not only combines to the full this dual character, but added thereto the inspiration of the artist, and whose exquisite drawings depict wildfowl in their haunts with a graphic power that can come only from long practical experience of the subject, and from deep instinctive intuition. None can study the illustrations in "The Fowler in Scotland" without realizing the nature and haunts of wildfowl in far clearer perspective than I can hope to give in reams of written words.

We have now penetrated (in imagination) afar into the desolation of tidal ooze and mudflat. The first point that strikes attention is the sheer immensity of these places-their dead-levels at first deceive eyesight. Objects that one had taken to be comparatively near, prove leagues away. I well remember (though it is over forty years ago), this feature being first impressed upon me by the following incident. Having noticed a moving object on a distant sandbank that, with naked eye, I took to be possibly a seal, on bringing the glass to bear, the object proved to be a man with a horse and cart collecting seaweed some four miles away! Similarly groups of bait-gatherers in farthest distance may be mistaken for curlews probing at half a mile; or vice versâ should the condition be reversed-such are the phantasies of space, and the tricks that atmosphere, on these farstretched flats, can play with eyesight.

All this, however, is digression, and we must get back on our course. The gunboat is now navigating mid-channel, and, maybe, a flock of white sea-gulls, some half-mile away, catch the eye. Close by these sits a second group, also white; but if your eyesight be keen it will detect a different quality in their respective colours, albeit both white. That of the detached group displays quite a glossy sheen as compared with the dull white of the gulls. The glass shows the former to be sheld-ducks, and several of them actually mix with the gulls. The latter are all asleep, or quiescent; but many of the sheld-ducks are seen to be poking about in the slob, picking up a light lunch of shell-fish and small crustaceans, varied with an occasional bite of green sea-grass. Sheld-ducks feed as much by tide as by the clock. Not needing these (nor probably able to approach them if they did), the fowlers turn attention to what resembles a long dark 388 


\section{WILDFOWL AND WILDFOWLING}

streak ruled across the waters to windward. They must "flatten" now -that is, lie prone on chest, propelling the boat by a setting-pole over the starboard quarter-for that thin dark line is a company of wigeon, perhaps fifty or sixty in number. The fact is presently proclaimed as a wild whistling "Oh-whee-you" from some watchful old drake resounds across the waters. The conspicuous white wing-coverts of these become visible as the low snakelike craft darts ahead, while the water hisses along her sides as she draws nearer and nearer at each stroke of the pole. Now we are within 100 yards - a few seconds more means realizing a round dozen, perchance a score. The bulk of the company are now seen to be rest ing half-afloat along the mud-edge; others paddle listlessly outside; a few toy idly with submerged fronds of zostera. For night is their time to feed in earnest, at least after November. But where those wigeon summered and bred in the Arctic, there is no night; hence wigeon up there (and other creatures likewise) assume irregular habits in this respect, and these they continue to observe on first arrival in European waters. Here, however, the persistent attentions of fowlers soon teach wigeon to seek a greater measure of safety in darkness. After November, wigeon spend the day at sea, or at least on open waters.

For some little time the fowlers have been conscious of a weird subdued chorus afar-as of a distant pack of hounds in full cry. On nearer approach the inspiring strain will be ascertained to proceed from another thin dark line, ruled as it were on the grey waters. This time, however, the line is visibly deeper, darker and denser. It is a nice pack of brent geese, 500 strong. These are the most important of all our British wild-fowl, and, in one sense only, the most obliging also. Since (reversing the nocturnal habits of wigeon and all the other game-ducks), geese feed by day, and may always be interviewed, at a safe distance, in such spots as they elect to frequent, from dawn till dusk. As the gunboat cautiously draws in towards their position, though still 600 yards away, it may hap that the crash of clanging voices seems suddenly to redouble, and the far horizon ahead is seen to be amove with changing forms and figuressome in masses like a whirling cloud or the smoke of a distant steamer, others in loose groups or strung out in rigid rectilineal formations. These, too, are all brent geese, fresh packs, perhaps straight "from foreign," or, it may be, disturbed elsewhere, and now coming in, in a score of separate companies and commands, to join their friends, the army-corps, on our front. The combined clamour from thousands of stentorian throats as 
the new-comers approach, exhilarates, but certainly defies all verbal effort to describe-a riot of varied intonations, gabblings, and shrilljarring discords. As the incomers lower their flight, the whole seascape ahead-grey waters with dimly seen dunes and distant hills beyondseems streaked and serried with infinite longitudinal stripes, all cleaving, wing to wing, in rigid precision to windward. Each unit being dark forward and snow-white aft, the effect of their lower lines, as seen against the sea, is as of a hundred huge centipedes crawling along !

When large bodies of wild-geese come in, as I have endeavoured to describe-that is, vast aggregations of geese composed of many separate parties-they sometimes, upon reaching their selected alighting place, develop an exhibition of ordered aerial evolutions as complex as-and even more perfectly executed than our most elaborate human manœuvres. Few scenes within my experience of wild bird-life are more amazing or more impressive than this; though perhaps the flashing quick -change evolutions of teal, or of a cloud of whirling dunlings, are not less marvellous. The latter is an everyday spectacle on our wilder coasts ; yet never is eye able to follow its lightning rapidity, nor can we understand how a complete reversal of massed formations moving at express speed can be executed twenty times in a minute with never a mischance or a collision.

With the geese the case is not quite analogous, nor the velocity so great. Here each distinct flock-all clearly under individual command -takes up its own position, every unit obeying with mechanical precision as the infinite divisions wheel and counter wheel, some to right, others to left, in a perplexing confusion of eddying, eccentric and opposing circles, ellipses and parabolas, till eye can no longer follow the mazy movement. Yet never an accident or mischance occurs in all these revolving circulating hosts; never does one detect a false move, or suddenly shifted helm-all is executed with a regularity and a perfect precision beyond the power of human calculation. Then, amidst a crash of reverberating voices, the sea flies up white over a couple of acres-they're down!

Needless to say, the full effect of such scenes can only be realized when the spectator is fairly near, or almost underneath them-a position that is, in practice, almost impossible to attain-but which I once had the luck to enjoy to perfection. We lay, awaiting the flood-tide in a creek, concealed (by mere chance) behind one of the rare abrupt ridges to be met with in 390 


\section{WILDFOWL AND WILDFOWLING}

such situations. No dramatic presentment in playhouse ever entranced my senses as did that wild scene in bird-life.

I have tried briefly to sketch some of the normal surroundings of the punt-gunner. Such scenes as the above he may-or may not-enjoy during a single winter's day afloat; more probably a much longer period would be required.

On the desolate oozes and mudflats where the Zostera marina luxuriates, he will find the geese by day; the mallards, wigeon, and other gameducks by night. The wading tribes do not affect the mud so much; their preference is for sand, a substance which, in parts of our littoral, spreads away in viewless plains, partly moist and firm; elsewhere red-brown in colour, dry and spongy; but in any case intersected by winding tidal channels of salt water.

It is in such spots as these that the fowler finds the waders- "henfooted fowl," I have heard them called-often in such hordes as to defy calculation or estimate of numbers. They comprise chiefly curlews, god wits, knots and plovers, with all their smaller congeners. Here, too, when winter gales do blow, and raging seas outside become untenable, the nocturnal game-ducks (especially mallard), may oft be found in shelter, dozing away the daylight hours. And, in those parts of our island frequented by grey geese, the sand-flats form a favourite roosting placeprovided always that such places lie well beyond the "full sea" mark. Thither those astute fowl will come down half-an-hour before dark, flighting from the inland stubbles and clover-leas, where they have spent the day feeding.

Note that the brent geese, already mentioned, never go inland; they feed by day in tidal oozes and spend the night asleep on the open sea.

In wildfowling the term "geese" is practically restricted to brent geese-so rarely are any other species obtained by punt-gunners. Being exclusively marine in their habitat, the brents, combined with wigeon, probably comprise eighty if not ninety per cent of the entire sum-total of wildfowl killed in British waters. That proportion would certainly apply to the northern, eastern and southern coasts where brent geese frequent in thousands every suitable estuary. Bernacle geese affect chiefly the western coast, though both species are found in Ireland.

Despite plain colouring and a modest dress, few fowl are smarter and more shapely than the brent geese. Their tails, it should be explained, are black, but are not visible, owing to the long white upper and under 
tail-coverts meeting beyond. Birds of the year are distinguished by the wing-coverts being boldly tipped with grey, forming a series of light transverse bands.

As regards the "grey geese," all the four British species are by nature of inland habit, feeding on tillage, clover, and meadowland. All appear instinctively to dislike salt water, and avoid it as far as possible. Were it not for the obvious dangers and frequent disturbance to which they are necessarily subject inland, I imagine that no grey goose would ever, of its own free will, alight on tidal waters.

The few casual grey geese that are ever killed by British coast-gunners are chiefly of the pink-footed species, with bean geese in rather lesser numbers, and the white-fronted kind at irregular intervals.

The Greylag goose (though commonly described as one of our winter wildfowl), I have never myself identified on British coasts during forty seasons' fowling. Its winter haunts lie in more southerly latitudes, its occurrences here being strictly local, and limited to certain favoured spots, perhaps half a dozen in all.*

When busy feeding on the ooze at low tide, both geese and wigeon habitually pull up by the roots far more of the sea-grass (zostera) than they are able to consume. At first, when hungry, they devour the whole plant; but as appetites slacken, the fowl become more epicurean, confining their attention exclusively to the succulent white roots, and leaving the yard-long green blades untouched. On examining the spot where big packs have been feeding, thousands of these rejected blades will be found scattered in regular swathes on the mud.

Whether the result arises from instinctive design or is merely accidental, at least the habit serves them a useful purpose. For such is the quantity of this-apparently-wasted grass, that on each ebb tide there is carried out to sea sufficient to enable the fowl, if need be, to remain "outside" for days together, subsisting entirely on this drift weed. Thus should they be unduly harassed and persecuted, the geese can elude pursuit by remaining at sea, where no punt can follow them; and so set at naught all the power and arts of their aggressors. In mild seasons, when geese

\footnotetext{
* In matters of specific identification I venture to express the opinion that most old-time records possess little or no value-often rather the reverse-unless collateral evidence be available to substantiate their accuracy. Fine specific distinctions were not recognized, or suspected, a few generations back. Bird-names, moreover, were ambiguous and used indiscriminately. Thus herons were confused with cranes, shovelers with spoonbills; while all grey geese were (and still are very generally) known as "grey lags." Few then distinguished one species from another-not every one does so correctly to-day! Few, indeed, of the old-time records, were it possible to put them to a test, would prove trustworthy.
}

392 


\section{WILDFOWL AND WILDFOWLING}

are few in numbers, I have known them remain at sea throughout almost their entire sojourn with us, depending for their food on the grass plucked by wigeon during the night, and carried out to them by the succeeding ebb.

One other class of fowl remains to be noticed ere completing this brief summary, to wit, the divers. Under this comprehensive term are here comprised several of the duck-tribe-some of these quite important to the gunner, such as, for example, the golden-eye and scaup ducks, the pochard and tufted duck-though in my long experience I have always found the two last-named distinctly averse to salt water-they never resort thereto till driven by ice and frost from inland lakes and marshes. There are other diving ducks, such as the scoters, the eider, and the longtailed ducks; but these rarely or never appear inside harbours or in sheltered waters where alone the punt-gunner can operate. The true home of these is the open sea, and their pursuit is only to be essayed under canvas.

Divers of all denominations-whether sea-ducks or mergansers, cormorants, grebes, or the Colymbi-by their nature are driven to avoid the oozes, mudflats and shallows with which we have been hitherto concerned. Their resorts are exclusively the deep-water channels and tideways, as well as the adjacent seas, where hardly a winter's day will pass afloat without the gunner meeting with some one or other of these beautifully specialized creatures. Many of these never go ashore at all-their whole winter is spent afloat. This applies specially to the big sea-divers (Colymbi) and the grebes, whose feet, in all probability, never touch dry land save only during a few weeks at the nesting season.* A similar remark would apply to other sea-fowl which fall outside our present ken, such as guillemots, razorbills, auks and puffins.

Haunts and habits.-The chosen haunts of wildfowl differ from those of all others in being (1) absolutely dead-flat, and (2) devoid of all covert. On tidal areas no covert can grow. Of marine plant-life there is abundance; but, owing to the conditions of its existence, its growth is necessarily recumbent. At full flood the various algæ and sea-grasses stand erect or wave sidelong in the currents, so long as they are water-borne and supported by the tide. At such times the Zostera marina, or sea-wrack, clothes many a thousand acres of ooze with a splendid sub-aquatic forest five or six feet in height. But the exquisite beauty of all marine plant-life-so

* I remember once seeing a grebe (Podicipes cristatus) ashore. 


\section{THE GUN AT HOME AND ABROAD}

charming as viewed from aboard a gunning -punt passing over it-is utterly lost as the tide recedes. Then all lies in recumbent masses, unseemly, and almost repellent, on its oozy bed. The only marine plant that $I$ have then noticed to maintain an erect attitude is the marsh-samphire (Salicornea herbacea), in form not unlike an equisetum. Its range, however, is restricted to very shallow waters, next the shore, where the sweep of the tide is hardly felt.*

It follows that denizens of such bare and shelterless levels must necessarily discard all attempt to seek safety by concealment. Obviously they enjoy no opportunity to conceal themselves; and the effects of such environment, operating during ages, have long eliminated any such ideas or desires from their natures. Wildfowl despise alike concealment, colourprotection and all the other safeguards that feebler creatures seek, or are said to seek. They rely for their safety exclusively upon their own powers and upon their alert senses of sight, scent, and hearing-senses which, during centuries of enforced usage, have been developed to a degree of perfection that few, very few save wildfowlers, have ever adequately realized. Watch them as they sit out there, a sonorous crowd, in the midst of verdant ooze that spreads away for leagues-to the limits of human vision-wildfowl verily seem of set purpose to defy human power, to challenge us and all our devices.

Wildfowl present an unanswerable negative to fantastic theories about "universal colour-protection" in birds, of which so much has been recently heard. None who have had opportunity to watch the long lines of brent geese gaggling and guzzling on the ebb-swept ooze; the hordes of whistling wigeon, or pintails in their thousands-all alike conspicuous both to eye and ear so far as our human senses will avail-none could see such sights and ever again dream such dreams.

So conspicuous are wildfowl that, as I mentioned in my "Art of Wildfowling" (p. 172), the species of mallards or other game-ducks can be clearly distinguished from geese with a good telescope at a distance of about three miles.

Colour-protection finds no more place in their scheme of self-defence than does concealment. Many wildfowl are most conspicuously coloured. Their clean-cut contrasts of bright opposing hues appear actually aggressive-witness the pintails and wigeon drakes, sheld-ducks, eider and

* In depicting wildfowl, artists often yield to temptation (very natural) in adding a background of bush, or rush, or sedge, or rocks - which, though it enhances the beauty of the drawing, is often incongruous, and conveys a false idea of the haunts and environment of many of the birds.

394 


\section{WILDFOWL AND WILDFOWLING}

shoveler drakes, wild swans, and many more. I remember reading (with amazement) the proposition soberly advanced that flamingos were "protectively coloured." Well ; from my experience of these birds in Spain, I should say that a regiment of British redcoats-the thin red line-marching across a ploughed field would hardly be more conspicuous than are the great five-feet, flame-hued flamingos in their usual environment of mud and muddy waters. The big gulls clearly owe no immunity to colour; their three years' adolescence in grey shows that. Again the females of several ducks are distinctly less conspicuous than their mates-a general rule which holds good throughout a great proportion of the animal world (our own race excepted). But in all the cases cited, the sexes (being monogamous) are of equal value in Nature's scheme. This and other cognate theories possess, beyond doubt, a fascinating attraction to contemplative minds. But that very fascination has perhaps misled theorists to expand the operation of their favourite hypotheses far beyond the limits (if any) assigned by Nature.

Nor can Nature's plans ever be arbitrarily gauged or subjected to hard and fast rules. No one, I presume, would question the fact that some game-birds are, in degree, protectively coloured. Yet the one species that appears to offer the most exquisite example, uses the safeguard least. I refer to the grouse, which from mid-October onwards, disdains concealment as utterly as wildfowl do.*

Passing over as too well-known to need special reference, their intensely specialized senses of sight and hearing-not that I estimate these faculties in wildfowl as being superior to those possessed by some other bird-groups, say the birds of prey, certain sea-gulls, gannets and some others-we come to the fact that wildfowl, in practice, are gifted with an extra safeguard which is virtually denied to game and the rest of the bird-world. I refer to the sense of smell. This faculty will usually reveal the human presence, though quite unseen, to either ducks or geese at considerable distances-in favouring circumstances, up to hundreds of yards.

In curious contrast with game, which are the most stationary of all birds, wildfowl include the most cosmopolitan of wanderers. For one flight of a game-bird that exceeds a mile, fifty will fall short of half that distance.

\footnotetext{
*The grouse is colour-protected, nevertheless-but, as it were, unconsciously and malgré lui-when, in the grey. brown atmosphere of late autumn, his dark form skims low over brown heather. Then you may see him as he tops a sky-line half-a-mile away: yet in the interval, aided maybe by some slight fold in the ground, he may be entirely lost to view even by the keenest eye - until he flashes up in your face not 50 yards away.
} 
THE GUN AT HOME AND ABROAD

With wildfowl space scarcely counts. They are hardly ever stationary for long; since, besides their regular biannual migrations in spring and autumn, they are kept continually on the move all the winter by the exigencies of their food-supply. A week's hard frost, congealing lakes and marshes, shallows, and even tidal oozes, cuts off their subsistencethey must shift. So soon as the Baltic and Danish Sounds are frozen up, their feathered denizens must seek refuge in Dutch and British waters; while, should the frost extend beyond, the enforced journey must be prolonged to France, Spain and the Mediterranean-even to Africa. These movements continue-to and fro, north and south, according to climatic conditions-throughout the entire winter. They may extend to hundreds, if not thousands, of miles; yet they are not migrations in the ordinarily accepted sense of that term, nor can they be co-related except only with the weather-conditions at various points.

Bearing these important facts in mind, I found it useful, during my keener fowling days, to study the "navigation reports" in the various shipping newspapers. When the submarine cables reported "Cronstadt icebound" one might make provisional arrangements for a fowling trip. If, a day or two later, Riga and other Baltic ports were telegraphed " closed by ice," one might safely start. Finally, when navigation ceased at Copenhagen, then you might expect the geese for certain within twenty-four hours. These are forecasts that never fail.

Even the seasonal migrations of wildfowl are far less regular than those of most land-birds, and present many strange anomalies. Thus the brent geese arrive in Holland by the end of September; on the western coast of France by the first week in December; yet on our north-east coast of England, we rarely have them in bulk before the New Year-often not till mid-January-and once they arrived by thousands in March-what time, in normal winters, they begin to think of returning northwards.

In the Solent Colonel Hawker regarded their appearance any time before Christmas as being noteworthy.

An instance illustrating the precision with which wildfowl instinctively (and without aid of submarine cables) anticipate climatic changes occurring hundreds of miles away, is given in my "Bird-life on the Borders" (second edition, p. 430). Eight wild swans had taken up their quarters in January, 1893, on a sheet of water within easy view of a railway connecting two big towns, exciting much comment and discussion. Early in February a local newspaper sent a representative to inquire my opinion. I told him 396 


\section{WILDFOWL AND WILDFOWLING}

that the swans were Whoopers: that they would remain where they had settled until the first steamer entered Copenhagen (which was then closed by ice) and that, within twenty-four hours thereafter, they would depart. Some weeks later this prediction was fulfilled to an hour. On Thursday, March 2, the ice broke up in the Sound, on Friday steamers entered Copenhagen, and on Saturday morning, March 4, the swans had disappeared. For an amusing corollary I may refer readers to the volume quoted.

\section{WILDFOWLING AT HOME}

From the foregoing it will be clear that, due in the first place to their bleak and exposed haunts, and secondly to the intensely specialized development of all their innate self-protective faculties, the pursuit of wildfowl presents an enterprise which I verily believe stands unrivalled by any form of wild sport on earth. Moreover, this sport is free to all comers. There are no "preserves," and the prizes fall only to those who are by nature best equipped to seize them.

A psychological condition affecting these free wildfowl is that they represent when obtained "hard cash." Each unit of their multitudes possesses a monetary value, and that in face of keen fowlers-mostly deep-sea fishermen-to whom dollars represent much. Probably no other British industry is more precarious than theirs, harder in its practice; and yet so poorly repaid. Those little colonies of sea-fishers, scattered irregularly around our coasts, deserve well of their country; in various ways they are a valuable asset; yet their reward is disproportionate. They are away to sea long before the winter's dawn, often in weather hardly fit to face, and a temperature more suited to Polar bears and walruses; yet the harvest of the sea is always uncertain, often scant, and in stormy periods it may be nil for days and weeks on end. Within their view there pass, day by day, in and out from the harbour, those gaggling skeins of geese and hordes of wigeon, every couple of which (could it be secured) is the equivalent, say, of three shillings. Thus a pack of 1,000 geese would sum up to a total of some $£ 70$ sterling - to them a fortune. No wonder the fowl are followed and harassed-never a chance to score off them neglected, whether by day or by night. That in practice so few, comparatively speaking, are ever killed-I have roughly estimated the proportion as varying between 10 and 15 per cent-bears eloquent testimony to the intensely wild nature and wondrous vigilance of wildfowl in general, and British wildfowl in particular. 


\section{THE GUN AT HOME AND ABROAD}

The normal hard luck of these sea-toilers has of late years been cruelly accentuated by the ubiquitous steam-trawler, which nowadays raids every yard of the coast, sweeping bare the very sea-frontage of the fishing hamlets-fishing-grounds which the local men had once regarded as their own particular privilege and heritage.

The difficulties and uncertainty are still further accentuated by another factor, mention of which should not be entirely omitted. I allude to the circumstance that fowling operations are ever necessarily subject to the vagaries of our winters' winds and waves, weather and tides-and that too, on the most shelterless areas that exist within the four seas. For days together these influences may utterly preclude all chances of success or indeed of effort; since no fowling-craft (to be of effective service) can live amidst rough seas, or the "chop" of an angry tideway. The soretried gunner may have at such times thousands of fowl within his view, crowded thick as they can stow in some mid-tide shelter, and yet dare not show his nose afloat. Worse still, should his patience be tempted, by a lull in the gale, to adventure a perilous dash for victory, he may find himself caught in some sudden renewal of the hurricane that will cut off his retreat and cost him bitter hours of exposure and misery-it has cost some their lives.

Again as regards night-work afloat-when success is dependent on the advantage of a full moon and spring-tides-all that advantage may be lost, and with it the opportunity for a whole month, by just such stress of weather, or by fog coinciding with the brief period of lunar effulgence.

Into the minutiæ of wildfowling in its infinite phases-punt-gunning by night and day, flighting, shooting to decoys, or under canvas, and the rest, including the mechanical construction of fowling-craft, their best dimensions for double or single-handed work, punt-guns with their gear and appurtenances, etc. - I have no intention of entering in detail. My reasons are these: Primarily because nowadays no one, or very few, care to adventure on this undertaking; secondly, because I have myself, in more than one volume, described all these things (including the life-history, seasonal migrations and habits, both by day and night, of every sort of British wild-fowl) with all the knowledge that I possess. To recapitulate would be merely to abuse both the patience and the intelligence of my present readers. I will therefore confine myself to a brief summary of the main features of the fowler's craft.

The fozeler's craft.-The first problem that confronts him is-not, as in 398 


\section{WILDFOWL AND WILDFOWLING}

most field-sports, to find his game; since there it is, in full view, on tide or ooze; but-so to contrive as to bring himself and his gun within effective range of a clearly visible quarry. This object he can attain in two principal ways, as follows :

(1) By direct approach. This, upon ceaselessly vigilant fowl, assembled on their chosen vantage-ground, is only feasible (if at all) by means of a fully equipped fowling-punt with stanchion-gun. The attempt by daylight, however smart the craft and skilled her crew, will probably fail, say eighteen times out of twenty-such is now the excessive wariness of all British wildfowl. With geese the failures will be in even greater disproportion. And even of the rare successful ventures, not all will be exploited to the fullest advantage-perhaps three or four times in half a dozen hard-won shots.

But why these eleventh-hour drawbacks? The reasons are well and bitterly known to craftsmen. The punt may touch the ground forward, or graze on half a dozen "winkles" aft, and so swing round in a racing tide-the effort to straighten her involves a deadly risk, and meanwhile your gun does not bear. Again, at precisely the critical moment, you may "lose bottom" in some unseen deep, and need to get out a longer setting-pole-a nerve-shaking manœuvre in the very face of a vigilant foe! There is the ever-present risk of a missfire-grievously frequent in the muzzle-loading days; a distant shot by another gunner; a straggling curlew or redshank giving alarm. A dozen such mischances might be enumerated; but, after all, the fowler's first anxiety and his chiefest skill centre round the handling of a stanchion-gun-that is, the placing of its central charge precisely on the right spot and at the right moment. This, remember, has to be accomplished while lying prone on a punt's floor at water-level. The shot has often to be taken from a lively boat dancing in a sea-way; at objects none too distinctly seen; and at a range of anything under 100 yards. Half-an-inch error in the elevation of the barrel ; an eighth of a second's miscalculation in "timing the shot," represents the difference between-say two score fowl and triumph; or total failure that vexes one's very soul!

In my humble judgment, all circumstances being considered, the highest pheasant that ever flew-and no disparagement to him-is not in the same horizon with a really scientific shot at lifting ducks with the stanchion-gun. Besides, should you miss your pheasant, there's another, or a dozen, or a score to follow, enabling you to correct errors 


\section{THE GUN AT HOME AND ABROAD}

of aim or allowance. In wildfowling that is not so. Every miss, or even partial failure, is a catastrophe.

At night, given favouring conditions and a straight issue, the chances of success by direct approach upon mallard, wigeon and other nocturnal ducks are distinctively-say twenty-fold-less precarious, though that is not saying much. On the other hand, the fowler has then the superadded difficulty of darkness to contend with. No slight handicap is that, since human sight at its best, is not crepuscular; while that of wildfowl is most distinctly so.

The importance of exactly " timing the shot," which, as above stated, is a first essential in successful gunning, is well illustrated by the difference in treatment as between ducks and geese. The latter, being heavier fowl, rise horizontally from the water; hence it is usually advisable to await their taking wing before dispatching the charge. Even in this case, however, the least undue delay-be it but fractions of a second-will materially reduce the result. A few geese still on the sea, or in the lower ranks, will be hit-the main body above escapes. With ducks the case is much more difficult; since these spring at a single impulse clear of the trajectory of a set punt-gun. The shot should be taken as soon as the ducks (if within range) indicate, by craning their necks, or otherwise, that they are on the point of rising. In that event, the charge, if smartly despatched, will very probably sweep them at the most favourable conjuncture-namely, just as their wings are spread, and while in the act of clearing the water. The most successful shots are invariably made at that critical moment-aided, not infrequently, by a sheer slice of luck. The risk of being an instant too late is serious, and the safest shot, though not the most productive, is to take them sitting.

I now come to the second method above indicated, namely :

(2) Flight-shooting, that is, awaiting either the arrival of the fowl at their feeding-grounds; or intercepting their passage at some salient point on their accustomed route between these and their normal resting places. To ascertain for oneself precisely those feeding-grounds, or the points at which the course of fowl may be commanded midway-(that is, to ascertain spots or points unknown or unobserved by rival fowlers) -involves much patience, time, and local observation, extending probably over miles of coast and coastal features. That patience, however, may result in reward, the memory of which will be cherished for life.

Annexed are half a dozen extracts taken almost verbatim from old wild400 

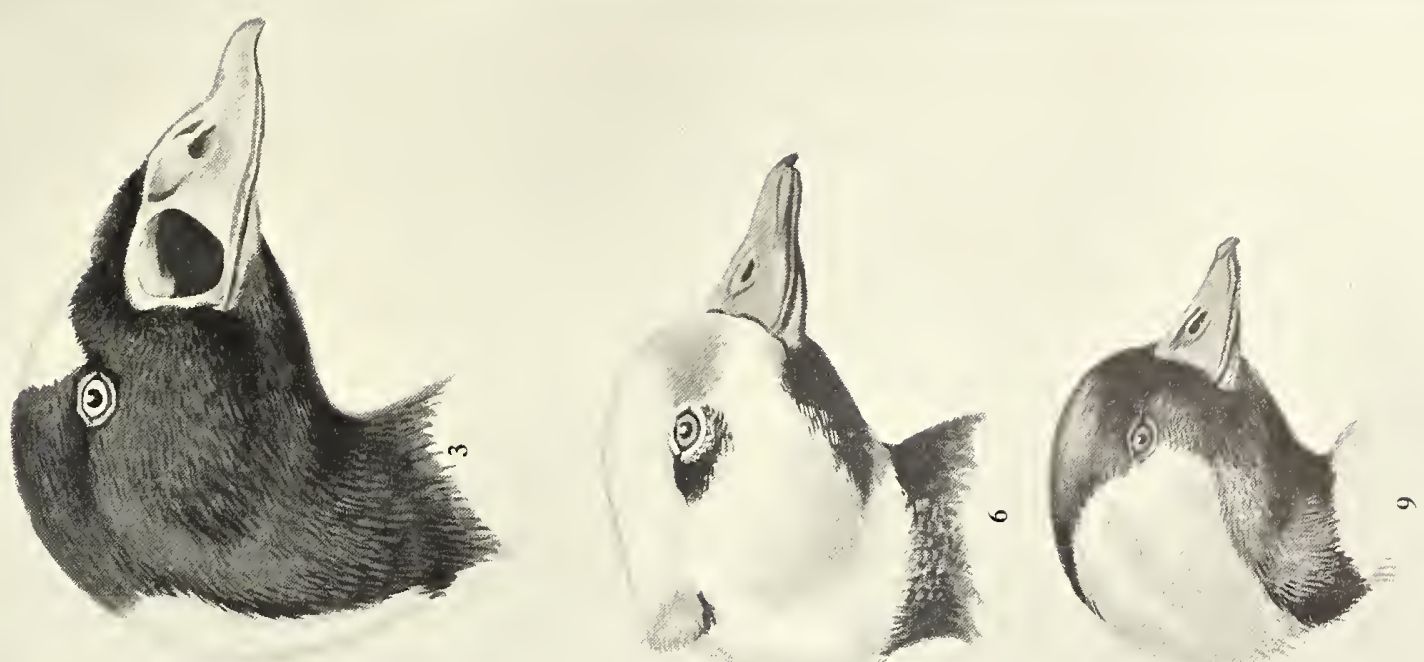

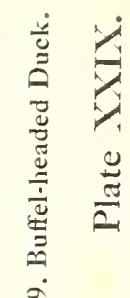
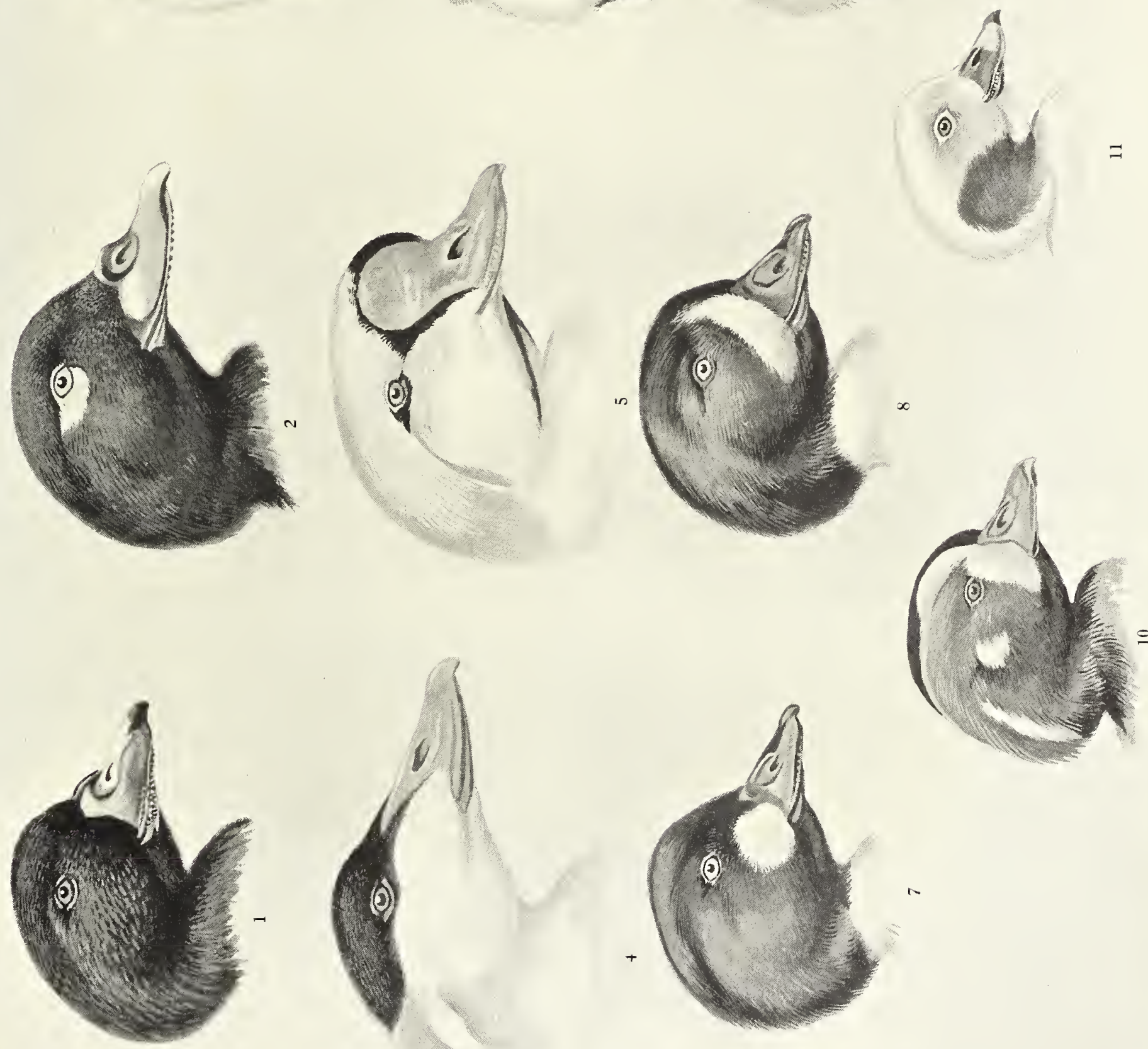

(c) 



\section{WILDFOWL AND WILDFOWLING}

fowling diaries, by way of illustrating the precarious nature of this pursuit -already emphasized:

October 29. After three stormy days (when we were never afloat), wind fell at midnight, and we started on quarter-flood at 6 a.m. Soon after dawn, sighted wigeon in a broad bight but all "sore squandered" as the puntsman put it. However, ere we drew in, the run of the flood-tide swept them well together and nicely " lined out" along our shore ; affording (what won't happen thrice in a lifetime!) a length-long shot, straight ahead. Gathered thirty-four, though there were not much over one hundred of them in all, and three or four cripples beat us on the rotten ooze. Saw hundreds of grey geese on the wing all the morning. Before noon, wind freshened, and by three we were driven home by rising sea. Gale all night, and glass having fallen to $28^{\prime} \mathbf{9 5}^{\prime \prime}$, returned home next day.

The one bit of luck in a week's work was catching those storm-tossed wigeon resting between gales.

December 2. Hard frost $\left(10^{\circ}\right.$ to $\left.14^{\circ}\right)$ since three days ago. Noticed succession of mallards flighting up North Channel; laid in wait at 3 p.m., and got nive (three at one shot, 10-bore). At dusk went to try for grey geese on sand-bar; but not a bird appeared. A fortnight ago, they were hundreds strong, but the frost has driven them South. It was amusing to watch half a dozen flight-gunners burying themselves in the bare brown sand-wastes on the merest offchance of geese alighting within range. None came.

December 3. Wind N.N.W., frost holding-afloat at 6, half-flood (neaps). At daybreak got in to two golden-eyes and stopped both with small gun, second a long way out. Fifteen brent geese came in from sea (they had arrived Nov. 14), set in to 120 yards, but refused the chance, and never got so near again. Fired at seven sheld-ducks on mussel-scap, 80 yards, BB, stopped four. Two, being winged, tried diving-they dive as well as wigeon. One was a superb adult drake, nearly $3 \frac{1}{2} \mathrm{lb}$. During full-sea found two lots of wigeon "inside "-had one fair shot, empunting eleven. A sailing boat put the others to sea. Coming home on ebb, shot fourteen golden plover and lost nearly as many more on the ooze. (See note on this later.)

December 4. Wind S., frost gone, a full gale and heavy sea; glass low and faliing. Thought to return home, but in afternoon glass rose rapidly; wind veered to N.W., gentle, with black frost, so stayed on. 


\section{THE GUN AT HOME AND ABROAD}

December 5. Frost gone and renewal of S.W. gale, strengthening towards dusk. Two blank days.

December 6. Still blowing, and sea too rough for punt. Having noticed four scaup in outer harbour, ran down in big coble to leeward; a greenwater job, and all wet as walruses. Made all snug, and let boat drive in on flood; killed three of the four scaup with 10-bore, most interesting specimens. (Here follow descriptions.) Had to tack round scaur-head, and beat home half-seas over, but shot an immature eider drake, required as a specimen, in very heavy sea off the bar.

December 7. Glass down to 28' $55^{\prime \prime}$, a full gale and furious sea. Went home.

December 19. Forty-eight hours without undressing, result fifty fowl. Went afloat 11 p.m. on 17 th, fine clear night, but moon too vertical, giving no "loom" and bad light ahead while a ripple blackened the shallows. First shot (2 a.m.) seemed to stop quite a score, though got but thirteen wigeon, several diving under the ice alongside which they had been sitting. (N.B. Till then I was unaware of the presence of ice.) An hour later got seven mallards, out of about a score, losing two others, after a heavy chase on the mud, by their going down rabbit-holes on the main shore. At 3 o'clock intended returning home to bed; but being held up by a sudden breeze that prevented our crossing "the deeps," had to weather out the night afloat-result, four hours of bitter starvation. A close shot in the grey dawn, at about a dozen mallards, stopped five and struck three more, two of which were lost through the sea haze preventing our marking them. Landed at 7, and lay down without undressing till near noon; during the afternoon flood, fired twice at geese, results, $2+8=10$, also shot two godwits with small gun. Afloat again at midnight; cloudy, and a strong breeze ruffling the water, could scarce see a shot ahead. Fired once and secured eight wigeon (six adult drakes), besides losing others in the darkness-in about 7.30 a.m. Lay down till lunch time.

All this day a strong breeze-confining our operations to the narrow waters, where during the afternoon, I managed to get four geese out of less than a score by a rather long flying shot. At night breeze freshened to a gale and, the glass falling, returned home next morning-luckily not a feather the worse for it all !

February 8. Splendid clear night, third-quarter moon, a touch of frost and steady northerly airs-a grand show of wigeon, "talking" 402 


\section{WILDFOWL AND WILDFOWLING}

in every direction. At $4.30 \mathrm{a} . \mathrm{m}$. (one hour before full-sea) we had, close ahead, a fine company, all " in charm " and in fair view under the lowering moon. Ten minutes' flood would have taken us right in to them; when sudden commotion spread across the oozes and, for no visible cause, every bird lifted with a roar that reverberated like distant thunder. At that moment we were lying flat, and absolutely motionless-watching and waiting. What earthly cause could have set them all away ? At dawn we knew the answer. A second gunner, whom we met afloat at daybreak, had, at that fateful moment, been "setting" to the fowl precisely one mile to the northward of us (distance measured on map), and, having unwittingly gone to windward of a bunch of wigeon unseen in the dark loom on his left, had given them the wind, and, through them, alarm to all the rest ! By this misadventure something like two miles of wigeon had been set on wing. Just on dawn we had a little squandered shot (all swimming) that realized seven. Home to breakfast by 7.30 a.m.

On February 28 (1896), My brother W. and I left before dusk for the evening-flight - unaware of an impending eclipse of the moon, which was full that night. The result was that for three bitter hours we were enveloped in a Stygian darkness-constrained to lie helpless on the mud; for in such conditions, unable to see a yard's length ahead, it was dangerous to attempt crossing the treacherous ooze. Not a duck moved-nor could we have seen a thousand, had they done so. Still the fact was curious, since wigeon were in great force at the time, and had flown well both the two preceding nights. Clearly they recognized the lunar phenomenon. Whether their "flight" was merely postponed, we knew not; for at 10 p.m., when the moon re-emerged from the penumbra, we at once set out for home-and dinner. It may, of course, be urged that we should have known of the coming eclipse; but no newspapers exist within fifty miles, and besides, when in full swing of fowling work, one has not time to read newspapers.

The above extracts being expressly selected as illustrative of the precarious nature of this pursuit-its dependence on the vagaries of wind, wave, and tide-may induce an unduly disheartening impression. An entry of the opposite kind may therefore be added by way of contrast:

January 26. Perfect fowling weather since the 15th. A grand show of geese, and a glorious week's sport afloat. Inland the country is snowclad, 


\section{THE GUN AT HOME AND ABROAD}

but here on the coast a keen black frost prevails, and scarce a breath of wind. The frost kills that, and the high-dried, rarified air never feels cold, though the thermometer has registered within $2^{\circ}$ of zero by night, and never above $16^{\circ}$ by day. Geese in thousands since 16th, and more arriving almost every day.

Fired each day this week from one to four shots, all at geese, and never a single blank.*

Each shot averaged eight to twelve geese gathered; the smallest four -there were only seven to fire at-while the best realized nineteen, all killed with nine ounces BB shot.

Some years later, it may be pertinently added, no less than twenty-two geese were secured by a single shot from this small punt-gun. That incident occurred in March, 1886, as fully described in "Bird-life of the Borders."

The recurrent losses of cripples and wounded fowl have been mentioned. Such, at times, are quite unavoidable. Fowlers, nevertheless, have sometimes been accused of cruelty in this respect-quite unjustly, though the charge is probably made in complete good faith, by tender-hearted folk, who know nothing of the conditions. These I illustrate below; but may interpolate, parenthetically, that the average fowler will expend his last ounce of energy in recovering every single "cripple" he can lay hands on. The few that escape-either in the dark or on rotten ooze where he cannot follow-are either picked up by coast-gunners and other long-shore prowlers, or promptly devoured by birds of prey-big blackbacks and glaucous gulls. None surely should presume to say that these predacious birds were created without some good purpose? Well, here is the illustration-roughly transcribed from diary :

"My brother W. and I set out together, occupying the gun-punt, and following-boat alternately .... at 4 p.m., after a shot at wigeon on the first of the ebb, W. followed three winged birds on to the ooze, which at that point was fairly sound-not much over ankle-deep. In the zeal of pursuit the tide was temporarily forgotten, and within an incredibly short space-four or five minutes, so fast did the ebb run off the flats, we were a mile apart. I aboard the punt had, of course, to keep my craft afloat, and now the softer intervening ooze was impassable. Nothing

\footnotetext{
* It should perhaps be mentioned that this note dates back rather more than thirty years. No such opportunity is at all likely to present itself nowadays-certainly not locally. Since writing the above, it is right to add that during the past winter, of 1911-12, we had a wonderful show of brent geese-almost like old times!
} 
remained but for $\mathrm{W}$. to plunge a mile or more through rotten ooze to the main shore; then to walk three miles (in sea-boots) to a point where a dogcart could be hired, and lastly to drive seven miles more.

"Meanwhile I was having my own troubles. A sea breeze blew up against the tide, causing a nasty choppy sea, and, being short handed, I could not safely keep the punt in tow astern; shipped a lot of wave, and in trying to weather a spit, got half water-logged, only reaching harbour an hour after dark with three inches of water in the hold, ammunition locker flooded, and wet as a drowned rat. It was past seven ere I got under a roof, and near midnight ere W. rejoined."

Those three cripples were over-dearly bought !

The examples above given refer (with but two or three exceptions), to the use of a comparatively small punt-gun carrying only nine ounces of shot, and chiefly employed against small quantities of fowl. They are not intended, nor do they give any adequate idea of the power and effect of the monster wildfowl artillery of the present day-say double guns carrying two and a half pounds of shot and upwards. Of such I have had no personal experience whatever, my heaviest charge never having exceeded sixteen ounces. It seems necessary, therefore, in order to complete this survey, to quote a few examples from the published records of other fowlers.

Col. Hawker's diary records the following :

1829, Jan.21. $\left\{\begin{array}{c}53 \text { wigeon } \\ 2 \text { mallards } \\ 1 \text { coot } \\ 30 \text { wigeon at another shot (night). } \\ \text { (Total brought in after eighteen hours' work : } \\ 101 \text { wigeon, } 4 \text { mallards, } 6 \text { plovers, etc.). }\end{array}\right.$

1829, Jan. 22. 4 whoopers (out of 5) at one shot.

Hawker, during the season of 1829 , killed 602 wildfowl in eight weeks, of which 433 were wigeon, 97 geese, 5 wild swans, etc.; 1838 was another of the Colonel's best seasons :

1838, Jan. 20. 42 wigeon and 9 geese at one shot.

1838, Jan. 27. 49 geese and 2 swans in four shots; best, 29 geese.

1838, Jan. 31. 21 geese at one shot.

1838, Feb. 3. 57 geese in three shots: 20,3 , and 34 .

1838, Feb. 5, 10 geese and 8 swans in three shots. 


\section{THE GUN AT HOME AND ABROAD}

Other good shots realized 20, 23, and 28 geese, 28 curlews, 8 swans, etc., while the total for the season reached 310 geese, 219 wigeon, 30 other ducks, 19 wild swans, 34 curlews, etc., etc.

The Colonel's grand total of wildfowl for that season amounted to 758 , of which 573 were ducks and geese.

The above magnificent results were, be it emphasized once more, quite exceptional-the harvest of two severe and peculiarly favourable winters. But they verily stand out as green oases in the midst of dreary deserts of blank days and weeks, and of months of labour lost during his long records extending over half a century.

The biggest shot at brent geese hitherto recorded in British waters was, I believe, that made by Sir Charles Ross, Bart., in Cromarty Firth in February, 1895, when no fewer than 52 birds were gathered.

\section{WILDFOWLING ABROAD}

Holland and France.-On the Dutch coast results are obtained far exceeding those possible at home. The well-known fowler, Captain G. I. Gould, R.E., has recorded the following totals, made with a gun carrying 32 ounces of shot.*

1894-5. 1,453 wildfowl. The best six shots produced 315 wigeon.

1897-8. 1,808 wildfowl in 67 shots; best shot, 121 wigeon.

1898-9. 1,478 wildfowl; three best shots : Oct. 11,149 wigeon;

Nov. 11, 122 wigeon and teal; Nov. 29, 132 teal.

The late Mr T. M. Pike, whose premature death came as a shock to me who well remembered his exceptional strength in old Rugby days, leased for many years from the Dutch Government the gunning rights on the Veere Gat, and recorded, among many interesting facts, his best shots thus:

26 pinkfooted geese at one shot (48 in all during that same day).

40 bernacle geese, one shot, Krammerske Slikken.

120 brent geese in four days, January, 1891.

163 ducks and geese in seven shots, season 1900-1.

On the western French coast (the Morbihan Estuary), another wonderful record has been made by $\mathrm{Mr}$ W. H. Pope. In the season of 1890-1, in company with Captain Gould, and using a gun carrying only sixteen ounces of shot, there were bagiged:

1,425 geese, wigeon and mallard.

*Quoted from Wildfowl, by L. H. de Visme Shaw and W. H. Pope (Longman's Fur and Feather Scrics). 406 


\section{WILDFOWL AND WILDFOWLING}

In 1892-3 2,061 geese, wigeon and mallard (in 85 shots).

In 1895-6* 1,794 geese, wigeon and mallard (in 68 shots).

On one occasion, during eight days, twelve shots realized 455 wigeon and mallard. On another, during seven days, twelve shots produced 400 brent geese and wigeon.

Wildfowling in Spain.-The Spanish peninsula consists in the main of a vast highland plateau, scored across by infinite mountain-ranges-all this being the abomination of desolation from a wildfowling point of view. It presents, nevertheless, on its southern and western faces, certain areas of low-lying littoral, fronting both the Atlantic and the Mediterranean, and these afford a winter resort to half the wildfowl of Europe.

Probably no more wondrous aggregation of wildfowl are known than those which throng the rice-grounds of Valencia, on the Mediterranean. These great marshes-originally reclaimed half a century ago for the purpose of growing rice-soon attracted wildfowl in such quantities as threw the prospective profit on rice completely into the background, and that fact was speedily realized by the shrewd peasant-proprietary. At the present day the shooting at Valencia is conducted upon the strictest upto-date commercial principles, being regulated and limited to certain fixed days, while the tenancy of the numerous shooting-posts is sold by auction previous to the opening day! Such has been the indirect success of rice-growing in Spain that the favourite gun-posts on the Caldereria to-day realize in public sale up to $£ 80$ or $£ 100$ ! a stiff rent, even though it secures to the purchaser some ten days' shooting (with intervals of a week between), and the opportunity of emptying some 500 or 1,000 cartridges on each occasion.

It is all flight-shooting with shoulder-guns (12-bores), and the system, as well as that practised at the adjacent Albufera, will be found set out in full detail in "Unexplored Spain."

Amidst an army of guns dispersed over horizon areas, it is estimated that upwards of 20,000 fowl have been secured in a single morning. This, however, includes a certain proportion (about 25 per cent) of coots.

The marismas of Guadalquivir, on the Atlantic seaboard, also attract wildfowl in quantities undreamt of in lands so "developed" as to banish nearly all denizens not domestic or quasi-domestic. Here the aboriginal Spanish idea (and deadly enough it was), centred on the stalking-horse.

\footnotetext{
* With a gun firing thirty-two ounces of shot.
} 
THE GUN AT HOME AND ABROAD

These vast flooded plains, it should be stated, are tenanted by droves of shaggy half-wild horses, mares and their foals, which in semi-feral state-along with wild camels !-splash about the wastes amidst multitudinous ducks, geese and flamingos. The fowl, in consequence, have long become habituated to equine companionship. By the use of these ponies, specially trained for the purpose, the fowler, or, better still, two or three in company, each crouching belind his sheltering cabresto -as the trained ponies are termed-can approach to closest possible quarters, and deliver a death-dealing broadside into acres of wholly unsuspicious fowl. Our own records frequently exhibit results of seventy to eighty, occasionally one hundred ducks secured thus at a single approach. On one occasion a broadside of five barrels (delivered from behind three ponies) realized 198 head, chiefly teal.

The native system, however, did not appeal to our, perhaps insular, tastes. For it was too deadly certain in its operation. Against that statement it may, of course, be urged that the fowling-punt, with its huge stanchion-gun, may also, at times, lend itself to immense "slaughter"-our critics revel in that word. But yet, as between the two systems, there lies, to a sportsman's intuition, all the difference in the world, a subtle difference it may be, one scarce to be discriminated or even understood of the vulgar mind; yet a difference wide asunder as the poles.

For whereas the Spanish system is all but certain in result, while demanding but a modicum of fieldcraft; our British plan, deadly though it may prove once in a hundred efforts, is always, and essentially, the reverse of certain; while whatever degree of success be occasionally achieved, is due in tenfold measure to a combination of cool, concerted skill, craftsmanship, quick decision and perseverance, and with permanent odds of 50 to 1 always standing against you. At any rate, in our own marismas, we have abandoned the cabresto-pony except merely as an interesting local exhibition-and, incidentally, as a wholly unrivalled means of studying the wildest of wild creatures, still unsuspicious, though almost within arm's length.

It is a curious collateral fact, not entirely explicable, that in Southern Spain the gunning-punt, after repeated trials, proved altogether ineffective. This we attribute-though merely tentatively-to the marismas being unnavigable; hence wildfowl never see a moving craft on their waters, save only those few which they recognize as hostile.

408 


\section{WILDFOWL AND WILDFOWLING}

The system chiefly adopted is shooting at the natural morning-flight; afterwards setting up the fowl then secured to act as decoys during the rest of the day. In the most favourable seasons-which occur only at irregular intervals, being dependent on rainfall at particular periodsexcellent results attend this flight-shooting. Totals of 100 up to near 200 , and on rare occasions more, have been recorded by single guns in the day. The variety of the game lends an added charm. No less than sixteen different species of the duck-tribe figure in our lists, while seven or eight will commonly be secured in a day's sport. The most numerous are always wigeon and teal, pintail in certain seasons running them fairly close, while shovelers abound. Next to these come gadwall, marbled duck (in autumn only), a few mallard and sheld-ducks of both kinds, together with pochards of three species, tufted ducks, and, in March, the garganey. The scoter I have once shot, but the singular white-faced duck only arrives in April-after the shooting is finished.

Add to these whirling hosts of varied wildfowl the weird forms of flamingos in thousands-some nearly always in sight-and stately skeins of greylag geese sailing in majestic flight through the hubbub of minor fowl, and you have within view a panorama of wild bird-life that would surely be hard to equal outside of this primeval corner of Europe.

The wild geese which winter in Spain are practically all greylags. Among thousands shot, we find but a single bernacle and a few stray bean geese, none of the latter within recent years.

No branch of the sport presents greater difficulties than the chase of the wild grey-goose, nor is any bird that flies harder to secure. His natural astuteness, ceaseless vigilance, and the tactical advantage derived from his bare, open haunts, place his pursuit all but outside ordinary chances of success. In Spain, after years of effort and devising many schemes-oft in vain-we have latterly developed certain methods to a degree of perfection that offers at least reasonable hope. These, however, being strictly local and applying only to particular circumstances in Spain, and as they have been already described in detail in the volume last quoted, they need not here be recapitulated. The following is a brief diagnosis :

(1) Driving. In very dry seasons, when the marismas are practically waterless, this system becomes possible. By sending three or four mounted men round a band of geese, the latter may, by skilled management, be driven towards a line of guns concealed on a sun-dried plain 
THE GUN AT HOME AND ABROAD

where no sort of natural concealment exists. Should this appear a contradiction in terms, I must leave the paradox to be solved by expert minds. Suffice it to say that the thing can be done; for we have secured thus (on fortunate occasions) from twenty to thirty greylag geese, scaling nearly ten pounds apiece, during a day, and sometimes more-to three or four guns. This is no ordinary triumph of mind over instinct.

(2) Awaiting the geese at certain spots to which they will regularly resort at certain fixed hours-though it should be specially stated that the said spots vary from day to day, and month to month, according to the season and the state of the water in the marisma-for three specific purposes. These threefold objects of the geese are as follows : At dawn they flight to defined areas for the purpose (a) of feeding, or (b) of replenishing the stock of sand (or grit) which every wild goose must carry in his gizzard for purposes of digestion; while (c) at dusk they repair to some point-always a broad expanse of shallow water-whereat they spend the night.

In the first and last cases the gunner may be concealed in a sunken tub; but on the sand it is usually necessary to dig a hole for the purpose. Decoys, either fashioned in wood, in form of a goose, or cut out of block tin, and suitably painted, may be effectively employed; but should, as a rule, be withdrawn so soon as daylight is fully established.

Those who are specially interested in this subject may read Chapter XI of "Unexplored Spain." The following are a few of the results achieved by this method. From twenty to twenty-five or even thirty greylag geese to one gun is not an unusual total for a single morning's shooting, extending possibly over two hours; but as many as forty have exceptionally been secured, while our records exhibit, on three occasions, the extraordinary totals of fifty-one, fifty-two, and fifty-nine geese baggged by a single gun (12-bore) between daybreak and, say, 9 o'clock in the morning.

Other notable wildfowl resorts of the Peninsula demand at least passing notice-as, e.g. the estuary of the Vouga, in Portugal, that of the Ebro, on the Mediterranean, and several more. I will, however, confine the survey to but one other, and that because-differing from all those cited-it lies far away inland, over 2,000 feet above sea-level, in the midst of Don Quixote's arid province of La Mancha. I refer to the Lagunas de Daimiel, an intricate series of lagoons and sedge-clad swamps which form the birth-place of the great river Guadiana, and which in winter 410 


\section{WILDFOWL AND WILDFOWLING}

attract wildfowl in countless multitudes. The shooting rights at Daimiel are held by an association of Spanish Grandees, whose skill with the gun (as well as the wondrous wildfowl resource of the locality) are attested by the following memoranda of results achieved. In favourable seasons, and when climatic conditions are suitable, as many as 1,000 ducks have been brought in by five guns as a result of a short day's shootingbeginning, say, before dawn and ending by noon. The best individual total stands at 393 ducks ! while, for second place, his late Majesty King Alfonso XII ran that record very close with 381 gathered in three and a half hours' shooting. Such results (with 12-bore guns) will take a lot of beating in any part of the globe. Besides the ordinary species of ducks-already named-a noteworthy addition is furnished at Daimiel by the Red-crested pochard, a striking and singularly handsome member of the genus, whose portrait is given in "Unexplored Spain."

As an index of the mobility of wildfowl, it may be added that ducks shot at dawn at Daimiel, are frequently found to be crop-full of rice. Now, the nearest rice-fields are at Valencia, on the Mediterranean, distant 180 miles. Hence these ducks, merely as incident to a single night's feeding, have journeyed 360 miles between dusk and dawn.

To distinguish wildfowl at a distance. -In "The Art of Wildfowling " (1896), I wrote instructions under this head, which, although now seventeen years old, I yet cannot pretend to improve, so carefully and accurately were they then thought out. The only excuse I can allege for recurring to the subject -two excuses, perhaps - are, that (1) my present readers may not all have read the work quoted, and (2) that I have since enjoyed further oppor tunities of observing several of the less common wildfowl. Some of these, it may be, are British only in name, or by repute.

Presuming the student to be at some remote spot on the coast, or on the shores of some broad estuary whereat wildfowl are accustomed to congregate, he will have opportunities, during each day's cruise or ramble, to see infinite assemblages of such birds; but always at such distances that neither the best ornithological books ever written, nor the most elaborate studies in museums, will enable him to identify their various species. No written words will ever, by themselves, effect that result; nor will any effort of his, short of long years' practical experience aboard a gunning-punt. In these pages I endeavour to crystallize, so far as such can be reduced to paper, the substance of some forty years' keen study of wildfowl. 


\section{THE GUN AT HOME AND ABROAD}

All ducks seen ashore, it may be relied on, are game-ducks, by which I mean surface-feeding ducks; the diving-ducks never go on to the ooze, but keep afloat in the creeks, pools, and tide-channels.

Mallards and wigeon can be told from geese, with a good telescope, up to three miles, by their sitting horizontal and so much lower-far lower than geese, which stand high on their legs and are more erect. When resting ashore, many mallards are seen to be squatting on their breasts on the mud, with beaks tucked back beneath the wing-coverts. Geese never sit thus, nor are they ever seen asleep, or even in postures of repose.

Wigeon, when ashore, also show very low and horizontal; but they are visibly smaller, slimmer, and more nimble than mallards, whose heavy bills, thick sinuous necks, puffed out or curled around the breast, give them a portly appearance, albeit ever graceful. When afloat, a company of wigeon are recognized because they show dark on the water, whereas mallards display a mottled appearance in general colour owing to the pearly-grey backs of the drakes.

On the wing, wigeon show far whiter beneath than any other of the game-ducks, while their wings (dark below and very rapidly beaten) have a fin-like appearance. No better idea can be conveyed than the picture in Millais" "Fowler in Scotland," p. 94.

Pintails (though they idealize the duck-type), differ from all others in their long, slim build, and very long necks. By these characteristics alone they can be distinguished on the wing even in a bad light, when colours are invisible. But in normal daylight the snow-white breast and fore-neck of the drakes-when at rest disposed in a graceful $\mathbf{S}$-shaped curve-present an infallible index. Excepting the exposed breast, the pintail, when afloat, shows no white above water-line.*

Gadwall, rarely met with on British coasts, and always a fresh-water lover at best, cannot safely be distinguished on the wing from mallard beyond the distance at which the white speculum is visible. That-and its note also-are unmistakable distinctions within moderate range.

The Shoveler needs no mention, nor do teal; though it may be worth stating that the Garganey is at once recognizable from the latter by the very conspicuous white superciliary stripe-extending above and backwards from the eye, and which is readily visible with the naked eye at

*I refer to smooth water only. In a sea-way (so to speak) the pintails, of course, display glimpses of their white undersides. So, for example, does the great crested grebe, which, in still water, exhibits no white whatever on the body - whether in summer or winter dress.

412 


\section{WILDFOWL AND WILDFOWLING}

100 yards' distance. No garganey, however, will ever rejoice the sight of British wildfowler, since it is here only a summer migrant, arrivingif at all-long after all shooting is over. Even in southern Spain it only appears towards March.

Sheld-ducks are sometimes found in company with mallards, and, though less sought after, are usually wilder, and thus give notice of danger to the more highly prized fowl. The pure white plumage of the sheld-ducks is peculiarly bright and glossy, easily distinguishable from gulls far beyond the range at which their black heads become visible. But, like gulls, swans, and all white-plumaged birds, sheld-ducks in certain lights, or when viewed against the light, show up quite dark; and in such case, by their figures, are not unlikely to be mistaken for brent geese. Similarly, small gulls sleeping afloat on a grey day often closely resemble wigeon or duck. The spyglass, however, in all such cases, will undeceive while yet many hundreds of yards away. Gulls floating at a distance may always be known by their buoyant carriage, their sterns sticking up as high as their heads.

Although the common sheld-duck is one of the most conspicuously coloured birds we possess-(catching one's eye afar under all conditions save only that of floating ice)-yet its one European relative, the Ruddy sheld-duck, is, while quiescent, almost unicolourous-a monotone in chestnuts, most difficult to depict in black and white. Despite that fact, the latter is nevertheless quite a conspicuous object in the marsh-girt landscape. For its colours are not only bright in hue, but possess a lustrous sheen that catches the light, while its paler head contrasts with every surrounding.

It is necessary, however, to emphasize the quiescent pose; since the moment those broad goose-like pinions are spread, there flashes into view a surprising revelation in sharply contrasted hues. Half the big wing is then seen to be of purest aggressive white, set off by gleaming black quills, black tail, and black tail-coverts, with a huge speculum of iridescent bronze-green. All these startling contrasts had, till that moment, been concealed beneath overlapping coverts and flank-feathers. The result is a regular transformation scene.

To witness such spectacles, however, one must travel 1,000 miles southwards; for the Ruddy sheld -duck is only technically a British bird.

Both in style of flight and in every attitude and pose, the sheld-ducks are obviously a link between the ducks and the geese.

The foregoing remarks have all applied exclusively to that group which 


\section{THE GUN AT HOME AND ABROAD}

I have elsewhere called the game-ducks-that is, the surface-feeders. From the diving-ducks these may always be distinguished by a different style of flight.

The build of the game-ducks is trim and shapely, while their wings are relatively large, and each wing-stroke-though by comparison slowis performed by the whole power of the limb from the body outwards. Thus their flight is visibly powerful and stately-though perhaps less imposing than that of the wild geese.

The diving-duclks, on the other hand, being short, squat, and heavily built, with less ample wing-expanse, progress by far more rapid wingstrokes, and those largely effected from the carpal joint outwards-that is, by the main quills, the inner half of the wing appearing to serve almost as much for the purpose of aerial flotation as of propulsion. While watching the two styles of flight, contrasted before my eyes, I have roughly estimated the mallard's wing-strokes as well under 200 to the minute; whereas droves of pochards and tufted ducks, travelling at similar speed, were doing somewhere about double, or more.

To set down such estimates-mere guesswork-in cold print is perhaps unwise, though previously tested time and again. The excuse is that there exist no means of actual proof. Photography may solve such points some day-and perhaps upset my calculations ! Meanwhile these aerial evolutions occur high in air beyond all range of camera.

Whether the calculations be approximately correct or otherwise, the description will at least serve to illustrate the essentially different characteristics presented by the two groups as seen on the wing.

Another phenomenon characteristic of the diving-ducks should be named before passing on to describe them specifically. It may be termed their "hurricane flight."

Let the reader, in imagination, place himself far away amidst those vast watery wastes which are still existent here and there in outmost corners of the earth, and which form the nuclei and the rendezvous of wildfowl in millions. To-day the fowl are perturbed, since guns are distributed over leagues of marsh; the heavens above are streaked and serried with moving masses, and the still air vibrates with pulsating pinions. Constantly a rushing sound, as of a mighty wind, strikes one's ear as some great pack sweeps by overhead-often three or four such rushes combined. But there occurs and recurs another and more violent sound-almost a roar, as when the backwash of heavy surf grinds and 
WILDFOWL AND WILDFOWLING

grates on a gravel beach. An hour passes. Excepting only a few thousand teal, the bulk of the game-ducks-always alert and mobile-have now passed on elsewhere to some undisturbed resort; but the hordes of diving-ducks, being more local and "strongly haunted," refuse to quit. It is to these, one now has opportunity to observe, that the recurrent cataclysms are due. Watch that mob careering through the skies-there are 500 of them, all pochards. Suddenly their onward flight is changed-changed in a flash, simultaneous as automata-and every unit of those 500 is plunging downwards in mad vertical descent. And the shriek of opposing air, rent by a thousand indrawn collapsed pinions resounds through space, like the tearing asunder of a thousand sheets of canvas.

By what conceivable means it is possible for immense bodies of heavy bircis proceeding at topmost speed, and in massed formations, thus to change course in full career, instantaneously, and with never an accident or collision, passes human comprehension. Suffice it to say that they do it. Mobs of teal, thousands strong, flash from white to black, then white again (according as backs or breasts are presented), twenty times in a minute-and moving all the time at a velocity I shall not estimate. Dunlings, as already indicated, are equally marvellous acrobats. The quick change from black to white is so continuous that a mass of them-say a quartermile long-trills like a cinematograph, a score of alternating silvery spaces flashing from fore to aft backwards along their lines. Picture a long cylinder painted black and white in diagonal bands: now make it revolve on its longer axis, and you get a somewhat similar effect.

To return to our pochards-so far as it is possible for human eye to follow lightning evolutions, and usually at some distance, the collapsed wings are held rigidly parallel, the primaries indrawn till their tips show inside the secondaries.

On British coasts the most abundant of the diving-ducks are the Scaup and Golden-eye, which arrive in October, and may be distinguished thus: Scaup (generally squandered in loose order) present a brown appearance, punctuated by the white "canvas backs" of the old drakes showing up conspicuously amidst the dark majority-golden-eyes, on the other hand, showing slate-blue, and never an old drake among them. Moreover both the young and female scaups (which constitute three-fourths of their company), carry the clean-cut white foreheads, which feature can be distinguished with a good glass at 200 yards; and, if flying, the white speculum is seen to extend across the whole wing -as it also does in tufted 


\section{THE GUN AT HOME AND ABROAD}

ducks-whereas in the golden-eyes it is confined to the secondaries. Both species have short necks and noticeably bulky heads; but even in this latter feature there is a difference, that of the golden-eye being bushy, while the scaup's head is hard in outline, the high crown showing like a boss, and, as just said, three-fourths of them display a white front, which the golden-eyes never have.

Tufted ducks afloat look as black and white as guillemots, and the drakes show far more white above water-line than any other of the duck tribe. Their beaks also are of that pale waxy blue that, in sunlight, gleams white as ivory. The young of these (but not the adult females) are also white-fronted, and both are far less conspicuously coloured than the old drakes-plain dark brown.

So far as colour goes, an old pochard-drake resembles a mallard, being dark fore and aft, silvery-grey amidships. But the thickset, squat outline will serve to distinguish him even when on grey days or in certain lights the red head cannot be seen. A single glint of sunshine, however, will reveal that feature to beyond 200 yards. Note that it is chiefly by the adult drakes that the identity of a company of ducks can be ascertained at a distance. Pochards may, nevertheless, be distinguished, even in the dullest of lights, by a marked difference in their profile-the long rising slope of the forehead giving their heads the form, as it were, of an isosceles triangle.

Before leaving the pochards, two other species of that sub-genus claim a passing note, since they are technically "British"-to wit: the Redcrested, and White-eyed pochards. Being intimately acquainted with the latter (and fairly so with the former species), in Spain, I am entitled to hold the personal opinion that neither has any rational claim to be considered British-certainly not the white-eyed pochard, or "ferruginous duck," as it is also named. Consider its geographical status. Even in southern Spain it is merely a summer-visitor, coming in thousands to breed, but departing in autumn to Africa. Only in the wettest winters (and then exceptionally) do a few linger in Andalucia. Yet we are asked to believe that it has occurred here in England, in some dozens of instances in mid-winter. So no doubt it has, but not of its own free will. Until very solid proof be forthcoming, I regard all such instances as merely " escapes," that is, quasi-domestic birds frozen out of private ponds and ornamental waters.

The White-eyed pochard shows up extremely dark in colour, whether 416 


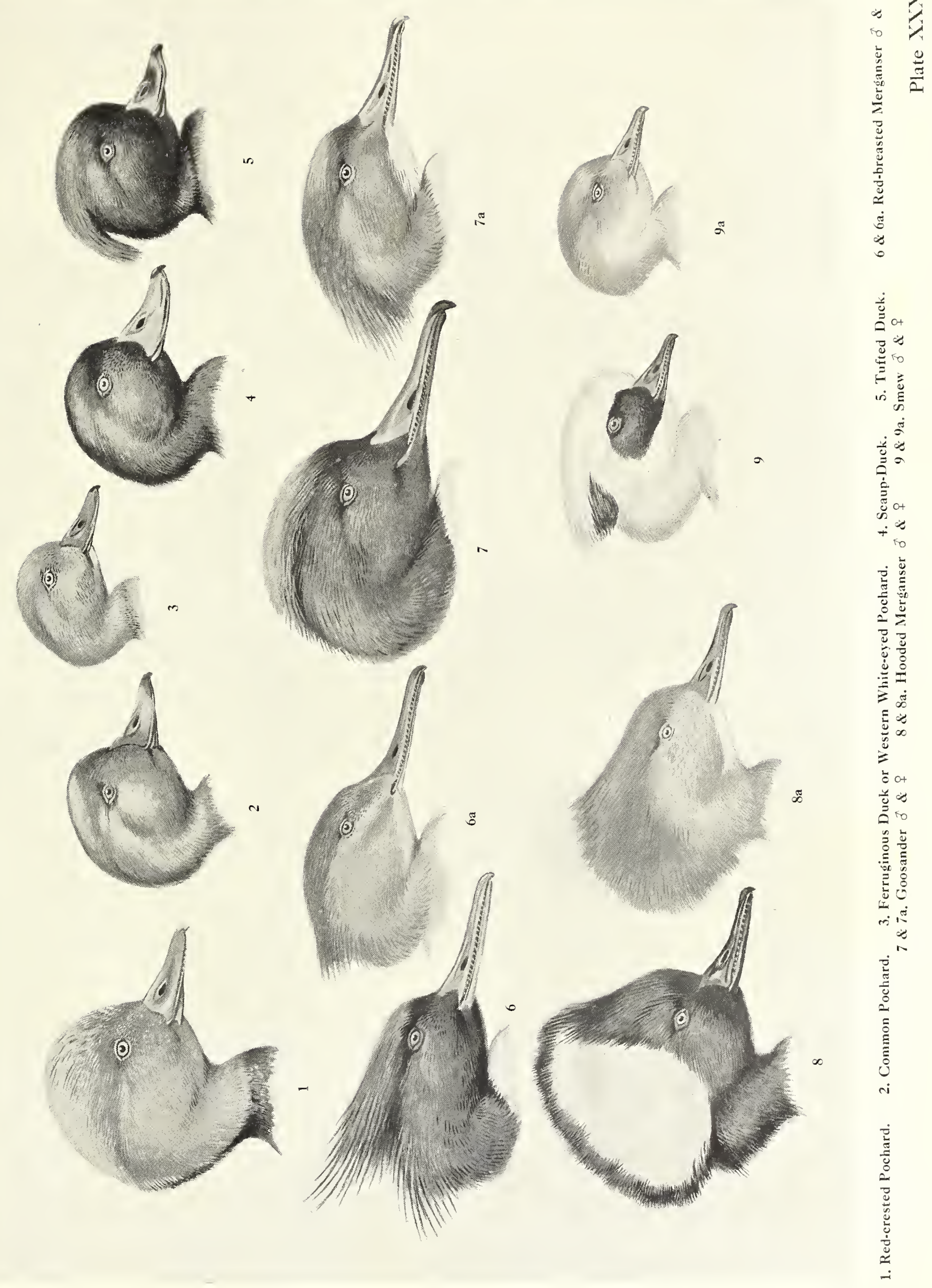





\section{WILDFOWL AND WILDFOWLING}

on wing or water-the reverse of the common kind-as indicated by its Spanish name of negrete. It shows no white whatever above waterline, except beneath the tail; indeed, the only other white in its plumage are the wing-bar and a small circular patch on the stomach-neither visible as it sits afloat. The bird is black above, while the head, neck, and sides are the richest glossy chestnut, very dark. The head very bulky, and body thickset, squat and round as a football. In none of the ornithological works that I happen to possess are the figures of these birds even approximately correct-that is, as they appear in life.

The Red-crested pochard differs essentially from its congeners. Far more slim in build, long in neck and wing, it would never have struck me as belonging to the Fuligulince at all. Of all the handsome wildfowl tribe, this is one of the smartest and most striking. With bright red beak and eye, and a bushy orange-chestnut head that gleams in the southern sunlight with a burnished effulgence; and its strong bodycontrasts of glossy black and rosy white, the red-crested pochard presents one of the most effective of bird-pictures. The conspicuous white patches on either shoulder (near inset of wings) are, when at rest, inclined almost vertically, and not horizontally, as by a slip I showed in my drawing of this bird in "Unexplored Spain," p. 186.

To return to British coasts: Should you see a straggling company swimming in some tidal channel, and the glass shows them to lie low in the water with a rakish carriage, and to keep diving three or four at a time, you may know them for mergansers. Scaup, golden-eye and the rest are often under water all at once; mergansers always leave sentries on the surface. All these fowl, nevertheless, are quite capable of realizing the presence of danger while yet submerged, and will, in such case, rise direct from the depths, treating water and air as though precisely alike.

The Goosander frequents inland lochs and salmon-rivers, and is rarely seen on salt water. This is one of the very few wildfowl that are " colourprotected "- -and that remark applies only to the adult drakes. I mentioned the point years ago in my "Bird-life of the Borders" (second edition, p. 226), and the accuracy of that observation was confirmed quite recently thus : While examining a moorland loch, I saw four fowl which I took to be goosander ducks, not over 200 yards distant. But on bringing the glass to bear, I found they were accompanied by two adult drakes, whose (apparently conspicuous) black and white dress, assimilating with the 
THE GUN AT HOME AND ABROAD

rippling wave and half-breaking wash, had escaped the naked eye, though the females had been detected at once.

It is, however, wrong to speak of them as "black and white." The main body-colour of the goosander-drake, especially the breast, is saffronyellow. This superb adornment is very evanescent, fading away immedi ately after death, and is never seen either in museum specimens or in coloured plates of the bird. I fancy that few naturalists have an idea of the fact, not having seen a freshly-killed example. Similarly the breast of a merganser-drake is a lovely rich salmon-pink, though usually described and depicted as white.* An analogous case is supplied by the eider-drake, whose upper wing-coverts in life are beautifully toned in lemon-yellow; but which is utterly lost in dried skins, and never shown in plates, or mentioned in descriptions.

Modes of diving. - The varied styles of diving in which sub-aquatic fowl take their plunge would form an interesting study; yet is rarely alluded to. In "The Art of Wildfowling," I instanced this divergent habit as a means of identifying birds seen at a distance. Undoubtedly, several species, such as, e.g., tufted ducks, pochards (both kinds), grebes, coots and shags, spring clean out of the water, taking a regular " header," with a momentary vision of wings half-opened. On calm, still, currentless waters, both scaup and golden-eye will do the same-but not on the tide. Thereupon the two last-named (and several more) simply drop their heads-there is a flash of opening wings, of flying spray, and they are down.

The precise style of diving, in short, varies in accordance with (a), the depth of water to be explored; (b), the strength of its current; and (c), when approached, by the degree of danger they may apprehend. With a gunning-punt close by, and levelled gun, there is obviously no time for ceremonious disappearance.

The distinctive objects sought as food by different birds clearly influence their individual methods. Thus the eiders, scoters, long-tailed ducks, guillemots, razorbills and all that class whose crustacean prey is more or less stationary, simply vanish from view at the precise spot whereat they sat-too quickly for human eye to see how. But those others that depend for their livelihood upon catching active fishes, naturally try to obtain some slight clue, before diving, as to the exact situation of

*The name "Red-breasted Merganser," when originally bestowed, was surely based on this conspicuous coloration in life. Nowadays, naturalists seem to refer its origin to the speckled band on the lower neck: but that is brown, and not in any sense red.

418 


\section{WILDFOWL AND WILDFOWLING}

moving shoals. Thus, by careful watching with the glass, one may often see mergansers or cormorants systematically swimming the deeps with heads submerged, only their low flat backs in sight, and almost awash. Presently follows a sort of convulsive action-the low black back has disappeared, and not a ripple left behind. But in shallower water - say some tidal channel, five or six feet in depth-the merganser (and goosander, too, in analogous situation) backs its own sub-aquatic powers entirely unaided by eye. Watch those six-for an instant, a single long slim neck rises to its full height; then, without any body-movement, the merganser plunges head first to catch what he can-sand-launce, flounders, shrimps not despised.

Incidentally it may be here recorded that both eider-ducks and cormorants, if threatened with sudden danger, can dive from the wing. I have seen two, three, or more, eiders, forming part of a pack of six, ten, or a score, flying several yards high, suddenly plunge vertically into the sea upon a shot being fired at a short distance-though not at them. In the Arctic also, I remember guillemots diving from the wing when attacked by the pirate skuas (Stercorarius crepidatus).

The big sea-divers (Colymbi) possess the power of submerging the whole body when alarmed, and one sees them, with grebes and cormorants, steaming full speed ahead, with nothing in sight but the head and neck-the back feathers just awash. All the sea-divers may be known by their thick erect necks, which in winter plumage show three-fourths white, and (at short distance) by the sharp-pointed head and beak carried at a rigid right angle. Moreover they are always single, as are also the grebes. They swim as low as mergansers; but the latter are, of course, recognizable at a glance by their long, slim necks, almost snake-like, and by their tufted heads.

As for wild geese, the Brent is by far the most numerous, and, being strictly marine in its haunts, affords the finest sport of all British wildfowl to the punt-gunner. The descriptions already given leave nothing further to be said.

The Bernacle goose frequents the West Coast and Ireland; but as I have had no personal acquaintance with it, I am not qualified to write anything about it.

Grey geese constitute a second group, chiefly (if not exclusively) inlandfeeders. There are four species of these-or five, if we include Anser 


\section{THE GUN AT HOME AND ABROAD}

erythropus-the lesser white-fronted goose, the only specimen of which ever killed in these islands, was shot by my late brother, Alfred Crawhall Chapman, in Northumberland, September 16, 1886, and which is now in my possession.*

These big geese are frequently to be seen passing overhead in $\mathrm{V}$-shaped skeins, and always high in air. On the wing, their species cannot be identified, whether by wildfowler or skilled ornithologist-there are not many who could name them when in hand.

In "Bird-life of the Borders," and "Unexplored Spain," the haunts and habits of the greylag are fully described.

Since there are but two species of Wild Swan available to the gunner, while their huge size (the biggest of British birds) and aggressive colour can leave no doubt as to their identity, it is needless to give detailed instructions in distinguishing them. In clear daylight, swans are visible at two miles, and often more. But on dull days it is surprisingly easy to overlook them while, with the light behind (like all white-plumaged birds), they show darker than less conspicuously coloured speciessay grey geese. Owing to their feeding in creeks and hollows of the mudflats, they are apt to remain unseen till the inflowing tide sets them afloat.

To distinguish the wild swans-whether the Whooper or the much smaller Bewick's swan, from the tame species (which in hard frosts may be driven to the coast, though personally I never met with them) is easy, with a good spy-glass, up to several hundred yards. The bright yellow beak running in pronounced slope far up the forehead-giving the wild swan's head a marked triangular appearance-contrasts unmistakably with the big black frontal knob on the mute, or tame swan. Moreover, the clear-toned resonant note, " hoop-hoop " when uttered is an infallible index.

The following table shows the normal autumn and winter distribution of wildfowl according to their natural predilection. It will be understood that abnormal conditions, such as excessive disturbance or extreme frost, may drive inland fowl to the tide. But should the frost last beyond a few

\footnotetext{
* Since the acquisition of this specimen was recorded (Zoologist, 1887, p. 14, and The Art of Wildfowling, p. 152) a few others have been obtained. Onc in Somersetshire (Zool. 1888, p. 227), another near King's Lynn, in Jan. 1900 (Brit. Orn. Club, Oct. 23, 1901, Zool. 1902, p. 85, and Trans. Norf. Nat. Soc. vii, 740). A lesser white-fronted goose in the collection of the late Sir H. Boynton, was said to have been killed in Yorkshire (Nelson, Birds of Yorkshire, ii, p. 413.). -Ed.
} 


\section{WILDFOWL AND WILDFOWLING}

days, the displaced birds will seek their desiderata abroad, rather than endure conditions averse to their natural instincts.

SALT WATER.

Brent geese.

Wigeon.

Scaup.

Sheld-duck.

Merganser.

Eider.

Long-tailed duck.

Scoters (both kinds)

Sea-divers (Colymbi).

Cormorants.

Curlews.

Godwits.

Grey plovers.
FRESH WATER.

Grey geese.

Mallard (native).

Pintail.

Gadwall.

Shoveler.

Garganey (summer)

Tufted duck.

Pochard (two kinds).

Goosander.

Golden plovers.
AT HOME ON EITHER.

Wild Swans.

Mallard (foreign).

Teal.

Golden-eyes.

Grebes.

It is to be observed that a limited number of wigeon habitually winter on inland waters; and that migrating fowl on passage occasionally pause to rest in unaccustomed places. Such occurrences, however, are exceptional, and do not affect the general rule.

ABEL GHAPMAN. 


\section{GAME LAWS AND LICENCES}

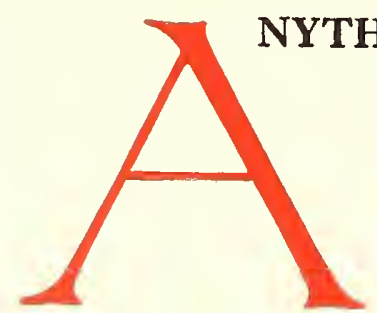

HING like a treatise on the Game Laws, a subject on which many volumes have been written, could hardly be expected in the present work. At the same time, in a publication dealing so fully with game and wildfowl and the sport which these birds afford with the gun, it seems desirable to devote a few pages to the consideration of the principal legal enactments of which every good sportsman ought to know at least the outlines. An attempt will therefore be made to give such a summary of the principal statutes relating to game as will enable the reader to see almost at a glance the purport of each, and by supplying him with the proper references assist him to find any Act which he may think applicable to his case.

It is surprising how few shooting men seem to have any real knowledge of the game laws; even those who are game preservers, employing perhaps sevoral keepers, and having frequent occasion to consider cases of poaching and trespass. This is the more to be wondered at because copies of any of the statutes may be procured for a few pence on application to the agents for the sale of Parliamentary papers, Messrs Wyman \& Sons, of Fetter Lane, London. From the solicitor's point of view, perhaps, private interpretation of the game laws is not to be encouraged, seeing the differences of opinion which have arisen on the construction of a section both at petty sessions and in the superior courts, necessitating in some cases recourse to the Court of Appeal. But, on the other hand, many simple questions from time to time arise which may be easily resolved on reference to an Act of Parliament if the inquirer knows where to look for it.

To begin with, it may be said that the principal Game Act, which governs most of the cases likely to arise, is that passed in 1831 ( 1 \& 2 Will. IV, c. 32). But three years earlier an important measure, known as the "Night Poaching Act, 1828," paved the way for it, and is still in force.

Altogether there are about a dozen statutes which game preservers and shooting men would do well to know something about; and perhaps the best way to deal with them here will be to take them in chronological order, and explain as briefly as may be the purport and the principal provisions of each. This method seems the more desirable because some of them are in the nature of amendments and have relation to others which precede them. It will be difficult to avoid digression by touching 422 


\section{GAME LAWS AND LICENCES}

upon many interesting points, and to abstain from quoting decided cases by way of illustration. But if that course were to be adopted the present summary would resolve itself into an elaborate treatise, which the reader of these pages will not expect. Let us therefore take the Acts as we find them, in order of date, with the proper references to enable the reader (if need be) to obtain copies of them, and with such details of their contents as are important, freed as much as possible from technicalities. Should the reader find on occasion that more information is needed he will be able without difficulty to provide himself with the full text of the Act in question.

First, then, we have the Act passed in 1828 :-

\section{THE NIGHT POAGHING AGT \\ 9 Geo. IV, cap. 69}

This Act, as its title implies, was designed to put a stop to the destruction of game and rabbits by night; accordingly the first section indicates the penalties to be incurred on conviction by those found trespassing for that purpose. The penalties are : for a first offence, three months' hard labour, with the onus of finding sureties for good behaviour at the end of the term; for a second offence, six months' hard labour and subsequent sureties; in the case of a third offence the offender is deemed guilty of a misdemeanour, and, when the Act was passed, was liable to transportation; but this was subsequently commuted to penal servitude by 20 \& 21 Vict., cap. 3.

Section 2 empowers an owner or occupier, or lord of the manor, his gamekeeper or servant, to seize the offender and take him before two justices. The prosecution of such offender must (under Sect. 4) be commenced within twelve months from the date of the offence; and any appeal from a conviction must be to the next Court of Quarter Sessions (Sect. 6).

Section 9 is an important one, for it deals with a "gang" of poachers, and provides that if three or more persons are armed with guns, nets or other engines, and enter upon land by night for the purpose of taking game or rabbits, each person is guilty of a misdemeanour, and is liable to penal servitude or imprisonment not exceeding two years.

Then come two definitions which one would have expected to find at the commencement of the Act instead of at the end, namely:-Section 12 defines "night" as commencing at the expiration of one hour after sunset, 
THE GUN AT HOME AND ABROAD

and ending at the beginning of the last hour before sunrise; and Section 13 defines game to include "hares, pheasants, partridges, grouse, black game and bustards." It is well to note the inclusion of bustards, because some persons are under the impression that since these birds ceased to breed in England, about 1838, no penalty can attach for killing any stray example that may happen to visit this country. This, however, is a mistaken notion, and the protection afforded to bustards by this Act is confirmed by the principal Game Act next to be considered. The close time in England is from March 1 to September 1, and in Ireland from January 10 to September 1.

THE GAME ACT, 1831

$1 \& 2$ Will. IV, c. 32

This Act repeals a number of statutes which had become obsolete, ranging from the time of Richard II to 59 Geo. III, and in Section 2 follows the language of the Night Poaching Act in the definition of game, as above quoted.

Section 3 prohibits the killing or taking of game on a Sunday or on Christmas Day, and fixes the various periods of close time as follows :-

Partridges .. .. between February 1 and September 1

Pheasants .. .. $\quad$, February 1 and October 1

Grouse $\quad . \quad$.. $\quad$, December 10 and August 12

Black Game.. $\quad$.. $\quad$ " December 10 and August 20

(Except in Somerset and Devon or in the New Forest, where it is between December 10 and September 1.)

Bustards .. .. between March 1 and September 1

A person killing or taking any of these birds between the dates specified is liable on conviction to a penalty not exceeding $£ 5$.

In this list of close times for game it will be seen that hares, although game, are not included, but this has been remedied by the Hares Preserva tion Act, 1892, to which reference will be made later under the head of "Ground Game."

Another important detail in Section 3 is the prohibition against laying poison on any ground frequented by game, whether enclosed or not, under a penalty not exceeding $£ 1$ for each bird killed. In connexion with this it may be mentioned that the Poisoned Grain Prohibition Act, 1863, forbade the use of grain steeped in poison calculated to destroy life on 424 


\section{GAME LAWS AND LICENGES}

any ground except for agricultural purposes, under a penalty of $£ 10$; but this statute, as well as the Poisoned Flesh Prohibition Act, 1864, have been repealed in their application to England and Ireland (but not Scotland) by the Protection of Animals Act, 1911, which is more explicit and likely to be more efficacious. [Section 8 of this last mentioned Act makes it an offence (under a penalty not exceeding $£ 10$ ) to sell or use poisoned grain, "except for bona fide use in agriculture," or to lay poison on any land except for the purpose of destroying rats, mice, or other small vermin (using all reasonable precautions). But Section 17 of this same Act of 1911 also provides that "nothing in Sect. 8 shall prevent owners or occupiers of land in Ireland from laying poison as therein described, after a notice has been posted in a conspicuous place, and notice in writing has been given to the nearest constabulary station.']

Section 4 relates to dealing in game, and prohibits the purchase or sale of it by a licensed dealer ten days after the expiration of the close time, or the possession of it after $\mathbf{4 0}$ days from the close season (except in a breeding place), under a penalty of $£ 1$ per head. But this does not apply to game received from abroad. Regina v. Guyer 23 Q.B.D. 100 (1889).

Sections 5 and 6 relate to the obligation of obtaining a licence to kill game, and the regulations affecting it; but as these have been amended by the Game Licences Act, 1860 , to be mentioned later, it will be unneces sary here to set out the details.

Section 11 enables a landlord who has reserved the game upon any land to authorize any holder of a game licence to kill it. The reason for this is that the game belongs by law to the occupier of the soil, who has a qualified right to it so long as it remains on his land, unless it has been reserved to the owner by the terms of the lease granted by him. Accordingly, if he has reserved it he must be empowered to authorize anyone to kill it; and it is this section of the Act which justifies a landlord in letting a farm to a tenant, reserving the game (or all sporting rights), and letting that to a third party.

Section 13 empowers the lord of a manor, by deed under hand and seal, to appoint a gamekeeper within the manor and authorize him to seize all dogs, nets, etc., used by any one not having a game licence.

Section 16 requires such appointment of a gamekeeper to be registered with the Clerk of the Peace for the county. 
Section 17 enables the holder of a game licence to sell game, but only to a licensed dealer in game.

Section 18 relates to the granting of licences. After the passing of this Act, and for many years subsequently, licences were granted by the justices in every county, who (under this section) held a special session for the purpose in the month of July. But in 1894 a Local Government Act was passed (56 \& 57 Vict., c. 73 ), by which the power to grant licences was transferred from the justices (by Sect. 27) to the District Councils, and all fees in respect of such licences are now payable to the District Council.

Section 22 provides that a game dealer convicted of any offence under this Act shall forfeit his licence.

Section 23 provides that any person killing game without a licence, or using a dog, gun, etc., for that purpose, is liable to a penalty of $£ 5$.

Section 24: imposes a penalty of $5 \mathrm{~s}$. for every egg taken out of the nest of any game bird, or any swan, wild duck, teal or wigeon.

Section 25 relates to selling game without a licence, the penalty for which is a sum not exceeding $£ 2$ for every head of game sold; and the four following sections (26 to 29) are framed to meet the various contingencies likely to arise in the buying and selling of game.

Section 30 deals with trespass in pursuit of game, the penalty for so doing being a sum not exceeding $40 \mathrm{~s}$. It is important to note here that this section will apply not only in the case of game, but also in the case of woodcocks, snipes, quails, landrails, and rabbits.

Section 32 provides that if any persons, to the number of five or more, be found trespassing by day in search of game or of woodcocks, snipes, quails, landrails or rabbits, and being armed offer resistance, every one of them is liable to forfeit $£ 5$ in addition to any other penalty they may have incurred, as, for instance, for shooting game out of season or without a licence. Compare Sect. 9 of the Night Poaching Act, 1828.

Section 34 defines "daytime" as commencing with the last hour before sunrise, and ending with the first hour after sunset. "Night" is defined by Sect. 12 of the last quoted Act.

Section 35 deals with exemptions, and provides that penalties for 426 


\section{GAME LAWS AND LICENCES}

trespass in pursuit of game are not to extend to any person hunting or coursing with hounds or greyhounds, or being in fresh pursuit of any deer, hare or fox; nor to any person claiming a right of free warren; nor to any gamekeeper appointed by a lord of a manor.

As to the remainder of this Act, Sections 36 to 43 embody further details in regard to the subject-matter of previous sections; and Section 44 provides that an appeal from any conviction under the Act lies to the next Quarter Sessions, of which three days' notice must be given in writing. Certain sections, as $39,40,43,45,47$, having been repealed by Summary Jurisdiction Acts, it is unnecessary here to consider their purport.

It will be seen from the foregoing summary that this Act is a remarkably long one, and so comprehensive as to make it one of the most important. On this account it is usually referred to as "the principal Game Act."

\section{THE NIGHT POAGHING ACT, 1844}

$$
7 \text { \& } 8 \text { Vict., c. } 27
$$

The object of this Act was to extend the provisions of the Night Poaching Act, 1828, the application of which was limited to offenders trespassing on enclosed land by night in pursuit of game. The Act of 1844 extended this to highways, public roads and paths, so as to make it impossible for a poacher, if summoned, to plead that he was not upon "the land" but upon the highroad.

\section{THE HARES ACT, 1848}

11 \& 12 Vict., c. 29

As it will be necessary to review the law relating to hares when we come to deal with ground game-hares and rabbits-it will suffice to state here very briefly that the object of this Act was to enable farmers to protect themselves from the damage done to their crops by hares, and it accordingly makes it lawful for any occupier of enclosed lands, or any owner having the right to kill game thereon, to kill any hare upon such lands without a game licence. It also authorizes (Section 4) the coursing of hares with greyhounds, or hunting them with beagles or harriers without having a game licence; and Section 8 provides that the Act is to extend only to England and Wales. 


\section{THE GUN AT HOME AND ABROAD}

\section{THE GAME LIGENGES ACT, 1860}

$23 \& 24$ Vict., c. 90

For several reasons this Act is one of great importance to shooting men. In the first place it repeals the duties imposed for licences under the old Acts of George III and William IV, converts the old game certificate (which cost more) into a game licence, and specifies the cost of such licence according to the period for which it is required. Thus for the whole season the cost is $£ 3$ (instead of, as formerly, $£ 313 \mathrm{~s} .6 \mathrm{~d}$.) ; for the period from July 31 to October $31, £ 2$; and if not taken out before November 1 , to expire on the following July 31 , 2 ; while for any continuous period of $\mathbf{1 4}$ days $£ \mathbb{1}$ only is chargeable.

Under the same section (2) the cost of a keeper's game licence is fixed at $£ 2$, and a licence to deal in game also $£ 2$. It may be here pointed out that any holder of a $£ 3$ game licence wishing to dispose of surplus game is not obliged to take out a dealer's licence for $£ 2$ in addition, but he can sell it only to a licensed dealer.

Section 4.-Another important alteration in the game laws is made by this section of the Act, which in effect adds to the game list, inasmuch as it renders it necessary to have a game licence in order to shoot any woodcock, snipe, quail, landrail, coney or deer. But there are certain exemptions, that is to say, no game licence is required for netting or snaring woodcock and snipe, for taking rabbits, for coursing or hare hunting, for hunting deer with hounds, or for killing deer in enclosed lands by the owner or occupier. Except in these cases, the penalty for killing game, or any woodcock, snipe, etc., as above mentioned without a licence is $£ 20$.

Section 10, which relates to the production of licences, provides that anyone found shooting or in pursuit of game with a gun, may be asked to produce his game licence; he is bound to produce it on demand, and to allow the person requiring it to read it or copy it. If not produced and he refuses his name and address, or gives a false name, he is liable to a fine of $£ 20$. The persons who may demand production are any officer of Inland Revenue, any lord of the manor or his gamekeeper, any holder of a game licence, or the owner, landlord, lessee or occupier of the land on which the person is found shooting. See also Sect. 9 \& 10 of the Gun Licence Act, 1870.

428 


\section{GAME LAWS AND LICENGES}

Section 11 provides that should any holder of a licence be convicted of any offence under the principal Game Act, or the Scottish Game Act (2 \& 3 Will. IV, c. 68) his licence shall be forfeited. As to this it may be observed that as neither of the Statutes just referred to applies to Ireland, this forfeiture does not extend to licences in that country.

\section{THE REVENUE ACT, 1861}

24 \& 25 Vict., c. 91

The object in passing this Act was to remedy an omission in the Game Licences Act, 1860 (last quoted), and accordingly the principal enactment is the imposition by Section $\mathbf{1 7}$ of a penalty upon any person who, having obtained a licence to deal in game from the District Council (formerly from the magistrates), shall proceed to act upon it before he has also obtained an excise licence authorizing him to do so.

\section{THE LARGENY ACT, 1861}

$24 \& 25$ Vict., c. 96

This Act, so far as it concerns our present purpose, relates chiefly to the taking of hares or rabbits in a warren at night, which is to be deemed a misdemeanour, for the commission of which a penalty of $£ 5$ is imposed by Section 17 ; and by a subsequent section (Sect. 103) power is given to apprehend the offender.

\section{THE POAGHING PREVENTION ACT, 1862}

\section{$25 \& 26$ Vict., c. 114}

The first section of this Act defines "game," which would seem to be hardly needed, since game had been already defined in two previous statutes, and the terms are practically identical.

Section 2 authorizes any constable in any highway or public place to search anyone whom he has good cause to suspect of coming from any land where he may have been unlawfully in pursuit of game.

Section 6 gives any one who may be convicted under this Act the right to appeal to the next General or Quarter Sessions. 


\section{THE GUN AT HOME AND ABROAD}

THE GUN LIGENGE ACT, 1870

\section{3 \& 34 Vict., c. 57}

By this Act an excise duty of ten shillings becomes payable by any person using or carrying a gun who has not at the time of using it a game licence in force. Under Section 7 anyone using or carrying a gun without a licence except in a dwelling house or the curtilage thereof is liable to a penalty of $£ 10$.

A gun is defined by Section 2 to be " a firearm of any description, or air-gun, or any other kind of gun from which a missile can be discharged."

The persons who are exempt from having to take out a licence under this Act are :-

(1) Anyone in the naval, military or volunteer service;

(2) Anyone holding a game licence;

(3) Anyone carrying a gun belonging to a person having a game licence ;

(4) An occupier of land, or person authorized by him, for the purpose of scaring birds or killing vermin in such land, provided the occupier has a licence to kill game or a licence under this Act.

With regard to "vermin," it has been settled in Scotland by a decision in Lord Advocate v. Young, 1898 (62 J.P. 199), that rabbits are not vermin. A report of the case will be found in "The Field" of April 2, 1898.

(5) Any gunsmith or his servant carrying a gun in the course of his business, or testing it in a place designed for that purpose;

(6) A common carrier having charge of a gun in the course of his ordinary business.

Section 9 provides that any officer of Inland Revenue or a constable may demand of any person the production of his gun licence or game licence, and his name and address, which must be given on demand under a penalty of $£ 10$. Moreover, in case of refusal the offender is liable to be arrested and imprisoned until the penalty is paid.

Section 10 empowers an officer of Inland Revenue or a constable seeing a person using a gun to enter upon the land for the purpose of demanding the production of a licence.

Section 11 provides that anyone who kills game having only a gun licence, thereupon forfeits the licence. 


\section{GAME LAWS AND LICENGES}

\section{THE WILD BIRDS PROTEGTION ACTS}

$$
\text { 1880-81-94-96-1902-04-08 }
$$

The general purport of these Acts collectively is to protect wild birds and their eggs from molestation between certain dates, the usual period being between March 1 and August 1; but on the application of any County Council or in Ireland of the Justices at Quarter Sessions a Secretary of State or the Lord Lieutenant may make an order varying or extending the close time, or protecting certain species named, or protecting certain areas specified. In pursuance of this proviso a great number of orders have been issued, with the result that much confusion now prevails in respect of the various close times, and the localities in which any particular birds and their eggs are or are not protected. With seven Acts of Parliament and at least a hundred orders varying them, it is now almost impossible to discover how the law stands. In every Act, and in the orders made in pursuance of it, there is a schedule of birds specially protected, and the law (to put it briefly) is that a person who kills or takes during the close time a bird mentioned in the schedule is liable to a penalty not exceeding $£ 1$; and in the case of any other bird not scheduled he is for a first offence liable to be reprimanded or discharged on payment of costs, and for every subsequent offence liable to a penalty not exceeding five shillings for every bird killed or taken, in addition to the costs.

But this section does not apply to any owner or occupier of land, or anyone authorized by him, killing or taking a bird that is not named in the schedule on land in his occupation. Under the Act of 1896 the Court may order, in addition to any penalty imposed, the confiscation of any trap, net, snare, or decoy bird; and under the Act of 1902 the Court may order any wild bird or egg to be forfeited and disposed of as the Court may think fit. This is perhaps the most important, as being the most deterrent, of all the Wild Birds Protection Acts, since it tends to prevent an offender from killing a bird which he might sell for perhaps a pound or two, at a cost to himself of a five-shilling fine. An offender convicted under this Act will find himself entirely out of pocket by the transaction.

It is under the combined operation of these Bird Protection Acts that the destruction of the various kinds of wildfowl is sought to be prevented by the appointment of a close season, during the period of the year in which they are engaged in rearing their young. The "close time" varies 


\section{THE GUN AT HOME AND ABROAD}

in different parts of the country, and is fixed by the orders issued by the Home Secretary or the Lord Lieutenant of Ireland, in pursuance of the power conferred by these statutes.

\section{GUSTOMS AND INLAND REVENUE ACT, 1893}

$$
56 \text { Vict., c. } 7
$$

This Act was passed in 1893 to get over a difficulty in regard to the importation and sale of game from abroad. In the case of Regina v. Guyer a licensed dealer, having partridges exposed for sale in the close time, was prosecuted and convicted at Westminster for selling game out of season. It was contended for the defence that the Act which imposed a penalty for so doing ( 1 \& 2 Will. IV, c. 32) did not apply to game received from abroad. On appeal from the magistrate's conviction it was held by two judges against one (Mr Justice Manisty) that the defendant was not liable. This decision having been followed in the case of Pudney $\mathrm{v}$. Eccles, where it was held that an excise licence was not required for the sale of foreign game (which would result in a loss of revenue), the Act of Parliament now under notice was passed to secure the revenue by enacting that an excise licence is necessary to deal in game imported from abroad.

\section{PARTRIDGE SHOOTING IN IRELAND AGT, 1899 62 Vict., c. 1}

Before the passing of this Act it was illegal to shoot partridges in Ireland before September 20, the game season ending on January 10 (37 Geo. III, c. 21) ; but on the representations of a certain number of Irish sportsmen made to the justices at Quarter Sessions, as well as to the Lord Lieutenant of Ireland, that it would be more convenient if partridge shooting in Ireland were to commence on September 1 and end on February 1, as in England, a Bill was introduced by Mr John Redmond, Mr Horace Plunket and others for the purpose of legalizing the alteration, and was passed on March 27, 1899.

In the opinion of many old sportsmen this Act was a mistake, as tending to increase the destruction of partridges in Ireland by allowing them to be killed at too early an age, and facilitating the shooting of them by unlicensed persons. These anticipations have been unfortunately realized, 432 


\section{GAME LAWS AND LIGENGES}

and at the present time partridges in Ireland are reported to be not nearly so numerous as they were before the passing of this Act.

THE POLE-TRAP AGT, 1904

$4 \mathrm{Edw}$. VII, c. 4

The cruelty and unnecessary suffering inflicted by the use of an unbaited trap set on the top of a pole has been so long recognized by the humaner portion of the public that it is surprising that legislative action was not sooner taken to make the practice illegal.

By the present Act, which was passed on April 28, 1904, the use of the pole-trap is now prohibited under a penalty not exceeding 40 s. for a first offence, and for a second or subsequent offence a penalty not exceeding \&5. If this Act is properly enforced it will not only prevent the great suffering caused to so-called "vermin," whose destruction by some means or other is considered necessary by game preservers, but will also save the lives of many innocent victims for whose capture it was never intended.

\section{THE BAITED FISH-HOOK AGT, 1908}

$8 \mathrm{Edw}$. VII, c. 11

This Act, like the last-named, is entitled "An Act to Amend the WildBirds Protection Acts." It was passed on August 1, 1908, and the principal section reads as follows:-

"Any person who shall take or attempt to take any wild bird by means of a hook or other similar instrument ... shall be liable on summary conviction to a penalty not exceeding $40 \mathrm{~s}$., and for a second or subsequent offence to a penalty not exceeding $£ 5 . "$

This Act was framed especially to put a stop to the cruel practice adopted by thoughtless persons at the seaside of catching gulls and other sea-birds with baited fish-hooks, thereby causing unnecessary and prolonged torture.

We come now to the law affecting hares and rabbits, but as in the present volume attention is confined to feathered game and wildfowl, it will be more convenient to defer the consideration of the Hares Act, 1848, the Ground Game Act, 1880, and the Hares Preservation Act, 1892, until, in a second volume, these animals will be separately dealt with.

J. E. HARTING. 


\section{INDEX}

Abercorn, Duke of, on Woodcock Shooting, 252

Alnwick, Woodeock at, 250

Alresford, Partridge Shooting at, 187

Ardilaun, Lord, Bags of Woodcock, 248

Ashford, Co. Galway, for Woodcock, 248

Baronscourt, Woodcock Shooting at, 252

Barrington, Sir Charles, on Woodcock Shooting, 255

Barrow's Golden-eye, 361

Beetle, Heather (Lochmoea), 86

Black Game, Description of Plumages, 22-24

General Distribution, 24

Allied Species, 25

Distribution in the British Isles, 25

Food, 25

Flight, 25

Breeding habits, 26

Nest, 27

Eggs, 27

General habits, 27-29

Position of Legs in Flight, 29.30

Hybrids, 30

Enemies, 31

Shooting, 32.43

Shooting with a Rifle, 40

Blaeberry, 88, 92

Good Bags, 42-43

Broomhead Moor, Burning as carried out on, 85 Buffle-headed Duck, 362-363

Burning Heather, see Heather-burning

Berry Hill, Notts, Partridge Shooting at, 185

Butts for partridge driving, 159

Capercaillie, Description of Plumages, 1-3

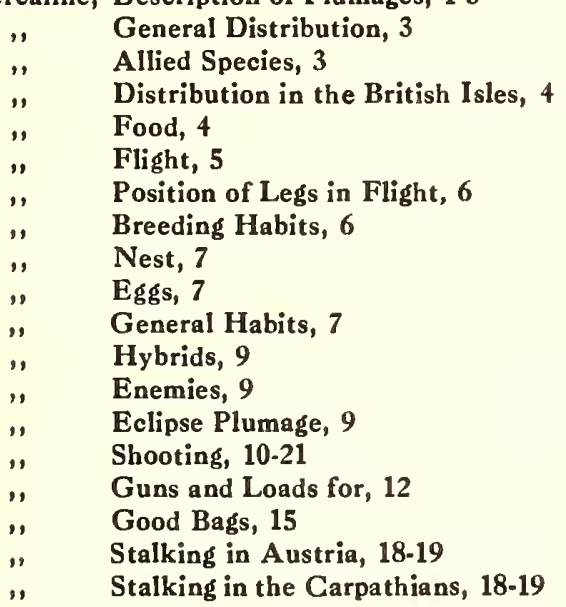




\section{THE GUN AT HOME AND ABROAD}

Chapman, Abel, on Wildfowling, 384-421

Cloudberry, 94

Coccidiosis described, 82

Committee on Grouse Disease, 82-84

Covey, a tame, 155, 160

Craft, the fowler's, 398

Cranberry, 88, 92, 94

Crowberry, 92

Day defined, 426

Diaries, Extracts from, on Wildfowling, 401-403

Diseases of Partridges, 147

$$
\text { " Pheasants, } 120
$$

Diving, Modes of, 418

, from the Wing, 419

Divers, 419

Drainage of Moors, 70

Ducks, Surface-feeding, 323

Diving Ducks, 345

Duck, Buffle-headed, 362

, Burrow, 324

, Eider, 350

" Ferruginous, 368

, Gadwall, 331

," Golden-eye, 359, 415

", Harlequin, 355

,. King Eider, 352

", Long-tailed, 357

, Mallard, 329

, Pintail, 333

" Pochard, 366

" " Baer's, 370

" $\quad$ Red-crested, 364

, Ring-necked, 373

" Scaup, 371

", Shoveler, 327

, Steller's Eider, 354

" Tufted, 374

" Wigeon, 335, 374, 416

," Wild, 329

Eagle, Golden, 96, 98

Eden Vale, co. Clare, Woodcocks at, 254, 255

Eggs, Chipped, 163

Eider Duck, 350, 351

" King, 352, 353

, Steller's, 354-355

Euston, partridge shooting at, 186

Falcon, Peregrine, 96

Field-glass for keeper, 167

Fish Hook Abolition Act, 433

Flight, Black-game, 25

" Capercaillie, 5

" Grouse, 52

" Partridge, 144

" Pheasant, 112

, Quail, 200 


\section{INDEX}

Flight, Snipe, 266

"Woodcock (Wildfowl), 234

, Shooting, 400

Foxes and Ptarmigan, 96

, in pheasant coverts, 135,136

, and sitting birds, 162, 163

Gadwall, 331

Game, Definition of, 424

Gamekeepers' views on heather burning, 85.86

Game Laws, 422-433

Night Poaching, 1828, 423

,

Game Act, 1831, 424

Night Poaching, 1844, 427

Hares Act, 1848, 427

Game Licences Act, 1860, 428

Revenue Act, 1861, 429

Larceny Act, 1861, 429

Poaching Prevention Act, 1862, 429

," Gun Licence Act, 1870, 430

" Wild Birds Protection Acts, 431

", Customs and Inland Revenue, 1893, 432

" Partridge Shooting, Ireland, 1899, 432

". Pole Trap Abolition Act, 1904, 433

", Baited Fish-hook Abolition Act, 1908, 433

Game Licences, 428, 429

Geese, 306, 307

Geese driving in Spain, 409

Glenstal, Co. Limerick, Woodcocks at, 255

Golden-eye, 359-360, 415

Goose, Barnacle, 320, 419

" Bean, 312, 419

, Brent, 317, 318, 419

, Black Brent, 319

" Canada, 322, 323

," Greylag, 308, 419

" Pink-footed, 314, 315, 419

, Red-breasted, 321, 322

". Snow, 315, 316

White-fronted, 309, 310, 419

, Lesser White-fronted, 311, 420

Goosander, 376-377, 417

Greylag, 307-309

Grit, supply of, on moors, 75, 87

Grouse, Description of Plumages, 44-49

, Different Types of Male, 46-47

" Young in Down, 50

Variations in Colour, 50

" Distribution in the British Isles, 51

Allied Species, 51

, Food, 51, 72

, Flight, 52

Breeding Habits, 52

, Nesting, 53

, Eggs, 53

" Young and Old Birds, 79

"General Habits, 53.55

" Effect of Snow on, 73

"Weight, 55 
THE GUN AT HOME AND ABROAD

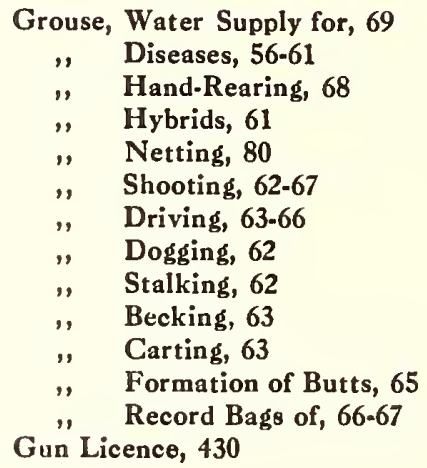

Harlequin Duck, 355-356

Hastings, Lord, on Woodcock Shooting, 260

Hatching, Favourable Season for, 167

Hawker, Col, Bags of Wildfowl, 405

Heather Burning, 71-72, 78, 82.88

" $"$ Directions for, 85.86

," ". Best time for, 74

Holkham, partridge shooting at, 184

Horningham, partridge shooting at, 187

Hungarian Partridges, Treatment of, 165

$$
\begin{array}{lll}
", & \text { Eggs not recommended, } 166 \\
, & \text { ", Exchange of, } 167
\end{array}
$$

Inbreeding, 164

Ireland, Partridges in, 432

Isle of Islay, Woodcock at, 256, 257

Lamps for heather burning, 86

Lanarth, Cornwall, Woodcock at, 258

Laws Relating to Game and Licences, $422-433$

Licences, Applications for, 428

, Authority to demand production of, 428, 430

, Forfeiture of, 426

, to deal in game, 429,432

Long-tailed Duck, 357-358

Mallard, 329-330

Manor, Lord of, powers of, 425

Melton Constable, Woodcock at, 260

Merganser, 376, 378-379

, Hooded, 382-383

Moors, drainage of, 70

" heather burning, 71

Moulton Paddocks, partridge shooting at, 188

Muckross, Killarney, Woodcock at, 256

Night defined, 423

Nor thumberland, Duke of, Marked Woodcocks, 252

Orwell Park, Partridge Shooting at, 189 


\section{INDEX}

Partridge, Common, 137-146

" " Plumages of, 137-140

" " $\quad$ Variations in Colour, 140

, ", Distribution, 141

, $\quad$ Food of, 144

, ", Flight, 144

" $\quad$ " Distribution in British Isles, 144

, " Breeding Habits, 144

" , Allied Species, 142

, ", Nest, 145

, , Eggs, 145

," , General Habits, 145

" $\quad$ " Enemies, 146

", Diseases, 147

," , Mortality of, 168

Partridge, Red-legged, 148-153

\begin{tabular}{|c|c|c|}
\hline " & $"$ & Plumages of, 148.149 \\
\hline$"$ & " & Nestling, 149 \\
\hline " & ", & Variations in Colour, 149 \\
\hline " & $"$ & General Distribution, 150 \\
\hline " & ", & Distribution in British Isles, 150 \\
\hline " & , & Allied Species, 150-151 \\
\hline$"$ & " & in Scotland, 150 \\
\hline$"$ & $"$ & Food, 152 \\
\hline " & ", & Flight, 152 \\
\hline " & ", & Breeding Habits, 152 \\
\hline " & 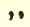 & Nest of, 152 \\
\hline ", & " & Eggs of, 152 \\
\hline " & ", & General Habits, \\
\hline
\end{tabular}

Partridge Rearing, 154-168

" Shooting, 169-192

" Walking up, 169.171

, Driving, 173-177

an Early Start, 177

" Moving up at a drive, 177-178

, Picking up after a drive, 178

, Whistles for keepers, 179

", Retrievers, 182

, Notable bags, 183.192

Partridge Shooting, Sandringham, 183

\begin{tabular}{|c|c|c|}
\hline ", & & Holkham, 184 \\
\hline ," & , & Berry Hill, Notts, 185 \\
\hline ", & ", & Euston, 186 \\
\hline ", & ," & The Grange, Alresford, 187 \\
\hline ," & ", & Honingham, Norfolk, 187 \\
\hline$"$ & " & Moulton Paddocks, 188 \\
\hline ", & ," & Packenham Hall, 189 \\
\hline ", & ", & Orwell Park, 189 \\
\hline ", & $"$ & Stratton Park, 189 \\
\hline ", & " & Welbeck Abbey, 190-191 \\
\hline & ", & Westacre, Norfolk, 191 \\
\hline & ", & Witchingham, Norfolk, 192 \\
\hline
\end{tabular}

Pheasant, natural history of, $101-120$

" Plumages of, 101-103

" Female assuming male plumage, 102

". Male assuming female plumage, 103

", Variation in colour, 103

General distribution, 103

"Introduction into the British Isles, 104 


\section{THE GUN AT HOME AND ABROAD}

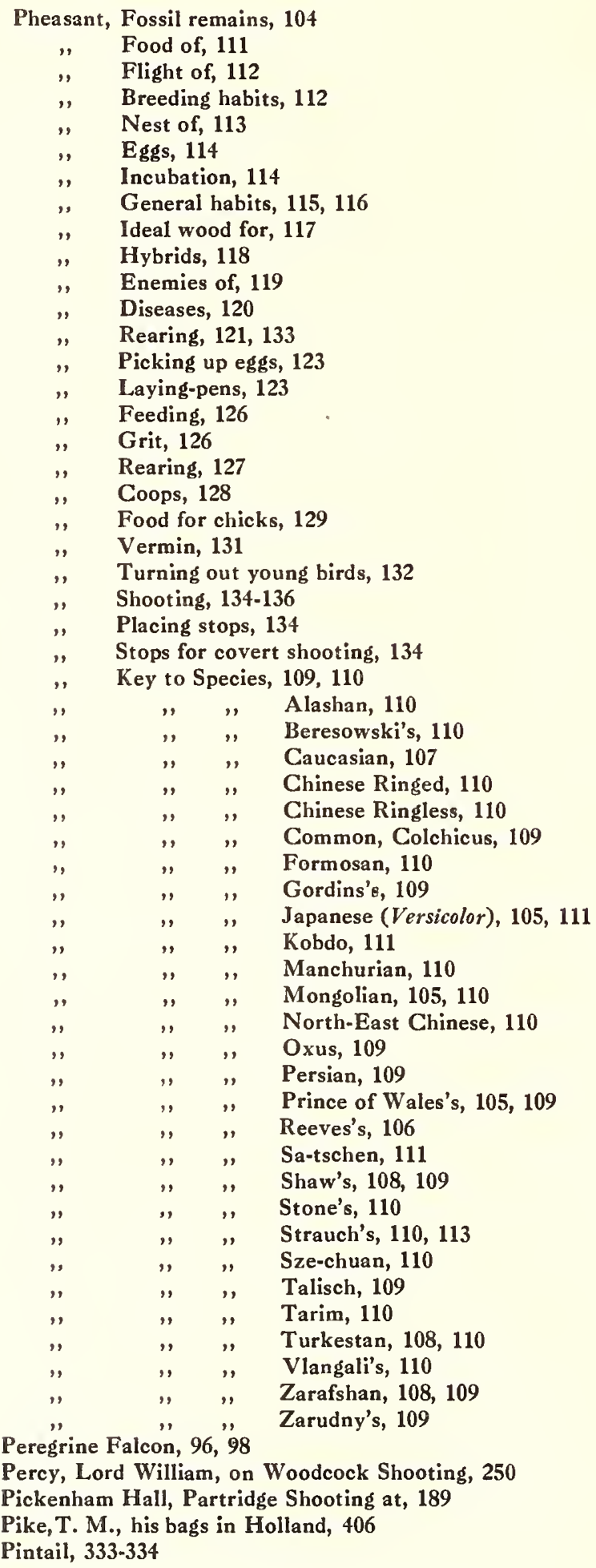




\section{INDEX}

Plants, Moorland, 73

Poaching, see Game Laws.

Pochard, 366-367, 416

" Baer's, 370

," Red-crested, 364-365, 417

" White-eyed, 370, 416

Ferruginous, 368-369

Poison, Prohibition against laying, 424, 425

11 Purchase and sale of, 425

Pole-trap abolition Act, 433

Ptarmigan, Natural History of, 89.97

, Description of plumages, 89-92

, Nestling, 90

, General Distribution, 91

" $\quad$ Allied forms, 91

, Distribution in British Isles, 92

Food, 92

Flight, 93

Breeding habits, 93

Nest of, 94

Eggs, 94

Incubation, period of, 94

General habits, 95

Hybrids, 97

Driving, 96, 99

Shooting, 98.100

Good bags of, 100

Enemies of, 96

Diseases of, 97

, Mountains for Ptarmigan, 99

Quail, 193-202

" Plumages of, 193

" Allied Species, 200

"Australian, 200

, Indian and Burmese, 200

, Japanese, 195, 200

" South African, 195, 200

, Colour variations, 196

" Distribution, 196

" in the British Isles, 197

, Close-time for, 197

" Destruction of, 198-199

, Netting in Egypt, 200

" Food of, 200

". Flight of, 200

" Breeding habits, 200

, Nesting, 201

, Eggs, 201

" General habits, 201

, Shooting in the British Islands, 203

" , Ireland, 205

" Algeria and the Sahara, 216

" Arabia and Palestine, 218

" Austria-Hungary, 211

Azores, 211

Balkan States, 214

Belgium and Holland, 208

Burma, 217 


\section{THE GUN AT HOME AND ABROAD}

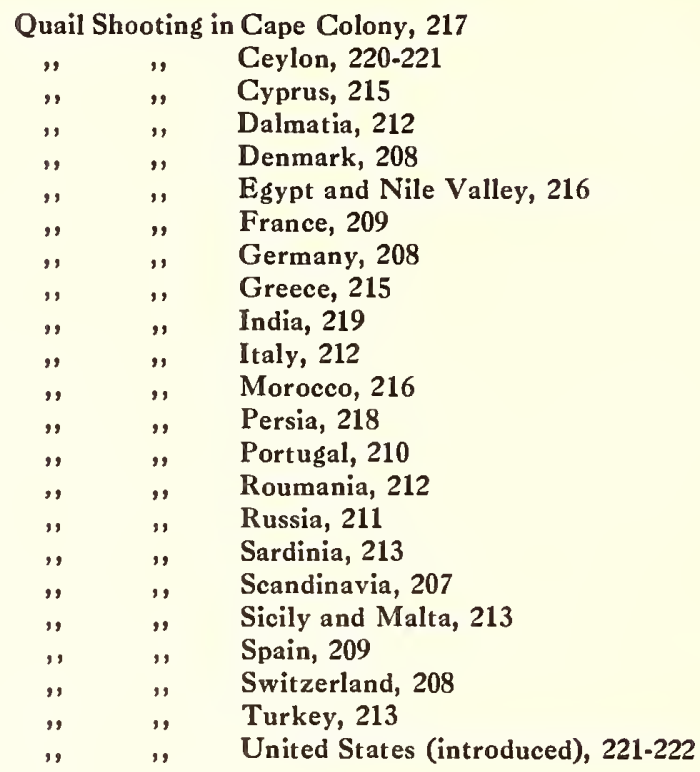

Rearing Partridges, 154-168

$$
\text { , Pheasants, 121-133 }
$$

Remises at Sandringham and Welbeck, 157, 191

Rimington Wilson, his keeper's views on burning, 85

Ring-necked Duck, 373

Sandringham, Partridge Shooting at, 183

$$
\text { " Remises at, 157, } 191
$$

Scaup Duck, 371-372, 415

Scoter, 345-346

,I Velvet, 348-349

, Surf, 347-348

Sheld-duck, 324-325

$$
\text { , Ruddy, } 325
$$

Sheep on Moors, 76-79

Sheep-farmer's views on heather burning, 84

Shoveler, 327

Smew, 380-381

Snipe, Common, 261-272

$$
\begin{aligned}
& \text {, , " Plumages, } 261 \\
& \text { " " } \quad \text { Variations in plumage, } 262 \\
& \text {, ", General distribution, } 262 \\
& \text {, } \quad \text { Allied species, 263-264 } \\
& \text {," " Distribution in British Isles, } 265 \\
& \text {, } \quad \text { Food of, } 265 \\
& \text { ", ", Flight of, } 266 \\
& \text { " " } \quad \text { Bleating or Drumming, } 267 \\
& \text {, " } \quad \text { Breeding habits, } 267 \\
& \text {, " Nesting, } 269 \\
& \text {, " Eggs, } 270 \\
& \text {, , General habits, } 270 \\
& \text { " , } \quad \text { Shooting, 283-288 } \\
& \text { Snipe, Great or Double, 273-276 }
\end{aligned}
$$




\section{INDEX}

Snipe, Great or Double, Distribution in British Isles, 274

"N Flight, 274

, ", Food, 274

,, " Breeding habits, 274-275

Snipe, Jack, 277-282

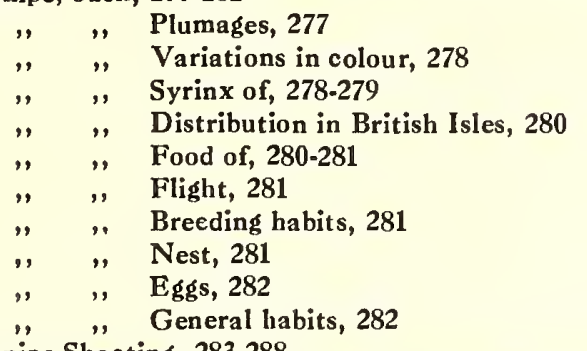

"̈" " "

Stackpoole, Mr Richard, on Woodcock Shooting, 254

Steller's Eider, 354

Stock, Necessity for a healthy, 159

" Amount of, required on a beat, 160-161

Stratton Park, Partridge Shooting at, 189

Strongylus pergracilis described, 82

Swans, 301-306

, Whooper, 302-303, 420

" Bewick's, 303-304, 420

Mute, 305

, Polish, 306

Teal, 338-340

" American, 340

", Blue-winged, 341-342

" Garganey, 343-344

Tenants, good understanding with, 161

Trapping, 162

Tufted Duck, 374-375, 416

Welbeck Abbey, Partridge Shooting at, 190-191

Westacre, Norfolk, Partridge Shooting at, 191

Wigeon, 335-336, 421

"I American, 337-338

Wildfowl, 289-304

" Key to the Species, 291-301

" Haunts and habits of, 393

"To distinguish at a distance, 411

, Colour protection, 394, 395

Wildfowling, 384-421
"
At Home, 397

,

Abroad, 406

Williams, Mr P. D., of Lanarth, on Woodcocks, 258

Wire Fencing on moors, 88

Witchingham, Norfolk, Partridge shooting at, 192

Woodcock, 223-242

" Plumages of, 223-224

" Distinction of sexes, 224

, Dimorphism in, 226

, Position of eye, 228

", Position of ear, 228

, Variations in plumage, 228 


\section{THE GUN AT HOME AND ABROAD}

Woodcock, General distribution, 228-229

" Allied forms, 229

" Distribution in the British Isles, 230

, Food of, 231

" Weight of, 232-234

," Flight, 234

" Migration, 235

, at French lighthouses, 235-237

, Breeding habits, 237.238

", Nesting, 338

, Eggs and young, 239

" Carrying young, 239-240

" General habits, 240

" Dressing its wounds, 241-242

" Shooting, 243.260

", Good Bags, 249-260

, Close Time, 247-248

, Cookery of, 248

Woodcock Shooting at Ashford, co. Galway, 248-250

",

", Alnwick, 250-252

Baron's Court, co. Tyrone, 252-254

Eden Vale, co. Clare, 254-255

Glenstal, co. Limerick, 255-256

Muckross, Killarney, 256

Islay, 256-257

Lanarth, Cornwall, 258-259

Melton Constable, Norfolk, 260 


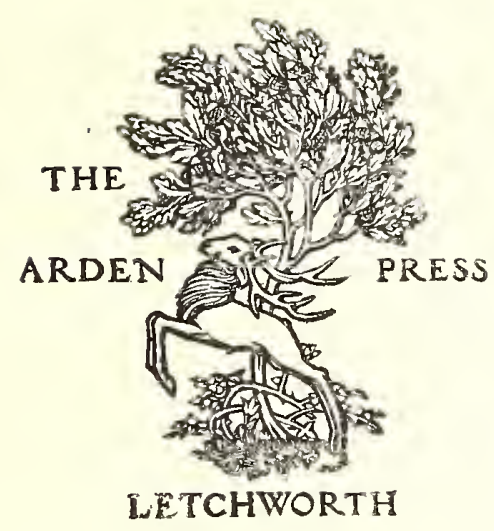







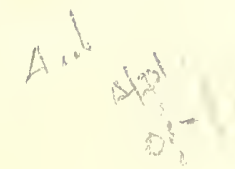


